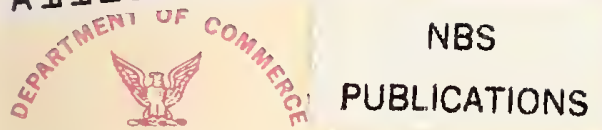

\title{
Environmental Speciation and Monitoring Needs for Trace Metal-Containing Substances from Energy-Related Processes
}




\section{NATIONAL BUREAU OF STANDARDS}

The National Bureau of Standards' was established by an act of Congress on March 3, 1901. The Bureau's overall goal is to strengthen and advance the Nation's science and technology and facilitate their effective application for public benefit. To this end, the Bureau conducts research and provides: (1) a basis for the Nation's physical measurement system, (2) scientific and technological services for industry and government, (3) a technical basis for equity in trade, and (4) technical services to promote public safety. The Bureau's technical work is performed by the National Measurement Laboratory, the National Engineering Laboratory, and the Institute lor Computer Sciences and Technology.

THE NATIONAL MEASUREMENT LABORATORY provides the national system of physical and chemical and materials measurement; coordinates the system with measurement systems of other nations and furnishes essential services leading to accurate and uniform physical and chemical measurement throughout the Nation's scientific community, industry, and commerce; conducts materials research leading to improved methods of measurement, standards, and data on the properties of materials needed by industry, commerce, educational institutions, and Government; provides advisory and research services to other Government agencies; develops, produces, and distributes Standard Reference Materials; and provides calibration services. The Laboratory consists of the following centers:

Absolute Physical Quantities² - Radiation Research - Thermodynamics and Molecular Science - Analytical Chemistry - Materials Science.

THE NATIONAL ENGINEERING LABORATORY provides technology and technical services to the public and private sectors to address national needs and to solve national problems; conducts research in engineering and applied science in support of these efforts; builds and maintains competence in the necessary disciplines required to carry out this research and technical service; develops engineering data and measurement capabilities; provides engineering measurement traceability services; develops test methods and proposes engineering standards and code changes; develops and proposes new engineering practices; and develops and improves mechanisms to transfer results of its research to the ultimate user. The Laboratory consists of the following centers:

Applied Mathematics - Electronics and Electrical Engineering ${ }^{2}$ - Mechanical Engineering and Process Technology ${ }^{2}$ - Building Technology - Fire Research Consumer Product Technology - Field Methods.

THE INSTITUTE FOR COMPUTER SCIENCES AND TECHNOLOGY conducts research and provides scientific and technical services to aid Federal agencies in the selection, acquisition, application, and use of computer technology to improve effectiveness and economy in Government operations in accordance with Public Law 89-306 (40 U.S.C. 759), relevant Executive Orders, and other directives; carries out this mission by managing the Federal Information Processing Standards Program, developing Federal ADP standards guidelines, and managing Federal participation in ADP voluntary standardization activities; provides scientific and technological advisory services and assistance to Federal agencies; and provides the technical foundation for computer-related policies of the Federal Government. The Institute consists of the following centers:

Programming Science and Technology- Computer Systems Engineering.

'Headquarters and Laboratories at Gaithersburg, MD, unless otherwise noted;

mailing address Washington, DC 20234.

'Some divisions within the center are located at Boulder, CO 80303. 


\section{Environmental Speciation and Monitoring Needs for Trace Metal-Containing Substances from Energy-Related Processes}

Proceedings of the DoE/NBS Workshop

Held at the National Bureau of Standards,

Gaithersburg, MD

May 18-20, 1981

\section{Editors:}

Frederick E. Brinckman

Chemical Stability and Corrosion Division

Center for Materials Science

National Measurement Laboratory

National Bureau of Standards

Washington, DC 20234

and

Richard H. Fish

Energy and Environment Division

Lawrence Berkeley Laboratory

University of California

Berkeley, CA 94720

Sponsored by the:

National Bureau of Standards

Washington, DC 20234

and

Department of Energy

Office of Health and Environmental Research

Washington, DC 20545

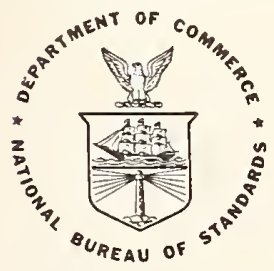

U.S. DEPARTMENT OF COMMERCE, Malcolm Baldrige, Secretary

NATIONAL BUREAU OF STANDARDS, Ernest Ambler, Director 
Library of Congress Catalog Card Number: 81-600140

National Bureau of Standards Special Publication 618 Nat. Bur. Stand. (U.S.), Spec. Publ. 618, 336 pages (Nov. 1981) CODEN: XNBSAV 


\section{PREFACE}

Increased national reliance on alternate sources for either extracting fuels and oils from fossil deposits or from recycled materials now requires that we direct our attention to examining the processing and environmental hazards shared by both technologies and their possible common measurement solutions. These joint concerns are raised because it is al ready clear that fossil sources, such as shale oil (kerogen) or coal, being of biogeochemical origin, contain significant bioaccumulations of many toxic elements, including arsenic, mercury, selenium, and cadmium. Similarly, dependence upon recycled materials as prospective sources for organic feed stocks requires equivalent consideration of the substantial anthropogenic incorporation of the same toxic elements during prior use. Underlying both technologies, therefore, is a major requirement for reliable and appropriate trace measurement methods and standards. These also can probably share common scientific and applications developments, not only because the analytes and matrices-are often similar, but especially because the processing favored in both technologies heavily involves interactions with ground waters and the atmosphere.

Assessing or monitoring environmental hazards or impacts of such processes and their aqueous effluents, whether in the public health sense or in occupational exposure, is inhibited by two major unsolved problems: (1) what are the specific (molecular) forms of the toxic elements and their dosage effects on specific organisms? (2) what are (or will be) the best means for detecting and quantitating these toxicants in the process environment as a timely monitoring control? Ultimately, this framework for data bases and decision-making must mesh with the existing body of environmental and health regulatory legislation: This is highlighted with recent passage of the National Materials and Minerals Policy, Research and Development Act (Public Law 96-479), which places identification of materials problems on parity with energy and environmental concerns.

Over the past several years, widespread scientific interest has risen with development of new element-specific methods suitable for "speciating" or characterizing at trace (ppm or ppb) concentrations those types of metal- or metalloid-containing molecules that exhibit bioactivity or are biogenic. The work so far is widely scattered and inadequately funded; it is not focused on energy or recycled materials. Consequently, the speciation field is not yet sufficiently developed to make full use of its potential contribution to these topics of concern, which form the reasons for this Workshop.

Against this backdrop, the Workshop germinated 2 years ago when we were greatly encouraged by Gerald Goldstein (DoE) and Joseph Berke (NBS) to attempt assembiy of a forum where active colleagues, expert in the necessarily diverse disciplines, could critically discuss such a timely but broad area. Following much deliberation and creation of a (by no means complete) "short 1ist," we contacted 24 possible speakers. Their immediate and enthusiastic response was later equally shared by some 40 more scientists invited from industry, academia, and Government to participate in the Workshop. Thus, this Workshop, unusual in its aim to address biogeochemical, analytical, and biological aspects of special classes of metal-containing materials in energy-processing or waste cycling, evolved. 
The reader will appreciate that no simple organization of formal papers could make transitions between such diverse topics flow evenly. Rather, we have taken on the task to incorporate essential features of the informal discussion accompanying each paper and during the longer discussion periods concluding each Session. We assume full responsibility for the inevitable editorial changes in the dialog, and trust that our fellow conferees will not be offended.

It should be noted that throughout these proceedings certain commercial equipment, instruments, or materials are identified in order to specify adequately experimental procedures. In no case does such identification imply recommendation or endorsement by the National Bureau of Standards or Lawrence Berkeley Laboratory, nor does it imply that the material or equipment identified is necessarily the best available for the purpose.

Continued interest and many forms of dedicated effort make a successful meeting; this Workshop was especially demanding of a great number of associates, only some of whom we can acknowledge here. We thank our sponsors, the Office of Health and Environmental Research, DoE, and the Office of Recycled Materials, NBS, for their financial support and guidance. To our colleagues who wrote the timely and critical papers which make this book possible, and to all of the Workshop participants whose questions and comments amplified significant points, we are most grateful. The Session Moderators formed a keystone for the active and imaginative dialog which characterized the sustained enthusiasm of the Workshop. Many coworkers at NBS and LBL, who remain anonymous, generously gave their time to read all the papers and insure a highest standard of quality. Finally, as editors, we wish to give special thanks to Joanne Lordon and Kathy Stang who made the Workshop run properly; to Hershey Young who did special text preparation and those extra administrative jobs that kept conferees happy and productive; and to CaRole Lamb who performed excellent feats of text revision and editing for the final camera-ready volume.

\section{FREDERICK E. BRINCKMAN}

Center for Materials Science National Bureau of Standards

RICHARD H. FISH

Lawrence Berkeley Laboratory University of California

September 1, 1981 


\section{ABSTRACT}

This book presents the Proceedings of the DOE/NBS Workshop on Environmental Speciation and Monitoring Needs for Trace Metal-Containing Substances from Energy-Related Processes held at the National Bureau of Standards, Gaithersburg, MD, on May 18-20, 1981. The Workshop was sponsored by the Office of Health and Environmental Research, DoE, and the Office of Recycled Materials, NBS.

The volume contains refereed papers submitted by 24 invited speakers, along with substantially complete text of the discussion following the papers, edited by the Cochairpersons. The Proceedings address three major topic areas forming the overall objective of the Workshop: (1) what are the general and specific types of metal- or metalloidcontaining substances occurring in energy-related process materials such as coals, oil shales, and waste products? (2) what are the current status and future prospects of element- and compound-specific measurement methods suitable for speciation of trace (ppm, $\mathrm{ppb}$ ) metal- and metalloid-containing substances transmitted to the environment by energyprocessing or waste cycling technologies? (3) for what toxic molecular forms of speciated process effluents should biological dose-response data be generated to assure reliable environmental impact and monitoring measurements? Main questions focused on providing assurance that the speciation methods (or their development) fit basic bioassay criteria along with appropriate standard reference materials for meeting quantitative process and waste monitoring or control needs.

Key words: bacterial mobilization; biogeochemical cycles; biological uptake; cellular toxicity-essentiality mechanisms; chromatography; element-selective speciation; environmental monitoring; fossil fuels; metal(1oid) complexes; organometallic compounds; trace element standards; waste cycling 
Preface . . . . . . . . . . . . . . . . . . . III

Abstract ............................ . . . . . V

Workshop Participants . . . . . . . . . . . . . . . . . . . . VIII

Session I - Prof. R. H. Filby, Moderator

Laboratory Characterization of Complex Environmental Contamination

Robert D. Stephens. . . . . . . . . . . . . . . . . . . . 1

The Role of Metal-Heteroatom Complexes in Fossil Fuel Production

Teh Fu Yen.

Chemistry of Trace Element Species in Coal Liquefaction Processes

R. H. Filby, D. R. Sandstrom, F. W. Lytle, R. B. Greegor, S. R. Khalil,

V. Ekambaram, C. S. Weiss, and C. A. Grimm.

Speciation of Aqueous Contaminants--The Role of the Geochemical Model

Everett $A$. Jenne.

Biogeochemical Cycles of Metals and Metalloids--The Role of Methylcobalamin and Some Other Chemical Routes to Methylation in the Environment

P. J. Craig and S. Rapsomanikis

Some Environmental Aspects of Organo-Arsenic, Lead, and Tin

Y. K. Chau and P. T. S. Wong .

Session II - Prof. S. E. Manahan, Moderator

Environmental Chemical Investigations of Trace Element Mobilization in

Synthetic Fuels Manufacture

Stanley E. Manahan, David M. Fraley, Corazon Vogt, and Dennis Yates

Speciation of Organic Compounds and Trace Elements in 0 il Shale Wastewaters

R. E. Sievers, M. K. Conditt, and J. S. Stanley . . . . . . . . . . .

Isolation of Metallic Complexes in Shale 0 il and Shale 0il Retort Waters

K. B. Olsen, C. L. Wilkerson, A. P. Toste, and D. J. Hayes......

The Use of Mass Spectrometry for Metal Analysis

Terence H. Risby

Session III - Prof. M. A. Anderson, Moderator

Diffusional Discrimination and Reversible Chemisorption for Speciation in Air

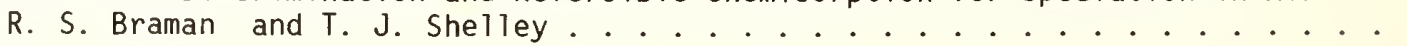

Kinetic and Equilibrium Control of Interfacial Reactions Involving Inorganic

Ionic Solutes and Hydrous Oxide Solids

Marc A. Anderson

Speciation of Labile and Quasi-labile Metal Complex Systems Using the Kalman

Filter

Teri F. Brown, Donna M. Caster, and Steven D. Brown 
Biological Uptake and Chemical Speciation of Copper in Sea Water Determined by Electrochemistry

E. A. Crecelius, J. M. Gurtisen, and C. W. Apts . . . . . . . . . . . . . . 173

Specific Element Detection in Chromatography by Plasma Emission Spectroscopy

P. C. Uden . . . . . . . . . . . . . . . . . . . . . . . 184

Application of Molecular Substituent Parameters for the Speciation of Trace

Organometals in Energy-Related Process Fluids by Element-Selective HPLC

C. S. Weiss, K. L. Jewett, F. E. Brinckman, and R. H. Fish . . . . . . . .

Session IV - Dr. B. A. Fowler, Moderator

Relationships Between Trace Element Speciation and Intracellular Mechanisms of

Toxicity

Bruce A. Fowler

Development of a Methodology to Assess Organometallic Effects on Bioenergetic

Systems

Lester Packer and Rolf J. Mehlhorn.

Duality of Concern with Trace Metals in the Environment--Toxic and/or Essential

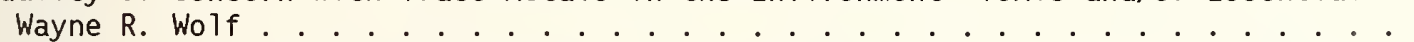

Analytical and Biomedical Aspects of the Transformation of Arsenic and Selenium Compounds into Biomolecules

K. J. Irgolic, C. H. Banks, N. R. Bottino, D. Chakraborti, J. M. Gennity,

D. C. Hillman, D. H. O'Brien, R. A. Pyles, R. A. Stockton, A. E. Wheeler,

and R. A. Zingaro ........................

Session V - Prof. J. A. Brierley, Moderator

Bacterial Processes for Transformation of Metals

James A. Brierley . . . . . . . . . . . . . . . . . . . . . . . . .

Microbial Accumulation of Uranium, Radium, and Cesium

G. W. Strandberg, S. E. Shumate II, J. R. Parrott, Jr., and S. E. North . . .

Microbiological Mobilization of Arsenic from Retorted 0il Shales--Speciation

and Monitoring Requirements

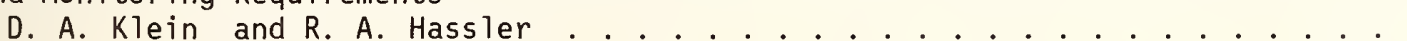

Mechanisms of Bacterial Resistances to Toxic Heavy Metals: Arsenic, Antimony,

Silver, Cadmium, and Mercury

Simon Silver 
NBS/DOE WORKSHOP ON ENVIRONMENTAL SPECIATION \& MONITORING NEEDS

May $18-20,1981$

National Bureau of Standards

Gaithersburg, MD 20877

F. E. Brinckman and R. H. Fish, Co-Chairpersons

(*Denotes Speaker; tDenotes Session Moderator)

Robert Alvarez

Office of Standard Reference Materials National Bureau of Standards

Washington, DC 20234

Marc A. Anderson* $\dagger$

Water Chemistry Program

University of Wisconsin

660 N. Park Street

Madison, WI 53706

Baldev Bathija

Environmental Protection Agency

401 M Street, S. W.

Washington, DC 20460

Donald A. Becker

Office of Recycled Materials

National Bureau of Standards

Washington, DC 20234

J. M. Bellama

Department of Chemistry

University of Maryland

College Park, MD 20742

Joseph G. Berke

Office of Recycled Materials

National Bureau of Standards

Washington, DC 20234

Robert S. Braman*

Department of Chemistry

University of South Florida

4202 Fowler Avenue

Tampa, FL 33620

Ronald J. Breteler

Battelle, New England Marine Research

Laboratories

397 Washington Street

Duxbury, MA 02332

Frank Briden

Environmental Protection Agency

Industrial Environmental Research

Laboratories

Research Triangle Park, NC 27711
James A. Brierley*t

Department of Biology

New Mexico Institute of Mining and Technology

Socorro, NM 87801

Frederick E. Brinckman

Chemical Stability and Corrosion Division

National Bureau of Standards

Washington, DC 20234

Steven D. Brown*

Department of Chemistry

Washington State University

Pul1man, WA 99163

Y. K. Chau*

Canada Centre for Inland Waters

867 Lakeshore Road

Burlington, Ontario, L7R 4A6, CANADA

Joseph J. Cooney

Chesapeake Biological Laboratory

University of Maryland

P. 0. Box 38

Solomons, MD 20688

Thomas D. Coyle

Chemical Stability and Corrosion Division National Bureau of Standards

Washington, DC 20234

P. J. Craig*

School of Chemistry

Leicester Polytechnic

P. 0. Box 243

Leicester LE1 9BH, ENGLAND

Eric Crecelius*

Battelle Pacific Northwest Laboratory

Marine Research Laboratory

358 Washington Harbor Road

Sequim, WA 98382

William Cunningham

National Bureau of Standards and

Food and Drug Administration

Building 235, Room B117

Washington, DC 20234 
Edward A. Dietz, Jr.

Hooker Chemical

Long Road, Grand Island, NY 14072

Richard A. Durst

Center for Analytical Chemistry

National Bureau of Standards

Washington, DC 20234

Roy H. Filby* $\dagger$

Department of Chemistry

Washington State University

Pullman, WA 99164

Richard H. Fish

Energy and Environment Division

Lawrence Berkeley Laboratories

University of California

Berkeley, CA 94720

Bruce A. Fowler*t

Laboratory of Environmental Toxicology

National Institute of Environmental

Health Science

P. 0. Box 12233

Research Triangle Park, NC 27709

John Fruchter

Battelle Pacific Northwest Laboratory

P. 0. Box 999

Richland, WA 99352

Thomas E. Gills

Office of Standard Reference Materials

National Bureau of Standards

Washington, DC 20234

Gerald Goldstein

Department of Energy

Office of Health and Environmental

Research

Washington, DC 20545

Philip K. Hooke

University of Illinois

1000 W. Western Avenue

Urbana, IL 61801

Kenneth G. W. Inn

Center for Radiation Research

National Bureau of Standards

Washington, DC 20234

Kurt J. Irgolic*

Chemistry Department

Texas A\&M University

College Station, TX 77843

Warren $P$. Iverson

Chemical Stability and Corrosion Division

National Bureau of Standards

Washington, DC 20234
Jo-Anne A. Jackson

Chemical Stability and Corrosion Division National Bureau of Standards

Washington, DC 20234

Everett A. Jenne*

Physical Sciences Department

Battelle Pacific Northwest Laboratory

Richland, WA 99352

Kenneth L. Jewett

Chemical Stability and Corrosion Division National Bureau of Standards

Washington, DC 20234

Rolf B. Johannesen

Chemical Stability and Corrosion Division National Bureau of Standards

Washington, DC 20234

William H. Kirchhoff

Office of Environmental Measurements

National Bureau of Standards

Washington, DC 20234

Donald A. Klein*

Department of Microbiology

Colorado State University

Fort Collins, CO 80523

Richard G. Lett

Department of Energy

Pittsburgh Energy Technology Center

P. 0. Box 20940

Pittsburgh, PA 15236

Stanley E. Manahan* $\dagger$

Department of Chemistry

University of Missouri

123 Chemistry Building

Columbia, MO 65211

Rolf J. Mehlhorn

Energy \& Environment Division

Lawrence Berkeley Laboratory

University of California

Berkeley, CA 94720

R. A. Nadkarni

Exxon Research and Engineering Company

P. 0. Box 4255

Baytown, TX 77520

Gregory J. 01 son

Chemical Stability and Corrosion Division National Bureau of Standards

Washington, DC 20234

K. B. 01 son* $^{*}$

Physical Sciences Department

Battelle Pacific Northwest Laboratories

Richland, WA 99352 
Lester Packer

University of California

2544 Life Sciences Building

Berkeley. CA 94720

Edwin J. Parks

Chemical Stability and Corrosion Division National Bureau of Standards

Washington, DC 20234

Richard E. Poulson

Department of Energy

Laramie Energy Technology Center

P. 0. Box 3395

Laramie, WY 82071

Greg Rici

Rockwell International

2421 West Hillcrest Drive

Newbury Park, CA 91320

Terence H. Risby*

Department of Environmental Health

Sciences

Johns Hopkins University

3100 Wyman Park Drive

Baltimore, MD 21211

James G. Sanders

Chesapeake Biological Laboratory

University of Maryland

P. 0. Box 38

Solomons, MD 20688

Donald R. Sandstrom

Department of Physics

Washington State University

Pullman, WA 99164

Samuel J. Schneider, Jr.

Center for Materials Science

National Bureau of Standards

Washington, DC 20234

Robert E. Sievers*

Department of Chemistry

University of Colorado

Campus Box 215

Boulder, CO 80309

Samuel Silberstein

Building Thermal Performance Division

National Bureau of Standards

Washington, DC 20234

Simon Silver*

Department of Biology

Washington University

St. Louis, MO 63130
Walter Slavin

Perkin-Elmer Corporation

Main Avenue

Norwalk, CT 06856

William C. Spare

Biospherics Incorporated

4928 Wyaconda Road

Rockville, MD 20852

G. W. Standberg*

Chemical Technology Division

Oak Ridge National Laboratory

P. 0. Box $X$

Oak Ridge, TN 37830

Robert D. Stephens*

California Department of Health Services

2151 Berkeley Way

Berkeley, CA 94704

Leticia Tehan

Environmental Protection Agency

Office of Toxic Substances, TS-778

401 M Street N. W.

Washington, DC 20460

Richard W. Traxler

Department of Plant Pathology and Entomology

University of Rhode Island

231 Woodward $\mathrm{Ha} 11$

Kingston, RI 02881

Ralph R. Turner

Environmental Sciences Division

Oak Ridge National Laboratory

Oak Ridge, TN 37830

Peter C. Uden*

Department of Chemistry

University of Massachusetts

GRC Towers

Amherst, MA 01003

Corazon R. Vogt

Environmental Trace Substance Research

Center

University of Missouri

Columbia, MO 65201

John D. Walker

Environmental Protection Agency

Office of Toxic Substances, TS -778

401 M Street, N. W.

Washington, DC 20460

Stephan J. Weeks

Chemical Stability and Corrosion Division

National Bureau of Standards

Washington, DC 20234 
Carl S. Weiss*

Chemical Stability and Corrosion Division

National Bureau of Standards

Washington, DC 20234

Connie L. Wilkerson

Battelle Pacific Northwest Laboratories

P. 0. Box 999

Richland, WA 99352

Joanne M. Wolcott

Department of Engineering Research

Louisiana State University

3418 C.E.B.A.

Baton Rouge, LA 70803

Wayne R. Wolf*

Department of Agriculture

Nutrient Composition Lab/DOA

Building 307, Room 213

Beltsville, MD 20705

Edwin A. Woolson

U. S. Department of Agriculture

Building 050 BARC-W

Beltsville, MD 20750

T. F. Yen*

Departments of Chemical and Environmental

Engineering and Biochemistry

University of Southern California

PCE 201, University Park

Los Angeles, CA 90007

Hershey Young

Chemical Stability and Corrosion Division National Bureau of Standards

Washington, DC 20234 

Laboratory Characterization of Complex Environmental Contamination

\author{
Robert D. Stephens \\ Hazardous Materials Laboratory Section \\ California Department of Health Services \\ 2151 Berkeley Way \\ Berkeley, California 94704
}

A major scientific task before us is that of assessing the environmental and public health impacts resulting from the generation and disposal of large volumes of residues containing toxic elements. These residues, which emanate primarily from fossil fuels and the mining industry, contain toxic elements in widely varying concentrations and which naturally occur geologically. Questions of impact, therefore, generally center on what concentrations of specific elements pose a hazard to the environment, and what is the "availability" of specific elements for environmental contamination. Environmental availability relates to the basic chemistry of the elements. Impact assessments considering these factors shall be discussed with several current laboratory tests i11ustrated.

Key words: availability; environmental contamination; extraction tests; fossil fuels; laboratory characterization; metals; mining industry; public health impacts; residues; toxic elements.

\title{
1. Introduction
}

Public and private institutions throughout the nation are struggling under the impact of Federal and state regulations on hazardous waste. The same can be said of most industrialized nations throughout the world. Hazardous waste regulations impact many components of these institutions, including the legal, the regulatory, the medical, and the chemical laboratory. In many ways, at least at this time, it is the chemical laboratory which is feeling the greatest impact. The complexity and the magnitude of the analytical problems encountered in dealing with hazardous waste, their residues, and their behavior in the environment is, to say the least, a formidable task. It is however an extremely important one, for the proper management of hazardous waste generated by today's economy, and dealing with the problems created by hazardous waste generated and disposed in less conscious times, must be firmly based on an adequate knowledge of waste composition and behavior. Fortunately, many excellent scientists and laboratories here in the United States and abroad are now directing their attention to these problems.

The perspective of my talk today will be that of a laboratory whose primary function is to support an active State regulatory program in hazardous waste and to support and conduct investigatory programs in uncontrolled hazardous waste sites throughout the State. In this capacity the laboratory is involved in a number of specific activities: 
- Waste classification relative to hazardous waste criteria

- Compliance monitoring for facilities permits and hauler manifests

- Spil1 identification

- Uncontrolled site investigations, definitions, and environmental and health effects assessment

0 Litigation support

This, I believe, represents close to the full range of activities which may be expected by a hazardous waste laboratory. Many labs would not find themselves in a situation of facing all of these different activities; however, the support of a State regulatory program does necessitate most of these activities. The purpose of highlighting the variety of laboratory functions is due to the necessity of relating laboratory response to program needs. For example, compliance monitoring of a well-characterized industry might be accomplished by a simple one or two physical or chemical parameter measurement, whereas, investigation of health effects from an uncontrolled site may require extensive quantitation and mass spectral identification of tens or even hundreds of waste components or their degradation products. The perspective of the work which will be presented is that of a laboratory whose primary function is to provide analytical, interpretive, and other technical information relative to existing problems in need of solution. This perspective frequently highlights deficiencies in knowledge, data bases, and technologies and often without the resources to research these deficiencies.

The discussion which follows will deal with some of the general approaches to and details of characterization of hazardous waste and other complex environmental samples. The paper deals generally with environmental samples and not exclusively inorganics or, specifically, metals.

\section{General Considerations}

A fundamental aspect of characterization of environmental samples is that no sample can in reality, or at least practically, ever be completely characterized. Therefore, an important initial decision in a characterization scheme is what are the most important parameters to be examined. Some factors which must be considered in parameter selection are:

What primary products of manufacture or processing were most likely the cause of the environmental contamination?

What were the secondary or by-products of these processes? What environmental degradation toxins can be expected? Are there predictable air, water, or soil reactions?

Many substances have soil and water chemistries which are a function of concentration. Parathion, for example, degrades rapidly in low soil concentrations and slowly in high concentrations. Is anything known about this? 
Should parameter selection be based on estimated risk from specific substances, thus concentrating analytical measurements on particular problem substances?

0 Should surrogate, or signal, parameters be chosen which reflect ease of environmental mobility or amenability to analysis?

0 Preliminary site characterizations often can be aided greatly by field measurements. Current technology, however, limits the scope, sensitivity, and reliability of such methods. Preliminary investigations may be made easier by choosing to search for generic groups of substances (such as chlorinated hydrocarbons, organophosphates, or metals).

\section{Media to be Analyzed}

A large number of potentially affected media at waste sites are subject to analysis, including soil, water, air, biota, and human tissues. Site characterization must be based on proper methods of sampling and choices of media to be sampled. Analysis must be based on consideration of the physical and chemical properties of waste components and of the contamination assessment. An example is that of dibromochloropropane (DBCP) in California ground waters.

Now, becoming more specific, I would like to discuss some of the important laboratory components necessary to deal with hazardous waste problems. Subsequently, I will illustrate these problems by discussing some of the rapid characterization methods we currently use and some of the more sophisticated quantitative methods.

The laboratory attempting environmental characterization must have broad range analytical capability in both organics and inorganics, which range from crude physical measurements to GC/MS computer analysis. Some of the most important techniques used are listed below. Details of how these are used for hazardous waste characterization will be given later.

1. Use of a phased or multilevel approach. Preliminary separation and characterization followed by specific compound quantitation when required.

2. Extensive use of thin layer chromatography (TLC) for both sampie cleaning, concentration, and qualitative identification.

3. Multielement analysis of both solids and liquids. These analyses are currently done by energy dispersive $x$-ray fluorescence.

4. Waste reactivity measurements. Flammability, heat sensitivity, and chemical compatabilities are part of a waste hazard assessment.

5. HPLC and infrared spectroscopy complex separations; those not possible with TLC are handled with HPLC.

An outline of this analytical scheme is shown in Table 1. 
Test Phase I

Field Tests

Test Phase II

Laboratory Hazard

Assessment
$\mathrm{pH}$, odor, gases, radioactivity, (reactivity)

Acidity, alkalinity, bioassay, extraction test

reactivity, flashpoint
Test Phase III

Sample Separation

and Qualitative Tests
Centrifugation

Qualitative Tests

Organic Aqueous Solids

\begin{tabular}{lll}
\hline Test Phase IV & Organics & Inorganics \\
Quantitative and & Gas chromatography & Atomic absorption \\
Confirmatory & HPLC & XRF \\
Analyses & & (ICP) \\
\hline
\end{tabular}

4. Test Considerations for Hazardous Energy Production Wastes

The characterization of contaminated environmental samples or hazardous waste samples is often for purposes of environmental or health risk assessment. The data required for such assessment begins with composition. Energy production wastes, for example, are analyzed for the complete spectrum of trace metals. Impact assessments of such materials must, however, consider environmental availability of potentially toxic elements. The laboratory approach to assessing this availability has been to design a short term extraction test to simulate conditions which a waste material or a contaminated soil might encounter in the environment. The U.S. Environmental Protection Agency has taken this approach in the development of regulations pursuant to the Resource Conservation and Recovery Act (RCRA) [1]. In this procedure, solid samples are extracted with an aqueous acetic acid solution at $\mathrm{pH} 5$ for 24 hours. After filtration, concentrations of certain elements are measured against an established standard. Hazardous materials management programs have developed similar, but more stringent laboratory tests in an attempt to simulate availability and mobility of metal ion in the environment [2]. Most of the work done by EPA, or their contractors, and by the State of California, to develop such laboratory "leachate simulation" tests has been directed toward test reproducibility and not toward validity of the test as simulating environmental conditions. Nevertheless useful information has been generated using these short term tests. 


\subsection{Example of Metal Refining Sludge}

Two examples of the behavior of inorganic sludges are given to exemplify the use of these tests. Figure 1 shows the behavior of copper in a metal refining sludge at an initial concentration of $3000 \mathrm{mg} / \mathrm{Kg}$ as it is extracted with de-ionized water and the California, Wet Extraction Test (WET) at pH 4 [2]. This simple comparison between the two extractant solutions is important, for there is the suggestion, particularly by the ASTM Committee D-34, that de-ionized water solubility be used as a measure of environmental availability.

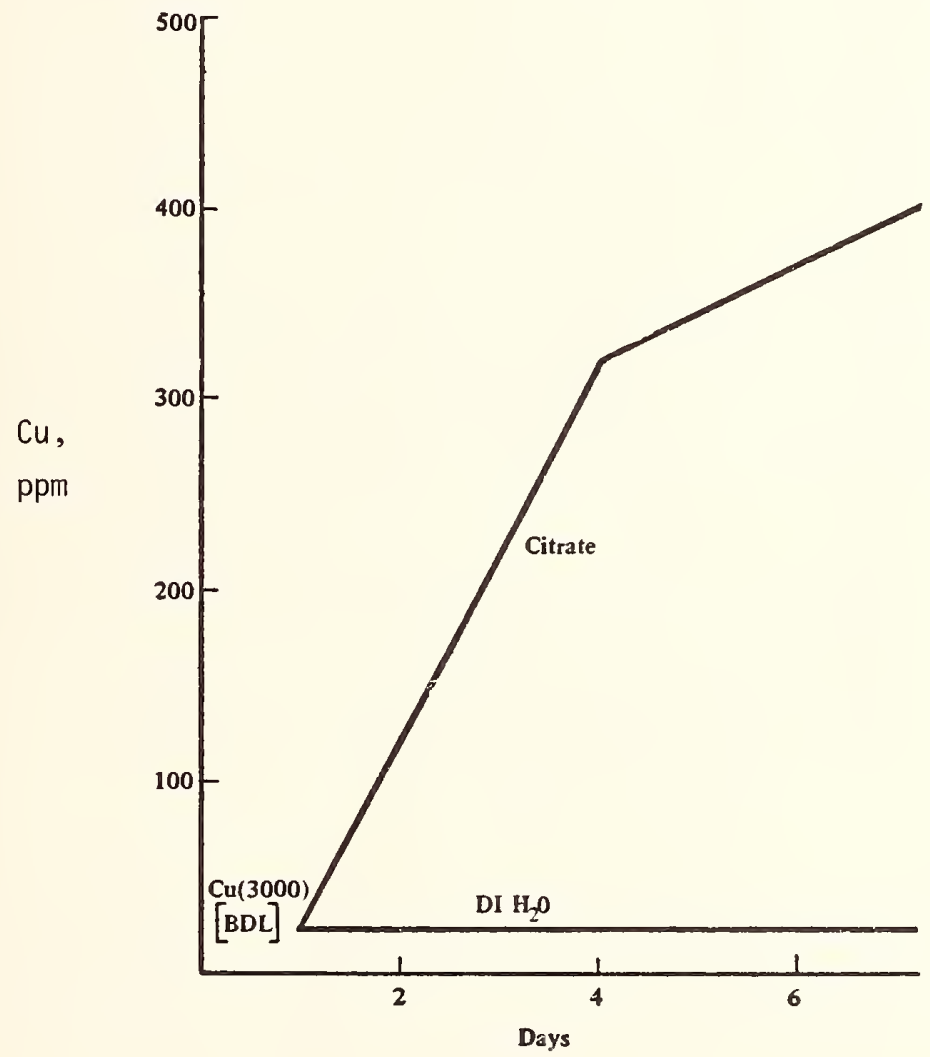

Figure 1. Extraction of metal refining sludge with citrate buffer at $\mathrm{pH} 4$ and de-ionized water

\subsection{Example of Coal-fired Boiler Ash}

In another example, Figure 2, the behavior of bottom ash from a coal-fired boiler in the California citrate-based extractant is shown. The concentration of several trace metals in the extractant solution is shown as it occurs over the 30-day time period of the test. It is apparent that even after 30 days of contact between the solution and the solids, equilibrium concentrations are not reached. Concentrations at any given time within this period is governed by relative kinetics of dissolution of each metal from an inert ash matrix. Important to note, is that certain metals, chromium for example, do not 
show detectable levels of soluble species until after 10 days of extraction. This phenomenon must relate to a slow breakdown of stable materials within the ash matrix. This behavior is important for risk assessments, and if related regulatory standards are based upon short term laboratory tests (< 10 days), significant errors will be made.

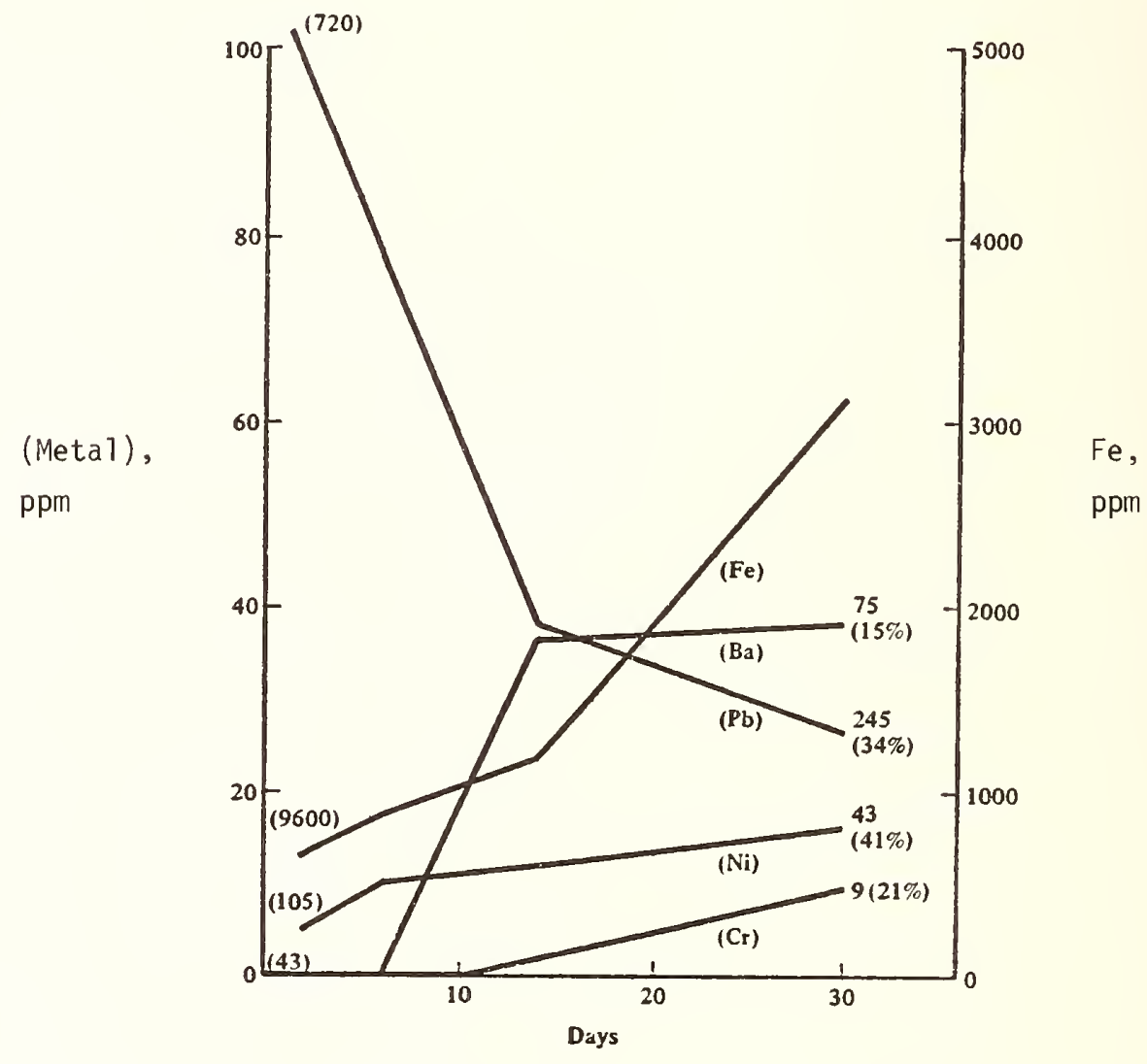

Figure 2. Extraction of incinerator bottom ash with citrate buffer at pH 4

\section{4. $3 \mathrm{pH}$ and Solubilization of Metals}

In addition to the kinetics of desorption of metals, one must certainly consider the $\mathrm{pH}$ solubility relationships. Although such solubility relationships have been known and described for decades, they are often not adequately considered in environmental impact assessments. Table 2 shows some selected values of metal release from fly ash which exemplifies this point.

Solubility characteristics are only one of the chemical parameters which must be considered for environmental impact. Again, referring to chromium, there has been considerable study and concern relating to the environmental and health impacts from chromiumbearing waste products. There is general agreement that $\mathrm{Cr}$ (VI) poses a significant environmental and health risk. There is much less agreement on the hazards posed by $\mathrm{Cr}$ (III). 
Table 2. Metal release at various $\mathrm{pH}$ (all values $\mu \mathrm{g} / \mathrm{g}$ of fly ash)

\begin{tabular}{lrlll}
\hline Metal & $\begin{array}{c}\mathrm{pH} \mathrm{3} \\
\mathrm{Avg}^{*}\end{array}$ & $\begin{array}{l}\mathrm{pH} \mathrm{6} \\
\mathrm{Avg}^{*}\end{array}$ & $\begin{array}{l}\mathrm{pH} \mathrm{9} \\
\mathrm{Avg}^{*}\end{array}$ & $\begin{array}{l}\mathrm{pH} \mathrm{12} \\
\mathrm{Avg}^{*}\end{array}$ \\
\hline Arsenic & 51.9 & 1.0 & 0.80 & 72.9 \\
Cadmium & 1.1 & 0.41 & 0.15 & 0.18 \\
Chromium & 9.4 & 1.9 & 2.0 & 2.4 \\
Lead & 9.1 & 1.4 & 0.73 & 0.91 \\
\hline
\end{tabular}

*Average of 11 samples

In low concentration $\mathrm{Cr}$ (III) is an essential nutrient, on the other hand, $\mathrm{Cr}$ (III) shows a substantial aquatic toxicity. Consideration must be given, however, to the appropriate redox equilibria and their $\mathrm{pH}$ dependence.

Equations (1) and (2) show that the chromate half-reaction and the oxygen-chromate couple may be of environmental importance. These reactions indicate that at $\mathrm{pH} 7$ and above (typical of ground and surface waters), the thermodynamically favored species is $\mathrm{CrO}_{4}{ }^{2-}$. These chemical properties must therefore be considered in impact assessments and related regulations of chromium-bearing wastes.

$$
\begin{array}{ll}
\mathrm{CrO}_{4}{ }^{2-}+4 \mathrm{H}_{2} \mathrm{O}=\mathrm{Cr}(\mathrm{OH})_{3(\mathrm{~s})}+5 \mathrm{OH}^{-} & \mathrm{E}^{\circ}=-0.3 \mathrm{~V} \\
4 \mathrm{Cr}(\mathrm{OH})_{3}+8 \mathrm{OH}^{-}+3 \mathrm{O}_{2}=4 \mathrm{CrO}_{4}{ }^{2-}+10 \mathrm{H}_{2} \mathrm{O} & \mathrm{E}^{\circ}=+0.52 \mathrm{~V}
\end{array}
$$

5. Conclusions

In summary, it must be emphasized that risk and impact assessments of hazardous wastes and other complex contaminants must not be based on compositional data alone. Chemical and physical properties of the individual components as well as the matrix in which they are contained must be considered. State and Federal agencies are developing regulations to mitigate the adverse impacts of hazardous wastes or other complex contaminants. The scientific community which understands this chemical behavior must give impact to the formulation of these regulations.

\section{References}

[1] 40CFR 261, Federal Register, U.S. Environmental Protection Agency, Vol. 45, No. 98, Book 2, May 19, 1980.

[2] California Assessment Manual for Hazardous Waste, California Department of Health Services, Hazardous Materials Management Section, June 1981. 
Discussion

Question (D. A. Klein): In over 30 days with citrate as a carbon source, I wonder what sort of interesting biological processes could be going on with your leaching tests. Do you have any way of stopping potential biological transformations in your test, or do you simply presume they don't occur?

Answer: We know this can be a complicating factor. Should one sterilize the medium, or run the test aerobically or anaerobically? The basic rationale behind the EPA test and the California WET is to model the real environment, including biological processes going on. That makes it more difficult to understand but now we let the biological activity take whatever route it chooses to take. We do the tests anaerobically, and in some cases this is a very important factor.

Question (W. H. Kirchhoff): In your 30-day test you found metal concentrations increasing, then later decreasing in the extract. Was this because of the analytical sampling procedure? [STide not presented in paper - Eds.]

Answer: No. Reproducibility of results becomes relatively good after 5 to 6 days, but after 24 hours reproducibility is poor. I think it is a function of sample active surface area, particle size among other things. Trying to base regulatory decisions on such time sample dependent tests with variable results is extremely difficult.

Question (W. H. Kirchhoff): Have you tried a chromatographic approach where you fill a column with the sample material and elute the citrate buffer through for a very long period of time? This would tend to duplicate the leaching process more accurately.

Answer: No, we haven't done that, but many people have in this country and Europe. The results are difficult to interpret and generally take a lot more work. I think the serial batch technique has advantages in terms of data handling and in terms of reducing analysis time. 
The Role of Metal-Heteroatom Complexes

in Fossil Fuel Production

Teh Fu Yen

University of Southern California

Los Angeles, CA 90007

Many metal-containing organic species of biological origin are present in the precursors of fossil fuel deposits which have undergone geological transformations through biostratinomy (change after death) and taphonomy (fossilization). The reactions of these molecules during extraction, recovery, conversion, refining, and combustion are anticipated to alter the composition and chemical nature of the fuel end-product and the pollutant by-products. Chemical modification, decomposition, and resynthesis of complexes and the consequent structural changes of the ligands together with the donor atommetal interactions are possible. The unique nature of nitrogen, sulfur, and oxygen bonding to various metals, before and after pyrolysis and carbonization, for coal, heavy oil, oil shale, and tar sands is discussed. Studies in this vast unexplored area are anticipated to provide insight into the planning of strategies for monitoring methodology and control technology.

Key words: fossil porphyrins; fuel conversion; fuel extraction; heterocyclics; metal chelates; metallo-complexes; pollutant properties; origin of pollutants; synfuel.

Chelation reactions in soil as well as the transport properties of metal chelates in plants are essential for many forms of biomass [1] (Figure 1). The taphonomy process, which represents the change from a living organism to fossil remains is as follows:

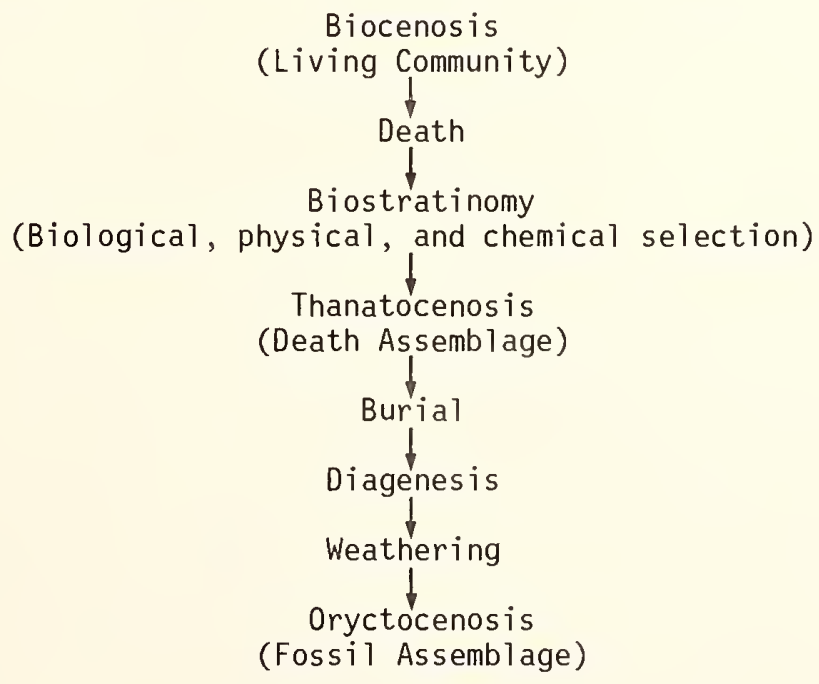




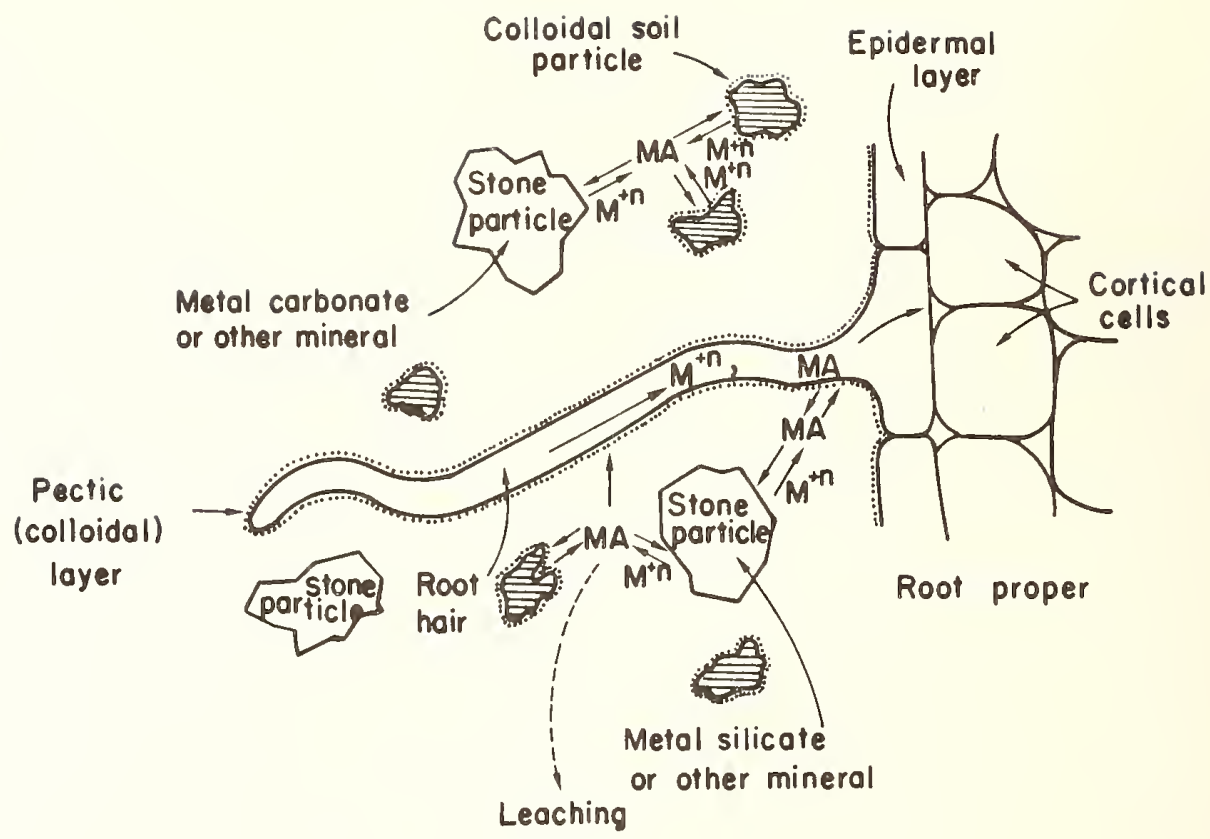

Figure 1. The transport of nutrients from soil to a plant by chelation; MA, is metal chelate [after Reference 1]. The moiety A of some MA can be synthesized by soil microorganisms.

During fossilization and the subsequent diagenesis and weathering process, the metal chelates or complexes also undergo various types of chemical reactions. For example, in general chlorophyll a is accepted as the precursor of most metallo-porphyrin complexes isolated in fossil fuels, including petroleum. Yet the final product is always the vanadyl chelate of porphyrin or arylporphyrin [2]. The stability of metallo-porphyrin complexes is the key for this phenomenon. For

$$
\mathrm{MP}+2 \mathrm{H}^{+} \rightrightarrows \mathrm{PH}_{2}+\mathrm{M}^{2+},
$$

where MP is metalloporphyrin and $\mathrm{PH}_{2}$ is free base porphyrin, stability increases as one reads downward:

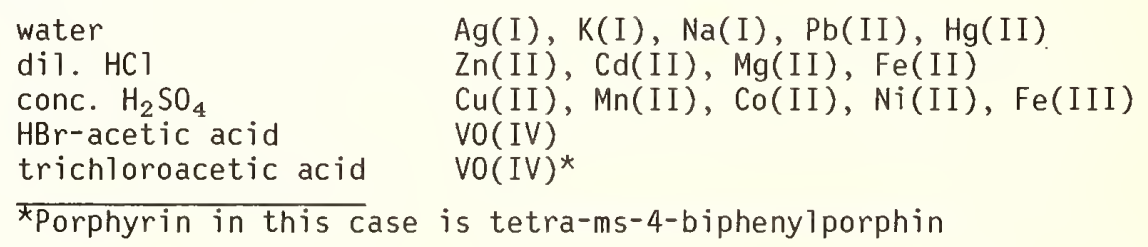

Demetallation proceeds with ease when the chelating metal is magnesium, but proceeds with great difficulty when the system is highly aromatic on the periphery of the 18-electron $\pi$-system and the metal is vanadium [3]. Depending on the environmental conditions, a metallo-complex can be demetallated or undergo the ligand exchange reaction. In many instances, the ligand, after the removal of metals, will undergo further chemical reactions, such as oxidation, degradation, and decomposition. This is evidenced by the presence of various metallic species in petroleum so far identified: 
(a) Metalloporphyrin chelates

(aa) vanadyl and nickel porphyrins

(ab) chlorophyll a and other hydroporphins

(ac) highly aromatic porphin chelates

(ad) porphyrin decomposition ligands

(b) Transition metal complexes of tetradentate mixed ligands such as $\mathrm{V}, \mathrm{Ni}, \mathrm{Fe}, \mathrm{Cu}$, $\mathrm{Co}$, and $\mathrm{Cr}$

(ba) simple complexes from resin molecules

(bb) chelates from asphaltene sheets

(c) Organometaliic compounds such as $\mathrm{Hg}, \mathrm{Sb}$, and $\mathrm{As}$

(d) Carboxylic acid salts of the polar functional groups of resins, such as Mo and Ge

(e) Colloidal minerals, such as silica and $\mathrm{NaCl}$.

Even in the Class (b) listed above, the possible mixed ligand sites of petroleum are:

\section{Ligand Sites}

$4 N^{*}$, porphyrins

$3 \mathrm{~N} 10$

$2 \mathrm{~N} 20^{*}, \alpha-$ ketimines

$1 \mathrm{~N} 30$, N(2-hydroxyphenyl) salicylidenimine

$40, \beta$-diketones

$3015^{\star}$

2025 , monothio- $\beta$-diketones

1035

$4 S^{*}$ dithiocarbonates

$3 S 1 N^{*}$

$2 \mathrm{~S} 2 \mathrm{~N}^{*}$

$153 \mathrm{~N}$

$\mathrm{S} 02 \mathrm{~N}$

SN2O

N02S

* found in resin molecules

One of the problems of porphyrins is that they undergo oxidative decomposition at elevated temperatures [4]. In case of oil shale, one of the nitrogeneous components of retort water organics is methylethyl maleimide (Figure 2) [5]. This single isomer must be derived from the precursor etioporphyrin (Figure 3). In this case it can be concluded there is no other type of prophyrin but the etio type. Little phyllo nor rhodo, petroporphyrins of carbon number greater or less than 32, exist in the Green River oil shale sample. Furthermore, it should be mentioned that vanadyl porphyrin in the oil may not be a pollutant, but its decomposition product, the maleimide, may be physiologically active.

The ligands of common chelates usually consist of multifunctional organic acids, phenols, and amines (Figure 4). Common pollutants of the phenolics in all fossil fuel production effluents are well known [6]. Formation of nitrogeneous compounds from phenols is also known [7](Figure 5). Large numbers of nitrogeneous heterocyclics have been identified from oil shale products and effluents, such as indoles, pyridines, quinolines, pyridines, etc. [8,9]. In the refractory, fraction of oil shale retort water the nitrogeneous compounds found are in a number of unusual systems, some containing other heteroatoms. Typical examples are shown in Figure 6 [10]. Many of these are physiologically active, e.g., the indole structures contribute hallucinatory and neurohumorous properties (Figure 7). 


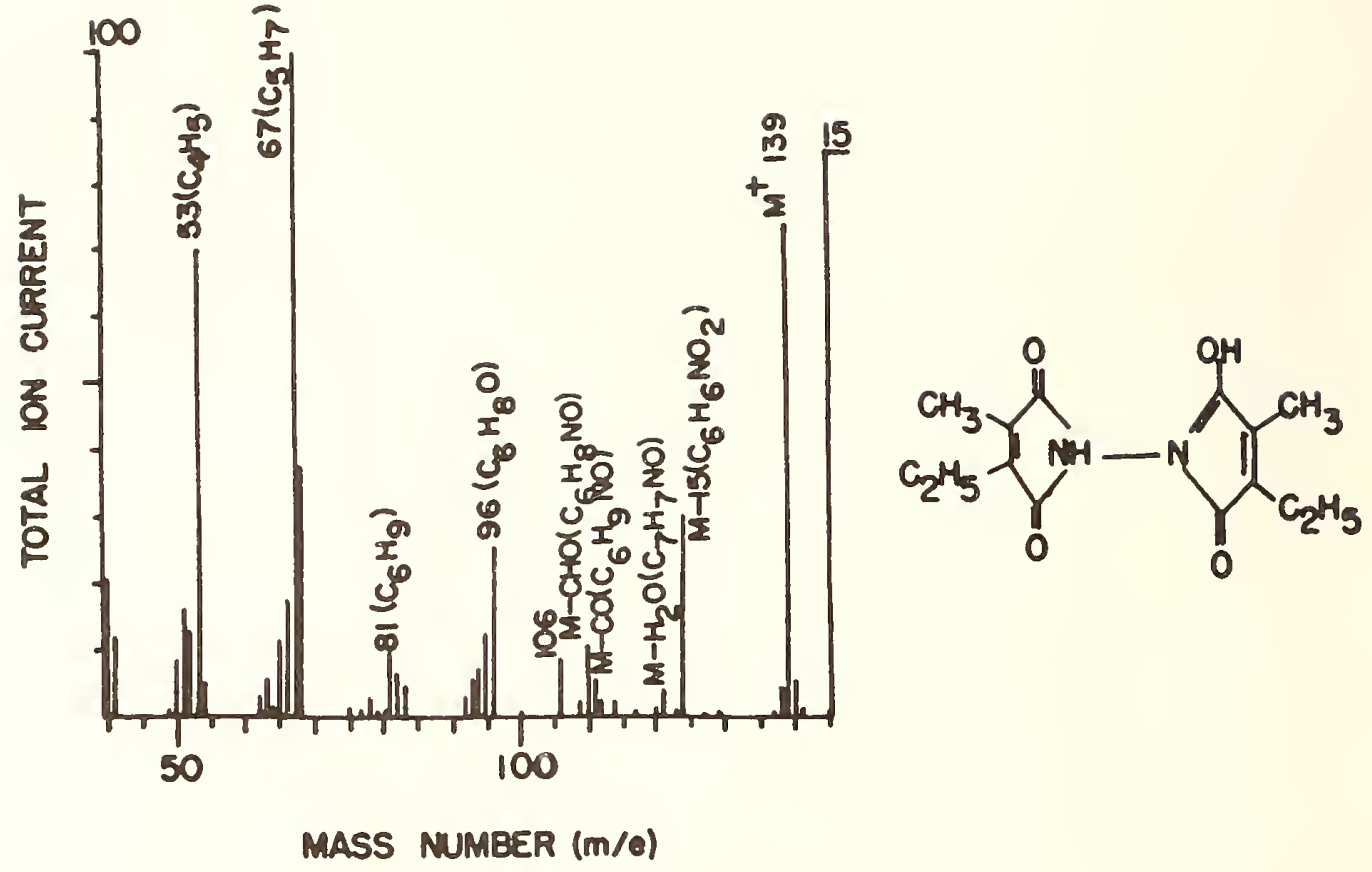

Figure 2. Mass spectrum of maleimide identified in oil shale retort water (wastewater is obtained from LETC 10-ton simulated in situ retort).

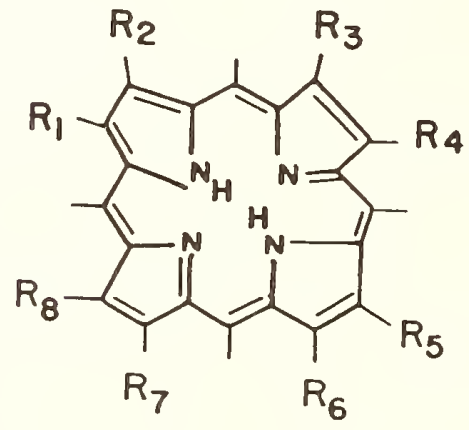<smiles>[R]C1=C([R])C(=O)NC1=O</smiles>

Figure 3. Oxidative degradation of porphyrin into maleimides 
<smiles>O=C(O)C[C@@]12CO[C@](O)(O1)C(O)(O)O[C@H]2O</smiles>

$\mathrm{Fe}(111)$ citrate (trihydrate)<smiles>O=C1CC2(O)CCOOC(O)(OC2)OO1</smiles>

Ca(II) citrate (hydrate)

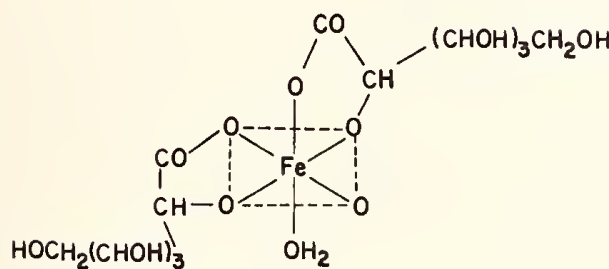

$\mathrm{Fe}(I I I)$ glucanote

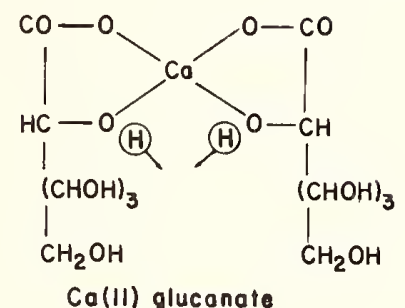

$\mathrm{Ca}(I I)$ gluconate

Figure 4. Chelates formed from common acids.

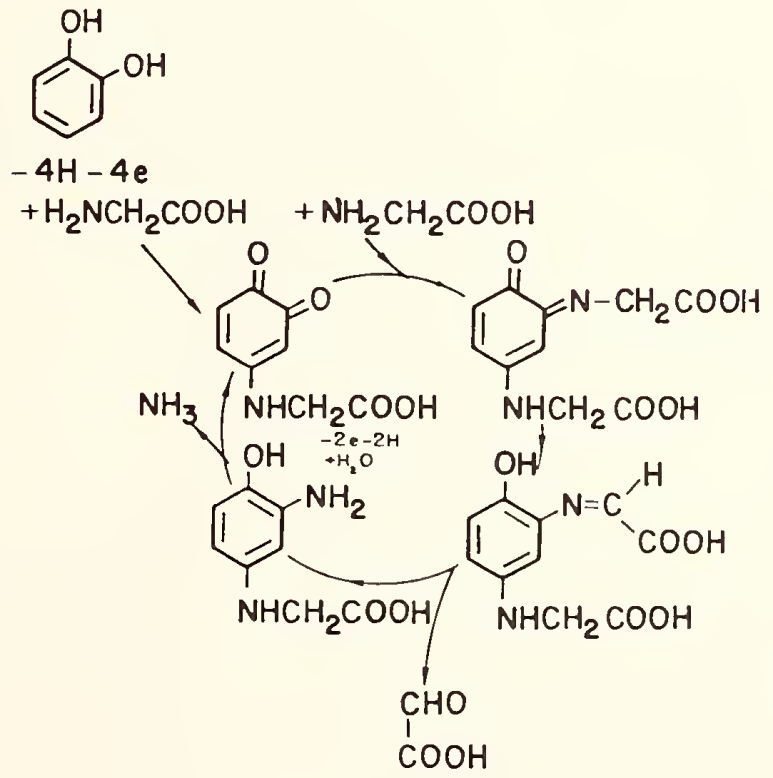

Figure 5. Formation of nitrogeneous compound from diphenols with amino acids in the presence of phenoxidases. 
<smiles>Nc1ccccn1</smiles>

2-PYRIDINAMINE<smiles>N#Cc1ccccc1C#N</smiles>

1,2-BENZFENE DICARBONITRTE<smiles>Cc1cnccn1</smiles>

2-METHYL PYRAZINE<smiles>CC1CC(=O)NC(=O)N1</smiles>

PYRAMTIDTNEDIONE<smiles>CC1NCNCNC(C)N1</smiles>

OCTAHYDROTETRAZOCDE

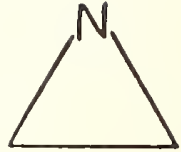

AZIRTDINE<smiles>Nc1ccno1</smiles>

5-AMTINOISOXAZOLE<smiles>O=C1CCC(=O)N1</smiles>

2, 5-PYRROLIDINEDIONE<smiles>CC1=CC2=CC=CCN2C=C1</smiles>

2H-QUINOLIZINE

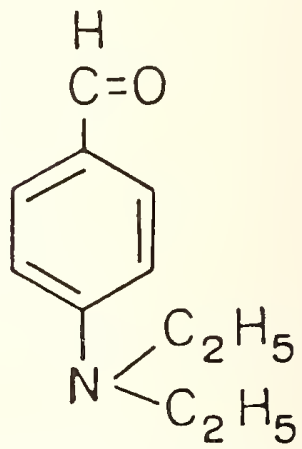

4-DIETHYLAMINO BENRAIDEHYDE

Figure 6. Some unusual nitrogen-containing ring systems found in the organic components of retort water 
<smiles>C[NH+](C)CCc1c[nH]c2cccc([P+](=O)[O-])c12</smiles>

PSILOCYBII, (from Psiliocybe)<smiles>COc1ccc2c(c1)[nH]c1c(C)nccc12</smiles>

HAPMINE (from Epéna snuff)<smiles>COc1ccc2c(OC)c1OCCN2</smiles>

MESCALINE (fron peyote cactus)<smiles>CN(C)CCc1c[nH]c2cccc(O)c12</smiles>

PSILOCIN (from Mexican mushroom)

$\mathrm{HO}$<smiles>CN(C)CCc1c[nH]c2ccccc12</smiles>

BUFOTENINE (from Indian srouff)<smiles>CCc1ncc(OC)c2c1[nH]c1ccccc12</smiles>

CPENATINE (from Pliocarfa)<smiles>COc1cc(OC)c(OC)c(OC)c1</smiles>

RESERPIN (antihypertensive albloid:

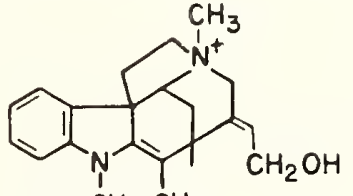

$\mathrm{CH}_{2} \mathrm{CH}_{2}$

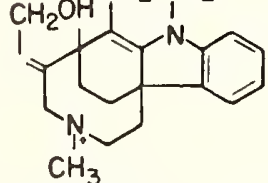

TRXIFERIlE I \& Calabast Curare

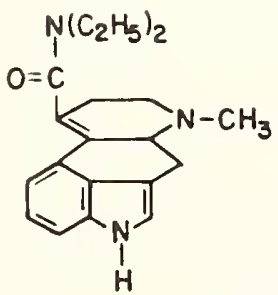

LSD (synthesized from ergot, a creal fungus)<smiles>COc1cc2[nH]c(OC)c(CCN3CCN(O)CC3)c2cc1OC</smiles>

OXYPERTINE (known antipsycholis<smiles>O=c1c2ccccc2nc2n1CCC1=C2NC2C=CC=CC12</smiles>

PUTECAPPI:E (Chiness bruo

CIRGDOUINE (from Remijia, antimalarial)

Figure 7. Compounds from naturally-occurring plants and cells containing indole systems

In order to produce transportable and pumpable fuels (portable), chemical conversion and refining methods involving heat are used on all types of raw fossil fuels. As a result, the weak linkages can be broken and metallo-organic bonds are disassociated. The resulting ligands would usually consist of heterocyclic atom-containing molecules. Such nitrogen-, oxygen-, and sulfur-bearing species will be polar and rather active toward other molecules. Therefore, the possibility of metal-ligand recombination is not ruled out. Ligand exchange resulting in different classes of metallo-organic complexes can be explained. 
We recently found a large number of $\mathrm{N}$-nitrosoamines in the coal wastewater [11]. We also observed some phenylhydrazines, but the $\mathrm{N}$-nitrosoamine was only found in the gas condensates. Possibly the generation is by oxidation, for example, if nitrous acid or dinitrogen trioxide is available.

$$
\begin{aligned}
& 2 \mathrm{NO}_{2}+\mathrm{H}_{2} \mathrm{O} \rightleftharpoons \mathrm{HONO}+\mathrm{H}^{+}+\mathrm{NO}_{3}^{-} \\
& 2 \mathrm{HONO}^{-} \rightleftarrows \mathrm{O}=\mathrm{N}-\mathrm{O}-\mathrm{N}=0+\mathrm{H}_{2} \mathrm{O}
\end{aligned}
$$

The presence of nitrous acid has been reported in coal gasification water [12]. Accordingly, in contact with an amine, a $\mathrm{N}$-nitrosoamine is formed.

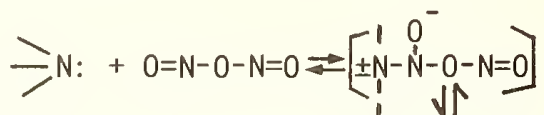

$$
\begin{aligned}
& \pm N-N=0+\mathrm{NO}_{2}{ }^{-}
\end{aligned}
$$

If the amine is secondary or tertiary with two alkyl substituents, then the N-nitrosodialkylamine will be formed. However, if there is a primary amine, a hydrazine is anticipated, the intermediate would be diazotic acid and diazonium salt in acidic conditions.

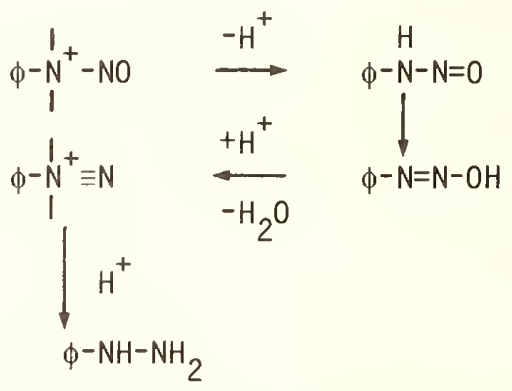

This will definitely suggest that the chemical composition of coal wastewater from gasification is different from that of liquefaction. Many pollutant by-products and co-products are a consequence of the reaction due to thermal decomposition or due to some other reactants which react with the active components from the thermal decomposed products. Assuming starting fossil fuel is $F_{j},(i=1,2, \ldots n)$, the conversion reactant or additive is $R_{i}$, the resulting species can have the following 4 major types, for which $M_{i}$ is intermediate.

(1) $F_{i} \longrightarrow M_{i} \longrightarrow 1_{i}$

(2) $R_{i}+F_{j}$ (or $M_{i}$, or $\left.1_{j}\right) \rightarrow 2_{i}$

(3) $1_{i}+2_{i} \rightarrow 3_{i}$

(4) $1_{i}+1_{i-1}\left(\right.$ or $\left.3_{i}\right) \rightarrow 4_{i}$

Since the generation and origin of many of the identified priority pollutants [13] are not known, basic research is greatly needed at this time. As described $1_{i}, 2_{i}, 3_{i}$, and $4_{i}$ are generically different pollutants; in other words they can be described as:

1. Molecules strictly derived from thermal decomposition of fossil fuel.

2. Molecules generated by the reactants added to fossil fuel, e.g., hydrogen, solvent, nitrogen, oxygen, catalysts, etc. 
3. Molecules obtained by the interaction of simple species to the thermally decomposed products. Simple species could be ammonia, hydrogen sulfide, chlorine, etc.

4. Molecules derived by the interaction between two decomposed species (from No. 1 route) or the species being chemically modified (from No. 1 to No. 3 ).

Different fossil fuels will have different compositions. For example, the major metal contents in the asphaltene fractions of petroleum, shale, and coal are considerably different (Table 1) [14]. Recently our findings $[15,16]$ of the geological pigment porphyrins indicate that the fossil porphyrins in each fuel are quite different. For porphyrins isolated from petroleum the carbon number varies from $C_{16}$ to $C_{50}$ and up. For coal this distribution has been observed to be limited only by $C_{32}$. For oil shale porphyrin, the variation is even more pronounced. The Devonian shale porphyrin has a number of homologs (more than petroleum) and also has the span of $\mathrm{C}_{26}$ to $\mathrm{C}_{38}$. On the other hand, for Green River oil shale, the porphyrin type is close to that of a low-ranking coal. This difference not only shows the distinctive features in geochemical genesis and deposition histories of fossil sources, but also provides a new insight in the properties of pollutants and their physiological activities. For example, even the aqueous extract of some typical coal liquids exhibited mutagenicity by histidine reversion using Salmonella (Ames test, Tier I) (see Figure 8) [17].

Table 1. Compositional Differences of Asphaltenes Isolated

\begin{tabular}{|c|c|c|c|}
\hline & Crude Petroleum & $\begin{array}{l}\text { Oil Shale } \\
\text { (Green River) }\end{array}$ & Coal \\
\hline \multicolumn{4}{|l|}{ General } \\
\hline Metals & $\mathrm{V}, \mathrm{Ni}$ & $\mathrm{Fe}, \mathrm{Ni}$ & Ge, Mo \\
\hline $\begin{array}{l}\text { Major Heteroatoms } \\
(\mathrm{N}, 0, \mathrm{~S})\end{array}$ & $S$ & N & 0 \\
\hline Aromatics & peri & kata or link & kata \\
\hline \multicolumn{4}{|l|}{ Structural Parameters } \\
\hline$f_{a}$ & $0.2-0.5$ & 0.4 & $0.6-0.7$ \\
\hline$L_{a}(\AA)$ & $10-15$ & $7-12$ & $7-14$ \\
\hline Lc $(\AA)$ & 20 & 15 & 10 \\
\hline$\sigma$ & $0.5-0.7$ & $0.5-0.6$ & $0.3-0.5$ \\
\hline $\mathrm{H}_{\mathrm{I}} / \mathrm{C}_{\mathrm{A}}$ & $0.3-0.5$ & $0.8-0.9$ & $0.6-0.8$ \\
\hline$n$ & $4-6$ & $2-3$ & $1-2$ \\
\hline \multicolumn{4}{|l|}{ Fossil Porphyrins } \\
\hline $\begin{array}{l}\text { C No. } \\
\text { type }\end{array}$ & $\begin{array}{l}C_{26}{ }^{-C_{50+}} \\
\text { DPEP, Etio, Phyllo }\end{array}$ & $\begin{array}{l}\mathrm{C}_{28}-\mathrm{C}_{32} \\
\text { Etio }\end{array}$ & $\begin{array}{l}\mathrm{C}_{26}-\mathrm{C}_{32} \\
\text { Etio }\end{array}$ \\
\hline distribution & smooth Gaussian & & $\begin{array}{l}\text { even no. } \\
\text { predominant }\end{array}$ \\
\hline $\begin{array}{l}\text { maturation } \\
\text { mechanism }\end{array}$ & therma 1 & $\begin{array}{l}\text { according to } \\
\text { deposition } \\
\text { environment }\end{array}$ & oxidative \\
\hline
\end{tabular}




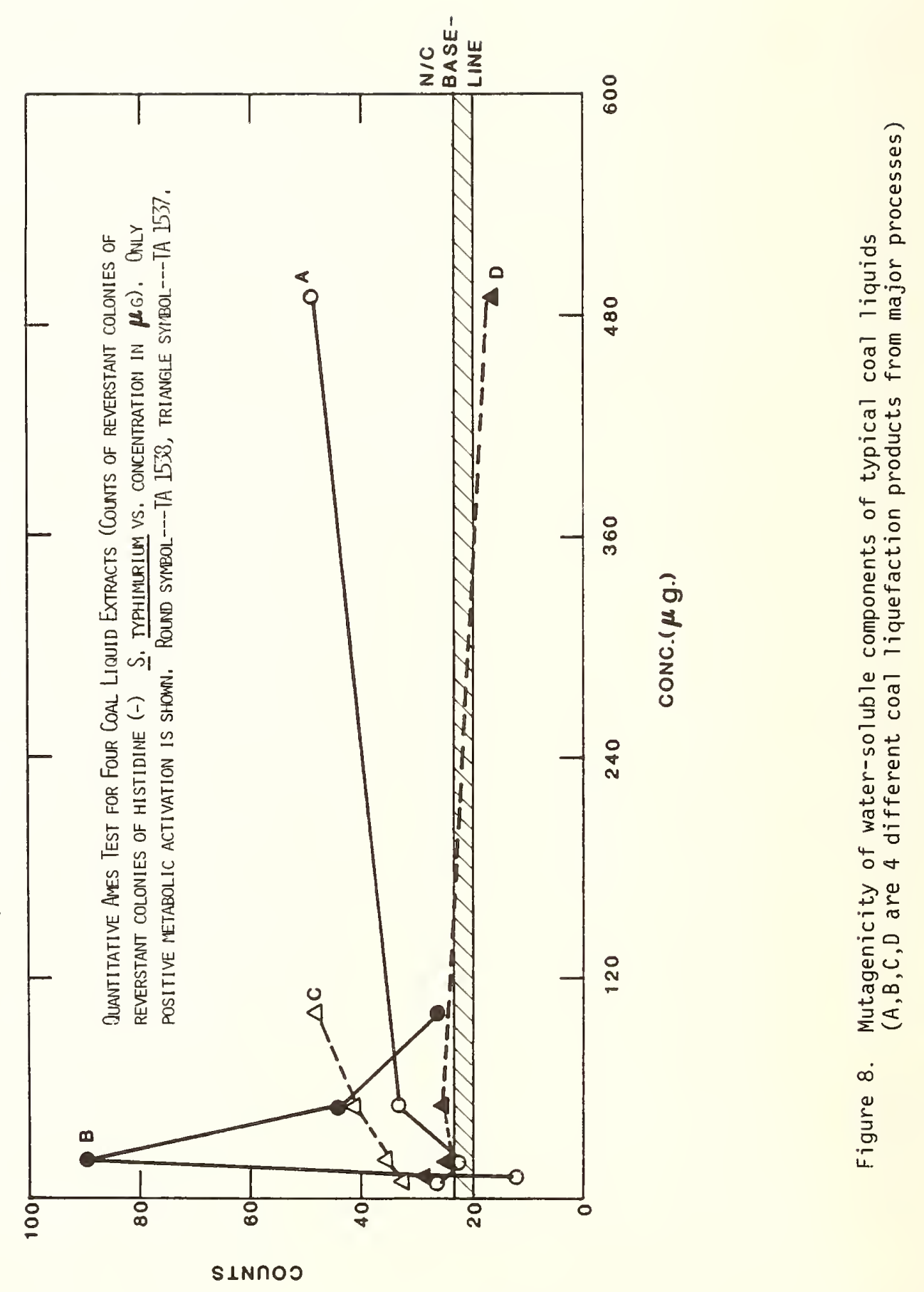


Fundamental studies in this area are lacking. It is important to acquire chemical information so that better planning of monitoring strategies and control technologies can be achieved.

Acknowledgment

The author gratefully acknowledges the support of U.S. Department of Energy under contract no. DE-AT03-76EV10017 and grant No. ET-78-G01-12162. Partial support from U.S. Environmental Protection Agency grant No. R806167 is also acknowledged.

References

[1] Chaberek, S.; Martel1, A. E. Organic sequestering agents. New York: Wiley; 1959.

[2] Yen, T. F. Terrestrial and extraterrestrial stable organic molecules, in Chemistry in space research. R. F. Landel and A. Rembaum, ed. New York, NY; El sevier Publ Co.; 1972. 105-153.

[3] Yen, T. F. The role of trace metal in petroleum. Ann Arbor: Ann Arbor Science Pub.; 1975.

[4] Mobashery, S.; Yen, T. F. unpublished work.

[5] Slawson, G. S.; Yen, T. F. Compendium reports on oil shale technology. Environmental Protection Agency. (U.S.) EPA-600/7-79-039; 1979.

[6] Yen, T. F.; Wen, C. S. The role of phenolic compounds in retort water. Fossil fuels technology, Rocky Mountain regional meeting, Laramie, WY, 1976 June 17.

[7] Ishiwatari, R. Organic polymer in recent sediments--Chemical nature and fate in geological environment, Doctoral thesis. Tokyo Metropolitan Univ.; 1971.

[8] Shue, F. F.; Yen, T. F. Concentration and selective identification of nitrogen- and oxygen-containing compounds in shale oil. Anal. Chem. in press.

[9] Shue, F. F.; Yen, T. F. unpublished work.

[10] Washburne, M. R.; Yen, T. F. Organic and inorganic pollutants in oil shale and coal conversion wastewaters. Toxic materials and the chemical industry. 70 th Annual AIChE technical meeting. Anaheim, CA: 1981 April 21.

[11] Yen, T. F.; Tng, J. I. S.; Washburne, M. R.; Cohanim, S. Analys is of hazardous organics present in liquid waste from coal conversion processes. Environmental Protection Agency. (U.S.) EPA-600/4,R-806167-02; 1981.

[12] Braunstein, H. M. ; Copenhaver; Pfuderer, H. A. Environmental health, and control aspects of coal conversion: an information overview. Vol. 1. Oak Ridge National Laboratory. ORNL/EIS-94; 1977.

[13] Tang, J. I. S. ; Kawahara, F. K.; Yen, T. F. Separation and identification of the organic species in coal conversion process wastewater, in Chemical and geochemical aspects of fossil energy extraction. Woburn, MA; Butterworth; 1981.

[14] Yen, T. F. Structural aspects of mesophase materials from petroleum, coal, and oil shale. 13th Biennial Conference on Carbon, Irvine, CA; 1977. Extended abstracts and program. 322-323.

[15] Lin, W. C.; Yen, T. F. A comparison of prophyrins in oil shale, shale oil, and petroleum sources. Second Chemical Congress of North America. Las Vegas, NV. 1980 Aug. 28. 
[16] Gu, Y. D.; Yen, T. F. Isolation of porphyrins from coals. Pacific Conference on Chemistry and Spectroscopy. Anaheim, CA: 1981 0ct. 19.

[17] Tang, J. I. S. Studies of liquid effluents from synthetic fuel conversion processes. Ph.D. dissertation. Univ. of Southern California; 1980.

Discussion

Question (R. H. Fish): Dr. Yen, could you address the vanadyl type complexes that have not yet been identified? You talked about the porphyrins and other possible ligands, but a large amount of other vanadium compounds have not been identified. I wonder if you could tell us what you know of those that have been identified or what is the status of the rest in crude oil?

Answer: In any crude oil about 50 percent are non-porphyrin vanadyl complexes. We have identified a few in the past and many of the mixed ligands. The situation is quite complex since there are examples of mixed ligands with sulfur, with nitrogen, maybe with two or three nitrogens with oxygen. [T. F. Yen, Energy Sources, $\underline{3}, 339$ (1978)]. These materials give some characterization problems. First of all, we are limited by the spectroscopic methods, such as high-resolution mass spectrometry which can show empirically that these complexes can exist. My feeling is that if you're trying to identify all the different types of vanadyl-chelates in crude oil it's a very difficult task. There are cases, particularly with sulfur, that may be of commercial interest, especially in catalysis or the refining of heavy oil. I think these things are not fully investigated; we are limited by effort. Maybe someone here could make such investigations. 


\section{Coal Liquefaction Processes}

R. H. Filby' ${ }^{1}$, D. R. Sandstrom ${ }^{2}$, F. W. Lytle $e^{3}$,

R. B. Greegor ${ }^{3}$, S. R. Khali ${ }^{4}$, V. Ekambaram ${ }^{1}$,

C. S. Weiss ${ }^{5}$ and C. A. Grimm?

Washington State University

Pullman, Washington 99164

A combination of chemical and physical techniques has been used to investigate trace element species in Solvent Refined Coal (SRC) solid and liquid products and in important waste streams. Neutron activation analysis, atomic absorption spectroscopy, and liquid chromatography have been used to obtain information on possible trace element species present in solid SRC I and liquid SRC II products derived from coal. EXAFS has been used to characterize Ti species in coal, SRC I, and SRC II liquefaction residues. The chemistry of volatile species of $\mathrm{Hg}$, As, and $\mathrm{Se}$ in the SRC processes is discussed in relation to their concentration in waste streams. The formation of metal-organic complexes by elements such as $T i, V$, etc., during coal hydrogenation is discussed in relation to their chemical forms in coals.

Key worcs: arsenic; cobalt; coal hydrogenation; chromium; liquefaction; mercury; nickel; process waters; selenium; solvent refined coal; titanium; trace elements

\section{Introduction}

Coal conversion processes represent potential discharges of toxic element species to the environment and, to date, relatively little work has been done to identify such species in environmental monitoring. Indeed, little is presently known about trace element moieties formed either in coal gasification or liquefaction processes although gross elemental material balance studies have been made for several important processes. This paper is an attempt to summarize recent trace element data on the Solvent Refined Coal (SRC) processes which relate to trace element speciation.

The similarities and differences among such conversion processes as direct coal liquefaction, heavy oil upgrading, coal gasification, and oil shale retorting are shown in Table 1. It can be seen that both non-catalytic direct coal liquefaction processes, exemplified by the SRC I and SRC II processes, and catalytic processes represented by the H-COAL and the Exxon Donor Solvent (EDS) processes, more closely resemble the conditions of catalytic

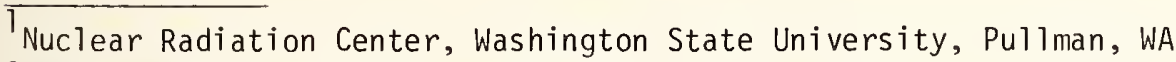

${ }^{2}$ Department of Physics, Washington State University

${ }^{3}$ The Boeing Company, Seattle, WA

${ }^{4}$ Department of Chemistry, University of Kentucky, Lexington, $\mathrm{KY}$

${ }^{5}$ National Bureau of Standards, Washington, DC
} 
heavy oil upgrading (e.g., hydrodesulfurization, hydrotreating, etc.) than either coal gasification or oil shale retorting. The relatively low temperatures $\left(450-550^{\circ} \mathrm{C}\right)$, high $\mathrm{H}_{2}$ pressure (100-150 atm), reducing conditions, and the presence of a reactive hydrogen-donor solvent provide conditions suitable for the formation of volatile hydrides or reduced species of certain elements, e.g., $\mathrm{Hg}^{\mathrm{O}}, \mathrm{AsH}_{3}, \mathrm{H}_{2} \mathrm{Se}$, etc. The presence of reactive free radicals formed during the pyrolysis stage of coal liquefaction may provide suitable conditions for the formation of organometallic complexes or other organic complexes of metals. Although the work reported here concerns primarily the SRC I and SRC II process, conclusions about the behavior of elements such as $\mathrm{Hg}$, Se, As, and $\mathrm{Ti}$ should apply to other direct 1 iquefaction processes.

Table 1. Comparison of general conditions of conversion processes.

\begin{tabular}{|c|c|c|c|c|c|c|}
\hline \multirow[t]{2}{*}{ CONDITION } & \multirow{2}{*}{$\begin{array}{l}\text { HEAVY OIL } \\
\text { UPGRADING }\end{array}$} & \multicolumn{2}{|c|}{$\begin{array}{c}\text { COAL } \\
\text { LIQUEFACTION }\end{array}$} & \multicolumn{2}{|c|}{$\begin{array}{c}\text { COAL } \\
\text { GASIFICAT ION }\end{array}$} & \multirow{2}{*}{$\begin{array}{l}\text { OIL SHALE } \\
\text { PYROLYSIS }\end{array}$} \\
\hline & & $N C^{*}$ & C & KOPPERS & LURGI & \\
\hline Temp $\left({ }^{\circ} \mathrm{C}\right)$ & $400-600$ & $450-550$ & $450-550$ & 1600 & $<1000$ & 900 \\
\hline Press (atm) & $70-140$ & $100-150$ & $100-150$ & 2 & 20 & 1 \\
\hline Catalyst & $\mathrm{Co} / \mathrm{Mo}$ & none & $\mathrm{Co} / \mathrm{Mo}$ & none & none & none \\
\hline Gas & $\mathrm{H}_{2}$ & $\mathrm{H}_{2}$ & $\mathrm{H}_{2}$ & $\mathrm{H}_{2} \mathrm{O} / \mathrm{O}_{2}$ & $\mathrm{H}_{2} \mathrm{O} / \mathrm{O}_{2}$ & air \\
\hline \multirow{4}{*}{$\begin{array}{r}\text { Product } \\
\text { Gases }\end{array}$} & $c_{1}-c_{5}$ & $C_{7}-C_{5}$ & $C_{1}-C_{5}$ & $\mathrm{CO} \quad \mathrm{CO}_{2}$ & $\mathrm{H}_{2} \mathrm{O} \quad \mathrm{CO}$ & $C_{1}-C_{4}$ \\
\hline & $\mathrm{H}_{2} \mathrm{~S}$ & $\mathrm{H}_{2} \mathrm{~S} \quad \mathrm{NH}_{3}$ & $\mathrm{H}_{2} \mathrm{~S} \quad \mathrm{NH}_{3}$ & $\mathrm{~N}_{2} \quad \mathrm{NH}_{3}$ & $\mathrm{H}_{2} \quad \mathrm{NH}_{3}$ & $\mathrm{H}_{2} \mathrm{~S} \quad \mathrm{CO}_{2}$ \\
\hline & $\mathrm{NH}_{3}$ & $\mathrm{CO} \mathrm{H}_{2} \mathrm{O}$ & $\mathrm{CO} \mathrm{H}_{2} \mathrm{O}$ & $\mathrm{H}_{2} \mathrm{O}$ & $\mathrm{CO}_{2}$ & $\mathrm{H}_{2} \quad \mathrm{NO}_{\mathrm{X}}$ \\
\hline & & $\mathrm{CO}_{2}$ & $\mathrm{CO}_{2}$ & & & $\mathrm{CO}$ \\
\hline
\end{tabular}

${ }^{\star} \mathrm{NC}=$ Non-Catalytic $\quad \mathrm{C}=$ Catalytic

Knowledge of the behavior and fate of trace elements in coal liquefaction processes, such as SRC I and SRC II, is important because of possible effects of trace elements on the conversion process (i.e., catalytic effects or catalyst deactivation), effects on product properties, and potential environmental effects. Some of the important environmental aspects of trace element behavior in the SRC processes which imply knowledge of chemical speciation are:

i) the potential for release of volatile toxic element species from gas streams, e.g., $\mathrm{H}_{2} \mathrm{Se}, \mathrm{Hg}^{\mathrm{O}}, \mathrm{AsH}_{3}, \mathrm{SbH}_{3}$

$\mathrm{ii}$ the possible formation of volatile carbonyls, e.g., $\mathrm{Ni}(\mathrm{CO})_{4}$ and release to the plant envi ronment

iii) the formation of toxic metal-organic complexes or true organometallic species and incorporation in products

iv) the mobilization of toxic element species from coal to process waters and their effect on water treatment processes. 
2. The Solvent Refined Coal Processes

Both SRC I and SRC II processes developed by the Pittsburg \& Midway Coal Mining Co., under contract to the U.S. Department of Energy, involve the non-catalytic hydrogenation of coal at elevated temperature and pressure in the presence of a hydrogen-donor solvent. In the SRC I process, coal is pulverized, mixed with a recycle solvent, and is heated at $450^{\circ} \mathrm{C}$ with $\mathrm{H}_{2}$ at $102 \mathrm{~atm}$ pressure for an effective reaction time of approximately 0.5 hours.

The liquefaction chemistry is complex and incompletely understood; in the initial pyrolysis step the coal matrix is partially depolymerized and the free radicals formed are hydrogenated via donor solvent molecules (e.g., tetralin, decalin, etc.) to give a mixture of low and high molecular weight hydrocarbons, hydrocarbon derivatives, heterocyclic compounds, Co, $\mathrm{CO}_{2}, \mathrm{H}_{2} \mathrm{O}, \mathrm{H}_{2} \mathrm{~S}$, and $\mathrm{NH}_{3}$ plus mineral matter and unreacted coal. After gas removal by pressure let-down, the slurry is filtered to remove mineral matter and unreacted coal, the solvent is flashed off the coal filtrate to recycle in the process, and the resulting solid product is low sulfur, low ash, SRC I. In the SRC II mode the process is similar, except that a higher hydrogen partial pressure (up to $140 \mathrm{~atm}$ ) is used and part of the reacted coal solution is recycled to the reactor to give a longer effective residence time $(0.8-1.0 \mathrm{hrs})$ of the coal in the reactor than in the SRC I process. After reaction, light gases are removed by pressure reduction, the liquid (+ mineral matter) stream is fractionated into light distillate (naphtha), middle distillate, heavy distillate fractions and a residual material (VB = vacuum bottoms) that contains most of the mineral matter, high molecular weight organic material, and unreacted coal. Comparison of the process conditions and yields for typical SRC I and SRC II runs are shown in Table $2[1,2]$. The processes are shown schematically in Figure 1 .

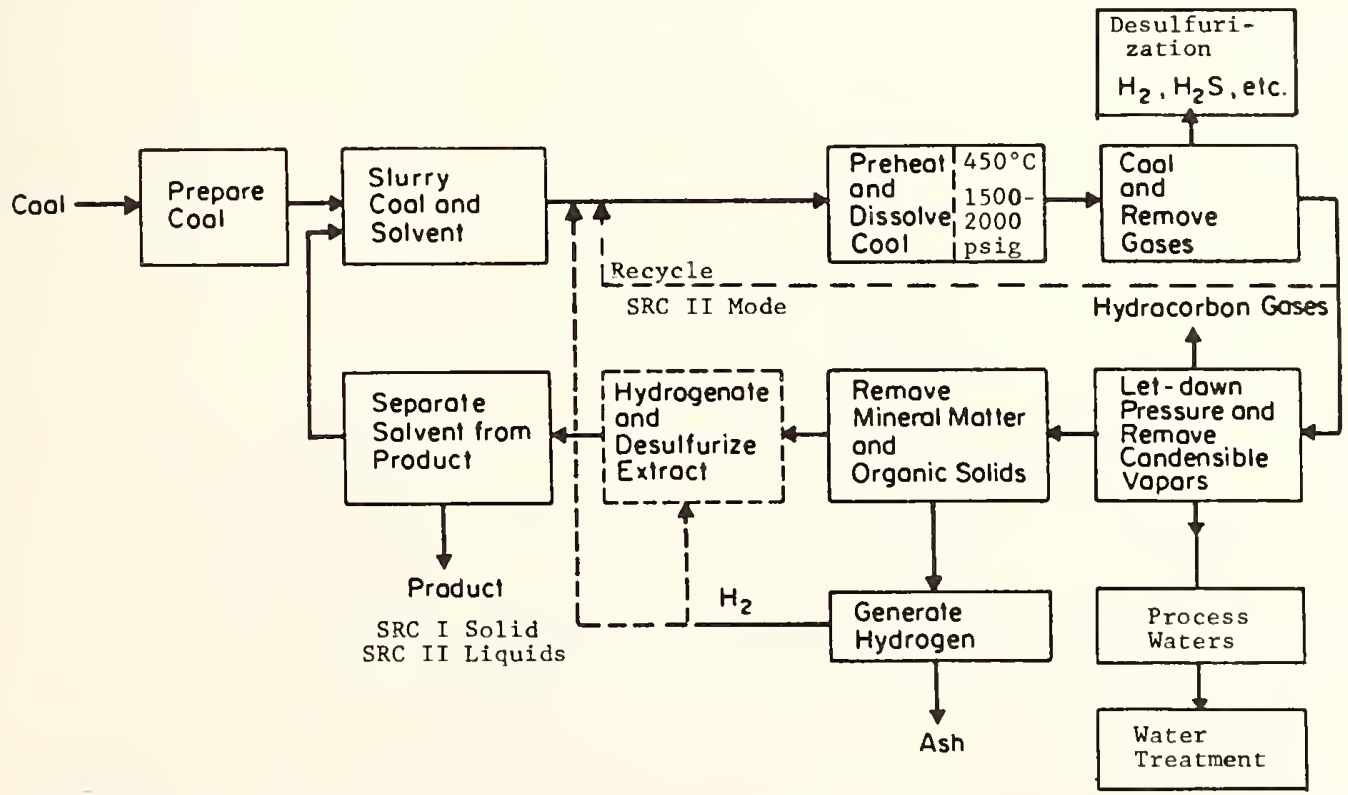

Figure 1. Schematic flow diagram of the Solvent Refined Coal processes, SRC I and SRC II 
Table 2. Comparison of typical conditions and products of SRC I and SRC II processes*

\begin{tabular}{|c|c|c|}
\hline Conditions & SRC I & SRC II \\
\hline Coal & bituminous & bituminous \\
\hline Mode & no recycle & slurry recycle \\
\hline $\begin{array}{l}\text { Average dissolver } \\
\text { temperature }\left({ }^{\circ} \mathrm{C}\right)\end{array}$ & 500 & 450 \\
\hline $\begin{array}{l}\text { Dissolver pressure } \\
\text { (atm) }\end{array}$ & 102 & 128 \\
\hline $\begin{array}{l}\text { Nominal residence } \\
\text { time }(h)\end{array}$ & 0.5 & 0.87 \\
\hline \multicolumn{3}{|l|}{ Products } \\
\hline \multirow[t]{3}{*}{ Gases } & $c_{1}-c_{4}$ hydrocarbon $(5 \%)$ & $\mathrm{C}_{1}-\mathrm{C}_{4}$ hydrocarbon $(10 \%)$ \\
\hline & $\mathrm{CO}, \mathrm{CO}_{2}, \mathrm{H}_{2} \mathrm{O}(5 \%)$ & $\mathrm{CO}, \mathrm{CO}_{2}, \mathrm{H}_{2} \mathrm{O}(10 \%)$ \\
\hline & $\mathrm{NH}_{3}, \mathrm{H}_{2} \mathrm{~S}(2 \%)$ & $\mathrm{NH}_{3}, \mathrm{H}_{2} \mathrm{~S}(3 \%)$ \\
\hline Liquids & light oils (10\%) & $\begin{array}{l}\text { naphtha }(7 \%) \\
\text { middle distillate }(18 \%) \\
\text { heavy distillate }(10 \%)\end{array}$ \\
\hline Solids & $\begin{array}{l}\text { SRC I }(70 \%) \\
\text { mineral residue }(10 \%)\end{array}$ & $\begin{array}{l}\text { vacuum bottoms residue } \\
\text { for gasification }(40 \%)\end{array}$ \\
\hline
\end{tabular}

*Data taken from references 1,2. Percentages in parentheses refer to approximate yields $(\operatorname{coa} 1=100 \%)$.

In the SRC I and SRC II processes there is a significant reduction in sulfur content of the product compared to the original coal. Pyrite, $\mathrm{FeS}_{2}$, is converted to pyrrhotite, FeS, thus:

$$
\mathrm{FeS}_{2(\mathrm{~s})}+\mathrm{H}_{2(\mathrm{~g})} \rightarrow \mathrm{FeS}_{(\mathrm{s})}+\mathrm{H}_{2} \mathrm{~S}(\mathrm{~g})
$$

In addition to a reduction of pyritic sulfur, some of the organically bound sulfur reacts to form $\mathrm{H}_{2} \mathrm{~S}$. This conversion is probably due to reaction of $\mathrm{H}_{2}$ with aromatic - SH groups and by reaction with -S-S- bridging groups in the coal structure. However, some sulfur functionalities, particularly ring-S (e.g., thiophenic S), are retained in the products. 3. Behavior of Trace Elements During Direct Liquefaction

In previous work [3-6] we have reported the distribution of 35 trace elements in both SRC I and SRC II process streams using neutron activation and atomic absorption spectroscopy as analytical techniques. Those studies have reported only elemental concentrations in input and output streams and have not considered chemical forms, al though certain 
deductions about species can be made. In the SRC I process, the filtered mineral residue is the "sink" for most trace elements, with the important exceptions of $\mathrm{Ti}, \mathrm{Cl}, \mathrm{Br}$, and $\mathrm{Hg}$. In genera1, the SRC I product has trace element concentrations of less than $2 \%$ of the concentrations in the coal. Data for some "non-volatile" elements (Ti, Al, K), "volatile" elements ( $\mathrm{As}, \mathrm{Sb}, \mathrm{Se}, \mathrm{Hg}$ ) and possible corrosion product elements ( $\mathrm{Fe}, \mathrm{Co}, \mathrm{Cr}, \mathrm{Ni}$ ) in the major SRC I (Kentucky coal) and SRC II process streams are shown in Table $3[3,4,5]$. In the SRC II process, the SRC II distillate product contains only minor concentrations ( $<1 \%$ of elemental content of the feed coal) of most trace elements, and the vacuum bottoms contain greater than $99 \%$ of each element present in the feed coal. However, $\mathrm{Hg}$ and to a lesser extent Se, As, and Sb are less depleted in the SRC II product. Both SRC I and SRC II process waters show elevated concentrations of $\mathrm{Hg}$, As, $\mathrm{Se}, \mathrm{Sb}$, and $\mathrm{Cl}$; the elements thus are appreciably volatile in the SRC processes. The volatility of $\mathrm{Hg}$, As, Se, and Sb during coal liquefaction is discussed further in Sections 6 and 7. A study of the behavior of $\mathrm{Hg}$ in the SRC II process [6] has shown that coal type is an important factor but it is not known why coals behave differently. In order to understand the chemistry of trace elements in the hydrogenation process, it is necessary to know the chemical and physical forms of such elements in the feed coals.

Table 3. Trace elements in SRC products (ppm)

\begin{tabular}{l|lll||lll}
\hline & \multicolumn{3}{|c|}{ SRC I PROCESS } & & \multicolumn{3}{c}{ SRC I I PROCESS } \\
& COAL & SRC I & RESIDUE & COAL & SRC I I PRODUCT & VB \\
\hline $\mathrm{Ti}$ & 530 & 465 & 3350 & 822 & 0.8 & 1770 \\
$\mathrm{~A} 1$ & 11800 & 200 & 77200 & 13300 & 5.20 & 28000 \\
$\mathrm{~K}$ & 1550 & 4.72 & 11100 & 1580 & 0.32 & 3220 \\
$\mathrm{Fe}$ & 21100 & 300 & 168000 & 14900 & 3.40 & 3500 \\
$\mathrm{Co}$ & 5.88 & 0.22 & 40.7 & 2.69 & 0.002 & 6.24 \\
$\mathrm{Ni}$ & 14.9 & $<3$ & 142 & 8.62 & $<0.02$ & 19.6 \\
$\mathrm{Cr}$ & 13.7 & 1.64 & 106 & 15.1 & 0.032 & 35.8 \\
$\mathrm{As}$ & 12.5 & 2.0 & 85.7 & 6.00 & 0.023 & 15.1 \\
$\mathrm{Se}$ & 2.0 & 0.12 & 16.5 & 1.35 & 0.039 & 3.04 \\
$\mathrm{Hg}$ & 0.113 & 0.040 & 0.508 & 0.170 & 0.023 & 0.094 \\
$\mathrm{Sb}$ & 0.76 & 0.06 & 7.21 & 0.30 & 0.0006 & 0.54 \\
\hline
\end{tabular}

4. Trace Elements in Coals

Many determinations of trace element concentrations in coals have been made in the past 50 years, but much less information is available on trace element species in coals. Elements which are present in the concentration ranges $0.1-10 \%$ are normally present as readily 
identifiable mineral species, e.g., Fe in pyrite, $\mathrm{FeS}_{2}$, or $\mathrm{Si}$ as quartz, $\mathrm{SiO}_{2}$. For elements present at much lower concentrations (i.e.,ppb to ppm), e.g., Hg, As, Se, Co, and $\mathrm{Ni}$, discrete mineral species, if present, are difficult to identify by conventional x-ray diffraction or petrographic techniques because of their low abundance and fine grained nature. In addition, some elements may not be present as discrete minerals but present as substituents in host minerals, e.g., As in pyrite, $\mathrm{FeS}_{2}$, and this association mode is probably very important for certain elements. A third possibility is the existence of organically combined trace elements. Such species probably exist because of the abundance of functional groups in coals and the fact that many elements, e.g., Ti, Fe, V, Cu, etc., form very strong humic acid complexes. The humates may be important for some elements because humic acids may be the precursors to coal macerals.

The identification of trace element species has been hampered by the complex nature of coal. Early work utilized primarily float-sink separations of coals into specific gravity fractions $[7,8,9]$. Recent work [11] has utilized SEFl-EDX and examination of bituminous coals has shown that inorganic associations are more probable than organic for many elements than had been predicted from float-sink data. Mean concentrations in U.S. coals [10] and probable associations of $\mathrm{Hg}$, As, $\mathrm{Sb}$, Se, $\mathrm{Fe}, \mathrm{Co}, \mathrm{Ni}$, and $\mathrm{Ti}$ are shown in Table 4 but it should be stressed that individual coals may show very different distributions depending on depositional factors and later geochemical history.

Table 4. Probable trace element associations in bituminous coals.

\begin{tabular}{lll}
\hline ELEMENT & MEAN CONTENT & \\
U.S. COALS $(\mu \mathrm{g} / \mathrm{g})[10]$ & PROBABLE ASSOCIATION
\end{tabular}

$\mathrm{Hg}$

As

$\mathrm{Sb}$

Se

$\mathrm{Fe}$

Ni

Co

$\mathrm{Ti}$
0.18

150

1.1

4.1

16000

15

7.0

800
Predominantly inorganic; $\mathrm{FeS}_{2}$ most probable host. Organic association possible. HgS and $\mathrm{HgO}^{\circ}$ are possible but rare in coals

Mostly as sulfides; $\mathrm{FeS}_{2}$ most important; FeAsS is rare; other suTfides, e.g., $\mathrm{As}_{2} \mathrm{~S}_{3}$ rare in coals

Mostly as sulfides; $\mathrm{Sb}_{2} \mathrm{~S}_{3}$ possible but not common

PbSe or in sulfides, $\mathrm{FeS}_{2}$, $\mathrm{ZnS}$

$\mathrm{FeS}_{2}, \mathrm{FeCO}_{3}, \mathrm{FeO} . \mathrm{OH}, \mathrm{FeSO}_{4}$

Sulfides, $\mathrm{NiS},\left(\mathrm{Co}, \mathrm{Ni}_{3} \mathrm{~S}_{4} ; \mathrm{FeS}_{2}\right.$ association

Probably sulfide; $\left(\mathrm{Co}, \mathrm{Ni}_{3} \mathrm{~S}_{4} ; \mathrm{FeS}_{2}\right.$

$\mathrm{TiO}_{2}$ (rutile, brookite, anatase), clays; strong organic association in some coals; $\mathrm{FeTiO}_{3}$ 
5. Potential Reactions of Trace Elements in Coal Liquefaction

Reactions of trace elements during hydrogenation at $\mathrm{T}=450^{\circ} \mathrm{C}$ and $\mathrm{P}_{\mathrm{H}_{2}}=100 \mathrm{~atm}$ can be classified as: ( $i$ ) formation of volatile inorganic compounds; (ii) formation of volatile organic compounds; ( $i i i)$ formation of non-volatile organic complexes; ( $i v$ ) changes in mineral structure or composition; and $(v)$ corrosion and/or erosion reactions producing trace element species.

\subsection{Formation of Volatile Inorganic Compounds}

In the reducing atmosphere of the coal solution reactor, formation of hydrides or elemental species may occur, for example in the case of $\mathrm{Hg}$ and As present as sulfides,

$$
\begin{aligned}
& \mathrm{HgS}_{(\mathrm{s})}+\mathrm{H}_{2(\mathrm{~g})} \rightleftharpoons \mathrm{Hg}_{(\mathrm{g})}{ }^{\mathrm{O}}+\mathrm{H}_{2} \mathrm{~S}_{(\mathrm{g})} \\
& \mathrm{As}_{2} \mathrm{~S}_{3(\mathrm{~s})}+\mathrm{H}_{2(\mathrm{~g})} \rightleftharpoons \mathrm{As}_{2} \mathrm{~S}_{2(\mathrm{~s})}+\mathrm{H}_{2} \mathrm{~S}_{(\mathrm{g})} \\
& \mathrm{As}_{2} \mathrm{~S}_{3(\mathrm{~s})}+3 \mathrm{H}_{2(\mathrm{~g})} \rightleftharpoons 1 / 2 \mathrm{As}_{4(\mathrm{~g})}^{0}+3 \mathrm{H}_{2} \mathrm{~S}(\mathrm{~g}) \\
& \mathrm{As}_{2} \mathrm{~S}_{3(\mathrm{~s})}+6 \mathrm{H}_{2(\mathrm{~g})} \rightleftharpoons 2 \mathrm{AsH}_{3(\mathrm{~g})}+3 \mathrm{H}_{2} \mathrm{~S}(\mathrm{~g}) \text {, }
\end{aligned}
$$

and in the case of Se as PbSe (clausthalite),

$$
\operatorname{PbSe}_{(\mathrm{s})}+\mathrm{H}_{2} \mathrm{~S}_{(\mathrm{g})} \rightleftharpoons \mathrm{PbS}_{(\mathrm{s})}+\mathrm{H}_{2} \mathrm{Se}_{(\mathrm{g})} \text {. }
$$

Although the carbon monoxide content of the SRC reactor product gases is low, carbonyls such as $\mathrm{Ni}(\mathrm{CO})_{4}$ may form in cooler zones (i.e.,pressure let-down units) by reaction of $\mathrm{CO}$ with $\mathrm{Ni}$ or $\mathrm{Ni}$ compounds formed as corrosion products of the high pressure alloys. Similar considerations apply to $\mathrm{Co}$, Mo, and $\mathrm{Cr}$ which are constituents of the alloys and which have been observed in liquid-liquid separator solids (see Section 6).

\subsection{Formation of Volatile Organometallic Compounds}

The elements $\mathrm{Hg}$, As, and Se form volatile inorganic species but it should not be overlooked that many organometallic compounds of these elements are known. Examples that may be important in coal liquefaction are $\mathrm{CH}_{3} \mathrm{HgX},\left(\mathrm{CH}_{3}\right)_{2} \mathrm{Hg}$; mercurated aromatic compounds, e.g., PhHgX, $\left(\mathrm{C}_{6} \mathrm{H}_{5} \mathrm{O}\right) \mathrm{HgX}$; $\left(\mathrm{CH}_{3}\right)_{2} \mathrm{Se}$; substituted arsines, arsonic acids, and arsinic acids, to mention only a few. No data presently exist to prove the formation of these compounds in the SRC processes.

\subsection{Formation of Non-Volatile Hetallo-organic and Organometallic Compounds}

There are many possible organic complexes or organometallic compounds that may form under liquefaction conditions, particularly during the coal pyrolysis stage. Likely candidates are metal complexes of aromatic compounds, e.g., phenols, polyphenols, $N$ and $S$ heterocyclic compounds and metal-asphaltene structures similar to those that have been identified in crude oils. Of particular interest is the nature of Ti species in SRC I solid and this topic is discussed in Section 8. 


\subsection{Changes in Mineral Composition}

Some mineral species found in coals undergo changes in composition during hydrogenation. The most important of these changes is the conversion of pyrite, $\mathrm{FeS}_{2}$ to pyrrhotite, FeS (see Section 2). Other changes are the formation of Wollastonite from $\mathrm{CaCO}_{3}$ and $\mathrm{SiO}_{2}$ and dehydration and/or organic complexing of clay minerals. These changes do not result in mobile metal species being produced in the process.

6. Behavior of $\mathrm{Hg}, \mathrm{Se}, \mathrm{As}, \mathrm{Sb}, \mathrm{Co}, \mathrm{Cr}$, and $\mathrm{Ni}$ in the SRC II Process

Evaluation of trace element distributions in SRC process streams [2] has shown that $\mathrm{Hg}$, $\mathrm{Se}$, As, and Sb are significantly volatile. High concentrations of these elements were found in certain liquid-liquid separator light oils and aqueous phases. It was also found that $\mathrm{Cr}$, $\mathrm{Co}$, and $\mathrm{Ni}$ were present in these materials at higher than normal concentrations. Solids were removed from the liquid-liquid separators (designated No. 1 and No. 3) and these solids have been analyzed by a variety of techniques [12]. Neutron activation analysis has shown that the solids also exhibit abnormally high concentrations of $\mathrm{Hg}$, As, $\mathrm{Se}, \mathrm{Cr}, \mathrm{Ni}, \mathrm{Co}$, and Sb. Mineralogical examination revealed that unaltered coal minerals were present-in the solids indicating physical transport of mineral matter from the reactor through the pressure let-down units to the liquid-liquid separators by mechanical entrainment. However, if the concentrations in the separator solids are converted to enrichment factors, $E_{f}$, relative enrichment (or depletion) compared to "non-volatile" $K$ can be estimated. The enrichment factor, $E_{f}$ is defined as

$$
E_{f}=\frac{[X]_{\text {solid }}}{[K]_{\text {solid }}} \cdot \frac{[K]_{\text {coal }}}{[X]_{\text {coal }}} \text {, }
$$

where $\quad X=$ element of interest

[ ] = concentrations; phase indicated by subscript.

Thus elements that have $E_{f} \simeq 1$ are transported by essentially the same process (i.e., physical entrainment in product gases) as is $K$. The $E_{f}$ values calculated are shown in Table 5 . The data show clearly that $\mathrm{Hg}$, Se, As, and $\mathrm{Sb}$ are enriched relative to $\mathrm{K}$ in all solids and that higher $E_{f}$ values are found in separator No. 3 solids than in separator No. 1 (except for $\mathrm{Hg}$ in $3 \mathrm{~A}$ ). This behavior is consistent in that separator Nu. 3 contains condensate from the first pressure let-down unit and therefore represents the major gas flow. The data also indicate that the volatility order as deduced from the concentrations in the solids for separator No. 1 is $\mathrm{Hg}>\mathrm{Sb}>\mathrm{As}>\mathrm{Se}$ and for separator No. 3 is $\mathrm{Hg}>\mathrm{As}>\mathrm{Sb}>\mathrm{Se}$. The $\mathrm{E}_{f}$ values for $\mathrm{Co}, \mathrm{Ni}$, and $\mathrm{Cr}$ indicate either transport of these elements (from the coal as volatile species, e.g., carbonyls) or concentration in the solids as a result of corrosion or erosion of construction materials which probably results in formation of sulfides. The latter process appears more likely because $\mathrm{Co}, \mathrm{Cr}$, and $\mathrm{Ni}$ are major constituents of high pressure alloys (e.g., Hastalloy C) and $\mathrm{H}_{2} \mathrm{~S}$ is a gas constituent.

Mineralogical examination [12] of the solids after low temperature ashing (LTA) showed the presence of both sulfide and non-sulfide minerals. Major non-sulfide minerals identified 
Table 5. Enrichment factors for separator solids.

\begin{tabular}{|c|c|c|c|}
\hline & ENRIC & JT FACTOR $E_{f}$ & $1.00)$ \\
\hline & SEPARATOR 1 & SEPARATOR 3A & SEPARATOR $3 B$ \\
\hline As & 1.72 & 9.90 & 22.6 \\
\hline $\mathrm{Se}$ & 1.58 & 2.09 & 7.92 \\
\hline $\mathrm{Hg}$ & 42.1 & 37.5 & 72.4 \\
\hline $\mathrm{Sb}$ & 3.57 & 6.95 & 12.3 \\
\hline $\mathrm{Fe}$ & 1.25 & 1.09 & 1.14 \\
\hline Co & 2.03 & 2.54 & 4.22 \\
\hline $\mathrm{Ni}$ & 4.56 & 19.1 & 92.3 \\
\hline $\mathrm{Cr}$ & 2.11 & 18.4 & 55.6 \\
\hline
\end{tabular}

ly $x$-ray diffraction (XRD), optical microscopy (OM), microprobe (MP) and scanning electron licroscopy-x-ray fluorescence (SEM-EDX) were illite, kaolinite, quartz, rutile, siderite, rarite, and wollastonite. The sulfide minerals identified are shown in Table 6 . Most of the minerals 7 isted have been identified in feed coals but some represent reaction products of the hydrogenation process, e.g., wollastonite, $\mathrm{CaSiO}_{3}$; pyrrhotite, $\mathrm{FeS}$; and the mixed $\mathrm{ir} / \mathrm{Fe} / \mathrm{Ni}$ sulfides that are probably corrosion products. The identification of realgar, ${ }^{t} \mathrm{~s}_{2} \mathrm{~S}_{2}$ is doubtful but if confirmed this would represent a condensate reaction product of Table 6. Sulfide species identified in liquid-liquid separator.

\begin{tabular}{|c|c|c|c|}
\hline MINERAL / COMPOUND & BULK COMPOSITION & IDENTIFICATION & IMPURITIES \\
\hline Pyrite & $\mathrm{FeS}_{2}$ & $\begin{array}{l}\text { XRD, OM, } \\
\text { SEM-EDX, MP }\end{array}$ & $\begin{array}{l}\mathrm{Ni}, \mathrm{Cr}, \mathrm{Co}, \\
\mathrm{Hg}, \mathrm{Zn}\end{array}$ \\
\hline Pyrrhotite & $\mathrm{FeS}_{\mathrm{x}}$ & $\begin{array}{l}\text { XRD, OM, } \\
\text { SEM-EDX, MP }\end{array}$ & $\begin{array}{l}\mathrm{Ni}, \mathrm{Cr}, \mathrm{Co}, \\
\mathrm{Hg}, \mathrm{Zn}, \mathrm{Se}, \\
\mathrm{Sb}\end{array}$ \\
\hline Sphalerite & $\mathrm{ZnS}$ & OM, MP & \\
\hline Realgar (?) & $\mathrm{As}_{2} \mathrm{~S}_{2}$ & SEM-EDX & \\
\hline Chromium Sulfide & $\mathrm{Cr}_{2} \mathrm{~S}_{3}$ & MP & $\mathrm{Fe}$ \\
\hline Mixed Sulfide & $(\mathrm{Cr}, \mathrm{Fe}, \mathrm{Ni})_{\mathrm{x}} \mathrm{S}$ & MP, SEM-EDX & \\
\hline Cr-Fe Sulfide & $(\mathrm{Cr}, \mathrm{Fe})_{2} \mathrm{~S}_{3}$ & MP, SEM-EDX & \\
\hline
\end{tabular}


the decomposition of $\mathrm{As}_{2} \mathrm{~S}_{3}$ or FeAsS present in the coal. Analysis of individual pyrite and pyrrhotite grains indicates that these minerals contain high concentrations of $\mathrm{Ni}, \mathrm{Cr}$, Co, $\mathrm{Hg}, \mathrm{Zn}$, Se, As, and Sb. These probably exist as coatings on the grains formed either by condensation of volatile species ( $\mathrm{As}$, Se, $\mathrm{Hg}, \mathrm{Sb}$ ) or by deposition of fine grained sulfides of $\mathrm{Cr}$, $\mathrm{Co}$, and $\mathrm{Ni}$ formed as corrosion products of $\mathrm{H}_{2} \mathrm{~S}$.

Thermodynamic equilibrium calculations of the behavior of $\mathrm{Hg}$, As, Se, and $\mathrm{Sb}$ can be made from existing data [13]. Depending on the chemical form of the element present in the coal, both sublimation and reaction with $\mathrm{H}_{2}, \mathrm{H}_{2} \mathrm{~S}$, or with a $\mathrm{H}_{2}$-donor (e.g., tetralin) may be important in controlling volatility. For example, in the case of $\mathrm{Hg}$, assuming that $\mathrm{HgS}$ is the form present in coal, partial pressures $\left(\mathrm{P}_{\mathrm{Hg}}\right)$ computed from thermodynamic data are large, as shown in Table 7 . Thus, either sublimation or reaction of $\mathrm{HgS}$ with $\mathrm{H}_{2}$ should result in almost complete volatilization of $\mathrm{Hg}$ from the coal during hydrogenation and $\mathrm{Hg}$ should be depleted in the residual vacuum bottoms, that is, the "sink" for the non-volatile elements. Despite thermodynamic prediction, coals from different localities behave differently and the percentage of $\mathrm{Hg}$ retained in the vacuum bottoms residue varies from $16-80 \%$ $[2,4]$. Thus, kinetic factors probably control the volatility of $\mathrm{Hg}$. One important factor may be diffusion out of pyrite-pyrrhotite grains during conversion, thus:

$$
\mathrm{FeS}_{2}(\mathrm{Hg})_{\mathrm{s}}+\mathrm{H}_{2(\mathrm{~g})} \rightarrow \mathrm{FeS}_{(\mathrm{s})}+\mathrm{H}_{2} \mathrm{~S}(\mathrm{~g})+\mathrm{Hg}_{(\mathrm{g})}
$$

Similar equilibrium calculations can be made for As and Se assuming $\mathrm{As}_{2} \mathrm{~S}_{3}$ or FeAsS as As minerals and PbSe as the Se mineral. Table 8 lists partial pressures of $\mathrm{AsH}_{3}, \mathrm{H}_{2} \mathrm{Se}$, and $\mathrm{Hg}^{\mathrm{O}}$ computed from thermodynamic data [13].

Table 7. Transformations of mercuric sulfide $\left(700^{\circ} \mathrm{K}\right)$ [13]

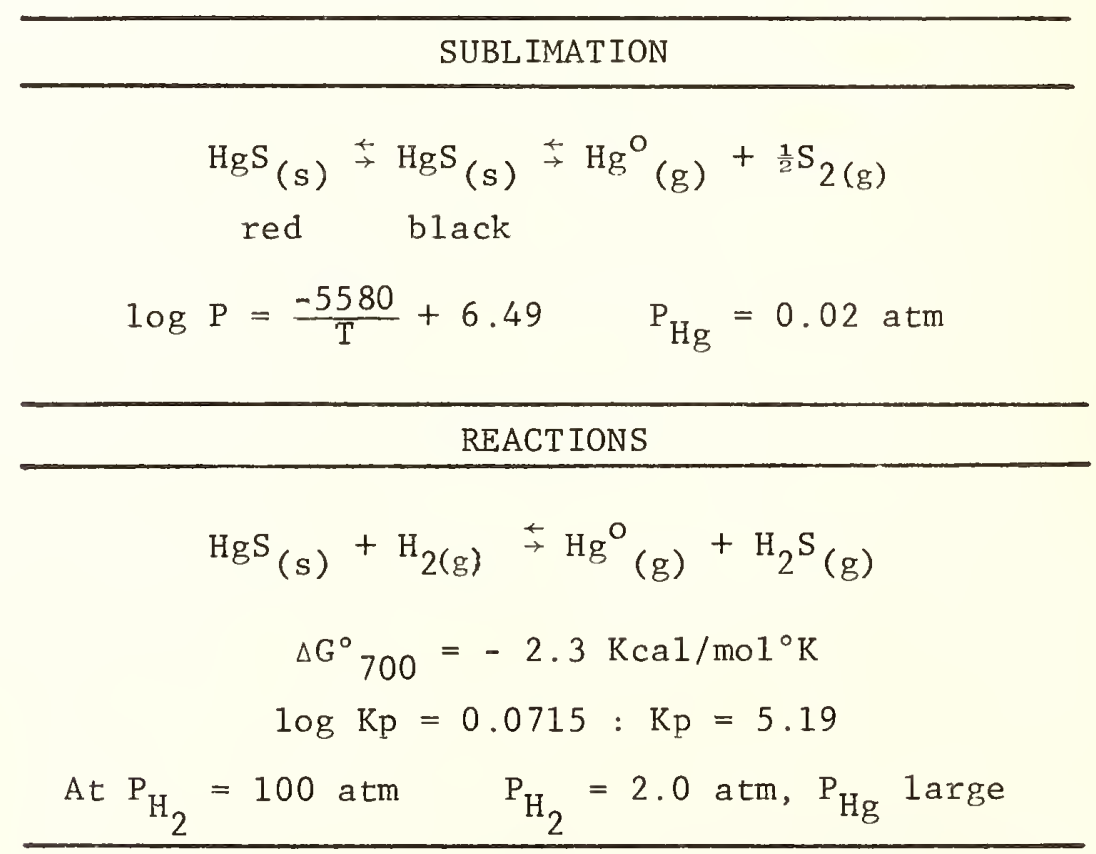


Table 8 lists partial pressures of $\mathrm{AsH}_{3}, \mathrm{H}_{2} \mathrm{Se}$, and $\mathrm{Hg}^{\circ}$. These data indicate that the volatility order is $\mathrm{Hg}>\mathrm{As}>\mathrm{Se}$, which is consistent with the order deduced from the separator solids data.

Table 8. Calculated volatility of $\mathrm{Hg}$, As, and Se [13].

\begin{tabular}{lc}
\hline REACTION & CALCULATED P (ATM)* \\
\hline $\mathrm{As}_{2} \mathrm{~S}_{2}(\mathrm{~s})+\mathrm{H}_{2}(\mathrm{~g}) \leftrightarrows \mathrm{AsH}_{3}(\mathrm{~g})$ & $2.06 \mathrm{E}-3$ \\
$\mathrm{FeAsS}_{(\mathrm{s})}+\mathrm{H}_{2}(\mathrm{~g}) \leftrightarrows \mathrm{AsH}_{3}(\mathrm{~g})$ & $4.7 \mathrm{E}-4$ \\
$\mathrm{PbSe}_{(\mathrm{s})} \leftrightarrows \mathrm{PbSe}_{(\mathrm{g})}$ & $2.0 \mathrm{E}-9$ \\
$\mathrm{PbSe}_{(\mathrm{s})}+\mathrm{H}_{2} \mathrm{~S}(\mathrm{~g}) \leftrightarrows \mathrm{H}_{2} \mathrm{Se}_{(\mathrm{g})}$ & $4.0 \mathrm{E}-5$ \\
$\mathrm{PbSe}_{(\mathrm{s})}+\mathrm{H}_{2}(\mathrm{~g}) \leftrightarrows \mathrm{H}_{2} \mathrm{Se}_{(\mathrm{g})}$ & $3.3 \mathrm{E}-6$ \\
$\mathrm{HgS}_{(\mathrm{s})} \leftrightarrows \mathrm{Hg}_{(\mathrm{g})}^{\circ}$ & $2.0 \mathrm{E}-2$ \\
$\mathrm{HgS}_{(\mathrm{s})}+\mathrm{H}_{2}(\mathrm{~g}) \rightleftharpoons \mathrm{Hg}^{\circ}(\mathrm{g})$ & 1arge \\
\hline
\end{tabular}

Further research needs to be done to determine the $\mathrm{Hg}$, As, Se, and $\mathrm{Sb}$ species produced during coal hydrogenation, particularly since organometallic compounds are possible products (Section 5.2) and have not been considered in the thermodynamic calculations.

7. Behavior of $\mathrm{Hg}$ in SRC II Process Waters

The volatility of $\mathrm{Hg}$, Se, and As in the SRC II process is reflected in relatively high concentrations of these elements in condensate process waters $[2,4]$. Table 9 shows the approximate composition of SRC II process waters, including $\mathrm{Hg}$, Se, As, and Sb concentrations and the percentages of each element in particulate form. The waters contain principally $\mathrm{NH}_{4} \mathrm{HS}$ and $\left(\mathrm{NH}_{4}\right)_{2} \mathrm{~S}$ plus some polysulfides (and $\mathrm{S}_{2} \mathrm{O}_{3}{ }^{2-}$ as an oxidation product) and high concentrations of phenols. The very low concentrations of particulate $\mathrm{Hg}$, Se, and As indicate that anionic species predicted by equilibrium theory, e.g., $\mathrm{Hg}(\mathrm{HS})_{2}^{-}$and $\mathrm{HgS}_{2}{ }^{2-}$, $\mathrm{pre}^{-}$ dominate. In the SRC II process, the process waters are treated by lowering the $\mathrm{pH}$ to approximately 6-7 by $\mathrm{Al}(\mathrm{OH})_{3}$ flocculation and further by bacterial degradation, primarily to remove phenols and some other organics.

The combined flocculation/biotreatment process reduces $\mathrm{Hg}$ levels in effluent waters 
Table 9. Approximate composition of SRC II process water.

\begin{tabular}{cc}
\hline COMPONENT & CONCENTRATION OR VALUE [12] \\
\hline $\mathrm{NH}_{3}$ & $0.33 \mathrm{M}$ \\
$\mathrm{S}^{2-}, \mathrm{HS}^{-}\left(\mathrm{S}_{2} \mathrm{O}_{3}{ }^{2-}\right)$ & $0.15 \mathrm{M}$ \\
$\begin{array}{c}\text { phenols (phenols, cresol, } \\
\text { naphthols, etc.) } \\
\text { TOC }\end{array}$ & $4000 \mathrm{mg} / \mathrm{L}$ \\
$\mathrm{pH}$ & $>4500 \mathrm{mg} / \mathrm{L}$ \\
$\mathrm{Hg}(\mathrm{ppb})$ & $9-9.6$ \\
$\mathrm{As}(\mathrm{ppb})$ & $120(0.8 \%$ particulate $)$ \\
$\mathrm{Se}(\mathrm{ppb})$ & $27(0.9 \%$ particulate $)$ \\
$\mathrm{Sb}(\mathrm{ppb})$ & $1300(0.3 \%$ particulate $)$ \\
\hline
\end{tabular}

to approximately $2 \mathrm{ppb} \mathrm{Hg}$. However, the clarifier solids [primarily $\mathrm{Al}(\mathrm{OH})_{3}$ ] and digested biotreatment solids have $\mathrm{Hg}$ concentrations of 47-95 ppm Hg and 17-38 ppm $\mathrm{Hg}$ (dry weight basis), respectively. Probable reactions of $\mathrm{Hg}$ in the water treatment process are summarized in Tables 10 and 11. Although the behavior of $\mathrm{Hg}$ can be understood in terms of inorganic species, the role of organic species of $\mathrm{Hg}$ should not be overlooked, particularly biomethylated species that could form in the biodigester under anaerobic conditions. Also, the high concentrations of phenols and heterocyclic compounds (e.g., thiophenes) could fayor mercuration reactions in the process waters [14]. The high concentrations of $\mathrm{Hg}$ (and Se, $\mathrm{As}$, and $\mathrm{Sb}$ ) in the waste solids are of environmental concern if these materials are to be disposed of by conventional techniques.

8. Behavior of $\mathrm{Ti}$ in the SRC Processes

In the SRC I process, most elements are efficiently removed in the mineral residue and are more than $98 \%$ depleted in product SRC I. Thus elements that are found predominantly in mineral rather than maceral components of the coal are efficiently removed, e.g., Fe, $\mathrm{Na}$, $\mathrm{K}, \mathrm{Rb}, \mathrm{Cs}, \mathrm{Al}, \mathrm{Ca}, \mathrm{Mg}$ and the rare earth elements. However, $\mathrm{Ti}$ is an important exception in that the concentration of Ti remaining in SRC I may be as high as $88 \%$ of the $\mathrm{Ti}$ in the original coal [1]. The small depletion of $T i$ in the SRC I process is consistent for a given type of coal [3] and several explanations for this behavior are possible:

i) $\mathrm{Ti}$ occurs in coal as very finely divided $\mathrm{TiO}_{2}$ (rutile) which passes through the filtration system unlike other minerals which are efficiently removed.

ii) Organic $\mathrm{Ti}$ compounds are present in the coal and are soluble in the coal-SRC solution.

$\mathrm{iii}$ ) Organic $\mathrm{Ti}$ compounds are formed from inorganic $\mathrm{TiO}_{2}$ during the hydrogenation process or from other organic Ti species in the coal.

Miller and Given [15] have postulated that $\mathrm{Ti}$ may be present in low rank coals bound to the 
Table 10. Mercury chemistry in treatment of coal liquefaction wastewaters.

\section{ZONE}

Condensation

$\left(300^{\circ} \mathrm{K}\right)$
REACTION

$$
\begin{aligned}
& \mathrm{Hg}^{\circ}(\mathrm{s})+\mathrm{H}_{2} \mathrm{~S}(\mathrm{~g}) \stackrel{\leftarrow}{\rightarrow} \mathrm{HgS}_{(\mathrm{s})}+\mathrm{H}_{2(\mathrm{~g})} \\
& \Delta \mathrm{G}_{300}^{\circ}=-4.0 \mathrm{Kcal} / \mathrm{mol}^{\circ} \mathrm{K}: \mathrm{K}=840
\end{aligned}
$$

$$
\mathrm{HgS}_{(\mathrm{s})}+\mathrm{s}_{(\mathrm{aq})}^{2-} \stackrel{\leftarrow}{\rightarrow} \mathrm{HgS}_{2(\mathrm{aq})}^{2-} \quad \mathrm{K}=3.72
$$

Process Water

(Condensate)

For $\mathrm{HgS}_{2}^{2-} \quad \mathrm{S}_{\text {sat }}=5.52 \times 10^{-5} \mathrm{M}(14.6 \mathrm{ppm} \mathrm{Hg})$

$\mathrm{pH}=9.0$

$[\mathrm{S}]_{\mathrm{T}}=0.18 \mathrm{M}$

$\mathrm{HgS}_{2(\mathrm{aq})}^{2-}+\mathrm{H}_{2} \mathrm{O} \stackrel{\leftarrow}{\rightarrow} \mathrm{HgS}_{(\mathrm{s})}+\mathrm{HS}^{-}+\mathrm{OH}^{-}$

Reactivator

$\mathrm{HgS}_{2(\mathrm{aq})}^{2-}+\mathrm{H}_{2} \mathrm{O}+\frac{1}{2} \mathrm{O}_{2} \stackrel{\leftarrow}{\rightarrow} \mathrm{HgS}(\mathrm{s})+\mathrm{S}^{\circ}+2 \mathrm{OH}^{-}$

Table 11. Behavior of mercury in SRC biodigester.

$$
\mathrm{Hg}^{2+}+\mathrm{H}_{2} \mathrm{~S} \stackrel{\leftarrow}{\rightarrow} \mathrm{HgS}(\mathrm{s})+2 \mathrm{H}^{+}
$$

$$
\begin{array}{r}
\mathrm{Hg}(\mathrm{II})+\text { bacteria } \rightarrow \mathrm{CH}_{3} \mathrm{Hg}_{(\mathrm{aq})}^{+}+\left(\mathrm{CH}_{3}\right)_{2} \mathrm{Hg}(\mathrm{g}) \\
2 \mathrm{CH}_{3} \mathrm{Hg}_{(\mathrm{aq})}^{+}+\mathrm{H}_{2} \mathrm{~S} \rightarrow\left(\mathrm{CH}_{3} \mathrm{Hg}\right)_{2} \mathrm{~S}(\mathrm{aq})+2 \mathrm{H}^{+} \\
\left(\mathrm{CH}_{3} \mathrm{Hg}{ }_{2} \mathrm{~S}(\mathrm{aq})+\left(\mathrm{CH}_{3}\right)_{2} \mathrm{Hg}(\mathrm{g})+\mathrm{HgS}_{(\mathrm{g})}\right. \\
\hline \mathrm{Hg}(\mathrm{II}) \stackrel{\leftarrow}{\rightarrow} \mathrm{Hg}^{\circ}(\mathrm{g}) \\
\text { CONDITIONS: } \begin{array}{r}
\mathrm{pH}=6.8-7.2 \\
\mathrm{pE}=-5-(-8) \\
\mathrm{S}_{\mathrm{T}}^{2-}=10^{-2} \mathrm{M}
\end{array}
\end{array}
$$


organic matrix and $\mathrm{Ti}$ has been shown to form strong bonds with humic acids [16]. However, in bituminous coals used in the SRC I process, it appears likely that most of the Ti present in the coal is $\mathrm{TiO}_{2}[11]$. Thus, explanations (i) or (iii) above may explain the behavior of Ti. Organic complexes of Ti, if formed, are not volatile under SRC II conditions because more than $99 \%$ of the $\mathrm{Ti}$ in the feed coal remains with the residual vacuum bottoms. There are several lines of evidence that point to organic Ti compounds being formed during coal hydrogenation. These are:

i) very low depletion of $\mathrm{Ti}$ in SRC I compared to feed coal

ii) loss of hydrocracking ability of Co-Mo hydrodesulfurization catalysts which has been attributed to organometalic forms of $\mathrm{Ti}$ [17]

iii) chromatographic behavior of $\mathrm{Ti}$ and $\mathrm{V}$

iv) x-ray absorption study of SRC I and SRC II residue.

Recent [18] chromatographic separation of THF soluble SRC I on $\mathrm{SiO}_{2}$ using the separation scheme of Farcasiu [19] has shown that Ti elutes in the ethanol-chloroform, ethanolTHF, and ethanol-pyridine fractions as shown in Figure 2. These fractions contain high concentrations of phenols, polyphenols, and other highly functional molecules [19]. Titanium forms highly stable phenoxides and may form complexes with highly functional multi-ring phenols and polyphenols. Such complexes, if formed, would probably be non-volatile under SRC II conditions. Size exclusion chromatographic data published recently [20] confirm an organic association for Ti in SRC I.

The most concrete evidence for organic species of $\mathrm{Ti}$ being formed in the SRC processes is provided by recent $x$-ray absorption spectroscopy studies carried out by Sandstrom et al., [21]. The use of x-ray absorption spectroscopy to probe chemical states of $T i$ and other elements has its physical basis in the absorption of x-rays which occurs upon photo-excitation or photoemission of the metal atom core-level electrons. For x-ray photon energies near the core-level binding energy, transitions occur to bound states of the molecule containing the metal atom, giving rise to characteristic structure in the absorption spectrum in the vicinity of the absorption edge. This near-edge structure has been measured for Ti in SRC materials in the present study.

For $x$-ray photon energies far above the core-level binding energy (e.g., $>50 \mathrm{eV}$ ) photoelectric transitions are to the continuum in which final states are delocalized among the atoms in the vicinity of the x-ray absorbing metal atom. An electron interference phenomenon then gives rise to oscillations in the $x$-ray absorption spectrum called the Extended $X$-ray Absorption Fine Structure (EXAFS). Near-edge Ti spectra were measured at the Stanford Synchrotron Radiation Laboratory of the feed coal (787 ppm Ti), SRC I product (445 ppm Ti), SRC I I vacuum bottoms (1540 ppm Ti) using procedures described by Sandstrom et a1., [21]. The results are shown in Figure 3 along with the near-edge spectrum of $2 \% \mathrm{TiO}_{2}$ in $\mathrm{SiO}_{2} \mathrm{glass}$ (fourfold $0-T i$ bonds). Although the coal spectra contain fairly high levels of noise, it is readily seen that both the SRC I product and SRC II vacuum bottoms spectra exhibit features at the energy position of the pre-edge peak in the $\mathrm{TiO}_{2}-\mathrm{SiO}_{2}$ spectrum for the glass.

The appearance of the pre-edge feature in the SRC product material spectra of Figure 3 , and its absence from the feed coal spectrum, provides evidence for the conversion of mineral 


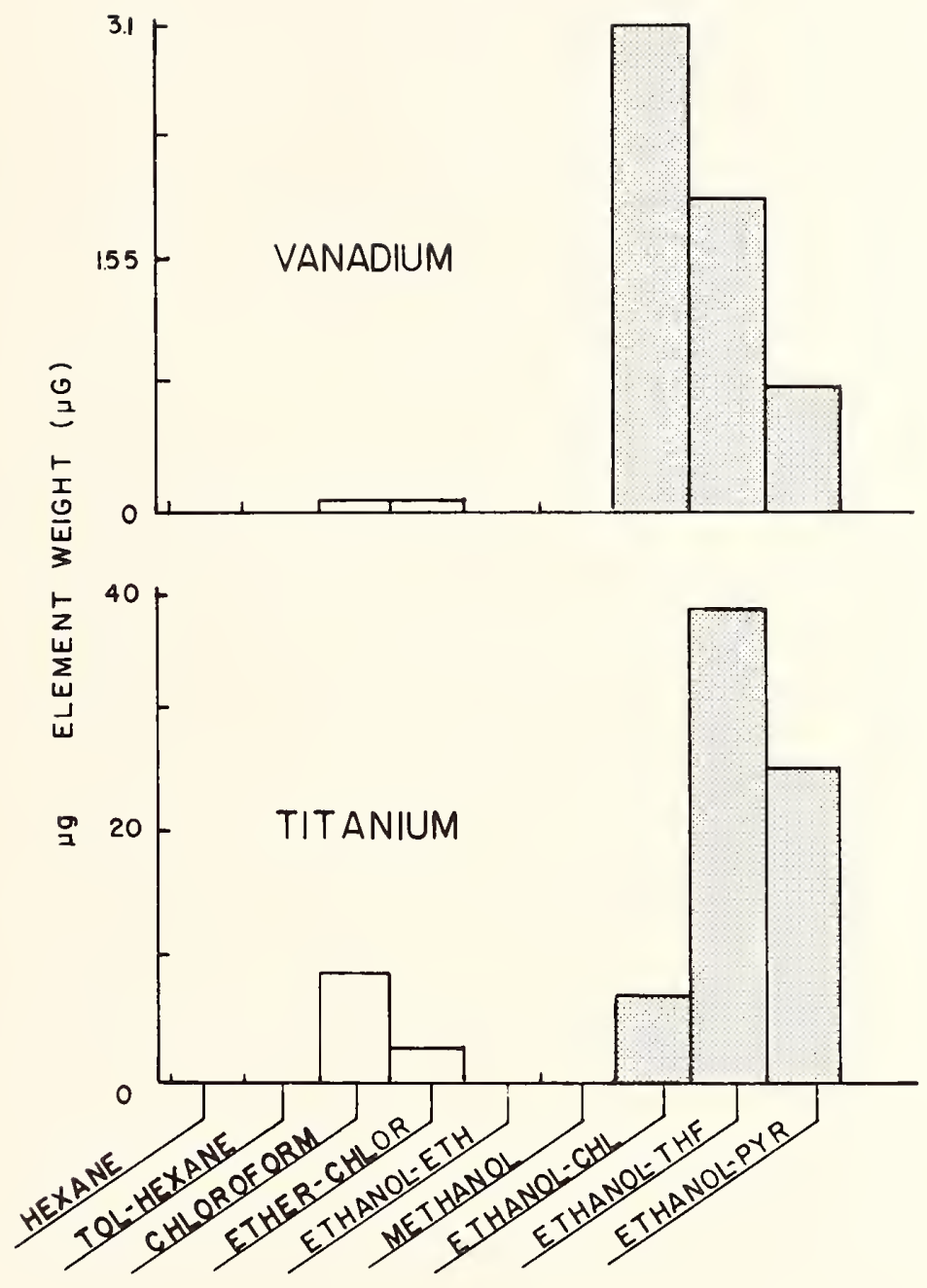

Figure 2: Separation of THF-soluble SRC I on $\mathrm{SiO}_{2}$ using different eluants $[18,19]$ 


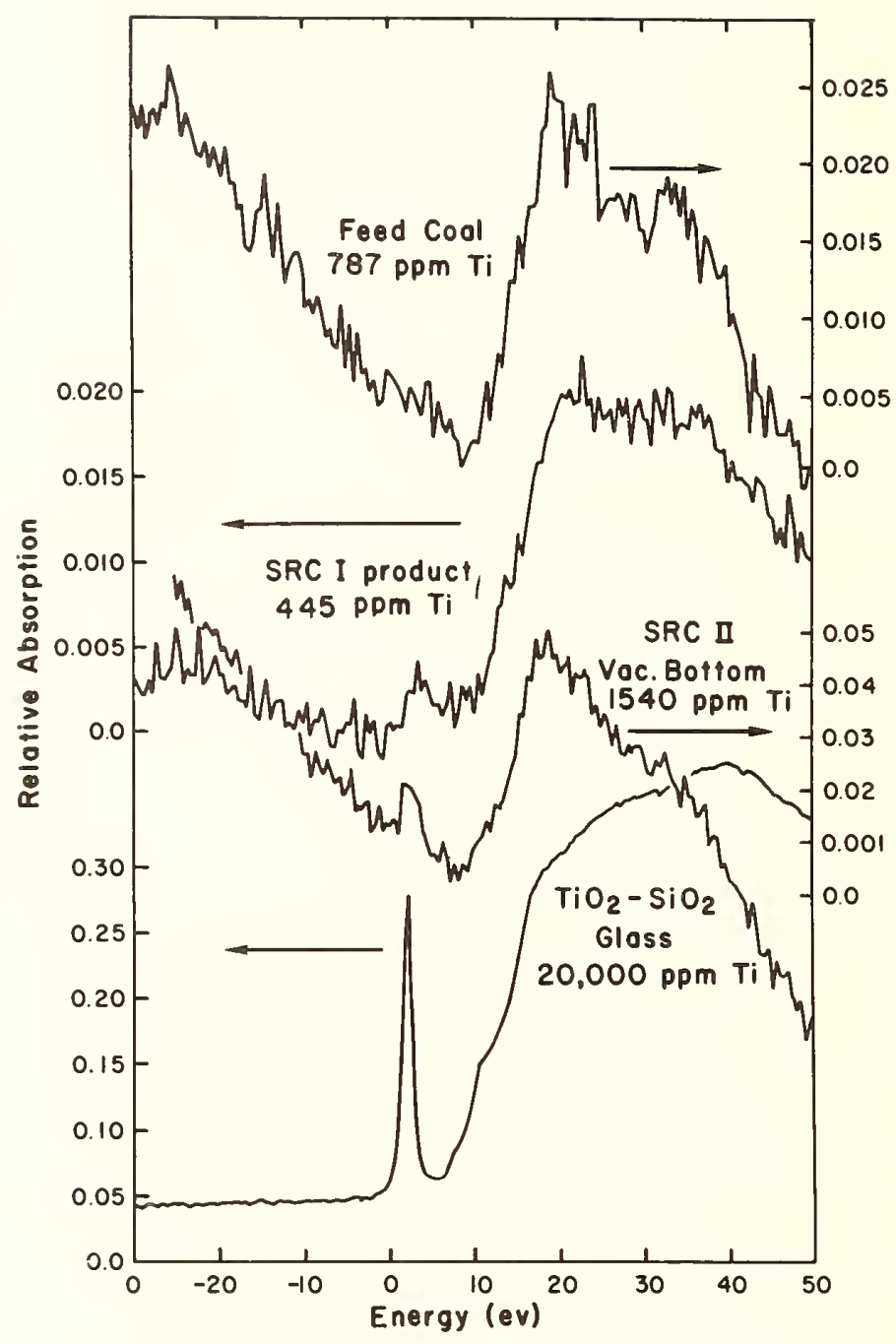

Figure 3: Near-edge x-ray absorption spectra for feed coal, SRC I, and SRC II vacuum bottoms [21]. 
forms of $\mathrm{Ti}$ (octahedral) to organic forms (tetrahedral) during coal liquefaction. A similar but enhanced pre-edge feature is seen in the SRC II vacuum bottoms when compared to the SRC I spectrum. If the pre-edge feature is associated with lower symmetry organic forms, the enhancement can be explained by the longer residence (reaction) time in the SRC II process.

\section{References}

[1] Filby, R. H.; Shah, K. R.; Hunt, M. L.; Khali1, S. R.; Sautter, C. A. Solvent Refined Coal process: trace elements. Part 6: The fate of trace elements in the SRC I process. U.S. Dept. of Energy Report FE/496-T17; 1978 Apri1 170 p.

[2] Filby, R. H.; Khalil, S. R.; Grimm, C. A.; Ekambaram, V.; Hunt, M. L. Solvent Refined Coal (SRC) Process: trace elements. Vol. 3. Part 6. The fate of trace elements in the SRC process (II). U.S. Dept. of Energy Report DOE/ET/10104-T11; 1980 December. $160 \mathrm{p}$.

[3] Filby, R. H.; Khalil, S. R.; Hunt, M. L. Solvent Refined Coal (SRC) process: trace elements. Part 6. The fate of trace elements in the SRC I process. U.S. Dept. of Energy Report DOE/ET/10104-T2. 1980 March. 92 p.

[4] Khali1, S. R. Solvent Refined Coal (SRC) Process: trace elements. Vo1. 3. Part 6. Fate of trace elements in the SRC I and SRC II processes. U.S. Dept. of Energy Report DOE/ET/10104-T3. 1980 February. 179 p.

[5] Filby, R. H.; Khalil, S. R. Trace elements in the Solvent Refined Coal Processes, SRC I and SRC II, in Synthetic Fuel Technology. K. E. Cowser and C. R. Richmond, eds. Ann Arbor, MI, Ann Arbor Science 1980, 102-115.

[6] Filby, R. H.; Khalil, S. R. Paper presented at 1980 American Chem. Soc. Meeting, Honolulu, Division of fuel chemistry.

[7] Gluskoter, H. J.; Ruch, R. R.; Miller, W. G.; Cahi11, R. A.; Dreher, G. B.; Kuhn, J. K. Trace elements in coal: 0ccurrence and distribution. I11. State Geol. Survey Circ. 499; 1977. 154 p.

[8] Zubovic, P. Physicochemical properties of certain minor elements as controlling factors in their distribution in coal. Chapter 13 in Coal Science, P. H. Given, ed. Adv. Chem. Ser. 55, Amer. Chem. Soc. 1966. 742 p.

[9] Ruch, R. R.; Gluskoter, H. J.; Shimp, N. F. Occurrence and distribution of potentia11y volatile elements in coal. I11. State Geo1. Survey Env. Geol. Note 72. 1974. 96 p.

[10] Swanson, V. E. (and others). Collection, chemical analysis and evaluation of coal samples in 1975. U.S. Geo1. Survey. Open file report 76-468. 1976. 503 p.

[11] Finkelman, R. B. Modes of occurrence of trace elements in coal. Univ. of Maryland, Ph.D. dissertation 1980. $301 \mathrm{p}$.

[12] Ekambaram, V.; Filby, R. H. Paper in preparation, 1981.

[13] Mills, K. G. Thermodynamic data for inorganic sulfides, selenides, and tellurides. London; Butterworths. 1974.

[14] Makarova, L. G., Nesmeyanov, A. N. The organic compounds of mercury. Amsterdam; North Holland Publishing Co., 1967.

[15] Miller, R. N.; Given, P. H. A geochemical study of the inorganic constituents in some low rank coals. U.S. Dept. of Energy Report FE-2494-TR-1. 1978 February. $314 \mathrm{p}$.

[16] Eskenazy, G. Adsorption of titanium on peat and coals. Fuel 51, 221-223 1972.

[17] Stanulonis, J. J.; Gates, B. C.; 01son, J. H. Catalyst aging in a process for 1iquefaction and hydrodesulfurization of coal. Amer. Inst. Chem. Eng. J. 22(3) 576-581 1976.

[18] Weiss, C. S. The detection of trace element species in Solvent Refined Coa1. Ph.D. dissertation Washington State University, 1980. $120 \mathrm{p}$. 
[19] Farcasiu, M. Fractionation and structural characterization of coal 1iquids. Fuel $56: 9-14 ; 1977$.

[20] Carpenter, B. S.; Filby, R. H. Determination of trace element forms in Solvent Refined Coal products. In Atomic and nuclear methods in fossil energy research. R. H. Filby, B. S. Carpenter, R. C. Ragaini, eds. New York, N. Y.; Plenum Press, Inc. 1981 83-96.

[21] Sandstrom, D. R.; Filby, R. H.; Lytle, F. W.; Greegor, R. B. Study of Ti in Solvent Refined Coal by x-ray absorption spectroscopy. Fuel (in press).

\section{Discussion}

Question (E. A. Woolson): Several years ago there were published papers on the fact that arsenic in coal existed in two forms: the sulfidic form that you mention here, and also as a clay contaminant--either iron arsenate or calcium arsenate. Would the processes that you've looked at pick that up or has that been discredited?

Answer: I personally have not seen that. Most of the arsenic that's normally present in coal, unless it is highly weathered, would be present as a sulfide species, and most of what I've seen could indicate that. Under conditions where there will be significant weathering oxidation, where we have conversion of pyrite to iron sulfate, it's possible that some of the arsenic could be converted to an arsenate form. 


\title{
Speciation of Aqueous Contaminants - \\ Role of the Geochemical Model
}

\author{
Everett $A$. Jenne \\ Pacific Northwest Laboratory \\ Richland, WA 99352
}

A combination of accurate, selected analytical determinations and a competent geochemical model constitutes the only possible means of achieving a sufficiently thorough and reliable aqueous speciation of waters for the evaluation of societal risks resulting from anthropogenic inputs from energy related technologies. Thorough aqueous speciation is essential to adequately estimate the thermodynamic activity of those solute species having biological availability, hence toxicity, as well as high sorption potential. A reliable calculation of the distribution of species requires analytical determination of: 1) the quantity of each element in true solution; and 2) the amount of quantitatively and/or environmentally important aqueous species which are in disequilibrium. Because redox couples are rarely at equilibrium, the quantity of each redox state of multiple valencestate elements must be analytically determined. Due to the: 1) very numerous organic compounds which may be present, 2) the absence of Gibbs free energy and enthalpy data defining the association of these organic compounds with trace and major elements, and 3) the lack of competence of speciation-solubility models for organic ligands, the quantity of organic, trace-element complexes must, at the moment, be addressed analytically.

Key words: aqueous speciation; computerized; geochemical model; heavy metals; redox couples; trace elements.

\section{Introduction}

Anthropogenic sources of heavy metals and other trace elements entering natural waters represent a significant societal risk. They have the potential to decrease the well being of the populace by increasing risk of disease. The conventional wisdom in the field is that different molecular species of an element may have markedly different bioavailabilities, different organ distribution patterns and, hence, toxicity. This dependence of bioavailability and toxicity upon chemical form in aqueous media is one of the reasons that aqueous speciation is so important. Unfortunately, considerable ambiguity presently exists concerning: 1) the exact factors determining which aqueous species are biologically available and the degree thereof; 2) the dependence of 
bioavailability upon aqueous species concentration, charge, and coordination; 3 ) the variability among different biotic taxa, species, and age; and 4) the possible interactive effects among these variables. However, it is generally believed that it is the lincomplexed ion that is the primary biologically available species [14]. Speciation calculations are also of major importance to the understanding and interpretation of the adsorption of inorganic elements by solid substrates, and therefore, their hydrologic transport because neutral inorganic species have a lesser tendency to be absorbed than charged species, especially the positively charged species.

Florence and Batley [7] have painted a rather dismal picture of the current speciation capability saying that "for natural waters at least, the prospects of developing an analytical procedure which can measure the concentration of all individual chemical species present in water are very bleak. Computer modeling techniques aim to perform this function, but until a great deal more reliable thermodynamic data become available, chemical modeling methods are unlikely to produce results which even approximate the true situation." Florence and Batley [7] have overemphasized the limitations of and discrepancies between geochemical models primarily because they considered models that were incompetent. 1 As will be pointed out later in two examples, omission of a single constituent can result in significant errors in speciation even if the thermodynamic data are adequate. Further, the need for critical evaluation of thermodynamic data is greater in many instances, than for new values. Florence and Batley [7] took 1ittle note of the discord observed between analytical determinations from different laboratories. It will, therefore, be instructive to note the uncertainties in the analytical data, as opposed to the thermodynamic data. Geochemical models have numerous uses in addition to speciation per se. These uses include the evaluation of the reliability of measured $\mathrm{pH}$ and $\mathrm{E}^{\mathrm{H}}$ and other analyzed constituents in the analytical scheme and determination of the need for lower analytical detection limits, as well as greater analytical accuracy. These evaluations can be made by using the geochemical model in a sensitivity analysis mode. Geochemical models may also be utilized to choose among discordant thermochemical data for a given complex or solid and to derive "apparent" solubility values.

The thrust of this paper is to point out the usefulness of computerized geochemical models in aqueous speciation, to identify the primary limitations on equilibrium and kinetic speciation modeling, as well as to suggest approaches to their resolution.

\section{Importance of Solute Speciation}

The limited number of studies conducted to date indicate that it is the uncomplexed metal ion which is predominately the bioavailable species [14]. Because most toxic effects require the uptake of an element, it is assumed that accumulation and toxicity are both functions of the activity of the bioavailable species of an element. The activity of a first transition series metal in highly polluted waters may be only a small

\footnotetext{
An incompetent aqueous speciation model is one lacking the necessary constituents, i.e., $\mathrm{Ca}, \mathrm{Cu}, \mathrm{NO}_{3}, \mathrm{NH}_{4}$, etc., and complexes to permit a sufficiently accurate speciation to address a given problem.
} 
fraction of its total concentration. In the combined surface- and ground-water drainages from a pile of retorted oil shale, inorganic complexation plus ionic strength effects may cause the activity of $\mathrm{Cu}^{2+}$ to be $2.4 \times 10^{-2}$ to $3.1 \times 10^{-10} \%$ of the analytical1y determined total soluble molality of $\mathrm{Cu}$. To obtain this information directly by analytical chemistry would require the analytical determination of a number of Cu species.

Magnuson et a1. [16], utilizing an earlier study by Andrew et a1. [1], computed the aqueous speciation of $\mathrm{Cu}$, carried out factor analyses and concluded that $60 \%$ to $70 \%$ of the toxicity to Daphnia magna could be attributed to the $\mathrm{Cu}^{2+}, \mathrm{CuOH}^{+}, \mathrm{Cu}_{2}(\mathrm{OH})_{2}^{2+}$, and $\mathrm{Cu}(\mathrm{OH})_{2}^{0}$ species. The combination of the data available and the statistical techniques used did not permit breakdown of the toxicity to individual species. Another $15 \%$ of the toxicity was attributed to anionic hydroxo $\mathrm{Cu}$ complexes. Another recent study indicates that toxicity to cutthroat trout is a function of $\mathrm{Cu}^{2+}, \mathrm{CuOH}^{+}$, and $\mathrm{Cu}(\mathrm{OH})_{2}^{0}$ species [4].

The adsorption study of Mattigod et a1. [17] shows that the sorption of $\mathrm{Ni}$ by kaolinite from nitrate or sulfate solutions yields a linear relationship with the activity of $\mathrm{Ni}^{2+}$ in suspensions of very similar $\mathrm{pH}$. However, the slopes of the adsorption curves are different from the nitrate than from the sulfate solution. This suggests the pos-

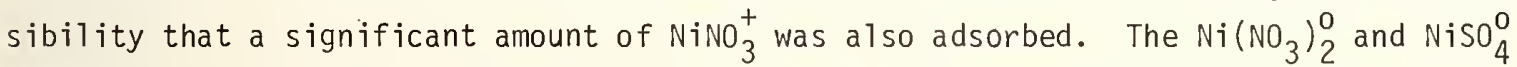
complexes, being neutral, would not be expected to adsorb. It is the dependence of adsorption on the species present that makes aqueous speciation important in modeling the hydrologic transport of trace elements in general and hydrolyzable metals in particular.

3. Geochemical Modeling

Geochemical models consist of both speciation and solubility submodels and may or may not contain submodels for adsorption, ion exchange and/or mass transfer (i.e., precipitation and dissolution) [12]. Kinetic submodels are much needed but are general1y missing from state-of-the-art geochemical models largely because most applications have been in situations where equilibrium is a reasonable possibility. There are basically two approaches to equilibrium speciation modeling--the process of free energy minimization and the equilibrium constant approach. The latter technique is used in the WATEQ geochemical model [12] which is the principal model in use at Pacific Northwest Laboratory.

Although aqueous speciation is the topic of this conference, some advantages of concomitant use of the solubility submodel should be pointed out. Erroneous analytical values can often be identified from mineral equilibria plots even when such values cannot be identified from the tabulated analytical data. To do this, it is necessary that there is presumptive evidence that the particular solid phase is serving as a solubility 1 imiting phase.

Geochemical modeling may also be used to evaluate the need for additional analytical parameters to be measured and for lower detection 1 imits. For example, in a study of drainage waters from the Missouri, Oklahoma and Kansas Tri-State mining area [13] a number of points were found to fall above the error band when the disequilibrium 
index ${ }^{2}$ for otavite, $\mathrm{CdCO}_{3}$, was plotted against conductivity. Considerable time was spent checking the thermodynamic data for otavite and searching for important cd complexes which might be missing from the model. It was then determined, by assuming various sulfide concentrations and making test runs with the geochemical model, that if dissolved sulfide was present at a fractional milligram per liter level, the complexation of cd by sulfide would be adequate to reduce the activity of Cd sufficiently to cause the otavite disequilibrium indices to be decreased and thereby fall within the error band for otavite. We have found a number of instances in the Piceance Creek Basin in the Colorado oil shale mining area in which the disequilibrium indices for ferrihydrite, amorphic $\mathrm{Fe}(\mathrm{OH})_{3}$, disequilibrium index indicates oversaturation. In some instances this may be the result, in part, of errors in the estimation of redox potential $\left(E_{P t}^{H}\right)$ with the platinum electrode used for the valence speciation of total dissolved Fe. However, this is not a likely explanation because the error would have to be as much as $400 \mathrm{mV}$ to account for the oversaturation. This apparent oversaturation with amorphic $\mathrm{Fe}(\mathrm{OH})_{3}$ is almost certainly due, in part, to $\mathrm{Fe}^{3+}$ complexation by organic 1 igands (Andy Felmy, Pacific Northwest Laboratory). In our geochemical modeling of waters contaminated by oil shale leachates, we have determined that detection limits for sulfide and phosphate need to be at least as low as $0.005 \mathrm{mg} \mathrm{L}^{-1}$ and $0.01 \mathrm{mg} \mathrm{L}^{-1}$, respectively, in order to reliably evaluate solubility equilibria for several metal sulfides and phosphates.

Geochemical modeling can be used to evaluate the accuracy of both $\mathrm{pH}$ and $\mathrm{E}^{\mathrm{H}}$ measurements. Various ground waters are supersaturated with $\mathrm{CO}_{2}$. When such waters exit at the land surface, the outgassing of $\mathrm{CO}_{2}$ results in a rise in $\mathrm{pH}$ which make the determination of $\mathrm{pH}$ values representative of the in situ ground water difficult, if not impossible. We have concluded, based on equilibrium between calcite, $\mathrm{CaCO}_{3}$, and ground water, that nongeothermal deep ground waters have increased as much as one $\mathrm{pH}$ unit during pumping and sampling as a result of $\mathrm{CO}_{2}$ outgassing. In ground waters where organic complexation is presumed to be minimal, we have estimated $E^{H}$ from ferrihydrite equilibrium using published water analyses. Although these analyses were published in 1965 and 1973 and may have relatively large standard deviations associated with them, the $E^{\mathrm{H}}$ values calculated from ferrihydrite equilibria agreed within $+50 \mathrm{mV}$ of values computed in a similar manner assuming equilibrium with siderite, $\mathrm{FeCO}_{3}$, as well as with sparse platinum electrode values [5].

In one instance geochemical modeling has been used to show that the accepted solubility value for fluorite, $\mathrm{CaF}_{2}$, was inconsistent with analytical data from geothermal waters [18]. It was then shown that a new solubility value obtained from a critical reevaluation of the literature was concordant with the analytical data on the geothermal waters. It has since been shown that this revised value for fluorite is appropriate to nongeothermal waters $[5,13]$. Similarly, we have recently observed in a creek draining a retorted oil shale area that barite, $\mathrm{BaSO}_{4}$, was greatly oversaturated although the

\footnotetext{
The disequilibrium index is the ratio of the activity product, AP, to the solubility value, Ksp, for the solid in question, e.g., AP/Ksp = 1 for the equilibrium condition. Oversaturation is indicated by $\mathrm{AP} / \mathrm{Ksp}>1$.
} 
disequilibrium index was relatively constant. Subsequently, an "apparent" solubility value for Ra-bearing amorphic $\mathrm{BaSO}_{4}$ was found in the literature [25]. This value was calculated from analytical measurement of dissolved $\mathrm{Ba}$ and $\mathrm{SO}_{4}$ following their addition to coprecipitate $\mathrm{Ra}$ as a $(\mathrm{Ba}, \mathrm{Ra}) \mathrm{SO}_{4}$ solid solution compound, from the waste water of a mining operation. The apparent solubility value of this "amorphic" barite agrees quite well with data from two field sites.

\section{Limitations on Aqueous Speciation}

It may be useful to identify the principal limitations imposed on the computation of the aqueous speciation by both analytical chemistry and geochemical models.

\subsection{Limitations of Analytical Data}

A total aqueous speciation by analyzing each species in tens of samples is simply impossible for several reasons which include the:

- sheer magnitude of the manpower required

- labile nature of the complexes (i.e., rapid rate of dissociation)

- $\quad$ small quantities present of many complexes

- chemical similarities between some complexes.

The accuracy of the computed speciation can be no better than the accuracy of analyses of the total dissolved constituents in waters having complex matrices of dissolved solids, as well as solutions separated from suspensions. For example, one of the technological problems of this decade is to assess the safety of nuclear repositories. To this end, literally thousands of measurements of radionuclide sorption have been made over the past two decades. One would suppose that the techniques of determining the loss of dissolved $\mathrm{Cs}, \mathrm{Sr}, \mathrm{Pu}$, etc. to solids suspended in the aqueous phase would have been thoroughly worked out. Unfortunately, this is not the case as illustrated in Table 1. The differences as measured by various laboratories, in Cs remaining in solution at "equilibrium," is marked and is of such a magnitude as to render speciation-adsorption modeling a pointless exercise. The same report [23] shows interlaboratory differences for a similar adsorption comparison, on splits of the same samples, for Pu where the distribution coefficient ${ }^{3}$ varied by several orders of magnitude. In an interlaboratory calibration study of marine waters (Table 2), Brewer and Spenser [3] report the coefficient of variation of the grand means for 7 of 15 trace elements to range from 18 to $34 \%$. This variance is of such a magnitude as to suggest that it is likely to be very difficult to show related bioavailability effects between studies simply because of the unreliability of the reported concentrations of trace inorganic constituents in waters.

It is apparent that it is both essential and unavoidable to use geochemical models for the bulk of the aqueous speciation. The key question then becomes "what are the most

\footnotetext{
3 Distribution coefficient is defined as the ratio of an element, usually at trace levels, to that sorbed by the suspended earth material to that remaining in solution, normalized to unit volume and mass (generally on $110^{\circ} \mathrm{C}$ dry weight basis).
} 
Table 1. Distribution Coefficient Values for $\mathrm{Cs}$ ( $\mathrm{mg} \mathrm{L}^{-1} \pm$ standard deviation) [After 23, Table 5]

\begin{tabular}{|c|c|c|c|c|c|c|c|c|}
\hline \multirow[b]{2}{*}{ Laboratory } & \multirow{2}{*}{$\begin{array}{c}\text { Subsampi } e^{a} \\
\text { Size }(g)\end{array}$} & \multicolumn{7}{|c|}{ Experiment } \\
\hline & & & 1 & & 2 & 3 & & 4 \\
\hline$A^{b}$ & 1 & 65 & \pm 2 & 0.14 & \pm 0.01 & $401 \pm 21$ & 1.48 & \pm 0.05 \\
\hline$B^{f}$ & $?$ & 1.3 & $\pm \quad 0.4$ & 0.2 & $\pm 0.4^{9}$ & $31 \pm 2$ & 1.4 & \pm 0.4 \\
\hline$c^{c}$ & 1 & 88 & \pm 1 & -0.12 & $\pm 0.12^{9}$ & $265 \pm 4$ & 0.6 & \pm 0.2 \\
\hline $\mathrm{D}^{f}$ & 1 or 2 & 49 & \pm 5 & 0.16 & \pm 0.9 & $296 \pm 10$ & 1.52 & \pm 0.04 \\
\hline$E^{b}$ & $?$ & 60 & \pm 30 & 0.5 & $\pm 0.5^{9}$ & $290 \pm 70$ & 1.6 & \pm 0.1 \\
\hline$F-I^{f}$ & 1 & 227 & $\begin{array}{l}- \\
\pm \quad 14\end{array}$ & 0.6 & \pm 0.3 & $380 \pm 5$ & 2.2 & \pm 0.2 \\
\hline$F-I^{d}$ & $?$ & 663 & \pm 61 & 0.1 & $\pm 0.3^{9}$ & $453+12$ & 1.79 & \pm 0.01 \\
\hline$G^{e}$ & 1 & 880 & \pm 160 & 3.3 & \pm 0.7 & $380 \pm 70$ & 4.6 & \pm 0.3 \\
\hline$H^{f}$ & 2 & 6.8 & $\pm \quad 0.6$ & 0.04 & $\pm 0.03^{g}$ & $255 \pm 7$ & 0.95 & \pm 0.13 \\
\hline
\end{tabular}

aral communication from John Relyea, Pacific Northwest Laboratory.

$b_{\text {Effluent was filtered. }}$

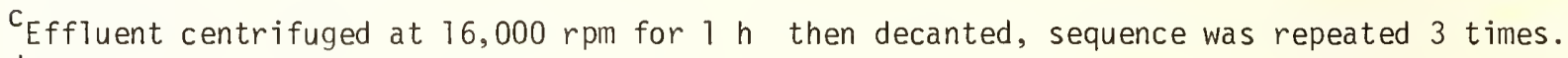

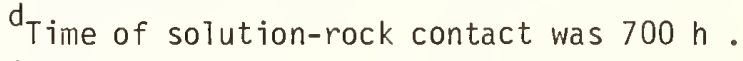

$e_{E f f l u e n t}$ centrifuged for $20 \mathrm{~min}$ at $7000 \mathrm{rpm}$.

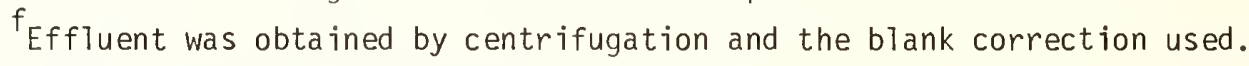

$g_{\text {Not significantly different from zero. }}$

Table 2. Elements Analyzed in Sea Water by Various Laboratories Ranked in Order of Increased Coefficient of Variation of the Grand

Means, Calculated From the Pooled Standard Deviations [3]

\begin{tabular}{|c|c|c|c|c|c|}
\hline Element & $\begin{array}{l}\text { Coefficient } \\
\text { of Variation }\end{array}$ & $\begin{array}{l}\text { Abundance } \\
\left(\mu \mathrm{g} \mathrm{kg}{ }^{-1}\right)\end{array}$ & Element & $\begin{array}{l}\text { Coefficient } \\
\text { of Variation }\end{array}$ & $\begin{array}{l}\text { Abundance } \\
\left(\mu \mathrm{g} \mathrm{kg}^{-1}\right)\end{array}$ \\
\hline
\end{tabular}

\begin{tabular}{lrrrrr}
\hline Sr & 2.5 & 8100 & Zn & 18.4 & 5 \\
$\mathrm{~F}$ & 2.8 & 1350 & $\mathrm{Cu}$ & 2.0 .4 & 3 \\
$\mathrm{Rb}$ & 5.4 & 127 & $\mathrm{Co}$ & 22.0 & 0.1 \\
$\mathrm{Cs}$ & 5.5 & 0.3 & $\mathrm{Mn}$ & 24.5 & 1.5 \\
$\mathrm{U}$ & 5.6 & 3.3 & $\mathrm{Fe}$ & 25.8 & 14 \\
$\mathrm{Sb}$ & 10.2 & 0.4 & $\mathrm{~Pb}$ & 29.2 & 5 \\
& & & $\mathrm{Ni}$ & 33.5 & 2 \\
\hline
\end{tabular}


pressing analytical needs to generate the maximum information with the required accuracy?" Some of these are presented in Table 3.

Table 3. Some Needed Aralytical Methodologies for Leachates of Solid Wastes from Fossil Energy Technologies

Constituent

Classes of organic compounds

Thiols

Reduced valence states

$S(0)^{\mathrm{a}}$ and other reduced sulfur species
Comments

Separation techniques are needed to permit determination of quantity classes of organic compounds present and provide samples for determination of trace element-organic association constants. This is one way to include organic ligands in the speciation calculations.

Needed for metal speciation calculations.

Needed for polluted waters high in dissolved organic compounds and/or dissolved solids. Methods need to have quite low detection 1 imit.

Needed for polysulfide, and $s^{2-} / s^{0}$ and $s^{0} / s^{6+}$, etc. redox couple computations in waters containing up to hundreds of $\mathrm{mg} \mathrm{L}^{-1}$ of dissolved organic carbon; perhaps carry out by 1 iquid chromatography.

\footnotetext{
${ }^{a}$ Roman numeral in parentheses following the symbol for an element indicates a valence state, i.e., $S(0)$ signifies all dissolved sulfur of zero valence whether complexed or not. This contrasts to superscripts which signify the valence of a particular aqueous species.
}

\subsection{Limitation of Geochemical Model ing Capability}

The two greatest 1 imitations in computing the aqueous speciation in natural waters, in general, are the absence of appropriate methods to address the complexation of metals by organic ligands and the disequilibrium between redox couples. Additional limitations include the lack of sufficient thermodynamic and kinetic data and the lack of competence of the available geochemical models.

It is likely that the preponderance of dissolved first transition metals in surface waters are complexed by organic ligands: this is also true to a slightly lesser extent in ground waters [11]. Water passing through piles of sol id wastes from fossil fuel technologies may contain from tens to many hundreds of milligrams per liter of dissolved organic carbon. The resulting complexation of metals may be so pervasive as to affect the speciation of $\mathrm{Ca}$ as well as first transition series and other heavy metals. The large number of organic compounds present in both natural and polluted waters, the great 
effort required to identify and quantify even the lower molecular weight portion of the organic compounds, and the lack of association constants for many of these compounds with the metals would appear to preclude an approach of modeling the speciation of the metals with individual organic ligands. However, it should be noted that the possibility remains, in relatively unpolluted waters, that a few ligands may be the dominant complexants of particular metals as has been found to be the case for the metabolic products of certain soil fungi [27]. Either a select group of organic compounds needs to be quantitatively determined or classes of organic compounds need to be quantified along with the determination of their association constants. This must be done for all metals of concern, in a routine way, for each water sample having a dissolved organic content of greater than some minimum. A significant effect of the very high dissolved organic carbon levels that occur in leachates of solid wastes of fossil energy technologies is that even Ca may be complexed by organic ligands to a degree which causes apparent oversaturation with solubility limiting phases such as calcite. A limited number of "conditional" stability constants for selected metals and natural dissolved organic materials, or fractions thereof, exist. However, these constants cannot be readily used in speciation modeling because "conditional" stability constants are calculated using concentration terms rather than activities. In the case of hydrolyzed metals, such as $\mathrm{Fe}(\mathrm{III})$, the conditional and thermodynamic stability consists may differ by orders of magnitude [15].

Certain trace element-organic complexes such as cobalamin or methylmercury derivatives, are said to be physiologically active, i.e., they pass membrane barriers intact. The formation of such complexes has the effect of increasing the bioavailability of the trace metal instead of decreasing its bioavailability, as is normally observed for trace element-organic complexes. The single reported observation, known to this author, indicating that organic ligand complexation increased the bioavailability of a toxic metal is that of George and Coombs [9]. However, there are ambiguities concerning their experimental technique. It seems likely that the organic complexes they used served to increase the "availability" of the metal in the soil fertility sense, i.e., decreased the rate and/or extent of its precipitation and/or adsorption.

The other primary 1 imitation on aqueous speciation is that of partitioning an element among its valence states. Use of platinum electrode potentials frequently results in a computed near-equilibrium with ferrihydrite, the amorphic iron oxide [2]. Rhodochrosite, $\mathrm{MnCO}_{3}$, computes to be an equilibrium phase in some reducing ground and interstitial waters where the redox potential was obtained with platinum electrodes or $\mathrm{Fe}^{2+} / \mathrm{Fe}^{3+}$ potentials. Thus, it appears that the $\mathrm{Fe}$ and $\mathrm{Mn}$ redox couples are frequently, if not generally, in near equilibrium. This would be expected from observations of the close proximity of $\mathrm{Mn}$ and $\mathrm{Fe}$ as electron acceptors during microbial-driven reduction of sediments [10, pp. 356, 367]. However, there is no evidence that the $\mathrm{Fe}^{2+} / \mathrm{Fe}^{3+}$ couple is in near equilibrium with the $\mathrm{s}^{2-} / \mathrm{S}^{0}, \mathrm{~S}^{0} / \mathrm{s}^{6+}, \mathrm{As}^{3+} / \mathrm{As}^{5+}, \mathrm{Cr}^{3+} / \mathrm{Cr}^{6+}, \mathrm{I}^{-} / \mathrm{IO}_{3}^{-}$and $\mathrm{O}_{2} / \mathrm{H}_{2} \mathrm{O}$ couples. In fact, the opposite is reported $[6,20,26]$. Thus, it could be quite valuable to know in detail the kinetics of both the oxidation of reduced valence states and 
reduction of oxidized states to predict the time-course of such reactions in natural and contaminated waters. It should be noted that oxidation rates of reduced valence states may be quite sensitive to the presence of both inorganic and organic catalysts. Because organisms, bacteria in particular, may derive energy from the oxidation of reduced valence states, there may be a significant biological factor in these oxidation reactions. Similarly, because the oxidized valence state $\left[0_{2}, \mathrm{Mn}(\mathrm{IV}), \mathrm{Fe}(\mathrm{III})\right.$ and $\left.\mathrm{S}(\mathrm{VI})\right]$ serve as electron acceptors, reduction rates will be greatly affected by microbial respiration rates. This could be one reason for differences, which can be enormous, between oxidation rates in the laboratory and in the field (Table 4) [6].

Table 4. The Computed pe and $E^{H}$ for Various Redox Half Reactions for the Oxygen-Sulfide Interface Zone of Sannich Inlet, British Columbia [After 6] (Subscripts: $g=$ gas, $s=$ solid)

\begin{tabular}{ccc} 
Couple & pe & $E^{\mathrm{H}}$ \\
\hline $\mathrm{O}_{2} / \mathrm{H}_{2} \mathrm{O}$ & 12.8 & 0.76 \\
$\mathrm{NO}_{3}^{-} / \mathrm{N}_{2}(\mathrm{~g})$ & 11.2 & 0.66 \\
$\mathrm{I0}_{3}^{-} / \mathrm{I}^{-}$ & 10.5 & 0.62 \\
$\mathrm{MnO}_{2}(\mathrm{~s}) / \mathrm{Mn}^{2+}$ & 8.9 & 0.53 \\
$\mathrm{CrO}_{4}^{2-} / \mathrm{Cr}^{2}(\mathrm{OH})_{2}^{+}$ & 6.6 & 0.39 \\
$\mathrm{~N}_{2}^{\mathrm{O}}(\mathrm{g}) / \mathrm{NH}_{4}^{+}$ & -2.6 & -0.15 \\
$\mathrm{FeOOH}_{(\mathrm{s}) / \mathrm{Fe}^{2+}}$ & -2.7 & -0.16 \\
$\mathrm{SO}_{4}^{2-} / \mathrm{HS}^{-}$ & -3.4 & -0.20 \\
\hline
\end{tabular}

There is a great need for certain thermodynamic data, and an equivalent intense need for critical evaluation of available, but often discordant, thermodynamic data. These are very labor intensive, and hence, costly efforts. For aqueous speciation, the experimental data needed are for association constants and their temperature dependence. Relatively little information appears to be available on the temperature dependencies of the association constants. Certain specific needs are listed in Table 5.

Aqueous speciation and other aspects of geochemical modeling are currently limited by the competence of the available models. Competence is used to indicate the completeness and comprehensiveness of the model, e.g., the inclusion of all necessary elements and complexes for aqueous speciation and all solids and their solid solution properties for solubility modeling. For example, a water draining from a pile of retorted oil shale had 0.03 vs $0.003 \mathrm{mg} \mathrm{L}^{-1}$ of total dissolved $\mathrm{Cu}$ depending upon the technique used for sample preservation. The 10-fold higher Cu level complexed an amount of $\mathrm{s}^{2-}\left(3.5 \times 10^{7}\right.$ 
Table 5. Summary of Urgently Needed Thermodynamic Data for Speciation Modeling Relative to Contamination of Water by Leachates of

Solid Wastes from Energy Technology

\begin{tabular}{|c|c|c|c|}
\hline Technology & Waste & $\begin{array}{l}\text { Gibbs Free Energy } \\
\text { (and Enthalpy) } \\
\text { of Formation }\end{array}$ & Comments \\
\hline \multicolumn{4}{|c|}{ Additional Data } \\
\hline $\begin{array}{l}\text { Nuclear \& } \\
\text { Fossil }\end{array}$ & $\begin{array}{l}\text { Coolant, } \\
\text { solid waste } \\
\text { leachate }\end{array}$ & $\mathrm{Cu}(\mathrm{OH})_{2}^{\mathrm{O}}$ & $\begin{array}{l}\text { Present literature estimates from the } \\
\text { literature differ by several orders of } \\
\text { magnitude }[21,22,24] \text {; this discrepancy } \\
\text { is major } 1 \text { imitation on computation of } \mathrm{Cu} \\
\text { speciation in nuclear cooling waters } \\
\text { mixing with coastal marine water. }\end{array}$ \\
\hline Fossil & $\begin{array}{l}\text { Leachate of } \\
\text { high organic } \\
\text { solid wastes }\end{array}$ & $s_{3}^{2-}$ to $s_{6}^{2-}$ & $\begin{array}{l}\text { Association constants are known only for } \\
\mathrm{Ag}, \mathrm{Cu} \text { and } \mathrm{Zn} \text {; needed for } \mathrm{Cd}, \mathrm{Pb} \text { and } \\
\text { other metals. }\end{array}$ \\
\hline A11 & & $\begin{array}{l}\mathrm{Fe}\left(\mathrm{SO}_{4}\right)_{2}^{-} \\
\mathrm{FeHSO}_{4}^{2+} \\
\mathrm{Fe}\left(\mathrm{HSO}_{4}\right)_{2}^{\circ}\end{array}$ & $\begin{array}{l}\text { The existence of these complexes needs to } \\
\text { be established, as well as their free } \\
\text { energy and enthalpy of formation } \\
\text { determined [19]. They may be important } \\
\text { in waters high in sulfate and ferrous } \\
\text { iron. }\end{array}$ \\
\hline
\end{tabular}

\section{Compilations and Critical Evaluations}

Fossil High organic $\mathrm{SO}_{3}, \mathrm{~S}_{2} \mathrm{O}_{3}$, Available data have not been critically content solid SCN, $\mathrm{S}(0)$ reviewed.

wastes
A11 leachates
$\mathrm{CaCl}^{+}, \mathrm{MgCl}^{+}$
Presence in one model caused outstanding
high in
difference in model comparison [20].

dissolved solids

mola1; $75 \%$ of total $\mathrm{S}^{2-}$ as $\mathrm{H}_{2} \mathrm{~S}$ ) that resulted in otavite, $\mathrm{CdCO}_{3}$, being at equilibrium solubility. The lower $\mathrm{Cu}$ level, however, resulted in apparent oversaturation with otavite. Because otavite is a solubility limiting mineral in drainage from mine tailings drainage [13], we take this as indicating that the higher dissolved Cu concentration is closer to the true value. Thus, reliable speciation model ing requires that all metals, 
which can form quantitatively important complexes with sulfide, be included in the model. By the same token, all ligands which can complex the metals must be included in the model. It follows that efforts might most profitably be directed towards improving the competence of existing models rather than the creation of new models. By virtue of the great effort required to develop such competence, new models tend to be incompetent except for rather restricted problems.

The importance of, and the kinetic limitation on, redox reactions necessitates that kinetic submodels be incorporated into equilibrium speciation models. This; along with the development of kinetic data, could provide a major increase in competence of speciation model ing.

Another major problem in the development of competent models is that investigators commonly feel that if a given complex does not account for at least a few percent of the total dissolved metal or 1 igand in the aqueous media in which they are working, the complex is not worth the required effort for inclusion in the model. However, inevitably another investigator obtains the model and attempts to use it on an aqueous media very high in either the metal or the ligand or both, not being aware of this particular limitation of the model. The result is that he finds the model incompetent and frequently concludes that geochemical modeling does not provide a useable tool for interpreting his data. It is unreasonable to expect that every user will have the competence and the time to independently determine that an additional complex needs to be added to the model for his application. Therefore, there needs to be a continuing effort [13] to establish that the competency of the model being used (e.g., "partially validated") by obtaining good agreement between measured and calculated speciation or by the fit of points of a solubility limiting phase for the waters being modeled. The concept of validation, thoroughly accepted in hydrologic modeling, is largely ignored by geochemical modelers.

\section{Summary}

An understanding of geochemical processes permits an assessment of the relative risk to man of leachable constituents from the solid wastes of alternative energy technologies and waste-disposal practices. Comprehensive and accurate aqueous speciation is valuable because it permits, along with other information, determination of the bioavailability of toxic elements from anthropogenic inputs. Aqueous speciation is an essential basis for future aquatic and terrestrial modeling of the accumulation, and distribution between biotic compartments, of toxic elements. Speciation is also essential to an adequate modeling of the hydrologic transport of toxic elements and radionuclides. Sufficiently accurate aqueous speciation is likewise a necessity for useful solubility model ing.

Comprehensive aqueous speciation is not feasible by analyzing individual complexes because of the enormous manpower required, the labile nature of many of the complexes, and the trace concentrations of various complexes. 
Currently, the most urgently needed support includes: 1) analytical techniques of separating dissolved organic compounds into classes, quick determination of stability constants which are independent of hydrolysis, other complexation, and ionic strength effects; 2) improved methods for the analytical valence speciation and/or information on estimating the redox potential of one couple from another redox couple; 3 ) increased competence of state-of-the-art geochemical models; and 4) critical evaluation of selected thermodynamic and kinetic data and collection of additional thermodynamic data on certain complexes.

The most meaningful application of analytical speciation efforts would be for the validation of computed speciation, as in the early paper on speciation of major ions in sea water by Garrels and Thompson [8] and the determination of important species which cannot be computed because of nonequilibrium conditions or the absence of thermodynamic data.

The very helpful reviews of Donald C. Girvin, Andy R. Felmy, and Kenneth M. Krupka and typing and proofing by Sharon Lepel are much appreciated.

\section{References}

[1] Andrew, R. W.; Biesinger, K. E.; Glass, G. E. Effects of inorganic complexing on the toxicity of copper to Daphnia magna. Water Res. 11: 309-315. 1977.

[2] Bal1, J. W.; Jenne, E. A.; Nordstrom, D. K. WATEQ2--A computerized chemical model for trace and major el ement speciation and mineral equilibria of natural waters. E. A. Jenne, ed. in Chemical modeling in aqueous systems. Speciation, sorption, solubility and kinetics; Amer. Chem. Soc. Symp. Series 93; $1979 . \quad$ 815-836.

[3] Brewer, G.; Spencer, D. W. Trace element intercalibration study. Report 70-62, unpub. ms. Woods Hole Oceanographic Institution, Woods Hole, MA. 63 p. 1970.

[4] Chakoumakas, C.; Russo, R. C.; Thurston, R. V. Toxicity of copper to Cutthroat trout (Salmo clarki) under different conditions of alkalinity, pH and hardness. Environ. Sci. Tech. 13: 213-219. 1979.

[5] Deutsch, W. J.; Jenne, E. A.; Krupka, K. M. Solubility equilibria in basalt aquifers: The Columbia Plateau, Edstern Washington. Battelle, Pacific Northwest Laboratory, Richland, WA. (manuscript) $22 \mathrm{p}$.

[6] Emerson, S. R.; Carnston, E.; Liss, P. S. Redox species in a reducing fjord: equilibrium and kinetic considerations. Deep-Sea Res. $26 \mathrm{~A}$ : 859-878. 1979.

[7] Florence, T. M.; Batley, G. E. Chemical speciation in natural waters. Chemical Rubber Co. Reviews in Anal. Chem. 9: 219-296. 1980.

[8] Garrels, R. M.; Thompson, M. E. A chemical model for sea water at $25^{\circ} \mathrm{C}$ and one atmosphere total pressure. Amer. J. of Sci. 260: 57-66. 1962.

[9] George, S. G.; Coombs, T. L. The effects of chelating agents on the uptake and accumulation of cadmium by mytilus edulis. Marine Biol. 39: 261-268. 1977. 
[10] Jenne, E. A. Controls of Mn, Fe, Co, Ni, Cu and $\mathrm{Zn}$ concentrations in soils and water--the significant role of hydrous $M$ n and Fe oxides. Adv. Chem . 73: $337-387.1968$.

[11] Jenne, E. A. Trace element sorption by sediments and soils--sites and processes. W. Chappe 11; K. Petersen, eds. Symposium on Molybdenum in the Environment, Vol. 2; New York, NY; M. Dekker, Inc. ; 1977. 425-553.

[12] Jenne, E. A. Geochemical modeling - a review. Battelle, Pacific Northwest Laboratory, Richland, WA. PNL-3574. 1981.

[13] Jenne, E. A.; Ba71, J. W.; Burchard, J. M.; Vivit, D. D., Barks, J. H. Geochemical modeling: apparent solubility controls on $\mathrm{Ba}, \mathrm{Zn}, \mathrm{Cd}, \mathrm{Pb}$ and $\mathrm{F}$ in waters of the Missouri Tri-State mining area. D. D. Hemphil1, ed. in Trace Substances in Environmental Health-XIV, Columbia, M0; Univ. of Missouri Press; 1980. 353-361.

[14] Jenne, E. A.; Luoma, S. N. The forms of trace elements in soils, sediments, and associated waters: An overview of their determination and biological availability. R. E. Wildung; H. Drucker, eds. in Biological implications of metals in the e nvironment; CONF-750929; NTIS; Springfield, VA; 1975. 110-143.

[15] Malcolm, R. L.; Jenne, E. A.; McKinley, P.W. Conditional stability constants of a North Carolina soil fulvic acid with $\mathrm{Co}^{2}$ and $\mathrm{Fe}^{3}$. D. W. Hood, ed. in Organic matter in natural waters; College, Univ. Alaska, Institute of Marine Science, Occasional Pub. No. 1; $1970 . \quad$. 479-483.

[16] Magnuson, V. R.; Harriss, D. K.; Sun, M. S.; Taylor, D. K.; Glass, G. E. Relationships of activities of metal-ligand species to aquatic toxicity. E. A. Jenne, ed. in Chemical mdeling in aqueous systems. Speciation, sorption, solubility and kinetics; Amer. Chem. Soc. Symp. Series No. 93; $1979 . \quad 635-651$.

[17] Mattigod, S. V.; Gibali, A. S.; Page, A. L. Effects of ionic strength and ion pair formation on the adsorption of nickel by kaolinite. Clays and Clay Minerals 27: 411-416. 1979.

[18] Nordstrom, D. K.; Jenne, E. A. Fluorite solubility equilibria in selected geothermal waters. Geochim Cosmochim Acta 41: 175-188. 1977.

[19] Nordstrom, D. K.; Jenne, E. A.; Ba11, J. W. Redox equilibria of iron in acid mine waters. E. A. Jenne, ed. in Chemical modeling in aqueous systems. Speciation, Sorption, solubility, and kinetics; Amer. Chem. Soc. Symp. Series 93; 1979. $51-80$.

[20] Nordstrom, D. K.; Plummer, L. N.; Wigley, T. M. L.; Jenne, E. A.; et al. Computer programs for the calculations of chemical equilibrium in aqueous solutions. E. A. Jenne, ed. in Chemical modeling in aqueous systems. Speciation, sorption, solubility, and kinetics; Amer. Chem. Soc. Symp. Series 93; 1979. 857-894.

[21] Paulson, A. J. Potentiometric studies of cupric hydroxide complexation. MS Thesis, Univ. Rhode Island, Kingston, RI. 1978. 102 p.

[22] Paulson, A. J. Copper (II) in hydrolysis in aqueous solution. J. Soln. Chem. 9: 209-277. 1980.

[23] Relyea, J. F.; Serne, R. J. Control sample program publication number 2: Interlaboratory comparison of batch Kd values. Battelle, Pacific Northwest Laboratory, Hanford, WA. PNL-2872; 1979. 15 p.

[24] Sunda, W. G.; Hanson, P. J. Chemical speciation of copper in river water - effect of total $\mathrm{Cu}, \mathrm{pH}$, carbonate, and dissolved organic matter. E. A. Jenne, ed. in Chemical modeling in aqueous systems. Speciation, sorption, solubility and kinetics; Amer. Chem. Soc. Symp. Series 93; 1979. 147-180. 
[25] Sebesta, Ferdinand; Benes, Petr; Sedlacek, Josef; John, Jan; Sandrik, Romea. Behavior of radium and barium in a system including uranium mine waste water and adjacent surface waters. Environ. Sci. Tech. 15: 71-75. 1981.

[26] Stauffer, R. E.; Jenne, E. A.; Ba11, J. W. Chemical studies of selected trace elements in hot spring drainages of Yellowstone National Park. Geological Survey Professional Paper 1044-F; 20p. 1980.

[27] Wildung, R. E.; Garland, T. R.; Drucker, H. Nickel complexes with soil microbial metabolites - mobility and speciation in soils. E. A. Jenne, ed. in Chemical modeling in aqueous systems. Speciation, sorption, solubility, and kinetics; Amer. Chem. Soc. Symp. Series No. 93; 180-200; 1979.

Discussion

Question (R. A. Durst): What evidence is there that redox disequilibrium is involved?

Answer: If one has analytical values for nitrite, nitrate, ammonia, and so on, and if one then computes the redox potentials from those, you get this kind of a range of computer potentials. It says they're in disequilibrium. If you use these values to compute the distribution of $\mathrm{Fe}$ (II) and $\mathrm{Fe}$ (III), you get a horrendous range in computed molarity of $\mathrm{Fe}^{2+}$ and $\mathrm{Fe}^{3+}$.

Question (R. A. Durst): Do you expect for the metallic couples you indicated earlier that these would be in equilibrium?

Answer: We have evidence that iron and manganese are in apparent equilibrium. We know that arsenic is not, and there is reason to think that chromium is not. We don't have data sets to compare to the other couples. For example, part of the problem is the nitrogen and sulfur couples are microbiologically driven, in fact catalyzed, but there may be some activation energy between them. I've seen some constancy through the difference in potentials, but never had data sets adequate to test the hypothesis.

Question (R. S. Braman): Could you again describe what you mean by the ratio of the activity product of the $\mathrm{K}_{\mathrm{sp}}$ ?

Answer: Actually, this is a way of presenting it which is conceptionally easy to understand. We are looking at the $\log K$ of reactions.

Question (R. S. Braman): The activity product, defined by the thermodynamic $K_{s p}$ is equal to what?

Answer: It is an equilibrium, consequently, we are using that as a test for equilibrium of the dissolved species to the appropriate solid for waters. 
Question (R. S. Braman): What kind of ionic strengths are in these waters?

Answer: Mostly below one molal. The extended Debye-Huckel equation will go up to sea water. Question (R. S. Braman): Sea water? Which extended Debye-Huckel? I thought it was only good to about 0.1 molal.

Answer: No. The V-dot [for example, see Petybridge, Prue, Progr. Inorg. Chem. 17, Part II: 327 (1972) - Eds.] 
Biogeochemical Cycles of Metals and Metalloids - The Role of MethylCobalamin and Some Other Chemical Routes to Methylation in the Environment

\section{P.J. Craig* and S. Rapsomanikis}

School of Chemistry, Leicester Polytechnic,

P.0. Box 143, Leicester LEI 9BH, England.

The evidence for the role of methylcobalamin, $\mathrm{CH}_{3} \mathrm{CoB}_{12}$, as the proximate source of the methyl group in heavy metal methylation is discussed. For metals in low or zero oxidation states other methyl donors are suggested. Chemical routes to methylation of already partially methylated species are detailed, particularly for the $\left(\mathrm{CH}_{3}\right)_{3} \mathrm{M}^{+}$ species $(M=S n, P b)$.

Key words: environment; GC-MS; heavy metals; 1ead; mass spectrometry; mercury; methylation.

1. Methylcobalamin as an Environmental Methylating Species

During the past decade there is little doubt that attention has been heavily focussed on methylcobalamin $\mathrm{CH}_{3} \mathrm{COB}_{12}$, as the proximate source of the methyl group donated to heavy metals in environmental methylation. $\mathrm{CH}_{3} \mathrm{CoB}_{12}$ may be simplistically described as an octahedrally coordinated cobalt(III) species with a cobalt methyl group bond. Its empirical formula, $\mathrm{C}_{63} \mathrm{H}_{91}{ }_{14} \mathrm{~N}_{13} \mathrm{PCO}$, however suggests its true complexity. A detailed structure for $\mathrm{CH}_{3} \mathrm{CoB}_{12}$ is available [I]. It is suggested that the methyl group donated to heavy metals (e.g., mercury) is that which is bound to the cobalt atom.

The origin of this suggestion arises in the seminal Wood, Kennedy and Rosen paper of 1968 [2]. $\mathrm{CH}_{3} \mathrm{CoB}_{12}$ proved an excellent substrate for methane formation in extracts of Methanobacterium omelianski $(\mathrm{MOH})$. When $\mathrm{Hg}^{2+}$ compounds were added, methane formation was inhibited and $\mathrm{CH}_{3} \mathrm{Hg}^{+}$and $\left(\mathrm{CH}_{3}\right)_{2} \mathrm{Hg}$ were formed. This suggests the organism may use the cobalamin methyl group for methane formation but in the presence of mercury may transfer it to the metal. The authors were able to carry out the methyl transfer from $\mathrm{CH}_{3} \mathrm{CoB}_{12}$ to $\mathrm{Hg}^{2+}$; a purely chemical, non-biological experiment.

This work provided an excellent candidate for the methylation factor in environmental mercury methylation. Following wood et al,a number of groups produced kinetic and mechanistic studies of the reaction of $\mathrm{CH}_{3} \mathrm{COB}_{12}$ with $\mathrm{Hg}^{2+}$ compounds in aqueous media in purely chemical systems, and in each case $\mathrm{CH}_{3} \mathrm{Hg}^{+}$was produced initially and $\left(\mathrm{CH}_{3}\right)_{2} \mathrm{Hg}$ more slowly [2-7]. These papers all suggest electrophilic attack of the mercury species on

\footnotetext{
* To whom correspondence should be addressed.
} 
$\mathrm{CH}_{3} \mathrm{COB}_{12}$ leading to removal of the methyl group as a carbanion. With this in mind, Wood has suggested that $\mathrm{CH}_{3} \mathrm{COB}_{12}$ might be a prime methylating factor in the environment as only this species can transfer a methyl group as $\mathrm{CH}_{3}^{-}$to other species. If the metal is present in the environment as an oxidized or electrophilic center $\left(\mathrm{M}^{\mathrm{n}+}\right)$ then it would tend to be reactive to carbanions. The other known environmental methylating species, S-adenosylmethionine and N-5-methyltetrahydrofolate, both lose methyl groups as carbonium ions which would tend not to transfer to positively charged metal centers [8]. We have to consider however if metals, even including mercury, are always present in an electrophilic condition in the environment. For chemical systems, however, as exemplified by mercury, we are left with the following transfer mechanism as a model for methylation of metals and with $\mathrm{CH}_{3} \mathrm{COB}_{12}$ as the methy 1 source.

$$
\mathrm{CH}_{3} \mathrm{COB}_{12}+\mathrm{Hg}^{2+} \stackrel{\mathrm{H}_{2} \mathrm{O}}{\longrightarrow} \mathrm{CH}_{3} \mathrm{Hg}^{+}+\mathrm{H}_{2} \mathrm{OCOB}_{12}{ }^{+}
$$

Does any more direct evidence exist for the role of $\mathrm{CH}_{3} \mathrm{CoB}_{12}$ in real systems? In fact there is a somewhat neglected paper by Imura et al. [9] which describes how tuna fish liver homogenates were incubated with ${ }^{203} \mathrm{HgCl}_{2}$ to produce $\mathrm{CH}_{3}{ }^{203} \mathrm{Hg}^{+}$. Methylation still occurred after autoclaving but it did not take place at all if the homogenates were exposed to visible light. This would accord with the methylation factor being $\mathrm{CH}_{3} \mathrm{CoB}_{12}$ which is unstable to light in solution, and it is present in liver and kidney tissue. Using $\left[{ }^{3} \mathrm{H}\right]-\mathrm{CH}_{3} \mathrm{COB}_{12}$ added to liver homogenates, the authors demonstrated that the radioactivity and the methylation factor were co-fractional after chromatography under conditions known to (a) trap and (b) release cobalamin derivatives. The authors suggested that their findings strongly indicate that $\mathrm{CH}_{3} \mathrm{CoB}_{12}$ was involved in methylation by tuna fish liver. Several authors have noted that addition of $\mathrm{CH}_{3} \mathrm{CoB}_{12}$ to incubating microorganism systems in the presence of mercury produced more $\mathrm{CH}_{3} \mathrm{Hg}^{+}$than produced by the organisms alone. However, such results could merely be the superimposition of an abiotic cobalamin based chemical methyl transfer to a natural mercury methylation process in the organisms which may not be cobalamin based. Where workers have used $\mathrm{CNCOB}_{12}$ (Vitamin $\mathrm{B}_{12}$ ), and extra $\mathrm{CH}_{3} \mathrm{Hg}^{+}$has been produced, then this is more telling evidence for the utilization of $\mathrm{CH}_{3} \mathrm{CoB}_{12}$ by the organisms [10-12]. However, it has also been reported that addition of $\mathrm{CH}_{3} \mathrm{CoB}_{12}$ did not increase the rate or extent of methylation of mercury in certain cases. For example, rats fed with $3 \mathrm{ppm}$ or $30 \mathrm{ppm} \mathrm{HgCl} 2$ dosed food did not produce any more $\mathrm{CH}_{3} \mathrm{Hg}^{+}$when $\mathrm{CH}_{3} \mathrm{CoB}_{12}$ was added to the diet [13]. A number of other authors have reported broadly similar conclusions.

Blum and Bartha have recently shown that a saline $\mathrm{HgCl}_{2}$ is methylated to a lesser extent by the microorganisms present than it is in freshwater conditions. As mercury is present in seawater predominantly as the $\mathrm{HgCl}_{4}^{2-}$ complex then, if methylation takes place as a carbanion transfer (as from $\mathrm{CH}_{3} \mathrm{CoB}_{12}$ ), the slower rate and lesser extent in saline conditions is easily understood [14]. Similar reductions in reaction rates when mercury is complexed with excess chloride ion have been observed in transalkylation reactions (vide infra) where a $\mathrm{CH}_{3}^{-}$group is transferred [15]. 
We can be sure then that $\mathrm{CH}_{3} \mathrm{COB}_{12}$ may transfer with ease its methyl group to mercury as a carbanion. It will enhance, as will $\mathrm{CNCOB}_{12}$, methylation of mercury by some other species and, therefore, is established as a credible methylation factor for mercury and perhaps other metals. However, there is also evidence of methylation which takes place by routes not involving $\mathrm{CH}_{3} \mathrm{COB}_{12}$.

Transfer of methyl radicals $\left(\mathrm{CH}_{3}{ }^{*}\right)$ from $\mathrm{CH}_{3} \mathrm{CoB}_{12}$ has also been discussed as a possible methyl transfer route, and this has been implicated in certain tin methylation reactions (vide infra). Carbanion transfer from $\mathrm{CH}_{3} \mathrm{CoB}_{12}$ is a Type I process, and radical transfer is Type II [8].

2. Other Routes to Heavy Metal Methylation

For the record it has been shown that ethylene and acetylene (both natural products) may convert $\mathrm{HgCl}_{2}$ to volatile alkylmercury compounds and mercury vapour [16]. The alky]mercury compounds were not identified but were, presumably, more likely to be ethy 1 rather than methyl derivatives.

It has also been shown that irradiation of aqueous $\mathrm{Hg}(O \mathrm{AC})_{2}$ in a quartz vessel by a lamp replicating sunlight produced $\mathrm{CH}_{3} \mathrm{Hg}^{+}$. The methylation probably occurred by initiąl production of $\mathrm{CH}_{3} \mathrm{COO}$ radicals and subsequent formation and attack of $\mathrm{CH}_{3} \cdot$ species [17-19]. Acetic acid is a natural biochemical metabolite and so this is, in principle, a route that could operate in the natural environment. It also suggests that extra care should be taken when, for example, conducting $\mathrm{CH}_{3} \mathrm{COB}_{12}$-based methyl transfer experiments with $\mathrm{Hg}(\mathrm{OAC})_{2}$. Two methylation routes might appear to exist. Chloride ion was shown to inhibit these methylations so this appears not to be a route applicable in marine or estuarine environments. Interestingly, photolysis of $\mathrm{Sn}(O A c)_{4}$ gives intermediate free radicals [20]. It is not known whether or not tin methylation could take place by this route. In a similar manner photolysis of aliphatic a-amino acids with $\mathrm{Hg}^{2+}$ salts produced $\mathrm{CH}_{3} \mathrm{Hg}^{+}$[2I].

Transmethylation reactions of the type shown below are well known in preparative organometallic chemistry, and can often operate in aqueous solutions [22]. Essentially a carbanion is being transferred in these reactions.

$$
R_{n} M_{1}^{(m-n)+}+M_{2}^{p+} \longrightarrow R_{n-1} M_{1}^{(m-n+1)+}+R M_{2}^{(p-1)+}
$$

For example, if excess $\left(\mathrm{CH}_{3}\right)_{3} \mathrm{Sn}^{+}$or $\left(\mathrm{CH}_{3}\right)_{3} \mathrm{~Pb}^{+}$are present with $\mathrm{Hg}^{2+}$ species then a methyl transfer to mercury may take place to give $\mathrm{CH}_{3} \mathrm{Hg}^{+}$. This has been suggested for sediments from Chesapeake Bay, USA $[23,24]$.

$$
\left(\mathrm{CH}_{3}\right)_{3} \mathrm{Sn}^{+}+\mathrm{Hg}^{2+} \longrightarrow\left(\mathrm{CH}_{3}\right)_{2} \mathrm{Sn}^{2+}+\mathrm{CH}_{3} \mathrm{Hg}^{+}
$$

Given an environment where two such species are in close proximity then the above reaction might be a feasible pathway for environmental mercury methylation [25].

Several organisms which do not utilize $\mathrm{CH}_{3} \mathrm{CoB}_{12}$ in their metabolism have been shown to methylate $\mathrm{Hg}^{2+}$ (e.g. Neurospora [26]). In this case, addition of L-methionine did not 
increase the yield of $\mathrm{CH}_{3} \mathrm{Hg}^{+}$, but the presence of $\mathrm{DL}$-homocysteine (though not in large excess), $\mathrm{DL}$-homoserine and L-cysteine stimulated methylation. It was concluded that $\mathrm{CH}_{3} \mathrm{Hg}^{+}$ was produced in an "incorrect" biosynthesis of methionine from a mercury-homocysteine complex, and this step could be best understood as a non $-\mathrm{CH}_{3} \mathrm{CoB}_{12}$ transfer of $\mathrm{CH}_{3}^{+}$to the electron-rich mercury complex with subsequent decomposition to $\mathrm{CH}_{3} \mathrm{Hg}^{+}$, viz.,

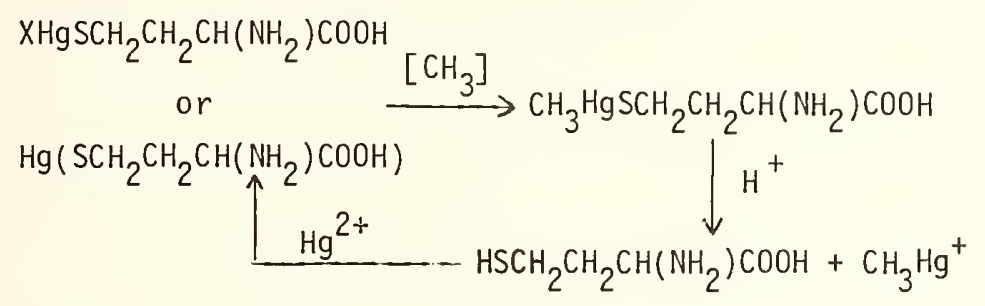

Although a carbonium ion transfer was postulated, it appears not to be a direct transfer from methionine or S-adenosylmethionine. However, it has been pointed out that $\mathrm{Hg}\left(\mathrm{SCH}_{3}\right)_{2}$ is produced under the conditions of this experiment [27] and so the mechanistic conclusions have to be treated with caution.

Other examples of $\mathrm{CH}_{3} \mathrm{Hg}^{+}$synthesis involving non- $\mathrm{CH}_{3} \mathrm{CoB}_{12}$ microorganisms have been reported, and the existence of mechanistic pathways not involving cobalamin have been postulated. The situation is still not clear; for example, $\mathrm{CH}_{3} \mathrm{CoB}_{12}$ is known to be involved in the methylation of homocysteine to methionine in certain microorganisms and trace levels of $\mathrm{CH}_{3} \mathrm{CoB}_{12}$ may occur in experimental nutrient solutions $[28,29]$. However, the existence of non- $\mathrm{CH}_{3} \mathrm{~B} 12$ methylation pathways for $\mathrm{Hg}^{2+}$ must be considered very seriously.

Another chemical route to full methylation may arise from the disproportionation or dismutation (catalysed or otherwise) of species which are al ready partially methylated. This has been shown to occur in the presence of $\mathrm{H}_{2} \mathrm{~S}$ or sulphide ion as follows:

$$
\mathrm{CH}_{3} \mathrm{Hg}^{+} \stackrel{\mathrm{H}_{2} \mathrm{~S}}{\longrightarrow}\left(\mathrm{CH}_{3} \mathrm{Hg}\right)_{2} \mathrm{~S} \stackrel{\mathrm{h \nu}}{\longrightarrow}\left(\mathrm{CH}_{3}\right)_{2} \mathrm{Hg}+\mathrm{HgS}
$$

This process has been demonstrated to occur under environmental conditions, and, in producing a volatile hydrophobic species from a complex which would bond firmly to a sediment matrix, may be a significant pathway for mercury transport in the environment [31] .

We have recently demonstrated that an analogous process may occur for $\left(\mathrm{CH}_{3}\right)_{3} \mathrm{Sn}^{+}$ species [32]. The reaction of $\left(\mathrm{CH}_{3}\right)_{3} \mathrm{SnCl}$ with $\mathrm{Na}_{2} \mathrm{~S}$ produced $\left\{\left(\mathrm{CH}_{3}\right)_{3} \mathrm{Sn}\right\}_{2} \mathrm{~S}$. Exposure of this latter material $(0.89 \mathrm{~g} 2.5 \mathrm{mmol})$ to visible or UV light at $24^{\circ}$ or $400^{\circ} \mathrm{C}$ (Philips $300 \mathrm{~W}$ sunlamp; Sylvania Blacklight $8 \mathrm{~W} \times 8$ lamps) for 24 hours produced $\left(\mathrm{CH}_{3}\right)_{4} \mathrm{Sn}$ and the $\left\{\left(\mathrm{CH}_{3}\right)_{2} \mathrm{SnS}\right\}_{3}$ trimer. The samples were identified by GC-MS techniques (V.G. Micromass 16F); over the above time period, typically, $\left(\mathrm{CH}_{3}\right)_{4} \mathrm{Sn}$ was detected in $10 \mathrm{w}$ yield and the trimer in $30 \%$ yield based on $\left\{\left(\mathrm{CH}_{3}\right)_{3} \mathrm{Sn}_{2} \mathrm{~S}\right.$ in experiments carried out at $24^{\circ} \mathrm{C}$. As the reaction did not occur in darkness a methyl radical transfer may be occurring; alternatively a concerted methyl migration with its electron pair may be occurring, viz. , 


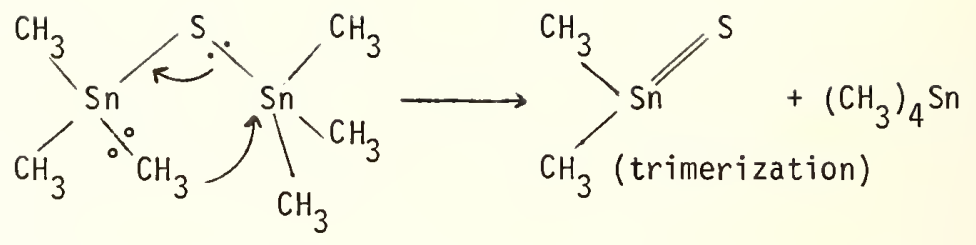

i.e., $\quad 3\left\{\left(\mathrm{CH}_{3}\right)_{3} \mathrm{Sn}\right\}_{2} \mathrm{~S} \longrightarrow 3\left(\mathrm{CH}_{3}\right)_{4} \mathrm{Sn}+\left\{\left(\mathrm{CH}_{3}\right)_{2} \mathrm{SnS}_{3}\right.$.

In this case, it seems that much $\left(\mathrm{CH}_{3}\right)_{4} \mathrm{Sn}$ must have been lost prior to detection or that the identification techniques were not quantitative. Hence, an overall yield or conversion cannot be quoted with confidence.

The conditions for the GC-MS analys is were as follows:

The column was giass of $4 \mathrm{~mm} i . d$. and 1,200 mm length, packed with $10 \% \mathrm{SP}-2100$ on

Supelcoport $80 / 100$ mesh. The temperature of the GC oven was kept constant at $80^{\circ} \mathrm{C}$ and the flow of helium gas was $30 \mathrm{~mL} / \mathrm{min}$. An electron impact ionization source was used at $70 \mathrm{eV}$. Total ion current traces were obtained as well as the mass-spectrum of each peak. This data confirmed the purity of the starting material and the production of $\left(\mathrm{CH}_{3}\right)_{4} \mathrm{Sn}$ and the trimer [32].

An analogous process has also been shown to occur for $\left(\mathrm{CH}_{3}\right)_{3} \mathrm{~Pb}^{+}$species in the presence of sulphide ion [33]. Under acid conditions $\left(\mathrm{CH}_{3}\right)_{2} \mathrm{~S}$ is the main product, but between $\mathrm{pH} 6$ and $7\left(\mathrm{CH}_{3}\right)_{4} \mathrm{~Pb}$ is found.

These results do suggest that transformation of partially methylated species is quite feasible under model environmental conditions and that volatile, easily transported, fully methylated products may be produced. This process is being investigated for other oxygen or sulphur-containing natural ligands upon which transformations akin to those above may take place, e.g., methyltin-tropolone complexes [34].

It is when we come to consider the case of methylation of purely inorganic metals and salts other than mercury that we find less success with $\mathrm{CH}_{3} \mathrm{CoB}_{12}$ as a mode1. $A$ number of groups have reported a lack of success in the direct reaction of $\mathrm{CH}_{3} \mathrm{CoB}_{12}$ with $\mathrm{Pb}^{2+}$ salts [35-38]. The reaction with $\mathrm{SnCl}_{2}$ has been reported al though the methyltin product was not fully identified; it does not seem to have been $\left(\mathrm{CH}_{3}\right)_{4} \mathrm{Sn}$. In this case an oxidizing agent was required ( $\mathrm{Fe} \mathrm{III}^{\mathrm{II}}$ ) in catalytic amounts and a free radical process involving $\mathrm{Sn}^{\text {III }}$ was postulated [39]. Characterization was by NMR.

$$
\mathrm{CH}_{3} \mathrm{Co}^{\mathrm{III}} \mathrm{B}_{12}+\mathrm{SnCl}_{2} \stackrel{\mathrm{Fe}}{\mathrm{III}} \rightarrow \mathrm{CH}_{3} \mathrm{SnCl}_{y}^{3-y}+\mathrm{Co}^{\mathrm{II}_{\mathrm{B}}}
$$

$\mathrm{CH}_{3} \mathrm{CoB}_{12}$ has been reported also to react with $\left(\mathrm{C}_{2} \mathrm{H}_{5}\right)_{2} \mathrm{~Pb}^{2+}$ to produce methyllead species but it is not known if the fully alkylated lead compound was formed [4O].

$\left({ }^{14} \mathrm{C}-\mathrm{CH}_{3}\right) \mathrm{CH}_{3} \mathrm{CoB}_{12}$ was found to be partially demethylated by $\mathrm{Pb}(\mathrm{OAC})_{4}, \mathrm{PbO}_{2}$ and $\mathrm{Pb}_{3} \mathrm{O}_{4}$ and the radioactivity was lost as a volatile product [41]. In principle, this could be $\left({ }^{14} \mathrm{C}\right)\left(\mathrm{CH}_{3}\right)_{4} \mathrm{~Pb}$ but it could also be, e.g., $\left({ }^{14} \mathrm{C}\right) \mathrm{C}_{2} \mathrm{H}_{6}$ or $\mathrm{CH}_{4}$. Close investigation of the identity of the products in this experiment seems called for.

The reactions of the model cobalamin complex $\left(\mathrm{CH}_{3}\right)_{2} \mathrm{Co}(\mathrm{DMG})_{2}$ with $\mathrm{Pb}^{2+}$ in isopropanol 
produced a complex with a methyllead bond but full methylation seemed not to occur [42].

Certainly then there appears to be 1 imitations in the reactivity of $\mathrm{CH}_{3} \mathrm{CoB}_{12}$ under normal conditions with metals other than mercury, especially in their low oxidation states. Although carbanion transfer from $\mathrm{CH}_{3} \mathrm{CoB}_{12}$ is both intellectually and practically satisfying, for electron-poor centers perhaps we should now search for parallel methylation routes, possibly involving carbonium ion transfer, in reactions with electron-rich centres as complementary additional pathways to the known $\mathrm{CH}_{3} \mathrm{COB}_{12}$ routes.

It has been shown recently [43] that $\mathrm{CH}_{3}$ I can act as a methylating agent for lead(II). Our own group and that of Dr. Jarvie of Aston University (Birmingham U.K.) have shown the role of $\mathrm{CH}_{3} \mathrm{I}$ in methylating lower oxidation states of lead $[44,45]$. This reaction is known in principle and has been used as a synthetic route for $\left(\mathrm{CH}_{3}\right)_{4} \mathrm{~Pb}$, but it has not been investigated under model environmental (aqueous) conditions.

For example, we have reacted lead metal (80 mesh to dust) with $\mathrm{CH}_{3} \mathrm{I}$ in darkness in aqueous media and have confirmed the formation of $\left(\mathrm{CH}_{3}\right)_{4} \mathrm{~Pb}$ by $\mathrm{GC}$ and $\mathrm{GC}-\mathrm{MS}$. We have also designed experiments to test whether $\mathrm{CH}_{3} \mathrm{I}$ reacts with $\mathrm{Pb}^{2+}$ salts under our conditions.

In the case of lead metal, reaction with $\mathrm{CH}_{3} \mathrm{I}$ produced a volatile identified as $\left(\mathrm{CH}_{3}\right)_{4} \mathrm{~Pb}$ (together with $\left(\mathrm{CH}_{3}\right)_{2} \mathrm{~Pb}^{2+}$ and $\left(\mathrm{CH}_{3}\right)_{3} \mathrm{~Pb}^{+}$in solution). We cannot yet confirm $\left(\mathrm{CH}_{3}\right)_{4} \mathrm{~Pb}$ formation from $\mathrm{Pb}^{2+}$. Our analytical technique may not be sensitive enough.

The methods used for the analys is of $\left(\mathrm{CH}_{3}\right)_{4} \mathrm{~Pb}$ were headspace GC-ECD (Pye-Unicam 104 series) and independent GC-MS (VG Micromass $16 \mathrm{~F}$ ). The conversion to $\left(\mathrm{CH}_{3}\right)_{4} \mathrm{~Pb}$ was less than $1 \%$ assuming a partition coefficient of $\left(\mathrm{CH}_{3}\right)_{4} \mathrm{~Pb}$ between water and air of $\simeq 1: 30$. Typically (500mg 2.5mnol) of $\mathrm{Pb}^{2+}$ or $\mathrm{Pb}^{0}$ were reacted in darkness with $\mathrm{CH}_{3} \mathrm{I}(2.13 \mathrm{~g} 15 \mathrm{mmol})$ in aqueous solution ( $50 \mathrm{~mL}$ ) in sealed containers. The head space vapours were analysed by GC-ECD An a 11-glass column was used, $4 \mathrm{~mm}$ i.d. and 1,200 mm length packed with 10\% SP-2100 on Supelcoport 80-100 mesh. The oven was kept at $65^{\circ} \mathrm{C}$ and the gas was $90 \mathrm{~mL} / \mathrm{min}$ of oxygenfree nitrogen. The retention times of the $\mathrm{CH}_{3} \mathrm{I}$ and $\left(\mathrm{CH}_{3}\right)_{4} \mathrm{~Pb}$ were 0.60 minutes and 3.85 minutes, respectively, for on-column injections and detector oven temperature $265^{\circ} \mathrm{C}$. Absolute identification of products was carried out by GC-MS. The MS used was at $70 \mathrm{eV}$ with an electron impact source, and spectra confirming the identity of the volatile species were obtained in each case [45]. In addition, both with GC and MS identification was made by comparison with an authentic sample of $\left(\mathrm{CH}_{3}\right)_{4} \mathrm{~Pb}$.

Evidence therefore exists that the reaction of $\mathrm{Pb}^{2+}$, or $\mathrm{Pb}^{0}$ complexed (i.e.,electronrich species) with $\mathrm{CH}_{3}$ I seems perhaps as plausible an environmental route as by reaction with $\mathrm{CH}_{3} \mathrm{COB}_{12}$. Attention here has to be focussed on the fact that $\mathrm{CH}_{3} \mathrm{I}$ is produced on a large scale by certain seaweed and algae. The large kelp Laminaria produces $\mathrm{CH}_{3} \mathrm{I}$ and in their environment the concentration can be $10^{3}$ that of the concentration of $\mathrm{CH}_{3} \mathrm{I}$ in the open ocean. It has also been suggested that the global production rate of $\mathrm{CH}_{3} \mathrm{I}$ at sea is 40 megatons per year $[46,47]$.

\section{Summary}

Perhaps we ought to look again at the importance of the work on As(III) methylation by Challenger and recently by McBride and Wolfe $[48,49]$. 
This work emphasized methyl carbonium ion transfer from SAM (S-adenosylmethionine) to As(III) for the conversion to $\left(\mathrm{CH}_{3}\right)_{3} \mathrm{As}$, as envisaged in the scheme below:-

$$
\stackrel{+}{+}\left(\mathrm{CH}_{3}\right) \mathrm{CH}_{2} \mathrm{CH}_{2} \mathrm{CH}\left(\mathrm{NH}_{2}\right) \mathrm{COO}^{-}+: \mathrm{As}^{\mathrm{III}} \longrightarrow\left(\mathrm{CH}_{3}\right)_{3} \mathrm{As}:
$$

This could be seen as $S_{N} 2$ attack by $A s$ (III) containing a lone electron pair. Such methyl transfer was confirmed by Challenger using a ${ }^{14} \mathrm{C}-1$ abelled methy 1 group from methionine.

$$
{ }^{14} \mathrm{CH}_{3} \mathrm{SCH}_{2} \mathrm{CH}_{2} \mathrm{CH}\left(\mathrm{NH}_{2}\right) \mathrm{COOH} \longrightarrow\left({ }^{14} \mathrm{CH}_{3}\right){ }_{3}^{\mathrm{As}}
$$

This work by Challenger was done in reducing environments which somewhat paradoxically may suggest an oxidative addition by $\mathrm{CH}_{3}^{+}$followed by reduction to $\mathrm{As}$ (III).

However under varying conditions $\mathrm{CH}_{3} \mathrm{CoB}_{12}$ can yield $\mathrm{CH}_{3}^{-}, \mathrm{CH}_{3}$ or $\mathrm{CH}_{3}^{+}$. Therefore, it could be involved in the methylation of heavy metals by routes other than $\mathrm{CH}_{3}^{-}$transfer.

It has been reported by a number of groups that $\mathrm{CH}_{3} \mathrm{COB}_{12}$ does not react with $\mathrm{Pb}$ (II) in chemical media, though it seems to react with $\left(\mathrm{CH}_{3}\right)_{3} \mathrm{~Pb}^{+}$, according to kinetic data based on $\mathrm{CH}_{3} \mathrm{CoB}_{12}$ conversion [50]. There was no positive identification of the product as $\left(\mathrm{CH}_{3}\right)_{4} \mathrm{~Pb}$.

We conclude that for metals in low oxidation states we should think more carefully about reactions involving oxidative additions (i.e., $\mathrm{CH}_{3}^{+}$transfer) or free radical $\mathrm{CH}_{3}$. transfer. We do not suggest that $\mathrm{CH}_{3} \mathrm{CoB}_{12}$ has no role to play in environmental methylation; only that it may be one of a number of environmental agents or routes that lead to methylated species. Our attention should therefore now focus on the identification of chemical methylating agents known to be present in the environment, and which are suitable substrates for the methylation of metals. This will enable us to suggest chemical routes and not to consider environmental methylation as being solely a bacteriological process.

We also emphasize the role of sulphides in promoting disproportionation or dismutation reactions of already partially methylated metals to fully methylated species. We should look for environmentally meaningful ligands other than $\mathrm{s}^{2-}$ for, e.g., $\mathrm{CH}_{3} \mathrm{Hg}^{+},\left(\mathrm{CH}_{3}\right)_{3} \mathrm{Sn}^{+}$, etc., that would promote or catalyse disproportionation to $\left(\mathrm{CH}_{3}\right)_{2} \mathrm{Hg},\left(\mathrm{CH}_{3}\right)_{4} \mathrm{Sn}$, etc. This route can be important; $\left(\mathrm{CH}_{3}\right)_{4} \mathrm{~Pb}$ may partially decompose and be remethylated again to $\left(\mathrm{CH}_{3}\right)_{4} \mathrm{~Pb}$ by this route. Methyltin compounds are also used and, in the laboratory at least, undergo conversion to $\left(\mathrm{CH}_{3}\right)_{4} \mathrm{Sn}$. In this case we would have an environmentally beneficial methylation as the fully methylated tin species is less toxic than the trimethyl compound from which it derives [51].

We are pleased to acknowledge the support of the following organizations and institutes for our work: Science Research Council, U.K. (S.R., stipend); National Bureau of Standards, British Council and Leicester Polytechnic, U.K. (travel assistance). 
[1] Pratt, J. M. The Inorganic Chemistry of Vitamin B 12 . New York: Academic Press, 1972.

[2] Wood, J. M.; Kennedy, F. S.; Rosen, C. G. Synthesis of methylmercury compounds by extracts of a methanogenic bacterium. Nature. 220; 173-174; 1968.

[3] Bertilsson, L.; Neujahr, H. Y. Methylation of mercury compounds by methylcobalamin. Biochem. 10: $2805-2808 ; 1971$

[4] De Simone, R. E.; Penley, M. W.; Charbonneau, L.; Smith, S. G.; Wood, J. M.; Hil1, H. A. O.; Pratt, J. M.; Ridsdale, S.; Williams, R. J. P. The kinetics and mechanism of cobalamin dependent methyl and ethyl transfer to mercuric ion. Biochim. Biophys. Acta. 304: 851-865; 1973.

[5] Chu, V. C.W.; Gruenwedel, D.W. On the reaction of methylmercuric hydroxide with methylcobalamin. Z Naturforsch. C,31: 753-755; 1976.

[6] Craig, P. J.; Morton, S.F. Kinetics and mechanism of the reaction between methy 1cobalamin and mercuric chloride. J. Organometal. Chem. 145: 79-89; 1978.

[7] Hill, H. A. 0.; Pratt, J. M.; Ridsdale, S.; Williams, R. J. P. Kinetics of substitution of coordinated carbanions in cobalt(III) compounds. Chem. Commun. 341 ; 1970.

[8] Ridley, W. P.; Dizikes, L. J.; Wood, J. M. Biomethylation of toxic elements Environ. Sci. 197: 329-332; 1977.

[9] Imura, N.; Pan, S-K.; Shimizu, M.; Ukita, T. Studies on mercury-methylation factor in some organisms. Chapter in New methods in environmental chemistry and toxicology (collected papers res. conf. new methods ecol. chem.). F. Coulston, ed. Tokyo, Japan: Int. Acad. Print Co.; 1973. 211-216.

[10] Tonomura, K.; Furukawa, K.; Yamada, M. Microbial conversion of mercury compounds. Proc. Iv IFS; Ferment. Technol. Today: 563-567; 1972.

[11] Vonk, J.W.; Sijpesteijn, A. K. Studies on the methylation of mercuric chloride by pure cultures of bacteria and fungi. J. Ant. V. Leeuwenhoek. 39: 505-513; 1973.

[12] Yamada, M.; Tonomura, K. Formation of methylmercury compounds from inorganic mercury by Clostridium cochlearium. J. Ferment. Technol . 50: 159-166; 1972.

[13] Kinoshita, K.; Masaji, K.; Nishizawa, Y.; Wakabayashi, T.; Watanabe, T.; Ueda, K.; Someya, N. Effect of methylcobalamin on biological methylation of inorganic mercury in vivo. Vitamins (Japan). 52 : $249-255 ; 1978$.

[14] Blum, J.E.; Bartha, R. Effect of salinity on methylation of mercury. Bul1. Environ. Contam. Toxicol. 25: 404-408; 1980.

[15] Jewett, K. L.; Brinckman, F. E.; Bellama, J. M. Chemical factors influencing metal alkylation in water. Chapter in Marine chemistry in the coastal environment (ACS Symposium Series No. 18). T. C. Church, ed. Washington, DC: American Chemical Society; $1975.304-317$.

[16] De Filippis; Pallaghy, C. K. A simple model for the non-enzymatic reduction and alkylation of mercuric salts in biological systems. Bull. Environ. Contam. Toxicol. 14: $32-37 ; 1975$.

[17] Takabatake, E.; Fujita, M.; Akagi, H.; Hashizume, K. Biological concentration and photochemical transformation of mercuric compounds. Chapter in New methods in environmental chemistry and toxicology (collected papers res. conf. new methods ecol. chem.). F. Coulston, ed. Tokyo, Japan. Int. Acad. Print. Co.; 1973. 199-210. 
[18] Agaki, H.; Takabatake, E.; Fujita, M.; Photochemical formation of methyl mercuric compounds from mercuric acetate. Chemosphere. 2(3): 131-133; 1973 .

[19] Agaki, H.; Fujita, Y.; Takabatake, E. Photochemical methylation of inorganic mercury in the presence of mercuric sulphide. Chem. Letters. 171-176; 1975.

[20] Janzen, E. G.; Blackburn, B. J. Detection and identification of short-lived free radicals by ESR trapping techniques. Photolysis of organolead, -tin, and -mercury compounds. J. Amer. Chem. Soc. 91: 4481-4490; 1969.

[21] Hayashi, K.; Kawai, S.; Ohno, T.; Maki, Y. Photomethylation of inorganic mercury by aliphatic $\alpha$-amino acids. Chem. Commun. 158-159, 1977.

[22] See for example Coates, G. E.; Green, M. L. H.; Wade, K. Organometallic compounds. London: Methuen; 3rd ed. 1967.

[23] Huey, C.; Brinckman, F. E.; Grim, S.; Iverson, W. P. The role of tin in bacterial methylation of mercury. Proc. Int. Conf. transport persistent chemicals aquatic ecosystem; Ottawa, National Res. Council; 1974. 73-78.

[24] Brinckman, F. E.; Iverson, W. P. Chemical and bacterial cycling of heavy metals in the estuarine system. Chapter in Marine chemistry in the coastal environment (A CS Symposium series No. 18). T. C. Church, ed. Washington, DC: American Chemical Society; 1975. 319-342.

[25] Brinckman, F. E. Environmental organotin chemistry today: experiences in the field and laboratory. J. Organometal. Chem. Library. In press, 1981.

[26] Landner, L. Biochemical model for the biological methylation of mercury suggested from methylation studies in vivo wi th Neurospora crassa. Nature. $230: 452-454 ; 1971$.

[27] Kaars Sijpsteijn,A.; Vonk, J. W. Methylation of inorganic mercury by bacteria and fungi. J. Ant. V. Lee uwenhoek. 40:393-400; 1974 .

[28] Summers, A. 0.; Silver, S. Microbial transformations of metals. Ann. Rev. Microbiol. 32: $637-672 ; 1978$.

[29] Reisinger, K.; Stoeppler, M.; Nürnberg, H.W. Evidence for the absence of biological methylation of lead in the environment. Nature. 291:228-230; 1981.

[30] Craig, P. J.; Bartlett, P. D. The role of hydrogen sulphide in environmental transport of mercury. Nature. 275: 635-637; 1978.

[31] Bartlett, P.D.; Craig, P. J. Total mercury and methyl mercury levels in British estuarine sediments - II. Water Res. 15: 37-47; 1981.

[32] Craig, P. J.; Rapsomanikis, S. The formation and decomposition of bis(trimethyltin) sulphide under model environmental conditions. Submitted for publication, 1981.

[33] Whitmore, A. P. A study of lead alkylation in natural systems. Thesis, University of Aston in Birmingham, U.K.; 1981.

[34] Craig, P. J.; Rapsomanikis, S. Unpublished work, 1981.

[35] Jarvie, A. W. P.; Marka11, R. N.; Potter, H. R. Nature. 255: 217-218; 1975. Chemica] alkylation of lead.

[36] Agnes, G.; Benelle, S.; Hi11, H. A. 0.; Williams, F. R.; Williams, R. J.P. Methylation by methy 1 vitamin $B_{12}$. Chem. Commun. 850-851; 1971 .

[37] Lewis, J.; Prince, R. H.; Stotter, D. A. Recent developments in the bio-inorganic chemistry of $\mathrm{B}_{12}$ - II. J. Inorg. Nuc 1. Chem. 35: 341-351; 1973. 
[38] Taylor, R. T.; Hanna, M. L. Methylcobalamin, methylation of platinum and demethylation with lead. J. Environ. Sci. Health - Environ. Sci. Eng. Al1: 201-211; 1976.

[39] Dizikes, L. J.; Ridley, W. P.; Wood J. M. A mechanism for the biomethylation of tin by reductive Co-C bond cleavage of alkylcobalamins. J. Amer. Chem. Soc. 100: 10101012; 1978 .

[40] Wood, J. M.; Cheh, A., Dizikes, L. J.; Ridley, W. P.; Rakow, S.; Lakowicz, J. R. Mechanisms for the biomethylation of metals and metalloids. Fed. Proc. 37: 16-21; 1978.

[41] Taylor, R. T.; Hanna, M. L. Methylation of chloroplatinate by methylcobalamin. Bioinorg. Chem. . 6: 281-293; 1976 .

[42] Weber, J. H.; Witman, M. W. Unstable organometallic intermediates in a protic medium. Chapter in Organometals and organometalloids - occurrence and fate in the environment (ACS Symposium No. 82). F. E. Brinckman and J. M. Bellama, eds. Washington, DC: American Chemical Society; 1978. 247-263.

[43] Ahmad, L.; Chau, Y. K.; Wong, P. T. S.; Carty, A. J.; Taylor, L. Chemical alkylation of lead(II) salts to tetralkyllead(IV) in aqueous solution. Nature. 287: 716-717; 1980.

[44] Jarvie, A. W. P.; Whitmore, A. P. Methylation of elemental lead and lead(II) salts in aqueous solution. Environ. Tech. Letters. 1981 (in press).

[45] Craig, F. J.; Rapsomanikis, S. Unpublished work, 1981.

[46] Lovelock, J.E.; Maggs, R. J.; Wade, R. J. Halogenated hydrocarbons in and over the Atlantic. Nature. 241: 194-196; 1973.

[47] Lovelock, J. E. Natural halocarbons in the air and in the sea. Nature. 256: 193-194; 1975.

[48] Challenger, F. Biosynthesis of organometallic and organometalloidal compounds. Ref. $42 ; 1-22$.

[49] McBride, B. C.; Merilees, H.; Cullen, W. R.; Pickett, W. Aerobic and anaerobic alkylation of arsenic. Ref. 42; $94-115$.

[50] Thayer, J. S. Transmethylation of methylmetal compounds by methyl cobalamin. Inorg. Chem. 18: $1171-1172 ; 1979$.

[51] Smith, P. J. Toxicological Data on Organotin Compounds. London, International Tin Research Institute; 1978. 
Comment (J. Walker): The Neurospora that you referred to in the Landner paper [Nature 230: 452-454 (1971)] is a fungus and not a bacterium. It would not be expected to synthesize methylcobalamin.

Answer: Yes, I made a mistake. The point I was making is that it does not involve methylcobalamin. You are agreeing with that.

Question (D. A. Klein): I just wanted any information on the highest temperatures at which you've seen these processes occurring. What is the highest temperature at which some of these processes are going on?

Answer: In a case of tuna fish liver referred to, light exposure stopped methylation, but sterilization by heat didn't. Methylcobalamin is fairly heat stable.

Question (D. A. Klein): I was wondering, as far as biological contributions go, what sort of temperature range?

Answer: Mostly, those people carrying out biological incubations with mercury(II) start about 20 up to $37^{\circ} \mathrm{C}$. People who are interested in biological systems tend to work at the temperatures at which the materials will survive satisfactorily.

Comment (D. A. Klein): There are also thermophilic bacteria.

Answer: I don't know if anybody's done any work on mercury methylation with thermophiles.

Question (R. D. Stephens): Are you familiar with any evidence of environmentally or biologically related methylation?

Answer: Yes, plenty. I think other papers in this Workshop will cover that [see, for example, Chau and Wong following--Eds.]. The problem is, sometimes it works, sometimes it doesn't work. There are some systems where you can incubate lead(II) salts in sediments and you can't find any tetramethyllead. In other situations you can. It appears to be less predictable, less routine than mercury methylation. But I'm pretty sure it happens. 
Some Environmental Aspects of Organo-Arsenic, Lead, and Tin

\author{
Y. K. Chau and P. T. S. Wong \\ Canada Centre for Inland Waters \\ Burlington, Ontario \\ Canada L7R 4A6
}

Organometals and organometalloids such as alkylleads, alkyltins, organoarsenics have been found in environmental samples. Apart from anthropogenic sources, amazingly, some of these compounds are synthesized by biotic and abiotic processes under environmental conditions. These compounds also undergo complex chemical and biological interactions including, for example, methylation, transmethylation, hydrolysis, photolysis, degradation, etc. For these studies, speciation identification and analysis are prerequisites.

The toxicity of organometals towards aquatic biota is closely related to the nature of the organic groups. Generally, toxicity increases with increasing carbon chain length, and also with the degree of alkylation on the metal nucleus. The possibility of using octanol/water partition coefficients of a number of alkyltin compounds to predict toxicity is discussed.

Key words: alkylleads; alkyltins; chemical speciation; GC-AAS techniques; LC-AAS techniques; organoarsenics; organometals; partition coefficients; toxicity.

\title{
1. Introduction
}

One of the many forms of metals in the environment is the organometal which distinguishes itself in a unique class with remarkably different biogeochemical and toxicological characteristics. With the advent of chemical technology during the turn of the century, organometallic compounds have been produced at an ever increasing rate because of their extremely versatile applications in almost any type of commodities in commercial and household, as well as in industrial and agricultural, areas.

Occurrence of organometals in the environment has been considered as a legacy of industrial civilization until recently it was found that some of the compounds can be synthesized by chemical and biological processes. These processes, however, have been known for almost a century since Gosio established that the garlic smelling "Gosio gas" liberated from a green-colored wallpaper (containing arsenic dyes) was an organoarsenic compound, which was later identified by Challenger as trimethylarsine [1]. Since the Minamata Bay incident of mercury poisoning in Japan in the early 1950's, studies on the biotic and abiotic methylation of metals and metalloids have intensified. These processes produce more toxic metal 
species and transport species leading to the mobilization of the element in the environment. The study of these processes and the investigation of their pathways has pushed the frontier of analytical chemistry to a new horizon, demanding element- and molecule-specific methodology. For toxicological assays, knowledge of the precise form of a compound becomes even more critical as the toxicity of an element is often not so much a function of concentration as it is the form of the element.

Environmental impacts of organometals have often been assessed by their toxicological behaviors. The characteristics of the organic moieties in the molecule can greatly modify the toxicity of the metal. The toxicity on a test biota can therefore be related to the length of the carbon chain and the degree of alkyl substitution. These parameters, however, are reflected by the overall lipophilicity of the compound which can be measured by the octanol/water partition coefficients. The possibility of using these coefficients to predict toxicity is discussed in this study.

This paper intends to illustrate the environmental and toxicological aspects of some organometals and to examine the state-of-the-art of their speciation analysis. It is not intended to provide an exhaustive review of the subject; toxicity information is 1 imited to aquatic biota only.

2. Occurrence and Toxicity of Some Organometals in the Environment

\subsection{Arsenic}

Organoarsenic compounds have been found in a variety of environmental samples as a mixed result of biotic and abiotic processes and from anthropogenic inputs. The inorganic forms of arsenic, As(III) and As(V), have been widely used as herbicides in controlling aquatic plants. The most common organoarsenic compounds, mono- and dimethylarsenates have been found in natural waters [2], in seaweeds, and even in human urine [3]. Production of methylarsines was observed from soils treated with inorganic arsenic compounds $[3,4]$. A study [5] indicated that both $A s$ (III) and $A s(V)$ ingested by man were converted to monoand dimethylarsenic acids and were excreted in urine.

Arsenobetaine has been identified as a major component of the organoarsenic in the muscle of western rock lobster in Australia [6]. Methylated arsenic acids have also been found in fish and in sediments near Moira River, Ontario, where there was an abandoned smelter [7]. A summary of the organoarsenic compounds in some environmental samples is given in Table 1.

Arsenic compounds are generally not very toxic to bacteria and algae. Several algal species could tolerate As at levels as high as $20 \mathrm{mg} / \mathrm{L}$ [7]. Toxicity of As depends, however, on its chemical state and valency, arsenite being more toxic than arsenate. Arsine and trimethylarsine were even more toxic to animals than arsenite [12]. Toxicity of methylarsines 
Table 1. Organoarsenic compounds in environmental samples

Moire River area, Ontario

\begin{tabular}{lccccc}
\hline Sediment & As (III), (V) & MMA & DMA & TMA & Ref. \\
\hline & & & & & \\
Lake & 1.92 & 2.14 & 3.25 & -- & 7 \\
River & 1.16 & 3.75 & 2.29 & -- & 7 \\
Pond & 6.03 & 0.63 & 2.93 & 7.59 & 7 \\
\hline
\end{tabular}

$50 \mathrm{~g}$ of sediment and $140 \mathrm{~mL}$ lakewater were incubated for about seven days and the solutions analysed for different species. MMA-monomethylarsenic acid; DMAdimethylarsinic acid; TMA-trimethylarsine oxide. Results in $\mu \mathrm{g} / \mathrm{L}$ as As.

Fish Samples (ng/g as As)

Fish

Yellow perch

White sucker

White perch

Alewife

Bullhead

Shrimp
As(III), (V)

68.00

0.67

16.90

1.33

2.05

1820
MMA

0.74

0.60

0.84

$--$

$--$

tr
DMA

2.45

0.24

$\begin{array}{ll}-- & 8 \\ - & -\end{array}$

$\begin{array}{ll}-- & 8 \\ - & 8\end{array}$

$\begin{array}{ll}-- & 8 \\ - & 8\end{array}$

tr $\quad 11$

Fish samples were taken from Bay of Quinte, 0ntario. $\operatorname{tr}=$ traces.

Natural Water and Seaweeds ( $\mathrm{ng} / \mathrm{g}$ as As)

$$
\text { As (III) }
$$

As (V)

MMA

DMA

Ref.

Seawater, Scripps Pier

Seawater, San Diego Trough

Lake Carrol, Florida

S. fluitans (S. Bermuda)

Sargassum sp. (Gulf of Mexico)

Moira River, Ontario

Bend Bay, Ontrio
0.019

0.017

1.75

1.49

-

1800

0

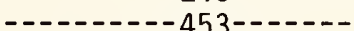

0.02

0.01

4. 39

0.12

0.21

6.31

9

9

10

$100 \quad 184$

$<5 \quad 100$

52

93
11

11

8

8

and many of the organoarsenicals to aquatic biota has not been reported. We have only carried out some tests on the toxicity of a mixture of volatile arsines to algae by bubbling biologically generated arsines from a flask containing sediment from the Moira River into the culture medium in another flask where a test alga (Chlorella pyrenoidosa) was grown. The primary productivity (by ${ }^{14} \mathrm{C}$ technique) and growth (by cell count) were suppressed by 45 and 44 percent respectively, as compared to control algae without exposure to arsines. It was not possible to measure the amount of methylarsines exposed, but chemical analysis of the algae indicated that the total As levels in the exposed algae were more than ten times that in the control algae. 


\subsection{Lead}

Organolead compounds in the environment have caused much concern because of their inherent toxicity. Lead alkyls in air and in environmental samples are probably derived from two major sources: from spillage and evaporation of leaded gasoline, and from natural synthesis through biotic and abiotic processes. Although it is outside the scope of this paper to discuss lead methylation, occurrence of alkyllead compounds in environmental samples has underscored its significance.

Tetraalkyllead compounds have been found in air [13,14,15] and in fish [16] (Table 2). Because of their volatile and lipophilic nature, they are not expected to be present in water and sediment or aquatic plants with low lipid contents. Tetramethyllead has been found to be accumulated by rainbow trout, mainly in the lipid layer of the intestine with a concentration factor of 16,000 [17]. Other organs such as gills, air bladders, liver, also accumulate much $\mathrm{Me}_{4} \mathrm{~Pb}$. When the exposed fish were placed in $\mathrm{Me}_{4} \mathrm{~Pb}-\mathrm{free}$ water, concentrations of $\mathrm{Me}_{4} \mathrm{~Pb}$ in the tissue decreased rapidly at first, followed by a slower decrease and eventually reached residual levels. Several species of fish and animals have been reported to metabolize tetraalkyllead to the trialkyllead species [18]. The trialkyllead compounds were responsible for the toxic actions in animals [19].

Table 2. Tetraalkyllead compounds in environmental samples Air $\left(\mathrm{ng} / \mathrm{m}^{3}\right.$ as $\left.\mathrm{Pb}\right)$

\begin{tabular}{lcc} 
Air $(\mathrm{ng} / \mathrm{m}$ as $\mathrm{Pb})$ & Tetraalkyllead & Ref. \\
\hline Urban air & $<6-206$ & 13 \\
Gas station & $210-590$ & 13 \\
Rural air & $0.5-230$ & 14 \\
College Street, Toronto & $\mathrm{Me}_{3} \mathrm{EtPb}(1) \quad \mathrm{Me}_{2} \mathrm{Et}_{2} \mathrm{~Pb}(2)$ & 15 \\
& $\mathrm{MeEt}_{3} \mathrm{~Pb}(1) \quad \mathrm{Et}_{4} \mathrm{~Pb}(8)$ & \\
& Total $\mathrm{Pb}(650)$ & \\
\hline
\end{tabular}

Fish (ng/g as $\mathrm{Pb})$

wt. of I II III IV $V$ Total Ref.

fish $(\mathrm{kg})$

\begin{tabular}{llllllllrl}
\hline Vineland Creek, Coho salmon & 1.23 & -- & 4.3 & 2.3 & 2.8 & -- & 75 & 16 \\
Coho salmon & 1.36 & 1.1 & 1.0 & -- & 1.8 & 9.3 & 95 & 16 \\
Stoco L., Yellow perch & 0.13 & 1.7 & -- & 7.1 & 4.4 & 2.7 & 325 & 16 \\
& Sucker & 1.00 & 2.0 & -- & -- & -- & -- & 45 & 16 \\
Rock bass & 0.14 & 0.6 & -- & -- & -- & 2.8 & 215 & 16 \\
Moira L., Sunfish & 0.13 & 0.9 & -- & -- & 2.7 & 1.9 & 300 & 16 \\
& Sucker & 1.0 & 1.0 & -- & -- & -- & 1.9 & 110 & 16 \\
& White bass & 0.47 & -- & -- & 0.3 & -- & 1.0 & 75 & 16 \\
\hline
\end{tabular}

$I=\mathrm{Me}_{4} \mathrm{~Pb} ; \mathrm{II}=\mathrm{Me}_{3} \mathrm{EtPb} ; \mathrm{III}=\mathrm{Me}_{2} \mathrm{Et}_{2} \mathrm{~Pb} ; \mathrm{IV}=\mathrm{MeEt}_{3} \mathrm{~Pb} ; \mathrm{V}=\mathrm{Et}_{4} \mathrm{~Pb}$.

Sediment $(\mu \mathrm{g} / \mathrm{g}$ as $\mathrm{Pb})$
Location

${ }^{a}$ Three locations in St. Lawrence River off Maitland, Ontario. 
Alkyllead compounds are very toxic to marine animals and algae. The ethyl derivatives are more toxic than the methyl derivative and the toxicity increases with degree of alkyl substitution with the tetra-substituted compounds being the most toxic [20]. In an experiment with freshwater green algae exposed to biologically generated $\mathrm{Me}_{4} \mathrm{~Pb}$ [21], we found that the primary productivity and cell growth of the three test algae were decreased after a four-hour exposure. For Chlorella pyrenoidosa and Scenedesmus quadricauda, the percentage decreases of growth were 74 and 32 percent and percentage decreases of primary productivity were 83 and 85 percent, respectively. The amounts of $\mathrm{Me}_{4} \mathrm{~Pb}$ passing through the cultures were estimated to be less than $0.5 \mathrm{mg}$ of $\mathrm{Pb}$. Some toxicity values of alkyllead on aquatic biota are summarized in Table 3.

Table 3. Toxicity of alkyllead compounds

\begin{tabular}{|c|c|c|c|c|c|c|c|c|}
\hline Test biotá & $\mathrm{Et}_{4} \mathrm{~Pb}$ & $\mathrm{Et}_{3} \mathrm{~Pb}^{+}$ & $\mathrm{Me}_{4} \mathrm{~Pb}$ & $\begin{array}{c}- \text { Toxic D } \\
\mathrm{Me}_{3} \mathrm{~Pb}^{+}\end{array}$ & $\begin{array}{l}(\mathrm{mg} / \mathrm{L})-- \\
\mathrm{Me}_{2} \mathrm{PbCl}_{2}\end{array}$ & $\mathrm{Et}_{2} \mathrm{PbCl}_{2}$ & $\mathrm{~Pb}^{2+}$ & Ref. \\
\hline $\begin{array}{l}\text { Shrimpa } \\
\text { Mussela } \\
\text { Plaice } \\
\text { Marine algae } \\
\text { Freshwater algae }\end{array}$ & $\begin{array}{l}0.02 \\
0.10 \\
0.23 \\
0.10\end{array}$ & $\begin{array}{l}5.80 \\
1.10 \\
1.70 \\
0.10\end{array}$ & $\begin{array}{r}0.11 \\
0.27 \\
0.05 \\
1.30 \\
<0.50\end{array}$ & $\begin{array}{c}8.80 \\
0.50 \\
24.6 \\
0.80 \\
1.50\end{array}$ & 300 & 75 & 5 & $\begin{array}{l}20 \\
20 \\
20 \\
20 \\
21\end{array}$ \\
\hline
\end{tabular}

$a_{96} h L_{50}$ values.

${ }^{b_{\text {Phaeodactylum tricornutum, }}} 6 \mathrm{~h} \mathrm{EC}_{50}$.

${ }^{C_{\text {Ankistrodesmus }}}$ falcatus, $4 \mathrm{~h} \mathrm{EC_{50 }}$.

$L C_{50}=$ lethal concentration killing 50 percent of the test organisms in a given time.

$\mathrm{EC}_{50}=$ effective concentration of toxicant that would affect $50 \%$ of the test organism in a given time.

$2.3 \operatorname{Tin}$

Because of the high consumption of organotin compounds used in plastic stabilizers and biocides, there is little doubt that residual levels of organotins can be found in environmental samples. The sources of organotin in the environment are mainly anthropogenic even though methylation of inorganic and organometalic forms of tin through biotic and abiotic processes have now been reported $[22,23,24]$. An excellent review on the biogenesis of methyltin transport species is available [25].

Organotins are likely to be found in waste waters in industrial plants where they are. produced and in environments where they are used. Harbors and docks with a large volume of navigation activities are places where leaching of alkyltin from marine antifouling paints occurs. Tributyltin and tripropyltin ions have been found in the leachates of a navy copolymer antifouling paint [25]. Degradation of tributyltin to dibutyltin species was also observed although the nature of the processes involved has not yet been ascertained. It is 
interesting to note that increasing methyltin concentrations were observed with increased anthropogenic tin inputs [25].

Apart from the particular organotin compounds detected in locales where they are used, methyltin species seem to be the main forms of organotin reported in natural waters, rain waters, and urine. Concentrations of alkyltins in some natural waters and biological samples are given in Table 4.

Table 4. Concentrations of alkyltin compounds in natural waters and biological materials ( $\mathrm{ng} / \mathrm{L}$ as $\mathrm{Sn}$ )

\begin{tabular}{|c|c|c|c|c|c|c|c|}
\hline Location & $\mathrm{MeSn}^{3+}$ & $\mathrm{Me}_{2} \mathrm{Sn}^{2+}$ & $\mathrm{BuSn}^{3+}$ & $\mathrm{Bu}_{2} \mathrm{Sn}^{2+}$ & $\mathrm{Bu}_{3} \mathrm{Sn}^{+}$ & $\operatorname{Sn}(\mathrm{IV})$ & Ref. \\
\hline $\begin{array}{l}\text { San Diego Bay } \\
\text { San Francisco Bay } \\
\text { Grand Haven, Mich. } \\
\text { Hamilton H., Ont. }\end{array}$ & $\begin{array}{l}2-8 \\
0 \\
13\end{array}$ & $\begin{array}{c}15-45 \\
0 \\
0\end{array}$ & $\begin{array}{r}0 \\
0 \\
1220 \\
10\end{array}$ & $\begin{array}{r}0 \\
0 \\
1600 \\
10\end{array}$ & 80 & $\begin{array}{l}6-38 \\
0.5 \\
490 \\
40\end{array}$ & $\begin{array}{l}26 \\
26 \\
26 \\
27\end{array}$ \\
\hline & $\mathrm{MeSn}^{3+}$ & $\mathrm{Me}_{2} \mathrm{Sn}^{2+}$ & $\mathrm{Me}_{3} \mathrm{Sn}^{+}$ & $\operatorname{Sn}($ IV) & Total & Ref. & \\
\hline $\begin{array}{l}\text { Human urine [11] } \\
\text { Rain [10] } \\
\text { Tapwater [2] } \\
\text { Freshwater [15] } \\
\text { Estuarine [10] } \\
\text { Saline } \\
\text { Chicken eggshe } 11^{\text {a }} \\
\text { Baltimore H. } \\
\text { Toronto H., Ont. } \\
\text { Port Dover, Ont. }\end{array}$ & $\begin{array}{l}90 \\
5.9 \\
4.3 \\
2.0 \\
2.4 \\
0.6 \\
\text { nd } \\
\text { nd } \\
960 \\
610\end{array}$ & $\begin{array}{l}73 \\
7.4 \\
1.3 \\
1.4 \\
1.7 \\
1.4 \\
0.08 \\
5-20 \\
290 \\
160\end{array}$ & $\begin{array}{l}42 \\
0.2 \\
1.5 \\
1.5 \\
0.5 \\
0.5 \\
\text { nd } \\
5-10 \\
\text { nd } \\
\text { nd }\end{array}$ & $\begin{array}{l}820 \\
11 \\
2.2 \\
4.2 \\
7.9 \\
1.7 \\
2.9 \\
\text { nd }-400 \\
540 \\
140\end{array}$ & $\begin{array}{c}1000 \\
25 \\
9.2 \\
9.1 \\
12 \\
4.2 \\
3.0\end{array}$ & $\begin{array}{l}28 \\
28 \\
28 \\
28 \\
28 \\
28 \\
28 \\
25 \\
29 \\
29\end{array}$ & \\
\hline
\end{tabular}

Numbers in brackets indicate no. of samples taken for average; nd = not detectable; $\mathrm{a}=\mathrm{ng} / \mathrm{g}$.

There are not too many documented data on organotin compounds in the environment chiefly because of the lack of suitable analytical methodology in the past. Speciation analysis of organotins will begin to accumulate in the very near future with the advent of highly sensitive speciation techniques discussed in the subsequent sections.

Toxicity of organometals, in general, is influenced by the organic moieties attached to the metal atom, hence the degree of substitution as well as the nature of the organic groups play important roles. In a study of the toxicity of organotins on aquatic biota [30], such structure toxicity relationships were further substantiated. Organotin compounds were generally more inhibitory to the primary productivity and reproduction of algae than the inorganic tin species. The responses were similar in pure culture of Scenedesmus quadricauda, Ankistrodesmus falcatus and Anabaena flos-aquae and also in natural phytoplankton of Lake 0ntario. The general order of toxicity of alkyltin compounds to $\underline{A}$. falcatus was trialkyl>dialkyl>monoalkyltin. This reflects that the toxicity is enhanced by the degree of substitution. Such an order was also observed with animals [31]. 
The effect of the size of the alkyl group is reflected by the increasing toxicity with increasing carbon chain length within the same series of the same degree of alkylation. Such effect is not so obvious in th monoalkyl series as compared to the trialkyl series. It appears to be that the size of the organic group has a definitive effect to influence toxicity because a unit increase in carbon chain length in the monoalkyl series is magnified three times in the trialkyltin series. The possible modes of action of the toxic effect of the trialkyltin derivatives have been discussed in another study [30].

The bioconcentration of a chemical by biota has been shown to be dependent on the partition behaviors of the compound between lipid and water phases. An arbitrary octanol/water partition system has been used successfully in determining the bioconcentration factors for chlorobenzenes and chlorophenols in trout muscles [32]. Toxicity of a chemical has been consequently deduced from this information. For organotins, the partition coefficient is a function of the number of organic groups attached to tin. Higher alkyltin series are more soluble in octanol than in water. The methyltin compounds are the most water soluble of the organotins. Within the trialkyltin series toxicity of the tin compounds on $\underline{A}$. falcatus, for example, is related to the lipophilicity of the compound as represented by higher octanol/ water partition coefficients. This relation, however, does not extend to all other organotins of different substitution. Obviously, lipophilicity is only one factor, among others, controlling the toxicity of a compound. Table 5 summarizes the $E_{50}$ values of a number of alkyltin compounds and their partition coefficients.

Table 5. Toxicity of alkyltin compounds on the primary productivity of alga Ankistrodesmus falcatus.

Sn compound $\quad \mathrm{ED}_{50}(\mathrm{mg} / \mathrm{L}) \quad \log \mathrm{P}\left(\right.$ Octanol: $\left.\mathrm{H}_{2} \mathrm{O}\right)$

$\begin{array}{lrr}\left(\mathrm{C}_{6} \mathrm{H}_{5}\right)_{3} \mathrm{SnCl} & 0.01 & 2.65 \\ {\left[\left(\mathrm{C}_{4} \mathrm{H}_{9}\right){ }_{3} \mathrm{Sn}\right]_{2} \mathrm{O}} & 0.02 & 2.29 \\ \left(\mathrm{C}_{3} \mathrm{H}_{7}\right)_{3} \mathrm{SnCl} & 0.02 & 0.93 \\ \left(\mathrm{C}_{2} \mathrm{H}_{5}\right)_{3} \mathrm{SnBr} & 0.20 & -1.74 \\ \left(\mathrm{CH}_{3}\right)_{3} \mathrm{SnCl} & 5.50 & -2.27 \\ \left(\mathrm{C}_{6} \mathrm{H}_{5}\right)_{2} \mathrm{SnCl}_{2} & 8.00 & 1.92 \\ \left(\mathrm{C}_{4} \mathrm{H}_{9}\right){ }_{2} \mathrm{SnCl}_{2} & 6.80 & 2.50 \\ \left(\mathrm{C}_{2} \mathrm{H}_{5}\right)_{2} \mathrm{SnCl}_{2} & 16.00 & -3.15 \\ \left(\mathrm{CH}_{3}\right){ }_{2} \mathrm{SnCl}_{2} & 21.00 & -3.03 \\ \left(\mathrm{C}_{6} \mathrm{H}_{5}\right) \mathrm{SnCl}_{3} & 19.00 & -0.20 \\ \left.\left(\mathrm{C}_{4} \mathrm{H}_{9}\right) \mathrm{SnCl}\right]_{3} & 25.00 & 0.41 \\ \mathrm{CH}_{3} \mathrm{SnCl}_{3} & 23.00 & -3.05 \\ \mathrm{SnCl}_{2} & 14.00 & -2.47 \\ \mathrm{SnCl}_{4} & 12.00 & -3.26\end{array}$

$\mathrm{ED}_{50}=$ Mean effective dose causing a 50 percent reduction of ${ }^{14} \mathrm{CO}_{2}$ fixation as compared to control.

$\mathrm{P} \quad$ = Partition coefficient between n-octanol and water. 


\subsection{The GC-AAS System}

Speciation analysis of heavy metals at environmental concentrations is one of the greatest challenges facing analytical chemists today. This requirement is indispensable because it is essential to almost any ecological and toxicological studies that the chemical form of an element, its valence state, and the organic groups it is associated with must be known before any valid interpretation can be made.

Metal elements in solution are generally speciated with regard to their valence state, aquocomplex (free aquated ion), and complexed forms. Electrochemical techniques are the most popular tools although some uncertainties are still yet to be resolved. For organometals, volatile molecular species and the highly polar solvated organometal species in solution as a result of biogenic and abiotic reactions are of interest. The approach for speciating volatile organometals has been collecting them in a cryogenic trap and sweeping them into a gas chromatograph for separation. Element-specific detectors, such as AAS [33], atomic fluorescence [34], have been used for determination of tetraalkyllead and dimethylselenides. Element-selective flame photometric detectors have also been used in speciation analysis of alkyltins [35,36]. The volatile molecular tetraalkyls of $\mathrm{Pb}, \mathrm{Sn}$, etc, have relatively high vapor pressure so that evacuation of the head space of a closed system [37] or purging of a water sample can drive them out of the solution [35]. Volatile tetramethyltin and alkyltin hydrides in estuarine waters have been so determined [35]. For determination of tetraalkyllead in air, a double trap device has also been developed to avoid the serious water condensation problems [38]. Thus the GC-AAS system has provided satisfactory methods for the molecular speciation of volatile organometals.

For the highly polar, solvated species in solution, chemical derivatization techniques have to be used to render the analytes sufficiently volatile for separation in the GC. Two approaches have been used. The first one is to convert the alkyl-bearing element to the corresponding hydrides before distilling to the detector. Methylated arsenic compounds have been analyzed using DC discharge emission [10] and AAS [7] as detectors.

The second derivatization method is peralkylation of the alkyl species after extraction into an organic solvent. For example, $R_{n} S n(4-n)+$ were treated with an excess of a selected $R^{\prime}$ Grignard reagent to convert them to tetraalkyltins $R_{n} S n R_{(4-n)}^{\prime}$ which have sufficient volatility to be separated in the GC column. Butyltin species have been analyzed after methylation by GC-MS [39] and after pentylation by GC with FPD detector [36].

Accordingly, we have developd a derivatization method [29] for the speciation of methyltins and $\mathrm{Sn}$ (IV) compounds by extracting all the tin species into benzene containing tropolone in the presence of $\mathrm{NaCl}$. The extract was butylated with $\mathrm{BuMgCl}$ to convert the tin species to methyl-butyl species. 


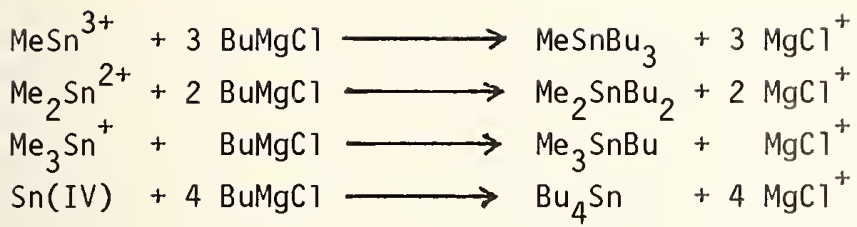

These tetraalkytin species are separated in an OV-1 column using temperature programs. The butylation is quantitative, and the complete procedure gives reproducible results. A GC-AAS chromatogram for the separation of the methyltin and $\mathrm{Sn}$ (IV) species ( $8 \mathrm{ng} \mathrm{Sn}$ ) is illustrated in Figure 1.

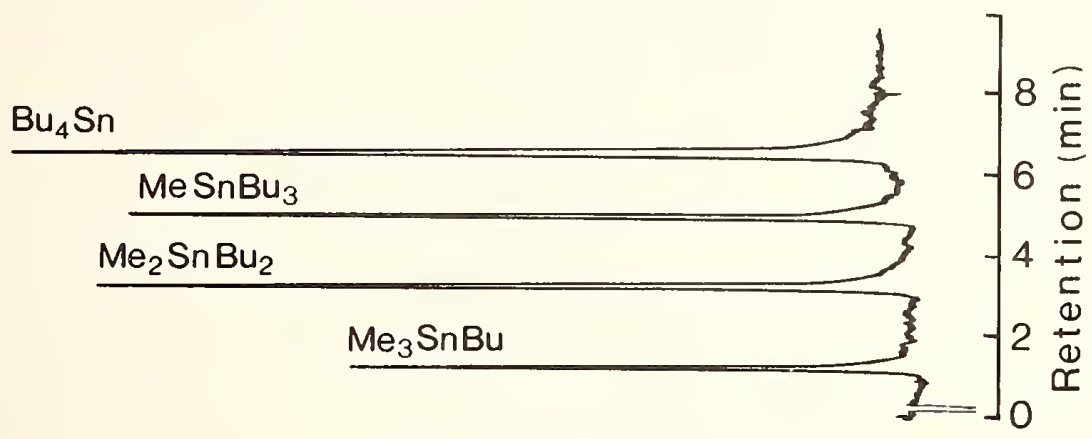

Figure 1. GC-AAS chromatogram of methyltins and $\mathrm{Sn}$ (IV) after butylation.

Column: $6^{\prime} 3 \%$ OV-1; temp. programs, $90^{\circ}-20^{\circ} / \mathrm{min}-180^{\circ}$;

$\mathrm{N}_{2}$ carrier gas, $65 \mathrm{~mL} / \mathrm{min}$. AAS: $\mathrm{Sn}(E D L) 224.6 \mathrm{~nm}$;

transfer line, $165^{\circ}$; Quartz tube furnace gases, $\mathrm{H}_{2}, 85 \mathrm{~mL} / \mathrm{min}$, air, $20 \mathrm{~mL} / \mathrm{min}$.

\subsection{The LC-AAS System}

In comparison, the peralkylation derivatization technique gives more consistent yield and reproducible results, but is less sensitive than the hydride reduction method, because only a $\mu \mathrm{L}-\mathrm{aliquot}$ is injected to the GC. On the other hand, the hydride method is a total sampling technique which introduces more analyte to the AA furnace. One disadvantage of the hydride generation is, occasionally, for unknown reasons, the occurrence of rearrangements of the alkyl groups which may cause erratic results.

For speciation of polar compounds in solution, it is recognized that HPLC in conjunction with an element-specific detector would provide the best system. The main difficulty in this system is the lack of a "perfect" interface for the HPLC and AAS, although several techniques have now been used.

The most successful interface technique so far is the use of an automatic sampler to sample aliquots of the LC effluent from an overflowing well periodically, and to inject into the graphite furnace for analysis [40]. This techrique gives pulsed signals, the frequency 
of which is governed by the cycle time of the graphite furnace (ca. $50 \mathrm{~s}$ per sample). Thus, we can see that if the chromatographic peak is sharp and lasts only ca. 3 min, the summation of peak heights can be quite variable, depending on how well the synchronization of the auto sampler is with the emergence of the peak. Continuous testing of the starting time is necessary to find out the optimum synchronization. By this technique, methylarsenic compounds, As(III) and As(V) [41,42], and di- and trialkyltin compounds [43] have been speciated. The sensitivity of this technique is limited by the volume of sample injected to the graphite furnace $(10-20 \mu \mathrm{L})$ which is only ca. 2 percent of the effluent stream.

Other interface techniques include direct piping the effluent into a flame AA burner which gives a continuous peak representing the whole sample. Sensitivity, unfortunately, is low. We have attempted to interface the HPLC effluent to an automatic hydride train with a hope to achieve the higher sensitivity and continuous peak signal for the hydride forming elements. The HPLC eluent, if containing organic solvents, interferes seriously with the hydride generation and causes a very noisy baseline.

A microprocessor-controlled interfacing system for LC-AAS has been described [44] with total sample consumption capability. The system is based on a "homemade" prototype and may not be readily built by other users. Another technique that has recently appeared is also making use of ion chromatography separation of arsenite, arsenate, monomethylarsonate, dimethylarsinate and $\mathrm{p}$-aminophenyl arsonate, followed by hydride reduction and AAS analysis with a detection limit less than $10 \mathrm{ng} / \mathrm{mL}$ for each species [45].

New techniques of interfacing HPLC and AAS will continue to be developed in this area.

\section{Summary}

We can see that organometals study occupy an important link in the biogeochemistry cycles in the aquatic environment. The field is just beginning to grow. The future research will gear very much on how much advancement is made in the speciation analysis leading to the understanding of the pathways. It is complex, involving thermodynamics and kinetics driving forces leading to momentary equilibria. Biological interventions can enter at any stage to start new cycles or to repeat old cycles again.

\section{References}

[1] Challenger, F. The biological methylation of compounds of arsenic and selenium. Chem. and Ind. (London) 54: 657; 1935.

[2] Braman, R. S.; Foreback, C. C. Methylated forms of arsenic in the environment. Science. 182: $1247 ; 1973$.

[3] Braman, R. S. Arsenic in the environment, in Arsenical pesticides, E. A. Woolson, ed. ACS Symposium Series No. 7, 108; 1975.

[4] Cox, D. D. Microbiological methylation of arsenic, in Arsenical pesticides, E. A. Woolson, ed. ACS Symposium Series No. 7, 81; 1975. 
[5] Crecelius, E. A. Changes in the chemical speciation of arsenic following ingestion by man, in Proceedings of the 8th materials research symposium. Washington, DC: Nat1. Bur. Stand. (U.S.) Spec. Pub1. 464; 1977. 495 p.

[6] Edmonds, J. S.; Francesconi, K. A.; Cannon, J. R.; Raston, C. L. ; Skelton, B. W.; White, A. H. Location, crystal structure, and synthesis of arsenobetaine, the arsenical constitutent of the western rock lobster Panulirus longipes cygnus George.

Tetrahedron Lett. 18: 1543; 1977.

[7] Wong, P. T. S.; Chau, Y. K.; Luxon, L.; Bengert, G. A. Methylation of arsenic in the aquatic environment, in Trace substances in environmental health-XI, D. D. Hemphill, ed. St. Louis: University of Missouri; 1977. 100 p.

[8] Wong, P. T. S. ; Chau, Y. K. unpublished data.

[9] Andreae, M. 0. Determination of arsenic species in natural waters. Anal. Chem. 49: $820 ; 1977$.

[10] Braman, R. S.; Johnson, D. L.; Foreback, C. C. ; Ammons, J. M. ; Bricker, J. L. Separation and determination of nanogram amounts o inorganic arsenic and methylarsenic compounds. Anal. Chem. 49: 621; 1977.

[11] Johnson, D. L.; Braman, R. S. The speciation of arsenic and the content of germanium and mercury in members of the pelagic Sargassum community. Deep Sea Res. 22: 503; 1975.

[12] Vallee, B. L.; Ulmer, D. D.; Wacker, W. E. C. Arsenic toxicology and biochemistry. AMA Arch, Indus. Health 21: 132; (1960).

[13] Harrison, R. M.; Perry, R. The analysis of tetraalkyllead compounds and their significance as urban air pollutants. Atmos. Environ. 11: 847; 1977.

[14] Harrison, R. M.; Laxen, D. P. H. Natural source of tetraalkyllead in air. Nature. 275: $738 ; 1978$.

[15] Radziuk, B.; Thomassen, Y.; Van Loon, J. C.; Chau, Y. K. Determination of alkylated lead compounds in air. Anal. Chim. Acta. 105: 255; 1979.

[16] Chau, Y. K.; Wong, P. T. S.; Kramar, 0.; Bengert, G. A.; Cruz, R. B. ; Kinrade, J. 0.; Lye, J.; Van Loon, J. C. Occurrence of tetraalkyllead compounds in the aquatic environment. Bull. Environ. Contam. Toxicol. 24: 265; 1980.

[17] Wong, P. T. S.; Chau, Y. K.; Kramar, 0.; Bengert, G. A. Accumulation and depuration of tetramethyllead by rainbow trout. Water Res. 15: 621; (1981).

[18] Botré, C.; Malizia, E.; Melchiorri, P.; Stacchini, E.; Terayanti, G.; Zorsi, C. D. Study and evaluation of organic lead levels in fishes and phytoplankton near 0trano. European Society for Toxicology, 19th Meeting; Copenhagen; 1977.

[19] Grandjean, P.; Nielsen, T. Organolead compounds: environmental health aspects. Residue Rev. 72: 97; 1979.

[20] Maddock, B. G.; Taylor, D. The accute toxicity and bioaccumulation of some lead alkyl compounds in marine animals, in Lead in the marine environment, M. Branica and Z. Konrad, eds. New York: Pergamon Press; 1980. 233-262.

[21] Silverberg, B. A.; Wong, P. T. S.; Chau, Y. K. Effect of tetraalkyllead on freshwater green algae. Arch. Environ. Contam. Toxicol. 5: 305; 1977.

[22] Huey, C.; Brinckman, F. E.; Grim, S.; Iverson, W. P. The role of tin in bacterial methylation of mercury, in Proc. inter. conf. on transport of persistent chemicals in aquatic ecosystems, A. S. W. de Freitas, D. J. Kushner, and S. U. Quadri, eds. Ottawa: National Research Counci1; 1974. 
[23] Chau, Y. K.; Wong, P. T. S.; Kramar, 0.; Bengert, G. A. Biological methylation of tin compounds in the aquatic environment, in Proc. of the 3 rd int. conf. on Organometal. Coord. Chem. Germanium, Tin, Lead. Dortmund, W. Germany: University of Dortmund; 1980.

[24] Coleman III, W. M. ; Cobet, A. B.; Guard, H. E. Formation of tetramethyltin from trimethyltin hydroxide in estuarine sediments and by sulfur containing and reducing agents, in Proc. of the 3rd int. conf. on Organometal. Coord. Chem. Germanium, Tin, Lead. Dortmund, W. Germany: University of Dortmund; 1980.

[25] Brinckman, F. E. ; Jackson, J. A. ; Blair, W. R.; 01son, G. J. ; Iverson, W. P. Ultratrace speciation and biogenis of methyltin transport species in estuarine waters, in Trace metals in sea water. NATO Adv. Res. Inst. Erice, Sicily, Italy: Plenum Publishing Corp. ; 1981, in press.

[26] Hodge, V. F.; Seidel, S. L.; Goldberg, E. D. Determination of tin(IV) and organotin compounds in natural waters, coastal sediments and macro algae by atomic absorption spectrometry. Anal. Chem. 51: 1256; 1979.

[27] Maguire, R. J. personal communication.

[28] Braman, R. S.; Tompkins, M. A. Separation and determination of nanogram amounts of inorganic tin and methyltin compounds in the environment. Anal. Chem. 51: 121979.

[29] Chau, Y. K.; Wong, P. T. S.; Bengert, G. A.; Kramar, 0. Determination of methyltin and $\mathrm{Sn}$ (IV) species in water by GC-AAS, submitted for publication.

[30] Wong, P. T. S.; Chau, Y. K.; Kramar, 0.; Bengert, G. A. Structure toxicity relationship of tin compounds on algae, submitted for publication. 1981.

[31] Zuckerman, J. J.; Reisdorf, R. P.; Ellis III, H. V.; Wilkinson, R. R. Organotins in biology and the environment, in Organometals and organometalloids--occurrence and fate in the environment, F. E. Brinckman and J. M. Bellama, eds. ACS Symposium Series No. 82. 331978.

[32] Neeley, W. B.; Branson, D. R.; Blau, G. E. Partition coefficient to measure bioconcentration potential of organic chemicals in fish. Environ. Sci. Tech. 8: 1113; 1974.

[33] Chau, Y. K.; Wong, P. T. S.; Goulden, P. D. Gas chromatography-atomic absorption spectrometry for the determination of tetraalkyllead compounds. Anal. Chim. Acta 85: $421 ; 1976$.

[34] Radziuk, B.; Thomassen, Y.; Butler, L. R. P.; Van Loon, J. C.; Chau, Y. K. A study of atomic absorption and atomic fluorescence atomization systems as detectors in the gas chromatographic determinations of lead. Anal. Chim. Acta 108: 31; 1979.

[35] Jackson, J. A.; Blair, W. R.; Brinckman, F. E. ; Iverson, W. P. Gas chromatograhic speciation of methylstannanes in the Chesapeake Bay using purge and trap sampling with a tin-selective detector, Environ. Sci. Technol., in press.

[36] Maguire, R. J.; Huneault, H. Determination of butyltin species in water by gas chromatography with flame photometric detection. J. Chromatogr. 209: 458; 1981.

[37] Chau, Y. K.; Wong, P. T. S. An element- and speciation-specific technique for the determination of organometallic compounds, in Environmental analysis, G. W. Ewing, ed. New York: Academic Press; 1977. 215-225.

[38] De Jonghe, W. R. A.; Chakrabarti, D. ; Adams, F. C. Sampling of tetraalkyllead compounds in air for determination by gas chromatography-atomic absorption spectrometry. Anal. Chem. 52: 1974; 1980.

[39] Meinema, H. A.; Burger-Wiersma, T.; Versluis-de Haan, G.; Gevers, E. Ch. Determination of trace amounts of butyltin compounds in aqueous systems by gas chromatography-mass spectrometry. Environ. Sci. Tech. 12: 288; 1978. 
[40] Brinckman, F. E.; Blair, W. R.; Jewett, K. L.; Iverson, W. P. Application of a liquid chromatograph coupled with a flameless atomic absorption detector for speciation of trace organometallic compounds. J. Chromatogr. Sci. 15: 493; 1977.

[41] Woolson, E. A.; Aharonson, N. Separation and detection of arsenical pesticide residues and some of their metabolites by high pressure liquid chromatography-graphite furnace atomic absorption spectrometry. J. Assoc. Off. Anal. Chem. 63: 523; 1980.

[42] Brinckman, F. E. ; Jewett, K. L.; Iverson, W. P.; Irgolic, K. J.; Ehrhardt, K. C.; Stockton, R. A. Graphite furnace atomic absorption spectrophotometers as automated element-specific detectors for high-pressure liquid chromatography: The determination of arsenate, arsenite, methylarsonic acid, and dimethylarsinic acid. J. Chromatogr. 191: 31 ; 1979.

[43] Jewett, K. L.; Brinckman, F. E. Speciation of trace di- and tri-organotins in water by ion exchange HPLC-AAS. J. Chromatogr. Sci. 19: 1981, in press.

[44] Vickrey, T. M.; Eue, W. A microprocessor controlled liquid chromatograph/atomic absorption sampling system. J. Automat. Chem. 1: 198; 1979.

[45] Ricci, G. R.; Shepard, L. S.; Colovos, G.; Hester, N. E. Ion chromatography with atomic absorption spectrometric detection for determination of organic and inorganic arsenic species. Anal. Chem. 53: 610; 1981.

Discussion

Question (L. Packer): Are the toxicity data you reported, and others report, on photosynthesis and growth made under conditions of batch culture or continuous culture? I ask the question because of the point you made about the lipophilicity of these compounds after they are methylated. Probably the strategy of the organism is to methylate metals so that they will be more permeable across the cell membranes. This is a mechanism whereby they can partition these compounds outside of the cell and get rid of them into the ocean outside which contains a low concentration. Therefore, if you are going to evaluate the potential toxicity to an organism, you need to define the entire constraints of the system.

Answer: Yes, we begin on batch culture. This is not the way we do our toxicity testing, because we worry that some of the compounds may get methylated in the water column before they get into the fish. When they go through the water column, algae are the first biota to be exposed to these compounds. That is the reason why we did algal testing on the volatile compounds. When the algae concentrate the compounds in the first step, and the fish is going to take it up in a bioconcentration step, you in fact find all these compounds in the lipid layer of the fish. If I dissect the fish and analyze the lipid layer, we find the organometallic compounds mainly concentrated in the fatty tissues. So this is exactly what lipophilicity is all about. All these toxic organometal compounds are concentrated in the fatty tissue. 
Question (R. D. Stephens): I'd like to return to the lead issue--it's really an important one, particularly in light of some recent decisions EPA has made. I think you have to be very careful in making judgments about the anthropogenic origin of substances particularly in reference to your comment on rural air and the presence of alkylmercury or alkyllead compounds in rural air. I'd like to comment on the recent findings of PCB in air off the coastal islands of California and the Pacific atolls far away from any industrial activity.

Also, in your studies on the organoleads in fish and sediments, have you considered looking at lead isotope ratios at all, in that they vary a great deal with the origins of lead? It's been shown by recent articles [Environ. Sci. Technol. 13: 105, 558 (1979)] that one might identify the origin of the organolead compounds from their lead isotope ratios. Therefore man-made organolead compounds in motor fuels might be identified by the lead isotope ratios. Maybe what you're looking at is not environment methylation but absorbance from lead motor fuel.

Answer: Yes, I think it's possible and I agree with you.

Question (D. A. Becker): Have you investigated the biomethylation potential of the high concentrations of lead found in used or waste lubricating oils? I might also mention that these oils also contain high concentrations of magnesium as well as chlorine and bromine.

Answer: No.

Question (R. J. Mehlhorn): I wonder about the toxicity sequence that you showed for the alkyltins? As I understand it, in animals, it's not the same order.

Answer: Yes, they're different. This sequence is mainly for aquatic biota, that is, freshwater algae.

Comment (R. J. Mehlhorn): I want to make a comment concerning the trialkyltins. They seem to be unique in a way, in that they don't exert their toxicity chemically, but rather in terms of their action at the membrane level. They seem to collapse pH gradients. They exchange chloride ions for hydroxide ions and only the trialkyltin ions have this action. This may explain the mechanism of toxicity.

Answer: Health people use rats and mice and the environmental people like to use algae, because these are in first link of the food chain. Algae are convenient for several reasons: it is easy to use a four-hour bioassay, whereas other test animals will need several days, and during that course of time the compounds may have chemically changed. 
Question (D. A. Klein): Can you comment on accommodation in the biological system, in other words, first and sequential additions of toxic metals to the system?

Answer: We used one-shot additions, because of time our bioassay is short--a four-hour exposure to 1ight. Because we use a one-shot addition, when we do the metal toxicity for a complexed metal or trace metal, in our continuous flow system, we take samples frequently to make sure it's still in that chemical form.

Question (E. Jenne): You have indicated something of the scope of the occurrence of certain of the alkylated metal species and some of the reactions. My question is, to what extent is it now possible to predict, given some adequate description of the sediment-water system, what will be the quantity of alkylated tin, arsenic, or mercury in the algae?

Answer: We have not tried that yet. I think it should be possible, based upon the nature of the metal. Wood has already outlined [Naturwiss. 62: 357 (1975); et al. Science, 197: 329 (1977)] the metals that can be methylated, and the metals that are difficult to methylate, and metals that are impossible to methylate. With that guidance, one could more or less estimate the feasibility of environmetal hazards of these elements. We are working on this 1ist. We are thinking about doing gallium methylation. Gallium would be affiliated with acid rain, and acid rain will be leaching out all our aluminum. Aluminum happens to be in the same Periodic Group as gallium. Wherever you find aluminum you find gallium.

Question (L. Packer): If the concentration of the such products are increasing in the environment, will the biological process be shut down by it?

Answer: The methylated product in this system is not a volatile one. It wouldn't go away, though methylation and demethylation are going on simultaneously. There are some bacteria which can do the job. A Japanese group has worked on demethylating bacteria to clean up Minimata Bay. We found that tetraalkyllead is methylated by the fish and we found trimethyllead species as an end product in the fish. There is an internal cycle in any aquatic environment and so I do not know whether your speculation is valid.

Comment (F. E. Brinckman): This goes back to earlier comments, especially the one by Dr. Jenne, and also by Dr. Packer, to Dr. Chau. There is an obvious need for the predicted fate, particularly of biological impact, by organometals in environmental circumstances. The problem requires full kinetic and thermodynamic considerations. Dr. Weiss will discuss some work in our laboratory dealing with molecular substituent parameters based on equilibrium measurements in thermodynamic conditions. Linear free energy relationships of these substituents can be shown to additively provide prediction for separation of materials in certain matrices. These are also related to factors such as the solvophobic constant of Hansch and Leo [Substituent Constants for Correlation Analysis in Chemistry and Biology, Wiley, New York, 1979]. They also relate to predicting the potential for the possible 
membrane or lipid uptake. Membrane solution is really what we're talking about, or, if you prefer, a membrane partitioning coefficient in the aquatic medium which is organism--or species-specific. The relationship of kinetic and thermodynamic measurements will now need to come forward in dealing with this special class of compounds, the organometals.

Question (R. H. Fish): I'd like to correct Wood's mechanism on the biomethylation of tin, which I think is still in doubt. Tin(III) is actually a tin radical. We did some unpublished experiments that where we reacted organotin radicals with methylcobaltoxime, a methylcobalamin model, and found no reaction taking place. Trialkyltin radicals $\left(R_{3} S n_{\text {. }}\right)$ are probably some of the most nucleophilic radicals known. If $R_{3} S n$. won't react, I doubt whether any $X_{3} S n$. will react. Does either Dr. Chau or Dr. Craig have any comments on that?

Answer (P. J. Craig): I think the mechanism involving tin(III) radicals was just a suggestion based on the reaction conditions because I'm not too sure that the electrode potentials are right for the production of tin(III). I don't know whether any further work has been done on that. However, I think methyl free radical or carbonium ion addition to tin(II) is probably a more realistic pathway than methylcarbanion attack on tin(II). You've got to oxidize the metal by removal of two electrons whereas oxidative addition does that for you. The chemical route involving $\mathrm{CH}_{3}{ }^{+}$appears very attractive where the metal is in a low oxidation state. The purpose of my talk was to focus attention on this alternative pathway.

I've got another point as we1]. I hear of methylating other metals besides the most popular ones. One must bear in mind is that many methylmetal species are extremely unstable under environmental conditions. Using non-aqueous solvents, you can make methylpalladium species; you can make methyl species out of almost any metal in the Periodic Table. Methylpalladium has been studied very carefully, and shown to decompose rapidly in water. So, unless there's some further stabilization by an organic ligand present in the environmental situation, I think we can narrow the list of methylmetals down quite considerably. The list of metals that we ought to look at should be those with methylmetal bonds that are very stable in water. I think we should bear that in mind. 
Environmental Chemical Investigations of Trace Element Mobilization

in Synthetic Fuels Manufacture

\author{
Stanley E. Manahan and David M. Fraley \\ Department of Chemistry \\ University of Missouri - Columbia \\ Columbia, MO 65211 \\ Corazon Vogt and Dennis Yates \\ Environmental Trace Substances Center \\ University of Missouri \\ Columbia, MO 65211
}

The principles of environmental chemistry may be applied to predict pollution problems from synthetic fuels manufacture, enabling corrective action to be taken at the design stage. One of the environmental concerns in synthetic fuels manufacture is the mobilization in soluble and/or volatile forms of trace elements originally present in the solid fossil fuel feedstock. Some of the conditions that may obtain during various coal conversion or shale $0 i 1$ retorting operations conducive to production of mobile trace element species are a hydrogen-rich reducing atmosphere, high carbon monoxide pressures, presence of aromatic compounds, and presence of chelating molecules. It is important to determine if mobile trace element species are produced; it is equal1y important to determine if they are not produced to avoid unnecessary concern over nonexistent environmental problems. This chapter describes studies of potential mobilization of trace elements from coal pyrolysis, simulated in situ coal gasification, and shale oil retorting

Key words: coal; environmental chemistry; shale oil; synthetic fuels; trace elements.

1. Introduction

\title{
1.1. Environmental Chemistry and Emerging Energy Technologies
}

Environmental chemistry may be defined as the study of the origins, transport, reactions, effects, and fates of chemical species in the water, air, terrestrial, and biological environments [1]. Ideally, with a broadly-based view of the interactions of chemical species in the hydrosphere, atmosphere, geosphere, and biosphere, the environmental chemist should be able to predict those aspects of new industrial operations that are likely to cause environmental problems and recommend corrective action before the problems actualiy develop.

Practiced for decades under other names, 1argely by non-chemists, environmental chemistry has emerged during the 1 ast 10 years as a distinct, viable sub-discipline in the field of chemistry. It should be noted that environmental chemistry is not simply analytical chemistry applied to environmental problems. The very rapid pace of development of analytical chemistry - as exemplified during the last decade by techniques such as high performance liquid chromatography and inductively-coupled plasma atomic emission spectroscopy - 
has greatly facilitated the study of environmental problems. However, the success of new analytical methodologies has resulted in the potential for a "data explosion" which, even with the assistance of computers, threatens to overwhelm investigators with numbers. The appication of environmental chemistry can help mitigate this problem through the design of research protocols designed to yield maximum information about potential environmental effects with minimum analytical data.

A major synthetic fuels industry in the U.S. poses the best opportunity to date for the application of environmental chemistry at the earliest stages of development of a large new industry which could cause considerable environmental harm, if not properly managed. This is particularly true in that the environmental problems about which least is known associated with this industry tend to be chemical problems. These include saline water contamination from spent oil shale, carcinogenic potential of coal liquids, organic contamination of groundwater by in situ coal gasification, and, the subject of this book, trace metal containing substances from energy-related processes. In some cases environmental and occupational health considerations may well determine which of two or more otherwise comparable synthetic fuels manufacturing processes will be developed commercially. Therefore, large sums of money and a huge public interest are dependent upon high quality, comprehensive environmental studies. It is not acceptable to wait until large commercial-scale plants are in operation to discover environmental and occupational health problems by monitoring the surrounding environment for pollutants and hazardous substances. Instead, the principles of environmental chemistry and engineering must be applied at the laboratory scale and thereafter so that environmental problems may be detected and appropriate remedial action taken.

1:2. Trace Elements in Coal

Coal used for fuel or coal conversion consists predominantly of organic matter, with a lesser amount of mineral matter. The organic matter in coal consists of a variety of moieties of variable and largely unknown structure. Figure 1 shows a hypothetical "molecule"

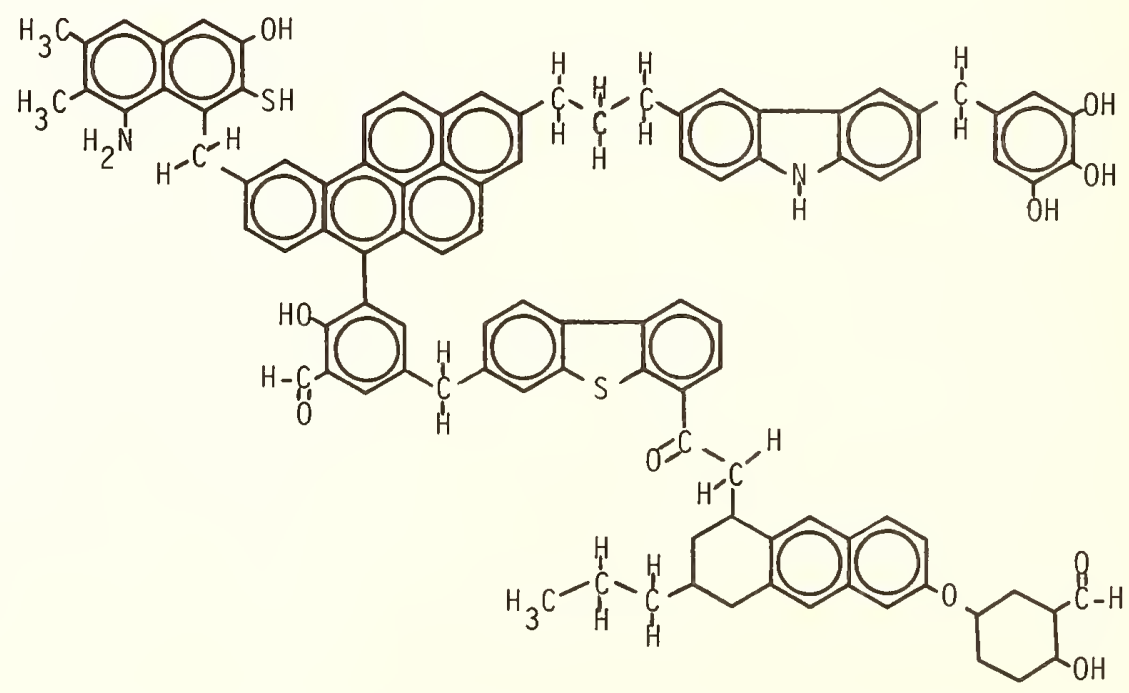

Figure 1. Hypothetical coal "molecule" with the approximate formula, $\mathrm{C}_{100} \mathrm{H}_{85} \mathrm{~S}_{2} \mathrm{~N}_{2} \mathrm{O}_{10}$. 
of coal with an approximate formula of $\mathrm{C}_{100} \mathrm{H}_{85} \mathrm{~S}_{2} \mathrm{~N}_{2} \mathrm{O}_{10}$ [2]. This formula approximates that of Illinois No. 6 bituminous coal. It is believed that coal consists largely of aromatic structures connected by linkages consisting of alkane, ether, and other groups. Organically bound sulfur and nitrogen in coal may be associated with the binding of some heavy metals to the organic coal matrix.

Practically any coal sample contains significant levels of trace elements at levels of the order of $1 \mathrm{ppm}$. Virtual1y al1 of the 91 naturally-occurring elements have been found in various coals. The occurrence of trace elements in coal is illustrated by the selected values given in Table 1, based on the analysis of 101 coals, largely from the Illinois Basin. In addition to illustrating the presence of a variety of trace elements, these

Table 1. Trace element content of selected coal samples ${ }^{a}$

\begin{tabular}{|c|c|c|c|c|}
\hline \multirow[b]{2}{*}{ Trace element } & \multicolumn{4}{|c|}{ Analytical value $(\mathrm{ppm})^{\mathrm{a}}$} \\
\hline & Mean & Minimum & Maximum & Standard deviation \\
\hline Antimony & 1.26 & 0.20 & 8.90 & 1.32 \\
\hline Arsenic & 14.0 & 0.50 & 93.0 & 17.7 \\
\hline Boron & 102 & 5.00 & 224 & 54.7 \\
\hline Beryllium & 1.61 & 0.20 & 4.00 & 0.82 \\
\hline Bromine & 15.4 & 4.00 & 52.0 & 5.92 \\
\hline Cadmium & 2.52 & 0.10 & 65.0 & 7.60 \\
\hline Cobalt & 9.57 & 1.00 & 43.00 & 7.26 \\
\hline Chromium & 13.8 & 4.00 & 54.0 & 7.26 \\
\hline Copper & 15.2 & 5.00 & 61.0 & 8.12 \\
\hline Fluorine & 60.9 & 25.0 & 143 & 21.0 \\
\hline Gallium & 3.12 & 1.10 & 7.50 & 1.06 \\
\hline Germanium & 6.59 & 1.00 & 43.0 & 6.71 \\
\hline Mercury & 0.20 & 0.02 & 1.60 & 0.20 \\
\hline Manganese & 49.4 & 6.00 & 181 & 40.2 \\
\hline Molybdenum & 7.54 & 1.00 & 30.0 & 5.96 \\
\hline Nickel & 21.1 & 3.00 & 80.0 & 12.4 \\
\hline Phosphorus & 71.1 & 5.00 & 400 & 72.8 \\
\hline Lead & 34.8 & 4.00 & 218 & 43.7 \\
\hline Antimony & 1.26 & 0.20 & 8.90 & 1.32 \\
\hline Selenium & 2.08 & 0.45 & 7.70 & 1.10 \\
\hline Tin & 4.79 & 1.00 & 51.0 & 6.15 \\
\hline Vanadium & 32.7 & 11.0 & 78.0 & 12.03 \\
\hline Zinc & 272 & 6.00 & 5,350 & 694 \\
\hline
\end{tabular}

a Data from Ruch, R. R.; Gluskoter, H. J.; Shimp, N.F. Occurrence and distribution of potentially volatile trace elements in coal. Illinois State Geological Survey Environ. Geol. Note 72; 1974.

${ }^{b}$ Standard deviation for analyses of 101 coals. 
values show a wide variation in the content of each specific trace element among different coals. The levels of trace elements in coal tend to be reasonably close to their average crustal abundance (Clarke values). Boron, chlorine, and selenium tend to be enriched relative to their Clarke values, as is arsenic in some cases.

Little is known about the binding of trace elements in coal. Float-sink separation of coal organic and mineral matter in solvents of appropriate densities have enabled determination of the affinities of trace elements for coal as compared to mineral matter associated with the coal. A compilation of these studies [3] has shown germanium to be consistently associated with the organic fraction; boron, beryllium, and titanium are predominantly bound to the organic fraction; cobalt, nickel, chromium, selenium, and copper show intermediate behavior; and zinc and arsenic are generally bound to mineral matter. It is expected that the chalcophilic (sulfur-seeking) elements, such as arsenic, cobalt, nickel, lead, and antimony, would tend to associate with sulfur minerals in coal. For those elements bonded to the organic fraction it is anticipated that the transition elements (e.g., vanadium, nickel, copper, iron) would be bonded to $\mathrm{N}$-containing moieties, because of their preference for nitrogen atoms as donors. Metals with high ionic potentials (boron, germanium, titanium, gallium, beryllium, selenium, aluminum) prefer oxygen atoms as donors, and may well be associated with oxygen-containing functional groups, particularly in lower rank coals.

\subsection{Mobile Forms of Trace Element Species from Coal Conversion Processes}

Conditions obtain under various coal conversion processes that are conducive to the mobilization of various trace elements as volatile or soluble species. A generally reducing atmosphere tends to prevent formation of generally immobile oxides and may even convert some metals (particularly mercury) to volatile elemental forms. The presence of hydrogen and carbon monoxide may lead to the formation of volatile hydrides and metal carbonyls, respectively. The presence of organic moieties may lead to the formation of $\pi$ complexes or arene carbonyls. Hetero atoms, particularly nitrogen, present on organic molecular products of coal liquefaction and byproducts of coal gasification may act as electron donors for the formation of metal complexes and chelates. Free radicals produced as transient species during the pyrolysis or hydrogenation of coal can react with metals to form organometallics. Organic moieties already bound to trace elements may be released by the breakdown of the coal molecular structure. It is by no means certain that all these occur, but there are abundant possibilities for trace element mobilization (see Figure 2).

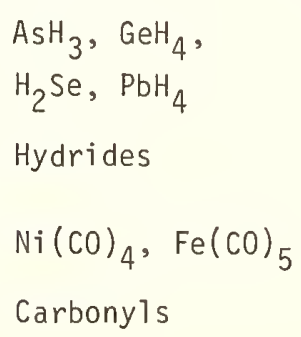

$\mathrm{AsH}_{3}, \mathrm{GeH}_{4}$,

$\mathrm{H}_{2} \mathrm{Se}, \mathrm{PbH}_{4}$

Hydrides

$\mathrm{Ni}(\mathrm{CO})_{4}, \mathrm{Fe}(\mathrm{CO})_{5}$

Carbonyls

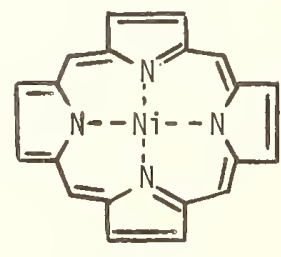

Porphyrin derivatives

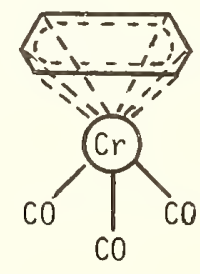

Arene carbonyls

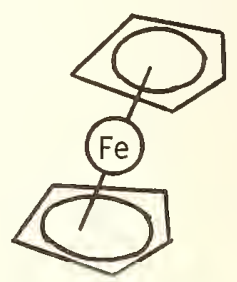

Metallocenes ( $\pi$ complexes)

Figure 2. Examples of mobile trace element species possibly produced by coal conversion. 
2. Volatilization of Trace Elements during Pyrolysis of Coal and Hydrogenated Coal 2.1. Coal Pyrolysis

Coal pyrolysis (coking) is practiced on a large scale for the production of metallurgical coke. It consists of heating the coal to a high temperature to drive off volatile organic gases and liquids, leaving a carbonaceous residue. Coal pyrolysis is the simplest coal conversion process for the production of gaseous and liquid hydrocarbons from coal because it takes advantage of the hydrogen content inherent to the coal, without adding hydrogen from an external source. The char product can be used as a furnace fuel. Because of the widespread metallurgical applications of coking, and its potential for synthetic fuels manufacture, the fate of trace elements during coking is a subject of considerable importance.

\subsection{Experimental Aspects of Coal Pyrolysis Studies}

Coal to be pyrolyzed was placed in a silica boat contained in a $20 \mathrm{~cm} \times 3 \mathrm{~cm} \mathrm{o.d}$. silica tube heated in a tube furnace. Volatile matter was swept from the tube into a system of four traps by a stream of helium gas. Traps 1 and 2 each contained $50 \mathrm{~mL}$ methyl isobutyl ketone (MIBK) to retain chelatable metals, acid-soluble species were trapped in $50 \mathrm{~mL}$ of $0.5 \mathrm{M} \mathrm{HNO}_{3}$ in a third trap, and the fourth trap contained $50 \mathrm{~mL}$ of 0.01 M EDTA at pH 10 to retain base-soluble species and chelatable metal ions. A 5 -g portion of coal was pyrolyzed by raising the temperature to $1000^{\circ} \mathrm{C}$ over a period of $85 \mathrm{~min}$, and maintaining this temperature for an additional $35 \mathrm{~min}$.

The bituminous coal used in this study was obtained from the Bruceton mine in Allegheny County, Pittsburgh, Pa. A 100-mesh size was used. The trace elements spiked into the coal were bromine, chlorine, vanadium, manganese, selenium, arsenic, chromium, and cobalt. The spiking levels used were of the order of $1 \mathrm{mg}$ per $\mathrm{g}$ of coal. The halides were added as sodium salts and the inorganic forms of the other elements as sulfides: $V_{2} S_{5}, M n S, S_{2} S_{2}$, $\mathrm{As}_{2} \mathrm{~S}_{3}, \mathrm{Cr}_{2} \mathrm{~S}_{3}$, and $\mathrm{CoS}$. The non-halide elements were added in the organically bound form as salts of coal humic acid prepared and purified as described in the 1iterature [4].

The coal, char residues, and trap contents were analyzed by instrumental neutron activation analysis (INAA) using standard methodologies [5]. For $\mathrm{Br}, \mathrm{V}, \mathrm{Cl}$, and Mn the INAA conditions used were 1-min irradiation at $8 \times 10^{13} \mathrm{n} \mathrm{cm}^{-2} \mathrm{~s}^{-1}, 20-\mathrm{min}$ decay, and 500-s counting time. The other elements were determined with a $10-\mathrm{h}$ irradiation at $3.5 \times 10^{13} \mathrm{n} \mathrm{cm}^{-2}$ $\mathrm{s}^{-1}$, 14-day decay (3-day for As), and a 500-s count.

\subsection{Results and Significance of Coal Pyrolysis Studies}

The results of these studies have been summarized [5]. During the course of the coal pyrolysis, $32 \%$ of the weight of the coal was lost as volatile matter; the remainder consisted of coke and ash staying in the boat.

The volatility data for the elements studied are summarized in Table 2. Some striking differences in volatility are observed among elements and between spiking forms of the same element. Significant losses of both bromine and chlorine were observed, although the maximum pyrolysis temperature $\left(1000^{\circ} \mathrm{C}\right)$ was below the boiling point of both $\mathrm{NaBr}\left(1390^{\circ} \mathrm{C}\right)$ and 
Table 2. Fate of trace element spikes in pyrolyzed coal

Total weight of element in

\begin{tabular}{|c|c|c|c|c|c|}
\hline \multirow{2}{*}{$\begin{array}{l}\text { Element and } \\
\text { spiking form }\end{array}$} & \multicolumn{2}{|l|}{ sample, mgb } & \multirow{2}{*}{$\begin{array}{l}\text { Percent } \\
\text { volatile }\end{array}$} & \multirow{2}{*}{ Weight recovered, $\mathrm{mg}^{\mathrm{d}}$} & \multirow{2}{*}{$\begin{array}{l}\text { Percent } \\
\text { recovery }\end{array}$} \\
\hline & a spiked coal & Coke & & & \\
\hline Inorg. $\mathrm{Br}$ & $4.13 \pm 0.38$ & $1.70_{-0}^{+} 0.16$ & 58.8 & $0.430 \pm 0.012$ & 51.6 \\
\hline Inorg. $\mathrm{Cl}$ & $24.8 \pm 1.2$ & $13.0 \pm 0.5$ & 47.6 & $3.49 \pm 0.07$ & 66.5 \\
\hline Inorg. $V$ & $4.18 \pm 0.15$ & $3.72 \pm 0.18$ & $\ldots f$ & $<3 \times 10^{-5}$ & $\ldots--^{f}$ \\
\hline org. v & $9.05 \pm 0.62$ & $8.63 \pm 0.74$ & $--^{f}$ & $<3 \times 10^{-5}$ & $--^{f}$ \\
\hline Inorg. Mn & $1.96 \pm 0.16$ & $2.32 \pm 0.29$ & $---^{f}$ & $<6 \times 10^{-4}$ & $---f$ \\
\hline Org. Mn & $18.7_{-2}^{+2} .2$ & $18.0 \pm 1.0$ & $--^{f}$ & $<6 \times 10^{-4}$ & $\ldots f$ \\
\hline Inorg. Se & $2.18 \pm 0.07$ & $0.414_{-0.021}^{+}$ & 81.0 & $1.89 \pm 0.03$ & 105 \\
\hline Org. Se & $2.75 \pm 0.15$ & $2.18 \pm 0.14$ & 21.0 & $0.606 \pm 0.018$ & 101 \\
\hline Inorg. As & $5.01 \pm 0.32$ & $2.58 \pm 0.02$ & 48.4 & $0.853 \pm 0.057$ & 68.5 \\
\hline Org. As & $1.65 \pm 0.10$ & $1.53 \pm 0.08$ & 7.5 & $0.0358 \pm 0.0033$ & 94.6 \\
\hline Inorg. $\mathrm{Cr}$ & $3.54 \pm 0.17$ & $3.86 \pm 0.35$ & $---^{f}$ & $<3 \times 10^{-5}$ & $--^{f}$ \\
\hline $\mathrm{Org} \cdot \mathrm{Cr}$ & $15.0 \pm 0.2$ & $14.4 \pm 0.7$ & $\ldots--^{f}$ & $<3 \times 10^{-5}$ & $\ldots f$ \\
\hline Inorg. Co & $2.04 \pm 0.22$ & $2.02 \pm 0.30$ & $\ldots f$ & $2.3 \times 10^{-4} \pm 0.3 \times 10^{-4}$ & $--f^{f}$ \\
\hline Org. Co & $2.15 \pm 0.15$ & $2.16 \pm 0.03$ & $\ldots f$ & $2.6 \times 10^{-4 \pm}-0.3 \times 10^{-4}$ & $-\ldots f$ \\
\hline
\end{tabular}

anorg. denotes inorganic spiking forms (Na halides, sulfides of other compounds); 0 rg. indicates spiking by organic coal humate salts.

${ }^{b}$ Total weight of element in original 5-g sample pyrolyzed (spiked coal) and in coke residue from that sample (coke).

Percent volatile $=\frac{\text { Wt. element in spiked coal }- \text { Wt. element in coke }}{W t \text {. element in spiked coal }} \times 100$

${ }^{d}$ Total weight of element recovered in four traps, usually the first trap.

Percent recovery $=$ Wt. element recovered in traps $+W t$. element in coke

f Percent volatile and percent recovery not calculated for these elements because of apparently complete retention in coke.

$\mathrm{NaCl}\left(1413^{\circ} \mathrm{C}\right)$. These elements were likely lost as volatile hydrogen halides or ammonium halides. The transition metals ( $\mathrm{V}, \mathrm{Mn}, \mathrm{Cr}, \mathrm{Co}$ ) did not appear to exhibit any significant volatility, and were retained with the coke product. Within the detection limits of the analytical methodology employed, cobalt was the only metal even detected in the traps. With the possible exception of cobalt, there was no evidence for the production of volatile metal species.

The most significant observation from this study was the striking difference in volatilities between inorganically and organically bound selenium and arsenic. Selenium spiked into coal in the inorganic form was $81 \%$ volatile, whereas selenium from the organic spike was only $21 \%$ volatile. The corresponding values for arsenic were $48.4 \%$ and $7.5 \%$, respectively. It is plausible that the sulfides of these elements are readily converted to volatile hydrides, whereas the organically bound elements are trapped by the char residue during pyrolysis and retained with the coke. 
3. Trace Elements in Shale $0 i 1$ Products

3.1. Fractionation and Analys is of Shale $0 i 1$

INAA has been applied to the determination of trace elements in fractions of shale oil $[6,7]$. The original shale oil in this study came from an in situ oil shale retort experiment conducted by the U.S.D.0.E. Laramie Energy Technology Center near Rock Springs, Wyoming, in late 1976. The fractions analyzed and their designations are dewatered shale oil (SO); residuum from upgrading distillation of shale oil (DR); heavy distillate from Hempel vacuum distillation of shale $011,200-300^{\circ} \mathrm{C}, 5300 \mathrm{~Pa}$ pressure (HD); light distillate from Hempel distillation, $106-200^{\circ} \mathrm{C}, 5300 \mathrm{~Pa}$ pressure (LD); naphtha from Hempel distillation, $50-200^{\circ} \mathrm{C}$, atmospheric pressure (NA); and waxes precipitating from heavy distillate as it is cooled from $25^{\circ} \mathrm{C}$ to $-23^{\circ} \mathrm{C}$ (WX).

For INAA a 11 irradiations were carried out at a flux of $1 \times 10^{14} \mathrm{ncm}^{-2} \mathrm{~s}^{-1}$. For the elements analyzed, the irradiation, decay, and counting times were, respectively, the following: $5 \mathrm{~s}, 15 \mathrm{~s}, 20 \mathrm{~s}$ (Se); $1 \mathrm{~min}, 3 \mathrm{~min}, 200 \mathrm{~s}$ (V, Al, S, I, As); and $1 \mathrm{~min}, 12 \mathrm{~min}$, $500 \mathrm{~s}(\mathrm{Br}, \mathrm{Mn}, \mathrm{Na}, \mathrm{Cl})$.

\subsection{Results and Significance of Shale 0il Study}

Table 3 shows the trace element contents of the shale oil fractions analyzed. As expected the elemental concentrations generally follow the trend $D R>H D>L D>N A$, reflecting accumulation in the less volatile fractions and residuum, The halides are apparent exceptions, suggesting that the lighter fractions should be analyzed for organohalide compounds. With the exceptions of $\mathrm{Al}, \mathrm{V}$, and $\mathrm{Na}$, the waxes are distinctly depleted in trace elements compared to the heavy distillate from which they precipitated. These waxes are paraffinic hydrocarbons $(>C-20)$ with little functionality capable of binding trace elements.

Table 3. Trace element contents of shale oil fractions.

\begin{tabular}{|c|c|c|c|c|c|c|}
\hline \multirow[b]{2}{*}{ El ement } & \multicolumn{6}{|c|}{ Trace element concentration (ppm) } \\
\hline & so & $\mathrm{DR}$ & $\mathrm{HD}$ & LD & $N A$ & $w X$ \\
\hline Al & 0.61 & 3.8 & 0.52 & 0.59 & 1.2 & 3.5 \\
\hline v & 0.11 & 0.18 & 0.001 & 0.0012 & 0.19 & 0.0034 \\
\hline S & $6.9 \times 10^{3}$ & $8.1 \times 10^{3}$ & $5.3 \times 10^{3}$ & $5.9 \times 10^{3}$ & $5.4 \times 10^{3}$ & $2.3 \times 10^{2}$ \\
\hline $\mathrm{Mn}$ & 0.08 & 0.14 & 0.11 & 0.16 & 0.013 & 0.09 \\
\hline I & 0.066 & 0.088 & 0.021 & 0.039 & 0.25 & 0.0062 \\
\hline $\mathrm{Cl}$ & 8.7 & 23 & 9.1 & 14 & 48 & 5.9 \\
\hline $3 r$ & 0.14 & 0.18 & 0.046 & 0.12 & 0.30 & 0.044 \\
\hline $\mathrm{Na}$ & 1.2 & $1.4 \times 10^{2}$ & 3.7 & 5.1 & 0.64 & 30 \\
\hline As & 4.6 & 11 & 4.4 & 1.4 &.- & 0.084 \\
\hline $\mathrm{Se}$ & 1.1 & 2.1 & 0.61 & 0.65 & 0.24 & 0.031 \\
\hline
\end{tabular}

${ }^{a}$ For letter designations of fractions, see Section 3.1 . 
4. Laboratory Tests of Fates of Trace Elements in In Situ Coal Gasification

4.1. The In Situ Coal Gasification Process

Underground, or in situ, coal gasification is a unique approach to the utilization of coal resources that cannot be exploited by conventional mining technology. The principles of in situ coal gasification are illustrated in Figure 3(A). The in situ process involves

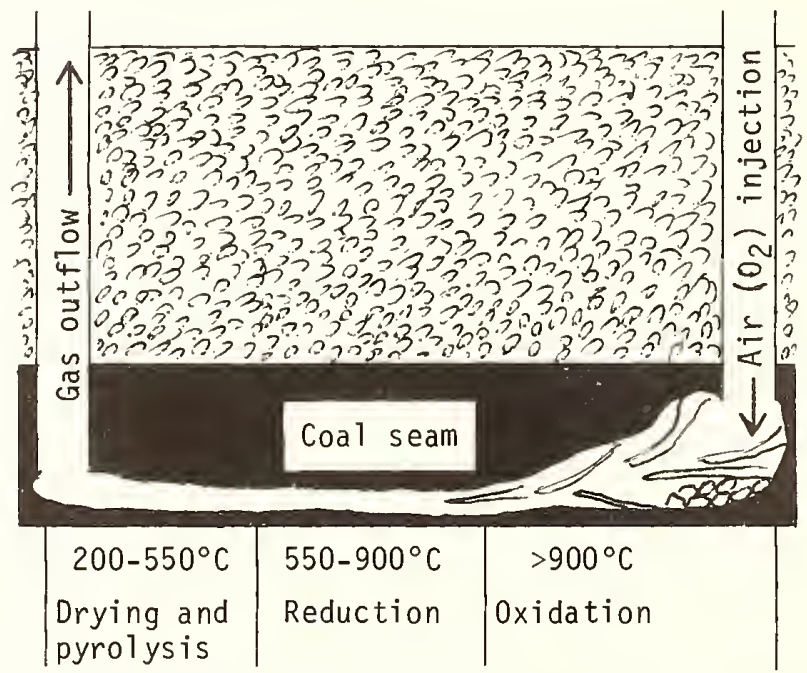

(A) In situ coal gasification

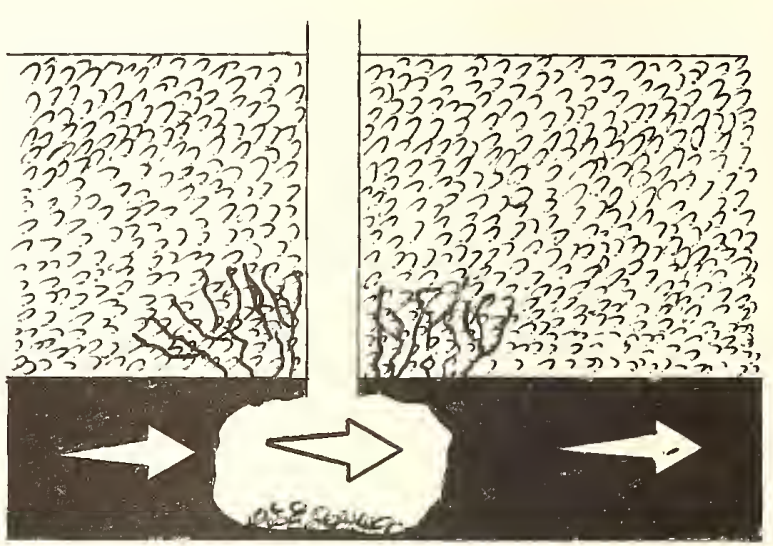

Natural ground- Ash leach- Plume of conwater flow ing taminated water

(B) Water contamination following gasification (end view of $(A)$ )

Figure 3. In situ coal gasification and plume of contaminated water therefrom.

combustion, gasification, and pyrolysis of coal between two wells drilled into a coal seam. oxygen from air or pure $\mathrm{O}_{2}$ injected into the injection well burns part of the coal and char to produce heat required for gasification. The main reaction producing combustible gas is between steam and hot carbon in char or coal:

$$
\mathrm{C}+\mathrm{H}_{2} \mathrm{O} \rightarrow \mathrm{CO}+\mathrm{H}_{2}
$$

Combustible methane gas is also produced, largely by pyrolysis of coal.

Many inorganic and organic byproducts are produced as a result of in situ coal gasification. The former includes soluble salts and gases, such as $\mathrm{NH}_{3}$ and $\mathrm{HCN}$. The latter includes literally hundreds of compounds, particularly aromatic compounds and phenols, as well as nitrogen and sulfur compounds. Byproduct species are mobilized in the vicinity of the cavity left by gasification by dissolution in infiltrating groundwater, as shown in Figure $3(B)$, and by transport through surrounding geological strata in the vapor form [8].

The fates of trace elements are particularly important in the case of in situ coal gasification because containment is largely dependent upon surrounding geological strata, and very few pollution control measures can be applied underground. Therefore, it is essential to have simple laboratory tests to determine the mobilization potential of trace elements. Figure 4 shows a simple apparatus for performing such tests. The operation of this device is discussed in Section 4.2 . 
4.2. Experimental Aspects of Simulated In Situ Coal Gasification Studies

The device used to simulate in situ

coal gasification shown in Figure 4 consists of a $1-\mathrm{cm}$ i.d., $12-\mathrm{cm}$ long silica tube connected to a trapping system for the removal of volatile byproducts from the gas product stream. Water-saturated air or $\mathrm{O}_{2}$ passes downward through a column of granular coal held in the tube. The coal can be gasified in either a forward or reverse burn mode to simulate forward and reverse burns in actual underground coal gasification. An initial reverse burn occurs when a flame front is initiated at the downstream (bottom) end of the column of coal. The flame front progresses upward counter to the flow of oxidant, leaving a residue of char containing approximately $3 \%$ methylene chlorideextractable coal tar. If allowed to continue, the flame front reverses direction at the top of the column and consumes the char in a "second forward" burn of char, leaving a sintered ash residue. An "initial forward" $\mathrm{H}_{2} \mathrm{O}$-saturated

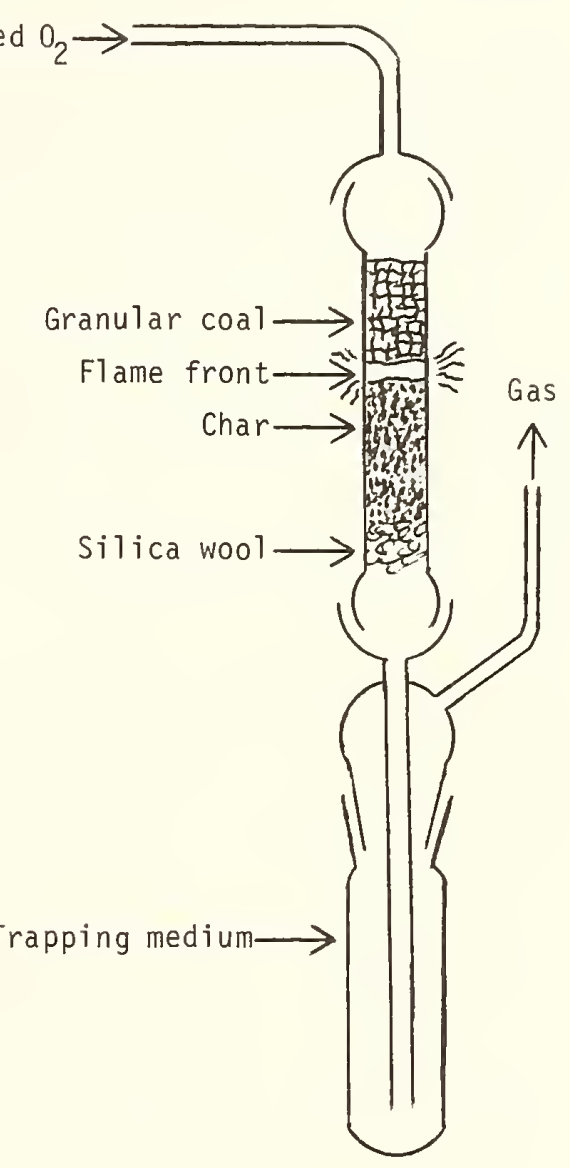

Figure 4. In situ coal gasification simlator. burn of coal can be carried out by initiating the flame front at the top of the coal column, such that it proceeds downward, completely consuming the coal and leaving a sintered ash residue. Because of the excesively high temperatures generated in a vertical forward burn, a modification in which the combustion tube is held horizontally is preferred for a forward burn.

This apparatus permits the collection of volatile products in traps containing organic and aqueous solvents; a train of several traps may be employed. Heavy tar that collects in the tube leading to the first trap may be collected. In addition, tar may be extracted from the char residue of a reverse burn. The char and ash may both be analyzed.

\subsection{Studies of Trace Elements in Simulated In Situ Coal Gasification}

The apparatus shown in Figure 4 enables rapid laboratory investigation of the fates of trace elements either inherent to the coal sample or spiked into it. Studies are currently underway to determine the degree of mobilization of trace metals spiked into subbituminous coal in various forms; the results will be reported in a later publication. An example of the type of useful information that may be obtained from the use of this 
apparatus has been cited [9]. In this case, the particular question to be answered was the possibility of conversion of inorganic chloride associated with coal to organochlorine compounds. To test this hypothesis, granular subbituminous coal was spiked with solutions of $\mathrm{NaCl}$ and $\mathrm{CaCl}_{2}$ and dried to give a product that was $0.5 \% \mathrm{Cl}$. This product and unspiked coal were subjected to separate reverse and initial forward burns; and the organic products collected in cyclohexane were subjected to gas chromatographic analysis employing electron capture detection of organochlorine compounds.

Figure 5 shows partial chromatograms of the organic byproducts of a reverse burn (A) and a forward burn (B) of $\mathrm{NaCl}$-spiked subbituminous coal employing electron capture detection. Both chromatograms were identical to those obtained with $\mathrm{CaCl}_{2}{ }^{-}$ spiked coal and unspiked coal. Thus, the presence of inorganic chloride had absolutely no effect upon the production of organochlorine compounds. In all cases only one major organochlorine peak, marked with an asterisk, was observed. Even this peak, as shown by comparison of chromatograms obtained with flame ionization detection represented a minor constituent compared to the other compounds present. Thus, it may be concluded on the basis of a simple laboratory

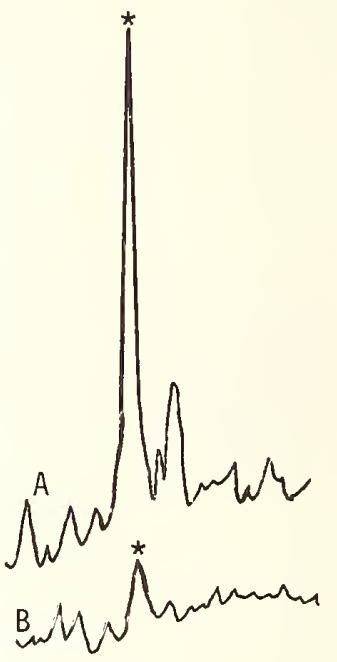

Figure 5. Chromatograms of the byproducts of a reverse burn (A) and a forward burn (B) of $\mathrm{NaCl}$-spiked subbituminous coal. test that a possible environmental problem with in situ coal gasification - incorporation of inorganic chloride into organochlorine byproduct compounds - does not in fact exist.

As shown in Figure 5, the quantity of the one significant organochlorine compound produced is much less for a forward burn than for a reverse burn. The same observation was made for nitrogen and sulfur compounds [9]. These observations are explained by the fact that during an initial forward burn tars are produced in a hydrogen-rich reducing atmosphere ahead of the flame front resulting in hydrogenation of molecules containing hetero atoms, with conversion of these atoms $(X)$ to their corresponding hydrides as shown in the reaction below:

$$
\text { (Organic) }-X+z\{H\} \rightarrow H_{z} X+\text { Hydrocarbon }
$$

\subsection{Conclusions}

As $i 17$ ustrated by the preceding examples, the many tools of analytical chemistry can be combined with an environmental chemical approach to predict, prove or disprove, and recommend corrective action for environmental problems related to trace elements in synthetic fuels manufacture. In many cases laboratory studies may be performed to provide satisfactory answers to some problems at a fraction of the cost and effort required to perform field 
investigations. Such laboratory studies are particularly useful in designing field analyses that will yield the maximum useful information.

An especially promising tool in determining trace element species mobilized as a result of synthetic fuels manufacture is the combination of gas or liquid chromatography with element-specific detection. In principle, chromatographic separations combined with inductively-coupled plasma atomic emission spectroscopy could provide such a tool [10]. Ideally, a "three-dimensional chromatogram" could be obtained giving a series of elements on different channels, with different species containing the same element on each individual channel of the plasma emission spectrometer output. In practice, elemental detection limits combined with the dilution inherent to chromatographic separations may preclude application of this technique to most samples of interest, but the promise of the method justifies continued research.

Helpful discussions involving aspects of this research were held with Richard Poulson and David Sheesley of the U.S.D.0.E. Laramie Energy Technology Center (LETC), Laramie, Wyoming. The in situ coal gasification studies were supported by U.S.D.O.E. Contract DEZ0 78L 00570 through LETC

\section{References}

[1] Manahan, Stanley E. Environmental chemistry, 3rd ed. Boston, Willard Grant Press, 490 p. 1979.

[2] Manahan, Stanley E. Coal chemistry: Aspects of analysis, structure, reactions, conversion, and byproducts. Proceedings of the third annual UMR-MEC conference on energy: $112-121 ; 1976$.

[3] Koppenaal, David W. Trace element studies on coal gasification process streams. thesis, University of Missouri - Columbia: 17, 1978.

[4] Manahan, Stanley E.; Poulson, Richard E.; Green John B; Farrier, David S. Coal humic substances and their application to pollution control in the synthetic fuels industry. LETC/RI-78/5, USDOE Technical Information Center, Oak Ridge, Tennessee,35p; 1978.

[5] Ting, Bill T.G. Study of mobilization and speciation of trace elements in coal pyrolysis. Ph.D. thesis, University of Missouri - Columbia, 152 p; 1979.

[6] Shaw, Peter G.; McKown, David; Manahan, Staniey E. Trace element determinations in shale oil products by neutron activation analysis. Anal. Chim. Acta. 123: 65-74; 1981.

[7] Shaw, Peter G. Analysis and characterization of trace elements in shale oil and shale oil products by instrumental neutron activation analysis. M.A. thesis, University of Missouri - Columbia, 109 p; 1978.

[8] Mead, S. W.; Wang, F. T.; Ganow, H. C.; and Stuermer, D. H. Environmental studies of underground coal gasification experiments in northeastern Wyoming. Livermore, California, Lawrence Livermore Laboratory, 380 p; 1981.

[9] Kapila, Shuhbender; Vogt, Corazon; Manahan, Stanley E. Chromatographic characterization of organic by-products of simulated in situ coal gasification. In Situ, 5: 25$42 ; 1981$.

[10] Fraley, David M.; Yates, Dennis A.; and Manahan, Stanley E. ICP-AES as a multiple element detector for metal chelates separated by HPLC. Submitted to App. Spec. 
Question (E. Jenne): Do you see a slug of mercury coming off initially in your retort?

Answer: We haven't looked for it. That's a good idea and it would be relatively simple to do. I think you could readily run the gas through a flameless mercury apparatus and just look for it.

Question (R. D. Stephens): In your model experiment, where you spiked the flame, what was the temperture you're talking about. Did you make any attempt to identify species?

Answer: We have tried to make some measurements on the flame front, but I wouldn't give any credence to the measurements. I cannot say what the temperature is there, but it's white hot. However, the transit time of the flame front through a particular zone is very short. It's hot enough to melt pyrex, but not hot enough to melt silica.

Question (R. D. Stephens): Pyrex melts down at what temperature, about $800{ }^{\circ} \mathrm{C}$ ?

Answer: I would imagine it is over $1000{ }^{\circ} \mathrm{C}$.

Question (R. H. Filby): What was the form of the organoarsenic species? Was it an oxidized species? An arsenate?

Answer: I believe that it was an arsenate salt that was added to the humic material which was then precipitated by acidification.

Question (R. H. Filby): And the inorganic form?

Answer: That was the arsenic sulfide. 


\author{
Speciation of Organic Compounds and Trace Elements \\ In 0 i 1 Shale Wastewaters \\ R. E. Sievers, M. K. Conditt, and J. S. Stanley* \\ Dept. of Chemistry and Cooperative Institute for \\ Research in Environmental Sciences,

$$
\begin{gathered}
\text { Univ. of Colorado, } \\
\text { Campus Box } 449 \\
\text { Boulder, C0 } 80309
\end{gathered}
$$

0il shale wastewaters are complex mixtures containing a large number of trace elements and organic ligands present at potentialiy significant concentrations. Speciation of the trace elements in these wastes is necessary in order to effectively evaluate possible environmental impacts. Speciation methods should include size fractionation measurements for trace elements and organic ligand identifications to fully account for possible complexes, both stable and labile. Ultrafiltration of $0 i 1$ shale wastewater has indicated that most trace elements exist as simple hydrated molecules or as labile complexes with organic ligands. Complexing measurements have shown that oil shale wastewaters contain significant concentrations of organic ligands that are capable of forming complexes with trace elements. The organic compounds that have been identified in this work as important ligands include substituted pyridines, quinolines, and anilines. The complexing ability measurements have indicated a correlation with the nitrogen base content in oil shale wastewaters from three different and distinct operations. Specific compounds, some of which form complexes, are toxic, and are biorefractory, have been identified.

Key words: alkylpyridines; dissolved organic compounds; gas chromatography/mass spectrometry; hydrophobic bases; metal complexation; nitrogen bases; oil shale; retort water; speciation; trace metals.

\title{
1. Introduction
}

Industrial wastewater quality studies have traditionaliy been focused on the measurement of potentialiy toxic trace elements and process-derived organic compounds. Typicaliy, measurements of the total concentrations of particular analytes (inorganic or organic) have been used to assess likely environmental impacts of new industrial activities. However, it

\footnotetext{
*Present address: Analytical Chemistry Dept., Midwest Research Institute, Kansas City, MO 64110.
} 
has been realized that the biological availability, toxicity, and transport of toxic trace elements can be influenced by interaction with complexing organic compounds. The advent of a large synthetic fuels program, in particular oil shale development, has been accompanied by recognition of the need to learn as much as possible about the speciation of toxic trace elements and organic ligands in solid and aqueous wastes. Wastewaters derived from processing raw oil shale have relatively high concentrations of dissolved solids and contain toxic trace elements at varying concentrations depending on the particular process or retort conditions. $0 i 1$ shale wastewaters or retort waters are also characterized by high concentrations of dissolved organic compounds, some of which are relatively strong complexing agents with nitrogen and oxygen functionalities [1].

Because many metal ions are substitutionally labile [2], attempts to speciate complexes which are likely to be present can usually only be successful if the overall mixture of potential complexing agents is examined. Only for a limited number of substitutionally inert complexes in which ligand exchange occurs slowly is it possible to isolate or identify a discrete complex stable enough to be characterized without dissociation or alteration in the process of probing or isolating it. Many metal complexes are in very rapid equilibrium with numerous 1 igands in the complex retort waters. Ligand exchange rates are of the order of milliseconds for most of these metal complexes, even though stability constants may be high and the predominant species determine or influence mobility, toxicity, bioavailability, etc. [2]. Since some complexes cannot be isolated without altering the species and the equilibrium, the wisest strategy is to learn as much as possible about the identities and concentrations of the ligands present and couple this information with knowledge of metal coordination chemistry to assess what form the complexes will likely assume. The more inert complexes can be studied by direct isolation and characterization.

The organic compounds or ligands that are of primary concern in this investigation are the heterocyclic nitrogen compounds and aromatic amines that are found in the basic extracts of crude shale oil. These types of compounds have been shown to partition into retort wastes and a number of nitrogen bases have been isolated and identified by Stanley $[3,4]$, Caolo et al. [5,6], Stuber [7], and Fish [7a] has identified arsenic species. These compounds are of interest because of potential interaction with toxic trace elements as complexing ligands and because fractions of crude shale oils containing nitrogen bases exhibit mutagenic activity [8], and tend to be bio-refractory [9].

\section{Results and Discussion}

Due to the complexity of the oil shale wastewaters, several approaches were required to attack the problems of identifying toxic trace element-organic ligand interactions. The analytical techniques included physical separation by membrane ultrafiltration, and pre-separation of constituents in the complex wastewaters by macroreticular and ionexchange resins. Toxic trace element concentrations were measured by high temperature graphite furnace atomic absorption spectrometry and inductively coupled plasma emission spectrometry. The nitrogen base organic ligands were identified by extracting the macroreticular resins and analyzing the concentrated extracts by high resolution, fused-silica, 
capillary chromatography with flame ionization detection, nitrogen-phosphorous selective detection, and mass spectrometry. The distribution of dissolved organic carbon in various fractions was determined with a total organic carbon analyzer, and the complexing ability of organic ligands in three different oil shale wastewaters was estimated by two methods $[3,4,18]$. The analytical procedures have been discussed in more detail by Stanley et al. $[3,4]$. The oil shale wastewaters examined during these studies included retort water from a true in-situ retort, a modified in-situ retort, and an above-ground retort. The collection and history of each of these samples has been recorded by several authors $[3,4,10-14$. It should be emphasized that these wastewater samples may not be indicative of an actual process or technology that will be used to commercially produce shale oil; however, they probably contain many of the compounds expected to contaminate water. The designations are for purposes of identification only, and should not be construed as indicating that water from one process is more or less polluted than from another. In the case of the true in-situ process, there was substantial dilution by groundwater.

2.1 Ultrafiltration Membrane Separation

Size fractionation by ultrafiltration has been used to study the distribution of several trace elements in a true in-situ retort water. Florence and Batley [15] as well as Hoffman et al. [16] have recently demonstrated the importance of this technique in studying trace element distrubutions in natural water systems. Size fractionation can be used to identify whether a toxic trace element is present in particulate matter $(>0.45 \mathrm{jm}$ diameter), adsorbed on organic or inorganic colloids (10-500 nm in diameter), or differentiated as stable organic or inorganic complexes (1-4 nm in diameter). Simple hydrated metal ions are separated and characterized as species that are less than $1 \mathrm{~nm}$ in diameter.

The ultrafiltration membranes used in this experiment were selected to separate compounds at molecular weight intervals of 500, 1000, 10,000, 20,000,30,000, and 50,000. The results from this experiment should not be interpreted as indicating the presence of compounds in this molecular weight range but, rather, should be considered as molecules that may pass through membrane pore sizes of less than $5.1 \mathrm{~nm}$ to less than $1.0 \mathrm{~nm}$. The true in-situ retort water used for this experiment has been previously filtered through a 0.45 micron cellulose acetate Millipore filter prior to introduction into the ultrafiltration cell. Each of the filtered solutions was analyzed for fifteen elements by inductively coupled plasma emission spectrometry, and by graphite furnace atomic absorption spectrometry for arsenic and selenium $[3,4]$.

The trace element analysis of the fractionated samples indicated that a large percentage of strontium, magnesium, and iron exist as fairly large molecules or are adsorbed onto particulate matter that cannot pass through the pores of a 0.45 micron Millipore filter. Concentrations of arsenic and silicon were also noted to decrease during this filtering step.

Very little other size fractionation was noted for any of the elements studied in this experiment with the exception of iron which did seem to show approximately a $50 \%$ difference between the ultrafiltration membrane equivalent to 20,000 molecular weight units 
and the membrane that allows molecules of less than approximately 10,000 molecular weight units or $1.9 \mathrm{~nm}$ in diameter to pass.

These results indicate that the majority of trace elements studied in this retort water exist as smali, simple ions not associated strongly with high"molecular weight compounds, with the possible exception of iron, or are readily dissociated. It is possible that the trace elements identified as small, simple hydrated ions in the smallest size fractions may actually exist as labile complexes with organic ligands in solution. Iron, magnesium, silicon and strontium removed by a 0.45 micron filter are possibly present as various mineral forms or, in the case of iron, as a hydrous oxide.

\subsection{Adsorbent Separation}

Three different oil shale wastewaters were fractionated by adsorption on macroreticular and ion-exchange resins by a procedure described by Leenheer and Huffman [18]. Hydrophobic solutes are adsorbed on Amberlite XAD- 8 resins and fractionated according to class by controlling the $\mathrm{pH}$ of each wastewater; hydrophilic solutes are concentrated on the ion exchange resins. The cation and anion exchange rosins allow a class fractionation of basic and acidic hydrophilic solutes, respectively. Trace element analyses were conducted for aliquots of the wastewater collected after elution through each resin (Table 1 )

The results from these experiments should not be interpreted as the isolation of metal-organic ligand complexes from the original wastewaters. Acidification of the retort water causes drastic changes in the aqueous chemistry. One of the most obvious changes occurs in the sulfur speciation of the retort waters. Thiosulfate is a major sulfur species in oil shale wastewaters and upon acidification results in the precipitation of copious amounts of elemental sulfur. The organic acids are also precipitated, as evidenced by their removal on the surface. Selenium, cobalt, lithium, and copper were removed after acidification by the second XAD-8 column that also removes organic solutes classified as hydrophobic acids. The cation exchange resin, AGMP-50, was effective for removing calcium, barium, manganese, and magnesium from eluent of the second XAD- 8 resin and molybdenum remaining in solution was effectively removed on passage through the AGMP-I anion exchange resin.

Arsenic did not behave the same in the three different water sampies. In the true in-situ retort water, $90 \%$ of the arsenic was removed by the final adsorbent column, the AGMP- $]$ anion exchange resin, indicating arsenic was present as a simple anionic species. Very little difference in arsenic concentration in the modified in-situ retort water was observed between the original water and the water collected at the end of the total fractionation scheme. The above ground retort water shows almost a $50 \%$ loss upon passing through the second XAD- 8 resin after acidification, but greater than $3 \mu \mathrm{g} / \mathrm{mL}$ of arsenic remained in the final solution.

The loss of selenium from the oil-shale retort water after acidification and passage through the second XAD-8 column is also very interesting. Leenheer and Huffman [18] studied a natural water that contained high concentrations of selenium using the adsorbent separation scheme; the selenium in the water was not reduced in concentration until it had passed through the anion exchange resin. However, the concentration of selenium was reduced significantly in the retort water following acidification and passage of the water 


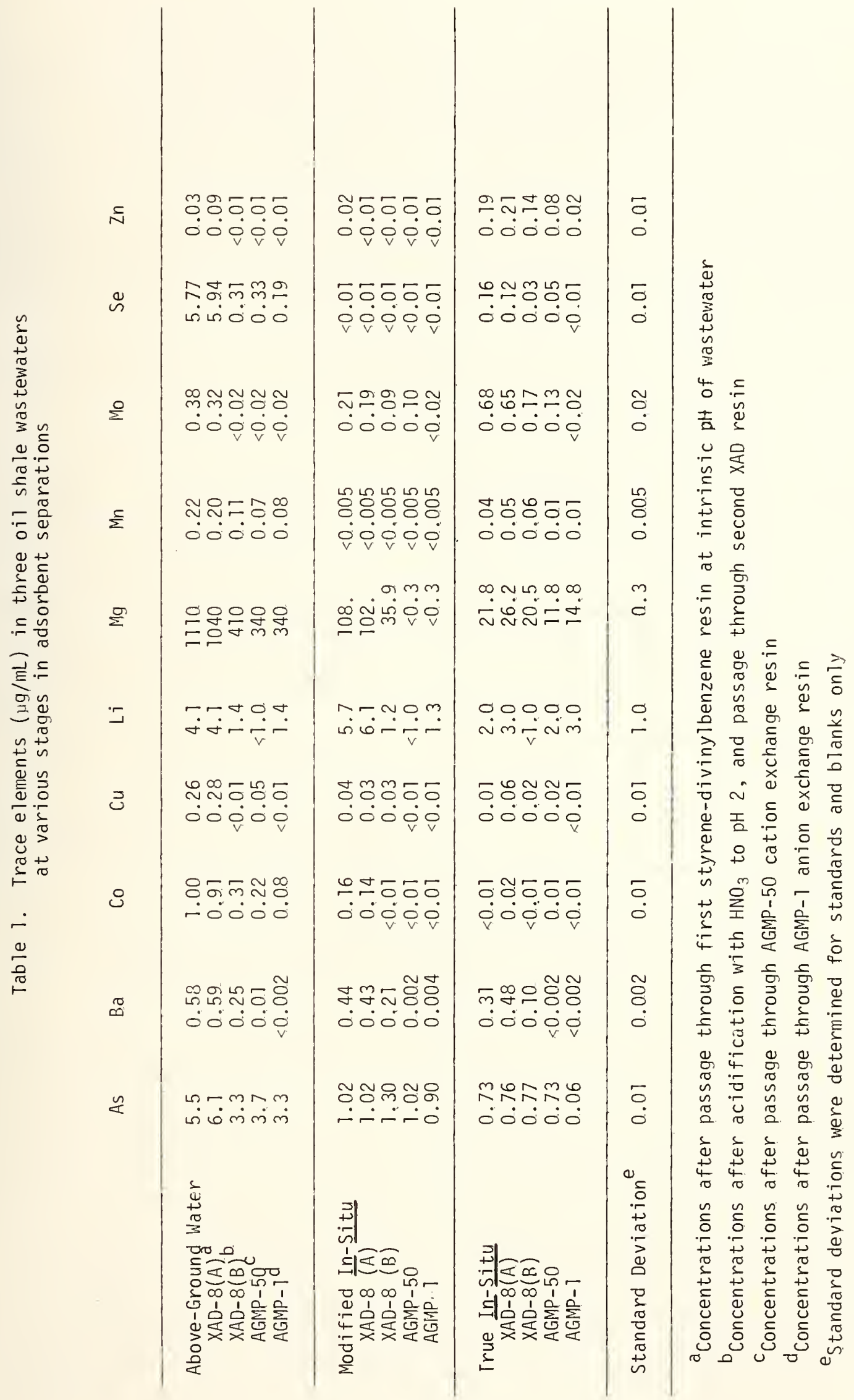


through the second XAD- 8 adsorbent. This suggests that the form of the selenium is different in retort waters than that in the creek water studied by Leenheer and Huffman.

2.3 Dissolved Organic Carbon Distribution and Complexing Ability Measurements

The oil shale wastewaters were further characterized by determination of the distribution of the total organic carbon content. Table 2 presents the data for hydrophobichydrophilic solute distribution and a breakdown of each major classification into acid, base and neutral subfractions, as well as an estimation of the complexing ability of each of the three wastewaters. Compounds classified as hydrophobic were removed by adsorption on XAD- 8 resins, while hydrophilic compounds were removed by ion exchange resins.

Table 2. Distribution of the dissolved organic carbon (DOC) content of three oil shale wastewaters and complexing capacity measurements

\begin{tabular}{|c|c|c|c|c|c|c|c|c|}
\hline \multirow{2}{*}{$\begin{array}{l}\text { Oil shale } \\
\text { Wastewater } \\
\text { Samples }\end{array}$} & \multirow{2}{*}{$\begin{array}{l}\text { Total } \\
\text { DOC } \\
(\mu \mathrm{g} / \mathrm{mL})\end{array}$} & \multicolumn{3}{|c|}{ Hydrophobic Solutes } & \multicolumn{3}{|c|}{ Hydrophilic Solutes } & \multirow{2}{*}{$\begin{array}{l}\text { Complexing } \\
\text { Ability } \\
\text { ( } \mu \mathrm{g} \mathrm{Cu/ml})\end{array}$} \\
\hline & & Acids & $\begin{array}{r}\mu \mathrm{g} / \mathrm{mL} \text { ) } \\
\text { Bases }\end{array}$ & Neutrals & Acids & $\begin{array}{l}(\mu \mathrm{g} / \mathrm{ml} \\
\text { Bases }\end{array}$ & Neutrals & \\
\hline $\begin{array}{l}\text { Above } \\
\text { ground }\end{array}$ & 41,900 & $\begin{array}{l}21,800 \\
(52 \%)\end{array}$ & $\begin{array}{l}2280 \\
(5 \%)\end{array}$ & $\begin{array}{l}5720 \\
(14 \%)\end{array}$ & $\begin{array}{l}1940 \\
(5 \%)\end{array}$ & $\begin{array}{l}5690 \\
(13 \%)\end{array}$ & $\begin{array}{l}4770 \\
(11 \%)\end{array}$ & $570 \pm 30$ \\
\hline $\begin{array}{l}\text { Modified } \\
\text { In-Situ }\end{array}$ & 2300 & $\begin{array}{l}630 \\
(27 \%)\end{array}$ & $\begin{array}{l}70 \\
(3 \%)\end{array}$ & $\begin{array}{l}420 \\
(18 \%)\end{array}$ & $\begin{array}{l}390 \\
(17 \%)\end{array}$ & $\begin{array}{l}<5 \\
(<1 \%)\end{array}$ & $\begin{array}{l}810 \\
(35 \%)\end{array}$ & $8.6 \pm 0.4$ \\
\hline $\begin{array}{l}\text { True } \\
\text { In-Situ }\end{array}$ & 1000 & $\begin{array}{l}190 \\
(19 \%)\end{array}$ & $\begin{array}{l}130 \\
(13 \%)\end{array}$ & $\begin{array}{l}170 \\
(17 \%)\end{array}$ & $\begin{array}{l}290 \\
(29 \%)\end{array}$ & $\begin{array}{l}120 \\
(12 \%)\end{array}$ & $\begin{array}{l}100 \\
(10 \%)\end{array}$ & $42 \pm 2.1$ \\
\hline
\end{tabular}

${ }^{a}$ Complexing ability measurements were made according to the procedure described by Manahan and Jones [19].

${ }^{b}$ Values in parenthesis represent percentage of total DOC.

${ }^{C}$ DOC values for the true in-situ water, reported by Leenheer and Huffman [18].

The complexing ability determinations for the three wastewaters were accomplished by following a procedure described by Manahan and Jones [19]. This technique involves the measurement of copper complexes in solution at pH 10. If no complexing ligands are present, the copper concentration would be less than $0.1 \mu \mathrm{g} \mathrm{Cu} / \mathrm{mL}$ due to precipitation of copper as copper hydroxide. The results in Table 2 indicate that each of the three wastewaters contain substantial amounts of complexing ligands that might influence the fate and transport of various trace elements. The order of complexing ability is above-ground $>$ true in-situ >modified in-situ wastewater. This is the same order noted for the concentrations of the basic components in the wastewaters. By contrast, there is no correlation of dissolved organic carbon concentrations with complexing ability. This suggests that important complexing agents exist in the hydrophobic base fraction, so the study focussed on the 
ligands present in that fraction.

2.4 Gas Chromatography/Mass Spectrometry Identification of Nitrogen Bases:

After the organic solutes from the oil shale wastewaters were separated into subclasses, the fractions were subjected to high resolution fused silica column gas chromatography coupled with mass spectrometry to identify as many individual compounds as possible. Identification of the nitrogen base compounds in the hydrophobic base fraction (Figure 1) was based upon examining fragmentation patterns of each peak in the chromatograms and matching of retention times of pure compounds on the SE-52 silicone coated capillary column. Methylene chloride solutions (splitless injection, $2 \mu \mathrm{L}$ ) stripped from the sorbent were analyzed with the column temperature programmed from 30 to $270^{\circ} \mathrm{C}$ at $4^{\circ} \mathrm{C}$ per minute. The peaks numbered in Figure 1 are identified in Table 3.

The differences in nitrogen base content in the three different wastewaters becomes apparent when the chromatograms in Figure 1 are compared. The true in-situ retort water has a more even distribution of pyridines, anilines, and quinoline compounds. By contrast, more quinoline compounds than pyridine or aniline analogs were identified in the extract from the modified in-situ retort water, while the above ground process water contains substantially greater amounts of substituted pyridines and simple anilines than quinoline derivatives. The above-ground process water also appears to contain more high boiling compounds than either the true in-situ or the modified in-situ retort waters. Compounds that have been identified by mass spectra and/or retention time in these three samples are given in Table 3 .

Each of the wastewaters contains 2,4,6-trimethylpyridine, which has been identified positively through mass spectra and retention time comparisons. Other compounds in these samples also exhibit similar fragmentation patterns, indicating that the other trimethylpyridine isomers are present. Van Meter et a]. [20] have identified the 2,3,5-,2,3,6-, 2,4,5- and 2,4,6-trimethylpyridine isomers in crude shale oils through distillation and formation of pyridine derivatives. The 2,4-,2,3-, and 2,5-dimethylpyridine isomers have been identified in the wastewaters and these plus the 2,6-, 3,4-, and 3,5-dimethyl isomers were also identified in the crude shale oils [20]. More extensively alkylated isomers of pyridines have also been tentatively identified $\left(\mathrm{C}_{4}-\right.$ and $\mathrm{C}_{5}$-alkyl substituted). Alky1substituted isomers, such as those with propyl, butyl, or pentyl groups have been reported [21] to be present in crude shale oils, but have not been previously observed in the aqueous waste. We have identified acridine, a known mutagen [22], in one sample of oil shale wastewater by both chromatographic retention time comparisons as well as mass spectrometry.

Aniline compounds have been previously reported to be present in crude shale oils by Brown et a1. [21] The extraction of these nitrogen compounds with XAD-8 resin from retort waters has been described by Stuber [7], who used HPLC techniques to identify several simple isomers. 

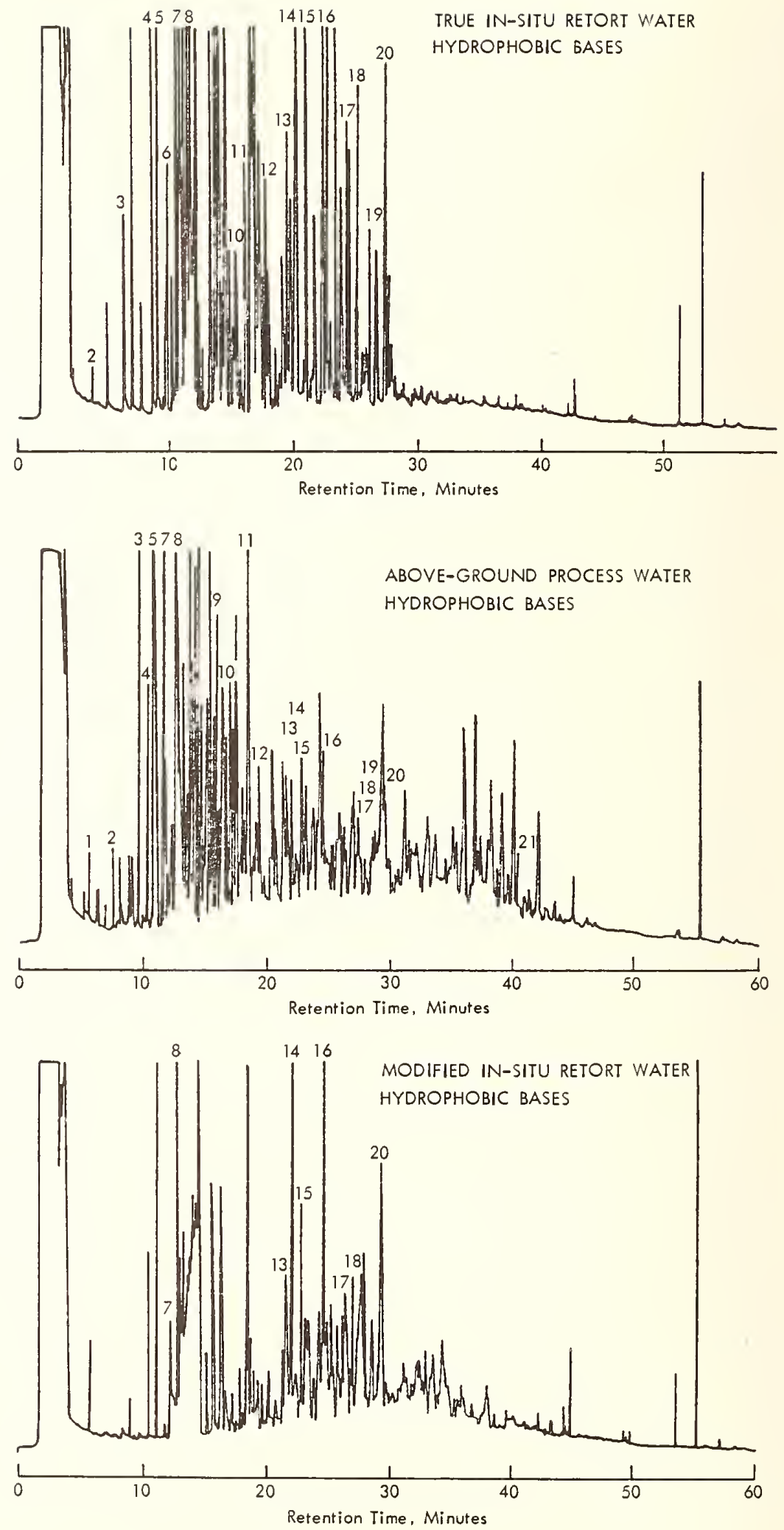

Fig. 1. Silica Capillary Chromatograms of Fractions of Various $0 i 1$ Shale Wastewaters 
Table 3. Nitrogen base compounds identified in the hydrophobic base fractions of three oil shale wastewaters.

\begin{tabular}{|c|c|c|c|c|c|c|c|}
\hline \multirow[t]{2}{*}{ Peak no. } & \multirow[t]{2}{*}{ Compound } & \multicolumn{2}{|c|}{ True In-Situ } & \multicolumn{2}{|c|}{ Modified In-Situ } & \multirow{2}{*}{$\begin{array}{l}\text { Above- } \\
\text { Ground } \\
\text { GC }\end{array}$} & \multirow[b]{2}{*}{ MS } \\
\hline & & GC & MS & GC & MS & & \\
\hline 1 & pyridine & $x$ & & & & $x$ & \\
\hline 2 & 2-methylpyridine & $x$ & $x$ & & & $x$ & \\
\hline 3 & 3-and/or 4-methylpyridine & $x$ & $x$ & & & $x$ & $x$ \\
\hline 4 & 2,4-dimethylpyridine & $x$ & $x$ & & & $x$ & $x$ \\
\hline 5 & 2,5-dimethylpyridine & $x$ & $x$ & & & $x$ & $x$ \\
\hline 6 & 2,3-dimethy lpyridine & $x$ & $x$ & & & & \\
\hline 7 & aniline & $x$ & $x$ & $x$ & $x$ & $x$ & $x$ \\
\hline 8 & $2,4,6$-trimethy 1 pyridine & $x$ & $x$ & $\mathrm{x}$ & $x$ & $x$ & $x$ \\
\hline 9 & N-methylaniline & & & & & $\mathrm{x}$ & $\mathrm{x}$ \\
\hline 10 & $\mathrm{~N}, \mathrm{~N}$-dimethylaniline & $x$ & & & & $x$ & $x$ \\
\hline 11 & N-ethylaniline & $x$ & & & & $x$ & $x$ \\
\hline 12 & 2,4-dime thylaniline & $x$ & $x$ & & & $x$ & $x$ \\
\hline 13 & $N$, iv-diethylaniline & $x$ & $x$ & $x$ & $x$ & $x$ & $x$ \\
\hline 14 & quinoline & $x$ & $x$ & $x$ & $x$ & $x$ & $x$ \\
\hline 15 & isoquinoline & $x$ & $x$ & $x$ & $x$ & $x$ & $x$ \\
\hline 16 & 2-methylquinoline & $x$ & $x$ & $x$ & $x$ & $x$ & $x$ \\
\hline 17 & 7-methylquinoline & $x$ & $x$ & $x$ & $x$ & $x$ & $x$ \\
\hline 18 & 3-methylquinoline & $x$ & $x$ & $x$ & $x$ & $x$ & $x$ \\
\hline 19 & 2,6 -and/or 2,7-dimethylquinoline & $x$ & $x$ & & & $x$ & $x$ \\
\hline 20 & 2,4-dimethylquinoline & $x$ & $x$ & $x$ & $\mathrm{x}$ & $x$ & $x$ \\
\hline 21 & acridine & & & & & $x$ & $x$ \\
\hline
\end{tabular}

$G C=$ identification by matching retention time of pure compound and demonstrating response to a nitrogen phosphorous selective detector.

MS = identification by comparing mass spectrum of eluent peak with that of known standard.

$X=$ denotes evidence of presence in the sample.

Other organic ligands that have been identified in the three wastewaters have included carboxylic acids and phenols, which are also recognized as complexing ligands.

3. Summary

In summary, several organic compounds have been identified in oil shale wastewaters that are known to be complexing agents [23,24] and may affect the mobilization and toxicity of trace elements. Phenols, carboxylic acids, alkyl pyridines, quinoline, isoquinoline, alkylquinolines, and acridine have been identified in wastewaters. Whether mobilization of toxic substances actually occurs under the various conditions that may exist in the field remains to be learned. 
The authors are grateful for the assistance and counsel of Robert Meglen and Robert Barkley. We also wish to acknowledge the advice and cooperation of Willard Chappell, Ralph Franklin, and Art Hartstein. The research was sponsored in part by the Department of Energy Contract DE-AC02-79EV10298 with the University of Colorado. J.S.S. Was the recipient of a Colorado Energy Research Incentive Program Fellowship and M.K.C. was awarded a Mining and Mineral Resources Research Center Fellowship.

\section{References}

[1] Chaberek, S., Marte11, A. E., Organic sequestering agents. John Wiley and Sons, Inc.; 12 p. 1959.

[2] Fredy, C. M. and Stuehr, J., Metal ions in biological systems. New York: Marcel Dekker, Inc.; vol. 1, 69 p. 1974.

[3] Stanley, J. S., Conditt, M. K., and Sievers, R. E., Trace elements and organic 1igands in oil shale wastes; 0il shale: Environmental research and coordination, W. Chappe11, ed., U. S. Dept. of Energy, Contract No. DOE 10298-2.

[4] Stanley, J. S., Investigations of trace elements and organic ligands; 0 il shale wastes, Ph.D. Thesis, University of Colorado, 1981.

[5] Caolo, M. A., Stanley, J. S., Swanson, D., Conditt, M. K., Sievers, R. E., Trace elements in oil shale, C00-10298-1, 1980; p. 294.

[6] Caolo, M. A., Sievers, R. E., Stanley, J. S., Trace elements in oil shale, Co04017-3, 1979; pp. 265-300.

[7] Stuber, H. A., Selective concentration and isolation of aromatic amines from water, Ph.D. Thesis, University of Colorado, Boulder; 1980.

[7a] Fish, R. H., Speciation of trace organic ligands and inorganic and organometallic compounds in oil shale process waters, J. H. Gary, ed., Proc. 13th 0 il Shale Symp., Golden, Colo.; 1980. p. 395.

[8] Gruen, M. R., Epler, J. L., and Gehrs, G. W., ORNL/RM 6390.

[9] Riley, R. G., Garland, T. R., Shiosaki, K., Mann, D. C., and Wilding, R. E., Environ. Sci. Tech. $15(6)$ : $697 ; 1981$.

[10] Wildeman, T. R., Laffoon, A. M., Dahlin, K., Ramsey, D., Trace elements in oil shale, C00-10298-1, 1980; pp. 113-175.

[11] Fruchter, J. S. Wilkerson, C. L., Evans, J. C., and Sanders, R. W., Environ. Sci. Tech. 14: $1374 ; 1980$.

[12] Fruchter, J. S., Wilkerson, C. L., Evans, J. C., Sanders, R. W., and Abe1, K. W., Source characterization studies at the paraho Semiworks 0 il Shale Retort, DOE/EY76-C-06-1830; May 1979.

[13] Farrier, D. S., Poulson, R. E., Skinner, 0. D., Adams, J. C., and Bower, J. P., Proc. 2nd Pac. Chem. Eng. Cong., Denver, Colo.; 1031 p. 1977.

[14] Flair, J., Goldstein, G., Grua, C., Smith, D., and Franklin, R., Environmental research on a modified in-situ oil shale process: A progress report from the oil shale task force, DOE/EV-0078; May 1980.

[15] Florence, T. M., and Batley, G. E., CRC Critical reviews in analytical chemistry, 9: $219 ; 1980$. 
[16] Hoffman, M. R., Yost, E. C., Eisenreich, S. J., and Maier, W. J., Environ, Sci, Tech., $15: 655 ; 1981$.

[17] Bailey, R. A., Clarke, H. M., Ferris, J. P., Krause, S., and Strong, R. L., Chemistry of the environment, New York: Acad. Press; 1976

[18] Leenheer, J. A., and Huffman, E. W. D., J. Res. U. S. Geol. Surv. , 4:737; 1976.

[19] Manahan, S. E., and Jones, D. R., Anal. Lett., 6:745; 1973.

[20] Van Meter, R. A., Bailey, C. W., Smith, J. R., Moore, R. T., Allbright, C. S., Jacobson, I. A., Hilton, V. M., and Ba11, J. S., Anal. Chem., 24:1758; 1952.

[21] Brown, P., Earnshaw, D. G., McDonald, F. R., and Jensen, H. B., Anal. Chem., 42:146; 1970.

[22] Lenninger, A. L., Biochemistry, New York: Worth Publishers; 653 p. 1972.

[23] Merte1, H. E., Mizzoni, R. H., Shaw, E. N. Tennenbaum, L. E., Yule, H. L., Pyridine and its derivatives, Part Two, E. Klingsberg, ed., New York: Interscience Publishers, Inc.; 1961.

[24] Tanaka, M., J. Inorg. Nuc1. Chem., 36:151; 1974.

Discussion

Question (E. Jenne): We made a fairly extensive effort about a year and a half ago to use the Leenheer scheme [Leenheer and Huffman, J. Res. U.S. Geol. Surv. 4: 737 (1976)], and in spite of extensive washing, we found so much residue came off with the sodium hydroxide wash that analyses were not meaningful. Did you have a problem with that?

Answer: We have not had a problem with that. I don't know whether it's related to the fact that we are using the new fused silica columns; however, we did have some problems with the older glass columns.

Question (E. Jenne): I'm speaking of the bleed from the macroreticular resin bed.

Answer: I can't say that we've had that problem. I thought you meant in high resolution chromatography. How did it show up? As degradation products?

Comment (S. E. Manahan): I might make a comment about that question. We have tried the Leenheer scheme with the typically contaminated water samples from in situ coal gasification. We have not had very good success. I think it works pretty well on some types of samples. We are in the process of developing a solvent extraction scheme using methylene chloride. If anybody is interested in trying this solvent extraction scheme, we'd be happy to send you the procedure. 
Answer (R. Sievers): Let me make another comment about the qualitative observation that as you go through the different steps in the Leenheer-Huffman cleanup, you'11 notice that the odor of the tar water changes markedly. In the case of the 0ccidental and the 0mega 9 waters, these became virtually colorless and odorless. Clearly, with the 100 or 200 compounds that I showed in the chromatograms, it's clear we are getting compounds back off of the resins as well.

Question (F. E. Brinckman): For other polar molecules besides gases such as Co, that you showed in the atmosphere sample, could you use this selective EC sensitization detection method? For example, could you see trace organometals? Has anybody done much with this?

Answer: That's an interesting proposal. I don't think anyone has tried using the sensitized electron capture for organometals; it should be tried. 
K. B. Olsen, C. L. Wilkerson, A. P. Toste, and D. J. Hayes

Pacific Northwest Laboratory operated by Battelle

Richland, WA 99352

This paper describes and discusses methods applied to the fractionation of trace metals in shale oil by silica gel and alumina chromatography and the fractionation of retort waters by $C_{18}$ partition chromatography. Direct current plasma emission spectroscopy was used to analyze $\mathrm{Fe}, \mathrm{Ni}, \mathrm{Cu}$, and $\mathrm{Mo}$ in the oi $1 \mathrm{~s}$ and $\mathrm{B}, \mathrm{Zn}, \mathrm{Mo}, \mathrm{Fe}$, and $\mathrm{Mn}$ in the waters. Instrumental neutron activation analysis (INAA) was used for the determination of arsenic in the oils. In the silica gel separation most of the metals eluted in two fractions corresponding to the moderately polar and highly polar fractions of the oil. In contrast, nickel eluted in the slightly polar fraction of the oils. Further separation of the nickel-enriched fraction on alumina yielded a fraction rich in nickel-porphyrin type compounds, ore of which was tentatively identified as Abelsonite porphyrin. Following $C_{18}$ Sep-pak fractionation of the retort waters, boron and manganese remained associated with the aqueous, or hydrophilic, fraction. Portions of the zinc, molybdenum and iron partitioned in the hydrophobic organic fraction of the retort waters.

Key words: chromatography; direct current plasma; hydrophi1ic; hydrophobic; metal complex; porphyrin; shale oil; speciation; trace metals.

\section{Introduction}

Considerable interest presently is being placed upon the speciation of trace metal contaminants in shale oils and retort waters from various retorting technologies including both aboveground and in situ processes. The significance of this interest is related to: (1) the potential for the trace metals to act as catalytic poisons during the refining process of the oil; (2) the choice of an appropriate waste water treatment facility; and (3) the direct impact of metals on the environment if shale oil is used as a boiler fuel.

Average trace metal concentrations present, in decreasing order, in shale oils are iron, arsenic, nickel, cobalt, molybdenum, silicon, selenium, vanadium, nickel, cadmium, and copper [1]. The major differences are quickly noted when comparing oils processed by aboveground and in situ retorting processes: (1) much higher concentrations of arsenic in the aboveground oils and (2) much higher concentrations of molybdenum contained within the in situ shale oils. 
The oxidation state of the metals contained within the shale oil and retort water matrices is of considerable interest due to the effect on the refining process and their mobility and toxicity in the environment. A well-known example is the comparison of $\mathrm{As}^{3+}$ to $\mathrm{As}^{5+}$. It has been empirically determined that $\mathrm{As}^{3+}$ is much more toxic to biota than its $\mathrm{As}^{5+}$ counterpart [2].

Retort waters co-produced with the shale oil during retorting are of special interest since they come in direct contact with shale oil and have a tendency to extract the hydrophilic compounds from the oils. High concentrations of arsenic ( 1 to $20 \mathrm{ppm}$ ) and boron (10 to $100 \mathrm{ppm}$ ) have been measured in some retort waters. Arsenic speciation studies have confirmed the presence of methylarsonic acid, phenylarsonic acid, and arsenate anions in the retort waters $[3,4]$. There is also interest in determining if the trace metals are associated with the hydrophobic organic fraction of the retort waters. This information, when applied to modeling of trace metal migration in ground water, will give a more accurate estimate of migration rates for these metals.

\section{Experimental}

\section{$2.10 \mathrm{i} l \mathrm{~s}$}

Two oils representing different retorting technologies were chosen to be fractionated on silica gel. Retort $A$ represents an aboveground retorting process and Retort $B$ represents a vertical modified in situ process. The oils were centrifuged for $60 \mathrm{~min}$ at $4100 \mathrm{G}$ followed by filtration with nitrogen through $0.45 \mu \mathrm{m}$ nuclepore membrane filter using a Millipore filtering aparatus. This procedure was carried out at $37{ }^{\circ} \mathrm{C}$ due to the high pour point of Green River retort shale oil.

A $19 \mathrm{~mm}$ i.d. $x 450 \mathrm{~mm}$ column was loaded with activated silica gel (heated $4 \mathrm{~h}$ at $120^{\circ} \mathrm{C}$ ) in hexane. One gram of filtered shale oil was dissolved in a minimal amount of hexane and loaded onto the column. The complete elution scheme is shown in Figure 1. Twenty-nine $75 \mathrm{~mL}$ fractions were collected. Each fraction was evaporated to dryness, weighed, and redissolved in $10 \mathrm{~mL}$ of methylene chloride for determination of nickel, chromium, iron and molybdenum by direct current plasma emission spectroscopy (DCP). Subsequently, an aliquot of the silica gel Fraction 9 of Retort B crude oil was dried, weighed, and redissolved in $2 \mathrm{~mL}$ of toluene then loaded onto a $10 \mathrm{~mm}$ i.d. $\times 150 \mathrm{~mm}$ glass column loaded with activated alumina in toluene. A total of five $25 \mathrm{~mL}$ fractions were collected starting with 100 percent toluene and ending with 100 percent chloroform (Figure 2). Each sample was analyzed by ultraviolet-visible (UV-VIS) spectroscopy, dried, weighed, and redissolved in $5 \mathrm{~mL}$ of methylene chloride and analyzed by DCP for nickel. The fraction with the highest nickel concentration was then analyzed by direct probe mass spectrometry. 
SILICA GEL

\begin{tabular}{|c|c|}
\hline $\begin{array}{c}\text { FRACTIONS } \\
(75 \mathrm{~m} / \mathrm{s})\end{array}$ & SOLVENT \\
\hline $\begin{array}{l}1 \\
2 \\
3 \\
4\end{array}$ & HEXANE \\
\hline $\begin{array}{l}5 \\
6 \\
7\end{array}$ & $25 \%$ TOLUENE $75 \%$ HEXANE \\
\hline $\begin{array}{r}8 \\
9 \\
10\end{array}$ & $\mathbf{5 0} \%$ TOLUENE $\mathbf{5 0} \%$ HEXANE \\
\hline $\begin{array}{l}11 \\
12 \\
13 \\
\end{array}$ & $75 \%$ TOLUENE $25 \%$ HEXANE \\
\hline $\begin{array}{l}14 \\
15 \\
16\end{array}$ & $25 \%$ ETHYLACETATE $75 \%$ TOLUENE \\
\hline $\begin{array}{l}17 \\
18 \\
19\end{array}$ & $\mathbf{5 0} \%$ ETHYLACETATE $\mathbf{5 0} \%$ TOLUENE \\
\hline $\begin{array}{l}20 \\
21 \\
22\end{array}$ & $75 \%$ ETHYLACETATE $25 \%$ TOLUENE \\
\hline $\begin{array}{l}23 \\
24 \\
25\end{array}$ & $50 \%$ ETHYLACETATE $\mathbf{5 0} \%$ METHANOL \\
\hline $\begin{array}{l}26 \\
27 \\
28\end{array}$ & METHANOL \\
\hline & ALUMINA \\
\hline $\begin{array}{c}\text { FRACTIONS } \\
(25 \mathrm{mls})\end{array}$ & SOLVENT \\
\hline $\begin{array}{l}1 \\
2\end{array}$ & $100 \%$ TOLUENE \\
\hline $\begin{array}{l}3 \\
4\end{array}$ & $10 \%$ CHLOROFORM $90 \%$ TOLUENE \\
\hline 5 & $100 \%$ CHLOROFORM \\
\hline
\end{tabular}

Figure 1. Fractionation parameters used to isolate nickel porphyrin compounds.

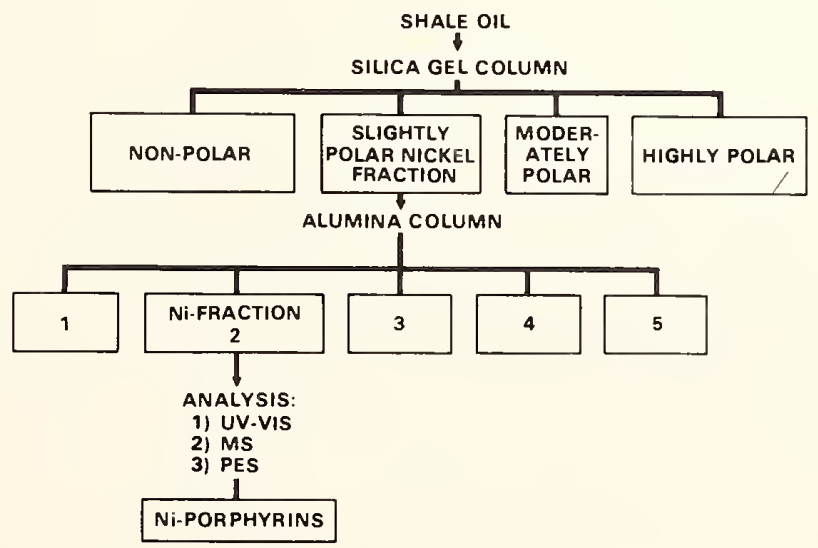

Figure 2. Isolation of nickel porphyrins from retort $B$ shale oil. 
Retort waters were filtered through $0.45 \mu \mathrm{m}$ filter just before $\mathrm{C}_{18}$ partition chromatography. Each $\mathrm{C}_{18}$ cartridge was activated by passing $2 \mathrm{~mL}$ of methanol through the cartridge followed by $4 \mathrm{~mL}$ of Milli-Q-purified water. For each of the retort water samples, $30 \mathrm{~mL}$ in $10 \mathrm{~mL}$ aliquots were forced through the Sep-pak with an all-glass syringe. For each subsequent extraction, $30 \mathrm{~mL}$ of the spent water was forced through each Sep-pak for a total of five extractions $\left(5 X\right.$ spent $\mathrm{H}_{2} 0$ ). Immediately following, each of the Sep-paks was rinsed with $2 \mathrm{~mL}$ of Milli-Q water. The $\mathrm{C}_{18}$-bound organics (hydrophobic organics) were then eluted with $2 \mathrm{~mL}$ of methanol. If samples had a high organic mass loading, the $\mathrm{C}_{18}$ cartridge was finally rinsed with $2 \mathrm{~mL}$ of methylene chloride. All the subfractions of each sample, i.e., spent water, rinsed water, methanol, and methylene chloride were combined and the total volume measured. The samples were then analyzed on the DCP for cadmium, boron, zince, molybdenum, iron, manganese, chromium, nickel, and copper (Figure 3).

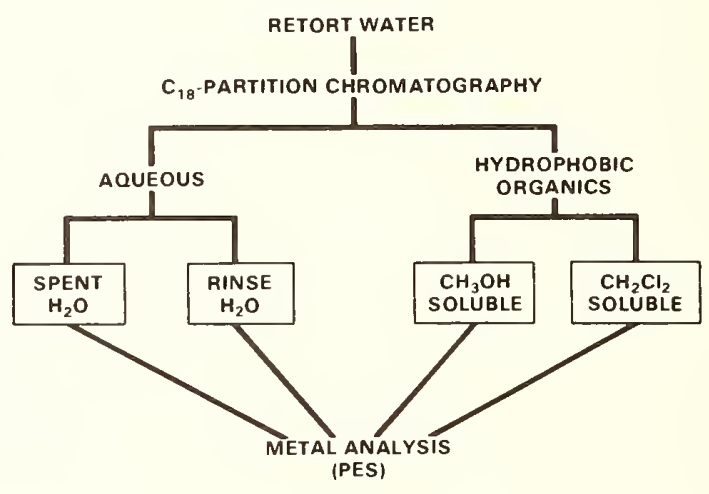

Figure 3. $\mathrm{C}_{18}$-fractionation of retort waters.

\section{3 Instrumentation and Standards}

\subsubsection{Plasma Emission Spectroscopy}

A Spectrometric Spectra Span III, three-jet, direct-current plasma emission spectrometer with a multielement cassette was used to analyze all metals except arsenic. The instrument was set up according to manufacturer's recommendations. For the methylene chloride solutions a Conostan D-20 standard diluted to 1 ppm metal concentration was used. The instrument was spanned to $1 \mathrm{ppm}$ concentration and blanked on pure methylene chloride. The methanol solutions were standardized by dissolving $1000 \mathrm{ppm}$ aqueous standards in methanol to a concentration of $1 \mathrm{ppm}$ metal. The instrument was then spanned to $1 \mathrm{ppm}$ metal concentration and blanked on pure methanol. After three samples the blank solution was aspirated to check baseline drift and stability. After six samples, the 1 ppm standard was aspirated. If the value drifted greater than \pm 10 percent of the original value, the instrument was respanned. 


\subsubsection{Instrumental Neutron Activation Analysis (INAA)}

Arsenic in the samples was analyzed by INAA. A $1 \mathrm{~mL}$ aliquot of the $10 \mathrm{~mL}$ oil fraction in methylene chloride was pipetted into pre-weighed $2 / 5$ dram polyethylene vials and evaporated to dryness under a heat lamp. One milliliter of hexane was added to each vial and evaporated to dryness. Each sample was then weighed and placed in two-dram polyethylene vials, heat sealed and sealed in polyethylene bags, and irradiated. The samples were irradiated for $5.5 \mathrm{~h}$ at a neutron flux of $1.1 \times 10^{12}$ neutron $\mathrm{cm}^{-2} \mathrm{~s}^{-1}$. Immediately following irradiation, $1 \mathrm{~mL}$ of methylene chloride was added to each sample and the vial and the contents placed in a clean two-dram vial and counted. A Ge(Li) detector, with an active volume of $86 \mathrm{~cm}^{3}$, a relative efficiency of 17 percent, and a resolution for the $1332 \mathrm{keV}{ }^{60}$ Co 1 ine of $2.12 \mathrm{keV}$, was used. The $559.1 \mathrm{keV} 1$ ine from ${ }^{76} \mathrm{As}\left(t_{\frac{1}{2}}=26.3 \mathrm{~h}\right)$ was used to compute quantitative As values in the sample as compared to standards.

\subsubsection{UV-VIS Spectroscopy}

A Cary 1605 UV-VIS spectrometer was used for the analysis of all of the Retort B fractionated shale oil samples. All solutions were analyzed in methylene chloride. Each of the samples was scanned from $350 \mathrm{~nm}$ to $700 \mathrm{~nm}$ at a scan rate of $40 \mathrm{~nm} \mathrm{~min}^{-1}$. The solutions were diluted when necessary.

\subsubsection{Mass Spectrometry}

A Hewlett Packard 5982 gas chromatograph-mass spectrometer (GC-MS) was used for the analysis of the nickel porphyrin fraction. The sample was introduced via a direct probe inlet. The probe temperature was $200{ }^{\circ} \mathrm{C}$, source temperature of $176{ }^{\circ} \mathrm{C}$ and the ionization voltage was $70 \mathrm{ev}$.

\subsubsection{Reagents}

Al1 the organic reagents were Burdick and Jackson HPLC-grade solvents. The water was supplied by a Millipore Milli-Q water purification system. All glassware was acid washed and rinsed with Milli-Q water. The silica gel used was Baker's analyzed grade 60-200 mesh. The alumina used was activated alumina catalyst grade Al-0102 made by Harshaw Scientific. The $\mathrm{C}_{18}$ Sep-paks were purchased from Waters Associates, Incorporated.

3. Results and Discussions

$3.10 \mathrm{ils}$

The two oils studied (Retort A and Retort B) had similar concentrations of iron (56 ppm vs $59 \mathrm{ppm}$, respectively) but radically different concentrations of nickel ( $3.6 \mathrm{ppm}$ vs $22 \mathrm{ppm}$ ), 
molybdenum (less than $0.2 \mathrm{ppm}$ vs $10 \mathrm{ppm}$ ), and arsenic (29.3 ppm vs $8.2 \mathrm{ppm}$ ) (Table 1). The weight distribution of the shale oils after silica gel fractionation showed (Figure 4) similarities in most of the fractions, specifically fractions 4 through 23 . However, notable differences occured in fraction 2 and 24 . Fraction 2 of Retort $B$ had a 44 percent greater mass than the same fraction of Retort $A$, indicating a higher percentage of nonpolar species. Fraction 24 in Retort A was 57 percent greater in mass than the same fraction of Retort $B$, demonstrating a much higher content of highly polar compounds.

Table 1. Chemical Composition of Filtered Dry Shale $0 i 1$.

\begin{tabular}{lcl}
\hline Element & $\begin{array}{c}\text { Retort A } \\
(\text { Surface) } \\
\mu \mathrm{g} / \mathrm{g}\end{array}$ & $\begin{array}{l}\text { Retort B } \\
\left(\text { in } \frac{\text { situ }}{\mu \mathrm{g} / \mathrm{g}}\right.\end{array}$ \\
\hline $\mathrm{Fe}$ & 56.0 & 59.0 \\
$\mathrm{Ni}$ & 3.6 & 22.0 \\
$\mathrm{Mo}$ & 0.2 & 10.0 \\
$\mathrm{As}$ & 29.3 & 8.2 \\
$\mathrm{Co}$ & 1.5 & 3.6 \\
$\mathrm{Se}$ & 1.46 & 2.6 \\
$\mathrm{~V}$ & 0.20 & 1.38 \\
$\mathrm{Zn}$ & 0.5 & 2.0 \\
$\mathrm{Cr}$ & 0.1 & $<.3$ \\
$\mathrm{Sb}$ & 0.051 & 0.050 \\
$\mathrm{Mn}$ & 0.09 & 0.08 \\
$\mathrm{U}$ & $<0.01$ & $<0.03$ \\
\hline
\end{tabular}

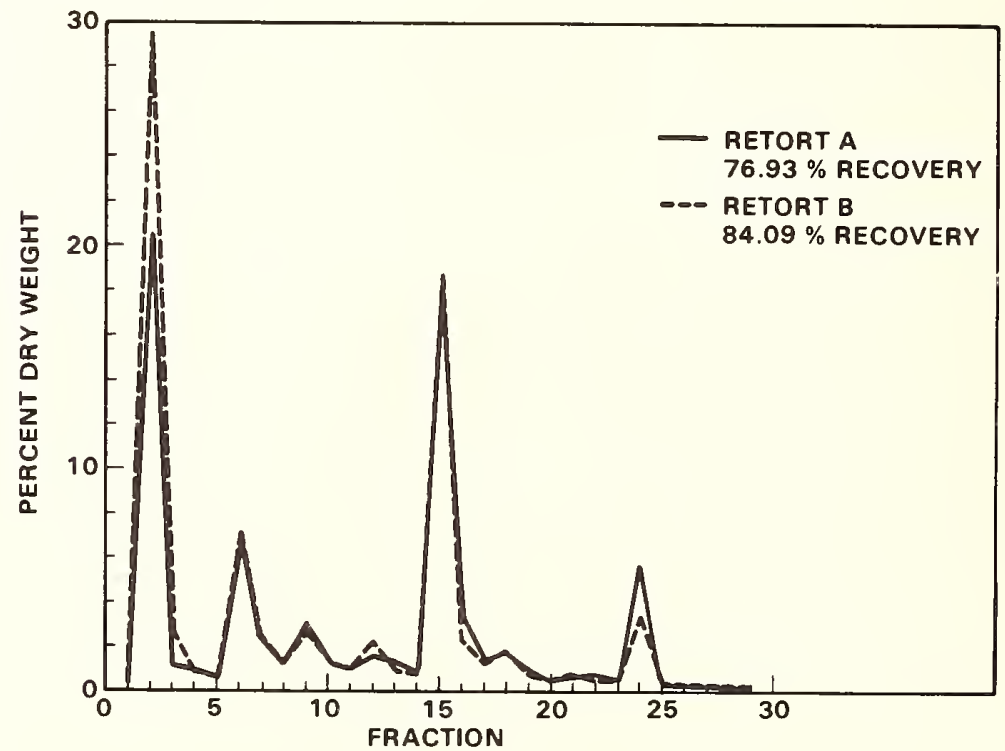

Figure 4. Weight distribution of fractionated shale oils. 
As Figures $5 \mathrm{~A}$ and $5 \mathrm{~B}$ indicate, no metals were detected in the nonpolar silica gel fractions, i.e., 1 through 6 . A significant amount of nickel chromatographed in the slightly polar fraction ( 8 through 10 ) of both oils. As the polarity of the eluant increased, beginning with fraction 15, iron, nickel, and arsenic eluted rapidly from Retort $A$ crude and molybdenum, iron, nickel, and arsenic eluted rapidly from Retort $B$ crude oil. Subsequently, the metal concentrations of the fractions dropped off sharply. Beginning with the highly polar fractions (23-28) metals began to elute once more. In Retort $A$ crude oil fraction 24, iron, nickel, and arsenic co-eluted. In Retort B crude oil, molybdenum, iron, nickel, and arsenic co-eluted. For Retort $A$ crude oil, arsenic and iron slowly bled off the column; for Retort $B$ crude $0 i 1$, molybdenum and arsenic slowly bled off the column. Close examination of Figures $5 A$ and $5 B$ reveals a number of similarities and differences between the two oils. In both cases a significant amount of nickel eluted in the moderately polar region ( 8 through 10 ). On the other hand, a high concentration of nickel eluted in the highly polar region (fraction 24) of Retort B crude, but none appeared in the highly polar region of Retort $A$ crude.
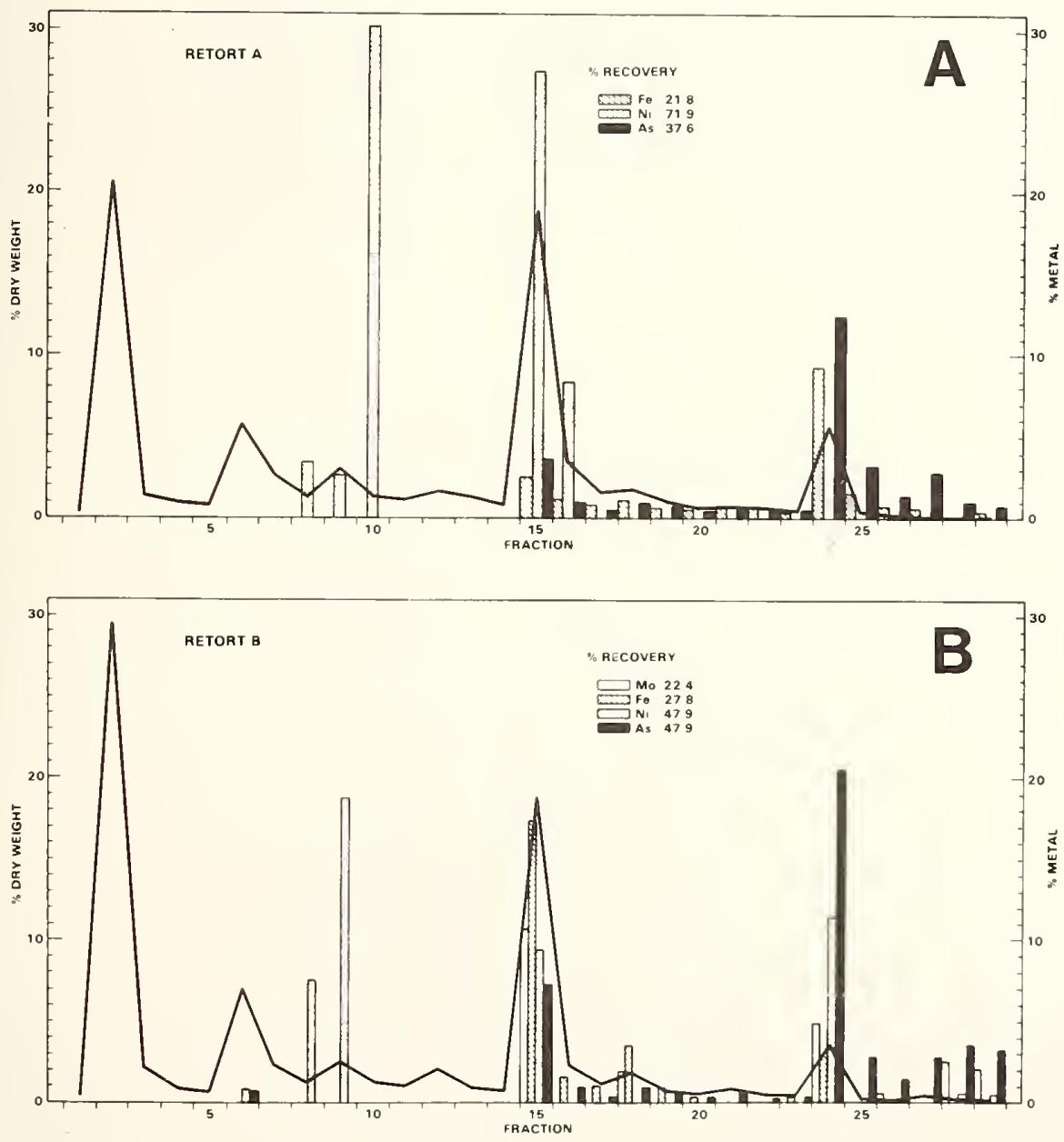

Figure 5. Silica gel fractionation of shale oil metals. 
All of the silica gel fractions of Retort B were analyzed by UV-VIS spectrometry. Fractions 8 and 9 in the slightly polar region absorb strongly at $392 \mathrm{~nm}$ and maximize in Fraction 9. This absorbance corresponds to the Soret band of a porphyrin complex. Evidence provided by the UV-VIS spectrometer and the results of the trace metal analysis on the DCP suggested that a nickel porphyrin had been partially isolated. However, on the basis of the UV-VIS spectrum, other organic material was present in this fraction, and further purification was necessary.

Purification of the porphyrin fraction was successfully carried out by chromatography on alumina. Of the five fractions collected, fraction 1 contained 72 percent of the total mass with only a trace of the nickel appearing. Conversely, fraction 2 contained only 3 percent of the mass but 90 percent of the nickel. Fractions 3, 4, and 5 contained from 2 to 5 percent of the mass with no detectable nickel being identified. When comparing the nickel concentration of the various fractions to the original oil, we see an enhancement of 1.73 in fraction 1 and 214 for fraction 2 (Figure 6). The UV-VIS spectrum of fraction 2 shows that most of the organic residue had been separated when compared to the spectrum of fraction 9 of the original silica gel separation (Figure 7). Nickel octaethylporphyrin was used as a UV-VIS standard (Figure 8). Although the spectra was not identical, the general characteristics were present. Milton et al. previously identified a nickel porphyrin in Utah Green River $0 i 1$ Shale deposits [5] (Figure 9). It exhibited a UV-VIS absorption spectra almost identical to the nickel porphyrin isolated in this work (Figure 10 ).

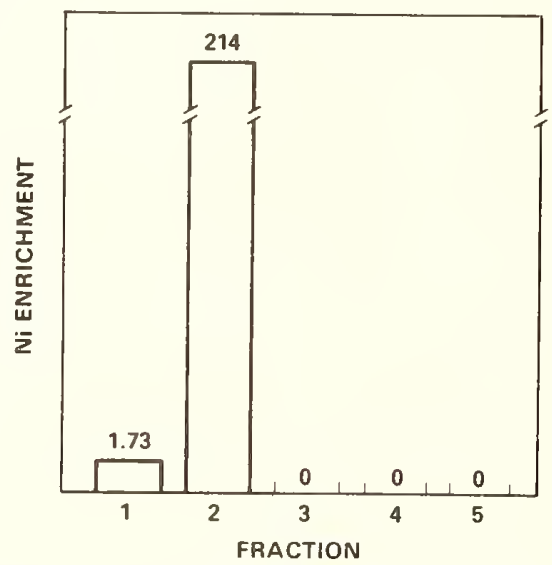

Figure 6. Enrichment of nickel after alumina separation (compared to original oil).

The alumina fraction 2 was further analyzed by mass spectrometry (Figure 11). The resulting spectrum showed the possible presence of three to four different porphyrin species with parent peaks located at $\mathrm{m} / \mathrm{e}=518,490$, and 487 . The ion cluster $\mathrm{m} / \mathrm{e}=503$ is probably due to the $\mathrm{M}-15$ (loss of $\mathrm{CH}_{3}$ ) of the $\mathrm{m} / \mathrm{e}=518$ ion cluster. This $518 / 503$ relationship compares well with the partial mass spectrum of the Abelsonite-type porphyrin published by 


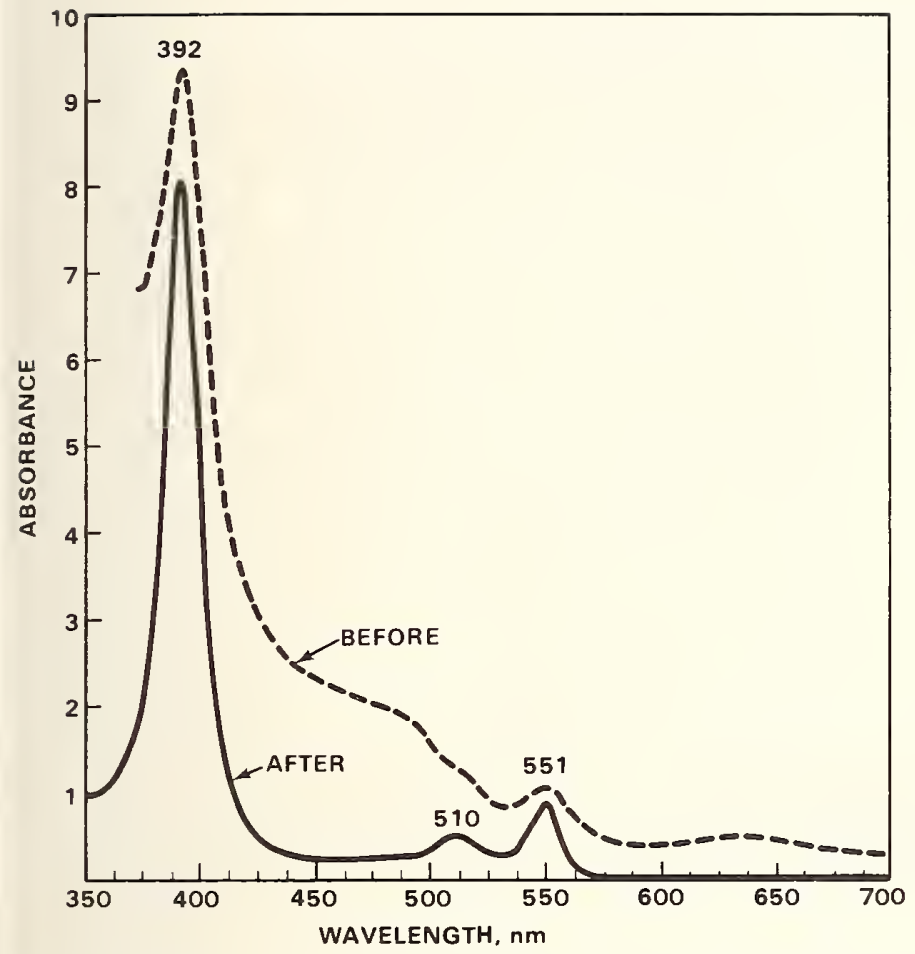

Figure 7. Nickel-aromatic fraction before and after alumina separation.

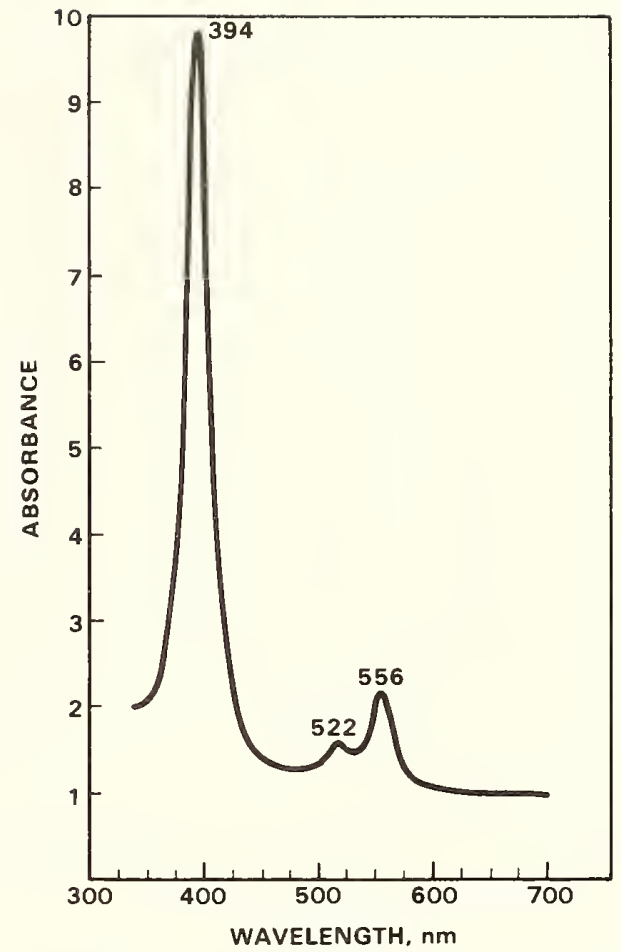

Figure 8. UV-VIS spectrum of nickel octaethylporphyrin.

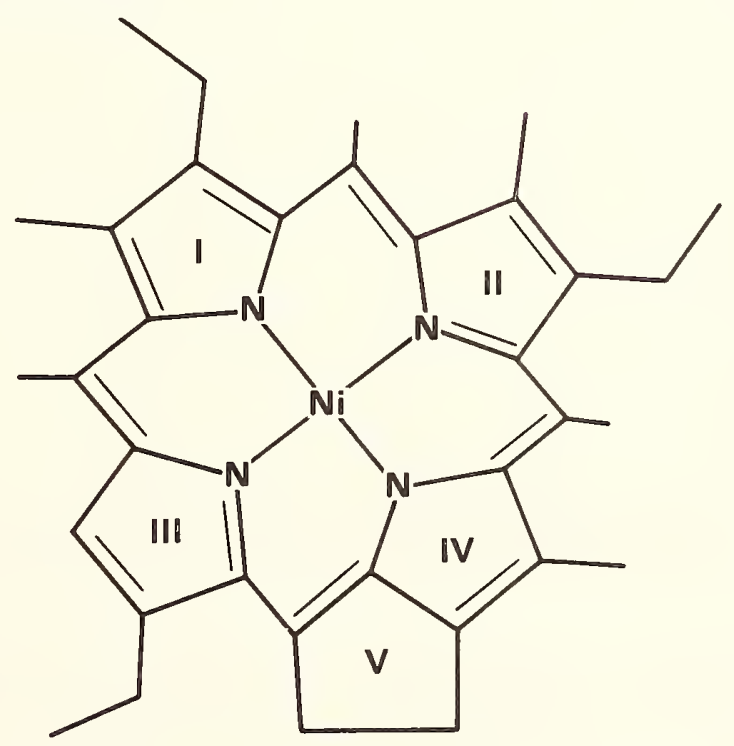

Milton, et.al. (1978)

Figure 9. Proposed molecular structure of Abelsonite $\mathrm{C}_{31} \mathrm{H}_{32} \mathrm{~N}_{4} \mathrm{Ni}[5]$. 


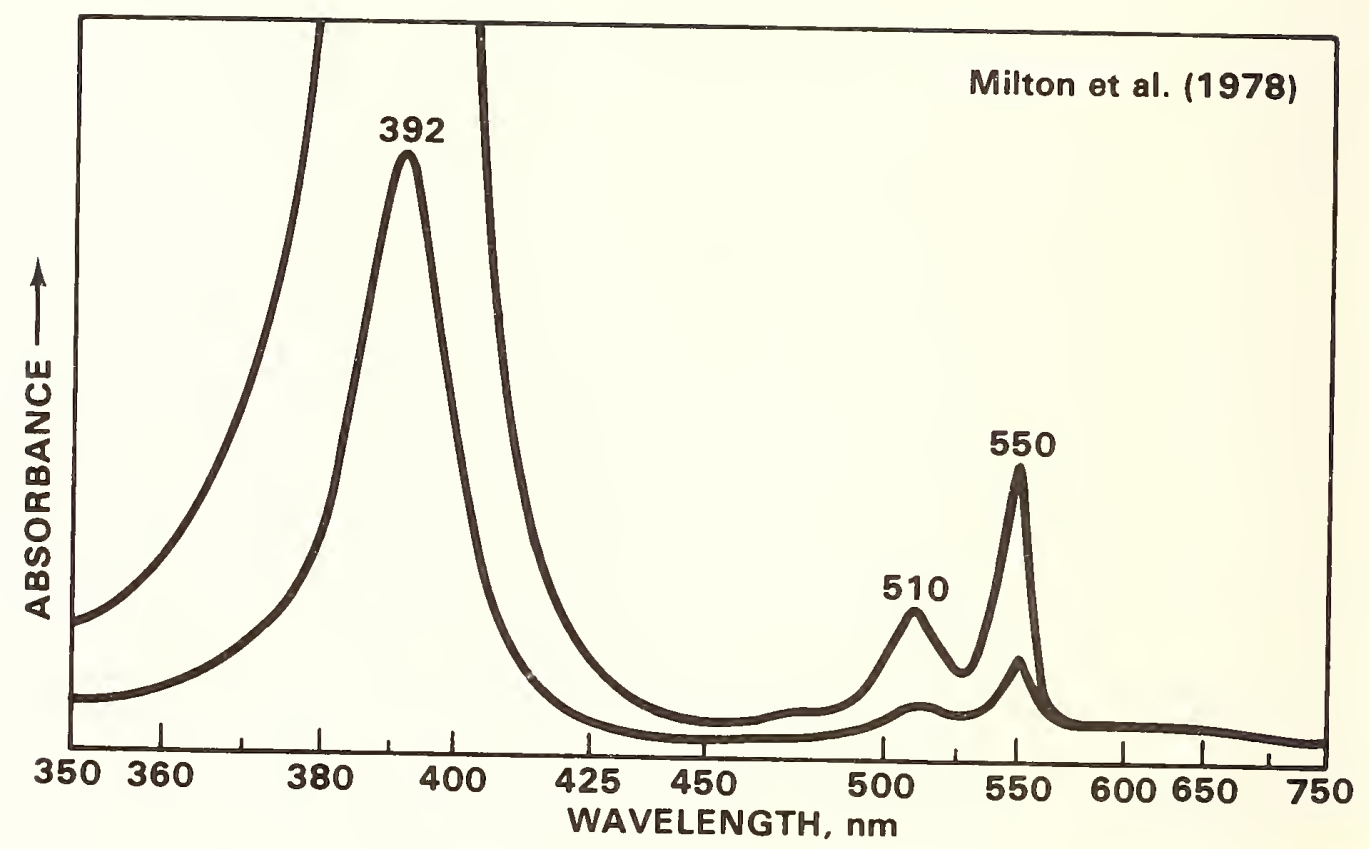

Figure 10. UV-VIS absorption spectrum of type Abelsonite (in benzene).

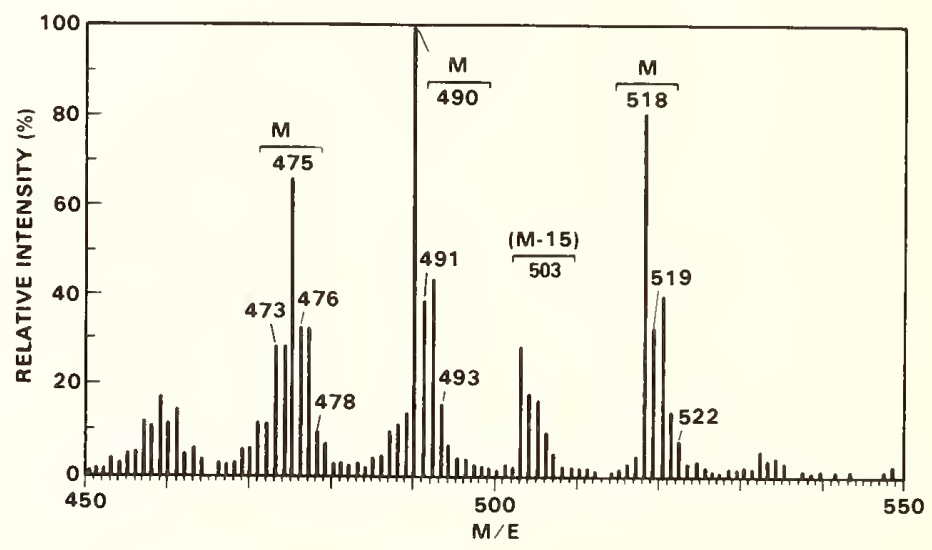

Figure 11. Mass spectrum of species in nicke1-aromatic fraction after alumina separation.

Milton et al. (Figure 12). With the evidence supplied by the UV-VIS spectrum, the DCP metal analysis, and the mass spectrum of the porphyrin-rich fraction, we tentatively can identify the presence of Abelsonite porphyrin in Retort B shale oil. 


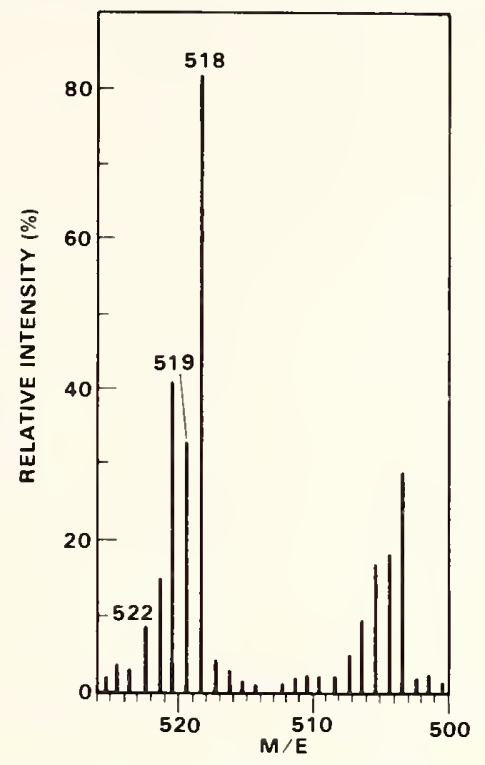

PARTIAL MASS SPECTRUM OF ABELSONITE FROM GREEN RIVER FORMATION, UTAH. Milton, et.al. (1978)

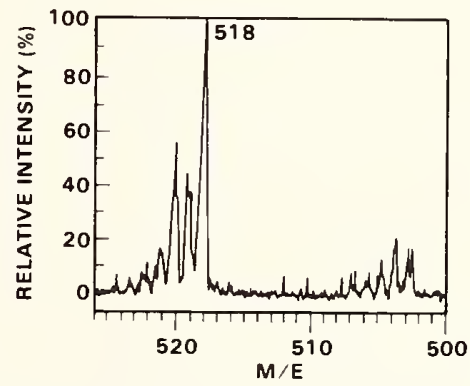

Figure 12. Comparison of $\mathrm{Ni}$ shale oil porphyrin and Abelsonite.

\subsection{Waters}

Three different retort waters with varying concentrations of trace metals were fractionated by $C_{18}$ partition chromatography (Table 2). Retort $A$ water was condensate water from an aboveground retort. Retort $B$ and $C$ waters were from a modified vertical in situ retorting process, but from different locations. The five metals studied were boron, zinc, molybdenum, iron, and manganese. Analysis showed that molybdenum in Retort $A$, molybdenum and iron in Retort $B$, and zinc and iron in Retort $C$ were associated with the hydrophobic organic fraction of the samples. A large amount of mass imbalance occurred with all waters, but to a lesser degree in $B$ and $C$ waters. This could possibly be due to the irreversible bonding of the metals to the walls of the $C_{18}$ cartridges or to the $C_{18}$ support itself. In all three waters, most of the metals remained associated with the spent retort waters or was lost on the $\mathrm{C}_{18}$ cartridge. Only portions of zinc, molybdenum, and iron partitioned with the hydrophobic organics (Figure 13). 


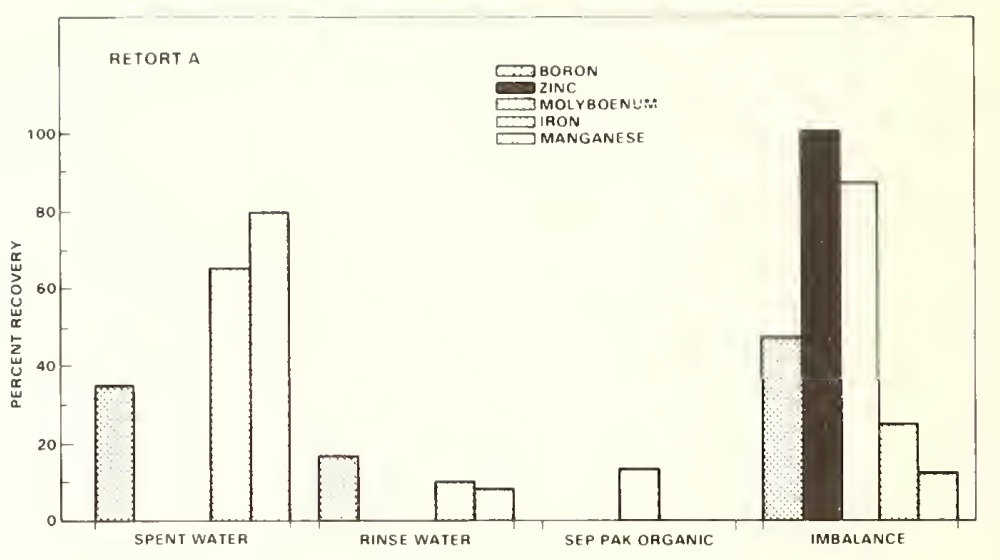

A

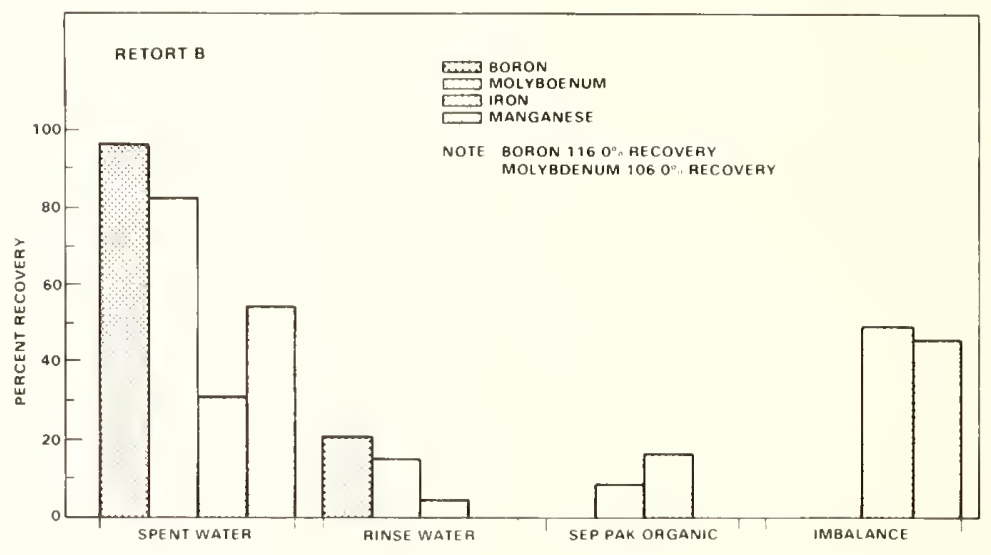

B

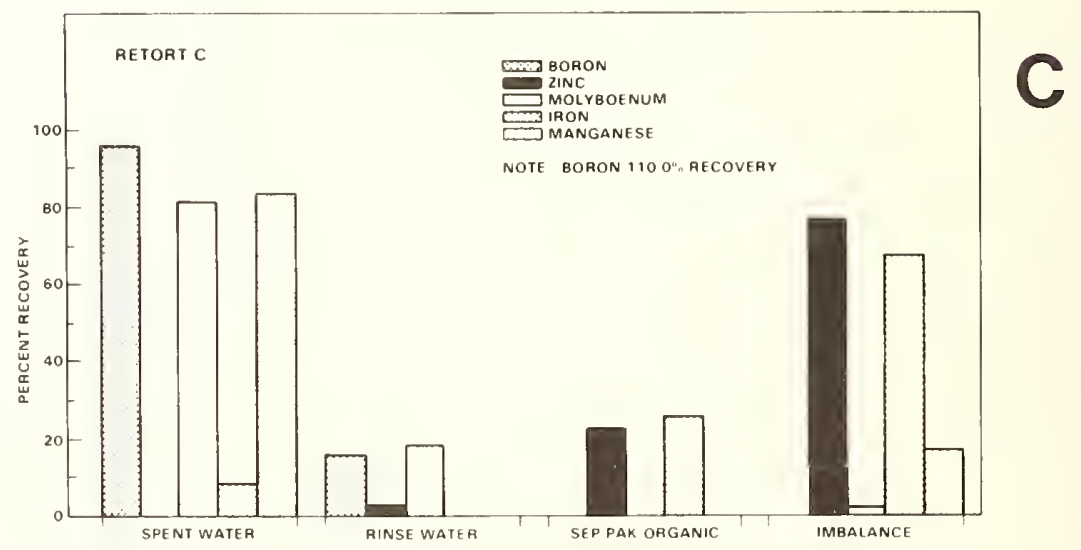

Figure 13. Fractionation of selected metals in retort waters by $\mathrm{C}_{18}$ partition chromatography. 


\begin{tabular}{lccc}
\hline Element & $\begin{array}{c}\text { Retort A } \\
\left(\begin{array}{c}\text { Condensate } \\
\mu \mathrm{g} / \mathrm{mL}\end{array}\right.\end{array}$ & $\begin{array}{c}\text { Retort B } \\
\mu \mathrm{g} / \mathrm{mL}\end{array}$ & $\begin{array}{c}\text { Retort C } \\
\mu \mathrm{g} / \mathrm{mL}\end{array}$ \\
\hline $\mathrm{Cd}$ & & & \\
$\mathrm{B}$ & 0.005 & 0.005 & 0.005 \\
$\mathrm{Zn}$ & 1.09 & 0.277 & 7.8 \\
$\mathrm{Mo}$ & 0.043 & 0.011 & 0.234 \\
$\mathrm{Fe}$ & 0.041 & 0.124 & 0.145 \\
$\mathrm{Mn}$ & 0.981 & 0.169 & 0.150 \\
$\mathrm{Cu}$ & 0.147 & 0.011 & 0.006 \\
$\mathrm{Al}$ & $<0.005$ & 0.005 & 0.013 \\
$\mathrm{Ni}$ & 0.005 & 0.048 & 0.040 \\
$\mathrm{Cr}$ & 0.032 & 0.005 & 0.008 \\
\hline
\end{tabular}

4. Conclusions

\section{1 0ils}

The isolation of the metallic complexes from the shale oil matrix by silica gel chromatography proved to be a suitable method for the partial separation of the metallic complexes from the other organic constituents of the shale oil. However, final verification of the existence of the nickel porphyrin requires a further purification. This was quite satisfactorily achieved by alumina chromatography.

The large number of samples generated in using silica gel chromatography required a rapid and accurate method of analysis for trace metals. Analysis procedures in common use would require either an acid digestion or fusion step or the use of INAA. These techniques are time consuming or costly, particularly when a large number of samples are analyzed. Using the DCP, a total of 60 samples could be analyzed daily with a total of 10 metals per sample. The detection limits were very low, ranging from 2 to $5 \mathrm{ppb}$ for most metals. The characterization of the nickel prophyrin Abelsonite in the shale oil demonstrated the ability of this and related compounds to survive the retorting process and be carried over into the shale oil.

The development of the chromatographic method will now enable us to investigate many of the other metallic complexes present in the shale oil. Specific interest will be on molybdenum and arsenic speciation and structural determinations of these complexes.

\subsection{Waters}

Metals did partition between the hydrophobic and hydrophilic fractions after $\mathrm{C}_{18}$ partition chromatography. It was interesting that most of the metals did not associate with the 
hydrophobic organics, and, of the metals that did, only a small percentage of the total metal was associated with the organics. The next step is to fractionate large quantities of retort waters so that the analysis of organometallic complexes present in the waters can proceed.

\section{Acknowledgments}

The authors would like to extend their thanks to the following individuals for helping make this work possible: Jon Fruchter, Roberta Myers, Chuck Veverka, Don Schoengold, John Evans, Bary Wilson, and Sylvia Downey.

\section{References}

[1] Wilkerson, C. L. Trace metal composition of Green River retorted shale oil. Fuel, in press.

[2] Buck, W. E. Toxicity of inorganic and aliphatic organic arsenicals, in Toxicity of heavy metals in the environment, part 1. F. W. Oehme, ed. New York: Marcel Dekker, Inc.; 1978. 357-374.

[3] Fish, R. H. Speciation of trace organic ligands and inorganic and organometallic compounds in oil shale process water, in Proceedings of the 13th oil shale symposium, April 16-18, 1980. James H. Gary, ed. Colorado School of Mines Press, Golden, C0; 1980. 385-391.

[4] Weiss, C. S.; Jewett, K. L.; Brinckman, F. E.; Fish, R. H. Application of molecular substituent parameters for the speciation of trace organometals in energy-related processes by high performance liquid chromatography. This volume, pp. 197-216.

[5] Milton, C.; Dwornik, E. J.; Estep-Barnes, P. A.; Finkelman, R. B.; Pabst, A.; Palmer, S. Amer. Mineralogist 63: 930; 1978.

Discussion

Question (B. Bathija): On this level of chromatography, where do you think the $\operatorname{Cr}$ (III) and Cr(VI) elute?

Answer: I have no idea.

Question (R. H. Fish): Have you identified any species other than the nickel porphyrin you showed? What about the arsenic compounds?

Answer: We have started a scheme involving arsenic speciation. We know where the arsenic elutes thus we can take a closer look at those latter fractions where the arsenic is associated. We tentatively have another porphyrin identified in the more polar regions, fraction number 24, I think. A soret band peak appears there. We are attempting to further purify and characterize the fraction. 
Question (R. H. Fish): What about molybdenum?

Answer: We haven't characterized any molybdenum-containing organometallics. We're continuing to work on that.

Question (R. H. Filby): Did you see any vanadium porphyrins? It's somewhat unusual to find the nickel and not the vanadium.

Answer: Not yet. The vanadium line we have on our detector cassette is above $350 \mathrm{~nm}$; that would require us to go back and to analyze the other vanadium line which is below $350 \mathrm{~nm}$.

Question (S. E. Manahan): I had a question in regard to the organophilic fraction or hydrophobic fraction on the waters in the methylene chloride. Was this analyzed by plasma emission analyses?

Answer: Yes.

Question (S. E. Manahan): With lines above $350 \mathrm{~nm}$ or below $350 \mathrm{~nm}$ ?

Answer: We did not use anything above $350 \mathrm{~nm}$ for the analysis in the plasma. I mean below that.

Question (S. E. Manahan): For the materials initially in water, it should be relatively easy to transfer the methylene chloride fraction to an aqueous medium. Presumably these materials are soluble in water and you can do that by simply putting the methylene chloride aliquot in the water and taking it off under vacuum. The materials are soluble in this aqueous medium and you should be able to use the other lines as you need to.

Answer: That's correct. 
The Use of Mass Spectrometry for Metal Analysis

Terence H. Risby

Division of Environmental Chemistry Department of Environmental Health Sciences

The Johns Hopkins University School of Hygiene and Public Health Baltimore, Maryland 21205

The measurement of the bioavailability and speciation of trace elements is extremely important for the assessment of potential health effects which may occur as the result of exposure to emissions from energy-related processes. This paper presents the current state-of-the-art in the use of mass spectrometry for trace analysis and also suggests areas for future research. Different methods of sample ionization are compared and contrasted and the advantages of various methods of sample introduction are discussed. Representative analyses are presented in order to exemplify the various conclusions which have been presented in this publication.

Key words: bioavailability; element speciation; gas chromatography; ionization processes; 1iquid chromatography; mass spectrometry.

\section{Introduction}

It is anticipated that during the next decade there will be a more extensive use of fossil fuels for the generation of electricity and for the production of synthetic fuels to be used for transportation and for feedstocks in the petrochemical industry. The high temperature combustion of these products typically results in the generation and the emission of ultrafine aerosols (particle size $<1.0 \mu \mathrm{m}$ ) which are difficult to remove with the usual control devices which are designed to trap larger particles and gases. The ultrafine particles are environmentally significant since they remain suspended in the atmosphere for significant periods of time. Also, particles with diameters less than $2.0 \mathrm{um}$ are of respirable sizes and, as a result, can enter the deep lung where they may be deposited by Brownian diffusion. This particulate matter, once deposited in the deep 1ung, will remain there until it is cleared by phagocytic cells or by muco-cillary action. The average clearance time for the removal of ultrafine particles is currently not known but it is expected to be on the order of days, and the clearance time will also be dependent upon particle shape. Since the deposition and clearance of ultrafine aerosols are not well characterized, it is difficult to quantify their potential biological effects. These effects will be dependent upon the solubility of the aerosols in the physiological fluids and cells that are found in the deep lung or in the gastro-intestinal tract. The 
particles enter the gastro-intestinal tract as a result of the action of swallowing the particles removed by muco-cillary action. The chemical composition of the ultrafine aerosols will be the dominant feature which accounts for their direct biological effects. The particles that are emitted from high temperature combustion sources will have both inorganic and organic character. The organic character of these particles consists of a predominately carbonaceous core with a minor amount of partially oxidized functional groups. Also, these particles have various organic molecules sorbed onto their surfaces. These molecules include such species as: carbonyls (e.g., acrolein), acids (e.g., hydroxybenzoic acid), bases (e.g., isoquinoline), polynuclear aromatic hydrocarbons (e.g., benzo(a)pyrene), and substituted polynuclear aromatic hydrocarbons (e.g., anthracene quinone, phenanthrone, hydroxyfluorenone, and nitropyrene) $[1,2]$. These organic compounds can also be sorbed onto the surface of the particles which are predominantly inorganic in character. The compositions of the inorganic particles are dependent upon the trace elements which are contained in the fossil fuels. These trace elements are generally emitted as the oxides or silicates, although the element can be emitted directly if it is volatile and stable. The mechanisms which produce these particles will also play a major role in their speciation. Another factor which stresses the importance of the ultrafine aerosol is that a number of publications have reported that the more toxic elements are concentrated in the smaller particles [3-6]. These data can be rationalized by the hypothesis that the toxic elements (lead, antimony, cadmium, selenium, arsenic, zinc, nickel and chromium) are emitted in the gaseous state at the temperature of the exhaust gases. If the hypothesis is valid then the volatile toxic elements, mercury and beryllium, should be added to this list.

The published data on the health effects of exposure to trace elements have traditionally been focused on acute toxicity but the current trend of investigations is to explore the effects of chronic or sub-chronic long-term exposures. The direct effects of such exposures can be expressed as increased incidences in cancer, chronic lung diseases, anemia and neurological, reproductive, or kidney disorders [7]. In addition, exposure to trace elements can result in indirect effects such as compromising the host to be more susceptible to infection or to the effects of exposure to other toxic chemicals [8]. Often the diseases, which are produced by exposures to acute levels of trace elements, are misdiagnosed as to their causes and the extents of misdiagnoses are magnified at the chronic or sub-chronic levels particularly since the diseases are seldom specific to a particular chemical agent.

In view of the difficulties of recognizing health effects of trace elements and also understanding the mechanisms which can explain these effects, most of the health effects studies have been obtained using concentrations of trace elements without regard to their speciation. This trend has been primarily caused by the analytical chemist who has developed techniques which are designed to quanitify elements. The major thrusts 
of analytical chemistry in recent years, have been towards developing techniques with increased selectivities and improving the limits of detection of all techniques. The implications of trace element interactions have also been recently realized as a result of the published work in the area of nutrition by Underwood [9] and Mertz [10]. These workers and others [11] have established that the copper dietary requirements are dependent upon the occurrence of molybdenium in the diet. Similarly, selenium has been found to protect experimental animals against cadmium poisoning [12]. This work has also been extended to include the interaction between selenium and arsenic or mercury. These data stress the importance of quantifying a series of elements when evaluating the results of toxicity experiments. Nutritionists have also made other important observations with regard to the influence of element speciation on bioavailability [10]. For example, the oxidation state of iron is important since Fe(II) is thought to be more available than Fe(III). Similarly, the coordination state has also been shown to be important since heme iron is readily absorbed as compared to non-heme iron, and the cobalt in vitamin $B_{12}$ is more important than the total cobalt concentration in serum. It is reasonable to expect that this trend will be followed by other elements which are also required for metabolism. In terms of toxicity of elements, there is much less available information on the importance of metal speciation apart from the well-known carcinogenic effect of $\mathrm{Cr}$ (VI) as compared to $\mathrm{Cr}$ (III) which is required for normal metabolism [11]. This area of research is currently receiving considerable attention since the biological effects of elements will be intrinsically related to whether there is an uptake of the element by the tissue. Currently, health effects scientists are hampered by the lack of availability of analytical chemistry techniques which are capable of monitoring low levels of elements in terms of their speciation. This is currently particularly important since there are a number of new industrial processes which are envisaged that could emit elements in a form not usually found in ambient air. An excellent example of this type of compound is the emissions which may be produced during the manufacture of synthetic fuels from coal or shale rock. These processes generally involve hydrogenation or reduction steps in order to increase the carbon-hydrogen ratio of the resulting fuel. These conditions can be expected to produce reduced forms of various elements such as arsine, stibine, hydrogen selenide, and metallic mercury which will have markedly different toxicities as compared to their oxides. Also, it is reasonable to expect that interactions will occur between the ultrafine aerosols and other pollutant gases since the former species are known to have long residence times in the ambient air. Atmospheric particles are known to sorb other species on their surfaces and, with the current levels of acidic species in polluted atmospheres, it is likely that some elemental oxides will be solubilized during their transport from the source. The resulting potential health effects of these chemically transformed particles will be very different from those produced by the particles prior to reaction. 
It should be therefore obvious that there is a considerable need for the development of analytical chemistry methodologies which will be able to monitor the speciation of elements at trace levels. There are a number of techniques which could conceivably be used for this application and this paper will discuss the use of mass spectrometry. Mass spectrometry is ideally suited to this problem since it is well-established in its ability to identify and quantify any species which can be vaporized and ionized.

Historically, mass spectrometry has been used since its inception to study inorganic species, for both Thomson [13] and Aston [13] used nickel carbonyl to obtain the isotopic abundances of nickel. While this work was not performed with the object of metal analysis, it can be considered to be the forerunner of trace element analyses by mass spectrometry.

The major limitation of any analysis by mass spectrometry has been the production of gas phase species characteristic of the element which can be ionized prior to separation on the basis of its mass-to-charge ratio. This generally does not present a problem with organic molecules, but inorganic molecules seldom exhibit sufficient volatility at typical temperatures. One approach to solve this problem has been the use of a radio frequency spark source which produces ions directly by the impact of high energy electrons. The technique has been used extensively for trace element analysis since it is a multielement technique and is capable of analyzing for any element with an atomic number greater than helium. An excellent monograph by Ahearn [14] has discussed this technique in detail. However, it has recently suffered an eclipse as a multielement technique with the introduction of optical spectrometric instrumentation such as the inductively coupled plasma atomic emission spectrometer since this is a multielement technique capable of quantification at the trace or ultratrace level [15]. However, the major use of the spark source high resolution mass spectrometer has continued to be its ability to measure isotopic ratios. The measurement of isotopic ratios has a major use in studies which are concerned with the measurement of the bioavailability of trace elements since it allows enriched stable isotopes to be used as markers. These types of markers are gaining in popularity since they can be used for those clinical studies in which the use of radioactive isotopes are not warranted or are potentially harmful. The major problem experienced with the use of spark source mass spectrometry for trace element analysis has been the presence of interfering matrices which make interpretation of the data difficult. This problem is particularly evident with biological samples. As a result, alternative methods of ionization have been adopted and one of the most promising has been the use of thermal ionization [16-19]. This method of ionization, while not novel, represents an analytical procedure which may be used to measure bioavailability by the use of enriched stable isotopes. The major advantage of thermal ionization is its simplicity since it can 
be performed with minor modification to most low and high resolution mass spectrometers. This modification involves replacing the standard solids probe with a probe which includes an electrically heated rhenium filament. The method of sample introduction involves placing an aliquot of the sample solution onto this filament. The preliminary reports to date have shown that this technique is ideally suited to the alkali metals and the alkaline earths with a minimum amount of sample pretreatment. While the published data have only been concerned with studying clinical specimens, such as urinary calcium in newborns and children [16], they could be applied to samples that are produced as a result of environmental or occupational exposures. The extension of this method of ionization to other trace elements is currently receiving considerable attention and these results will establish whether this methodology has as wide an application as spark source mass spectrometry.

The use of standard solids probes for the introduction of inorganic samples has also been reported by a large number of researchers but these applications have been limited by the volatility of the sample species. This limitation has generally meant that the trace elements must be reacted with ligands to form volatile complexes. The development of this latter field has paralleled the development of gas chromatography, although gas chromatography has more stringent requirements for volatility and thermal stability of the solute. The use of gas chromatography to separate metal complexes was pioneered by Lederer in 1955 [20] and various reviews have discussed the development of this field [21-25]. The most common 1igands have been based on 2,4-pentanedione by the substitution of the heteroatom fluorine. Table 1 lists some of the more common anions..

Table 1. Anions of $\beta$-diketones

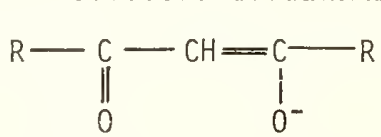

\begin{tabular}{|c|c|c|}
\hline R & $R^{1}$ & \\
\hline $\mathrm{CH}_{3}-$ & $-\mathrm{CH}_{3}$ & 2,4-pentanedionato ( $\mathrm{acac}$ ) \\
\hline $\mathrm{CF}_{3}-$ & $-\mathrm{CH}_{3}$ & $\begin{array}{l}\text { 1, } 1,1 \text {-trifluoro 2,4-pentanedionato } \\
(\text { tfa) }\end{array}$ \\
\hline $\mathrm{CF}_{3}-$ & $-\mathrm{CF}_{3}$ & $\begin{array}{l}1,1,1,5,5,5 \text {-hexaf1uoro } \\
2,4 \text {-pentanedionato ( } h f a)\end{array}$ \\
\hline $\mathrm{CF}_{3} \mathrm{CF}_{2} \mathrm{CF}_{2}-$ & $-\mathrm{C}\left(\mathrm{CH}_{3}\right)_{3}$ & $\begin{array}{l}1,1,1,2,2,3,3 \text {-heptafluoro } 7,7- \\
\text { dimethy } 1-4,6 \text {-octanedionato (fod) }\end{array}$ \\
\hline$\left(\mathrm{CH}_{3}\right)_{3} \mathrm{C}-$ & $-\mathrm{C}\left(\mathrm{CH}_{3}\right)_{3}$ & $\begin{array}{l}2,2,6,6 \text {-tetramethy } 1,5- \\
\text { heptanedionato (thd) }\end{array}$ \\
\hline $\mathrm{CF}_{3} \mathrm{CF}_{2-}$ & $-\mathrm{CF}_{2} \mathrm{CF}_{3}$ & $\begin{array}{c}1,1,1,2,2,6,6,7,7,7 \text {-decafluoro } \\
\text { 3,5-heptane-dionato (d fhd) }\end{array}$ \\
\hline
\end{tabular}


These ligands have been used more successfully for trivalent metals than divalent metals, and for this latter group of metals Uden and his coworkers have developed bidentate and tetradentate $\beta$-ketoamines [25]. However, in spite of the wealth of published information on the gas chromatography of metal complexes, only beryllium, chromium, and possibly aluminium, can be separated at the trace or ultratrace levels. This limitation probably results from irreversible adsorption on the chromatographic column and will probably be solved by the use of fused silica capillary columns. These columns are currently revolutionizing the field of gas chromatography since they enable new classes of compounds to be separated successfully.

The first electron impact mass spectrum of a metal $\beta$-diketonate $\left[\mathrm{Cr}(\mathrm{acac})_{3}\right]$ was reported by McLafferty in 1957 [26] and, since that time, a considerable number of researchers have reported the mass spectra of these complexes. These publications have dealt with the measurement of appearance potentials of metal complexes to the analysis of chromium in lunar materials and a recent review has discussed this research [27].

One of the major problems experienced in these studies was the production of intense parent ions for these metal complexes as often the analyses were performed using the more intense fragment ions. This difficulty was magnified when mixtures of metal complexes were analyzed. For this reason, chemical ionization has received considerable attention since it simplifies the mass spectrum and increases the intensity of the molecular ion. Chemical ionization is a more gentle form of ionization than electron impact ionization and, in the positive ion mode, produces sample ions as a result of ion-molecule reactions between the gaseous sample and the reactant ions. The resulting ion is generally formed by proton transfer or by hydride abstraction. This method of ionization was found to produce intense molecular ions for the metal complexes with very minor intensities of fragment ions [27]. Negative ion detection of the species, produced in a chemical ionization source, has also been used successfully to study the mass spectra of metal complexes. These studies have shown that all the complexes studied will form stable negative ions as a result of the resonance capture of thermal electrons [27]. The conclusions which may be drawn from these studies are that negative ions appear to be more useful than positive ions since there are no competetive ion-molecule reactions to change the isotopic abundances of the sample ions. Two applications of chemical ionization were reported: the determination of ruthenium on membrane filters and the use of enriched ${ }^{54} \mathrm{Fe}$ to study iron absorption [27]. The sensitivities of electron impact ionization and chemical ionization were comparable $10^{-7}$ to $10^{-13} \mathrm{~g}$ of element since the limitation in sensitivities has been the methods of sample introduction.

Metal complexes have been introduced into the source of the mass spectrometer via the solids probe or by the gas chromatographic inlet. The former mode of intro- 
duction suffers from the irreproducible loss of sample by sublimation during the insertion of the probe through the vacuum seal, and the latter from the irreversible absorption on the column. These sample losses cause this methodology to be unsuitable as a general analytical technique for trace or ultratrace element analysis although it does provide excellent analyses for those metals which form stable and volatile chelates ( $\mathrm{Cr}, \mathrm{Be}$ and $\mathrm{Al}$ ). Gas chromatography-mass spectrometry could, however, be used to speciate and quantify those elements which are emitted as volatile species. Examples of such applications are as follows: volatile hydrides of arsenic, antimony, selenium, and tellurium; metal carbonyls of iron, chromium, molybdenum, and tungsten; and the alkyl derivatives of mercury, lead, and tin. All these compounds have been successfully separated and quantified by gas chromatography using more conventional detection systems [22]. The analysis of metals via the formation of volatile complexes can only be used for those studies which are concerned with the quantification of trace elements since these types of complexes are unlikely to be potential environmental emissions. However, the major advantages of the formation of metal complexes are that they can be used to concentrate the metals by solvent extraction into a suitable organic solvent, or else can be used to remove the metal from an interfering matrix. Also, the formation of metal complexes could conceivably be used to quantify unbound metal species if there is a difference between the formation constants for the bound metal versus the metal chelate.

The most exciting recent advance in the field of mass spectrometry has been the successful coupling of a liquid chromatograph to a mass spectrometer. This advance has recently been reviewed by Arpino and Guiochon [28]. Liquid chromatography only requires that there exist a difference between the interaction of the solute and the mobile phase versus the solute and the column packing materials. This field of separation offers a wide variety of mobile phases and column packing materials which allow the separation of almost any sample. In fact, the only limitation to the type of sample which can be separated has been the paucity of detectors to monitor the column effluent.

The publications which have reported the separation of metal species by liquid chromatography have been extensive. Ion-exchange chromatography has been the most popular, and studies reporting the high performance liquid chromatographic separation of metal complexes have been less prolific even though the first application of this technique was reported by Huber et al. in 1972 [29]. The major limitation has been monitoring the column effluent since metal species are often ultraviolet transparent. This problem has been solved by the use of various atomic spectrometric detection systems and already these detectors have enabled metal speciation to be performed. Van Loon has recently reviewed these very limited applications $[30,31]$. This mode of identification relies extensively on the chromatographic retention data and the use of 
known standards since the detector is element specific. The liquid chromatograph-mass spectrometer will remedy this obvious deficiency.

A number of designs for the interface have been reported and, currently, commercial interfaces are available [28]. The pioneers of this field have been Horning, McLafferty, Scott, Vestal, and McFadden and all their designs have attempted to overcome the major problem which is the removal of large volumes of mobile phases. This difficulty has been solved by a variety of methods and, often, the residual mobile phase, has been used as the reactant gas to ionize the sample via chemical ionization. The results to date have been encouraging, and detection limits on the order of $10^{-12} \mathrm{~g}$ have been obtained. An additional benefit has been accrued by the direct coupling of a liquid chromatograph to a mass spectrometer since with this system it has been shown that it is possible to obtain the mass spectra of non-volatile samples. This advantage was predicted by Giddings et al. in 1970 [32], and will be a major utility in the speciation of trace elements. However, if the volatility of the sample does present a problem in the generation of intense mass spectra then post-column reactions between the column effluent and suitable reagents could be used to increase the volatility of the sample. Currently, most of the published reports have been more concerned with the development of improved interfaces and, as a result, the applications of direct-coupled liquid chromatographsmass spectrometers are still limited. Although no applications of this recent advance have been reported in the area of trace element analyses it is probably only a matter of time since this area has major significance.

\section{Conclusions}

Mass spectrometry is an analytical technique which can provide important information on the bioavallability and speciation of trace elements. These measurements are crucial if the emissions from energy related sources are to be evaluated for their potential health risks.

\section{Acknowledgment}

This work has been partially supported through grants from the U.S. Environmental Protection Agency (R803651 and R806558). 


\section{References}

[1] Schuetzle, D.; Lee, F. S.-C.; Prater, T. J.; Tejada, S. B. The identification of polynuclear aromatic hydrocarbon derivatives in mutagenic fractions of diesel particulate extracts. Int. J. Environ. Anal. Chem., in press.

[2] Risby, T. H.; Yasbin, R. E.; Lestz, S. S. Diesel particular matter: chemical and biological assays. Int. Symp. Health Effects of Diesel Engine Emiss. 1: 359; 1980.

[3] Lee, R. E. Jr.; Crist, H. L.; Riley, A. E.; MacLeod, K. E. Concentration and size of trace metal emissions from a power plant, a steel plant, and a cotton gin. Environ. Sci. Technol. 9: 643; 1975.

[4] Lee, R. E. Jr.; Von Lehnder, D. J. Trace metal pollution in the environment. J. Air. Pollut. Control Assoc. 23: 853; 1973.

[5] Bennett, R. L.; Knapp, K. T. Chemical characterization of particulate emission from oil-fired power plants. 4th Conference on Energy and the Environment, Cincinnati, $\mathrm{OH}$; 1976.

[6] Natusch, D. F. S.; Wallace, J. R.; Evans, C. A. Jr. Urban aerosol toxicity, the influence of particle size. Science 183: 202; 1974.

[7] Mertz, W. Present status and future development of trace element analysis in nutrition, in Ultratrace metal analysis in biological sciences and environment, Vol. 172.

T. H. Risby, ed. Adv. Chem. Ser. Washington, D.C.: American Chemical Society; 1979.

[8] Top, F. H. Environment in relation to infectious disease. Arch. Environ. Health 9: $699 ; 1964$.

[9] Underwood, E. J. Trace elements in human and animal nutrition. New York: Academic Press; 1976.

[10] Mertz, W. Defining trace element deficiencies and toxicities in man, in Molybdenum in the environment, Vol. 1. W. G. Clappel1 and K. K. Petersen, eds. New York: Dekker; 1976.

[11] Kovalski, V. V.; Jarovaya, G. A.; Shmavonjan, D. M. Changes in purine metabolism in man and animals in various molybdenum-rich biogeochemical provinces. Z. Obsc. Biol. 22: $179 ; 1961$.

[12] Parizek, J.; Kalouskova, J.; Babicky, A.; Benes, J.; Pavlik, L. Interaction of selenium with mercury, cadmium, and other toxic metals, in Trace element metabolism in animals, Vol. 2. W. G. Hookstra, I. W. Suttie, H. E. Ganther, and W. Mertz, eds. Baltimore: University Park Press; 1974.

[13] Aston, F. W. Mass spectra and isotopes. New York: Longmans Green and Co. ; 1933.

[14] Ahearn, A. J. Trace analysis by mass spectrometry. New York: Academic Press; 1972.

[15] Fassel, V. A.; Knisely, R. N. Inductively coupled plasmas. Anal. Chem. 46: 1155A; 1974.

[16] Yergey, A. L.; Viera, N. E.; Hansen, J. W. Isotope ratio measurements of urinary calcium with a thermal ionization probe in a quadrupole mass spectrometer. Anal. Chem. 52: 1811; 1980.

[17] Moore, L. J.; Michlan, L. A. High accuracy determination of calcium in blood serum by isotope dilution mass spectrometry. Anal. Chem. 44: 2291; 1974.

[18] Stahl, W. Calcium isotope variations of natural samples. Proc. Int. Conf. Mass Spectrosc. Kyota, Japan 707: 1969. 
[19] Huber, W. K.; Rettinghans, G. Adaption of a thermal ion source to a quadrupole mass spectrometer. Adv. Mass. Spectrom. 8B: 1638; 1980.

[20] Lederer, M. Separation of rare-earth elements. Nature. 176: 462; 1955.

[21] Moshier, R. W.; Sievers, R. E. Gas chromatography of metal chelates. New York: Pergamon Press; 1955.

[22] Guiochon, G.; Pommier, C. Gas chromatography of inorganics and organometals. Ann Arbor, MI: Ann Arbor Science Publishers; 1973.

[23] Gasco, L.; Risby, T. H. Separacion cromatografica de quelatos metallicos en fase gaseosa. Energia Nucl. 78: 421; 1972.

[24] Burgett, C. A. Gas chromatography of diketonates. Separ. Purif. Methods. 5: 1; 1976.

[25] Uden, P. C.; Henderson, D. E. Determination of metals by gas chromatography of metal complexes: Review. Analyst. 102: 889; 1977.

[26] McLafferty, F. W. Mass spectrometry in chemical research and production. Appl. Spectrosc. 11: 148; 1957.

[27] Risby, T. H. Use of negative chemical ionization mass spectrometry for the trace analysis of metals. Environ. Health Perspect. 36: 39; 1980.

[28] Arpino, P. J.; Guiochon, G. LC/MC coupling. Anal. Chem. 51: 862A; 1979.

[29] Huber, J. F. K.; Kraak, J. C.; Verning, H. Rapid separation of metal chelates by column liquid-liquid chromatography using ultraviolet detection. Anal. Chem. 44: 1554; 1972.

[30] Van Loon, J. C. Metal speciation by chromatography atomic spectrometry. Ana]. Chem. 51: 1139 A 1979.

[31] Van Loon, J. C. Metal speciation studies using metal-specific detectors for chromatography. Amer. Lab. 13: 47; 1981.

[32] Giddings, J. C.; Myers, M. N.; Wahrhaftig, L. Problems in the gas phase isolation of non-volatile molecules by high pressure jets for mass spectrometry. Int. J. Mass Spectrom. Phys. 4: 9; 1970.

Discussion

Question (R. E. Sievers): I'm wondering if the problem that you mentioned with respect to the instability of the iron-THD complex in the chromatographic system could be overcome by using a column with little less active surface, like a fused silica capillary column. Have you tried that yet?

Answer: No, we haven't tried for this obvious solution. I'm really quite interested in trying liquid chromatography-mass spectrometry (LC-MS) because of its ability to separate geometric isomers. 
Question (R. E. Sievers): I think you're going to have a problem looking at geometrical isomers of at least iron(III) complexes by LC, because of the expected rapid rate of interconversion.

Answer: The point that I was trying to make is that LC doesn't introduce a new dimension.

Question (R. S. Braman): Please explain how you're going to interface a liquid chromatograph with a mass spectrometer.

Answer: There are two commercially available LC-MS systems. One involves a moving band in which the column effluent, before it goes into the mass spectrometer, is evaporated leaving a residual component.

Question (R. S. Braman): How does the band get into the mass spectrometer when the mass spectrometer is pumped down?

Answer: That's really not a major problem, because you can go through seals. That is the Finnegan system. There is another system which has been used which is based on a heated drum. The column effluent passes it through a heated drum at very fast pumping speeds.

Question (R. S. Braman): Are there some types of prepumping stage with a control inlet?

Answer: There are various designs in the vessel system, one case even uses a oxyacetylene torch to evaporate the sample. There's another group here at NBS with Harry Hertz, who is involved in LC-MS design [Christensen, Hertz, Meiselman, White, Anal. Chem. 53: 171 (1981)]. He's just taking a small portion of the overall sample. The point is valid; whenever you use the gas as a mobile phase, it's relatively easy to remove through separators and pumps. With liquid chromatography, that is a major problem. You've got a liquid mobile phase which means a lot more material must be vaporized. It is quite probable that the designs that are available now aren't the ultimate designs.

Question (R. Braman): Those little technology problems sometimes can get very big, and that's why I asked the question.

Answer: The amount of analytical chemistry one possibly finds when interfacing on LC with a mass spectrometer is extensive. I think it was in 1979, Arpino and Guiochon wrote a review [Anal. Chem. 51: 682A (1979)]. There was a whole series of designs given. 
Question (W. R. Wolf): You mentioned use of mass spectrometry for speciation, and that the species must be volatile for identification. Except for those of us who have spent so many years working with volatile metal chelates--the $\beta$-diketones--the interest as far as health aspects and exposure to these is rather limited. How do you propose to look at volatile species which may be of more interest from a health aspect?

Answer: The point is valid. Mercury is one example, the nonmetals such as arsenic, antimony, and selenium are other examples known to form volatile hydrides. These are reasonable species that can be analyzed by mass spectrometry. In terms of metals that occur naturally complexed with humic acid metal-chelating complexes, I think that's where LC-MS is going to be an important area; where you hope you don't require the stability or volatility necessary for analysis by gas chromatography/mass spectrometry. LC-MS will be very useful in speciation of metals. Ideally, one hopes that the column effluent will retain its integrity during the process of passage into the mass spectrometer.

Question (W. R. Wolf): You mentioned the stability of some of these $\beta$-diketones. What are some other classes of ligands or chelates that could be used to form stable compounds? Or can you use these for some metals which don't form stable $\beta$-diketonates?

Answer (R. E. Sievers): The work of Prof. Uden with respect to formation of Schiff base complexes, starting with a $\beta$-diketonate and something like ethylenediamine or the higher polyamines, applies here. He has shown that, for certain of the divalent elements, the coordination sphere of the metal ion is higher in the case of the divalent metal ions, such as the alkaline earth ions or certain of the divalent nickel or cobalt ions. Where these extra coordination sphere positions can be filled by something besides water, you end up with a more stable complex. These complexes are not likely to decompose due to selfhydrolysis to form refractory polymers. I think there is promise also in building multidentate $\beta$-diketonates that have the potential for greater stability. There are literature reports in the last few years on several $\beta$-diketonate moieties combinations giving intrinsic additional stability. So those are two possible directions in which one might go.

I think we picked up on what Dr. Risby said concerning speciation of oxidation states. If you can form the derivative that's volatile and can get information about it without an oxidation state change, then you're ahead of the game. I think it's generally assumed that there will be very few compounds of the metals that are sufficiently volatile for mass spectrometry. Nevertheless, given that in many of the processes for upgradings, say pyrolysis of oil shale to get the first crude shale oil, you're still getting measurable concentrations of certain elements appearing in the distillates. Assuming that these are not physically transported by some sort of aerosols, these had to get into the gas phase. We don't need anywhere near the volatility to obtain a mass spectrum that we need to get progression through a gas chromatographic column at an appreciable rate. So, a combination of more stable complexes, more inert chromatographic media, and fused silica capillary columns are a great help in that respect. 
Question (S. E. Manahan): Dr. Uden, your work has been mentioned so much this afternoon ... Do you have any comments?

Answer (P. C. Uden): Regarding to Dr. Wolf's last question, I think one area of possible development which is not being pursued too much at the present time concerns metal speciation of volatile $\pi$-bonded organometallics, not the $\sigma$-bonded organometallics of the tetraalkyllead variety. In that context, I mention this in my paper, the cyclopentadienylchromium carbonyl. Apparently, some people feel that such species may be related to the uptake of metals in actual energy-related systems.

I think my observations are very near Dr. Siever's comments on the fused silica columns. Many things which previously were thought not susceptible to chromatography we now know are at least worth a try. That is quite an exciting development.

If the chemistry compound allows the organometallic to be volatilized or sublimed, then there's a good chance that it can be handled in this way.

Question (R. H. Fish): Dr. Sievers, I'm particularly interested in polymeric ligands. What about putting $\beta$-diketones onto polystyrene backbones for removal arsenic compounds and vanadium compounds, etc. from some of these effluents, such as shale, retort oils, water, and heavy crude oils. It seems to me this is an interesting area. One method would be to react these effluents with immobilized macroligands. Do you have feelings about specificity and types of polymers that could be made or are available?

Answer (R. E. Sievers): Indeed, there is and has been activity in the introduction of complexing groups in polymer matrices for a variety of very interesting applications, not the least of which is the removal of gold and other precious metals from mine waters. The patent work of Ernst Bayer and his colleagues [Chem. Abstr. 85: P13139t (1979) et seg.] relates to very specific ligand-containing moieties that have much higher affinity and selectivity for the precious metals than for the common metals. Consequently, you don't load up on your resin with unwanted elements like iron. It is just a question of determining what you want to do and whether you can bear the cost for those elements you need to remove, and whether there's value in recovering them or whether you're only trying to immobilize them and to provide alternative waste treatments. 
Question (F. E. Brinckman): Dr. Risby, this applies to your comments on the coupling of LC with mass spectrometry, or possibly other detectors, and the comments made by a number of speakers today on the need for speciation of metals or metalloids with respect to their oxidation states. The difficulty frequently lies in the separation methodology available for liquid chromatography, particularly ion exchange chromatography and ion-pair chromatography. You must have a proper system with some salt content, some ionic strength. What prospects do you, or others here, see in solving the mass transport of buffer solution plus the analyte in going across and removing an aqueous, at least water-containing effluent from the column, plus the salt, and still retaining the integrity of separated analyte species?

Answer (P.C. Uden): There's one approach some people might be aware of. Barry Karger has shown a continual extraction process for reverse-phase separations where you can handle systems difficult for mass spectrometry. You continue the extraction process then transfer into a liquid phase which is more compatible with the mass spectrometer. Karger set up this particular design for the Finnegan moving band system about a year and a haif ago, but it's certainly amenable to any particular system that's been devised.

Comment (T. H. Risby): But the problem with that is that it's not designed for ion exchange.

Answer (P. C. Uden): No. One has to address the problem of the chemistry; you have to put your extraction chemistry to work and your reaction chemistry to work because there is a real gap between some of the separation processes and some of the detection processes. It's a hard problem and I think many people are going to spend a lot of many years over this.

Question (R. E. Sievers): In relation to your studies in which you're trying to very gently separate things and see whether there are any associations that can be made, have you considered what's called droplet counter-current chromatography? The counter current streams moving little droplets that people in natural products chemistry have used so successfully in the last couple of years. Has anyone here had any luck with droplet counter-current chromatography? It would appear to me that this is a very gentle and yet effective way of pulling things apart for further examination, whether by MS, AA, or whatever. No! We11, I think that's something we're going to try then. 
Diffusional Discrimination and Reversible Chemisorption for Speciation in Air

R. S. Braman and T. J. Shelley

Department of Chemistry

University of South Florida

Tampa, Florida 33620

Hollow air sampling tubes having chemisorbing interior coated walls offer several attractive features useful in preconcentration for air analysis. A high discrimination of gaseous versus particulate forms is achieved based upon the much greater diffusional activity of molecules. Since the preconcentration of gases is achieved without the use of filters, particle-gas interconversions are avoided. The dynamics of such a system have been described mathematically and form the basis for accurately determining the diffusion coefficients, and hence the molecular form of gases in air, even at sub-ppb concentrations. Several different selective chemisorbing surfaces can be used for studies of mercury, arsines, sulfur compounds, and nitrogen compounds in air.

Key words: air analysis; diffusion; hollow tubes; mercury; preconcentration.

\section{Introduction}

Speciation for trace analytes in air analysis is often done by a combination of preconcentration, separation and detection techniques. Selective absorption on surfaces in packed tubes or cold trapping are often used followed by gas chromatographic analysis. In most cases, little attention is given to discriminating between the gaseous and particulate state of an analyte or in determining its molecular form or associations in ambient air.

A number of problems can arise in preconcentration and analysis of air samples. Photochemical oxidants are generally present in much greater amounts than many trace analytes sought. Ozone can range from 30 to $100 \mathrm{ppb}$, even in comparatively non-polluted air. Nitric acid, $\mathrm{N}_{2} \mathrm{O}_{4}$, and PAN are often present in significant amounts. When analytes are preconcentrated by some general physical method such as cold trapping, considerable amounts of the oxidants are also trapped and interaction of trapped materials on surfaces can occur to alter the analyte composition.

Filters are subject to the same and similar problems when trying to discriminate between the particulate and gaseous forms of an element. Reactions on filter surfaces can alter analytes. Alkaline trapped particles can react with acidic gaseous molecules. Vapors can be absorbed on trapped organic particulate and thus appear to be in the particulate.

Filters also are limited in the discrimination that can be made in particle size. The smallest filter sizes used appear to be near 0.1 micrometers. Determinations of particle size distributions are made above this size using filter stacks. The larger particles in the 2 to 10 micrometer range generally have the greater mass of total particles. The entire range of analyte physical sizes from molecular to 0.01 micrometers are not easily studied, largely because appropriate analytical methods are not readily available. 
Optical light scattering methods are usually employed for the sizes below 0.3 micrometers. The main thrust of this discussion is to examine a new analytical approach involving the collection of analytes on the specific chemisorbent interior coatings of hollow tubes as preconcentrators. This technique has the following characteristics:

* Volatile components are preferentially removed from gas samples without encountering filter reaction problems.

* Experimental results agree closely with the mathematically modeled dynamics of the tubes.

* Diffusion coefficients of chemisorbed gases can be determined with reasonable precision.

* Diffusion coefficient studies permit the prediction of the molecular form or detect the presence of weak associations of detected molecules.

* Studies can be carried out on ambient air samples at ambient concentrations.

* The technique is applicable for any analyte for which a rapid surface chemisorption reaction and reversible desorption, or removal, is available.

The general approach is to preconcentrate gaseous analytes on a specific absorbing surface and particulate analytes on a filter or packed tube. This is followed by an analysis of either, or both, preconcentrators. To date, only a few specific applications have been made, but the potential applicability is great. The theory of the hollow tube functions will be developed first below followed by a review of current and projected applications.

2. Theoretical Behavior of Hollow Tubes in Laminar Flow

2.1 Fundamental Equations

The deposition of gases and particles from a gas stream under conditions of laminar flow has been described mathematically by Gormley and Kennedy [1]. Laminar flow (as contrasted to turbulent) is a condition in which the distribution of particles or molecules from the tube stream is parabolic to the tube surface. Deposition of molecules or particles is by diffusional transport. In a practical sampling system, a certain length of intake tubing is required to establish laminar flow. This length, $L$, depends upon flow rate, tube diameter and the kinematic viscosity of air (which is influenced by temperature). From equation 1 which relates $L$ to the Reynolds number, Re, and tube radius $r$,

$$
L=0.1 \mathrm{r} \operatorname{Re}
$$

one can obtain

$$
L=0.2 \mathrm{~F} / \pi 0.1562
$$

which relates $L$ to the air flow rate in $\mathrm{cc} / \mathrm{s}$ and the kinematic voscosity of air at $25^{\circ} \mathrm{C}$, 0.1562 stokes. From equation $2 \mathrm{~L}$ for $1.5 \mathrm{~L} / \mathrm{min}$ is $10.2 \mathrm{~cm}$. Sampling tubes are, consequently, constructed with $10-15 \mathrm{~cm}$ of uncoated lead-in sections. 
A second major requirement is that collisions be effective and essentially irreversible. This is likely the case for particles and multimolecular aggregates. For molecules reacting with a chemisorbing surface, the following equilibrium is important:

$$
\begin{array}{ll}
A(g) \underset{k_{2}}{\stackrel{k_{1}}{\rightleftarrows}} & A(p) \underset{k_{4}}{\stackrel{k_{3}}{\rightleftarrows}} A(c) \\
\text { gas phase } & \text { physisorbed } \quad \text { chemisorbed }
\end{array}
$$

The rate constant of transfer to a chemisorbed (or reacted) state, $k_{3}$, must be sufficiently rapid that the absorption rate constant $k_{1}$ becomes the overall rate-controlling process. The rate constant, $k_{4}$, of reversible chemisorption is generally vanishingly sma11 except for thermally reversible cases at higher temperatures.

When the above conditions are met, the first three terms of the Gormley-Kennedy equation describe gas and particle absorption:

$$
\begin{aligned}
C / C^{\circ}= & 0.819 \exp \left(-3.6568 \pi \mathrm{D} \cdot \mathrm{LF}^{-1}\right) \\
& +0.0976 \exp \left(-22.3 \cdot \pi \cdot \mathrm{D} \cdot \mathrm{LF}^{-1}\right) \\
& +0.032 \exp \left(-57 \pi \mathrm{DLF}{ }^{-1}\right)
\end{aligned}
$$

In equation $4, C / C^{\circ}$ is the fraction of analyte leaving a hollow tube of length $L \mathrm{~cm}$, having a diffusion coefficient $\mathrm{D} \mathrm{cm} \mathrm{cm}^{2} / \mathrm{s}$, with a gas flow rate of $\mathrm{F} \mathrm{cc/s}$. Some typical values for analyte absorption efficiencies calculated from equation 4 are given in Table 1. In making these calculations only the first term of equation 2 is significant, a situation which persists down to values of $\mu=0.2$, where $\mu=\pi \cdot L \cdot D \cdot F^{-1}$. Diffusion coefficients for most small molecules fall in the range of 0.1 to $0.2 \mathrm{~cm}^{2} / \mathrm{s}$, and so the efficiences calculated may be considered typical. Hollow tube preconcentrators then are usually $30-40$ $\mathrm{cm}$ in length and operated with 0.5 to $1.0 \mathrm{~L} / \mathrm{min}$ flow rates to obtain maximum efficiency.

Equation 4 is not precise for particles or larger molecules having small diffusion coefficients and becomes increasingly inaccurate for values of $\mu=0.05$ or less. For $\mu=0.05$ or less, the particle diffusion equation of Gormley and Kennedy [1] is used.

$$
N / N^{0}=1-2.56 \mu^{2 / 3}+1.2 \mu+0.177 \mu^{4 / 3}
$$

In equation $5, \mathrm{~N} / \mathrm{N}^{\circ}$ is the fraction of analyte particles or molecules passing through the hollow tube and $\mu$ is the grouping $\pi \mathrm{DLF}^{-1}$, as before. A combination of equations 4 and 5 can be used to describe collection of gases through small particles on hollow tubes. 
Table 1. Calculated Hollow Tube Absorption Efficiencies

\begin{tabular}{|c|c|c|c|}
\hline $\begin{array}{l}\text { Tube Length } \\
\qquad(\mathrm{cm})\end{array}$ & $\begin{array}{l}\text { Diffusion Coefficient } \\
\qquad\left(\mathrm{cm}^{2} / \mathrm{s}\right)\end{array}$ & $\begin{array}{c}\text { Flow Rate } \\
\text { (L/min) }\end{array}$ & $\%$ Trapped \\
\hline 10 & 0.20 & 1.0 & 79.4 \\
\hline 20 & 0.20 & 1.0 & 94.8 \\
\hline 30 & 0.20 & 1.0 & 98.7 \\
\hline 5 & 0.20 & 0.2 & 97.4 \\
\hline 10 & 0.20 & 0.2 & 99.9 \\
\hline 10 & 0.10 & 1.0 & 58.9 \\
\hline 20 & 0.10 & 1.0 & 94.8 \\
\hline 30 & 0.10 & 1.0 & 89.6 \\
\hline 40 & 0.10 & 1.0 & 94.8 \\
\hline 5 & 0.10 & 0.2 & 85.4 \\
\hline 10 & 0.10 & 0.2 & 97.4 \\
\hline
\end{tabular}

Discrimination of hollow tubes against diffusional collection of particles is shown in Table 2. Particles in the 0.1 micrometer range constitute a smal1 fraction of the total particulate mass and even these have only an extremely small collection efficiency. Collection of particles by gravitation is small but minimized by vertical mounting of hollow sampling tubes [2].

\subsection{Tubes of Finite Capacity}

Equations 4 and 5 were developed with the assumption that no tube depletion occurs. In chemisorption active sites or chemical capacity is diminished upon use. Collected analyte deposits at the inlet end down the tube length and depletes the tube in what is a first-order process dependent upon analyte concentration, gas flow rate, and tube capacity, which is a function of tube length assuming a linear homogeneity in coating capacity.

Equation 4, using only the first term, then becomes:

$$
C / C^{\circ}=0.819 \exp \left(-3.6568 \pi \cdot D F^{-1} \text { Lo exp }-k t\right)
$$

where Lo is the apparent capacity at time zero and $k=f \cdot C^{\circ} / g$, for a total tube capacity of $g$. Equation 6 has been used to model tube depletion over reasonable values of $\mu$ which 
also decreases during tube depletion. By taking the logarithm of equation 6, twice the following is obtained:

$$
\ln \left(-\ln C / C^{\circ} 0.819\right)=\ln 3.6568 \cdot \pi \cdot D \cdot \operatorname{LoF}^{-1}=k t
$$

Plotting $\ln \left(-\ln C / C^{\circ} 0.819\right)$ versus $t$ gives a straight line. The value of $k$ can be determined from the slope and Lo from the intercept. Although diffusion coefficient values may theoretically be determined from the intercept, they were found to be less accurate and precise than the method discussed later.

Table 2. Theoretical Discrimination of Gases vs. Particles

\begin{tabular}{lccc}
$\begin{array}{l}\text { Size, } \\
\text { Radius }\end{array}$ & $\mathrm{D}\left(\mathrm{cm}^{2} / \mathrm{s}\right)^{\mathrm{a}}$ & $\begin{array}{l}\text { Efficiency of } \\
\text { Collection }\end{array}$ & $\begin{array}{c}\text { Equation } \\
\text { Used }\end{array}$ \\
\hline $0.1 \mu \mathrm{M}$ & $2.2 \times 10^{-6}$ & $0.36 \%$ & 5 \\
$0.01 \mu \mathrm{M}$ & $1.4 \times 10^{-4}$ & $5.4 \%$ & 5 \\
$\mathrm{HNO}_{3}$ & 0.12 & $95.5 \%$ & 4 \\
$\mathrm{NH}_{3}$ & 0.236 & $99.7 \%$ & 4 \\
$\mathrm{Hg}$ & 0.16 & $98.3 \%$ & 4
\end{tabular}

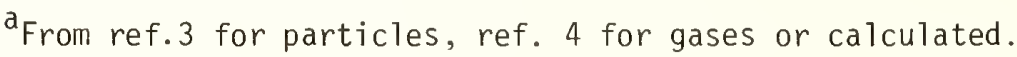

${ }^{b}$ For $1.0 \mathrm{~L} / \mathrm{min} .35 \mathrm{~cm}$ tube.

\subsection{Diffusion Coefficient Determination}

Hollow tubes have been used to determine diffusion coefficients of particles and gases. Thomas [5] reported the use of "diffusion batteries" for determining the diffusion coefficients of comparatively high concentrations of ammonia and sulfur trioxide in air, and of particles of sodium chloride in air. Sinclair [6] and Sinclair et al. [7] have also used the diffusion battery for particle diffusion coefficient work. All of these methods analyzed the particle or gas concentration coming through the apparatus rather than analyzing the trapped analytes. No attention was given to the problem of finite tube capacity.

In earlier work [8], it was shown that, for a single analyte, equation 4 can be used to describe the amount of the analyte absorbed in various sections of a long hollow tube. A section-by-section analysis verified the prediction of equation 4 that an absorbed analyte is distributed exponentially down a tube. 
Equation 4, in terms of the amounts found on the first hollow tube in a series is:

$$
S_{1}=S_{T}\left[1=0.819 \exp \left(-3.6568 \pi \cdot D \cdot L_{1} F^{-1}\right)\right]
$$

where $S_{1}$ is the analyte found on the first tube and $S_{T}$ is the total analyte passed through the tube series. If, in a pair of tubes, sufficient length of the second one is used, it can be considered to collect essentially $S_{T}-S_{1}$ of the analyte. From the ratio $S_{1} / S_{T}$ and a carefully measured tube length, reasonably precise values of $D$ can be calculated. Samples sizes must be sufficiently small so as not to significantly depelete the first tube. Samples used in recent work have been on the order of $1 \%$ of the total tube capacity, an advantage of sensitive detection techniques. If the depletion rate constant, $k$, is known for a tube, an estimate of its mean effective length can be made and an appropriate correction applied.

\subsection{Error Function for Diffusion Coefficient Determinations}

The precision of diffusion coefficient values determined from use of hollow tubes and equation 8 depends upon the precision in measuring $L, F$ and $S_{1}$ and $S_{T}$. The precision in $D$ is directly proportional to the precision of $L$ and $F$ which can be measured to within $1 \%$ r.s.d. An error function can be derived to determine the effect of precision in the analysis data ratio, $S_{7} / S_{T}$, on the precision of $D$. If $S_{1} / S_{T}=R$, equation 8 is rearranged and the logarithm taken;

$$
\ln (1=R / 0.819)=-b D
$$

where $-b$ is $-3.6568 \pi \cdot L / F$. Differentiation of equation 9 leads to:

$$
d D=\frac{1}{b} \frac{1}{1-R}=d R
$$

Division of equation 10 by equation 9 , and assuming $d D=\Delta D$, obtains the error function for $D$ in terms of $\Delta R$.

$$
\frac{\Delta D}{D}=-\left[\frac{1}{(1-R \ln (1-R) / 0.819}\right]^{\Delta R}
$$

The value of the function in the brackets may be determined versus $R$ as is shown in Table 3. The minimum is also a minimum in $\triangle D / D$. The minimum error is a $R$ value of 0.70 , but reasonably good precision is obtained over a wide range of $R$ values. Experimental conditions of $L$ and $F$ can be adjusted so that $R$ is in the minimum error range. 
Table 3. Error Function for Diffusion Coefficient Determination

\begin{tabular}{cccc}
\hline$R\left(S_{1} S_{T}\right)$ & Error Function & $R\left(S_{1} / S_{T}\right)$ & Error Function \\
\hline 0.20 & 53.3 & 0.70 & 3.33 \\
0.30 & 9.10 & 0.80 & 3.55 \\
0.40 & 5.36 & 0.86 & 4.04 \\
0.50 & 4.05 & 0.90 & 4.76 \\
0.60 & 3.49 & 0.96 & 8.28 \\
0.66 & 3.35 & 0.98 & 13.47 \\
\hline
\end{tabular}

From Table 3 it can be seen that a $1 \%$ uncertainty in $R, \Delta R=0.01$, produces a $3 \%$ uncertainty in $D$. Several determinations can be averaged. The precision of diffusion coefficient determinations is on the order of a few percent, suitable for detecting the presence of hydrates, dimers, and aggregates.

Equation 11 is quite similar to the equation expressing the error plot for spectrophotometric measurements. In the analogy, $1-R$ corresponds to transmittance and $L$ to concentration.

\subsection{Diffusion Coefficients from Physical Data}

Molecular diffusion coefficients of compounds in air can be calculated with reasonable accuracy $( \pm 8 \%)$ using the method of Wilke and Lee [4]. Data are needed on the molal volume of the liquid at its boiling point, its composition, and boiling point temperature. Since very little is available on the diffusion coefficients or organometallic compounds, few calculations for selected compounds of interest have been made. Values calculated using the best molal volume and boiling point numbers available are in the $0.06-0.12 \mathrm{~cm}^{2} / \mathrm{sec}$ range.

From the diffusion equation of Wilke and Lee one can observe two important characteristics of diffusion coefficients. They depend inversely upon total pressure and

$$
D=\frac{T^{3 / 2}}{P} k
$$

directly upon the 1.5 power of the absolute temperature. (The constant $k$ in equation 12 is a collection of physical data not dependent upon temperature or pressure.) Day-to-day fluctuation in pressure will exert on $1 y 1-2 \%$ changes in $\mathrm{D}$. Corrections to $25^{\circ} \mathrm{C}$ can be made for purposes of comparison. Hollow tube preconcentration systems should not be operated at reduced pressures if diffusion coefficients are to be measured. 


\section{Applications}

\subsection{Review}

Applications of hollow tubes in air analysis are given in Table 5. Hollow tubes were first used to remove interferences from gas streams being analyzed. Nitric acid was removed from an air stream being analyzed for total $\mathrm{NO}_{\mathrm{x}}$ compounds in a method developed by Shaw [9]. A parallel sampling line not having a nylon filter was analyzed simultaneously; the difference could be attributed to nitric acid. Stevens et al. [10] used the absorption of $\mathrm{NH}_{3}$ on phosphoric acid for its removal to avoid interferences in $\mathrm{H}^{+}$analysis of aerosols. Durham et a1. [11] have used the method for removing $\mathrm{SO}_{2}$ from aerosols.

Ferm [2] developed a hollow tube preconcentration method for ammonia in air based upon absorption of ammonia on an oxalic acid surface. The tubes were washed out and analyzed for ammonia by ion-selective electrode.

The only completely developed regenerative surface method to date is that of Braman et a1. [8] using tungstic acid, an amphoteric solid surface on quartz, which collects both ammonia and nitric acid and then is analyzed by thermal regeneration and detection by a chemiluminescent analyzer. Fractional ppb concentrations of the analytes could be determined.

$$
\begin{aligned}
2 \mathrm{NH}_{3}+\mathrm{H}_{2} \mathrm{WO}_{4} & \longrightarrow\left(\mathrm{NH}_{4}\right)_{2} \mathrm{WO}_{4} \\
2 \mathrm{HNO}_{3}+(\mathrm{HO})_{2} \mathrm{WO}_{2} & \longrightarrow\left(\mathrm{NO}_{3}\right)_{2} \mathrm{WO}_{2}+\mathrm{H}_{2} \mathrm{O} \\
\left(\mathrm{NH}_{4}\right)_{2} \mathrm{WO}_{4} \text { heat } & \longrightarrow 2 \mathrm{NH}_{3}+\mathrm{H}_{2} \mathrm{WO}_{4} \\
\left(\mathrm{NO}_{3}\right)_{2} \mathrm{WO}_{2} \mathrm{H}_{2} \mathrm{O}+\text { heat } & \longrightarrow 2 \mathrm{NO}_{2}+\mathrm{H}_{2} \mathrm{O}_{2}+\mathrm{H}_{2} \mathrm{WO}_{4}
\end{aligned}
$$

\begin{tabular}{|c|c|c|c|}
\hline Analyte Sought & Collecting Surface & Remarks & Ref \\
\hline $\mathrm{NH}_{3}$ & oxalic acid & not regenerated & 2 \\
\hline $\mathrm{NH}_{3}, \mathrm{HNO}_{3}$ & $\mathrm{H}_{2} \mathrm{WO}_{4}$ & regenerated $\mathrm{NO}_{x}$ analyzer, $\mathrm{ppb}$ & 8 \\
\hline $\mathrm{NO}_{2}$ & $\mathrm{Ag}$ & regenerated $\mathrm{NO}_{x}$ analyzer, $\mathrm{ppb}$ & 15 \\
\hline $\mathrm{Hg}$ & $\mathrm{Ag}$ & regenerated, d.c. discharge & 12 \\
\hline $\mathrm{AsH}_{3}, \mathrm{CH}_{3} \mathrm{AsH}_{2},\left(\mathrm{CH}_{3}\right)_{2} \mathrm{AsH}$ & $\mathrm{Ag}$ & potential application, regen. & 16 \\
\hline $\mathrm{H}_{2} \mathrm{~S}, \mathrm{SO}_{2}, \mathrm{DMS}, \mathrm{COS}, \mathrm{CS}_{2}$ & $\mathrm{Au}$ & potential application, regen. & 17 \\
\hline $\mathrm{HNO}_{3}$ & $\mathrm{NaCl}$ & $\begin{array}{l}\text { not regenerated solution } \\
\text { analysis, ppb }\end{array}$ & -- \\
\hline
\end{tabular}

Diffusion coefficient data were also obtained in this work.

Table 4. Applications of Hollow Tube Preconcentration 


\subsection{Elemental Mercury}

In earlier work [12] on the speciation of mercury in air, tubes packed with silver or gold coated glass beads were used to preconcentrate mercury compounds. Mercury was desorbed by heating and detected in a d.c. discharge. Detection limits were on the order of $0.01 \mathrm{ng} \mathrm{Hg}$ per sample.

The same detection system is being used in current work but with silver metal coated hollow tubes as preconcentrators. To date, investigations have been limited to studies of elemental mercury, but silver does not preconcentrate dimethylmercury nor collect particulate mercury so some speciation is provided. Elemental mercury was found to preconcentrate. on silver hollow tubes and is readily thermally desorbed in 5 - 15 seconds so that sharp peaks are observed.

The diffusion character of elemental mercury indoors proved to be interesting and complex. Published values of diffusion coefficients, $0.15-0.16 \mathrm{~cm}^{2} / \mathrm{s}$, indicated that elemental mercury could be efficiently removed by amalgamation on $25 \mathrm{~cm}$ lengths of preconcentrator surface at 0.5 to $1.0 \mathrm{~L} / \mathrm{min}$. This was not found to be the case for mercury. Syringe samples of saturated mercury vapor in air essentially all passed through silver hollow tubes without collection and were collected on packed tubes which collect the particulate forms.

Subsequent analyses were made of room air and breakthrough capacity runs were carried out using silver tubes. These indicated that the mean apparent diffusion coefficient for mercury was well below the reported range. Table 5 gives values from selected analyses. Mathematical analysis of the flow rate versus $S_{7} / S_{T}$ indicates that more than one mercury component is present, one having the $0.16 \mathrm{~cm}^{2} / \mathrm{s}$ diffusion coefficient (65\%) and another having a diffusion coefficient typical of condensation nuclei sized particles (35\%). It appears that mercury in air, at least for indoor air samples, is in an equilibrium. Saturated mercury

$$
\times \mathrm{Hg} \rightleftarrows(\mathrm{Hg}) \times(0.01-0.001 \mu)
$$

in air likely has a much higher percentage of condensing mercury droplets.

\subsection{Other Applications}

As indicated in Table 4, a number of applications of hollow tube preconcentration are already indicated by recent, current work. In the area of organometallic preconcentration the arsines are the most likely target analytes. Arsines are basic in character, being chemical analogs of ammonia and the amines. Consequently, an acidic coating such as oxalic acid, phosphoric acid or the regeneratable tungstic acid could be used. Silver was used in the referenced work.

Metals need not be used, nor thermally regenerable surfaces. The variety of acidbase, complexation or redox-surfaces is only limited by the chemical character of analytes sought. 
Table 5. Diffusion Coefficient Data on Mercury

$\begin{array}{lcc}\frac{\text { Flow Rate }}{\mathrm{L} / \mathrm{min}} & \frac{\text { Calculated D. }}{\mathrm{cm}^{2} / \mathrm{s}} & \text { Remarks } \\ 0.90 & 0.0729 & \text { Room air } \\ 0.80 & 0.0669 & " \\ 0.70 & 0.0604 & " \\ 0.60 & 0.0681 & " \\ 0.50 & 0.0617 & " \\ 0.40 & 0.0617 & " \\ 0.30 & 0.0550 & " \\ 0.20 & 0.0477 & "\end{array}$

$\begin{array}{lll}1.0 & 0.17 & \begin{array}{c}\text { Filtered room } \\ \text { air }\end{array} \\ 0.12 & 0.0539 & \begin{array}{l}\text { From breakthrough } \\ \text { capacity study }\end{array}\end{array}$

Series, $\quad 0.16$

$0.9-0.2$

0.16 Room air, from mixture analysis

$0.160 \quad 25^{\circ} \mathrm{C}$, Ref. 13

$0.160 \quad 25^{\circ} \mathrm{C}$, Ref. 14

This work was supported in part by EPA grant no. R-806688010. The assistance of Carol Beadle in the work with mercury is hereby acknowledged.

4. References

[1] Gormley, P.G.; Kennedy, M. Diffusion from a stream flowing through a cylindrical tube. Proc. Royal Irish Acad. 52A:163-169; 1949.

[2] Ferm, M. Method for determination of atmospheric ammonia. Atmos. Environ. $13: 1385-1393 ; 1979$.

[3] Davies, C.N. Deposition from moving aerosols, chapter 12 in Aerosol Science, C.N. Davies, ed. New York, N.Y.: Academic Press:1966. 393-446.

[4] Wilke, C.R.; Lee, C.Y. Estimation of diffusion coefficients for gases and vapors. Ind. Eng. Chem. 47:1253-1257; 1955.

[5] Thomas, J.W. The diffusion battery method for aerosol particle size determination. J. Colloid Sci. 10:246-255; 1955. 
[6] Sinclair, D. A portable diffusion battery. Amer. Ind. Hyg. J. 33:729; 1972.

[7] Sinclair, D.; Countess, R.J.; Lin, B.Y.H.; Pui, D.Y.H. Experimental verification of diffusion battery theory. J. Air Po11. Ctr1. Assoc. 26: 661-663; 1976.

[8] Braman, R.S.; Shelley, T.J.; McClenny, W.A. Tungstic acid for preconcentration and determination of gaseous and particulate ammonia and nitric acid in ambient air. Ana1. Chem. Submitted 1981.

[9] Shaw, R.W.; Dzubay, T.G.; Stevens, R.K. Current methods to measure atmospheric acid and nitrate artifact. EPA-600/2-79-051, U.S. Environmental Protection Agency; March, 1979.

[10] Stevens, R.K.; Dzubay, T.G.; Russwurm, G.; Ricke1, D. Sampling and analysis of atmospheric sulfates and related species. Atmos. Environ. 12: 55-68; 1977.

[11] Durham, J.L.; Wilson, W.E.; Bailey, E.B. Application of a sulfur dioxide denuder for continuous measurement of sulfur in submicrometric aerosols. Atmos. Environ. 12:883-886; 1978.

[12] Braman, R.S.; Johnson, D.L. Selective absorption tubes and emission technique for determination of ambient forms of mercury in air. Environ. Sci. Technol. $8: 996-1002 ; 1974$.

[13] Mikhailov, V.K.; Kochegarova, M.I. Diffusion and thermal diffusion of mercury vapor in air. Sb. Nauch. Tr., Gos. Nauch.-Issled. Inst. Isvet. Metal. No. $25 ; 138-144.1967$.

[14] Spier, J.L. The determination of the coefficient of diffusion of mercury vapor i and cadmium vapor in nitrogen. Physica 7:381-384; 1940.

[15] Braman, R.S. Unpublished data.

[16] Johnson, D.L.; Braman, R.S. Alkyl and inorganic arsenic in air samples. Chemosphere $6: 333-338 ; 1975$.

[17] Braman, R.S.; Ammons, J.M.; Bricker, J.L. Preconcentration and determination of hydroger, sulfide in air by flame photometric detection. Anal. Chem. 50:992-996; 1978.

Discussion

Question (R. E. Sievers): What is your evidence that the gas being regenerated when you heat the tungstic acid after you collected nitric acid is, in fact, $\mathrm{NO}_{2}$ rather than gaseous $\mathrm{HNO}_{3}$ ?

Answer: The gaseous $\mathrm{HNO}_{3}$ would collect on the transfer tube, and it doesn't.

Question (R. E. Sievers): What is your transfer tube?

Answer: Tungstic acid. 
Question (R. E. Sievers): I don't understand, nitric acid is the transfer tube.

Answer: That is to separate the ammonia out; when you heat the first tube, $\mathrm{NO}_{2}$ from the nitric comes out and ammonia from ammonium tungstate comes out. If you just simply ran it straight into the detector both give a single peak because they would both come out at the same time. What we need to do is separate the ammonia from the $\mathrm{NO}_{2}$. So, if we run through a cold tungstic acid tube, that tube takes out the ammonia and allows the $\mathrm{NO}_{2}$ to go through. Then you heat it up, and off comes the ammonia.

Question (R. E. Sievers): One more question. If you put gaseous nitric acid through a tungstic acid tube at the one part per billion level, what do you measure coming out the other end, that is, what fraction is actually measured exiting the end of the tube?

Answer: These tubes are really preconcentrators. What you do is pull air samples through for a definite period of time, as a collector, and then when you heat it you get the spike. For example, I might typically collect 10 or 20 liters of air by preconcentrating from that many liters of air. You then get off into the short period of time the spike that's one or two analytes.

Question (R. E. Sievers): I understand that. I mean during the collection step, what doesn't get collected? What do you measure coming out of the bottom of the tube?

Answer: We don't actually measure anything, we collect the particulate on a packed tube in the sampling step and what comes out is simply air that's had nitric acid and ammonia removed from it. Plus the particles also.

Question (R. E. Sievers): What's the detection limit, because that's important?

Answer: We11, for my set-up, it's around a nanogram. We've also used a "Knox box," and we were able to detect nitric acid and ammonia with about a one liter sample. So they give a better detection limit and that of course is one of the problems. I have to collect 40 liters but the knox detector would only require ten or two.

Question (R. E. Sievers): I still don't know what percentage of the nitric acid is being collected as it goes through the tube.

Answer: 100 percent or close to it. For a 30 centimeter tube you can calculate this from the Gorman-Kennedy equation and you get exactly that efficiency.

Question (R. E. Sievers): I understand that you can calculate, but I want to know experimentally what's retained?

Answer: 95.6 percent of it. Exactly what's predicted by the Gorman-Kennedy equation. 
Kinetic and Equilibrium Control of Interfacial Reactions

Involving Inorganic Ionic Solutes and Hydrous Oxide Solids

Marc A. Anderson

Water Chemistry Program, University of Wisconsin

Madison, Wisconsin 53706

Environmental ecosystems are largely heterogeneous with most chemical and biochemical reactions occurring at a solid-liquid interface. The availability of chemical species for biological assimilation and/or physical transport is governed by factors that influence the kinetic and equilibrium controls of this partitioning. This paper addresses the current state-of-the-art models that describe interfacial reactions of inorganic ionic solutes. Discussion is divided into equilibrium versus kinetic controls over interfacial reactions. Experimental data is compared with the prediction of current models and inadequacies are assessed.

Key words: adsorption; desorption; hydrolyzable cations; hydrous oxides; kinetics; protolyzable anions; thermodynamics.

\section{Introduction}

Competition between solids, liquids, and gas for various chemical species in the environment effectively buffers external perturbations and determines the chemical compositions of an ecosystem. This competition can be described using a variety of "partition coefficients". A good example would be the competition for $\mathrm{CO}_{2}$. Distribution of $\mathrm{CO}_{2}$ between the atmosphere and water is described by Henry's Law coefficient $\mathrm{K}_{\mathrm{H}}$. In the aqueous solution, $\mathrm{CO}_{2}$ undergoes hydrolysis and dissociation according to coefficients $\mathrm{K}_{\mathrm{CO}_{2}}^{*}, \mathrm{~K}_{1}$, and $\mathrm{K}_{2}$, which specify the species distribution of $\mathrm{H}_{2} \mathrm{CO}_{3}^{*}, \mathrm{HCO}_{3}^{-}$, and $\mathrm{CO}_{3}$, respectiveiy. If sufficient $\mathrm{Ca}^{++}$ions are present, $\mathrm{CaCO}_{3}$ precipitates according to the degree dictated by its solubility product $\mathrm{K}_{\mathrm{SP}} \mathrm{CaCO}_{3}$. Thus, if $\mathrm{CaCO}_{3}$ is present as a solid species in a system open to the atmosphere, three phases will compete for $\mathrm{CO}_{2}$. Diagrammatically, this competition process which serves to buffer the $\mathrm{pH}$ of many alkaline lakes [1] is shown in Figure 1.

In addition to other inorganic and organic ligands which may also compete for soluble $\mathrm{CO}_{2}$, thereby forming aqueous complexes or solid precipitates according to their own distribution coefficients, the biological community also competes for this and other essential nutrients in a very rigorous fashion. Indeed, biological competition may tremendously alter the species distributions that might otherwise be predicted from purely geochemical considerations. Both active and passive uptake of essential and nonessential chemical species can occur at the organism-aqueous solution interface $[2,3]$. The role of phytoplankton, for instance, in cycling nutrients [2], as well as heavy metals [4], is well 


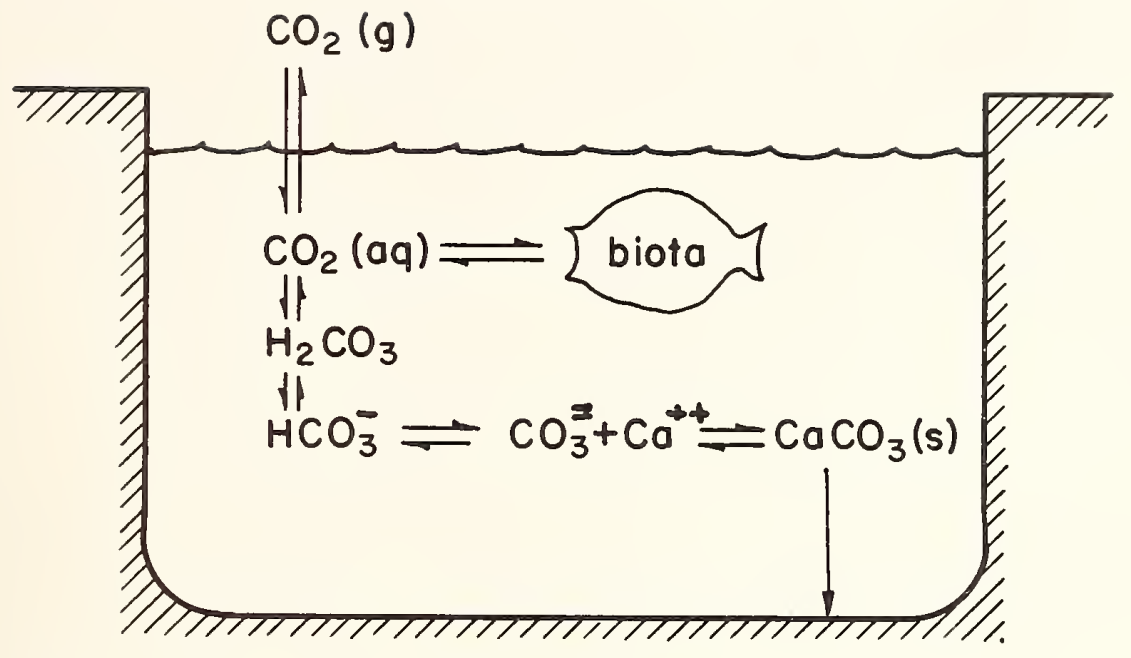

PARTITION COEFFICIENT
REACTION

$$
\begin{aligned}
& \mathrm{CO}_{2}(\mathrm{~g}) \rightleftharpoons \mathrm{CO}_{2}(\mathrm{oq}) \\
& \mathrm{CO}_{2}(\mathrm{oq})+\mathrm{H}_{2} \mathrm{O} \rightleftharpoons \mathrm{H}_{2} \mathrm{CO}_{3} \\
& \mathrm{H}_{2} \mathrm{CO}_{3} \rightleftharpoons \mathrm{HCO}_{3}^{-}+\mathrm{H}^{+} \\
& \mathrm{HCO}_{3}^{-}=\mathrm{CO}_{3}^{-}+\mathrm{H}^{+} \\
& \mathrm{CO}_{3}^{-}+\mathrm{Ca}^{++} \rightleftharpoons \mathrm{CaCO}_{3}
\end{aligned}
$$

Figure 1. Multiphase competition for $\mathrm{CO}_{2}$ in an alkaline lake system open to the atmosphere.

established. Biotic uptake of heavy metals is supplementary to hydrous oxide influence on these species in aquatic systems through adsorption processes [5].

Species composition is therefore subject to both abiotic and biotic control and, since most environmental systems are heterogenous, controlling reactions for chemical species, especially trace constituents, are interfacial reactions. While our understanding of both homogenous and heterogenous systems is reasonably complete with respect to major species distribution, it is severely limited when it comes to interfacial reactions involving trace ionic species. Present knowledge of interfacial equilibrium and kinetics is simply not sufficient from which to predict system composition. The thrust of this paper is to review the current body of knowledge concerning the equilibrium and kinetic aspects of trace ion species distribution between inorganic solid substrates and aqueous solutions. Attention is primarily focused on the adsorption of protolyzable anions and hydrolyzable cations to oxy-hydroxy surfaces. Since similar physical-chemical principles probably govern the passive uptake of nutrient anions, such as phosphate, and toxic metals, such as $\mathrm{Hg}^{++}$, by biotic surfaces, implications for biological interfacial processes are immediately apparent. The text that follows presents a short historical perspective of major developments in 
adsorption chemistry. It highlights the predominant variables in adsorption modeling and gives the reader a general idea of where we've been, what has gone wrong, and what needs to be done. For a recent and more comprehensive review of ionic adsorption see The Adsorption of Incrganics at the Solid-Liquid Interface by Anderson and Rubin [6].

\section{Equilibrium Modeling of Adsorption Reactions}

A. Effect of:

(1). Solute or adsorbate concentration

Early attempts to describe the partitioning of anions and cations between solids and aqueous solutions invoived the use of simple equilibrium models (e.g., the Langmuir model) or empirical equations (e.g., the Freundlich equation). These early attempts were designed to describe the frequently observed dependence between solution adsorbate concentration and the degree of its adsorption to solid substrates. Adsorption studies were often conducted under a wide range of experimental conditions with adsorption as the independent and concentration as the dependent variable. Little consideration was given to the stability of the solid, $\mathrm{pH}$, ionic strength, or reaction time frame; temperature was perhaps the only controlled variable other than concentration. Years of effort resulted in a bewildering array of adsorption isotherms, each having its own system-specific set of empirical constants which described the functional dependence between "equilibrium" adsorbate concentration $\left(C_{e q}\right)$ and adsorption coverage $(\Gamma)$. System-specific modeling was somewhat enhanced by a variety of methods to mathematically linearize otherwise curvilinear adsorption isotherms. Subsequently, these methods led to a statistically better means for interpreting and analyzing data, and thereby fitting empirical constants. They also led to early suggestions that adsorption was not simply a single process of binding one adsorbate species to a single receptor site on the solid surface. Muljadi et al. [7j, for example, noticed that, over a large "equilibrium" adsorbate concentration range, a single set of model constants could not be used to describe the entire data set. Instead, speculation arose that more than one adsorption site, or binding mechanism was involved. This concept is illustrated graphically in Figure 2 where a linearized Langmuir equation is "fit" to hypothetical data using three sets of $K_{L}$ and $\Gamma_{\max }$ values.

(2). $\mathrm{pH}$

At this same time, and despite uncertainty concerning binding sites, research was being conducted on the effect of $\mathrm{pH}$ [8]. In general, this dependence, shown diagrammatically in Figure 3 for hydrous oxide adsorbents, is such that hydrolyzable cation adsorption increases and protolyzable anion adsorption decreases with increasing $\mathrm{pH}$. Matajevic et a1. [9] postulated that this abrupt rise in the adsorption-pH envelope with respect to cation adsorption was associated with cation hydrolys is and subsequent adsorption of the hydrolyzed species. James and Healy [10, 11, 12] later disputed this claim as coincidental, and attempted to show $\mathrm{pH}$ dependence was related with hydration energies in bonding cations to surfaces. Hohl and Stumm [13], as well as Shindler [14], on the other hand, suggested that the $\mathrm{pH}$ dependence could be interpreted simply by adsorption 


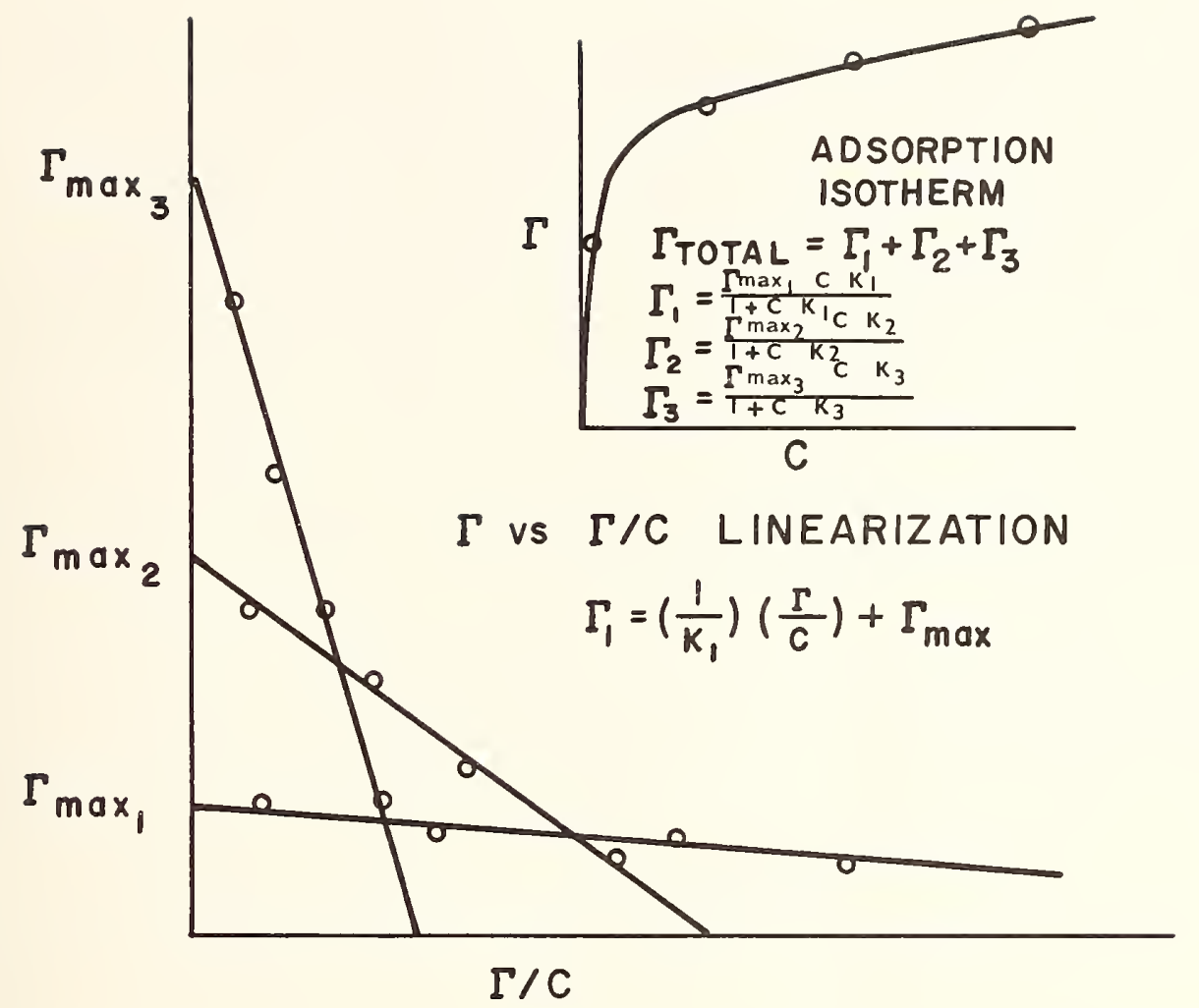

Figure 2. Linearization of the Langmuir equation showing three separate binding regions each having its own binding constant, $K_{L}$, and associated $\Gamma_{\max }$ saturation value.

stoichimetry which they reasoned to be surface complex formation:

$$
\begin{aligned}
& \mathrm{SOH}+\mathrm{Pb}_{\mathrm{S}}^{2+} \stackrel{{ }^{*} \mathrm{~K}_{\mathrm{Pb}^{2+}}^{\text {int }}}{\longrightarrow}\left[\mathrm{SO}^{-}-\mathrm{Pb}^{2+}\right]+\mathrm{H}_{\mathrm{S}}^{+}
\end{aligned}
$$

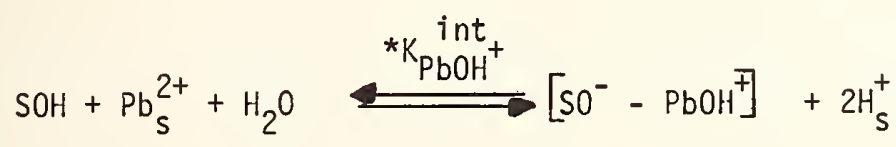

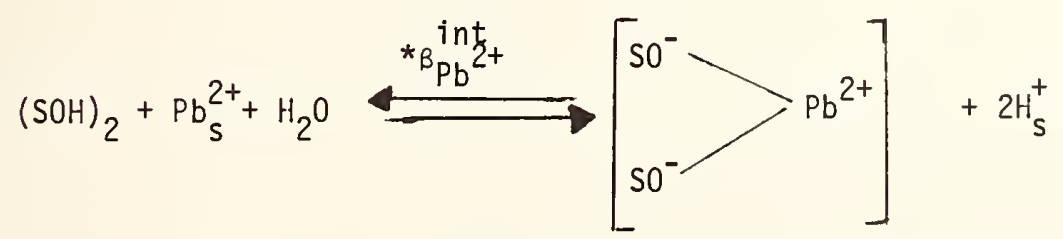

$$
\begin{aligned}
& 2 \mathrm{SOH}+3 \mathrm{H}^{+}+\mathrm{AsO}_{4}^{3-} \stackrel{1 /{ }^{*}{ }^{i n t}}{\mathrm{H}_{2} \mathrm{AsO}_{4}}
\end{aligned}
$$




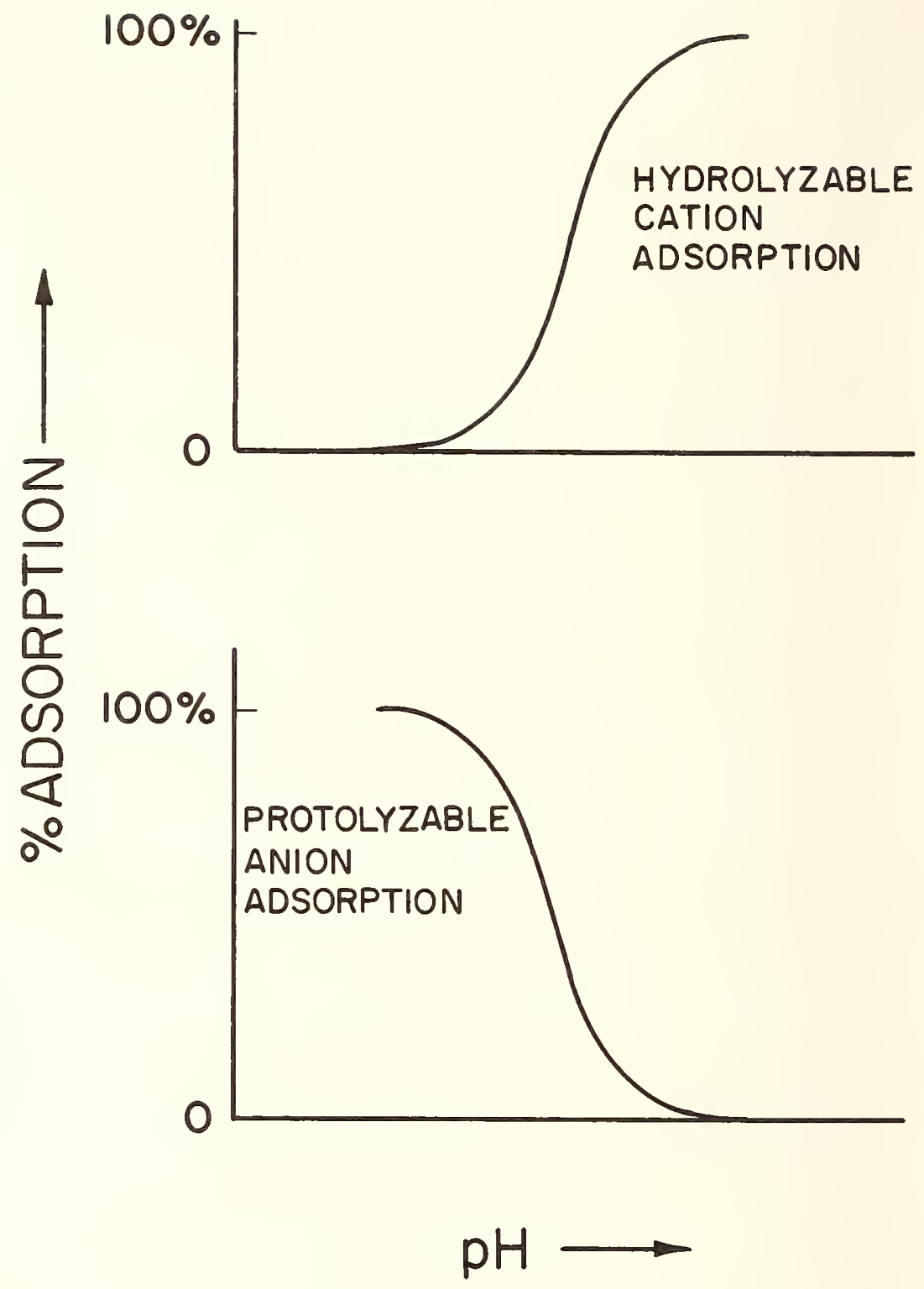

Figure 3. Diagrammatic pH dependence for protolyzable anion and hydrolyzable cation adsorption on hydrous oxide adsorbents.

The adsorption-pH envelope could then be "fit" by a suitable choice of binding constants. On the other hand, Hingston et a]. [15] suggested that adsorption was a function of acid dissociation constants and the number of protons that could be donated by adsorbing ions. It should be noted that these ionic adsorption reactions are not simply ion exchange reactions, but involve energies in excess of those commonly attributed to electrostatics. That is not to say, however, that electrostatic effects are not important. 


\section{(3). Electrostatics}

The chemical and electrostatic effect on adsorption was discussed long ago by Stern [16]. More recent versions of Stern's equation have been used by Bowden et al. [17] and by Anderson and Malotky [18] to model the role of electrostatics. Qualitatively, electrostatic contributions to adsorption can be demonstrated most dramatically. In Figures $4 A$ and $4 B$, which are adaptations from the original data of Anderson et al. [14], adsorption of a protolyzable anion onto an amphoteric hydrous oxide, such as amorphous aluminum hydroxide, shifts the isoelectric point of the solid. Depending on the degree of coverage, a new isoelectric pH is created above which adsorption diminishes due to electrostatic repulsion. In a sense, it is difficult to separate electrostatic and pH effects since the proton can directly affect both.

\section{(4). Ionic strength}

Equilibrium modeling became even more complex with the observation by Yates and Healy [20] that ions, thought previously to be inert, were actually reacting with the surface.

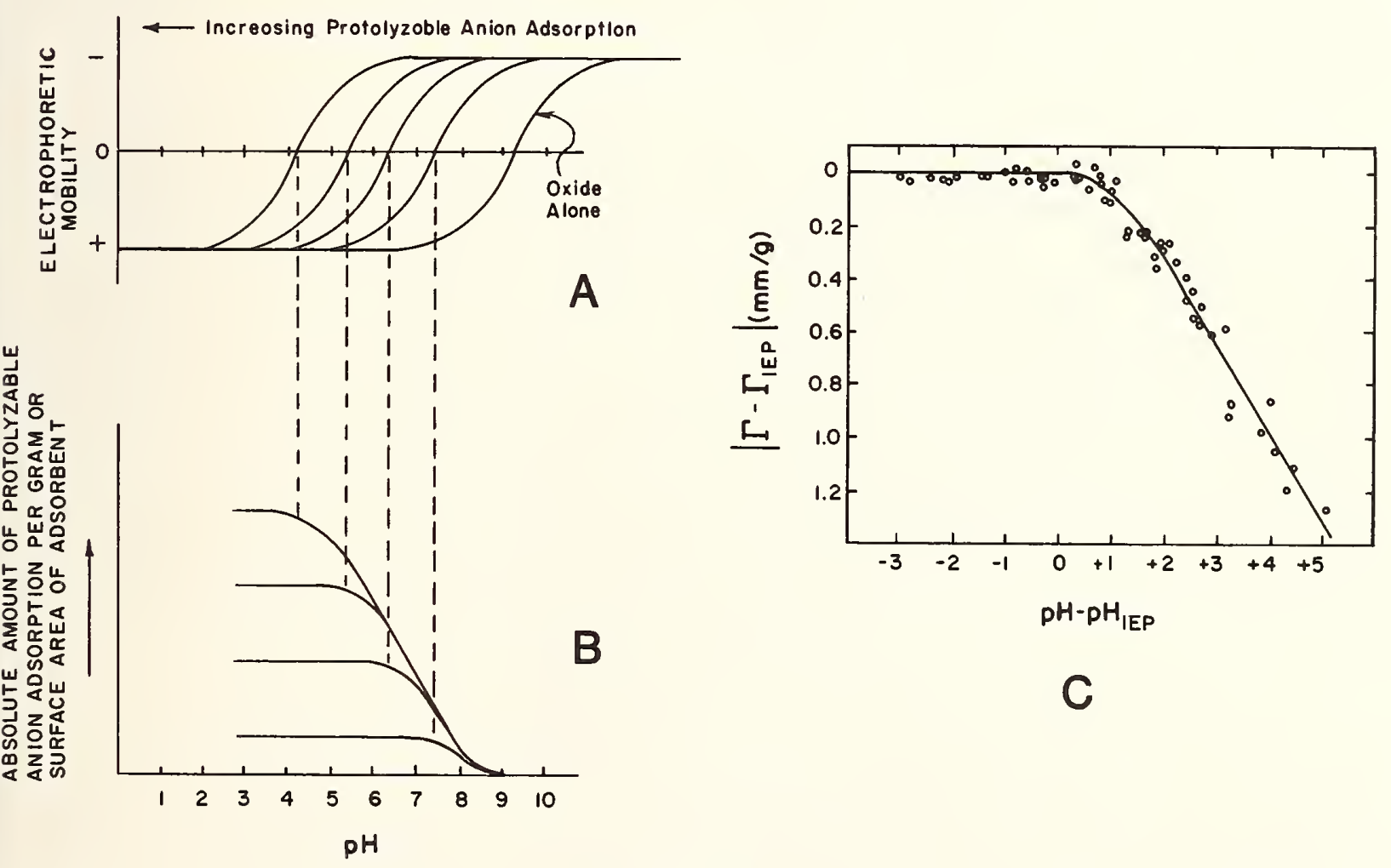

Figure 4. A. Diagrammatic mobility dependence on adsorption and $\mathrm{pH}$ for protolyzable anion adsorption on amorphous aluminum hydroxide. B. Adsorption envelopes showing decrease in adsorption at $\mathrm{pH}$ values greater than isoelectric $\mathrm{pH}$ for a given degree of anion adsorption (after Anderson et al. [19]). C. Reduction of curves in B. 
Research then began to reexamine reactions conducted in constant ionic media such as potassium perchlorate and nitrate solutions. On close examination of previous data, it became clear that extrapolation to zero charge conditions produced constants that were functions of ionic concentration [21]. Adsorption now, was not just a matter of describing concentration dependence, but pH, electrostatics, and ionic media had to be included as we11.

\section{(5). Chemical speciation}

Elemental speciation can have profound effects on adsorption as shown in Figure 5 for arsenite and arsenate adsorption on the hydrous oxide adsorbents of iron and aluminum. Arsenate adsorption is seen to saturate at high equilibrium adsorbate concentrations. Arsenite adsorption, on the other hand, is linear for the entire concentration range examined. Effects of redox state, ligand characteristics, and degree of protonation are all factors that have been implicated in determining the degree of ionic adsorption. While some speciation modeling has been performed with computer analysis [22], 1ittle experimental work with respect to verification of surface species has been done. Obviously", more spectroscopic surface analysis is needed.

B. Thermodynamic model

In an attempt to account for all the above reaction variables, Davis and Leckie [21] devised an adaptation of the complexation model. This highly sophisticated "triple layer" (triple layer because it balances charge by considering ionic contributions at three interfacial planes) model includes interfacial capacitance, total site density, and ionic binding constants for protons, counterions and coions, and adsorbates. A computerized model was developed at Stanford which employs the program MINEQL [23] as an operational tool for handling the complex array of equations which must be solved simultaneously. In Figure 6 , this model is employed to illustrate sensitivity to changes in binding constants. The original data is from Hohl and Stumm [13]. Experimentally, Hohl and Stum [13] determined the binding constant of $\mathrm{Pb}^{++}$to $\mathrm{Al}_{2} \mathrm{O}_{3}$ to be $\mathrm{pK}=5$ from potentiometric titration data. Notice that a change in binding constant from $p K=5$ to $p K=3$ results in a $40 \%$ better "fit".

C. Inadequacies in equilibrium adsorption modeling

At present, equilibrium adsorption modeling is ahead of experimental verification. Models employed currently assume reaction stoichometry and utilize adjustable binding constants, which cannot be verified experimentally. To illustrate these problems, Westal and Hohl [24] in a recent paper, examined five electrostatic equilibrium adsorption models and concluded that they could represent experimental data equally well regardless of model chosen, but that the values chosen to represent the same parameter in each model were different. Hence these parameters were not al1 representative of physical reality. The simplest model for a given system should be the model of choice since no model seems to totally reflect physical reality. Benjamin and Leckie [25] found that the Davis and Leckie [21] model could not be applied over a large concentration and pH range and instead 
invoked a multi-site density model not unlike that of the original model proposed by Muljadi et al. [7]. It would seem that research on this subject has come full circle.

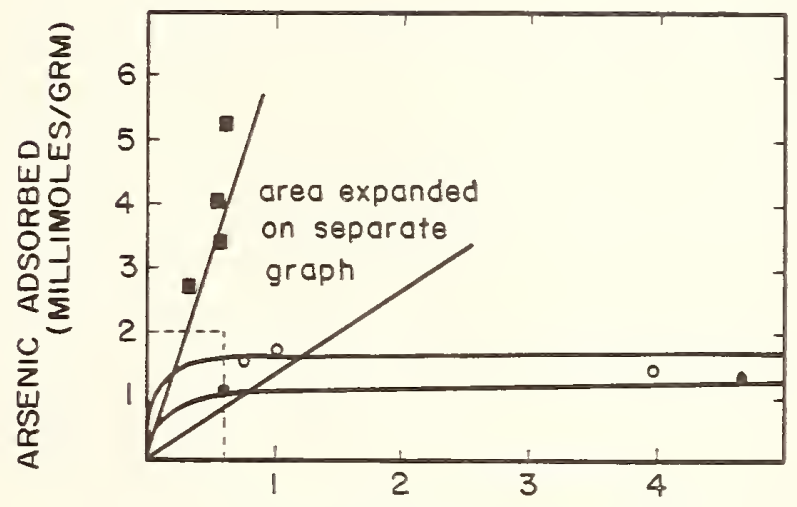

A. FULL CONCENTRATION RANGE

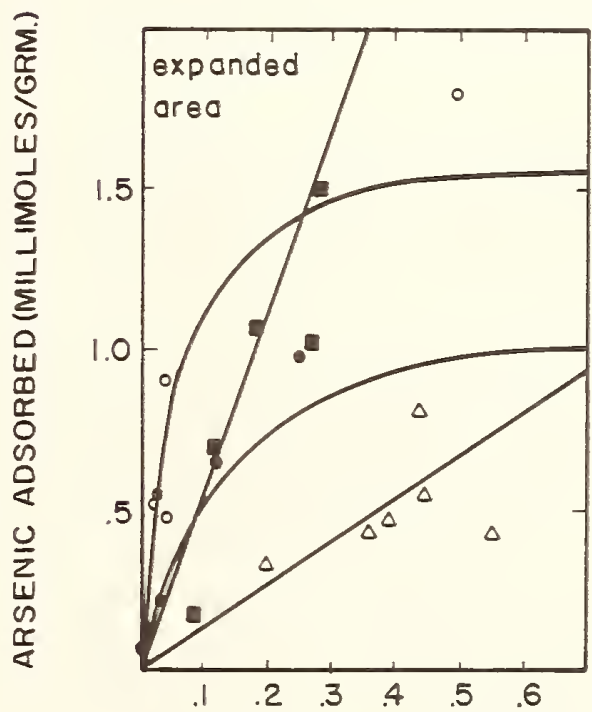

B. LOW CONCENTRATION RANGE

Figure 5. The dependence of adsorption on elemental speciation. Arsenite and arsenate adsorption on amorphous oxices of iron and aluminum. High and low concentration

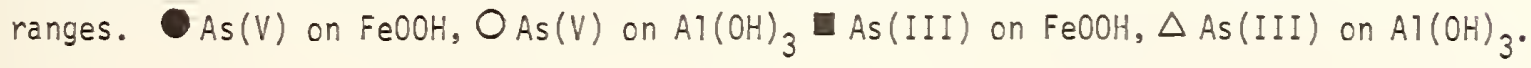




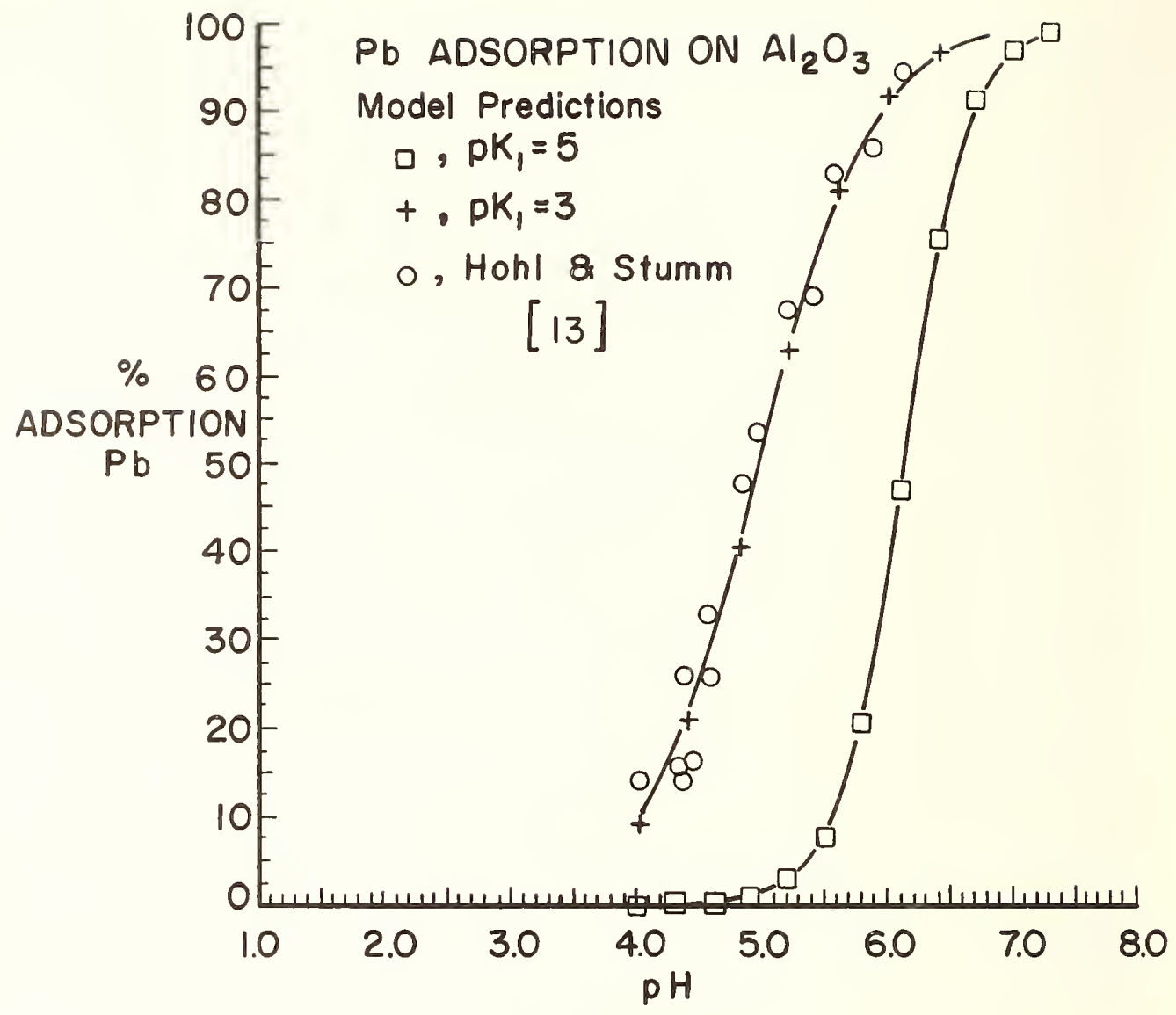

Figure 6. Lead adsorption on $\mathrm{Al}_{2} \mathrm{O}_{3}$ fit by Stanford Model [21] using $\mathrm{pK}_{\mathrm{Pb}^{++}}=5$ and $\mathrm{pK}_{\mathrm{Pb}^{++}}=3$. Original data is that of Hohl and Stumm [13].

3. Adsorption Kinetics

Most of the experiments m!entioned above involved a wide variety of independent parameters and were conducted over variable "equilibration" periods. For the most part, little attention was given to reaction kinetics. In the few cases where kinetics were investigated, surface reactions were found not to be single step reactions [26, 27]. Even in the recent paper by Benjamin and Leckie [25], trace metal adsorption was found to involve two steps; first, a rapid and almost complete uptake lasting no more than one hour, followed by a second, slower uptake process perhaps lasting days, weeks, or possibly months. The first was thought to be true adsorption, and the second to be slow adsorbate diffusion into the solid substrate. Earlier results using isotopic exchange [28, 29, 30], as well as observations showing desorption hysterisis [31], further illustrate that adsorption is a complex process. It may be that these processes are largely irreversible and therefore impossible to model using thermodynamic first principles implied above. In any case, it appears that each mechanism must be individually modeled before any universal system applicability can be achieved. 
A. Effects of :

(1). Time

The adsorption kinetics of phosphate onto geothite examined by Stanforth [32] are illustrated for a very low adsorbate concentration range in Figure 7 . The initial

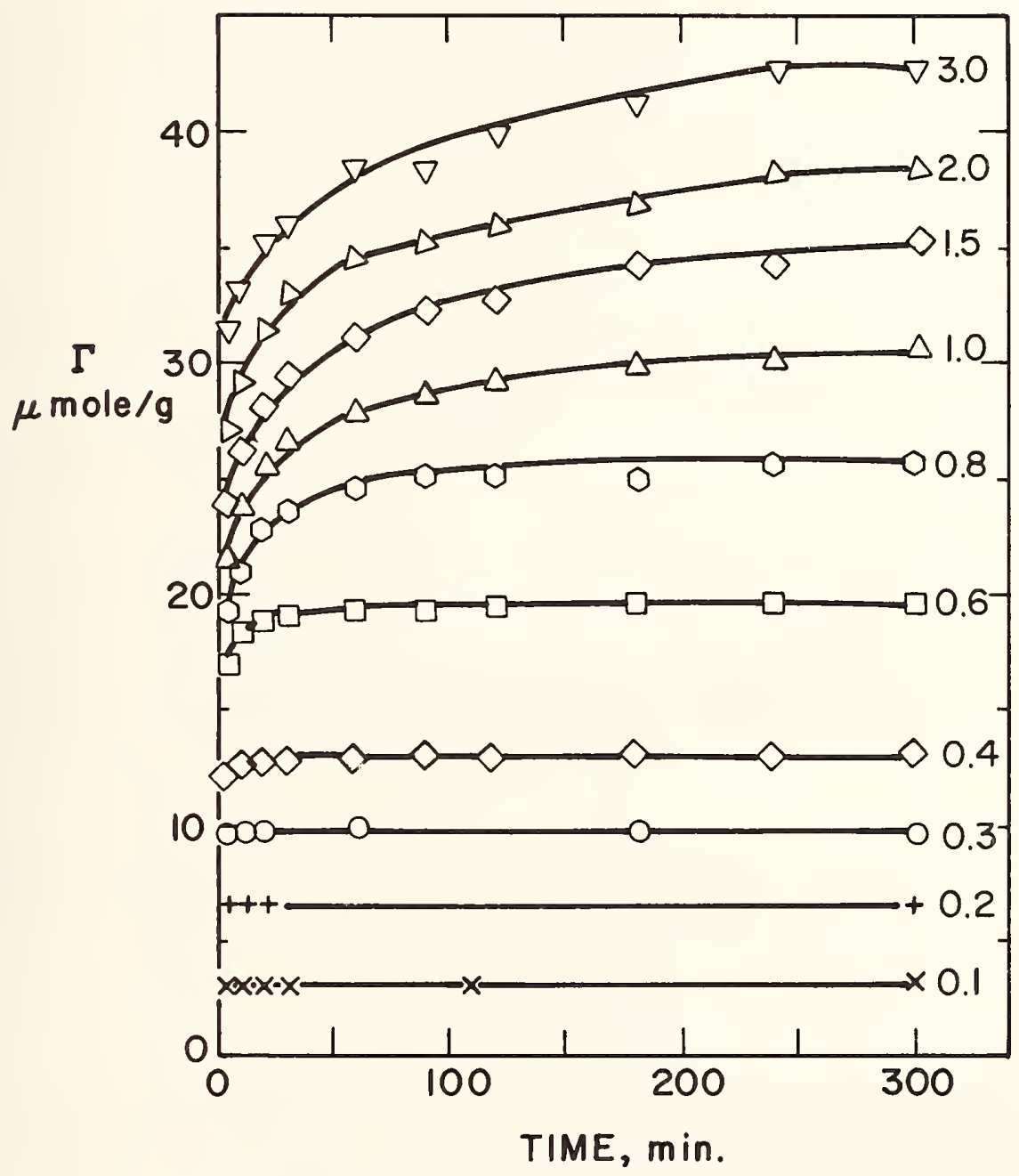

Figure 7. Adsorption kinetics of phosphate on goethite for initial concentrations of phosphorus ranging from 0.1 to $3.0 \mu \mathrm{M}$ and for solids concentrations of $0.02975 \mathrm{~g} / \mathrm{L}$ $\left(20^{\circ} \mathrm{C}\right.$ ) (from Stanforth [32]). 
concentration of phosphate is varied in these experiments holding temperature, $\mathrm{pH}$, and amount of solid constant. Adsorbate concentrations were kept low in an attempt to minimize iron phosphate precipitation. It is readily apparent, for higher initial phosphate concentrations, that rapid initial uptake occurs in less than five minutes. This is followed by a much slower process of uptake requiring several hours or days. For adsorption levels less than $10 \mu \mathrm{moles} / \mathrm{g}$, uptake removes almost all solution phosphate within five minutes.

These results may be interpreted by one of several speculative hypothesis: 1. rapid binding followed by slow rearrangement [31], 2. rapid binding followed by diffusion into the solid [8, 25], or 3. rapid binding followed by precipitation [26]. The most recent precipitation hypotheses was developed by Van Riemsdijk and Lyklema [33, 34] in order to explain the two-step process of phosphate adsorption onto gibbsite. While the first attachment process is almost instantaneous, precipitation of aluminum phosphate also occurs very early in the reaction time frame, even at concentrations as small as $5 \mu$ moles/L. Only below this concentration range were these authors able to study the attachment mechanism solely. These findings are partially in agreement with observations shown in Figure 7 as calculations for "monolayer" coverage [32] indicate that "monolayers" are achieved at surface densities $<10 \mu$ moles/g and precipitation or multilayer formation may occur at higher levels.

\section{(2). Isotopic exchange}

Two minute isotopic exchange was used by Stanforth to study the attachment of phosphate onto goethite at various times into the adsorption reaction [32]. The results are shown in Figure 8, and indicate that: 1. a very small percentage of phosphate is exchangeable in two minutes and 2. this amount decreases with reaction time. This would imply some removal mechanism is effectively burying phosphate with time. At these adsorption levels, it could be postulated that the reaction is already into the precipitation mode.

\section{(3). Temperatu: -}

The temperature dependence of both adsorption and isotopic exchange are complex. In Stanforth's study [32], the initial 5 min adsorption increased with temperature, but adsorption rates after 5 min were independent of temperature. On the other hand, Chen et al. [26] found initial $24 \mathrm{~h}$ adsorption of $\mathrm{P}$ onto hydrous aluminum oxide to be independent of temperature, while for longer reaction times adsorption increased slightly with temperature. Van Riemsdijk and Lyklema [33,34] found a strong temperature dependence for long term reactions. Stanforth [32] also found isotopic exchange to be a complex function of temperature. Since both Chen et a1. [26] and Van Riemsdijk and Lyk1ema [33, 34] observed precipitation after long reaction times, it is reasonable to hypothesize a three-step reaction: 1. an initial adsorption step which is temperature dependent, 2 . a surface rearrangement that is temperature independent followed by, 3 . a temperature-dependent 
precipitation or crystallization step. Different studies utilizing widely varying $P$ concentrations have emphasized one or another of these steps in the solid-P interaction.

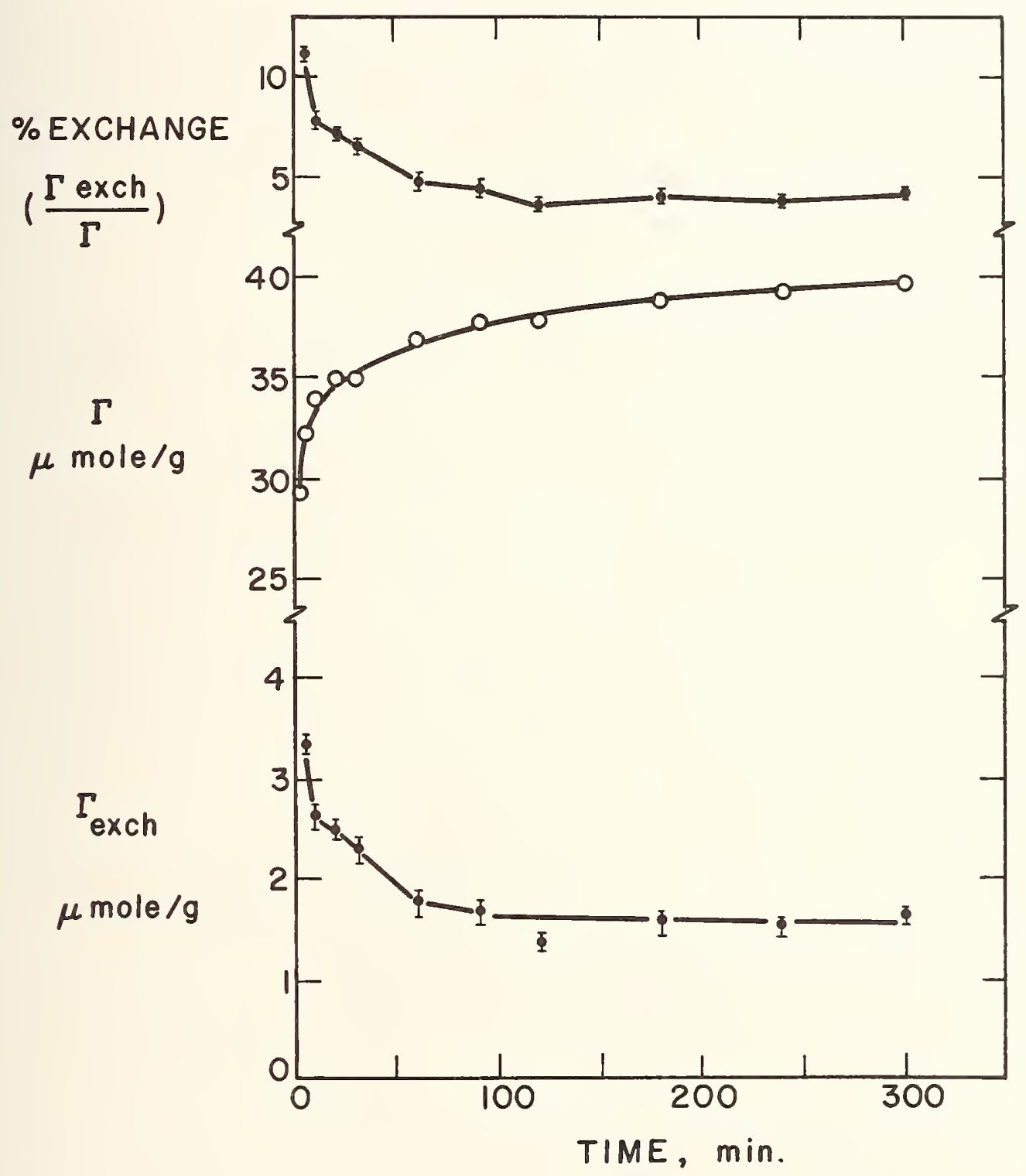

Figure 8. Two minute isotopic exchange kinetics for phosphate adsorption on goethite as a function of reaction time. Initial concentration of phosphate was $6 \mu$ M whereas solids concentrations were $0.118 \mathrm{~g} / \mathrm{L}\left(20^{\circ} \mathrm{C}\right)$ (from Stanforth [32]). 


\section{B. Kinetic Models}

Kinetic modeling attempts have for the most part failed to adequately describe adsorption over large concentration and time ranges due to the fact that interfacial reactions cannot be described by a single mechanistic step. Conventional first-or second-order reaction rate equations have usually failed. For the most part, mathematical descriptions have largely been empirical. A few of these mathematical expressions are illustrated in Table 1. The Elovich equation [27] is the most applicable over large concentration ranges

Table 1. Kinetic models

\begin{tabular}{|c|c|c|}
\hline \multicolumn{3}{|c|}{ Non-mechanistic ${ }^{[27]}$} \\
\hline \multicolumn{3}{|c|}{$\begin{array}{l}\text { Adsorption-desorption }[35] \\
\qquad \begin{aligned} \mathrm{d} \phi / \mathrm{d}+ & =k_{1}(1-\phi)(1-\phi / 2) \mathrm{e}^{-\mathrm{B} \phi} \\
& +k_{2}(1-\phi / 2) \mathrm{e}^{\mathrm{B}(2-\phi)}-\phi^{2} / 2 \mathrm{e}^{\mathrm{B} \phi}\end{aligned}\end{array}$} \\
\hline \multicolumn{3}{|c|}{$\begin{array}{r}\text { Mechanistic }[3 \overline{3}, 34] \\
\left(\Gamma_{m}-\Gamma_{A}\right)^{-2}=A+B+ \\
\Gamma_{p}=1.6 \times 10^{-5} \mathrm{C} \sqrt{t}\end{array}$} \\
\hline where: & $\begin{array}{l}\Gamma=\text { adsorption } \\
\Gamma_{A}=\text { attachment adsorption } \\
\Gamma_{\max }=\text { "monolayer" adsorption } \\
\Gamma_{p}=\text { precipitation (adsorption) } \\
\phi \quad=\text { fraction adsorbed }\left(\Gamma / \Gamma_{\max }\right) \\
t \quad=\text { time }\end{array}$ & $\begin{array}{l}c=\in q . \text { adsorbate concentration } \\
k_{1}=\text { adsorption rate } \\
k_{2}=\text { desorption rate } \\
A_{,} B=\text { empirical adjustable constants } \\
\ell n=\text { natural logarithm }\end{array}$ \\
\hline
\end{tabular}

but it has no mechanistic meaning and fails to describe desorption hysterisis. The equation describing rates of adsorption and desorption [35] accounts for differences between ions being taken up or released by surfaces. It does not indicate that adsorption itself is a two- or three-step process. The recent equations proposed by Van Riemsdijk and Lyklema [33, 34], even though empirical, have the most mechanistic boundaries with respect to concentration and time. In spite of having a more reasonable format, this model fails to describe the desorption process. Unfortunately these models do not account for the effects of $\mathrm{pH}$ ionic 
strength and electrostatics upon the adsorption rate. In spite of the fact that constants used in thermodynamic modeling were not validated experimentally, these constants did possess physical significance. Kinetic models, on the other hand, contain constants with no physical significance.

\section{Conclusion}

Partitioning of chemical species between solids and aqueous solutions plays a key role in determining the environmental pathway and fate of chemical components in an ecosystem. In spite of many years of effort in the attempt to interpret these interfacial reactions, there are only limited use system-specific models from which to predict chemical composition This failure can largely be ascribed to the indiscriminate selection of systems, parameters, and time frames which have been used to interpret these reactions.

Adsorption on hydrous oxides can have an important effect on the concentration of many trace metals and anions in an ecosystem. A complete understanding of partitioning of these materials between the different phases and between different species in one phase requires a better understanding of the adsorption process, particularly adsorption as well as desorption kinetics. While equilibrium models have been used successfully to interpret parametric affects in site-specific situations, these models have postulated mechanisms using unvalidated stoichiometrics and artificial physical constants. On the other hand, kinetic experiments have suggested a complex variety of mechanisms without a totally unifying or satisfactory model.

It would seem at this time there is more need to enhance kinetic interpretations and modeling of these interstitial processes by using stable systems and a very selected set of parameters with which to describe the individual reaction mechanisms that go on at the surface of solid substrates. Beyond describing rate expressions and reaction mechanisms, an effort should be made to interpret the effect of the key variables in these systems, e.g. pH, adsorbate concentration, ionic strength, and electrostatic effects. In addition, consideration should be given to the stability of the solid substrate, the type of solid substrate ligands, the affect of oxidation potential, as well as chemical speciation on solid solution reactions. Only then will there be not only a means of predicting composition but also the time frame in which this composition is achieved.

\section{References}

[1] Stumm, W.; Morgan, J.J. Aquatic chemistry. New York: John Wiley and Sons, Inc.; 1970.

[2] Van der Borght, J.P.; Wollast, R.; Billen, G. Kinetic models of diagenesis in disturbed sediments. Limnol. Oceanogr. 22(5):787-803; 1977.

[3] Fujita, M.; Hashizume, K. Status of uptake of mercury by the fresh water diatom. Water Res. 9:889-894; 1975.

[4] Talbot, R. Atmospheric fluxes and geochemistries of stable $\mathrm{Pb}, \mathrm{Pb}-210$ and $\mathrm{Po}-210$ in Crystal Lake, Wisconsin. Ph.D. Thesis, University of Wisconsin, Madison, WI. 1981. 
[5] Jenne, E. A. Heterogensis interaction of Arsenic in aquatic systems. Adv. Chem. Ser. No. 93,337 ; 1968.

[6] Anderson, M.A.; Rubin, A.J. Adsorption of inorganics and the solid-liquid interface. Ann Arbor, Michigan: Ann Arbor Science; 1981.

[7] Muljadi, D.; Posner, A.M.; Quirk, J.P. The mechanism of phosphate adsorption by kaolinite, gibbsite and pseudoboehmite. Part 1 the isotherms and the effect of ph on adsorption. J. Soil Sci. 17:212-229; 1966.

[8] Scholten, A.G. The reaction of phosphate with mineral surfaces and iron oxide gels. Ph.D. Thesis, University of Wisconsin, Madison, WI. 1965.

[9] Matijevic, E.; Matai, K. G.; Ottewi11, R. H.; Kerker, M. Detection of metal ion hydrolys is by coagulation III aluminum. J. Phys. Chem. 65:826; 1961.

[10] James, R.0.; Healy, T.W. Adsorption of hydrolyzable metal ions at the oxide-water interface I. $\mathrm{Co}$ (II) Adsorption on $\mathrm{SiO}_{2}$ and $\mathrm{TiO}_{2}$ as model systems. J. Colloid Interface Sci. 40:42; 1972

[11] James, R.0.; Healy, T.W. II. Charge Reversal of $\mathrm{SiO}_{2}$ and $\mathrm{TiO}_{2}$ colloids by adsorbed Co(II), La(III) and Th(IV) as mode T systems. J. C.olloid Interface Sci. 40:53; 1972.

[12] James, R.0.; Healy, T.W. III. A thermodynamic model of adsorption. J. Colloid Interface Sci. 40:65; 1972.

[13] Hohl, $\mathrm{H}$.; Stumm, W. Interaction of $\mathrm{Pb}^{++}$with hydrous $r \cdot \mathrm{Al}_{2} \mathrm{O}_{3} \mathrm{~J}$. Colloid Interface Sci. 55:281-288; 1976.

[14] Schindler, P.W. Surface complexes at oxide-water interfaces, in The adsorption of ions at the solid-liquid interface. M.A. Anderson and A.J. Rubin, eds. Ann Arbor, Michigan: Ann Arbor Science; 1981.

[15] Hingston, F.J.; Atkinson, R.J.; Posner, A.M.; Quirk, J.P. The specific adsorption of anions. Nature $215: 1459-1461 ; 1967$.

[16] Stern, 0. The theory of the electrolytic double layer. Z. Electrochem. 30:508-516; 1924.

[17] Bowden, J.W.; Posner, A.M.; Quirk, J.P. Ionic adsorption on variable charge mineral surfaces. Theoretical charge development and titration curves. Austr. J. Soil Res. $15: 121-136 ; 1977$.

[18] Anderson, M.A.; Malotky, D.T. The adsorption of protolyzable anions on hydrous oxides at the isoelectric pH. J. Colloid Interface Sci. 72:413-427; 1979.

[19] Anderson, M.A.; Ferguson, J.F.; Gavis, J. Arsenate adsorption on amorphous aluminum hydroxide. J. Colloid Interface Sci. 54:391-399; 1976.

[20] Yates, D.E.; Healy, T.W. Mechanism of anion adsorption at the ferric and chromic oxide/water interface. J. Colloid Interface Sci. 52:222-228; 1975.

[21] Davis, J.A.; Leckie, J.0. Surface ionization and complexation at the oxide/water interface. 3. Adsorption of anions. J. Colloid Interface Sci. 74:32-43; 1980.

[22] Sigg, L.; Stumm, $W$. The interaction of anions and weak acids with the hydrous goethite $(\alpha \cdot \mathrm{FeOOH})$ surface. Colloids and Surfaces $2: 101-117 ; 1981$.

[23] Westa11, J.C.; Zachary, J.L.; Mcrel, F.M.M. MINEQL-a computer program for the calculation of chemical equilibrium composition of aqueous systems. Technical Note 18, Dept. of Civil Engineering. Massachusetts Inst. Tech. Cambridge, MA; 1976 
[24] Westall, J.; Hohl, H. A compariscn of electrostatic models for the oxide/solution interface. Adv, in Colloid Interface Sci. 12:265-294; 1980.

[25] Benjamin, M.; Leckie, J.0. Muttisite adsorption of $\mathrm{Cd}, \mathrm{Cu}, \mathrm{Zn}$ and $\mathrm{Pb}$ on amorphous iron oxyhydroxide. J. Colloid Interface Sci. 79:109-221; 1981.

[26] Chen, Y.R.; Butler, J.N.; Stumm, W. Kinetic study of phosphate reaction with aluminum oxide and kaolinite. Environ. Sci. Tech. 7:327-332; 1973.

[27] Vanderdeelen, J.; Baert, L. Adsorption and exchangeability of phosphate on gibbsite. Pedologie 21:360-366; 1971.

[28] Atkinson, R.J.; Posner, A.M.; Quirk, J.P. Kinetics of heterogeneous isotopic exchange reactions. Exchange of phosphate at the $\alpha \cdot \mathrm{FeOOH}$-aqueous solution interface. $J$. Inorg. Nucl. Chem. 34:2201-2211; 1972.

[29] Kyle, J.H.; Posner, A.M.; Quirk, J.P. Kinetics of isotopic exchange of phosphate adsorbed on gibbsite. J. Soil Sci. 26:32-43; 1975.

[30] Hingston, F.J.; Posner, A.M.; Quirk, J.P. Anion adsorption by goethite and gibbsite: II Desorption of anions from hydrous oxide surfaces. J. Soil Sci. 25:19-26; 1974.

[31] Kafkafi, V.; Posner, A.M.; Quirk, J.P. The desorption of phosphate from kaolinite. Soil Sci. Soc. Assoc. Proc. 31:348-353; 1967.

[32] Stanforth, R.R. The kinetics and isotopic exchange of phosphate on goethite. Ph.D. Thesis (Water Chemistry) University of Wisconsin, Madison, WI 1981.

[33] Van Riemsdijk, W.H.; Lyklema, J. Reaction of phosphate with gibbsite beyond the adsorption maximum. J. Colloid Interface Sci. 76:55-66; 1980.

[34] Van Riemsdijk, W.H.; Lyklema, J. The reaction of phosphate with aluminum hydroxide in relation with phosphate bonding in soils. Colloids and Surfaces 1:33-44; 1980.

[35] Bansol, 0.P.; Prasad, M.; Srivastava, S.N. Kinetic studies of the adsorption and interaction of oxamyl on illites. Soil Sci. 131(2), 69-75. 1981.

\section{Discussion}

Question (B. A. Fowler): On behalf of the biology I would like to say yes to everything that you've said here. We have the same problem in biological systems except, to add on top of that, each of the parameters have been changed as the organism responds. In other words, the question of absorption of incoming species to cell membranes or inside the cell must recognize that an organism is an agent that's capable of responding by producing more or less binding by changing essentially the absorbing surfaces.

Answer: I think that's very true. My research right now, with regard to biological substrates, is looking at phytoplankton uptake of arsenicals. My interest involves the process of what happens at the cell wall because the component has to get to the cell wall before it gets actively transported through it. I'm interested in seeing what happens, but it's a difficult thing to do because I'm not a biologist and I've got to get biology people interested in physical chemistry. 
Comment (B. A. Fowler): If you treat the algae or other organisms over a period of time you will find that the plot that you predict based on a lot of these sound chemical principles will vary. It isn't that the plot's wrong, it's just that the animal has changed in response to the incoming agent. We've seen this time and time again, typical cell membranes and the permeability characteristics change and the absorption characteristics change. 
Speciation of Labile and Ouasi-labile

Metal Complex Systems Using the Kalman Filter **

Teri F. Brown ${ }^{*}$, Donna M. Caster ${ }^{*}$, and Steven D. Brown ${ }^{*}$
Department of Chemistry, University of California
Berkeley, CA 94720
and

Materials and Molecular Research Division

Lawrence Berkeley Laboratory

Berkeley, CA 94720

One approach used in the study of trace metal speciation is the measurement of metal-complex stability constants, which are then combined with models of the metal systems under study to predict the species present. The electrochemical techniques used to measure metal complex species have the advantage of sensitivity and specificity, but suffer a number of limitations. For voltammetric techniques, these include requirements of excess 1igand and rapid kinetics. We have developed a new approach to voltammetric studies of metal complexes; this approach uses the Kalman filter, a recursive, 1inear, digital filter, to model overlapped electrochemical peaks arising from parallel reduction paths, including the situation where two or more complexes undergo slow exchange. Stability constants are calculated from the individual electrochemical responses extracted by the filter.

This approach has been applied to studies of the complexation of NTA with various trace metals. A description of the model and results for the systems will be discussed.

Present address: Department of Chemistry, Washington State University, Pul1man, WA 99164.

This work was supported by the Director, Office of Energy Research, Office of Basic Energy Sciences, Chemical Sciences Division of the U.S. Department of Energy under Contract No. W-7405-ENG-48. 
Key words: cadmium-NTA; convolution voltammetry; electrochemistry; Kalman filter; metal speciation; modeling; semiderivative; stability constants; voltammetry; Zinc-NTA.

\section{Introduction}

Electrochemical techniques have long been used in studies of metal complexation. Potentiometry and voltammetry are fairly common methods for measuring metal complex stability constants required for the accurate modeling of chemical species [1]. Additionally, both methods have been used for detection of the aquo complex of certain metals in partitioning schemes [2].

The measurement of metal-complex stability constants by voltammetry is still largely based on the method first used by de Ford and Hume in 1951 [3]. In this scheme, the curve obtained by plotting the shift in the voltammetric response (usuall $\forall$ the polarographic half-wave potential) as a function of the ligand activity is analyzed by polynomial rearession. The regression coefficients are equal to the stability constants for the metal complex system.

This method, however, involves an inconvenient assumption. The complexes $\mathrm{ML}^{\mathrm{nt}}$, $\mathrm{ML}_{2}{ }^{\mathrm{n}}$, ...,MLp ${ }^{\mathrm{n}+}$ are a11 presumed to be in equilibrium with each other and with the aquo complex (designated $M^{n+}$ ) at all times and in all regions of the solution, including the diffusion layer; even the passage of current during the experiment is presumed not to disrupt this equilibrium. The assumption limits study to systems capable of very rapid ligand exchange relative to the time of the electrochemical measurement $[4,5]$. The assumption also requires that the ligand be in sufficiently large excess that its concentration change is negligible in the double layer as the aquo complex reduces.

A1though specific systems have been studied $[6,7]$, no general way of circumventing this assumption has been developed. Complexometric titrations have been used to study non-labile complexes with some success [8], and Shuman [9] has developed an empirical approach for examination of the quasi-labile complex CdEDTA ${ }^{2-}$.

The work described in the present paper uses a new method for peak separation based on the kalman filter to extract the voltametric peak produced by the reduction of the aquo complex, and thus determine the concentration of the aquo complex. Titrations of ligand with metal or metal with ligand can be performed, and plots of "free" metal concentration versus moles of titrant can be analyzed by non-linear regression analysis to yield stability constants for the metal-ligand complexes. This method is similar to a 
potentiometric titration, but should be more versatile because a wide variety of voltammetric and polarographic techniques could be used in place of a metal specific electrode enabling studies at low concentration.

To demonstrate the feasibility of this approach, two systems with multiple reduction peaks were studied.

2. Theory

For a solution in which the ligand is not in excess, the diffusion layer contains the metal aquo complex, the metal-ligand complex(es), and (perhaps) some uncoupled ligand. These species are presumed to be in equilibrium before the electrochemical experiment. For a suitably rapid scan over the appropriate potential range, the aquo complex reduces first, disrupting the equilibrium in the diffusion layer as a result of the lack of excess ligand, and causing some subsequent dissociation of the metal-ligand complex to form free meta1. The metal released will be observed as a second peak, cathodic of the peak produced by reduction of the aquo complex; the cathodic shift depends in part, upon the concentration of the ligand in solution and upon the stability constant of the metal-ligand complex $[6,10]$. This second peak can also be broadened by the kinetics of the dissociation reaction [5]. Other peaks may occur as a result of the direct or indirect reduction of the metal-1igand complex(es).

The approach taken here separates the peak produced by reduction of the aquo complex from subsequent reduction waves. The model treats the observed current as the sum of currents produced by reduction of the individual species, and assumes no shape dependence upon concentration for the various electrochemical peaks. With these assumptions, the current, $i$, due to reduction is:

$$
i(E)=\underline{C}^{\top} \cdot \underline{S}(E)+v(E)
$$

where $\underline{C}^{\top}$ is the row vector of surface concentrations for each component, $\underline{S}(E)$ is the column vector of the normalized current response of each component, and $\nu(E)$ is the noise in the measurement. For the aquo complex, the surface concentration is equal to the bulk concentration, since the system began at equilibrium.

The vector $\underline{C}^{\top}$ is estimated using a recursive minimization algorithm known as the Kalman filter [11]; the filter has previously been used for multicomponent analysis in 
electrochemistry [12] and in ultraviolet spectroscopy [13]. The filter requires that $\underline{S}(E)$ be known. Previously, $\underline{S}(E)$ has been generated by normalizing voltammograms of pure components by their concentrations [12]. Other approaches using theoretical waveforms [14] or empirical, multicomponent waveforms are also possible. In this study, al1 three approaches have been used to model the $\underline{S}(E)$ vector. Details are discussed below. The Kalman filter outputs estimates of the peak height and the variance for each of the components.

Theoretical waveforms were generated from the equation for a reversible semidifferential wave $[15,16]$ :

$$
e(E)=n^{2} F^{2} A C_{0 x}^{*}\left(U D_{0 X}\right)^{\frac{1}{2}} / 4 R T \operatorname{sech}^{2}\left[n F / 2 R T\left(E-E_{\frac{1}{2}}\right)\right]
$$

In equation 2, $\mathrm{n}$ is the number of electrons involved in the charge transfer, $F$ is the Faraday, $A$ is the surface area of the electrode, $C_{0 x}^{\star}$ is the concentration of species, $v$ is the scan rate, $D_{0 x}$ is the diffusion constant of the oxidized species, $R$ is the gas constant, and $T$ is the absolute temperature. The parameter $E_{\frac{1}{2}}$ is the reversible half-wave potential [15]. Semidifferential waves are readily produced from linear scan voltammograms by differintegration [17]. They have the advantage of being narrow, symmetric waves with a simple theoretical description, unlike linear scan voltammograms. They also provide better resolution in the Kalman filter because they allow a more sensitive observation of the innovations sequence [14]. Parameters used for the generation of theoretical waveforms were obtained by fitting experimental data using simplex optimization [18].

\section{Experimental}

Standard solutions of $\mathrm{Cd}(\mathrm{II})$ and $\mathrm{Zn}$ (II) were prepared from reagent grade $\mathrm{CdCl}_{2}$ and $\mathrm{Zn}\left(\mathrm{NO}_{3}\right)_{2}$, respectively. They were titrated with standard EDTA, and their concentrations were found to be $[\mathrm{Cd}(\mathrm{II})]=1.596 \times 10^{-2} \mathrm{M}$ and $[\mathrm{Zn}(\mathrm{II})]=2.39 \times 10^{-2} \mathrm{M}$. Aldrich "Gold Labe1" nitrilotriacetic acid (disodium salt) was dissolved in distilled water to give a $3.07 \times 10^{-2} \mathrm{M}$ solution whose $\mathrm{pH}$ was adjusted to 6 using reagent grade $\mathrm{HClO}_{4}$. The supporting electrolyte used was $0.13 \mathrm{M} \mathrm{NaClO} \mathrm{N}_{4}$.

Standard addition curves for $\mathrm{Zn}$ (II) and $\mathrm{Cd}$ (II) were taken over concentration ranges spanning those observed for the free metals in the speciation studies; both were strictly linear, with regression coefficients greater than 0.999 . 
Thirty-seven NTA additions were made to a $6.35 \times 10^{-5} \mathrm{M} \mathrm{Cd}(\mathrm{II})$ solution held at $\mathrm{pH}$ 4.05 \pm 0.05 ; NTA concentrations ranged from $1.222 \times 10^{-5} M$ to $5.69 \times 10^{-4} \mathrm{M}$. In both cases, the temperature was held at $295.4 \mathrm{~K}$ and the $\mathrm{pH}$ was recorded before each run. Eight NTA additions were made to a $1.010 \times 10^{-4} \mathrm{M} \mathrm{Zn}$ (II) solution held at $\mathrm{pH} 5.6 \pm 0.1$; NTA concentrations ranged from $2.44 \times 10^{-5} \mathrm{M}$ to $1.942 \times 10^{-4} \mathrm{M}$.

A Princeton Applied Research Model 173 potentiostat was used to apply potentials, and a Model 176 current-to-voltage converter was used to monitor the working electrode. Potentials were applied using a Digital Equipment Corp. IIINC 11-B microcomputer interfaced to the potentiostat through a 16 bit digital-to-analog converter and a scan generator. Data were analyzed on a separate PDP-11/23 microcomputer equipped with 128K words of memory, floppy disks and graphics terminal. Programs used to perform linear scan voltammetry, to filter data and to perform semidifferentiation have been described previously $[16,18]$. Details of the Kalman filter algorithm are reported elsewhere [12]. MINIQUAD [19] was used to perform non-linear least-squares regression on the curves of $\left[M^{n+}\right]$ vs. total NTA; the program was modified to run on the PDP $11 / 23$ used for this study $[20]$.

4. Results

Figure 1 shows plots of ten of the thirty-seven semiderivative voltammograms produced by NTA additions to Cd(II). Two peaks are readily visible. Initial application of the Kalman filter, using the Cd aquo-complex peak observed before NTA additions as a model of the first peak and a theoretical sech ${ }^{2}$ waveform as model of the second peak, showed the presence of a third peak in all scans. This peak was modelled by simulating a reversible charge transfer preceeded by a homogeneous chemical reaction. A typical fit using a three-component model in the Kalman filter is shown in Fiqure 2.

It was observed that the first peak, presumed to be due to reduction of the Cd aquo complex, did not shift potential nor broaden with additions of NTA. The height of this peak was related to the bulk concentration of the $\mathrm{Cd}$ aquo complex using a standard addition curve measured previously. Figure 3 shows the titration curve obtained. The irregularities in the curve are due to smal1 pH fluctuations in the unbuffered solution. The second peak appears to shift cathodically with the first additions of NTA and then remain stationary; however, the shape did not change with additions of NTA. The second peak is attributed to reduction of $\mathrm{Cd}$ aquo complex obtained by homogeneous dissociation of the CdNTA ${ }^{-}$complex [20-22]. The third peak did not shift or change shape with NTA additions; its position was sensitive to $\mathrm{pH}$ changes. This effect is visible in Figure 1. Regression analysis gave a stability constant of 9.34 (log $K$ ) for the CdNTA complex, in 


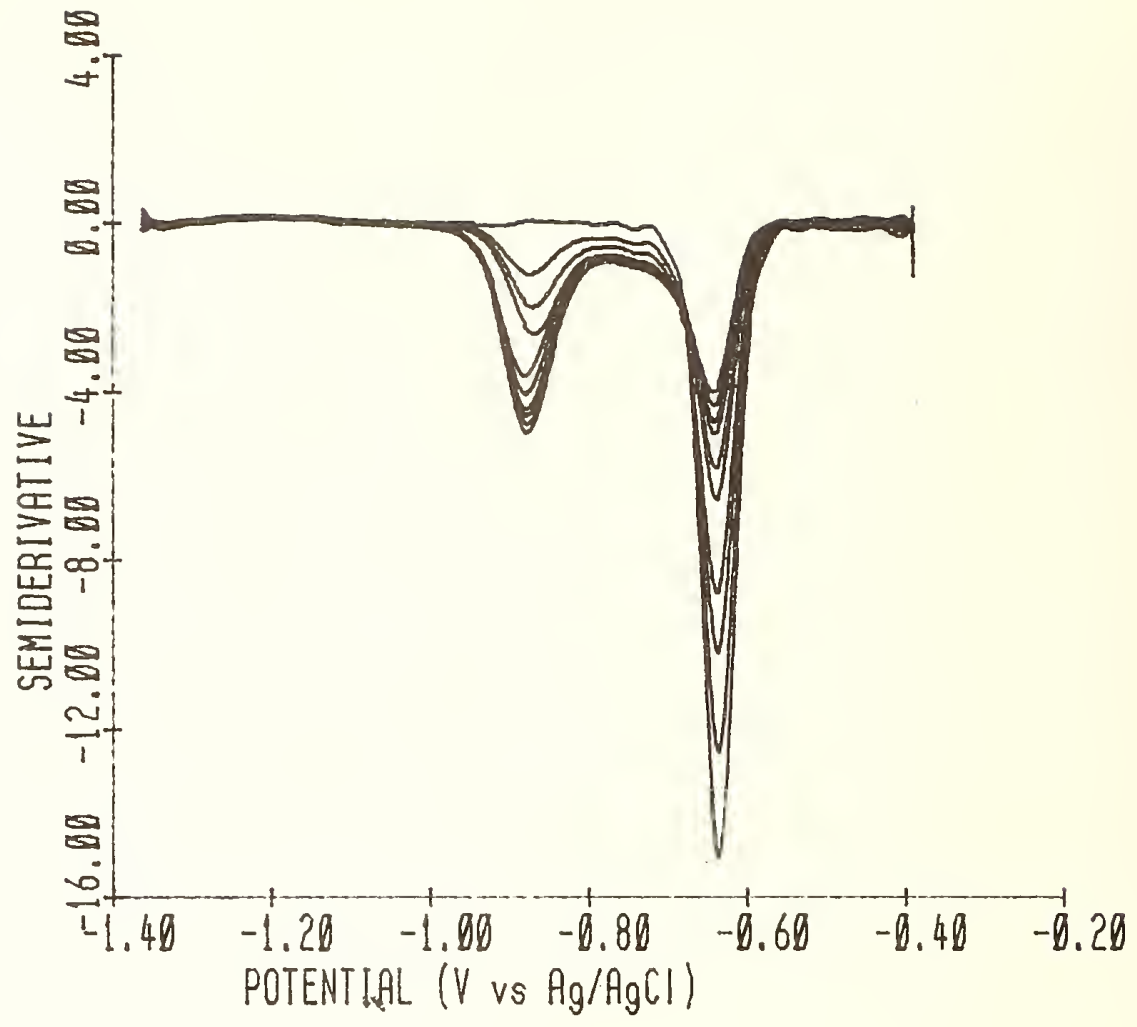

Figure 1: Semiderivative voltammograms of NTA additions to Cd(II)

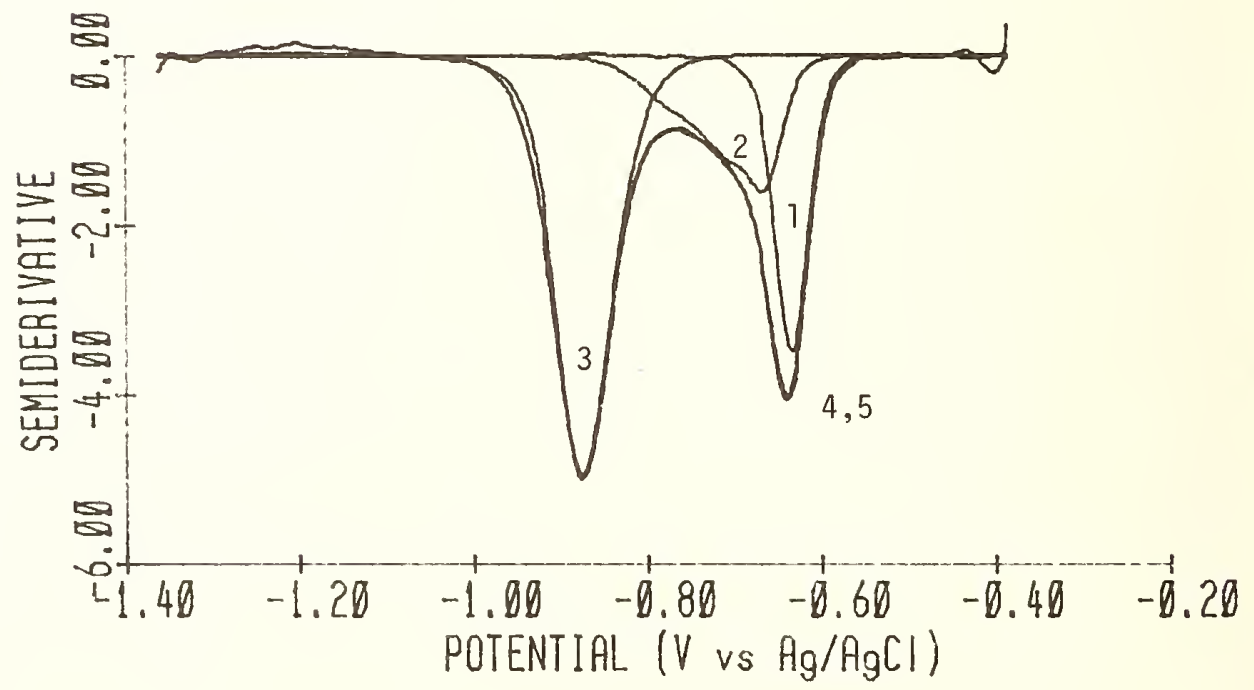

Figure 2: Typical results from a Kalman filter fit to one of the Cd-NTA semiderivative voltammograms. Curve 1 is due to the "free" Cd(II); curve 2 is due to Cd(II) in equilibrium with Cd-NTA; curve 3 is due to the direct reduction of Cd-NTA; curve 4 is the original voltammogram; and curve 5 is the fit voltammogram 


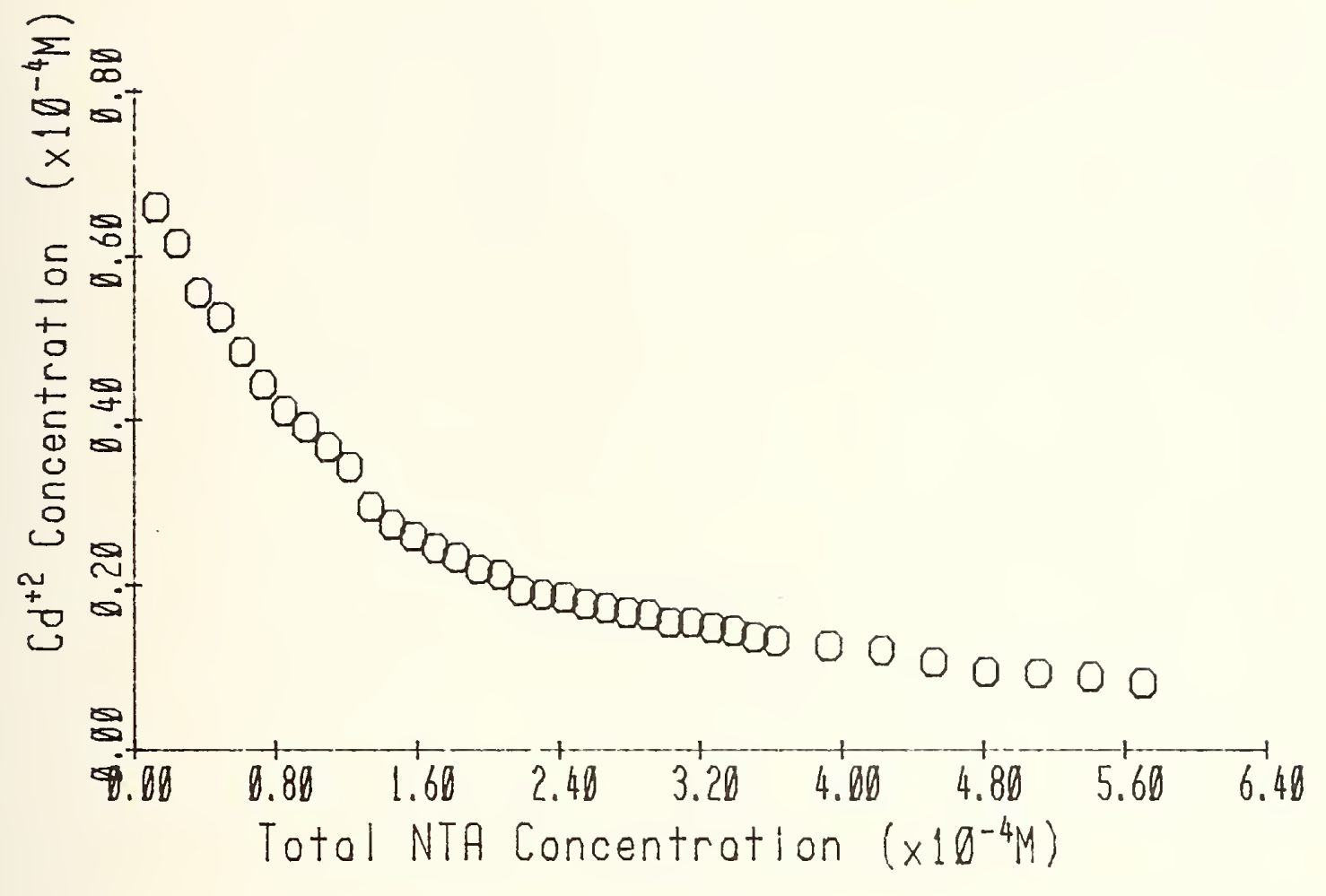

Figure 3: Titration curve for Cd with NTA

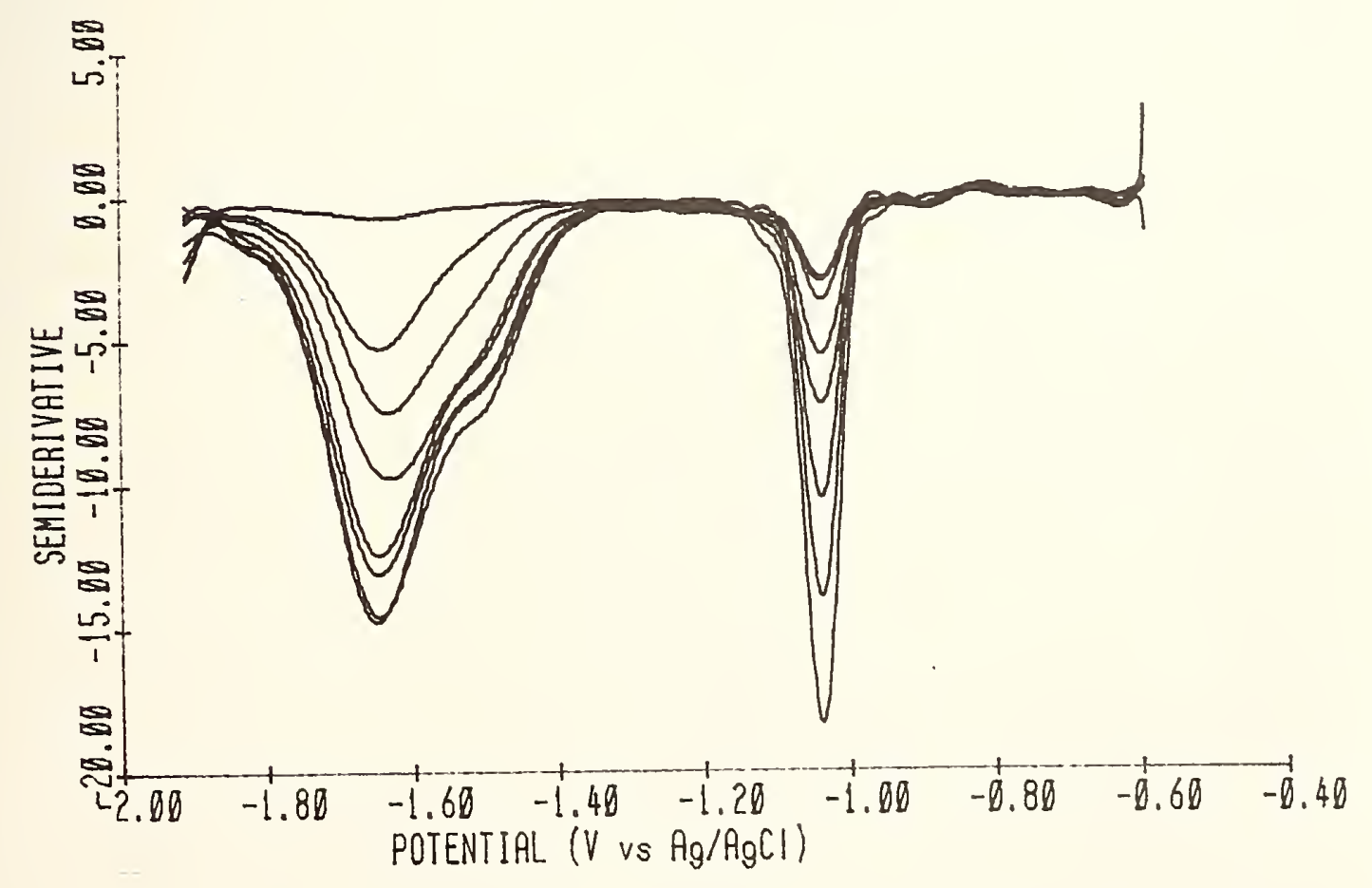

Figure 4: Semiderivative voltammograms of NTA additions to $\mathrm{Zn}$ (II) 
excellent agreement with literature values [23].

Figure 4 shows plots of the eight semiderivative voltammograms produced by additions of NTA to $\mathrm{Zn}$. Here, three peaks are evident. Because the peak due to the reduction of the $\mathrm{Zn}$ aquo complex was well separated from the others, the Kalman filter was not required to separate peaks. However, the filter was used to separate the two peaks produced by reduction of the NTA complexes. Theoretical $\operatorname{sech}^{2}$ models were used to separate the two overlapped peaks; neither was found to shift or to change shape upon addition of NTA. The uneven spacing of peak heights for these peaks presumably results from slow exchange kinetics [24]. The peak height for the $\mathrm{Zn}$ aquo complex was related to the bulk $\mathrm{Zn}$ concentration using a standard addition curve obtained previously. Non-linear regression on the curve obtained by plotting the concentration of the $\mathrm{Zn}$ aquo complex versus the concentration of NTA added gave a value of 10.51 (1og K) for the $\mathrm{Zn}(\mathrm{NTA})^{-}$complex, in excellent agreement with reported results $[23,25]$.

\section{Conclusions}

This study demonstrates the feasibility of using peak separation techniques, such as the Kalman filter, to obtain accurate estimates of the peak height of the aquo complex in a quasi-labile metal-complex system without large excesses of 1igand. The metal aquocomplex concentrations thus obtained can be regressed as a function of ligand addition to obtain stability constants. Examples using NTA show the constants thus obtained agree wel1 with those determined by other means. Extention of this work to more labile systems is in progress.

\section{References}

[1] Hartley, F.R.; Burgess, C.; Alcock, R. Solution equilibria. New York: Halstead Press; 1980. $361 \mathrm{p}$.

[2] Florence, T.M.; Batley, G.E. Chemical speciation in natural waters. C.R.C. Critical Reviews in Ana1. Chem. 9:219-296; 1980.

[3] Deford, D.D.; Hume, D.N. The determination of consecutive formation constants of complex ions from polarographic data. J. Amer. Chem. Soc. 73:5321-5323; 1951.

[4] Davison, W. Defining the electroanalytically measured species in a natural water sample. J. Electroana 1. Chem. 87: 395-404; 1978.

[5] Van Leeuwen, H.P. Kinetic classification of metal complexes in electroanalytical speciation. J. Electroanal. Chem. 99: 93-102; 1979.

[6] Butler, C.; Kaye, R.C. The polarographic reduction of metal complexes. J. Electroana1. Chem. 8:463-471; 1964.

[7] Ringbom, A. and Erikson, L. The evaluation of complexity constants from polarographic data. Acta Chem. Scand. 7:1105-1111; 1953. 
[8] Matson, W.R. Trace metals: equilibrium and kinetics of trace metal complexes in natural media. Dissertation. Mass. Inst. Technology: Cambridge, MA; 1968.

[9] Shuman, M.S.; Woodward, G.P. Chemical constants of metal complexes from a complexometric titration followed with anodic stripping voltammetry. Anal. Chem. 45:2032-2035; 1973.

[10] Macovschi, M.E. Equations of the polarographic waves of simple or complexed metal ions. J. Electroanal. Chem. 18:47-59; 1968.

[11] Kalman, R.E. A new approach to linear filtering and prediction problems. Trans. ASME Ser. D, J. Basic Eng. 82:34-45; 1960.

[12] Brown, T.F.; Brown, S.D. Resolution of overlapped electrochemical peaks with the use of the Kalman Filter. Anal. Chem. August, 1981 (in press). Lawrence Berkeley Laboratory Report 11917; 1981. 39 p.

[13] Poulisse, H.N.J. Multicomponent analysis computations based on Kalman Filtering. Anal. Chim. Acta 112:361-374; 1980.

[14] Brown, T.F.; Brown, S.D. manuscript in preparation.

[15] Goto, M.; Ishii, D. Semidifferential electroanalysis. J. Electroanal. Chem. $61: 361-365 ; 1975$.

[16] Toman, J.J.; Corn, R.M.; Brown, S.D. Convolution voltammetry of metal complexes. Anal. Chim. Acta 123:187-199; 1981.

[17] 01dham, K.B. An algorithm for semiintegration, semidifferentiation and other instances of differintegration. J. Electroanal. Chem. 121:341-342; 1981.

[18] Toman, J.J.; Brown, S.D. Peak resolution by semiderivative voltammetry. Anal. Chem. August, 1981 (in press). Lawrence Berkeley Laboratory Report 11738; 1980. 38 p.

[19] Sabatini, A.; Vacca, A.; Gans, P. MINIQUAD:A general computer programme for the Computation of formation constants from potentiometric data. Talanta 21:53-77; 1974.

[20] Cizek, J.; Koryta, J.; Koutecky, J. Polarographische Ströme, die durch die Dissoziation einer Elektroaktiven Verbindung in einen Elektroaktiven Stoff und in einen Elektroaktiven Stoff bedingt sind. Col1. Czech. Chem. Comm. 24:663-677; 1959.

[21] Cizek, J.; Koryta, J.; Koutecky, J. Polarographische Ströme, die durch die Geschwindigkeit der Bildung eines Elektroaktiven Stoffes aus zwei Elektroinaktiven Stoffen, wovon keiner im überschuss ist, bestimmt sind. Coll. Czech. Chem. Comm. $24: 3844-3860 ; 1959$.

[22] Shuman, M.S.; Shain, I. Study of the chemical reaction preceeding reduction of cadmium nitrilotriacetic acid complexes using stationary electrode polarography., Ana 1. Chem. 41:1818-1825; 1969.

[23] Sillen, L.G.; Martell, A.E. Stability constants of metal-ion complexes. Supplement 1. London: The Chemical Society; 1971. 865 p.

[24] Biernat,J.; Kortya ,J. Kinetik der Elektrodenvorgänge von Komplexen in der Polarographie IV: Abscheidung des Mangans aus dem Komplex mit Nitrilotriessigsäure., Col1. Czech. Chem. Comm. 25:38-47; 1960.

[25] Schwarzenbach,G.; Gut,R. Die Komplexe der Seltenen Erdkationen und die Gadoliniumecke., Helv. Chim. Acta 39:1589-1599; 1956.

Discussion

Question (Y. K. Chau): I have the feeling that you have not solved the problem of adsorption, that is, electroabsorption?

Answer: No, in fact we haven't.

Question (Y. K. Chau): I think most biological systems involve very weak complexes, such as copper-glycine. I don't think any electrochemical technique can differentiate free copper, aquo-copper(II), and copper-glycine or even weaker complexes. Copper acetate has a pK value below 10. NTA has a pK value of 10; and we use it to define whether it is labile copper or free copper. I do not think that your system can do any weak complexes below pK 10 ? 
Answer: It can't. We have looked at systems other than copper. We avoid copper because of irreversibility; we can't fit it as well. If we look at lead hydroxide and other systems we see double peaks. The reason we use the Kalman filter is that the double peaks are very close together. The Kalman filter can pull them apart with essentially no error in the fitting. All the error comes from the electrochemistry. We are able to get constants from that. But you're quite correct about adsorption. The reason I don't show the lead hydroxide system, is there are preadsorptive layers of the hydroxide species. We are currently modifying the filter to try and model the adsorption. The problem is that there aren't very good models for the adsorption. One student who has been working on this for about two years originally started with the adsorption models, but decided to go to speciation because it was easier.

Question (M. A. Anderson): The discussion on these surfaces a while ago suggests what we really need some good experimental methods for determining equilibrium constants on surfaces, providing that we have thermodynamic control. In a system where you have a lead ion adsorbing less, say, to an aluminum oxide surface, as I showed here from the data of Hohl and Stümm [J. Colloid. Interface Sci. 55: 281 (1976)], you can use this technique. Suppose you have arsenic or selenium, how do you apply the technique here to get surface binding complexation constants?

Answer: The problem here is that the ligand exchange rate has to be such that the electrochemistry can handle it. If the ligand exchange rate is very slow, as in the case of some of these...

Question (M. A. Anderson): Well the point is that I don't think that you can use an electrode to detect these things?

Answer: No. You can't detect the ligands, being complex species.

Question (M. A. Anderson): Al1 you can detect is the proton?

Answer: You can detect the proton or you can detect the free lead, but that would be it. Question (M. A. Anderson): If there is no lead in this system?

Answer: Free arsenic plus three you can detect, but not $A s(V)$. 
Biological Uptake and Chemical Speciation of Copper

In Sea Water Determined by Electrochemistry

E.A. Crecelius, J.M. Gurtisen, and C.W. Apts

Battelle, Pacific Northwest Laboratory

Marine Research Laboratory

439 West Sequim Bay Road

Sequim, Washington 98382

The relationship between electroactive $\mathrm{Cu}$ concentrations and biological uptake of $\mathrm{Cu}$ was investigated to determine if electroactive Cu concentrations would better predict bioavailable $\mathrm{Cu}$ than total $\mathrm{Cu}$ concentrations. Measurements of electroactive $\mathrm{Cu}$ were made using differential-pulse anodic stripping voltammetry (DPASV) at $\mathrm{pH} 8$ with a mercury-coated glassy carbon electrode. The $\mathrm{Cu}$ complexing capacity of Pacific Northwest coastal waters averaged 18.7 $\mu \mathrm{g} \mathrm{L^{- }}$ (S.D. $\left.=5.5, N=57\right)$. When $\mathrm{Cu}$ is added at concentrations that exceed the complexing capacity we observe both increased DPASV-measurable Cu and increased $\mathrm{Cu}$ body burdens in exposed animals. DPASV is a practical method for monitoring biologically active forms of $\mathrm{Cu}$ in contaminated waters.

Key words: anodic stripping; bioavailability; complexing capacity; copper speciation.

1. Introduction

One of the major problems limiting prediction of effects of a contaminant, such as $\mathrm{Cu}$, in the marine environment is the inability to relate an analytically defined fraction of the total amount of material in the environment with a biological response. The toxicity of $\mathrm{Cu}$ to marine organisms is reduced by its ability to complex with other ions or compounds. By adding organic or inorganic $\mathrm{Cu}$ chelating compounds to $\mathrm{Cu}$ bioassay systems, the toxicity of $\mathrm{Cu}$ was reduced $[1,2,3,4]$. The purpose of this study was to develop an analytical method that could be used to predict the Cu uptake rate and toxicity to marine animals. The relationship of electrochemically measured $\mathrm{Cu}$ and $\mathrm{Cu}$ uptake by marine organisms was investigated.

* This work was supported by the Department of Energy under Contract \#DE-AC06-76RL0 1830. 


\section{Experimental Design}

Whole body $\mathrm{Cu}$ uptake experiments were conducted on the bivalve, Macoma inquinata, and the shrimp, Pandalus danae. Animals were collected from an unpolluted bay (Sequim Bay) about $75 \mathrm{~km}$ northwest of Seattle, Washington. The bay is clean, with Cu concentrations of $0.18 \pm 0.11$ SD $\mu \mathrm{g} \mathrm{L}^{-1}$ [5]. The animal exposure consisted of $100 \mathrm{~L}$ tanks holding 20 animals each for each Cu concentration. Sea water flowed through each tank at a rate of $3 \mathrm{~L} \mathrm{~min}^{-1}$. This was equivalent to a tank retention time of less than three hours. Copper was added from a $\mathrm{CuSO}_{4}$ de-ionized water stock solution through a mixing funnel and metering pump at dilution rates to maintain $\mathrm{Cu}$ concentrations of 5 , 10,17 and $30 \mu \mathrm{g} \mathrm{L^{-1 }}$.

All exposure tanks were monitored daily for dissolved $\mathrm{O}_{2}, \mathrm{pH}$, salinity and temperature. The following ranges were observed for these variables, $0_{2}, 7-9 \mathrm{mg} \mathrm{L}^{-}{ }^{1}$; $\mathrm{pH}, 7.8$ - 8.2; salinity, $29-30^{\circ} \%$; and temperature, $10-12^{\circ} \mathrm{C}$. Dissolved organic

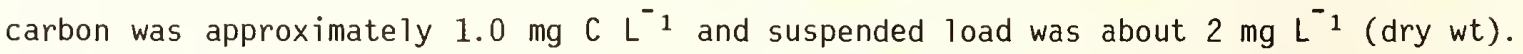
After exposures of one month, clams were depurated in fresh sea water for three days, shucked, dried at $60^{\circ} \mathrm{C}$, digested in hot concentrated reagent grade $\mathrm{HNO}_{3}$, taken to dryness, resolubilized in $0.4 \mathrm{~N} \mathrm{HNO}_{3}$, and analyzed for total $\mathrm{Cu}$ on an Instrumentation Laboratories 251 atomic absorption spectrophotometer. National Bureau of Standards SRM 1577 Bovine Liver was analyzed by the same method and yielded Cu values consistent with NBS certified values.

\section{Analytical Methods}

Measurements of $\mathrm{Cu}$ in sea water were made using a Princeton Applied Research 174A Polarographic Analyzer in the differential pulse mode linked to a Houston $20000 \mathrm{mni}$ graphic XY Recorder. The Sylon-CT ${ }^{\circledR}$-coated borosilicate electrolytic cell (PAR 9330) connects to a plastic top with five ports that support the working Mercury Film Electrode (MFE), reference, and counter electrodes.

A teflon-coated stir bar $(9 \times 2 \mathrm{~mm})$ within the cell was activated to 300 R.P.M. by a Magnestir unit. The working electrode (MFE) was a PAR 9333 Glassy Carbon electrode. The glassy carbon electrode was lapped on a buffing wheel prior to the application of a fresh mercury film. A - 1.00 V. vs. SCE was applied for $45 \mathrm{~s}$ to the glassy carbon electrode which was immersed into $1 \mathrm{mg} \mathrm{Hg}^{++} \mathrm{L}^{-1}$ solution. This procedure insures a workable mercury film. 
The analysis of electroactive $\mathrm{Cu}$ in sea water was carried out at ambient $\mathrm{pH}$. A plating voltage of $-0.5 \mathrm{~V}$ vs. SCE was used. The system was standardized by the method of standard additions. To determine the $\mathrm{Cu}$ complexing capacity of sea water, several aliquots of sea water were spiked with $\mathrm{CuSO}_{4}$ solution to give total Cu concentration of 5 to $50 \mu \mathrm{g} \mathrm{Cu} \mathrm{L}{ }^{-1}$. These aliquots were analyzed for electroactive Cu after more than 3 hours of aging to allow the $\mathrm{Cu}$ time to complex. The $\mathrm{Cu}$ complexing capacity was calculated by plotting instrumental response to electroactive $\mathrm{Cu}$ versus concentration of $\mathrm{Cu}$ added. The resulting curve usually becomes linear after the $\mathrm{Cu}$ complexing capacity has been reached. The $\mathrm{Cu}$ complexing capacity is the point where this linear portion, when extrapolated, crosses the $\mathrm{Cu}$ added axis [6]. For analysis of total copper in sea water, $30 \mathrm{~mL}$ of sea water was acidified to $\mathrm{pH} 2.2$ with U1trex $\mathrm{HNO}_{3}$ and analyzed 1 hour later for electroactive $\mathrm{Cu}$ at $-0.8 \mathrm{~V}$.

\section{Results}

The concentrations of electroactive $\mathrm{Cu}$ compared to total $\mathrm{Cu}$ (equivalent to $\mathrm{Cu}$ added) in the unaged and aged tanks are shown in Table 1. In the unaged tanks, approximately half the $\mathrm{Cu}$ is complexed or not electrochemically active in the sea water dosed

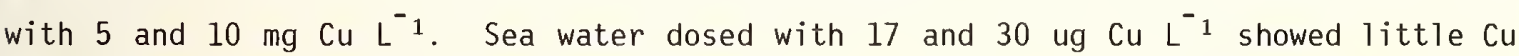
complexation. Electroactive Cu levels were lower in the tanks containing Cu-dosed sea water aged for 72 hours than those in the unaged tanks. Total Cu concentrations in al1 tanks were within $5 \%$ of the dosed concentration, indicating wall loss was not a significant problem.

Measurements of electroactive $\mathrm{Cu}$ by DPASV indicate that when $\mathrm{Cu}$ is added to sea water the concentration of electroactive $\mathrm{Cu}$ decreases rapidly at first and continues to decrease during the next 3 days before approaching equilibrium (Figure 1 ). The relative percentage of $\mathrm{Cu}$ remaining as electroactive species increased with increasing concentrations of total $\mathrm{Cu}$ added (Table 1 ).

Total body burdens after exposure to unaged $\mathrm{Cu}$-seawater solutions increased in clams and shrimp with increasing total seawater- $\mathrm{Cu}$ concentrations. The increase with respect to total seawater $\mathrm{Cu}$ is not linear, but more closely approximates an exponential or sigmoid function. Copper body burdens in both clams and shrimp were less for animals exposed to the aged copper seawater as compared to unaged $\mathrm{Cu}$ dosed sea water ( Table 1). 


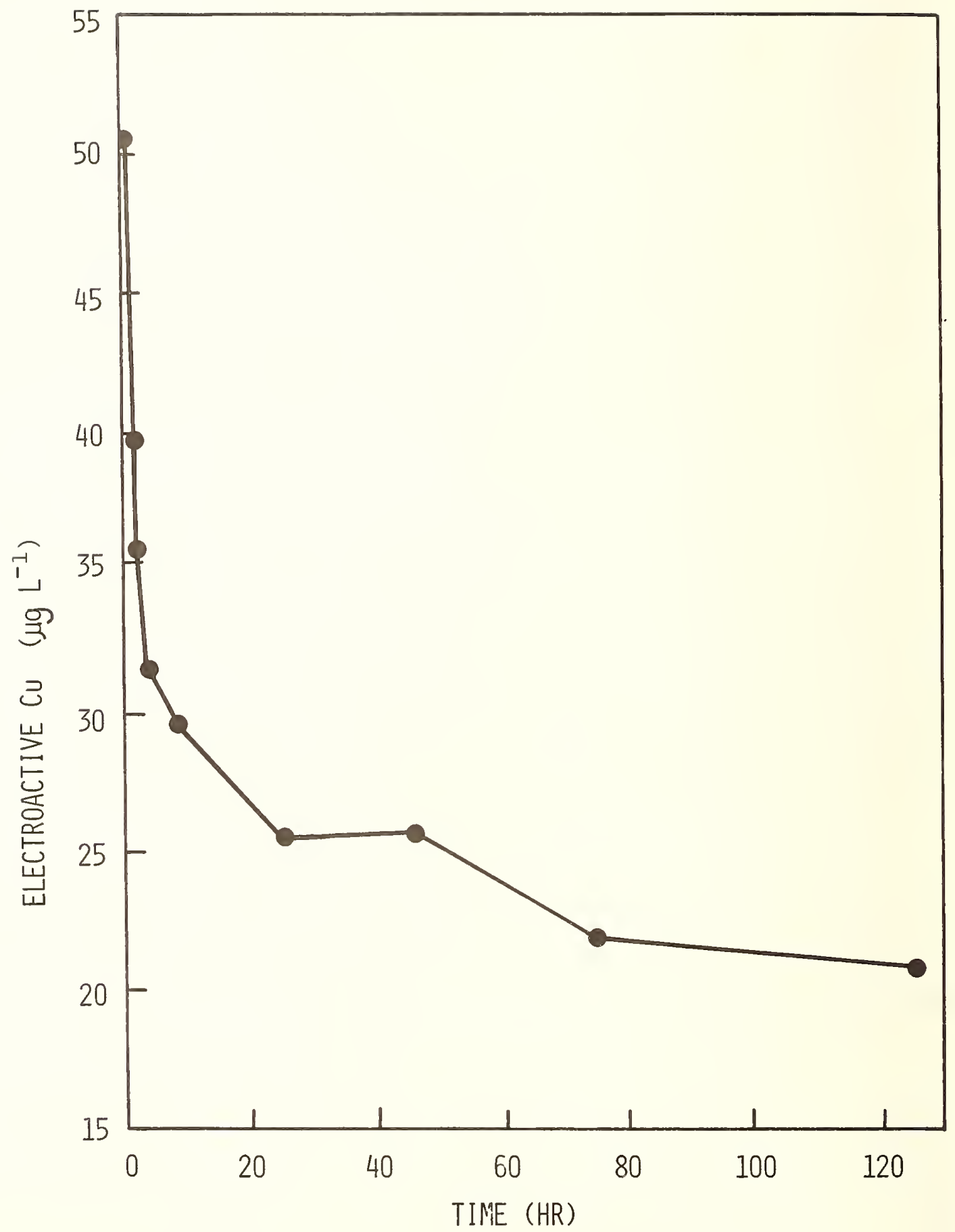

Figure 1. The concentration of electroactive $\mathrm{Cu}$ decreases as a $\mathrm{Cu} /$ seawater mixture ages. 
Table 1. Cu body burdens after one-months exposure to $\mathrm{Cu}$ without sediment present in the clam $\underline{M}$. inquinata and the shrimp P. danae.

\section{UNAGED}

\begin{tabular}{|c|c|c|c|c|c|c|c|c|c|c|c|}
\hline \multirow[t]{2}{*}{$\begin{array}{l}\text { Added } \\
\text { Cu Con. } \\
\mu g L^{1}\end{array}$} & \multicolumn{5}{|c|}{$\begin{array}{l}\text { Electroactive } \\
\text { Cu Concentration after } \\
72 \mathrm{~h} \mathrm{equilibration} \\
\mu \mathrm{g} \mathrm{L} \mathrm{L}_{1}\end{array}$} & Clam & \multicolumn{3}{|c|}{$\begin{array}{l}\text { Body Burden } \\
\text { ppm Cu dry wt }\end{array}$} & \multicolumn{2}{|c|}{ Shrimp } \\
\hline & $\underline{N}$ & $\bar{x}$ & \pm & S.D. & $\mathrm{N}$ & $\bar{x}$ & \pm & S.D. & $N$ & $\bar{x}$ & \pm S.D. \\
\hline 0 & 3 & 0.00 & & 0.00 & 10 & 15 & & 8 & 20 & 65 & 16 \\
\hline 5 & 3 & 2.00 & & 0.12 & 20 & 25 & & 17 & 19 & 146 & 23 \\
\hline 10 & 3 & 5.2 & & 1.02 & 15 & 28 & & 18 & 19 & 190 & 19 \\
\hline 17 & 3 & 16.0 & & 0.24 & 6 & 97 & & 34 & 15 & 260 & 32 \\
\hline 30 & 3 & 28.7 & & 2.00 & 5 & 84 & & 26 & 8 & 322 & 46 \\
\hline
\end{tabular}

\section{AGED}

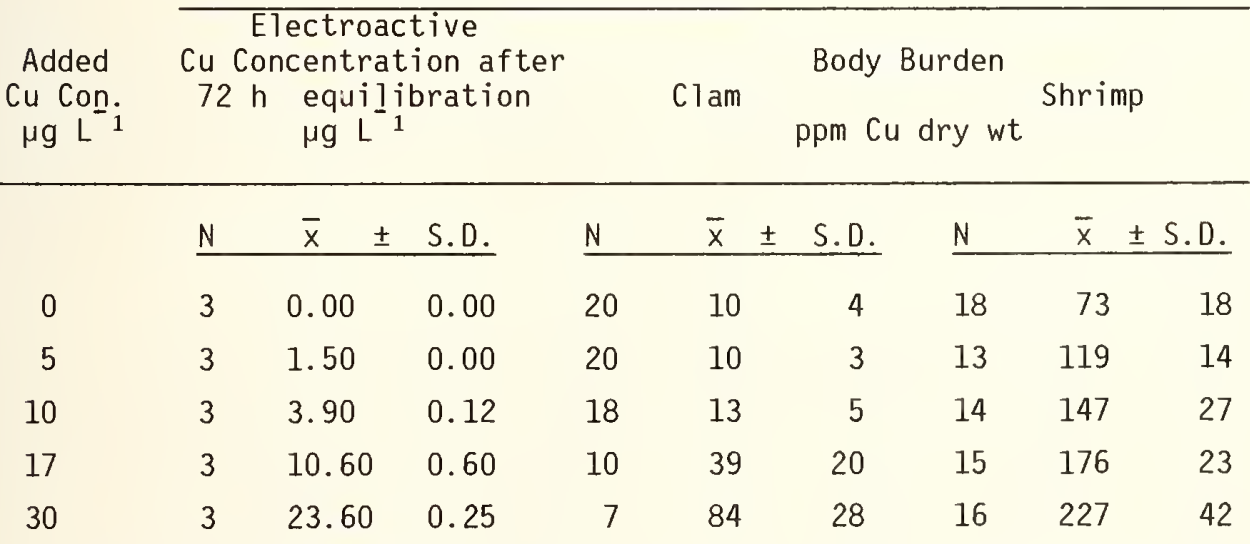

Thus, aging of seawater-Cu solutions prior to animal exposure reduced the bioavailability of $\mathrm{Cu}$. This probably occurs through a slow complexation of the added ionic $\mathrm{Cu}$ by natural organic compounds present in the sea water. The same concentration of $\mathrm{Cu}$ present in sea water will result in $\mathrm{Cu}$ body burdens approximately $2 \frac{1}{2}$ times 
lower in animals when the sea water is "aged" for 72 hours. That is, Cu that has been aged in sea water is significantly less bioavailable to clams and shrimp than unaged $\mathrm{Cu}$. The higher $\mathrm{Cu}$ concentrations were stressful to the animals. Survival of shrimp and clams during the 30-day exposure was high in controls, but markedly reduced at 17 and $30 \mu \mathrm{g} \mathrm{L}^{-1}$ (Table 1 ). Electroactive $\mathrm{Cu}$ concentrations in sea water during the exposures averaged 25\% 1ower in aged than in unaged Cu-seawater solutions (Table 1 ). Copper uptake appeared to be determined more by the concentration of electroactive $\mathrm{Cu}$ than the total $\mathrm{Cu}$ concentration in sea water. Thus, final $\mathrm{Cu}$ body burdens occurring during the 1-month exposure of clams increased with increasing concentrations of electroactive $\mathrm{Cu}$ present in sea water according to:

$$
Y=12.7+3.03 \times\left(n=10, r^{2}=0.83\right)
$$

and for shrimp: $Y=107+7.16 \times\left(n=10, r^{2}=0.83\right)$

where: $Y=\mu \mathrm{g} \mathrm{Cu/g}$ dry wt, and

$$
X=\text { concentration of electroactive } \mathrm{Cu} \text { in } \mu \mathrm{g} \mathrm{L}^{-}
$$

Thus, our results with shrimp and clams indicate that the concentration of $\mathrm{Cu}$ as measured by anodic stripping voltammetry is a better indicator of the amount of bioavailable $\mathrm{Cu}$ than measurements of total $\mathrm{Cu}$ concentrations in the water (Figure 2).

\section{Discussion}

Our results indicate that dissolved substances present in sea water reduce the proportion of electroactive $\mathrm{Cu}$ and at the same time reduce $\mathrm{Cu}$ bioavailability. It is likely that in many oceanic and freshwater environments, especially those with high concentrations of dissolved organics, Cu exists primarily in the complexed form and is not bioavailable. Copper-seawater concentrations used in the animal exposures ranged from $<1 \mu \mathrm{g} \mathrm{L}^{-1}$ (control sea water) to $30 \mu \mathrm{g} \mathrm{L}^{-1}$. This range lies between those reported for natural sea water [7] and extremely contaminated coastal waters [8]. The $\mathrm{Cu}$ chelation capacity of sea water falls in about the same range as our Cu exposure concentrations, ranging from $3 \mu \mathrm{g} \mathrm{L}^{-1}$ for oligotrophic to $40 \mu \mathrm{g} \mathrm{L}^{-1}$ for eutrophic marine waters and is apparently due to organic substances with molecular weights $<10,000$ daltons $[5,9]$. 


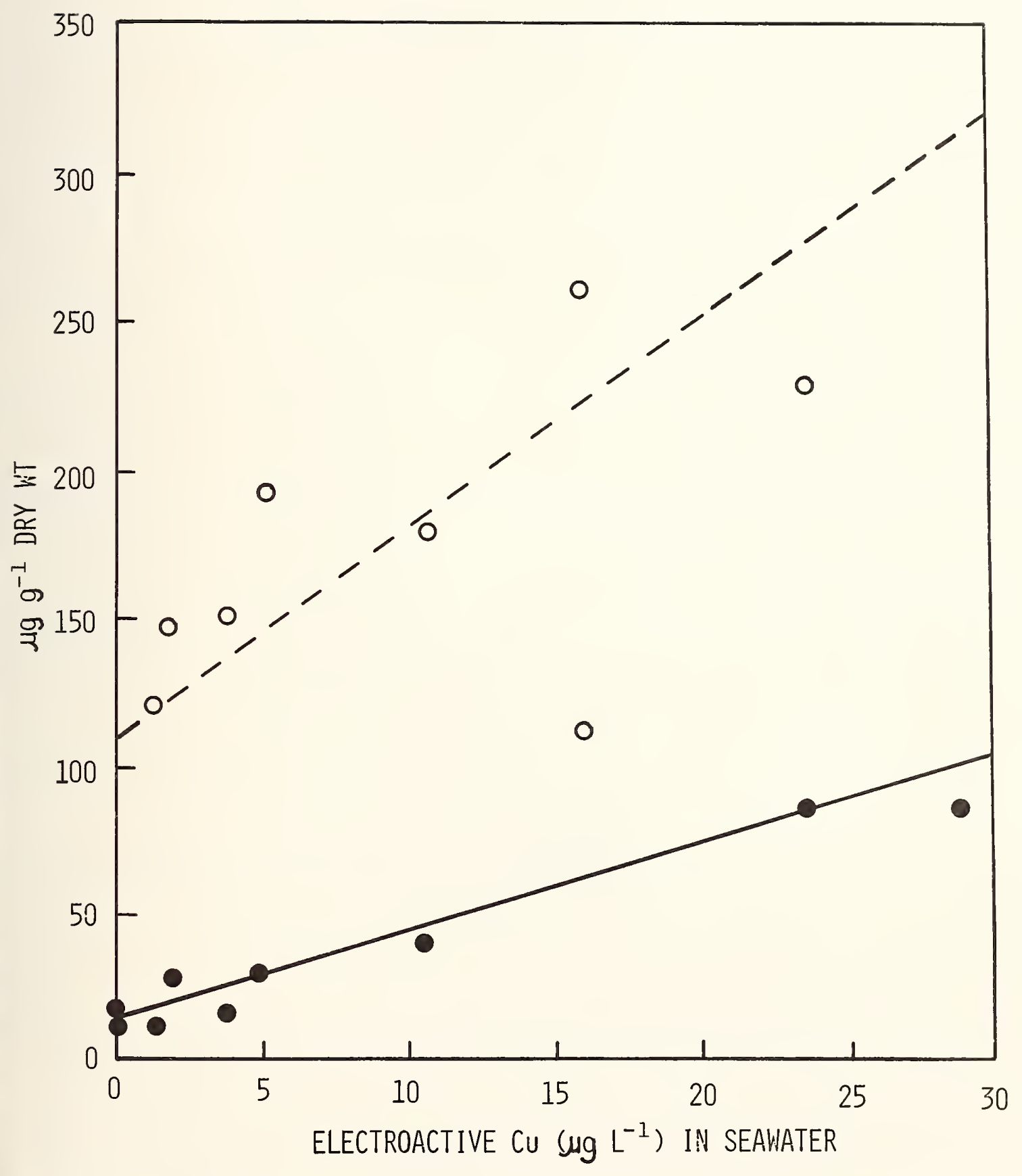

Figure 2. Cu bioaccumulation increases linearly according to the concentration of electroactive $\mathrm{Cu}$.

$0=\operatorname{shrimp}(\underline{P} \cdot \underline{\text { danae}}) ; \bullet=\operatorname{clam}(\underline{M}$. inquinata) 
Ionic $\mathrm{Cu}^{+} 2$ is believed to be the Cu species primarily responsible for toxicity $[4,10]$. DPASV measurements of electroactive $\mathrm{Cu}$ concentrations includes ionic $\mathrm{Cu}^{+{ }_{2}}$ and $\mathrm{Cu}$ weakly complexed by organic or inorganic ligands but not the strongly complexed $\mathrm{Cu}$ species. Previous work in our laboratory has shown that DPASV-measurable Cu was a good indicator of toxic copper to shrimp zoeae and uptake by clam gi11s [5, 11]. Our results further indicate that DPASV can be a useful analytical tool for determining the bioavailable fraction of $\mathrm{Cu}$ and possibly other metals present in sea water.

In setting water quality standards and in predicting the bioavailability of toxic trace elements, careful attention should be paid to existing knowledge of chemical speciation and biological species differences. Copper levels known to be toxic to oligotrophic waters may become complexed and totally innocuous in eutrophic waters or in sediment. Our results, as well as others discussed here, point to the fact that measurements of (ionic) free copper concentrations in water are important in predicting potential toxicity or bioaccumulation of $\mathrm{Cu}$.

\section{References}

[1] Lewis, A.G.; Whitfield, P.; Ramnarine, A. Some particulate and soluble agents affecting the relationship between metal toxicity and organism survival in the calanoid copepod Euchaeta japonica. Mar. Biol. 17:215-221; 1972.

[2] Lewis, A.G.; Whitfield, P.; Ramnarine, A. The reduction of copper toxicity in a marine copepod by sediment extract. Limnol. Oceanog. 18:324-326; 1973.

[3] Davey, E.W.; Morgan, M.J.; Erickson, S.J. A biological measurement of the copper complexation capacity of sea water. Limnol. Oceanog. 18:993-997. 1973

[4] Sunda, W.; Guillard, R.R.L. The relationship between cupric ion activity and the toxicity of copper to phytoplankton. J. Mar. Res. 34:511-529; 1976.

[5] Young, J.S.; Gurtisen, J.M.; Apts, C.W.; Crecelius, E.A. The relationship between the copper complexing capacity of sea water and copper toxicity in shrimp zoeae. Mar. Environ. Res. 2(4): 265-272; 1979.

[6] Chau, Y.K; Gachter, R.; Lum-Shu-Chan, K. Determination of the apparent complexing capacity of lake waters. J. Fish. Res. Bd. Can. 31(9):1515-1519; 1974.

[7] Batley, G.E.; Gardner, D. A study of copper, lead and cadmium speciation in some estuarine and coastal marine waters. Estuarine Coastal Mar. Sci. 7:59-70; 1978. 
[8] Waldhauer, R.; Matte, A.; Tucker, R.E. Lead and copper in the waters of Raritan and lower New York Bays. Mar. Poll. Bul1. 9:38-42; 1978.

[9] Gillespie, P.A.; R.F. Vaccaro. A bacterial bioassay for measuring the copper chelation capacity of sea water. Limnol. Oceanog. 23(3);543-548; 1978.

[10] Pagenkopf, G.K.; Russo, R.C.; Thurston, R.V. Effect of complexation on toxicity of copper to fishes. J. Fish. Res. Bd. Can. 31:462-465; 1974.

[11] Crecelius, E.A.; Hardy, J.T.; Gibson, C.I.; Schmidt, R.L.; Apts, C.W.; Gurtisen, J.M.; Joyce, S.P. Copper bioavailability to marine bivalves and shrimp: Relationship to cupric ion activity. Mar. Environ. Res. (In press); 1981.

\section{Discussion}

Question (S. E. Manahan): Could you say a bit more about your digestion procedure at pH 2 to establish the total copper level. Is this an oxidation type of digestion?

Answer: Yes, we added nitric acid and heated it for a while. It's not an absolute method. We don't get all the copper out of the system, but it allows us to digest the sample, free up most of the copper in the water, and analyze electrochemically in fairly simple and fast manner.

Question (S. E. Manahan): Did you check it with furnace atomic absorption?

Answer: Yes, but for furnace atomic absorption we have to preconcentrate, and different preconcentration methods have been used. We are not necessarily removing all copper from the system.

Comment (S. E. Manahan): This could give some problems; we have found that some humic-type complexes, which you probably don't have in your system, with copper, tend to be stable even at that low $\mathrm{pH}$ and could precipitate out of the solution. To get true total copper you might want to look at this also.

Question (J. A. Brierley): Did copper uptake by the clam gill itself or are there microflora on the surface in the gill participating in the uptake? 
Answer: We believe it is the clam gill itself. We tested this by putting antibiotics in the water, but the results can't be taken as conclusive. We've also removed the gill after the gill has been exposed and dipped it in dilute acid for a short time. It doesn't desorb a significant amount of copper, but that doesn't prove that the copper wasn't absorbed.

Question (R. J. Breteler): In your gill experiment you showed the copper uptake in the filtered aged seawater is almost the same as in the nonfiltered aged water. Doesn't it indicate that the most inorganic species foster complexation and decrease the bioavailability?

Answer: It indicates that, in this exposure, filtering the water did not remove a significant amount of copper complexing capacity. Whether you filtered or did not filter the water, if you added copper(II) and aged it awhile, the body burden in the gill did not change over a 24-hour period.

Question (R. J. Breteler): You said earlier that the organic matter is probably a component in seawater that complexed the copper, and therefore decreased its bioavailability. But filtering it depends on the filter process? I would imagine you take out most of your organic ligands.

Answer: In coastal seawater there is about a milligram per liter of dissolved organic carbon with only about a few tenths of a milligram per liter of particulate organic carbon. Most of the organic matter in seawater is dissolved in our system. If you get very high suspended loads, particulate organics will become predominant.

Question (S. M. Silverstein): Would you care to speculate on what you think the nature of the complexing agent is?

Answer: We made major attempts to determine the stability constant for the dissolved organic copper and dissolved organic matter and found about $10^{9}$. Then that information was put into a chemical model for copper speciation in sea water. The chemical model said that it is not a strong enough complexing agent and we need a stability constant of about $10^{16}$ to $10^{18}$ before the dissolved organic matter would become important. So we have a tremendous disagreement between the analytical measurement and the chemical speciation model. Dr. Jenne and I are trying to resolve this.

Comment (Y. K. Chau): It is dangerous to assume that the copper loss is due to complexation alone. Algal exudates will account for most of the complexing capacity of natural waters. We were working in fresh water where algae excrete material in the first few minutes with the free copper. This exudate has a pk value of about 8 to 9 , and that would account for most of the complexing capacity of natural water. Speculating on the nature 
of this thing, we measured the pK value for several algal exudates and compared the pK value of humic and fulvic acids with copper. We also measured the molecular weight using amicon filtration and found the molecular weight cut-off point between 5000 and 100,000. This is very wide molecular weight range and falls in with the copper complexes of humate and fulvate materials.

Answer: I quite agree and mention that we haven't ruled out that absorption might be the process that's removing the available copper from the water.

Comment (J. G. Sanders): Dr. Chau, is that in fresh water that you are working? We find that in marine systems and estuarine systems the copper is associated with much lower molecular weight organics. So it may not just be humic material. 
Specific Element Detection in Chromatography by Plasma Emission Spectroscopy

$$
\text { P. C. Uden }
$$

Department of Chemistry

University of Massachusetts

Amherst, Massachusetts 01003

The concept of direct interfacing of specific elemental and molecular identification devices with high-resolution gas chromatographs is established in such areas as GC/MS and GC/IR. Emission spectroscopic detection for element speciation has in recent times taken on new importance and this paper discusses some of the current trends in this field. Particular attention is paid to the interfacing of plasma emission spectrometers and the advantages of alternative systems are discussed. An atmospheric pressure helium microwave plasma is discussed for trace determinations in packed and open tubular column GC. Metal compounds and halogen compounds aré covered with discussion of applications in the area of chlorinated organics in aqueous systems.

The atmospheric pressure DC argon plasma is applied for both gas chromatographic and high pressure liquid chromatographic studies involving various mobile phase combinations. An echelle spectrometer is incorporated in the system and applications include the determination of metal complexes and organometallics such as gasoline additives.

Key words: chromatography; detection; metals; plasma emission; specific elements; spectroscopy

\section{Introduction}

In all forms of chromatographic separation, of both high and low resolution, the identification of eluted peaks or developed bands is of primary importance. Identification is needed to assure the integrity of known species for quantitative purposes and to identify and characterize unknown members of multi-component mixtures [1]. While in GC practice, the greatest development in directly interfaced peak characterization has been in the area of mass spectrometry (GC-MS) [2] and vapor phase infrared spectroscopy (GC-IR) [3], other functional parameters of eluted species, measurable in the vapor phase, have been employed; these include thermal fragmentation [4], and molecular weight measurement [5] among others. All of these methods offer primarily information on the molecular form of eluates.

Increasing attention is being paid in GC to specific element detection and monitoring, since for many complex mixtures, adequate resolution of the species of concern, either involving themselves or matrix interferences, is not possible in a single chromatographic experiment. If the components of analytical interest share some common property, the use of a detector responsive solely to that particular parameter may serve to simplify qualitative and quantitative analysis; specific element detection exemplifies such a procedure. 
In HPLC the eluate matrix is more complex than in GC since the liquid solvent mobile phase is almost always present in the detector along with the eluates. Eluate characterization is thus greatly facilitated through measurement of a property not apparent in the mobile phase. Here element-specific detection not only fulfills this function but introduces many practical advantages.

In the area of environmental speciation and monitoring needs for inorganic substances including those from energy-related processes, concern is usually for trace determination in samples containing large quantities of interfering species. Atomic spectroscopic methods are singularly appropriate for specific metal monitoring in both GC and LC applications. While both flame and furnace atomic absorption have been employed with good effect for metal specific detection as has, to a limited extent, atomic fluorescence [6], these techniques suffer limitations in sensitivity, in their inability to accommodate simultaneous multielement measurements and in furnace AA, the necessity for discontinuous segmented profiling.

By contrast with atomic absorption spectroscopy, atomic emission spectroscopy has the advantage of multielement capabilities and frequently has a linear dynamic range up to five or six orders of magnitude. The advent of various accessible plasma sources, particularly in combination with high-resolution monochromators to minimize spectral interferences, has provided a resurgence of analytical application of atomic emission methods. The chromatographic application of plasma sources is most attractive. The latter have been variously applied for element-selective detection with most development being for microwave-induced and sustained plasmas (MED) in gas chromatography. Other plasma systems have also been demonstrated as viable for both GC and HPLC, notably the DC argon plasma (DCP) and the inductively coupled plasma (ICP).

The major advantages of interfacing plasma emission spectroscopy in chromatography are: (a) ability to perform speciation, either before or within the chromatographic column for many metals and non-metals. Application may be either direct or by derivatization. (b) ability to tolerate non-ideal chromatographic conditions and elution characteristics. The specificity of plasma emission enables the analyst to tolerate incomplete resolution, a factor of great importance in complex matrices. Here the selectivity of the particular element is the primary concern. (c) sensitivity of plasma emission detection which, with the possible sole exception of the electron capture-GC detector, is more sensitive than any other GC detector (pg/s and lower). (d) potential multielement capacity of plasma emission. (e) compatibility with existing chromatographic systems through the incorporation of simple interface devices.

2. The Microwave Induced and Sustained Atmospheric-Pressure Helium Plasma Emission GC Detector (MED)

McCormack et al. [7] first used a low-power, $2.45 \mathrm{GHz}$, electrodeless, atmosphericpressure argon discharge in a tapered cavity to detect organic compounds containing I, S, $\mathrm{C} 1, \mathrm{Br}$, and $\mathrm{P}$ atoms. The column was directly interfaced to the plasma tube within the cavity. Emission was observed laterally across the tube. The design was improved by Bache and Lisk [8,9], who utilized a helium plasma discharge at 5-10 mm pressure. The reduced-pressure MED discharge was shown effective for selective metal detection of 
$\mathrm{Hg}[9] ; \mathrm{Cr}$, Be and $\mathrm{Al}[10]$, and $\mathrm{Cu}, \mathrm{Ga}, \mathrm{Fe}, \mathrm{Sn}$, and $\mathrm{V}[11]$; in addition to many non-metal1ic elements such as $\mathrm{As}$ and $\mathrm{Sb}$ [12] and $\mathrm{P}, \mathrm{S}, \mathrm{Br}, \mathrm{Cl}, \mathrm{I}, \mathrm{C}, \mathrm{H}, \mathrm{D}, \mathrm{N}$, and 0 [13]. Line emission is observed for all spectra in the helium plasma making it preferable for selective detection over the argon discharge in which some elements such as $\mathrm{F}, \mathrm{Cl}, \mathrm{Br}, \mathrm{N}$ and 0 exhibited only diatomic molecular emission. Problems arise from the deposition of carbon from solvents on the quartz emission tube; eluting solvent may also extinguish the plasma [10,11]. The former problem has been solved by adding oxygen scavenger gas, but in general, from the standpoint of the chromatographic interfacing, the disadvantages inherent in the use of discharge at reduced-pressure adds to the complexity of maintaining a constant vacuum at the exit from the chromatograph.

Mclean et a1. [13], employed a low-pressure helium plasma, sustained in a thick-walled quartz capillary of 10-mm o.d. and 1-mm i.d. and overa11 1ength of $15 \mathrm{~cm}$. Pressure was adjustable from 0.25 torr, and microwave power from 100 to $200 \mathrm{~W}$ at $2.45 \mathrm{GHz}$ was applied. A 10-cm plasma was typically obtained. Detection limits for C, H, D, F, C1, Br, I, and S, ranged from $3 \times 10^{-11}-9 \times 10^{-11} \mathrm{~g} / \mathrm{s}$ and for $N$ and 0 , were about $3 \times 10^{-9} \mathrm{~g} / \mathrm{s}$ selectivities over carbon were usually below 1000, however. An important feature of the plasma system is that response is proportional to the number of atoms of a particular element present and is independent of structure. Thus, it is possible, by comparing element response ratios of unknown compounds with those of a standard containing the same elements, to determine empirical formulae. This system has been subsequently developed as a commercial unit (Applied Chromatography Systems Ltd., Luton, England).

The $\mathrm{TM}_{010}$ cylindrical resonance cavity described by Beenakker [14] gives such increased efficiency of transfer of microwave power to the discharge that an atmospheric pressure helium (or argon) plasma can be sustained at the same low power levels as used with previous cavities. This offers a great advantage in GC applications. A further facility offered by this design is the ability to view light emitted from the plasma axially. With cavities in which the helium plasma is operated at reduced pressure, it was viewed transversely through the walls of the quartz discharge tube. Deposition of materials on the discharge tube walls and devitrification of the quartz result in gradual attenuation of sample response with time. The addition of small amounts of oxygen or nitrogen to the helium to acts as a scavenger gas reduces carbonaceous deposits, but deposition of metals and devitrification still present limitations for low pressure cavities which are not experienced in the Beenakker design.

The $\mathrm{TM}_{010}$ cavity has been successfully interfaced with both packed columns and open tubular columns in GC. One limiting feature of this cavity is its low tolerance for large eluting peaks (such as solvent). A practical limit is between 50 and $100 \mu \mathrm{g}$ of organic material entering the discharge. Greater amounts will extinguish the plasma and require cleaning or replacing the discharge tube. This drawback is avoided by either inserting a high temperature low dead volume switching valve between the GC and MIP to divert large solvent peaks from the plasma [15] or by utilizing a fluidic logic gas switching system [16]. When clexible high resolution fused silica capillary columns are employed, and if dual detection with a parallel flame ionization detector is not required, an even simpler approach 

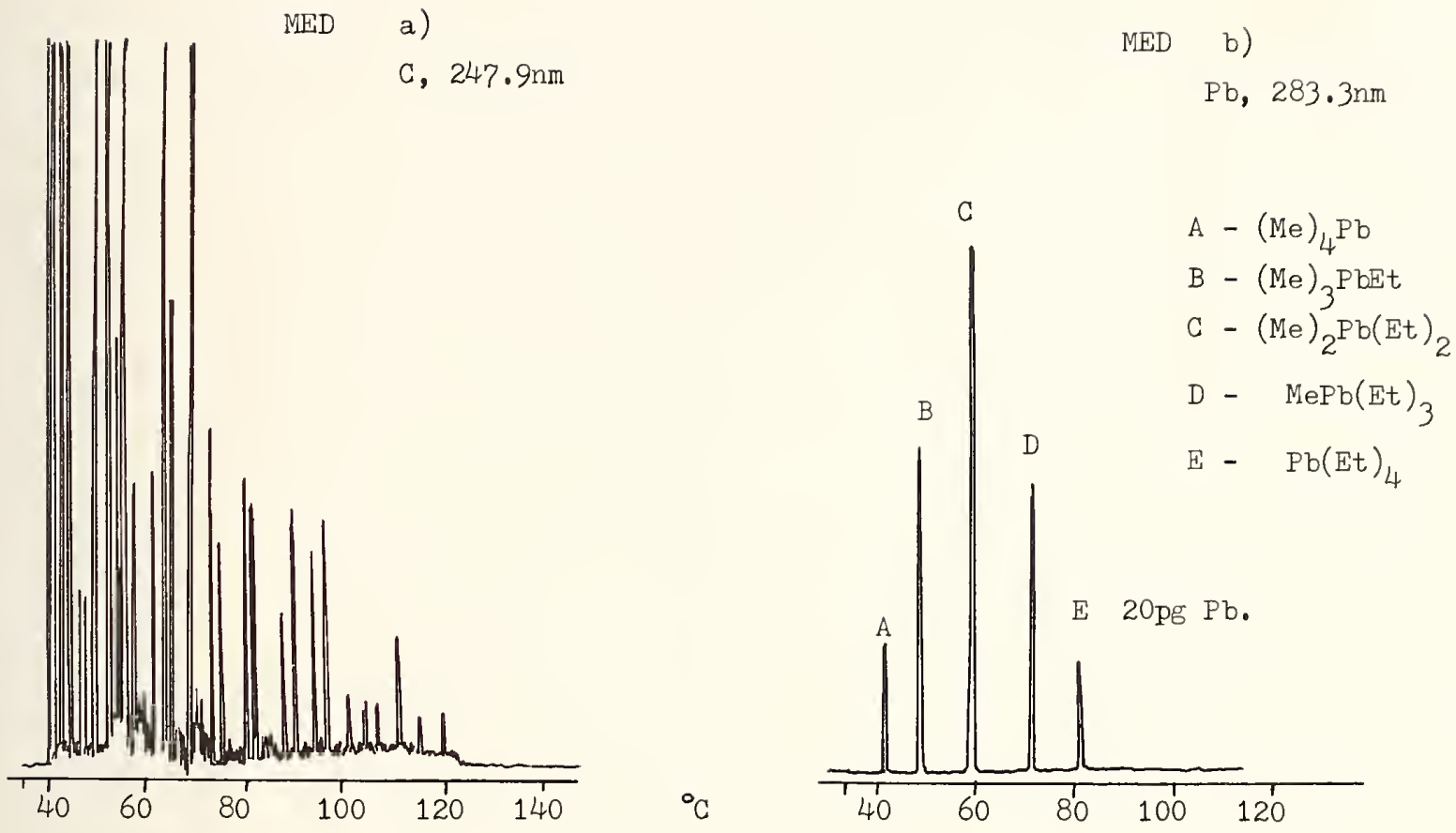

Figure 1. MED element specific detection of lead alkyls in leaded gasoline. Column $12.5 \mathrm{~m}$ SP 2100 fused silica capillary, temperature programmed from 40 to $140^{\circ} \mathrm{C}$ at $5^{\circ} \mathrm{C}$ per minute. $0.1 \mu \mathrm{L}$ sample split 1:100. a) carbon at $247.9 \mathrm{~nm}$, b) Lead at $283.3 \mathrm{~nm}$.

allows the column to be terminated within a few millimeters of the plasma. In this case sample injection splitting is employed to attain allowable plasma sample levels [16]. Power supplies, tuners, and spectrometers employed are fully described in the original papers [15-17]. Both a high-resolution echelle grating monochromator (Spectrametrics, Andover, MA) and a low-resolution 0.35 meter, Czerney-Turner monochromator have been used effectively.

In addition to specific element heteroatom detection, a 'non-selective' mode from the GC point of view is in carbon-specific detection for organics. In Figure 1 is illustrated carbon-specific and lead-specific detection for a leaded gasoline sample. The trace a shows a typical carbon trace obtained on a fused silica capillary column, while trace b shows clearly the five tetraalkyllead compounds present in the sample. Selectivity of lead over carbon at $283.3 \mathrm{~nm}$ is ca. $2.5 \times 10^{5}$.

In Figure 2 is depicted a comparison between carbon specific detection at $247.9 \mathrm{~nm}$ and flame ionization detection for a series of n-alkane hydrocarbons. A glass capillary column is employed with a 1:1 effluent split to plasma and F.I.D.; the fluid logic gas switching system is employed. The absolute detection limit of 2-3 pg/s for carbon rivals or exceeds that of the F.I.D.

An extensive application of the GC-MED system has been specific halogen detection for 


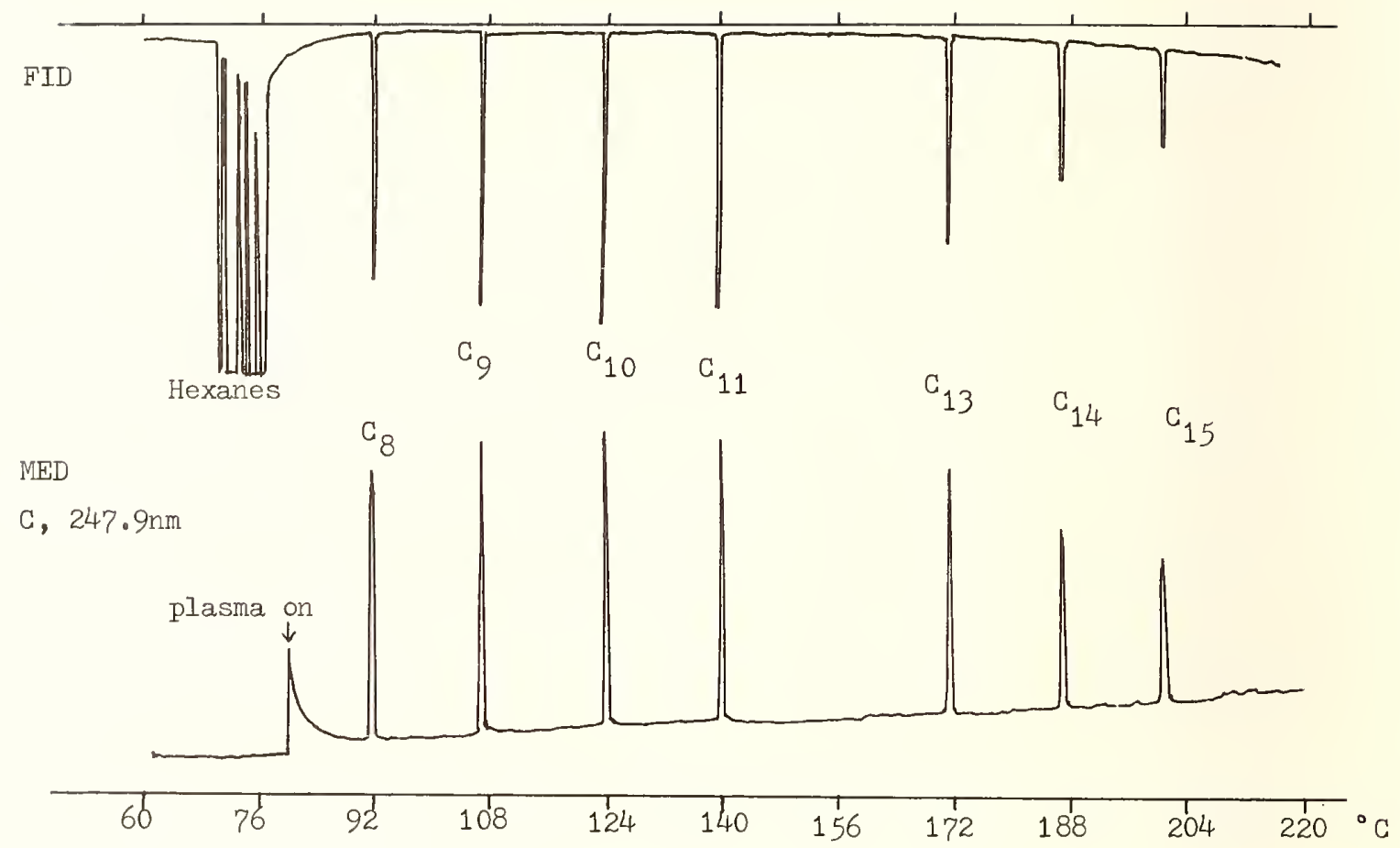

Figure 2. Dual detection chromatogram of an n-alkane mixture; top F.I.D., attenuation $x$ 128; bottom carbon MED detection at $247.9 \mathrm{~nm}$. Column $30 \mathrm{~m}$ OV-101 glass SCOT. $0.2 \mu \mathrm{L}$ sample split 1:25.

$\mathrm{C} 1$ and $\mathrm{Br}[18,19]$. Utilizing purge-and-trap techniques, detection limits for trihalomethanes and other purgable organohalides in water are below the parts-per-bi11ion level. A major advantage is the consistent molar response factors for halogen atoms determined regardless of chemical environment. This is in contrast to the behavior of the electron capture detector, for example. Sensitivity is comparable to the Hall electrolytic detector for a11 halogenated species and is appreciably better in some instances. Its major advantage is individual determination of halogens rather than total response to halogens exhibited by the Hall detector. The MED has proved very useful in capillary-column GC studies of the volatile or volatilizable aqueous chlorination products of humic and fulvic acids, the naturally occurring macromolecular organic species in water [19]. The method has been applied with advantage to the characterization of drinking water samples.

A comparison between non-methylated and methylated chlorinated humic acid samples is shown in Figure 3 with chlorine-specific detection at $481.0 \mathrm{~nm}$. In the upper trace peaks 1,2 and 3 correspond, respectively, to chloroform, trichloracetic acid and 2-chloropheno 1. In the 1ower trace peaks, 1-5 correspond respectively to chloroform, methyl trichloroacetate, 2,4,6-trich1orophenol methyl ether, 2-ch1orophenol and pentach1orophenol methyl ether. As has been noted, both detection limits and selectivity over carbon are particularly 
Chlorinated Humic Acid

a) Non-methylated

MED, Cl $481.0 \mathrm{~nm}$

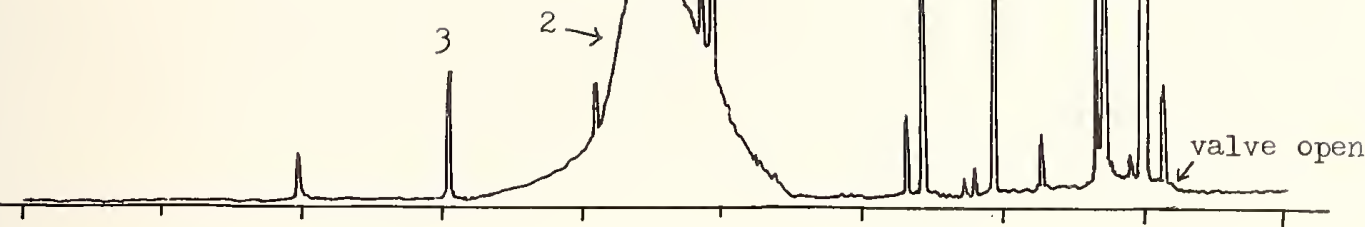

b) Methylated

MED, CI $481.0 \mathrm{~nm}$
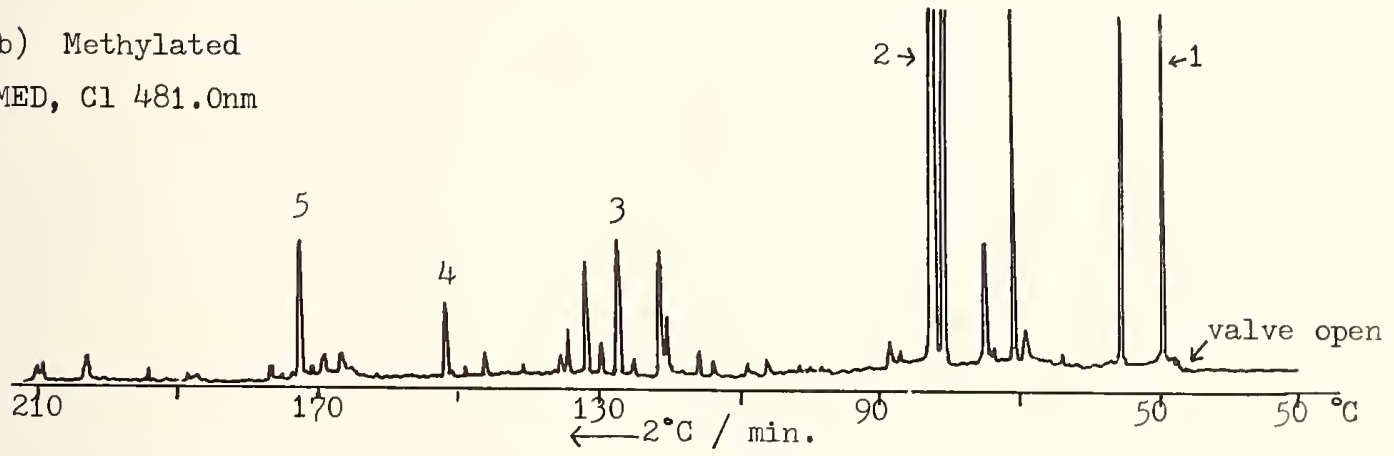

Figure 3. MED chlorine selective chromatogram of non-methylated chlorinated humic acid extract (above) and chlorinated humic acid methylated with diazomethane (below). Column $100 \mathrm{~m}$ OV-225 glass SCOT. (Reprinted by permission from "Analytical Chemistry" reference [19], copyright 1980, American Chemical Society).

important for interfaced GC applications. Differences in the quality of peak shape for different compounds necessitates quoting both an absolute detection limit for each element and a 'rate-based' detection limit. In Table 1 are given operational values for a number of elements of particular interest in environmental and energy related studies.

3. The Atmospheric Pressure DC Argon Plasma Detector for GC

For general application of an interfaced plasma emission technique for chromatographic detection, the ability to employ readily available spectroscopic instrumentation is important. This led to the development of a system based on a commercially available atmospheric pressure DC argon plasma (the Spectraspan System, SpectraMetrics, Inc., Andover, MA) as an excitation source, together with a single channel high-resolution echelle monochromator. This system was employed for both GC detection [20] (GC-DCP) and HPLC monitoring [21] (HPLC$D C F)$. For $G C$ interfaces have been designed for quantitative transfer of relatively high boiling metal complexes and organometallics without peak broadening or sample degradation.

An important criterion in interface design is to avoid hot or cold spots in the transfer line at which high-boiling components could be lost or labile species degraded. The transfer line must also have a sufficiently small volume to avoid band spreading and loss of 
Table 1. MED detection limits, selectivities and linear dynamic ranges

$\begin{array}{lllll}\text { Element \& } & \text { Absolute } & \text { Detection } & \text { Selectivity } & \text { Linear } \\ \text { emission } & \text { detection } & \text { Timit, pg/s } & \text { vs Carbon } & \text { dynamic } \\ \begin{array}{c}\text { wavelength, } \\ \text { nm }\end{array} & \text { Timits, pg } & & & \text { range }\end{array}$

\begin{tabular}{|c|c|c|c|c|c|c|c|c|c|}
\hline $\mathrm{Hg}$ & I & 253.7 & 60 & 0.60 & 7.69 & $x$ & $10^{4}$ & & $10^{3}$ \\
\hline B & I & 249.8 & 27 & 3.6 & 9.25 & $x$ & $10^{3}$ & 5 & $\times 10^{2}$ \\
\hline A1 & I & 396.2 & 19 & 5.0 & 3.90 & $x$ & $10^{3}$ & 5 & $\times 10^{2}$ \\
\hline C & I & 247.9 & 12 & 2.7 & 1.00 & & & & $10^{3}$ \\
\hline Si & I & 251.6 & 18 & 9.3 & 1.58 & $x$ & $10^{3}$ & 5 & $\times 10^{2}$ \\
\hline Sn & I & 284.0 & 6.1 & 1.6 & 3.58 & $x$ & $10^{5}$ & & $10^{3}$ \\
\hline $\mathrm{Pb}$ & I & 283.3 & 0.71 & 0.17 & 2.46 & $x$ & $10^{5}$ & & $10^{3}$ \\
\hline P & I & 253.6 & 56 & 3.3 & 1.06 & $x$ & $10^{4}$ & 5 & $\times 10^{2}$ \\
\hline As & I & 228.8 & 155 & 6.5 & 4.70 & $x$ & $10^{4}$ & 5 & $\times 10^{2}$ \\
\hline $\mathrm{Se}$ & I & 204.0 & 62 & 5.3 & 1.09 & $x$ & $10^{4}$ & & $10^{3}$ \\
\hline${ }^{a_{S}}$ & I & 545.4 & 140 & 52 & 4.59 & $x$ & $10^{3}$ & 5 & $\times 10^{2}$ \\
\hline${ }^{a} \mathrm{Cl}$ & I I & 479.5 & 310 & 86 & 1.49 & $x$ & $10^{3}$ & 5 & $\times 10^{2}$ \\
\hline$a_{B r}$ & I I & 470.5 & 212 & 67 & 1.06 & $x$ & $10^{3}$ & 5 & $\times 10^{2}$ \\
\hline
\end{tabular}

a) Values obtained with refractor plate spectral background correction.

resolution, this being most important in capillary column applications. Stainless steel, nickel and flexible fused silica tubing have all been employed, the latter proving best [22].

Of importance also is the optimal positioning of the transfer line exit orifice underneath the plasma excitation spot. This has been accomplished conveniently by the construction of a suitable holder which allows ready positional adjustment. The orifice position is particularly critical when a fused-silica, narrow-bore capillary column, which can be passed directly through the heated interface from the GC oven to the plasma, is employed. The usual experimental arrangement for packed-column and glass-capillary-column gas chromatography permits a one-to-one or some other suitable ratio split at the end of the column between the transfer line to the plasma and a flame ionization detector. In this way simultaneous detection was obtained for a11 species and for the element of interest.

We have recently devised a similar split system for fused silica column operation $[22]$.

The DC argon plasma has proven to be a suitable detector system for metallic elements where efficient excitation is obtained and also for such elements as boron and silicon 
which are of interest in chemical derivatization for GC. A major advantage for silicon is the absence of elemental spectral response produced from the quartz plasma tube used in the MED. The greater selectivity of silicon over carbon, $\left(2 \times 10^{7}-\right.$ Table 2$)$ as compared with that seen for the MED $\left(1.5 \times 10^{3}\right.$ - Table 1$)$ is also a considerable advantage although the higher resolution of the echelle spectrometer contributes in part to this improvement.

In Figure 4 are shown dual detection chromatograms for two samples containing silicon and iron respectively. Both chromatograms were obtained utilizing a wide bore (320 $\mu \mathrm{m} i . d$. fused silica column from which the eluent was split equally to the F.I.D. and the dc plasma. The split lines were made from coated fused silica lengths set to give equal hold-up to both detectors [22]. Samples were injected in the splitless mode to maximize the amount of material seen by the detectors in individual peaks. Figure 4 a depicts chromatography of a trimethylsilyl derivative of anthranalic acid. It may be noted that both chromatograms show a 'solvent' response, in the case of the F.I.D., the response is from the acetonitrile solvent and excess silylating agent while in the DCP trace, it derives solely from the latter or silylated by-products. The chromatogram of ferrocene shown in Figure $4 \mathrm{~b}$ indicates the high selectivity of the DCP detector which allows low level peaks to be readily seen
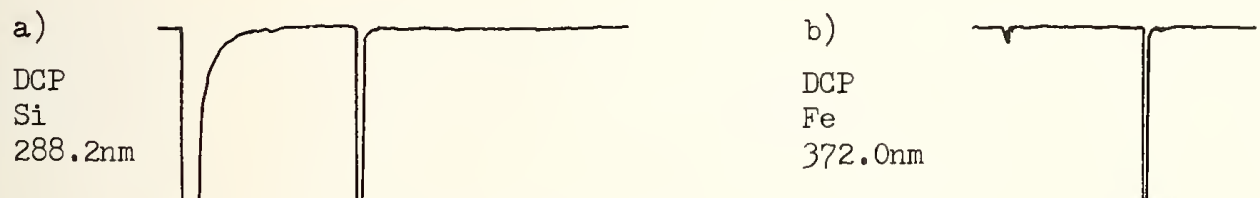

Trimethylsilyl-

anthranilic acid

Ferrocene

ca. $20 \mathrm{ng}$ Si

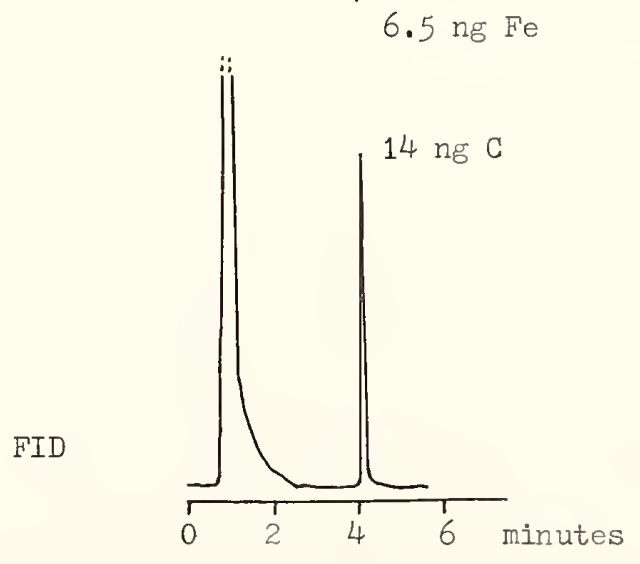

FID

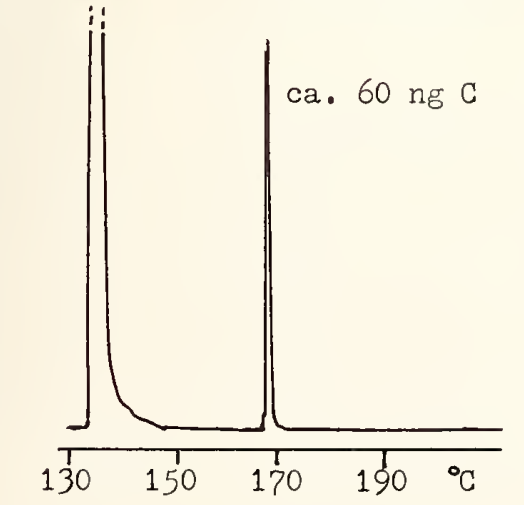

FID

Figure 4. Dual detection chromatograms by flame ionization and dc argon plasma emission. Coiumn $11 \mathrm{~m}, 320 \mu \mathrm{m}$ i.d. SE 30 fused silica capillary (J and $W$ ). a) temperature programmed from $130^{\circ} \mathrm{C}$ at $5^{\circ} \mathrm{C} /$ minute; top, silicon detection at $288.2 \mathrm{~nm}$ of trimethylsilylanthranalic acid, bottom F.I.D. detection. b) isotherma 1 at $110^{\circ} \mathrm{C}$; top, iron detection at $372.0 \mathrm{~nm}$, bottom F.I.D. detection. 
Table 2. GC-DCP detection limits, and selectivities

\begin{tabular}{|c|c|c|c|}
\hline \multicolumn{2}{|c|}{$\begin{array}{l}\text { Element } \\
\text { emission } \\
\text { wavelength } \\
\quad \mathrm{nm}\end{array}$} & $\begin{array}{l}\text { Detection } \\
\text { limit, pg/s }\end{array}$ & $\begin{array}{l}\text { Selectivity } \\
\text { vs Carbon }\end{array}$ \\
\hline $\mathrm{Cr}$ & 267.7 & 4 & $5 \times 10^{8}$ \\
\hline $\mathrm{Cu}$ & 324.7 & 5.6 & $>10^{6}$ \\
\hline $\mathrm{Ni}$ & 341.4 & 320 & $>10^{6}$ \\
\hline Si & 251.6 & 25 & $2 \times 10^{7}$ \\
\hline Sn & 286.3 & 60 & $2.5 \times 10^{6}$ \\
\hline $\mathrm{Pb}$ & 368.3 & 100 & $5 \times 10^{5}$ \\
\hline $\mathrm{Hg}$ & 253.6 & 65 & $6 \times 10^{5}$ \\
\hline$B$ & 249.8 & 3 & $3 \times 10^{5}$ \\
\hline
\end{tabular}

a) Values obtained for 2 electrode plasma jet (Ref. 20).

b) Values obtained for 3 electrode plasma jet (Ref. 22).

in the presence of large amounts of co-eluting solvents.

In Table 2 are shown operational values for GC-OCP for a number of elements. In comparison with the GC-MED data, the absolute detection limits for some elements such as lead and mercury are some two orders of magnitude higher. Others, such as boron are similar. For individual analyses there are different advantages seen for the two systems. The atmospheric pressure MED is ideally suited to high resolution capillary column work and its very low detection limits allow trace determinations to be made in small injected samples. It is limited however in its capacity to handle larger samples, packed column applications demanding solvent venting systems to be used. The DCP system is somewhat less convenient to interface to the gas chromatograph although fused silica transfer lines have helped to simplify this problem. For most elements the DCP has lower absolute sensitivity but this problem is offset by its ability to handle large injected volumes without extinction of the plasma. Further, the very high selectivities shown vs carbon enable good detection in the presence of high level backgrounds.

Both instrumental systems are relatively simple to set up and analytical applications in many areas of environmental and energy concern are readily envisaged.

With regard to the application of the DCP to specific element detection in HPLC [21], initial investigations have shown considerable promise using both 2 electrode and 3 electrode plasma jets. Unlike the atmospheric pressure microwave plasma the DCP (and the inductively coupled plasma - ICP) can accommodate the continuous solvent flow rates required in HPLC. Problems in these applications presently center on the difficulties experienced with non-aqueous solvent systems but a number of groups are exploring possibilities for 
both plasmas [23-26]. As yet 1ittle exploited for trace metal monitoring purposes, HPLCplasma emission techniques promise much both for direct determination and speciation of individual chemical species and possibly in derivatization to introduce specific elements for characterization.

The potential of the combination of chromatographic separations and elemental atomic emission spectroscopy is now beginning to be realized and major developments will undoubtedly occur in many fields of application.

The author acknowledges the support and assistance of many colleagues and students; Professor Ramon M. Barnes, William G. Elliott, Scott A. Estes, John 0. Beyer, Bruce D. Quimby, Michael F. Delaney, Robert J. Lloyd and Frank P. DiSanzo. This work has been supported in part by the Department of Energy.

\section{References}

[1] Ettre, L. S. Selective detection in column chromatography. J. Chromatogr. Sci. 16: 396-417; 1978.

[2] McFadden, W. H. Techniques of combined gas chromatography/mass spectrometry. New York: Wiley-Interscience; 1973.

[3] Krishnan, K.; Curbelo, R.; Chiha, P.; Noonan, R. C. Design and applications of a high sensitivity chromatographic Fourier transform infrared system. J. Chromatogr. Sci. 17: $413-416 ; 1979$.

[4] Groenendyk, H.; Levy, E. J.; Sarner, S. F. Identification of functional groups by controlled thermolytic dissociation. J. Chromatogr. Sci. 8: 599-606; 1970.

[5] Bennett, C. E.; DiCave, L.W.; Pau1, D. G.; Wegener, J. A.; Levase, L. J. 'Mass Chromatography', a versatile new qualitative and quantitative analytical tool. Amer. Lab. $\quad 3: 67-73 ; 1971$.

[6] Van Loon, J. C. Metal specific detectors for chromatography. Amer. Lab. $13(5): 47-53 ; 1981$.

[7] McCormack, A. J.; Tong, S. C.; Cooke, W. D. Sensitive selective gas chromatography detector based on emission spectroscopy of organic compounds. Anal. Chem. 37: $1470-1476 ; 1965$.

[8] Bache, C. A.; Lisk, D. J. Determination of organophosphorus insecticıde residues using the emission spectrometric detector. Ana1. Chem. 35: 1477-1480; 1965.

[9] Bache, C. A.; Lisk, D. J. Selective emission spectrometric determination of nanogram quantities of organic bromine, chlorine, iodine, phosphorus and sulfer compounds in a helium plasma. Anal. Chem. 37: 786-789; 1967.

[10] Kawaguchi, H.; Sakamoto, T.; Mizuike, A. Emission spectrometric detection of metal chelates separated by gas chromatography. Talanta. 20: 321-326; 1973 .

[11] Dagne11, R. M.; West, T. S.; Whitehead, P. The determination of volatile metal chelates by using a microwave-excited emissive detector. Analyst. 98: 647-654; 1973.

[12] Talmi, V.; Norvel1, V. E. Determination of arsenic and antimony in environmental samples using gas chromatography with a microwave emission spectrometric system. Ana 1. Chem. 47: 1510-1516; 1975. 
[13] McLean, W. R.; Stanton, D. L.; Penketh, G. E. A quantitative tunable element-selective detector for gas chromatography. Analyst. 98: 432-442; 1973.

[14] Beenakker, C. I. M. A cavity for microwave induced plasmas in helium and argon at atmospheric pressure. Spectrochim. Acta B, 31: 483-486; 1976.

[15] Quimby, B. D.; Uden, P. C.; Barnes, R. M. Atmospheric pressure helium microwave detection system for gas chromatography. Ana1. Chem. 50: 2112-2118; 1978.

[16] Estes, S. A.; Uden, P. C.; Barnes, R. M. High resolution gas chromatography of trialkyl lead chlorides with an inert solvent venting interface for microwave excited helium plasma detection. Ana1. Chem. 54: to be published, August, 1981.

[17] Estes, S. A.; Uden, P. C.; Barnes, R. M. Microwave excited atmospheric pressure helium plasma emission detection characteristics in fused silica capillary gas chromatography. Ana1. Chem. 54: to be published, 1981.

[18] Quimby, B. D.; Delaney, M. F.; Uden, P. C.; Barnes, R. M. Determination of triha7omethanes in drinking water by gas chromatography with a microwave plasma emission detector. Ana\}. Chem. 51: 875-880; 1979.

[19] Quimby, B. D.; Delaney, M. F.; Uden, P. C.; Barnes, R. M. Determination of the aqueous chlorination products of humic substances by gas chromatography with microwave emission detection. Anal. Chem. 52: 259-263; 1980.

[20] Lloyd, R. J.; Barnes, R. M.; Uden, P. C.; Elliott, W. G. Direct current atmospheric pressure argon plasma emission echelle spectrometer as a specific metal gas chromatographic detector. Anal. Chem. 50: 2025-2029; 1978.

[21] Uden, P. C.; Quimby, B. D.; Barnes, R. M.; El1iott, W. G. Interfaced DC argon plasma emission spectroscopic detection for high-pressure liquid chromatography of meta1 compounds. Ana1. Chim. Acta. 101: 99-109; 1978.

[22] Uden, P. C.; Beyer, J. 0. unpublished observations.

[23] Uden, P. C.; Kosman, J.; Barnes, R. M. unpublished observations.

[24] Morita, M.; Uehiro, T.; Fuwa, A. Speciation and elemental analys is of mixtures by high performance liquid chromatography with inductively coupled argon plasma emission spectrometric detection. Ana1. Chem. 52: 349-357; 1980.

[25] Fraley, D. M.; Yates, D.; Manahan, S. E. Inductively coupled plasma emission spectrometric detection of simulated high performance liquid chromatographic peaks. Ana1. Chem. 51: 2225-2229; 1979.

[26] Gast, C. H.; Kraak, J. C.; Poppe, H.; Maessen, F. J. M. J. Capabilities of on-1ine element specific detection in high performance liquid chromatography using an inductively coupled argon plasma emission source detector. J. Chromatogr. 185: 549-561; 1979. 


\section{Discussion}

Question (J. J. Cooney): As a microbiologist, I don't know anything about fused silica columns. I don't know what problems you have using them--would you give us an idea?

Answer: This is very much a gas chromotographer's technology. In the last year and a half a very major change over in high resolution gas chromatography with development from a number of sources of very inert, very efficient, open tubular silica columns giving you a high efficiency chromatography. The problems in the past have been degradation of low level samples on active sites within glass columns. Over decades, an immense amount of work has been done on trying to get inactive chromatograph systems. These true silica columns which are now commercially available from a number of places go a long way to answering that problem of column instability. They also, in process, are very good because they can be made very long and very flexible, and you can do things with them: surface phases can be bonded onto them so that they have high temperature utility. There are other many nice advantages too. The disadvantage is that they don't take very much sample. If your lab is in any way involved in gas chromatography these days, silica capillary columns offer very current and very important technology advances in gas chromatography.

Question (R. D. Stephens): Could you expand on your statement about microwave plasmas and inductively coupled plasmas on nonmetals, and their advantages?

Answer: In the data which I've seen so far on inductively coupled plasmas [ICP], I have yet to see any sensitivity values for halogens for instance, which approach within 4 or 5 orders of magnitude of most of the metals. This is a spectral problem and not a chromatographic one, obviously. There is another debate because inductively coupled plasmas are highly energetic; temperatures of about 9,000 to $10,000{ }^{\circ} \mathrm{C}$ are regularly considered. The microplasmas are very small: it is a tiny little plasma between 90 and 100 watts but its plasma density is very high. The energy density for a small area is high. So all this has to do with the total energy; it has to do with the way in which the elements behave, whether atoms or ions are produced, whether you are looking at the atomic emission or the ion emission. Our observation so far is that the microwave emission plasma has given by much the best data that I have seen anywhere yet for the halogens.

Question (W. Slavin): A characteristic difference is that you do the microwave plasma work in helium, and you do the ICP work typically in argon. For reasons that have to do with the energy level distribution in the rare gas, the halogens aren't excited in the argon atmosphere. 
Answer: Some very subtle physics here, I think. It is not simply looking at ionization potentials and saying you can make it better. Maybe you have some comment whether you have looked at the halogens problem.

Answer (C. R. Vogt): We have not looked at the halogens in GC-ICP al though I understand that there is a group at our University that is looking for the organometallics. The sensitivity is very much comparable to what you have quoted in that picogram/second rate; these are classical volatile organometallic model compounds.

Answer: The microwave plasma system can be put together for a few thousand dollars, as opposed to the ICP costs, and it takes typically 50 to $100 \mathrm{~mL}$ per min of helium to run instead of large quantities of argon. With miniturized ICP's coming along this means improved costs, though.

Comment (C. R. Vogt): I would like to also mention that your interface using fused silica is, I think, a very good idea. We are using the same interface with the ICP. -As you said, with the flexible nature of the silica, you are able to just put it right into the plasma itself. Therefore, the chromatographic efficiency that you get from the capi1lary column is well preserved and not lost during the transfer line. As you said, one problem that needs to be resolved with fused silica is that the surface is very nonpolar, or deactivated. In one way this is an advantage to chromatographic techniques, but the disadvantage of this nature surface is that you cannot put a very polar liquid phase onto it. 
Application of Molecular Substituent Parameters for the Speciation of Trace Organometals in Energy-Related Process Fluids by Element-Selective HPLC

C. S. Weiss ${ }^{\star}$, K. L. Jewett ${ }^{1}$, F. E. Brinckman' ${ }^{1}$, and R. H. Fish ${ }^{2}$

${ }^{1}$ Chemical and Biodegradation Processes Group

National Bureau of Standards

Washington, DC 20234

${ }^{2}$ Energy and Environment Division

Lawrence Berkeley Laboratory

University of California

Berkeley, CA 94720

High performance liquid chromatographic separations coupled with elementselective detectors provide trace molecular speciation methods applicable to energy-related process fluids and associated waste leachates. These materials present a challenge because they contain complex matrices whose chemistries are not well understood, and the processes have the potential to generate compounds containing toxic metals and metalloids that are either unexpected or have not been previously identified. Consequently, the ability to reliably ascertain the molecular structures of such unknown substances by relatively simple measurements of their chromatographic retention properties is very desirable. Our present work shows a linear correlation of the logarithm of the chromatographic capacity factor with the linear sum of the appropriate structural substituent parameters for a number of organoarsenicals, separated by an ion-exchange mechanism, and a number of organotins, separated by a hydrophobic mechanism. An illustration of the application of this linear free energy relationship as a diagnostic in the separation of trace organoarsenicals, by ion-exchange chromatography, was performed on the analysis of process waters from $0 i 1$ shale retorting and on leachates from raw oil shale.

Key words: atomic absorption; energy-related process fluids; leachate;

linear free energy; liquid chromatography; molecular substituent; oil shale; organoarsenic; organotin; retention index; speciation.

1. Introduction

1.1 Trace Element Speciation

The molecular characterization, or chemical speciation, of metal and metalloid species, at trace levels has provided valuable information in the areas of: the aquatic chemistry of trace metals [1]; the microbial transformations of trace metals [2,3]; the biochemistry of trace metals [4]; and the chemistry of controlled release biocides containing metals [5]. This information is not obtainable by total trace metal analysis [6].

National Research Council--National Bureau of Standards Postdoctoral Research Associate, 1980-1982. 
A widely used method for trace metal speciation is the chromatographic separation of the metal-containing compound, with element-selective detection in either on-line or off-line modes. This technique is capable of characterizing trace metal species in the presence of numerous other interfering compounds which may prohibit the use of many, if not a11, direct spectroscopic identification techniques. Thus, chromatographic separations with element-selective detection have been and will be used extensively to characterize trace metal-containing compounds in the variety of complex matrices generated from energyrelated processes [7-9]. In general, both gas and liquid chromatographic systems are used. Element-selective detectors are preferably used on-line, thereby minimizing sample handling, analysis time, and the time needed to optimize the chromatographic system. The element-selective detectors include: emission and atomic absorption spectroscopy, and electrochemical, and radioactivity detectors [10]. The technique relies upon the elution of the trace metal-containing compound with a retention time unique from all other compounds containing the trace metal under investigation, as determined by an authentic standard.

Gas chromatographic retention has been related to volatility, and that relationship has provided a useful index of retention, the Kováts Index [11]. In speciation studies involving liquid chromatographic separations, it would be useful to have a rational system based on thermodynamic properties, with due consideration of kinetic rates on the chromatographic time scale, in order to:

a. predict the retention of a sought after compound;

b. predict the possible structure(s) of unknown compounds from the experimentally determined retention times;

c. predict the possible co-elution of interfering compounds; and,

d. optimize chromatographic systems for the desired separation.

The relationship between structural substituent parameters and chromatographic retention has provided a starting point for such a system and has been applied to the separation of many organic compounds [11-13].

\subsection{Structural Substituent Parameters}

The electronic structural substituent parameter, $\sigma$, is based on the ionization of a derivative compound with respect to its parent compound. The determination of $\sigma$ is based on equation 1 ,

$$
\rho \sigma=\log K_{x}-\log K_{H}
$$

where $K_{x}$ is equal to the ionization constant of the derivative compound, and $K_{H}$ is the ionization constant of the parent compound. The constant was first introduced by Hammett [14] in 1935, based on benzoic acid as the parent compound, with meta and para derivatives. In 1953, Jaffé et a1. [15] published $\sigma$ values for aromatic phosphonic acids. In 1956, 
Mastryukova and Kabachnik [16] published $\sigma^{\phi}$ values for the aqueous ionization of a large variety of substituted phosphorous acids.

The hydrophobic structural substituent parameter $(\pi)$ is based on the partitioning of a derivative between octanol and water, with respect to the partitioning of its parent compound, expressed as,

$$
\pi_{x}=\log P_{x}-\log P_{M} \text {, }
$$

where $P_{x}$ is the partition coefficient of the derivative and $P_{M}$ is the partition coefficient of the parent compound [17]. The hydrophobic (or lipophilic) parameter as well as the octanol-water partition coefficients have been applied to: the transport of compounds across biological membranes [18]; the chromatographic separation of organic compounds [12], including herbicides [19]; the correlation of the bioaccumulation of organic compounds in both fish and microbes $[20,21]$; and toxicological structure activity relationships [22].

1.3 Application of Molecular Substituent Parameters to Chromatographic Retention

Two publications have laid the foundation for the elucidation of the mechanisms of chromatographic separations, based on thermodynamic principles, as well as the prediction of liquid chromatographic retention. In 1949, Martin [13], while discussing theoretical aspects of partition chromatography, predicted that the addition of a substituent group to a parent compound would change the partition coefficient by a certain factor dipendent upon the nature of the substituent group "but not on the rest of the molecule". Lederer [23], in 1957, reviewed the paper chromatographic applications of this principle to homologous series of compounds, differing only in the number of methylene groups, in relation to solvent selection and temperature variations.

In 1976, Horváth et al. [24] presented a model of solvophobic chromatographic separations based on thermodynamic principles. Chen and Horváth [25] then extended this work to determine quantitative structure-retention relationships, and Naham and Horváth [26] have evaluated octanol-water partition coefficients from chromatographic measurements. Baker [11] has developed retention indices for liquid chromatographic separations based on Hansch's $\pi$ parameter that are similar to Kováts Indices, used for gas chromaiography. In these studies, the solutes were all biogenic organic acids and bases, and a wide variety of drugs. Other reports of quantitative structure-retention relationships for phenols [27] and herbicides [19] have been made.

The first application of thermodynamic principles to the chromatographic retention of organometal molecules involved the separation of di- and triorganotins by ion-exchange chromatography with atomic absorption detection. Jewett and Brinckman [28] demonstrated a linear relationship between the logarithm of the chromatographic capacity factor $k$ ' and the $\sigma^{\phi}$ molecular substituent parameter, with a correlation coefficient of 0.992 , based on 
23 individual $k^{\prime}$ values for five trialkyltin compounds, separated in water as the $\mathrm{R}_{3} \mathrm{Sn}^{+}$ cations.

\section{Experimental}

\section{1 Instrumentation}

The high-performance liquid chromatograph (HPLC) coupled with graphite furnace atomic absorption (GFAA) detector is illustrated schematically in Figure 1. For the separation of the arsenicals, the HPLC consisted of two dual-piston pumps, computerized chromatographic controller, high pressure mixing chamber, and an ultra-violet (UV) absorbance detector. The injection valve was equipped with a $200 \mu \mathrm{L}$ sample loop. The GFAA spectrophotometer was equipped with an As electrodeless discharge lamp, a dual-channel recorder, for recording both UV absorbance and the histogrammic GFAA output, and a digital integrator for more accurately determining the GFAA output.

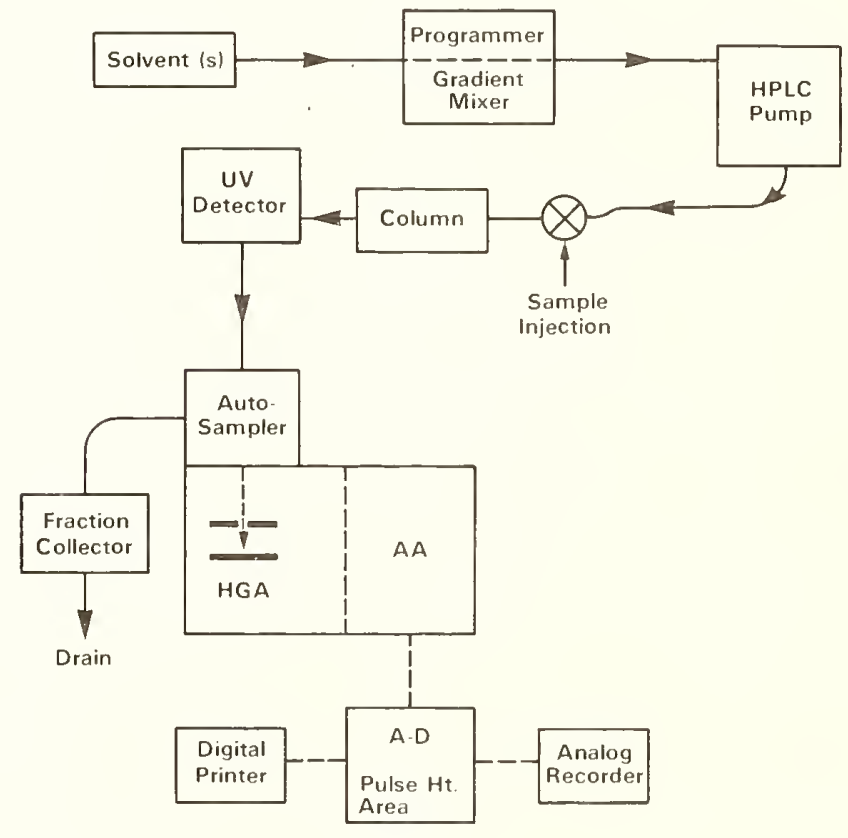

Figure 1. Schematic of HPLC-GFAA system showing programmed solvent gradient flow and in-line UV and GFAA detectors $[5,28]$. The GFAA spectrophotometer consists of a heated graphite atomizer (HGA) and an atomic absorption spectophotometer $(A A)$.

For the separation of the tetraorganotins, the HPLC employed a single piston pump (with pulse dampener) and a UV absorbance detector. The injection valve was equipped with a $20 \mu \mathrm{L}$ sample loop. The GFAA unit was equipped with an electrodeless discharge Sn lamp. The data were collected on a dual channel recorder, and an integrator was used to digitize the GFAA output.

The experimental parameters for the two atomic absorption spectrophotometers used during this study are presented in Table 1. 


\begin{tabular}{lcc}
\hline AA Unit & $\begin{array}{l}\text { Dual-pump } \\
\text { HPLC-AA system }\end{array}$ & $\begin{array}{l}\text { Single-pump } \\
\text { HPLC-AA system }\end{array}$ \\
\hline Element & As & $\mathrm{sn}$ \\
Wavelength & $193.7 \mathrm{~nm}$ & $224.6 \mathrm{~nm}$ \\
Band-pass & $0.7 \mathrm{~nm}$ & $0.7 \mathrm{~nm}$ \\
Dry & $20 \mathrm{~s}, 115{ }^{\circ} \mathrm{C}$ & $20 \mathrm{~s}, 85^{\circ} \mathrm{C}$ \\
Char & --- & --- \\
Atomize & $7 \mathrm{~s}, 2700{ }^{\circ} \mathrm{C}$ & $7 \mathrm{~s}, 2700{ }^{\circ} \mathrm{C}$ \\
Integrate & Peak Ht, $8 \mathrm{~s}$ & Peak Ht $8 \mathrm{~s}$ \\
\hline
\end{tabular}

\subsection{Chromatographic Systems}

The separation of the arsenicals was based on the work of Woolson and Aaronson [29]. The chromatographic column was a weak anion exchange column ( $3 \mathrm{~mm} \times 250 \mathrm{~mm}$ ). The gradient elution employed consisted of elution with 80:20 (vol.\%) $\mathrm{H}_{2} 0: \mathrm{MeOH}$ initially for ten min, and a linear gradient of $5 \% \mathrm{~min}^{-1}$ to $85: 15 \mathrm{H}_{2} \mathrm{O}: \mathrm{MeOH}\left[0.02 \mathrm{M}\left(\mathrm{NH}_{4}\right)_{2} \mathrm{CO}_{3}\right]$. The separation of the organotins was accomplished under isocratic conditions using a $\mathrm{C}_{18}$ (octadecylsilane) reversed bonded-phase column ( $10 \mu \mathrm{m}$ particle size). The mobile phase employed was

93: 7 ( $v 01 . \%$ ) methanol: $\mathrm{H}_{2} \mathrm{O}$.

\section{3 Reagents and Standards}

The distilled water employed during this study was further purified using an exchange resin system to obtain $18 \mathrm{M} / \mathrm{cm}$ resistivity. The methanol used for the separation of the arsenicals was spectrograde, while the methanol used for the separation of the organotins was chromatographic grade. The ammonium carbonate used was analyzed reagent grade. The arsenic standards employed were obtained commercially and from Profs. Irgolic and Zingaro (Department of Chemistry, Texas A\&M University), whose generosity is greatly appreciated. The organotin compounds were either obtained commercially or synthesized in our laboratories.

3. Results and Discussion

3. 1 Relationship Between Chromatographic Retention and Molecular Substituent Parameters

3.1.1 Separation of Arsenicals

The calculation of the $\Sigma \sigma^{\phi}$ values for the arsenic compounds chromatographed is simply the linear sum of the $\sigma^{\phi}$ parameters of the individual molecular substituents, which 
replace the ionic oxygen substituents in the parent compounds. The method for calculating the $\Sigma \sigma^{\phi}$ values is presented in Table 2; the parent compound is taken as the trisubstituted form of arsenate whose $\Sigma \sigma^{\phi}$ value is designated as 0 , where $A=B=C=0^{-}$. The ionic form of the derivative compound is very important because simple monoprotonation of the compound contributes $-0.39 \sigma^{\phi}$ unit to the total $\Sigma \sigma^{\phi}$ value of the derivative. In most cases, the ionic form of the derivative was determined by considering the $\mathrm{pK}_{\mathrm{a}}$ of the compound with respect to the $\mathrm{pH}$ of the eluting solvent. In the cases of dimethylarsinic acid and the diphenylarsinic acid, the neutral forms were considered in an attempt to obtain the best fit of the data. Considering the $\mathrm{pk}_{\mathrm{a}}$ 's of these compounds, to ascribe these as neutral forms is not entirely satisfactory; however, there might be some non-additive electronic effects due to the presence of two organic substituents on the central arsenic atom.

Table 2. The Calculation of the $\Sigma \sigma^{\phi}$ for Organoarsenic Acids

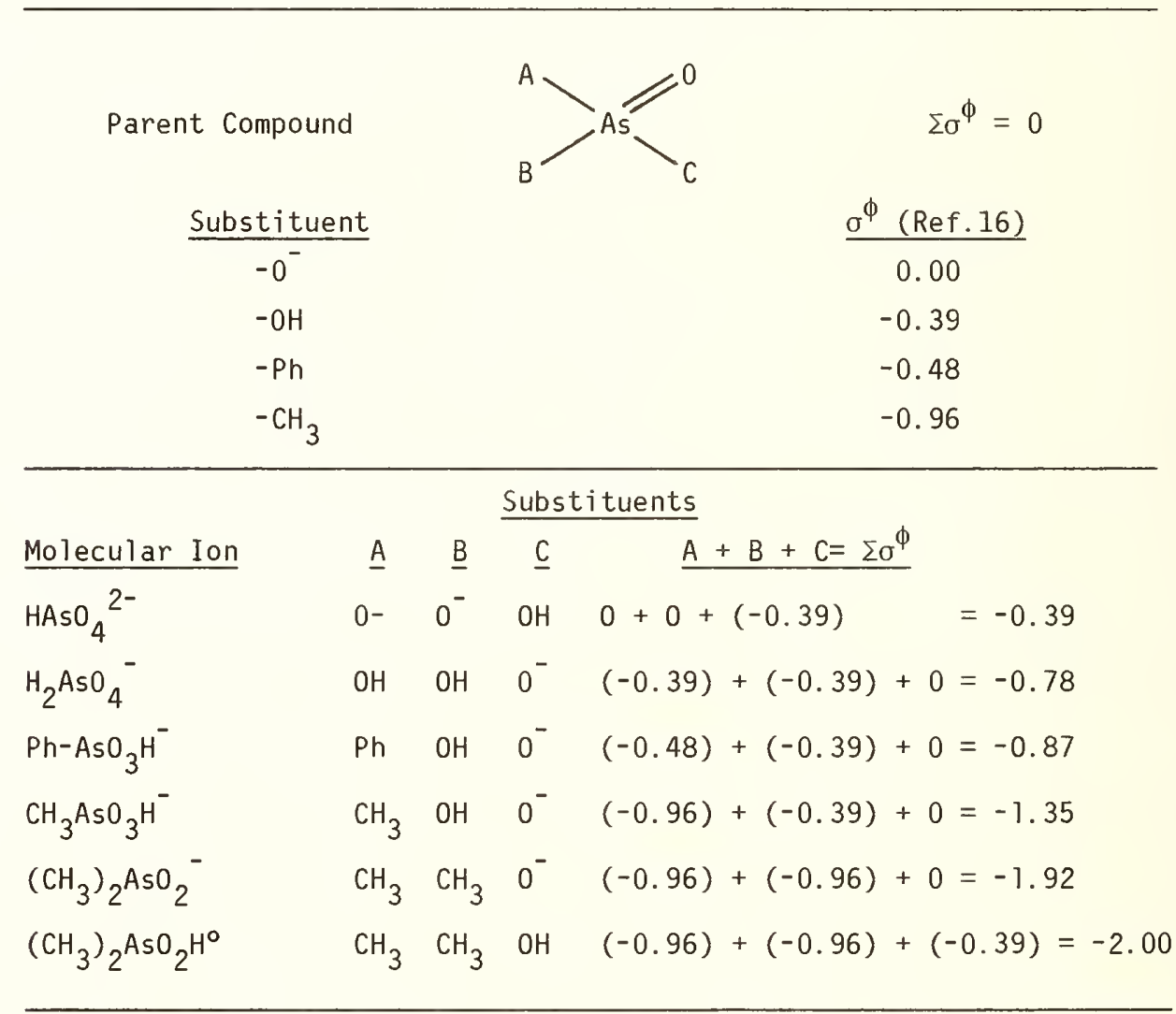

The separation of the arsenicals, using the HPLC-GFAA system, is demonstrated in Figure 2. The non-response of the UV absorbance detector is to be noted with the exception of the chromophore 4-aminophenylarsonic acid. The histogrammic output of the GFAA signal results from the discrete sampling of the HPLC effluent limited by the drying, charring, atomization, and cooling cycle of the graphite furnace at approximately $45 \mathrm{~s}$ intervals [5].

The relationship between the natural logarithm of the chromatographic capacity factor for the arsenic compounds and the calculated $\Sigma \sigma^{\phi}$ values for these compounds is pre- 


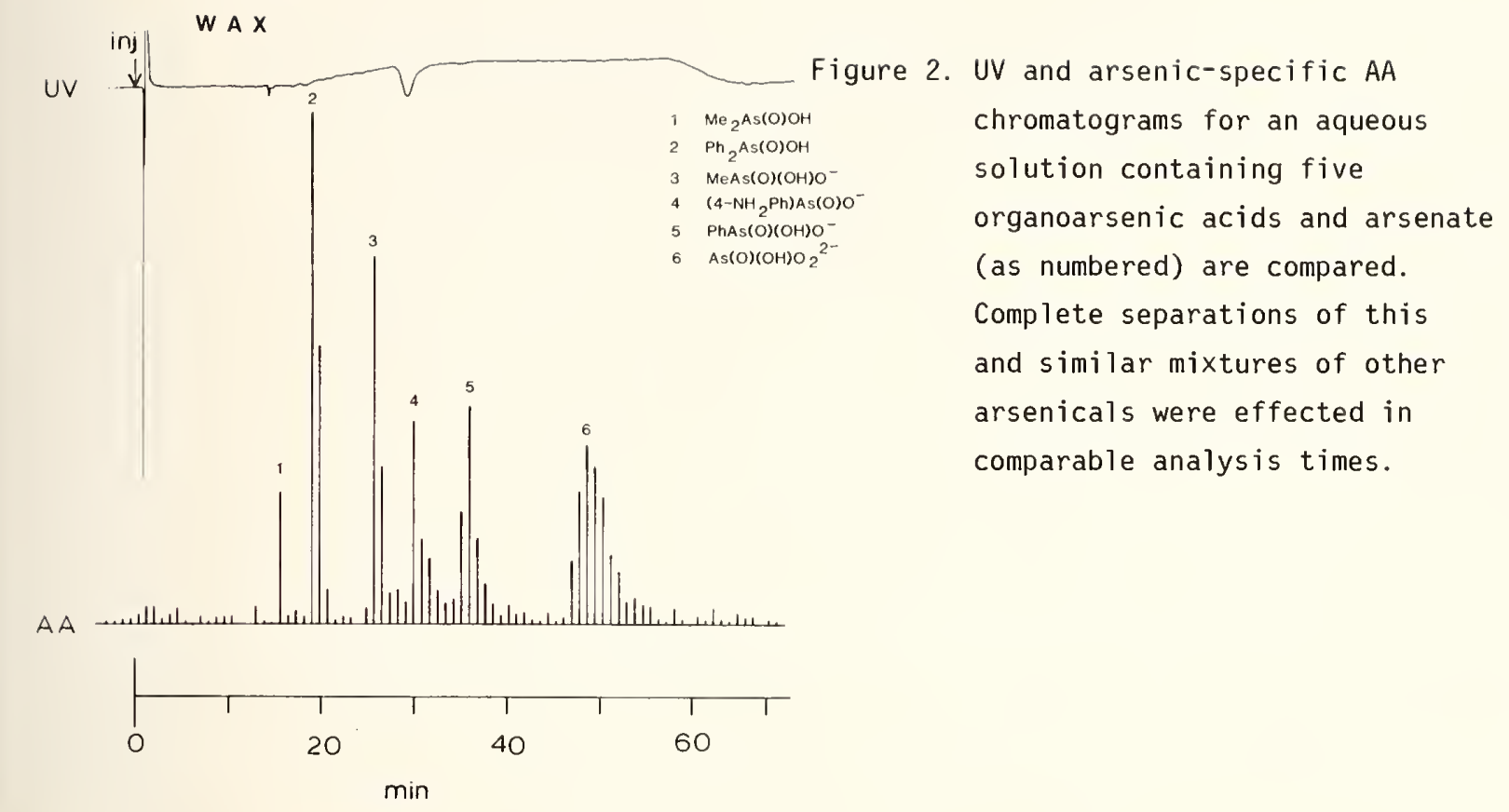

sented in Figure 3. The relationship is linear, with a correlation coefficient of 0.971 based on 111 data points. Similar linear relationships also were obtained using different non-linear convex and concave HPLC elution gradients. This linear relationship provides a method for: predicting the retention time of a sought after compound based on the calculated $\Sigma \sigma^{\phi}$ value; predicting the co-elution of an interfering compound, based on the compounds which have a similar $\Sigma \sigma^{\phi}$ value; and optimizing the desired separation by changing the chromatographic system to achieve the needed change in retention time for the difference in $\Sigma \sigma^{\phi}$ values of the compounds to be separated.

\subsubsection{Separation of Organotins}

The method for obtaining the $\Sigma \pi$ values for the $R_{4-n} R^{\prime}{ }_{n} S n$ tetraorganotins used in this work is presented in Table 3 . The $\Sigma \pi$ value for each neutral organotin molecule is simply calculated by the linear summing of the individual $\pi$ substituent parameters.

The separation of the organotins using the HPLC-GFAA system is demonstrated in Figure 4. The non-response of the UV-absorbance detector is to be noted, with the exception of the chromophoric dibutyldiphenyltin and the tetraethyltin. In the case of the tetraethyltin, the UV response possibly arises from the large column loading of this compound, due to the difficulty in detecting volatile compounds because of losses during the drying cycle of the GFAA. 


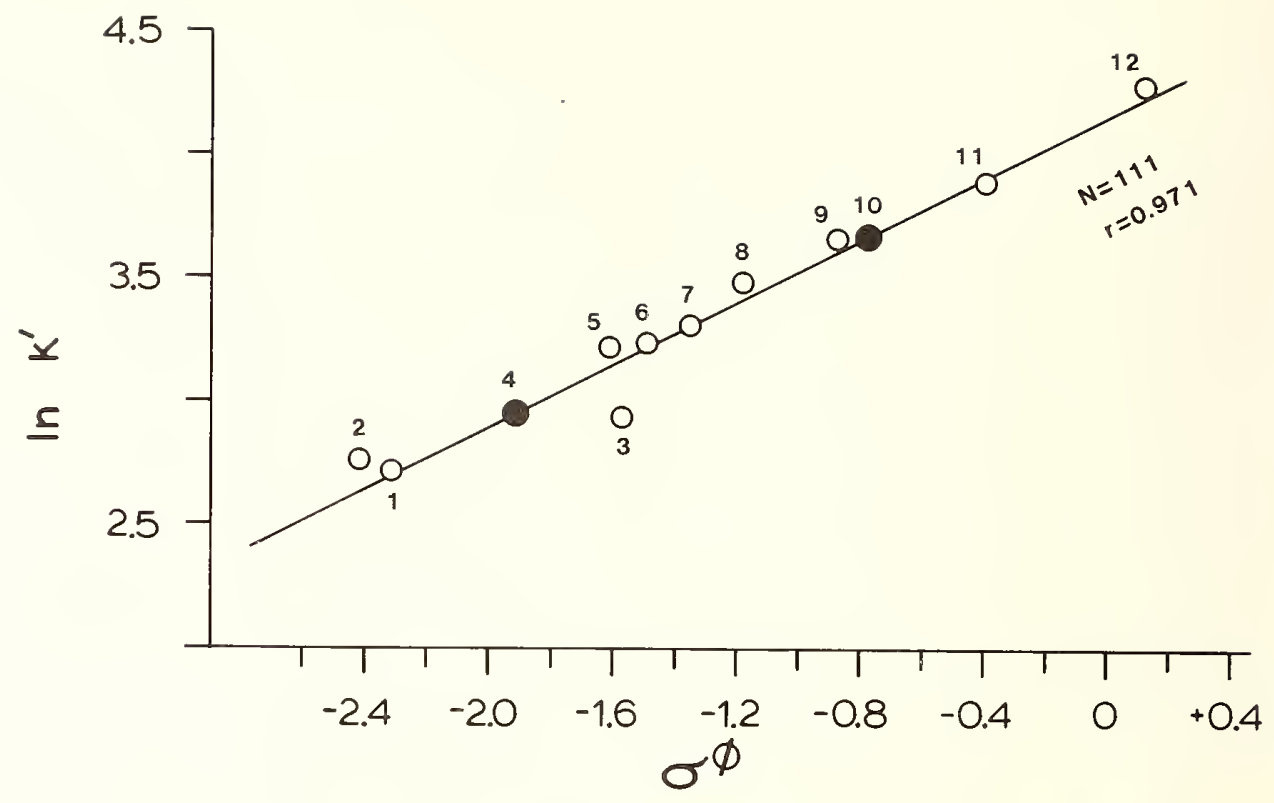

Figure 3. The linear regression between $1 n k^{\prime}$ and $\Sigma \sigma^{\phi}$ obtained on a weak anion exchange column (WAX) is shown for the following arsenicals: 1, $\mathrm{Me}_{2} \mathrm{As}(\mathrm{O}) \mathrm{OH} ; 2, \mathrm{Pe}_{2} \mathrm{As}(0) 0^{-}$; 3, $\mathrm{Ph}_{2} \mathrm{As}(\mathrm{O}) \mathrm{OH} ; 4, \mathrm{Me}_{2} \mathrm{As}(\mathrm{O}) 0^{-} ; 5, \operatorname{BuAs}(0)(\mathrm{OH}) 0^{-} ; 6, \operatorname{EtAs}(0)(\mathrm{OH}) 0^{-} ; 7, \operatorname{MeAs}(0)(\mathrm{OH}) 0^{-}$; 8, $\left(4-\mathrm{NH}_{2} \mathrm{Ph}\right) \mathrm{As}(\mathrm{O})(\mathrm{OH}) \mathrm{O}^{-} ; 9, \operatorname{PhAs}(\mathrm{O})(\mathrm{OH}) \mathrm{O}^{-} ; 10, \mathrm{AsO}(\mathrm{OH})_{2} \mathrm{O}^{-} ; 11, \mathrm{As}(\mathrm{O})(\mathrm{OH}) \mathrm{O}_{2}{ }^{2-}$; 12, $\left(4-\mathrm{NO}_{2} \mathrm{Ph}\right) \mathrm{As}(0) \mathrm{O}_{2}{ }^{2-}$. The black circles indicate estimated $\mathrm{ln} \mathrm{k}^{\prime}$ for alternate choices of protonated or deprotonated arsenic species not acceptable in the fit shown.

Table 3. The Calculation of $\sum \pi$ for Tetraorganotins, $R_{4-n} R^{\prime} S_{n}$

\begin{tabular}{|c|c|c|c|}
\hline \multicolumn{3}{|c|}{ Substituent } & Solvophobic Parameter ( $\pi$ ) [17] \\
\hline$-\mathrm{CH}_{3}$ & & & 0.56 \\
\hline$-\mathrm{C}_{2} \mathrm{H}_{5}$ & & & 1.02 \\
\hline$-\mathrm{C}_{3} \mathrm{H}_{7}$ & & & 1.55 \\
\hline $\mathrm{i}-\mathrm{C}_{3} \mathrm{H}_{-}$ & & & 1.53 \\
\hline$-\mathrm{C}_{4} \mathrm{H}_{9}$ & & & 2.13 \\
\hline$-\mathrm{C}_{6} \mathrm{H}_{5}$ & & & 1.96 \\
\hline$\underline{\mathrm{R}}$ & $\underline{\mathrm{R}^{\prime}}$ & $\underline{\mathrm{n}}$ & $\underline{\Sigma \pi}$ \\
\hline $\mathrm{CH}_{3}$ & & 0 & $4 \times 0.56=2.24$ \\
\hline $\mathrm{CH}_{3}$ & $\mathrm{C}_{2} \mathrm{H}_{5}$ & 2 & $(2 \times 0.56)+(2 \times 1.02)=3.16$ \\
\hline $\mathrm{C}_{2} \mathrm{H}_{5}$ & & 0 & $4 \times 1.02=4.08$ \\
\hline $\mathrm{C}_{3} \mathrm{H}_{7}$ & & 0 & $4 \times 1.53=6.12$ \\
\hline $\mathrm{C}_{6} \mathrm{H}_{5}$ & $\mathrm{C}_{4} \mathrm{H}_{9}$ & 2 & $(2 \times 1.96)+(2 \times 2.13)=8.18$ \\
\hline $\mathrm{C}_{6} \mathrm{H}_{5}$ & $\mathrm{C}_{4} \mathrm{H}_{9}$ & 1 & $(3 \times 1.96)+2.13=8.01$ \\
\hline
\end{tabular}




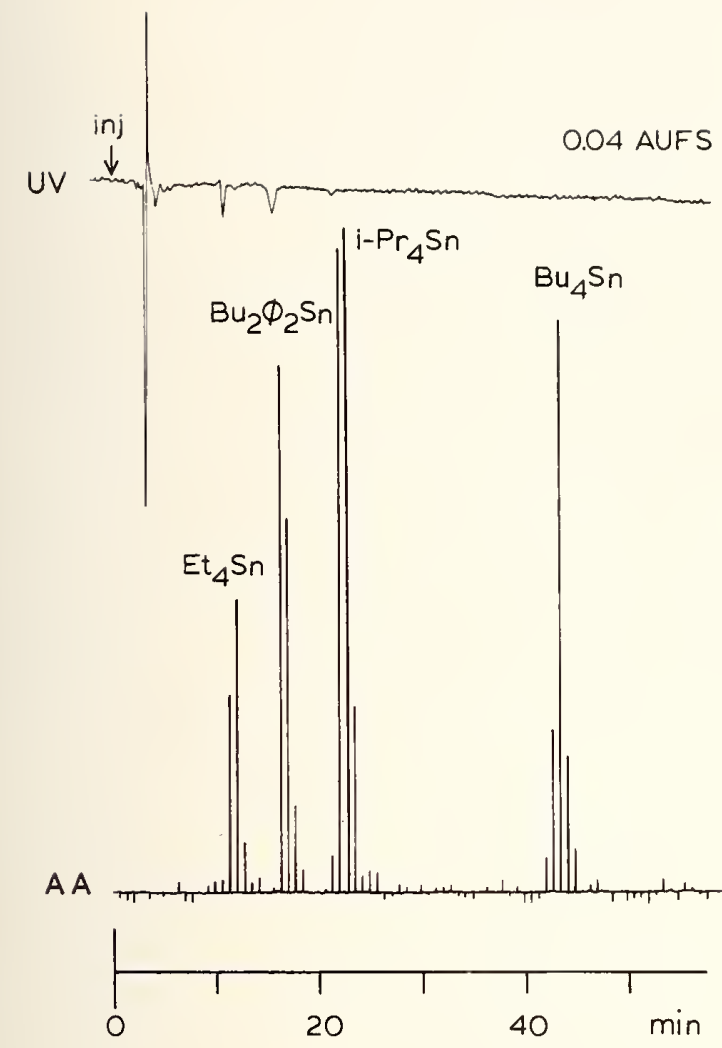

Figure 4. The isocratic separation of four tetraorganotins on an octadecylsilane chemically bonded phase columns, using methanol: $\mathrm{H}_{2} \mathrm{O}$ (93:7 vol.\%) at a flow rate of $1.0 \mathrm{~mL} \min ^{-1}$.

The relationship between the natural logarithm of the chromatographic capacity factor for the organotins and the calculated $\pi$ values for these compounds is presented in Figure 5. The relationship for the alkyl and mixed alkyl derivatives is linear, with a correlation coefficient of 0.989 , based on 41 data points. The relationship for the mixed butyl-phenyl organotins is also linear, with a correlation coefficient of 0.989 , based on 31 data points, but with a much larger slope. The difference in behavior between the alkyl and phenyl derivatives is possibly due to steric, electronic, or solution properties of the phenyl group operating differently under the bulk conditions, used to determine the octanol-water partition coefficients, and the sterically constrained octadecylsilane chain configuration, present in the $C_{18}$ bonded-phase HPLC column.

\subsection{Application to 0il Shale}

Elemental analysis of sedimentary deposits has shown the enrichment of a number of elements, including As, in the carbonaceous deposits of coal, black shale, petroleum, and asphalt over average crustal abundances [30]. Both coal and oil shale, in general, contain higher concentrations of these elements than petroleum. The increased use of coal and oil shale as alternatives to petroleum will cause the redistribution of arsenic contained in 


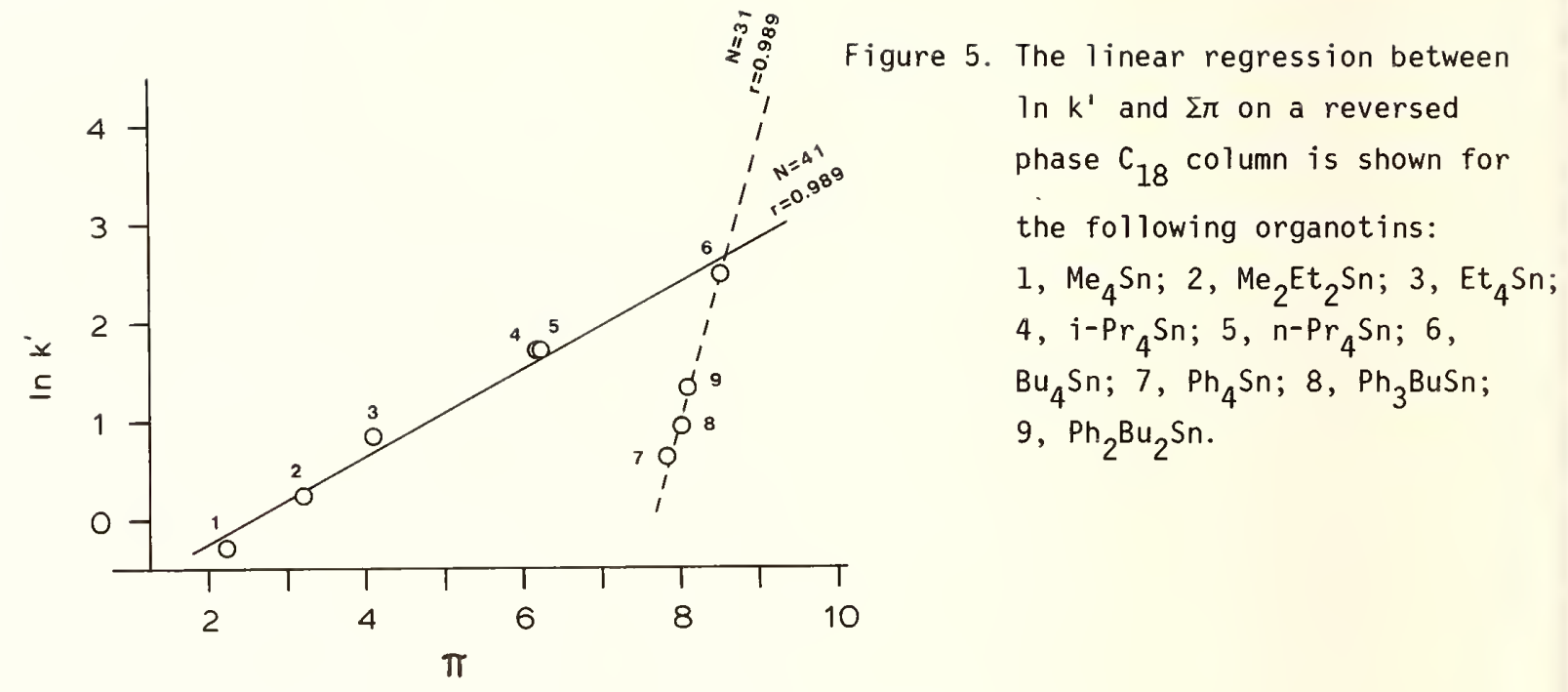

these matrices depending upon the form of arsenic originally present, the type of process used to convert these materials to conventional liquid fuels, and on their final use.

The association of arsenic with sulfide deposits, particularly pyrite, in coal has been reported [31], although no analogous conclusions have been reported for arsenic in oil shale. The accumulation of arsenic by modern day algae may indicate the manner of enrichment of arsenic in oil shale, the fossilized remnants of ancient algal mats, by initial bioaccumulation and the subsequent metamorphosis of arsenic [32].

The partitioning of arsenic during simulated in situ oil shale retorting has shown that a significant quantity of arsenic is distributed to the product oil and the retort waters [33]. The application of the weak anion exchange separation of arsenic containing compounds to a number of retort waters generated during oil shale retorting has been performed [32], and is illustrated in Figure 6a. The chromatogram reveals the presence of arsenate, phenylarsonic acid, methanearsonic acid and a neutral arsenic-containing compound.

The origin of these organoarsenic compounds is not clear. It is possible that they are synthesized during the retorting process by the reaction of alkylhalides with arsenite, according to the Meyer reaction [34]. It is also conceivable that these organoarsenicals were initially present in the oil shale, being liberated during the retorting and partitioned into the retort waters. In order to investigate this possibility ground oil shale 
was extracted, via a Soxhlet apparatus, with methanol. Figure $6 \mathrm{~b}$ shows the separation of arsenic containing compounds in this methanol extract, indicating the presence of a neutral arsenic containing compound, phenylarsonic acid, and arsenate. At the present time, the identification of phenylarsonic acid is only tentative because of interference from a less ionic form of arsenate found in methanolic solutions, as previously reported [29]. This less ionic form of arsenate is probably the dimethyl ester of arsenate, which has a $\Sigma \sigma^{\phi}$ value of -0.24 . It is therefore predicted to elute from the column with a retention time similar to phenylarsonic acid. A recent report on the hydrolysis of arsenate triesters indicates that the first and second hydrolysis steps are very rapid, when conducted at $\mathrm{pH} \sim 12$ [35]. In the present work the hydrolysis rate does not appear to be as rapid on the chromatographic time scale, possibly due to the lower pH (7.1 to 8.1) of the eluting solvent, the ammonium carbonate buffer, and the presence of the column substrate. Preliminary hydrolysis experiments of the methanol oil shale extract indicate the presence of phenylarsonic acid, but more extensive kinetic experiments and the use of an alternate measurement method are now necessary to confirm and quantitate phenylarsonic acid.

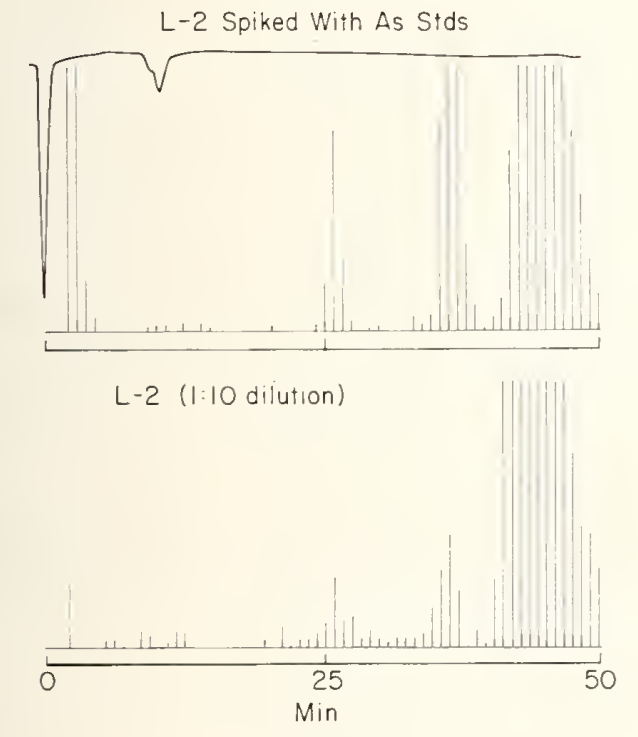

(A)

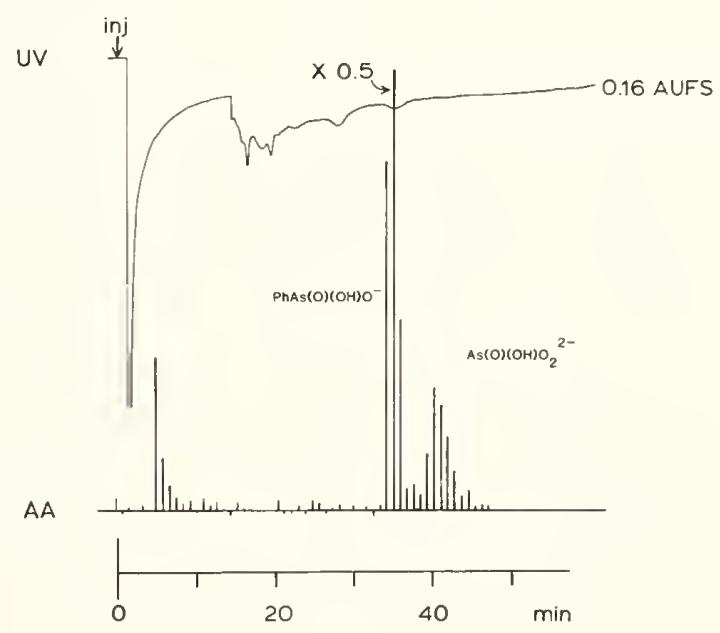

(B)

Figure 6. (A) The separation of arsenicals in a process water generated by a simulated in-situ retorting process (Lawrence Livermore National Laboratory L-2). (B) The separation of arsenicals in a methanolic extract of ground oil shale (NBS).

\section{Conclusions}

The correlation of the linear sum of the appropriate structural substituent parameter with the logarithm of the chromatographic capacity factor for organoarsenicals $\left(\sigma^{\phi}\right)$ and tetraorganotins $(\pi)$ has been found to be linear. This allows the prediction of: the 
retention time of a sought after compound, the possible structure(s) of unknown compounds from experimentally determined retention times, and the possible co-elution of interfering compounds. In addition, this relationship can be used to optimize diverse chromatographic systems, including ion exchange and solvophobic mechanisms, for a desired separation. The analysis of a methanol oil shale extract has demonstrated the utility of structural substituent parameters as a diagnostic tool in the liquid chromatographic speciation of trace metals and metalloids in complex matrices commonly associated with energy-reiated processes.

\section{Acknowledgment}

RHF wishes to acknowledge the support of the Assistant Secretaries for Fossil Energy and 0i1, Sas and Shale Technology, and the Bartlesville Energy Technology Center (Project Manager, Dexter Sutterfield) of the U.S. Department of Energy under contract No. W-7405-ENG-48.

\section{References}

[1] Jackson, J. A.; Blair, W. R. ; Brinckman, F. E.; Iverson, W. P. Gas chromatographic speciations of methylstannanes in the Chesapeake Bay using purge and trap sampling with a tin-selective detector. Environ. Sci. Technol.; in press.

[2] Cheng, C.-N.; Focht, D. D. Production of arsine and methylarsines in soil and in culture. Appl. Environ. Microbiol. 38: 494-498; 1979.

[3] 01 son, G. J.; Iverson, W. P.; Brinckman, F. E. Volatilization of mercury by Thiobacillus ferrooxidans. Cur. Microbiol. 5: 115-118; 1981.

[4] Kahn, N.; VanLoon, J. G. Atomic absorption spectrophotometry as a chromatography detector for copper-amino acid complexes in human serum. J. Liq. Chromatogr. 2: 23-36; 1979.

[5] Parks, E. J.; Brinckman, F. E. ; Blair, W. R. Application of a graphite furnace atomic absorption detector automatically coupled to a high performance liquid chromatograph for speciation of metal-containing macromolecules. J. Chromatogr., 185: 563-72; 1979.

[6] Dulka, J. J.; Risby, Terrence H. Ultra trace metals in some environmental and biological systems. Anal. Chem. 48: 640A-653A; 1976.

[7] Hausler, D. W. ; Hellgeth, J. W. ; Taylor, L. T.; Borst, J. ; Cobley, W. B. Trace metal distribution in fractions of solvent refined coal by ICP-OES and implications regarding metal speciation. Fuel, 60: 40-46; 1981.

[8] Schwager, I.; Yen, T. F. Coal-liquefaction products from major demonstration processes. 1. Separation and analysis. Fuel 57: 100-104; 1978.

[9] Weiss, C. S. The detection of trace metal species in solvent refined coal. Dissertation, Washington State Univ., 1980.

[10] Ettre, L. S. Selective detection in column chromatography. J. Chromatogr. Sci. 16: $396-417 ; 1978$.

[11] Baker, J. K. Estimation of high pressure liquid chromatographic retention indices. Anal. Chem., 51: 1693-97; 1979.

[12] Tomlinson, E. Chromatographic hydrophobic parameters in correlation analysis of structure-activity relationships. J. Chromatogr., 113: 1-45; 1975. 
[13] Martin, A. J. P. Some theoretical aspects of partition chromatography. Biochem. Soc. (London) Symp., 3: 4-20; 1949.

[14] Hammett, L. P. Some relations between reaction rates and equilibrium constants. Chem. Rev., 17: 125; 1935.

[15] Jaffé, H. M. ; Freedman, L. D.; Doak, G. O. The acid dissociation constants of aromatic phosphonic acids. I. Meta and para substituted compounds. J. Am. Chem. Soc., 75: 2209-11; 1953.

[16] Mastrykova, T. A.; Kabachnik, M. I. The application of the Hammett equation with the constants $\sigma^{\phi}$ in the chemistry of organophosphorous compounds. Russian Chem. Rev., 38(10): 795-811; 1969.

[17] Hansch, C.; Leo, A. Substituent constants for correlation analysis in chemistry and biology. John Wiley and Sons, NY; 1979, p. 339.

[18] Rekker, R. F. The hydrophobic fragmental constant its derivation and application a means of characterizing membrane systems. Elsevier Scientific Publ. Co., Amsterdam, 1977.

[19] Braumann, T.; Grimme, L. H. Determination of hydrophobic parameters for pyridazinone herbicides by liquid-liquid partition and reversed phase high-performance liquid chromatography. J. Chromatogr. 206: 7-15; 1981.

[20] Neely, W. B. ; Branson, D. R. ; Blau, G. E. Partition coefficients to measure bioconcentration of organic chemicals in fish. Environ. Sci. Technol., 8(13): 1113-15; December 1974.

[21] Steen, W. C.; Karickhoff, S. W. Biosorption of hydrophobic organic pollutants by mixed microbial populations. Chemosphere, 10: 27-32; 1981.

[22] Dagani, R. Toxicologists seek structure activity links. Chem. \& Eng. News, 26-29; March 9, 1981.

[23] Lederer, M. Some theoretical considerations in paper chromatography. Proc. 2nd Int1. Congr. Surface Activity, 3: 506-15; 1957.

[24] Horváth, C.; Melander, W.; Molnár, I. Solvophobic interactions in liquid chromatography with non-polar stationary phases. J. Chromatogr., 125: 129-56; 1976.

[25] Chen, B-K.; Horváth, C. Evaluation of substituent contributions to chromatographic retention: quantitative structure-retention relationships. J. Chromatogr., 171: $15-28 ; 1979$.

[26] Nahum, A.; Horváth, C. Evaluation of octanol-water partition coefficients by using high-performance liquid chromatography. J. Chromatogr., 192: 315-22; 1980.

[27] Rittich, B.; Polster, M.; Králík, 0. Reversed-phase high-performance liquid chromatography. I. Relationship between $\mathrm{Rm}$ values and Hansen's $\pi$ parameters for a series of phenols. J. Chromatogr., 197: 43-50; 1980.

[28] Jewett, K. L.; Brinckman, F. E. Speciation of trace di- and triorganotins in water by ion-exchange HPLC-GFAA. J. Chromatogr. Sci., 19: ; 1981, in press.

[29] Woolson, E. A. ; Aharonson, N. Separation and detection of arsenical pesticide residues and some of their metabolites by high pressure liquid chromatography--graphite furnace atomic absorption spectrometry. J. Asso. Off. Anal. Chem., 63: 523-28; 1980.

[30] Krauskopf, K. B. Sedimentary deposits of rare metals. Econ. Geol. 50th Anniversary Volume, pp. 411-470; 1955. 
[31] Finkleman, R. B. Modes of occurrence of trace elements in coal. Dissertation, University of Maryland, 1980.

[32] Fish, R. H.; Brinckman, F. E.; Jewett, K. L. Fingerprinting inorganic arsenic and organoarsenic compounds in situ oil shale retort and process waters using a liquid chromatograph coupled with an atomic absorption spectrometer as a detector. Environ. Sci. Technol., in press.

[33] Fox, J. P.; Mason, K. K.; Duva11, J. J. Partitioning of major, minor, and trace elements during simulated in situ oil shale retorting in a controlled-state retort. in Twelfth oil shale symposium proceedings. Gary, J. H. ed. Colorado School of Mines Press, pp. 58-71; 1979.

[34] Meyer, G. Ueber einige anomale reaktionen. Ber. 16: 1439; 1883.

[35] Baer, C. D.; Edwards, J. 0.; Rieger, P. M. Kinetics of the hydrolysis of arsenate(V) triesters. Inorg. Chem. 20: 905-907; 1981.

Discussion

Question (E. A. Woolson): I noticed that near retention time of arsenite you have a peak in the retort waters, is that arsenite or is that just an artifact?

Answer: I am pretty sure that doesn't point to arsenite, it is some other neutral species eluting.

Answer (R. H. Fish): It is not arsenite. It is a neutral compound not an organic material but an arsenical like a trialkyl-or triarylarsine oxide that comes off with the solvent front. It is unfortunate, we should do other columns to further show the retention times.

Comment (E. A. Woolson): This work is done on the Dionex column. The Bio-Rad Aminex A27 using radial compression will give you better resolution separation than the Dionex column. You have to use a stronger ammonium carbonate buffer, you have to go to 0.2 molar instead of 0.02 which you use with the Dionex. But that will separate out some additional things at the beginning that the Dionex will not. That may help you there.

Question (Y. K. Chau): Also in that HPLC-GFAA chromatogram I notice that you have only one peak, one histogram. Suppose if your interfacing your automatic sampler is a few seconds off phase, you miss that peak altogether. What is the minimum peak width of your HPLC that would enable you to be statistically sound, to sample quantitatively?

Answer (F. E. Brinckman): You must do two things. The minimum width in time is $\Delta t$, that is $\frac{1}{2} \Delta t$, the half-width between one pulse. You must run replicates in order to get whatever confidence interval you want. In this case, for a single peak we do not regard that as a quantitation peak, it cannot be. We have discussed this in literature, so I won't expand on it [Brinckman et al. J. Chromatogr. Sci. 15: 493 (1977)]. Normally, we would run, in 
these cases ran, four to six replications where we accept as a 90 to 95 percent confidence interval the mean retention time plus or minus about $3 \sigma$.

Second, I would say that this method coupled with the method of standard additions for quantitation is prerequisite because of the limitations of an histogrammic output as opposed to a continuous wave or analog output.

Question (K. B. 01son): I have a few questions. What percentage of the arsenic was extracted from the oil shale by the methanol?

Answer: I think on the order of 20 percent. That is based on preliminary information from the Office of Standard Reference Materials, NBS.

Question (K. B. 01son): When you did your determination of the arsenic on the graphite furnace, did you use a complexing agent?

Answer: No I didn't.

Question (K. B. 01son): What percentage of the total arsenic eluted off the column when you looked into retort waters?

Answer (R. H. Fish): These retort waters were analyzed for total arsenic concentration. They varied from about 3 to $15 \mathrm{ppm}$ and it is very difficult to account for all the arsenic in the samples. We attempted by the method of standard additions to semiquantitate each of these compounds coming off, but not in all cases could we totally account for $15 \mathrm{ppm}$ in each peak or their sums. I think it is probably more important that we identify the compound than be specific on its concentration.

Comment (F. E. Brinckman): Not only for the retort waters, but really for any system such as this. In this case the detector is not operating under optimal conditions. It couldn't for two reasons. Even under isocratic conditions, which these are not, the gradient conditions used non-linear changes. Therefore, the composition of the mobile phase being dried, charred, and volatilized in the ionization process, is itself undergoing constant change. So unless you want to operate the GFAA with a considerably complicated computer feedback program in order to test this change, you really tend to operate it at some guessed at or empirically learned best mean conditions for the furnace. In consequence, you will get very good apparent detection limits in one case but not other cases, depending on the species. That is one consideration. The other can be optimized as Dr. Woolson has elegantly shown [Woolson, Aharonson, J. Assoc. Off. Ana]. Chem. 63: 523 (1980)] where you can get coincident calibration slope. You should get the theoretical effect of having the same apparent system sensitivity for any species. Still another consideration is to use postcolumn derivatization; this has been reported in literature. In this instance, after the molecular separation has occurred and the effulent is delivered from the column to the 
point of sampling for the AA or other detectors, as the case may be, you would simply blend in a stream because you are in laminar conditions. Our peak broadening is less than 3 percent for the whole system, so that the peak eluting then could be then treated, either continuously or by design with a program to give you a more optimal response. We haven't bothered with it because you see the analytical time is still not convenient and we would rather find out what's out there right now than quantitate. I wouldn't know what quantitation means yet because the water samples were not obtained by us in the field, although they were sterile, we know that.

Question (W. Slavin): Two questions, or comments; have you used some of the newer techniques, for instance the use of platforms with the graphite furnace, which should very greatly reduce the difference in seeing the different species of arsenic compounds. I am surprised you are getting that much variation, but the techniques in the graphite furnace where the sample is deposited onto a platform provide thermal conditions which are largely independent of the physical characteristics of the sample. In other words, the organic compound in which it is present.

A second question relates to the question that Dr. Chau asked. Can't you use your histogrammic techniques for establishing the time at which the particular compounds of interest elute from the LC column and then schedule the graphite furnace sampling so that you are within the center of the peaks. Because all that is required for sample volume by the graphite furnace is $10 \mu \mathrm{L}$ per sample or smaller and your chromatographic peaks is certainly very much larger in peak width than that. Can't you do that?

Answer: Yes.

Comment (Y. K. Chau): I'11 comment on that, we cannot, because the graphite furnace takes one minute cooling time. This is dictated by the cooling time needed so the sampling pipette arm would not be melted. Secondly, the ashing time, drying time, and atomization time all add up to about one more minute, minumum. With one minute cooling time it takes two minutes of hardware for every sample we injected.

Comment (E. A. Woolson): With the GFAA we can inject at every $43 \mathrm{~s}$ as low as at $40 \mathrm{~s}$, in some cases; that is about the minimum.

Comment (F.E.Brinckman): You're right, Dr. Slavin. the platform can be used but it is a question of lifetime. If you will convince me at $\$ 500$ per box we can get a 100 or 1000 bangs done in a few hours and avoid a lot of failures in midstream I am all for it. That's the only reason we haven't pursued it.

Answer (W. Slavin): Lifetime is not a problem. 
Comment (D. A. Becker): I was asked yesterday about the results from an 0 il Shale Workshop held here about 3 or 4 years ago. Dick Fulsom from Laramie said whatever became of that ton of oil shale that they shipped to NBS. I did some investigating, and I will report a little bit. First of all, there is an SRM shale oil [NBS SRM-1580] issued last year that has been certified for ten organic compounds including five PNA hydrocarbons. In addition, that ton of oil shale has been ground and is in the possession of NBS in powder form. I think that is the same oil shale that weiss et al. used in their leachate studies. I am not sure exactly what is going to be done in terms of a SRM or a reference material. Tom Gills of the Office of Standard Reference Material has responsibility for that, perhaps he can say what exactly the priority for an oil shale SRM or reference material is in terms of the immediate future.

Comment (T. Gills): In view of reading the papers so far on synfuels, I don't know if OSRM wants to make a committment at this time with the allocation of funds for it. I would solicit, however, any letters, comments that you can give to me during the conference to support my effort in trying to get it into our priority listing. June 19, 1981 is the date that we begin to look at proposals both from inside and outside to make some decisions for FY 82. If you can assure me that it will be of great need and interest and can give me some projection of the number of sales then, I will support that in view of our priorities. I have heard just a few people comment on the need of it; I haven't gotten any feeling that it is really needed.

Comment (D. A. Becker): There is another class of materials called reference materials that are not certified for components but are of proven homogeneity, and made available. I know that the Office of Recycled Materials that I am a part of will make some of these available which are much less expensive. That might want to be considered also in terms of having homogeneous materials that everybody could work on. This would facilitate intercomparisons but would not necessarily be nearly as expensive as having certified materials. Both approaches are possible.

Question (R. D. Nadkarni): With the shale oil SRM for organics, is there any plan to certify it for trace elements?

Answer (T. E. Gills): I think that is the plan. In fact, based on some data that I have gotten from Dr. Brinckman on some other shale oils, it generated interest within the OSRM for looking at trace elements, especially things like arsenic. We are going to move ahead on that front. Already we have asked activation analysis group here at NBS to survey the . shale oil for trace element content. I think that is one we will move ahead on. 
Comment (M. A. Anderson): I have one other written question that is addressed to me by Dr. Kirchhoff from NBS concerning the same type of subject matter. That is, the interest in using SRM to look at adsorption reactions. I think that is the case well taken. Too many people in my area of research are using a tremendous variety of solid substrates as well as absorbates to look at the adsorption reactions over the huge concentration ranges in a variety of time frames. A good start on this system would be our approach with respect to standard reference solids, particularly if you use some standard reference oxides. We could use a standard reference clay, perhaps a carbon source, and then we could do some research on it. I support that idea whole heartedly.

Question (M. A. Anderson): I have a question for Dr. Creceilius. You showed uptake of copper, the noncomplexed copper just continuing to go up and you didn't show any kill rate or anything. How long does this go on? I mean does it reach some saturation? I am talking about the electroactive species.

Answer (E. Crecelius): This uptake, do you remember if this is a whole animal or the clam gi11?

Answer (M. A. Anderson): I don't know if it was the clammed up clam or what it was.

Answer (E. Crecelius): You have the whole clams checked out in the copper how high you can go. In a clam gill you keep going for at least several days and then that is all the longer you work with that system. In the case of whole animals, after you get the body burdens above a certain level, they start dying.

Question (M. A. Anderson): It must have been the clam gill and you just ran out of time?

Answer (E. Crecelius): Yes, we only bought it up 24 hours. When we started with cadmium, you could go to several thousand ppb before you stop inhibition of cadmium in the clam gill and then the uptake rate would slow down. So we could get about four orders of magnitude concentration change. It took a very high concentration of metal to affect the clam gill in, say, 48 hours.

Question (M. A. Anderson): I have one further question of Dr. Brinckman and his coworkers here, and particularly all you chromatographers. Essentially I use batch system chromatography involving $\mathrm{pH}$ and ionic strength, and we look at absorption mechanisms on the surface. It is no different from what you are doing except that you, for instance, fix the $\mathrm{pH}$ and you don't look at that as a variable. I am interested in these arsenic species; you have essentially determined their binding constants for solid surfaces. Could you comment on using these methods a little bit more, for, let's say, the effective binding constants in terms of the other variables, ionic strength, $\mathrm{pH}$, temperature? In getting kinetics too, that is a timely thing, can that be done? 
Answer (F. E. Brinckman): The elegance of the chromatographic method comes about because of something that is common knowledge; that is, the array of rather well defined surfaces chemically bound to support substrates. It means you have a large range of even potentially immobilized ligands or competitive sites--Brønsted acids or bases if you prefer. This has really been done: I will cite three areas of work that respond to this question. First, there is an excellent review by C. Horváth et al. which appeared in J. Chromatogr. [186: 371 (1979)] who put as nicely as one can a restatement in this particular context of modern HPLC. From first principles, the situation was treated for either ionic exchange or solvophobic exchange mechanisms which includes partition somewhere in the interim, on the solidliquid interface. One can draw a very nice thermodynamic model. Indeed, on a relative basis the ratios of the stability constants predicted by these defined surfaces, using one compound as a marker, once you have the column constants that Dr. Weiss showed, is what we are generating is a column as binding constants. Although in this case, we have done it in gradient elution but it works just as well in linear or isocratic elution. Once you have that you can predict the relative stability coefficients and they work.

This has been done the other way around. Segar in this institution several years ago, gave a very nice paper [Segar, Canti110, NBS Spec. Pub1. 464. Methods and standards for environmental measurement. November 1977, p. 491] which showed using immobilized copper on a column and passing the ligand through, and so with a competitive ligand directly measuring stability coefficients. I think this sort of work is just understated, that has been in the literature now for five or six years. Lastly, the work of Yoza in Japan [Yoza, Kouchiyama, Miyajima, and Ohashi, Anal. Lett. 8(9): 641-653 (1975)], who worked with polyphosphates using element-selective detections, as did Segar. I think the opportunity to control, in a laminar flow system, selected element measurements and retention times, allows you to make these direct measurements under virtually thermodynamic conditions, that is equilibrium conditions.

Question (M. A. Anderson): How do you explain the electrostatic problems? Do you see that?

Answer (F. E. Brinckman): Yes, there is, but it can be minimized with stable surfaces. I would say the reason is that the effective surface area now available with 5 to 10 microns type particulates and especially those with nonswollen substrates are ideal. We are using nonswelling bonded phase substrates with the exception of Dionex which is pretty important in that regard, there are problems with that. You have in fact a chance of getting a good base-line equilibration. Your analytes are at very low concentration with respect to the chemistry going on continuously with the supporting electrolyte. In consequence, you are in a very non-perturbed system, it is almost at rest at all times. It is a poised system.

Comment (C. R. Vogt): I would like to comment on the reverse-phase chromatography that you have used. In that technique, I think you could modify the mechanism of separation. You could introduce an ion pair in the reverse phase and then what you are essentially doing is an ion exchange. I think you could have it as immobilized ion pairing which means that it 
is not chemically bonded anywhere. What I would like to propose is for somebody to come up with a column that will give both functional groups, but they are also both chemically bonded. What this will entail will be the chemical bonding of an ionic site, whether this is anion and cation, in addition to the reverse-phase functionality.

Question (M. A. Anderson): What you are suggesting then is bonding in the phase of electrostatic repulsion, for instance?

Answer (C. R. Vogt): Yes, you can get both repulsion and attraction on these kinds of surfaces depending on the species and ion sizes. I believe by this mechanism that you can get the desired separation along with the desired column stability. No commercial columns are available which are both functionally and chemically bonded [but see Liao, Vogt, J. Chromatogr. Sci. 17: 237 (1979)--Eds.]. The approach now is to introduct ion-pairing agents into mobile phase which gets trapped, or immobilized, within a reverse-bonded phase, such as $C_{18}$. The ion-pairing site, in effect, gives an ion exchange function along witb solvophobic properties. 


\title{
Relationships Between Trace Element Speciation and Intracellular Mechanisms of Toxicity
}

\author{
Bruce A. Fowler \\ Laboratory of Pharmacology \\ National Institute of Environmental Health Sciences \\ Research Triangle Park, North Carolina
}

The mechanisms and thresholds of trace element toxicity are highly dependent upon chemical form, differential binding to intracellular ligands, and interactive effects with other toxic or essential biological agents. In vivo methylation or demethylation conversions have been demonstrated for arsenic and mercury, respectively, but the precise influence of these processes on cellular toxicity is undefined. Major intracellular ligands, such as metallothionein for cadmium and inclusion bodies for lead, play a primary role in mediating toxicity by competing with target organelles for these elements. Interactive effects between lead and cadmium greatly reduce renal lead concentrations and formation of inclusions but not lead toxicity, thus indicating the importance of intracellular speciation to assessment under multi-element exposure conditions.

Key words: arsenicals; cadmium metallothionein; cellular toxicity; elemental interactions; lead inclusion bodies; methylmercury derivatives; methylation/demethylation.

1. Introduction

\subsection{In Vivo Metabolism of Toxic Trace Metals}

Biological organisms are capable of greatly influencing the toxic potential of trace elements by metabolic conversions that may render a particular element more or less toxic within a given dose range. These reactions may involve methylation/demethylation for elements such as arsenic [1] and methylmercury species [2], respectively; synthesis of high-affinity cellular ligands such as metallothionein [3], or similar low molecular weight proteins in marine bivalves [4], for cadmium; and formation of nuclear inclusions for lead [5]. In addition, recent studies [6,7] have identified a number of elemental interactions which may greatly influence both the intracellular chemical species formed and the ultimate toxicity of the elements involved.

\subsection{Cellular Mechanisms of Toxicity}

The biochemical mechanisms by which toxic trace elements may injure cells are many. At a given dose level primary effects may occur as the result of damage to cell membranes [8], mitochondria [9], lysosomes [10] or nuclear (genetic) function [11]. Higher doses may produce simultaneous effects at a number of sites. The following discussion will attempt to briefly summarize some current concepts of how biological organisms respond to toxic trace 
element species and what is known about the relationships between reactions and organellespecific damage on an element by element basis. The impact of trace element interactions on these relationships will also be examined.

\section{Specific Toxic Elements}

\subsection{Arsenic}

The primary pathway for metabolism of inorganic arsenicals in mammals, including man, appears to involve methylation of the trivalent $\left[\mathrm{As}^{3+}\right.$ ] species following inhalation [12] or ingestion [13] leading to the formation of methylarsonic and dimethylarsinic acids [1,12, 13]. For $\mathrm{As}^{3+}$ it is clear that this metabolic conversion simply requires transfer of the methyl groups to this atomic species. Excretion of these methyl derivatives following exposure to pentavalent $\left[\mathrm{As}^{5+}\right\rfloor$ arsenate would necessitate an initial reduction of $\mathrm{As}^{5+}$ to $\mathrm{As}^{3+}$. This reaction, which has been reported to occur in rats [14] and dogs $[15,16]$, has been the subject of controversy, but it is of potentially great importance since $\mathrm{As}^{3+}$ is regarded as being more highly toxic than $\mathrm{As}^{5+}$ due in part to its longer biological half-time in the body [17].

In terms of toxicity, cellular respiration, which is primarily localized in the mitochondrion, is highly sensitive to either chemical species $[9,18,19]$. In vivo studies $[9,18$, 19] have demonstrated the preferential effects of $\mathrm{As}^{5+}$ and $\mathrm{As}^{3+}$ on mitochondrial NAD-linked mitochondrial respiration in both rats and mice. The biochemical mechanism for $\mathrm{As}^{3+}$ inhibition of mitochondrial oxidation of these substrates (pyruvate/malate, and $\alpha$-ketoglutarate) is thought to involve complexation of this species with the disulfhydryl groups of the lipoic acid moiety of the enzyme complex responsible for oxidation of these substrates [19]. In the case where $\mathrm{As}^{5+}$ is administered, it has been suggested [20] that the observed similarity of effect could be due to mitochondrial reduction of $\mathrm{As}^{5+}$ to $\mathrm{As}^{3+}$. Alternatively, Matlib and Srere [21] have shown that simple swelling of hepatic mitochondria by phosphate wi11 produce a similar effect on mitochondrial respiration, presumably due to disruption of the physical relationship between the mitochondrial matrix enzymes and the electron transport chain. Hence, the high amplitude mitochondrial swelling observed with arsenicals could be responsible for the effect on respiration supported by NAD-1inked substrates.

other in vivo effects of arsenicals on the mitochondria involve changes in membrane structure and function [9] that are accompanied by concomitant increases in mitochondria] protein synthesis, suggesting a compensatory biological response to this agent. In addition, arsenical-induced changes in mitochondrial heme biosynthesis [22] with attendant porphyrinuria have provided a potentially useful biological index of mitochondrial toxicity in vivo.

The main points to be derived from the above are that arsenicals undergo metabolic conversions in vivo and that the precise relationships between these conversions, formation of active species and observed toxic effects are currently unknown but of critical 
importance since the acute toxicity of the various arsenic species varies greatly. A second point is that biological organisms appear capable of some degree of compensatory response to arsenical toxicity if doses are low enough and administered over prolonged time periods. Processes regulating these responses and the degree of arsenical effect on mitochondrial respiration, heme biosynthesis or conformational behavior are also currently unknown but of critical importance to toxicity assessment.

\subsection{Methylmercury Derivatives}

In contrast to arsenic, the primary detoxification pathway for methylmercury species involves its in vivo demethylation to $\mathrm{Hg}^{2+}$ which is subsequently excreted via the kidneys [23]. This process also produces the situation where both chemical species $\left[\mathrm{CH}_{3} \mathrm{Hg}^{+} \mathrm{and} \mathrm{Hg}^{2+}\right]$ are present in target tissues and raises the question of whether the observed cellular toxicity is due to one or the other chemical species or both. The answer is that no one really knows for certain. A study performed in our own laboratory [2], using fetal rats whose mothers had been exposed to methylmercury compounds in drinking water, showed the presence of both forms in the livers of these animals, but the fractional percentage of $\mathrm{Hg}^{++}$ appeared to increase with dose suggesting that the demethylation reaction might not be linear but capable of changing as a function of the dose given.

Correlative ultrastructural morphometric/biochemical studies showed that the earliest manifestions of mitochondrial toxicity were detectable at dosages below those at which marked demethylation had occurred, suggesting that $\mathrm{CH}_{3} \mathrm{Hg}^{+}$was the more active species. Since both forms were present, however, there is no way of excluding $\mathrm{Hg}^{2+}$ from the toxicity observed. Future studies must focus not only on the rates of $\mathrm{CH}_{3} \mathrm{Hg}^{+}$conversion to $\mathrm{Hg}^{2+}$ but also the intracellular binding sites of both species since biological inactivation by binding to high affinity ligands such as metallothionein in the case of $\mathrm{Hg}^{2+}$ also mediate toxic potential.

\subsection{Cadmium}

The synthesis of major intracellular ligands, such as the low molecular weight protein metallothionein, [3] in response to $\mathrm{Cd}^{2+}, \mathrm{Zn}^{2+}, \mathrm{Bi}^{2+}$, and $\mathrm{Hg}^{2+}$ exposure greatly influences the toxicity of these agents in mammalian and many non-mammalian organisms. The protein metallothionein, which has a molecular weight of 6600,30 percent cysteine residues and no aromatic amino acids, has been found to account for 70-80 percent of the total cellular binding of cadmium. A chemically different protein of similar size [4] has also been reported to fulfill a similar function in bivalve molluscs. The importance of the ability of biological organisms to synthesize high affinity ligands in response to some toxic trace elements cannot be underestimated with respect to the disposition of chemical species entering the cells or the bioavailability of these species for producing toxicity. One important determinate in regulating the relationship between metal binding to proteins like metallothionein and toxicity is protein turnover. Metallothionein, like all other proteins, undergoes turnover [24]. In some tissues such as the liver, the amount of $\mathrm{Cd}$ and $\mathrm{Zn}$ bound to the protein 
remains relatively constant over long time periods due to synthesis of new metallothionein at rates apparently matching degradation. In contrast, the kidney, which accumulates Cd over time, has been found [24] to show a rise and fall in the amount of $\mathrm{Cd}$ and $\mathrm{Zn}$ bound to the metallothionein peak over a 6-month period with an apparent redistribution of the increasing cellular Cd burden to other cellular compartments. Therefore, it is important to realize that while metallothionein is the major intracellular repository for elements like $\mathrm{Cd}$, the role played by this ligand in some target tissues is not static and protein turnover may greatly change the intracellular complexation of the metal in the cells. The exact mechanism of $\mathrm{Cd}$ toxicity to target cells, such as those in the proximal tubule of the kidney, is unknown but studies from our laboratory [10] and others [3] have shown that the circulating Cd-metallothionein complex following injection is nephrotoxic and produces a proteinuria similar to that observed with chronic Cd exposure. Ultrastructural morphometric and biochemical data [10] have suggested that proteinuria develops as a result of Cd-induced inhibition of secondary lysosome formation and, indirectly, via an inhibition of lysosomal protease activity following degradation of the complex. In addition, studies have indicated that the toxic effects and cell death occur as a result of a $\mathrm{Cd}$ ion inhibition of basic cell biochemical functions, in particular, RNA synthesis, due to the rapid release of the Cd ion within the cell following degradation of the metallothionein molecules. The point here is that the normal process of protein degradation may play a central role in generating toxic chemical species.

\subsection{Lead}

The main intracellular pathway for lead involves the cellular production of intranuclear inclusion bodies $[5,26]$. These structures, which account for a high percentage of the total intracellular lead burden [5,25-6], have been suggested [5] to play a protective role in preventing lead toxicity to sensitive biochemical systems. More recent studies [26] have demonstrated the presence of cytosolic proteins in kidney tubule cells which may play a role in the initial cellular binding of lead and possibly formation of the nuclear inclusions. The point here is that cells contain high affinity ligands/compartments which contain most of the intracellular lead burden. A primary area of research concern now centers on the relationship between initial cytosolic binding of lead, formation of nuclear inclusions and cellular toxicity.

In terms of toxic mechanisms, lead interaction with the cell and mitochondrial membranes appears to be a primary focus of effect [25,27-29]. Lead binding to the mitochondrial membranes has been found to be a dose dependent process [29] which leads to depressed membrane energization during respiration. In vivo, competitive binding between mitochondrial membranes and cytosolic and/or nuclear inclusion body compartments must certainly exist. This process which also appears to be dynamic would control the relationship between biological availability of lead ions and toxic effects. At the moment, we know little about 
these relationships and the rates at which they occur in vivo.

\section{Elemental Interactions}

In recent years, it has become clear that interactions between elements play an important role in mediating both the intracellular speciation of elements and toxicity. A recent comprehensive review [23] of interactions between elements is available which describes many interactive factors in detai1. Two of the more interesting and important interactions concern mercury-selenium and lead-cadmium and these witi be summarized below to iliustrate how these interactions may alter the relationships between intraceliular metal species and toxic effects.

\subsection{Mercury-Selenium}

Early studies by Parizek and Ostadalova [30] showed that concomitant administration of selenite protected against mercuric chloride induced renal injury. Subsequent studies [6] showed that chronic exposure to mercuric chloride and selenate caused formation of nuclear inclusions in renal proximal tubule cells with an atomic ratio for $\mathrm{Hg}$ :Se of 0.5:1 determined by $X$-ray microanalysis and loss of cell damage compared to that noted in animals given $\mathrm{Hg}^{2+}$ alone. The formation of these structures in target cells for $\mathrm{Hg}^{2+}$ with an observed absence of toxic effects indicates a change in the intracellular binding of $\mathrm{Hg}^{2+}$ due to formation of a new $\mathrm{Hg}-\mathrm{Se}$ species.

\subsection{Lead-Cadmium}

Recent studies $[7,31,32]$ have shown an in vivo interaction between lead and cadmium leading to a marked decrease in formation of renal intranuclear inclusion bodies [31] which is correlated with up to a $60 \%$ reduction of total lead in the kidney and other tissues [7]. Despite these decreases in tissue lead burdens, lead-induced porphyrinuria, which is 'used as an index of toxicity, was not decreased [7,32] thus indicating that the biologically active lead fraction was not affected. The mechanism of this interaction is presently unknown but appears to be related in part to decreased lead absorption from the gut and an apparent interaction between lead and cadmium at the cell membranes of target tissues.

The importance of the above interactions is that they document marked changes in the intracellular chemistry and biological effects of toxic trace elements by simultaneous exposure to other elements. It is hence clear that such interactive effects should be taken into account in examining the relationship between intracellular chemical species and toxicity in multielement exposure situations.

\section{References}

[1] Braman, R. S.; Foreback, C. C. Methylated forms of arsenic in the environment. Science 182(4118): 1247-1249; 1973. 
[2] Fowler, B. A.; Woods, J. S. The transplacental toxicity of methyl mercury to fetal rat liver mitochondria: Morphometric and biochemical studies. Lab. Invest. $36(2)$ : $122-130 ; 1977$.

[3] Nordberg, M.; Kojima. Y. ed. Report on metallothionein and other low molecular weight metal binding proteins in Metallothionein; Proceedings of first international meeting on metallothionein and other low molecular weight metal-binding protein. Kagi, J.H. R.; Nordberg, M. ed. 1978 July 17-22; Zurich, Switzerland Basel: Birkhauser-Verlag; 1979. 41-124.

[4] Ridlington, J. W.; Fowler, B. A. Isolation and partial characterization of a cadmium-binding protein from the American oyster (Crassostrea virginica). Chem. Biol. Interact. 25(2): 127-138; 1979 .

[5] Goyer, R. A.; Leonard, D. L.; Moore, J. F.; Rhyne, B. C.; Krigman, M. R. Lead dosage and the role of the intranuclear inclusion body. An experimental study. Arch. Environ. Health. 20(6): 705-711; 1970 .

[6] Carmichael, N. G; Fowler, B. A. Effects of separate and combined chronic mercuric chloride and sodium selenate administration in rats: Histological, ultrastructural and X-ray microanalytical studies of liver and kidney. J. Environ. Pathol. Toxicol. $3(2) ; 399-412 ; 1979$.

[7] Mahaffey, K. R.; Capar, S. G.; Gladen, B. C.; Fowler, B. A. Concurrent exposure to lead, cadmium and arsenic: Effects on toxicity and tissue metal concentrations in the rat. J. Lab. Clin. Med. (In press).

[8] Kempson, S. A.; Ellis, B. G.; Price, R. G. Changes in rat renal cortex, isolated plasma membrane and urinary enzymes following the injection of mercury chloride. Chem. Biol. Interact. 18(2); 217-234; 1977 .

[9] Fowler, B. A.; Woods, J. S.; Schiller, C. M. Studies of hepatic mitochondrial structure and function: Morphometric and biochemical evaluation of in vivo perturbation by arsenate. Lab. Invest. 41(4); 313-320, 1979.

[10] Squibb, K. S.; Taylor, J. A.; Fowler, B. A. Early biochemical effects of cadmiumthionein in the rat kidney. Fed. Proc. 40; 836; 1981.

[11] Choie, D. D.; Richter, G. W. Lead poisoning: Rapid formation of intranuclear inclusions. Science 177(4054); 1194-1195; 1972

[12] Smith, T. J.; Crecelius, E. A.; Reading, J. D. Airborne arsenic exposure and excretion of methylated arsenic compound. Environ. Health Perspect. 19; 89-94; 1977 .

[13] Crecelius, E. A. Changes in the chemical speciation of arsenic following ingestion by man. Environ. Health Perspect. 19;147-150; 1977. 
[14] Lang, H. Jr.; Wallace, $P_{74} C_{\text {. }}$; Hamilton, J. G. The metabolism of arsenic in laboratory animals with As as a tracer. Univ. Calif. Publ. Pharmacol 2; 263-282; 1950.

[15] Ginsburg, J. M.; Lotspeich, W. W. Interrelations of arsenate and phosphate transport in the dog kidney. Amer. J. Physiol. 205(4); 707-714; 1963.

[16] Ginsburg, J. M. Renal mechanisms for excretion and transformation of arsenic in the dog. Amer. J. Physiol. 208(5); 832-840; 1965.

[17] Vahter, M.; Norrin, H. Metabolism of ${ }^{74}$ As-labeled trivalent and pentavalent inorganic arsenic in mice. Environ. Res. 21(2); 446-457; 1980 .

[18] Fowler, B. A.; Woods, J. S. The effects of prolonged oral arsenate exposure on liver mitochondria of mice: Morphometric and biochemical studies. Toxicol. Appl. Pharmaco1. 50(2); 177-187; 1979 .

[19] Fluharty, A. L.; Sanadi, D. On the mechanism of oxidative phosphorylation II. Effects of arsenite alone and in combination with 2,3-mercaptopropanol. J. Biol. Chem. 236(10); 2772-2778; 1961 .

[20] Crane, R. K.; Lipman, R. The effect of arsenate on aerobic phosphorylation. J. Biol. Chem. 20(1); 235-243; 1953.

[21] Matlib, M. A.; Srere, P. A. Oxidative properties of swollen rat liver mitochondria. Arch. Biochem. Biophys. 174(2); 705; 1976.

[22] Woods, J. S.; Fowler, B. A. Altered regulation of mammalian hepatic heme biosynthesis and urinary porphyrin excretion during prolonged exposure to sodium arsenate. Toxicol. App1. Pharmacol. 43(2); 361-371, 1978 .

[23] Nordberg, G. F. ed. Factors influencing metabolism and toxicity of metals: A consensus report by the task group on metal interaction. Environ. Health Perspect. 25; 3-41; i 978 .

[24] Ridlington, J. W.; Winge, D. R.; Fowler, B. A. Long-term turnover and stability of cadmium-metallothionein following an initial low dose in rats. Biochim. Biophys. Acta. 673(2); 177-183; 1981 .

[25] Fowler, B. A.; Kimme1, C. A.; Woods, J. S.; McConnel1, E. E.; Grant, L. D. Chronic low level lead toxicity in the rat. III. An integrated toxicological assessment with special reference to the kidney. Toxicol. Appl. Pharmacol. 56(1); $59-77 ; 1980$.

[26] Oskarsson, A.; Squibb, K. S.; Fowler, B. A. Subcellular binding of ${ }^{203} \mathrm{~Pb}$ in rat kidneys - detection of a low molecular-weight cytosolic lead-binding component. The Toxicologist $1 ; 81 ; 1981$. 
[27] Goyer, R. A.; Kral1, A. R. U1trastructural transformation in mitochondria isolated from kidney of normal and lead-intoxicated rats. J. Cell Biol. 41(2); 393-400; 1969.

[28] Victery, W.; Vander, A. J.; Mouw, D. R. Effect of acid-base status on renal excretion and accumulation of lead in dogs and rats. Amer. J. Physio1. 237(5); F398-F407; 1979 .

[29] Fowler, B. A.; Taylor, J. A.; Oskarsson, A. Compartmental binding of Pb in rat kidney mitochondria: The relationship to respiratory function and ethidium bromide binding. Fed. Proc. 40(3398); 828; 1981.

[30] Parizek, J.; Ostadalova, I. The protective effects of small amounts of selenite in sublimate intoxication. Experientia 23(2); 142-143; 1967.

[31] Mahaffey, K. R.; Fow]er, B. A. Effects of concurrent administration of dietary lead, cadmium, and arsenic in the rat. Environ. Health Perspec. 19; 165-171; 1977.

[32] Fowler, B. A.; Mahaffey, K. R. Interactions between lead, cadmium, and arsenic in relation to porphyrin excretion patterns. Environ. Health Perspec. 25; 87-90; 1978.

Discussion

Question (M. A. Anderson): Do you do autoradiography, and label the lead? Perhaps it would be another way of looking at where it is in the cell.

Answer: Yes.

Question (M. A. Anderson): Is it a very difficult technique? I'm interested in techniques.

Answer: The problem is resolution and the energy of the isotope used. If it is a particular high-energy isotope, the resolution of a section of tissue would not be particularly great. We don't know if we have a grain there, if it came from here, or over here in terms of where it ultimately wound up. With metal isotopes this generally is the case. You can do this at the light microscope level and you will see that some cells have lead and other cells don't. What we have found, and I think what may be more reasonable in the case of lead, would be to use energy dispersive analysis or x-ray mapping. You can get sufficient excitation of this element in the biological tissue. That in itself is another story. 
Question (M. A. Anderson): Most of these are done by separating the various fractions by centrifugation?

Answer: Yes. What is done here, for those of you who are not in biochemistry, is essentially to homogenize the tissue and then centrifuge out different compartments and different organelles in a sucrose gradient, and then analyze it for either the metal or the isotope.

Question (M. A. Anderson): We thought about doing that and then further speciating that part--arsenic species in each compartment.

Answer: That has not been done. I would like to see somebody do something like this. 
Development of A Methodology to Assess Organometa11ic Effects on Bioenergetic Systems

Lester Packer and Rolf J. Mehlhorn

Membrane Bioenergetics Group,

Energy and Environment Division Lawrence Berkeley Laboratory, University of California, Berkeley, CA 94720.

A methodology for assessing the impact of subacute concentrations of organometallic agents on bioenergetic and oxidative damage processes in animals, cells and energy transducing subcellular organelles is described. Several of the assays are noninvasive and thus lend themselves to human tests. At the wholeanimal level we utilize a treadmill chamber where physiological parameters of exercising animals are monitored. These include parameters of whole animals' work performance such as oxygen consumption, carbon dioxide evolution and endurance. Oxidative damage can be monitored in experiments by analyzing expired air of the animals for ethane and n-pentane. These alkanes correlate with lipid peroxidation in vivo. At the cellular and subcellular levels, respiratory activity, lipid peroxidation and free radical species are assayed. Respiratory activity is measured in muscle homogenates and isolated mitochondria using substrates which feed into different segments of the electron transport chain. To demonstrate how these assay procedures correlate, iron deficiency anemia in rats was analyzed. Physiologically, iron deficiency caused a $90 \%$ decrease in endurance which correlated with an $80 \%$ decrease in pyruvate-malate oxidation rates in muscle homogenates. Significant but smaller effects were seen in hemoglobin/hematocrit levels ( $50 \%$ decrease) and in maximal oxygen consumption ( $50 \%$ decrease). Tissue free-radical signals observed by ESR at room temperature increased with exercise. Respiratory organelles have been shown to be a major source of endogenous freeradicals which initiate tissue oxidation; hence it is plausible that our exercise system will aggravate the effects of organometallics which act as pro-oxidants and that the proposed animal exercise system may be particularly appropriate for evaluating the potential impact of these substances on humans.

Key words: animal toxicity; breath analysis; endurance; free-radicals; iron; organometalloid toxicity; pentane; respiration.

\section{Introduction}

Much is known about acute toxicity mechanisms of hazardous substances in the environment. Our knowledge of the biological effects of chronic exposure is relatively sparse, yet, as our understanding of human aging, carcinogenesis, and other disease processes evolves, we are becomming increasingly aware that some hazardous substances exert deleterious effects that may not express themselves for years or even decades. Hence, we are discovering a need 
for short-term biological assays that will warn us of such latent harmful agents in the environment. Microbial assays, particularly the Ames test, continue to serve a useful function in screening potential carcinogens, but it is now clear that a significant number of potent carcinogens elude detection with the Ames system. We are presently developing an assay system which will evaluate substances which may not exert their effect directly on DNA, but, rather, may react with other biological target molecules, possibly potentiating carcinogenic agents. A particularly interesting group of substances in this category is chemicals which initiate or promote oxidative free-radical reactions.

There is a strong correlation between oxygen tension and the lifespan potential of human cells in culture [1]. In mammals a linear correlation between inverse metabolic activity and lifespan has been demonstrated provided that tissue levels of the antioxigenic enzyme superoxide dismutase are taken into account [2]. These and other data illustrate the hazard posed to aerobic life by oxygen and respiratory activity. A model of oxidative damage has been evolved. This model focuses upon free radicals as well as the excited singlet species as being responsible for the destructive effects of oxygen. Endogenous free radicals, arising during normal respiratory activity are viewed as the initiators of free-radical chain reactions in which a variety of biomolecules are oxidized. Antioxidants like vitamin $E$ protect against such damage by terminating free-radical chain reactions. Other protective mechanisms in cells include three enzymes: catalase, which decomposes hydrogen peroxide and thus eliminates a potential source of hydroxyl radicals; superoxide dismutase, which decomposes superoxide radicals; and glutathione peroxidase, which decomposes both organic hydroperoxides and hydrogen peroxide. Within the framework of this model of oxidative damage, chronic effects of hazardous substances would be manifested in terms of interfering with cellular protective machinery or by acting as initiators of oxidative reactions.

\subsection{Mechanisms of Metal Toxicity}

A brief survey of toxicity mechanisms of metals and metalloids reveals a prevalence of mitochondrial and oxidative reactions. For example, mercury is a potent sulfhydryl reagent. Methylmercury ion has been shown to inhibit coupled mitochondrial respiration [3] and to cause the appearance of characteristic porphyrin precursors in the urine of treated animals [4]. Selenium also reacts with sulfhydryl groups, possibly acting as a crosslinking reagent in the formation of selenotrisulfides [5]. Selenium also has the potential to substitute for sulfur within essential amino acids [6], thus causing possible errors in protein structure. Arsenicals exert destructive effects in at least two ways: inorganic pentavalent arsenates compete with phosphate in a number of biosynthetic reactions [7], including oxidative phosphorylation. Trivalent arsenic is a sulfhydryl reagent, having been shown to combine particularly avidly with lipoic acid [8] of the pyruvate dehydrogenase enzyme complex. Thus, arsenicals interfere with respiratory energy coupling mechanisms. Trialkyltin compounds act as lipid-soluble, ion-pair formers with anions $[9,10]$ and thus exert their toxic action in cells by exchanging chloride ions for hydroxyl ions. In mitochondria this causes $\mathrm{pH}$ gradients to collapse and thus interferes 
with energy-coupling mechanisms. These examples of metal toxicity illustrate the prevalence of reactions that interfere with mitochondrial metabolism and thus strengthens our assertion that aerobic metabolic functions are an excellent assay system for potential destructive effects of hazardous metals and metalloids in the environment.

An example of an environmental agent of concern, particularly with the probable forthcoming exploitation of oil shale resources, is arsenic. Epidemiological studies strongly implicate arsenic as a carcinogenic agent, yet no definitive studies have demonstrated that arsenic compounds can cause cancer in laboratory animals, despite extensive experimentation [11]. Thus it may well be that arsenic acts as an agent that potentiates the action of other carcinogens, perhaps by promoting oxidative reactions.

The assay system we are developing will examine the antioxigenic potential of a biological system. This antioxigenic potential will be stressed by means of the relatively harmless protocol of forced exercise. In this preliminary report we describe one example of how our assay system is used - that of iron deficiency anemia.

2. Procedures, Results and Discussion

\subsection{Whole Anima1 Studies}

Physiological parameters are measured in environmentally controlled exercise chambers for rodents. The animals are forced by means of electric prods at the rear of the chamber to run on a treadmill which moves at a predetermined rate. The chamber currently in use (access generously provided by Professor Brooks of the Exercise Physiology Laboratory with whom we are collaborating) is equipped for measuring oxygen consumption, carbon dioxide evolution and electrocardiograms. It is planned to construct modified chambers which will provide opportunities for collecting substance in the air expired by the animals using a cold-finger trap. Of particular interest is pentane, which is a breakdown product of peroxidized polyunsaturated lipids and volatile metabolites of metalloid substances ingested by the animals. Pentane evolution from mammalian lungs (but not necessarily originating in the lung) has been shown to be correlated with the vitamin E status of animals and to increase with exercise. A physiological parameter which has proven useful as an indicator of whole-animal integrity is maximum endurance, i.e., the time required for an animal to become totally exhausted as a result of running on a treadmill at submaximum speed. Another useful parameter is response to exercise training. As shown in the Table, endurance can be increased about five-fold by training in unstressed rats.

Table: Effect of Endurance Training

\begin{tabular}{lllll}
\hline Group & $\begin{array}{l}\text { Mitochondrial } \\
\text { Content of } \\
\text { Muscle, } \mathrm{mg} / \mathrm{g}\end{array}$ & $\begin{array}{l}\text { Muscle Cyto- } \\
\text { chrome oxidase } \\
\text { moles/min/g }\end{array}$ & $\begin{array}{l}\mathrm{VO}_{2} \mathrm{max} \\
\mathrm{mg} \mathrm{kg}-1 \cdot \mathrm{min}^{-1}\end{array}$ & $\begin{array}{l}\text { Maximal } \\
\text { Endurance }\end{array}$ \\
\hline Control & $18.2 \pm 0.7$ & $37.4 \pm 3.1$ & $76.6 \pm 1.2$ & $36.3 \pm 2.2$ \\
$\begin{array}{l}\text { Endurance } \\
\text { Trained }\end{array}$ & $36.2 \pm 1.6 *$ & $75.9 \pm 5.4 *$ & $87.7 \pm 2.0 *$ & $182.6 \pm 10.4 *$ \\
\hline
\end{tabular}

$* \mathrm{P}<0.01$ controls vs. endurance trained (t-test), $\mathrm{n}=10$. 
Summary -- $100 \%$ increase in mitochondrial content of muscle, $100 \%$ increase in muscle oxidative capacity, $14 \%$ increase in $\mathrm{VO}_{2} \max , 403 \%$ increase in endurance. Thus endurance is highly correlated with mitochondrial content of muscle, and muscle oxidative capacity but only moderately correlated with $\mathrm{VO}_{2}$ max. Endurance training provides a useful and physiologic tool for the study of muscle energetics and whole-animal respiration.

\subsection{Tissue, Cellular and Subcellular Studies}

Respiratory activity of tissue, particularly muscle homogenates, is performed in a Clark-type electrode using succinate and pyruvate-malate as substrates. A full battery of bioenergetic parameters, including respiratory control and $\mathrm{VO}_{2}$ max, is measured. Similar assays are conducted with mitochondria isolated from these tissues. Mitochondrial yields are related to muscle weight. Lysosomal membrane integrity is evaluated with latency assays of intralysosomal enzymes. Lipid peroxidation is measured by means of the thiobarbituric acid procedure [12]. Endogenous free radicals are monitored both in tissue and homogenates with room temperature EPR techniques. The status of protective enzymes and antioxidants in isolated mitochondria is evaluated by detecting free radicals with nitroxide and nitrone spin traps under conditions where free-radical reactions are induced with exogenous initiators.

\subsection{Effect of Iron Deficiency on Endurance Capacity and Respiratory Activity}

Iron deficiency anemia in rats was used as a model system to study the correlation between physiological dysfunction and subcellular bioenergetic parameters [l3]. It was of interest to determine whether gross, noninvasive exercise parameters might yield evidence of tissue damage of comparable sensitivity to measurements of respiratory enzyme activities.

Rats were made anemic by means of dietary iron deficiency over a period of three weeks. The blood hematocrits of the deficient rats were about $20 \%$ compared to those 'of normal rats with $40 \%$ hematocrits. The most striking effect of iron depletion was a $90 \%$ reduction in the endurance capacity, $i . e .$, the time period that endurance trained rats ran until total exhaustion. A comparable but less dramatic decline was seen in the pyruvate-malate oxidation rates, where an $80 \%$ reduction was seen for muscle homogenates and a $70 \%$ decline was noted for isolated muscle mitochondria. Whole animal maximal oxygen consumption, $\mathrm{VO}_{2}$ max, diminished by $50 \%$. When hematocrits of the deficient rats were increased by means of blood transfusion, $\mathrm{VO}_{2}$ max values reached nearly normal levels whereas no significant changes occurred in endurance capacities. The latter result demonstrated that oxygen utilization at the level of the respiratory chain rather than oxygen delivery via hemoglobin was limiting in endurance capacity (see accompanying Figure). 

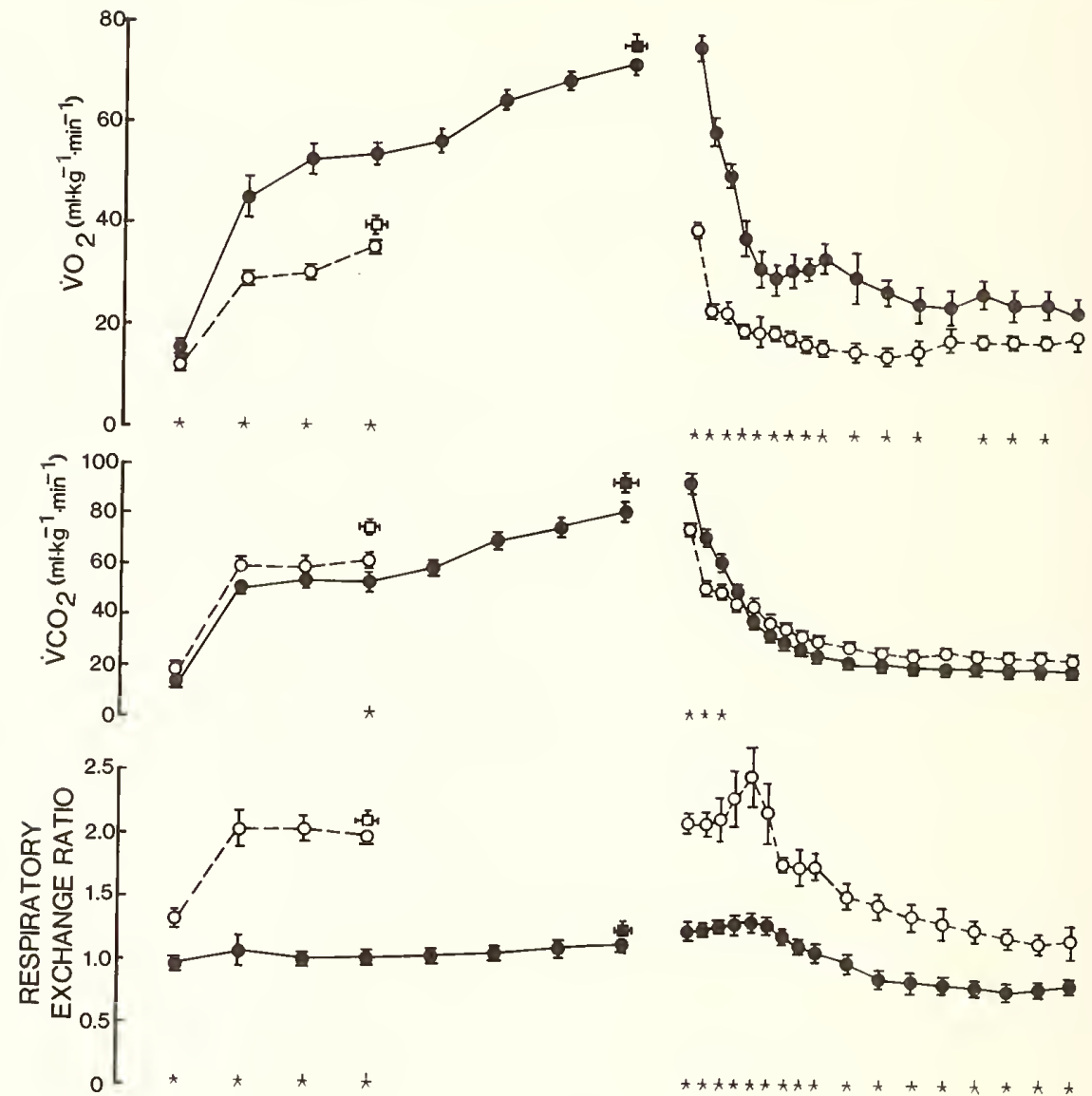

क्षा गे
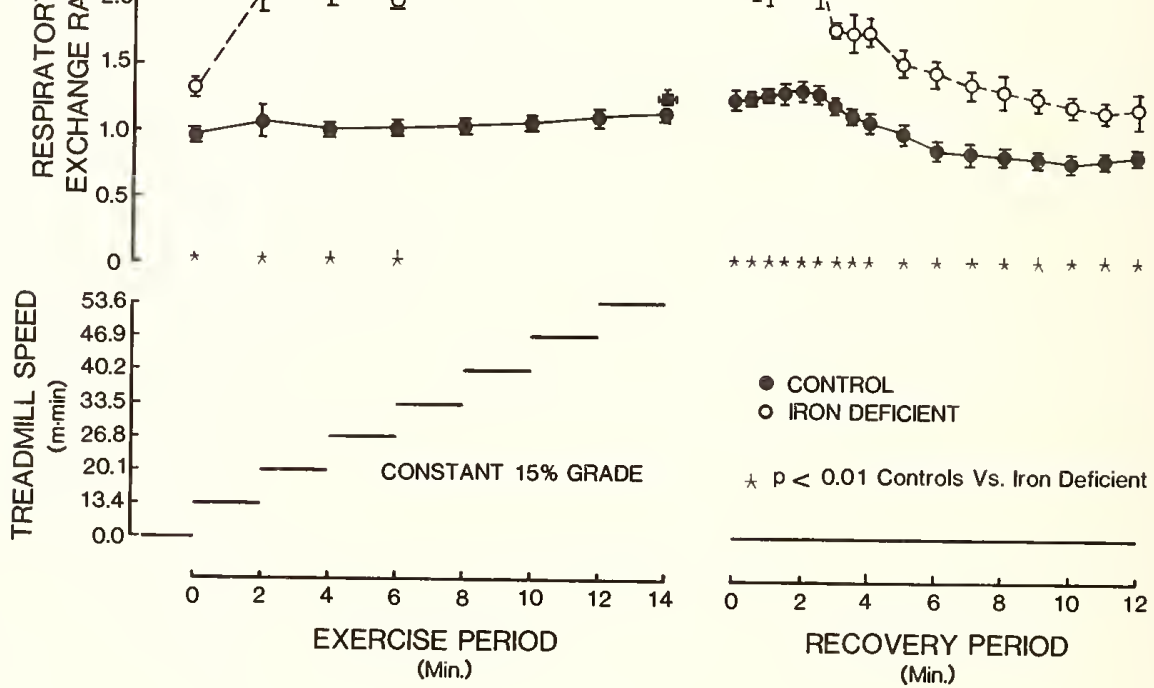

* $p<0.01$ Controls Vs. Iron Deficient

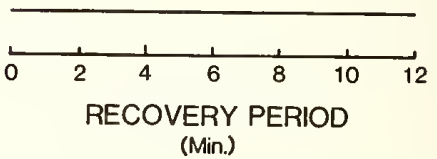

FIGURE. Demonstration that exercise enhances the effects of iron depletion upon $\mathrm{VO}_{2}$ and the respiratory exchange ratio. A substantial reversal of these enhancements occurs within a few minutes of subsequent rest [14]. 
2.4 Relationship Between Exercise, Vitamin E Status, Free-Radical Signals and Damage

Vitamin E is a lipid soluble antioxidant which is found in biological membranes. Dietary vitamin E manipulations have provided an important tool for demonstrating suspected free radical reactions involving membranes. Usually the most effective procedure for testing in vivo free radical involvement is to compare vitamin E-deficient animals with supplemented ones, since normal diets contain adequate concentrations of this vitamin. In the study described below, such animals were used to examine the correlation between vitamin E status, exercise and damaging free-radical reactions.

Two groups of rats, a control group and another group which had been fed a vitamin E-deficient diet for six months were forced to run in the exercise chambers to exhaustion [15]. The control group had about twice the endurance of the deficient rats. Both liver and muscle homogenates exhibited larger free-radical ESR signals in the exercised rats than in non-exercised animals, regardless of vitamin E status. Results in non-homogenized tissues were similar and free-radical signals varied in intensity over a range of about three among the different preparations. Lipid peroxidation. respiratory activity and lysosomal latency all revealed a correlation between increased free-radical signal tissue damage. Concerning the effect of vitamin E deficiency, the most marked effects were increased lipid peroxidation and a greater fragility of lysosomal membranes as reflected in in decreased latency of alkaline phosphatase activity in the deficient rats.

These results show that the stress of forced exercise exacerbates free-radical mediated tissue-oxidative processes and lends credence to our proposal that this regimen will enhance the biological effects of organometallics.

2.5 Susceptibility of Tissue to Free Radical-Attack

Our recent ESR data suggests that increased metabolic activity during exercise gives rise to increased generation of endogenous free radicals. Thus a number of oxidative reactions are likely to be promoted during exercise, as has been shown for evolution of pentane during lipid peroxidation in the lung. Therefore pentane production is expected to increase as a function of exercise duration. During the course of these oxidative reactions the antioxidant defenses of tissues will be progressively depleted and hence their susceptibility to further oxidative ractions will be increased. In view of these considerations cellular studies of free radical propagation may also provide sensitive assays of organometallic damage.

To study tissue susceptibility to free radical attack isolated mitochondrial preparations will be treated with free-radical initiators. Subsequent propagation reactions will be assayed with nitrone and nitroxide free-radical traps [16] and by means of the TBA assay for lipid peroxidation. The extent of free radical propagation caused by these initiators will provide a measure of the antioxidant status of the tissue.

2.6 Relationship of Iron Deficiency Study to Organometallic Toxicity Assays

Organoarsenicals and perhaps other organometallics react chemically with sulfhydryl compounds in the mitochondrial enzyme pyruvate dehydrogenase. The iron deficiency study 
revealed a good correlation between loss of pyruvate-malate oxidation rates and maximum endurance, suggesting that endurance capacity might be similarly impaired when animals are exposed to certain organometallics. This suggestion is being tested in the exercise system. The coupling of exercise to the measurement of alkanes and organometalloids in breath expired by animals and humans offers a new biological assay system which may provide sensitive information about biological damage occurring during exposure to subacute doses of hazardous environmental agents. Further detailed information which is required for an understanding of the biological transformations of metalloids and hence their toxicity mechanism is the chemical speciation of these expired substances by means of state-of-theart chromatography with element-specific detectors.

This work was supported by the Assistant Secretary for Environment, Office of Health and Environmental Research, Life Science Division of the U.S. Department of Energy under Contract No. W-7405-ENG-48.

\section{References}

[1] Packer, L.; Fuehr, K. Low oxygen concentration extends the lifespan of cultured human diploid cells. Nature 267: 423-425; 1977.

[2] Tolmasoff, J.M.; Ono, T.; Cutler, R. G. Superoxide dismutase: Correlation with 1ifespan and specific metabolic rate in primate species. Proc. Nat1. Acad. Sci. USA 77: 2777-2781; 1980 .

[3] Fowler, B. A. ; Woods, J. S. The transplacental toxicity of methyl mercury to fetal rat 1 iver mitochondria. Lab. Invest. 36: 122-130; 1977.

[4] Woods, J. S.; Fowler, B. A. Renal porphyrinuria during chronic methyl mercury exposure. J. Lab. Clin. Med. 90: 266-272; 1977.

[5] Painter, E. P. The chemistry and toxicity of selenium compounds with special reference to the selenium problem. Chem. Rev. 28: 179-213; 1941.

[6] Godwin, K. 0.; Fuss, C. N. The entry of selenium into rabbit protein following the administration of $\mathrm{Na}_{2}{ }^{75} \mathrm{SeO}_{3}$. Austral. J. Biol. Sci. 25: 865-871; 1972.

[7] Doudoroff, M. ; Barker, H. A. ; Hassid, W. Z. Studies with bacterial sucrose phosphorylase: III arsenolytic decomposition of sucrose and of glucose-1-phosphate. J. Biol. Chem. 170: 147-150; 1947.

[8] Peters, R. A.; Rydin, H.; Thompson, R. H. S. The relation of pyruvic acid in brain to certain tissue poisons. Biochem. J. 29: 63-71; 1935.

[9] Wieth, J. 0.; Tosteson, M. T. Organotin-mediated exchange diffusion of anions in human red cells. J. Gen. Physiol. 73: 765-788; 1979.

[10] Tosteson, M. T.; Wieth, M. T. Tributyltin-mediated exchange diffusion of halides in lipid bilayers. J. Gen. Physiol. 73: 789-799; 1979.

[11] Fraumeni, J. F. Jr. Respiratory carcinogenesis: an epiodemiologic appraisa?. J. Nat. Cander Inst. 55: 1039-3046; 1975.

[12] Buege, J. A.; Aust, S. D. Microsomal lipid peroxidation in methods in enzymology, Vol. 52. S. Fleischer and L. Packer, eds. New York: Academic Press; 1978. 302-310. 
[13] Davies, K. J. A.; Donovan, C. M.; Refino, C. J.; Brooks, G. A.; Packer, L.; Dal1man, P.R. Iron deficiency and work capacity: distinguishing the effects of anemia and muscle iron deficiency on exercise bioenergetics in the rat. J. Clin. Invest., submitted.

[14] Davies, K. J. A.; Maguire, J. J. ; Brooks, G. A.; Dallman, P.R.; Packer, L. Muscle mitochondrial bioenergetics, oxygen supply, and work capacity during dietary iron
deficiency and repletion. Am. J. Physiol., submitted.

[15] Davies, K. J. A.; Quintanilha, A. T.; Brooks, G. A.; Packer, L. Does exercise produce damaging free radicals? Nature, submitted.

[16] Janzen, E. G. A critical review of spin trapping in biological systems, in Free radicals in biology, W. A. Pryor, ed. New York: Academic Press; 1980. 115-154.

\section{Discussion}

Question (R. E. Sievers): An obvious conclusion from your talk would be if you want to live longer, you lay flat and breath shallow?

Answer: There have been no good studies done on longevity and exercise, except in insects. In insects it is very clear, all you have got to do is blow some air on an insect and they will fly. Or you can raise their temperature. Since insects have no temperature regulatory mechanism; the higher the temperature the more the insects will metabolize. That is inversely related to their life span. Of course, most of their oxygen consumption occurs in insect flight muscle. So it's a muscle problem again does that happen in man? We don't know. The only studies that have really been done, have been done with athletes. A couple of years after they finish school they are all lethargic and they don't keep up exercising, so they are not a good population to study. Probably the best population to ask is Norwegians or Scandinavians who ski throughout their lives and are generally active throughout life. Such studies have not been done. So we really don't know, but people do feel better if they exercise and that is very important.

Question (J. D. Walker): After you determined that the sprint-trained rats did not have greater endurance, did you test them for their ability to run faster? If you train rats for endurance, they are going to naturally have greater endurance but if you necessarity train them for shorter runs they aren't necessarily going to run faster.

Answer: Their $\mathrm{VO}_{2}$ max which is determined by progressively increasing the work load is exactly the same. They can work at no higher work loads than the sprint-trained animals. The stimulation of oxygen consumption in the two animals, the total simulation that can be obtained, just below the maximum work load, is the same.

Question (R. J. MehThorn): You have mentioned pentane in your talk, could you go into this a little bit? 
Answer: Pentane and other gases like ethane are decomposition products of lipids. Lipids, of course, are mainly in biological membranes and one of the main processes involved in oxidative damage is decomposition of lipids. The importance of the pentane and ethane is that you can determine the decomposition of lipids at the level of the whole animal by evaluating how much of these appears in the breath. Even though only one percent of the carbon as a result lipid peroxidation ends up in pentane or ethane, depending on what kind of fatty acid it is, the test is very sensitive. So you can monitor the generation of free radicals in the intact body. It doesn't tell you where in the body these are coming from, but there are other ways to find that out. We can certainly relate it to exercise, and it is known that during exercise that the amount of pentane that comes out in the breath is increased by about 2- to 3-fold. 
Duality of Concern with Trace Metals in the Environment-Toxic and/or Essential

Wayne R. Wolf

U.S. Department of Agriculture, Nutrient Composition Laboratory Beltsville Human Nutrition Research Center, Human Nutrition

Science and Education Administration, Beltsville, Maryland 20705

Both health science professionals and the general public express a high level of concern with exposure levels of "trace" metal containing substances in the environment. Although a great portion of this concern has been with the potential toxic or detrimental effects of exposure to these substances, a countering body of concern has developed regarding the nutritional or positive biological effects of a number of the "trace" elements. This duality of concern encompasses a widely overlapping list of elements. The same "trace" element can exhibit multiple biochemical roles from detrimental deficiency effects at very low levels of exposure, to beneficial optimal nutritional levels, to toxic effects at higher levels. These different biochemical roles can depend not only upon the absolute level of exposure, but also upon the interactions with varying levels of exposure of other nutrients or hazardous substances. These differing roles also depend strongly upon the differing forms or species of the element present. Levels of exposure, biotransformations, and interactions of these species must be understood, quantitated, and monitored before knowledgable recommendations on cleaning-up "toxic" elements or supplementing "nutritional" elements can be made, especially for these elements of dual concern.

Key words: environmental; essential elements; speciation; toxic; trace elements.

There is an increased awareness, concern, and public health interest of the biological role of micro or trace inorganic elements. These public health interests arise on one hand from the toxicological concerns regarding exposure to detrimental levels of trace elements. Examples of these concerns regarding energy related areas have been discussed in other papers in these proceedings. Additional examples are: lead in paint, cadmium and other heavy metals in plants grown on soil treated with sewage sludge, and mercury in water or fish. On the other hand, public health interests also arise from concerns of underexposure or subadequate intake of essential trace elements. Examples of this are the widespread incidence of iron deficiency anemia in the U.S., the rapidly increasing clinical concerns with recognized and potential zinc deficiency, and a widening general concern with potential inorganic deficiencies of other trace elements such as copper and chromium.

In the not too distant past, these two concerns were usually expressed and studied by two separate groups. The environmentalists/toxicologists reported cases of high levels of exposure resulting in detrimental or tragic public health situations. These cases were used as examples to indict lower and lower levels of exposure of these "toxic" metals as 
their analytical techniques and expertise improved. Another group, the nutritionists, have historically studied the trace elements shown or suspected to be "essential" or required for life. They have routinely expressed concern that the levels of intake are not adequate for many of these elements and that potentially marginally deficient intakes may exist. often these two groups were concerned with the same elements. Table 1 lists the elements considered to be of nutritional interest in humans and/or animals and those elements which enviornmentalists consider to be of potentially toxic interest.

Table 1. Micro inorganic elements of interest in human health

\begin{tabular}{ll} 
Nutritional $^{\mathrm{a}}$ & \multicolumn{1}{c}{ Toxic $^{\mathrm{b}}$} \\
\hline As, Co, Cr, Cu, F, & As, Be, Cd, Co, Cr, \\
Fe, I, Mn, Mo, Ni, & F. Hg, Mn, Mo, Ni, \\
Se, Si, Sn, V, Zn, & Pb, Pd, Se, Sn, Tl, \\
\hline
\end{tabular}

\footnotetext{
a Adapted primarily from [1]

b Adapted primarily from [2]
}

This duality of interest between beneficial and harmful effects of micro inorganics in food is evidenced by the specific examples of the elements selenium, arsenic, and chromium. The element selenium had been regarded only as a toxic substance responsible for conditions such as alkali disease in livestock [3]. Nutritionally beneficial aspects of Se were documented with the report in 1957 of a dietary role for Se in rats [4] and later reports of desirable effects and biological functions in other animal species [5]. Recent works from New Zealand [6] and the Peoples Republic of China [7] have shown beneficial effects of Se supplementation for persons thought to be consuming Se-deficient diets. Indeed, the recent reports from China have indicated the possibility of both Se-toxic and Se-deficient populations in separate regions resulting from local consumption of foods grown on soils with differing levels of Se. Careful definition of the Se content of the foods in these different regions would be very important in formulating public health measures to prevent either deficiency or toxicity in these situations.

The element arsenic has been known for a very long time to be quite toxic and has a long illustrious history in use as a poison, both fictionally and in reality [8]. It has also been known for a long time that arsenic in the diet protected against selenium toxicity $[9,10]$. Recent reports have established the essentiality of arsenic in several species of animals [11]. Suggestions have been made that the arsenic levels in human diets are dropping with time, although this trend may reflect improvements in analytical methodology [12]. While the evidence is certainly not yet conclusive for the essentiality and potential deficiency of arsenic in man, there is a growing biochemical-nutritional interest in this "trace" element and a challenge to analytical methodology to accurately measure lower and lower levels of As in foods. 
The element chromium has been shown to be beneficial in human metabolism and cases of $\mathrm{Cr}$ deficiency and response to $\mathrm{Cr}^{3+}$ supplementation have been reported $[13,14]$. On the other side of the chromium coin, toxicological effects have been observed following industrial exposure to high levels of $\mathrm{Cr}^{6+}$ [15]. These incidences of high level exposures have in some cases indicated $\mathrm{Cr}$ as a "bad" element and periodically generate a "demand" for analytical methods to analyze $\mathrm{Cr}^{6+}$ content of foods, even though no evidence has been shown that $\mathrm{Cr}^{6+}$ exists in the presence of organic material which readily reduces $\mathrm{Cr}^{6+}$ to $\mathrm{Cr}^{3+}$. Chromium in the $3+$ oxidation state has not been shown to have any harmful effects. More and more knowledge is becoming available regarding a wide range of biological and metabolic interactions between micro elements. In addition to the example of arsenic protection against selenium toxicity cited above, a complex network of reported interactions has been cited $[16,17]$. Protective interactions of some essential elements with toxic elements might be attributed to competition for binding sites on ligands involved in homeostatic capabilities.

Other examples of interactions are: 1) the exaggeration of lead toxicity as a consequence of deficiencies of calcium, phosphorus, iron, zinc, and in some cases, copper [18]; 2) the interaction and protective effects of selenium with mercury $[19,20]$; 3) interactions of zinc, selenium and cadmium [21]. These are only a few of the many reported interactions which have been detailed in the proceedings of a recent symposium on this topic [22].

Many of these interactions between elements and the movement of these elements through the environment depend upon the chemical species or form of the element. For example, the element selenium can exist in soils as elemental selenium ( $\mathrm{Se}^{0}$ ), as selenites ( $\mathrm{Se}^{4+}$ ), as selenates $\left(\mathrm{Se}^{6+}\right.$ ), or bound to heavy metals as the selenide ( $\mathrm{Se}^{2-}$ ). Each of these species can react differently in movement from soil through plants and animals in the environment. Some of the species, such as insoluble elemental selenium, are not as "biologically active" or must be biochemically changed to more active species before utilization [3]. In biological and metabolic pathways, selenium can be incorporated or bound to a number of amino acids, protein or other organic compounds, and act in a variety of mechanisms such as its role as a component of glutathione peroxidase [23]. Some of these organoselenium species are "biologically active" while others such as the methylselenides are volatile and excreted through exhalation. The biochemistry of these species is complicated by their interactions with other metals. For example, the relatively non-toxic species dimethylselenide has been observed to demonstrate a synergistic toxicity with certain mercuric salts leading to toxic effects greater than either substance alone [20].

Knowledge of the mutiple biochemical roles of the micro inorganic elements, from a very low level deficiency state, to adequate beneficial nutritional levels, to harmfully toxic pharmacological effects at higher levels, has brought a more general awareness of the overall role of these elements in man. This awareness has generated a need to much more closely define their levels of exposure and intake. It is no longer sufficient to merely identify the presence of these elements or to say that a "trace" exists. The exact levels must be defined and the variations in these levels quantitated. 
These multiple biochemical roles and levels of action have been recognized in the latest edition of the Recommended Dietary Allowances [24] which recommend ranges of estimated safe and adequate intakes of selected inorganic elements (Table 2). Implied in these recommendations for a range of intakes is the concept of lower limits for adequate intake and upper limits for safe intakes. For many of the trace elements there is insufficient information to precisely define these adequate and safe levels.

Table 2. Estimated safe and adequate daily diętary adult intakes of selected inorganic elements ${ }^{a}$

\begin{tabular}{lc}
\hline Element & Recommended Daily Intakes, mg \\
\hline Copper & $2.0-3.0$ \\
Manganese & $2.5-5.0$ \\
Chromium & $0.05-0.20$ \\
Selenium & $0.05-0.2$ \\
Molybdenum & $0.15-0.5$ \\
\hline
\end{tabular}

a Adapted from [24]

Since the major exposure of these elements to humans comes through the intake of food, a complete, accurate and quantitative knowledge of the levels and variation of the micro elements in foods is required. Data on micro inorganic composition of foods are used for a wide variety of purposes. From a toxicological point of view, food composition data are used to identify and quantitate actual or suspected exposures leading to acute clinical or longer term sub-clinical effects in man. Identification and quantitation of levels and sources of exposure are necessary to formulate recommendations, policies and actions to prevent future exposure to harmful levels through the food. A good knowledge of levels and sources is also necessary in order to study the metabolic and biochemical consequences of exposure to these elements and to make valid assessments of the risks involved in exposure to these ubiquitously occurring elements. From the nutritional point of view, nutrient composition data are used by dietitians and nutritionists formulating clinical or institutional dietaries, by policy planners in large scale governmental food programs such as school lunch or the WIC program; by the food industry in required and voluntary labeling of foods; by nutrition research professionals carrying out research into the metabolic and biochemical effects of these elements in the diet; and by government and state agencies for regulatory purposes.

The ultimate goal of ascertaining and providing for optimum nutrition of the human population rests upon a sound basis of knowledge in several areas [25]: 1) a complete understanding and knowledge of the requirements of humans for a 11 the nutrients; 2) a complete and accurate knowledge of the nutrient composition of and the flow of nutrients through the food supply consumed by the population; 3 ) readily available sources of appropriate foods that are safe and free from harmful constituents either naturally occurring or introduced during growth, processing, transportation or marketing. A complete, accurate, 
useful base of nutrient composition data requires that it contain only good quality analytical data for each individual food and nutrient. It also requires that the data be comprehensive in describing and being representative of the foods actually consumed by the population. At the present time, the extent and quality of available knowledge and analytical data on composition of foods is not completely satisfactory for any of the micro inorganic elements.

A recent assessment of the state of knowledge of micro inorganic nutrient composition of foods showed that when some 37 different food commodities or categories were considered only iron ( 10 commodities), zinc ( 7 commodities) and copper ( 6 commodities) were shown to have substantial data available in any of the categories [26]. The other commodities had either inadequate or little to no data available for these three elements. All of the other nutrient micro elements assessed, namely chromium, selenium, iodine, fluorine, manganese, nickel, cobalt, silicon, tin and vanadium, had little or no data available. The availability of data for individual foods on toxic elements such as cadmium, lead, mercury, antimony, and others is certainly not much better. These insufficiencies in the available data are due to several factors, including deficiencies in the analytical methodologies available to produce the data.

Only within the last twenty years have many of the elements of concern today been of interest. Alsu only within the past twenty years have analytical technique and procedures become sensitive and selective enough to measure these elements more than qualitatively or at "trace" levels. In fact, the terminology "trace" element has become scientifically imprecise in light of today's sophistication in analytical techniques and knowledge of the complexities of the metabolism and biochemical interactions of these micro elements. The recognition of both harmful and beneficial roles for the same element at different levels require a much more precise quantitation of levels in foods. For some of these elements the analytical techniques are available for this definition of food levels (Table 3). They remain to be applied in concerted large scale studies on a wide varieties of foods.

Table 3. Assessment of analytical methodology for routine analysis of micro inorganic elements in foods

State of Methodology ${ }^{a}$

Adequate

Can give reliable data at low cost, short time

Substantia]

Can give reliable data at

high cost and/or long time

\section{Element}

Iron

Zinc

Copper

Manganese

Chloride

Selenium

Mercury

Lead

Cadmi um 


\section{Conflicting}

No good agreement between

separate reports of data

Inadequate

Consensus disagreement
Iodine

Chromium

Tin

Vanadium

Arsenic

Fluoride

Cobalt

Nickel

Molybdenum

a Methodology assessment adapted from [27].

Most of the very sensitive analytical techniques available give information on total amount of the inorganic element present. In the future, more and more interest will be directed to identifying the different chemical species or forms that exist for the element in foods. Analytical quantitation of each species will become more and more important as more knowledge is gained regarding the biological roles of each species. For many of the elements, the level of some particular species, which may be in small proportion to the whole amount, may be far more important, biologically, than the total amount of the element. This points towards the need to develop even more sensitive and more selective analytical methods for metal-containing species in foods and biological samples. Development and application of these analytical techniques will lead to an increase in knowledge exceeding the increase in knowledge of the roles of "trace" elements which has occured in the 1950's and 1960's in conjunction with the growth and development of sensitive analytical spectroscopic techniques, such as atomic absorption spectrometry. Only when the individual species can be identified and quantitated can their metabolic role be studied and understood.

\section{References}

[1] Underwood, E. J. Trace elements in human and animal nutrition, 4th Ed., New York: Academic Press. $19 / 7$.

[2] Monitoring environmental materials and specimanbanking. P. Luepke, Ed. Proceeding Of International Workshop, Berlin, Oct. 1978. Martinus Nijhoff Publishers, The Hague/Boston/London. 1979.

[3] National Academy of Sciences, Committee on Medical and Biological Effects of Environmental Pollutants, Washington, D.C. Selenium (ISBN-0-309-02503-6). 1976.

[4] Schwarz, K. and Foltz, C. M. Selenium as an intergral part of factor 3 against dietary neurotic liver degeneration. J. Amer. Chem. Soc., 79: 3292-3293. 1957.

[5] Stadtman, T. C. Biological functions of selenium. Trends In Biochem. Sci., 5: 203-206. 1980.

[6] Van Rij, A. M., Thompson, C. D., McKenzie, J. M. and Robinson, M. F. Selenium deficiency in total parenteral nutrition. Amer. J. Clin. Nutr., 32: 2076-2085. 1979. 
[7] Keshan Disease Research Group. Observations on effect of sodium selenite in prevention of Keshan disease. Chinese Med. J., 92: 471-476; and Epidemiological studies on the etiologic relationship of selenium and Keshan disease. Chinese Med. J., 92: 477-482. 1979.

[8] National Academy of Sciences, Committee on Medical and Biological Effects of Environmenta] Pollutants, Washington, D.C. Arsenic (ISBN-0-309-02604-0). 1976.

[9] Moxon, A. L. The effect of arsenic on the toxicity of seleniferous grains. Science, 88: 81.1938.

[10] Levander, 0. A. Metabolic interrelationships between arsenic and selenium. Environ. Health Perspect., 19: 159-164. 1977.

[11] Anke, M., Guin, M. and Partschefeld, M. The essentiality of arsenic for animals. In Trace Substances in Environmental Health. Hemphil1, D. D., ed. University of Missouri, Columbia. 10: 403. 1976.

[12] Horwitz, W. Review of commonly used methods of analysis for arsenic in foods. Food and Agriculture Organization Conference Document, EC/MSA/FC/78/9 (Revised Sept. 1978). Rome, Italy. 1978.

[13] Chromium in Nutrition and Metabolism. Vol. 2 in Developments in Nutrition and Metabolism. D. Shapcott and J. Hubert, eds. Amsterdam/New York/ Oxford, Elsevier/NorthHolland Biomedical Press. 1979.

[14] Anderson, R. A. Nutritional role of chromium. The science of the total environment, 17: 13-29. 1981.

[15] National Academy of Sciences, Committee on Medical and Biological Effects of Environmental Pollutants, Washington, D.C. Chromium (ISBN-0-02217-7). 1974.

[16] Sandstead, H. H. Interactions of toxic elements with essential elements: Introduction. in micronutrient interactions: Vitamins, minerals and hazardous elements. Annals of New York Academy of Sciences, 355: 282-284. 1980.

[17] Parizek, J. Interrelationships among trace elements. In effects and dose-response relationships of toxic metals. G. F. Nordberg, ed. Amsterdam/0xford/New York, Elsevier Scientific Publishing Company. 1976. 489-510.

[18] Levander, 0. A. Lead toxicity and nutritional deficiencies. Environ. Health Perspect., 29: 115-125. 1979.

[19] Ganther, H. E. Interactions of vitamin E and selenium with mercury and silver. In Micronutrient interactions: Vitamins, minerals and hazardous elements. Annals of New York Academy of Sciences, 355: 212-226. 1980.

[20] Parizek, J., Ostadalova, I., Kalouskova, J., Babicky, A. and Benes, J. The detoxifying effects of selenium. Interrelations between compounds of selenium and certain metals. in Newer trace elements in nutrition. W. Mertz and W. E. Connatzer, eds. New York, Marcel Dekker, Inc., 1971. 85-122.

[21] Whanger, P. D., Ridlington, J. W., Halcomb, C. L. Interactions of zinc and selenium on the binding of cadmium to rat tissue proteins. in Micronutrient interactions: Vitamins, minerals and hazardous elements. Annals of New York Academy of Sciences, 355: 333-345. 1980.

[22] Micronutrient interactions: Vitamins, minerals, and hazardous elements. Annals of the New York Academy of Sciences, Vol. 355. 1980. 
[23] Rotruck, J. T., Pope, A. L., Ganther, H. E., Swanson, A. B., Hofeman, D. G. and Hoekstra, W. G. Selenium: Biochemical roles as a component of glutathione. Science, 179: 588-590. 1973.

[24] National Research Council. Recommended Dietary Allowances, 9th Revised Edition, National Academy of Sciences, Washington, D.C., 178 p. 1980.

[25] Stewart, K. K. In nutrient analysis of foods: The state of the art for routine analysis, Symposium Oct. 1979, AOAC, Washington, D.C. 1980.

[26] Stewart, K. K. Testimony before the Select Committee on Nutrition and Human Needs of the U.S. Senate, Hearings on Food Quality in Federal Food Programs, Sept. 28, 1977, U.S. Government Printing Office, Washington, D.C.

[27] Wolf, W. R. Inorganic nutrient analysis. in Nutrient analysis of foods: The state of the art for routine analysis, Symposium Oct. 1979, AOAC, Washington, D.C. 64-85. 1980.

Discussion

Question (D. A. Klein): With sulfur and some of the noble metals at low levels you see stimulation of biological activity. Do you see that with any of these types of materials in these test systems?

Answer: Yes, when you get into a marginal state such as this. If the organism is in a marginal state, if you add the element you can get up to the optimum state very definitely. This is one of the main ways that these elements have been shown to be essential. They are put onto very defined food diets where all the elements taken out are those which are made marginally deficient and then brought back up. This is one of the mechanisms of showing or proving that there is a positive effect of these elements.

Question (R. E. Stephens): You made a comment about the incompatability of chromium(VI) and the lack of toxicity of chromium(III). I think there are problems in both of these statements: (1) chromium(VI) is only a strong oxidant at acidic $\mathrm{pH}^{\prime} \mathrm{s}$, and at $\mathrm{pH} 7$ and above, can easily co-exist with organics, and (2) there may not be much literature on human toxicity of chromium(III) but there is a lot of literature on aquatic toxicity. I think many of the concerns, in certain quarters, for environmental hazards come from aquatic toxicity.

Answer: I may not be as familiar with that literature.

Question (E. A. Woolson): Trace elements can exist in many different forms, such as selenate, selenite, arsenate, arsenite, or organic forms. Of course, all these different forms have different bioavailabilities. It has been well documented for the selenium forms. Do you have any thoughts on what forms are required? We have recently done some work with arsenic forms in food products. There is very little inorganic there, it is almost all organically bound. It may not be bioavailable. 
Answer: I don't think it is really possible to make a general statement about all of the elements.

Comment (E. A. Woolson): We could be getting into some severe problems because EPA has recently come out with ambient water criteria for arsenic. Surface waters of a thousand times less than sea water. You would never be able to detect it.

Comment: I would like to make a comment in some aspects of the problem. If we try to clean up the environment as much as the regulations say we would run into a deficiency problem. What I am saying is that we need to define, make these regulations, for both sides of dose-response curves, not just the top side.

Question (R. H. Fish): How does selenium protect against methylmercury poisoning. Could you discuss that a little? Whose mechanism is this?

Answer: I've got a paper here by Howard Ganther [Ann. N. Y. Acad. Sci. 355: 212 (1980)]; I am not a biochemist and, as I said, I really use these as general examples.

Answer (B. A. Fowler): Fundamentally, there are several things that can happen, and I am glad to you brought that up about mercury and selenium. One of the things that happens in kidneys is that there will be complexes formed with mercury-selenium, as with lead, one can find inclusions in the kidney tubule cells. This is a paradoxical thing here that Gunther Parazak, who was probably the first person to identify this [et al. Experimentia. 23: 142 (1967)], found that tissue levels of mercury would be maybe two times what they would be in the case of selenium, but the toxic effects in the kidney would diminish. What it was really telling us is that later from these conclusions people would analyze them by energy dispersive x-ray analysis. We've done this too. It seems what we have is a compound that has atomic ratio of two seleniums to one mercury. That's part of it. I think the other thing, to tie the comments that Dr. Packer made, and that I would make, is that selenium is great for stabilizing membranes in many ways. If you proposed a mechanism that would involve hydrolysis of the membrane somehow influence turnover of the external membrane, then it might be what we are seeing is essentially a protective effect.

Question (R. H. Fish): What functionalities would it be on the membranes; would it form sulfur-selenium bonds?

Answer (B. A. Fowler): That is one possibility. Another is an enzyme called glutathioneperoxidase. This particular enzyme is involved in one of the things the toxicologists are conerned with lately. This is the available pool of glutathione as a conjugated sequestor of reactive materials. Not only metals but other kinds of free radicals seem to be conjugated with glutathione. 


\title{
Analytical and Biochemical Aspects of the Transformation of
} Arsenic and Selenium Compounds into Biomolecules

K. J. Irgolic, C. H. Banks, N. R. Bottino,* D. Chakraborti, J. M. Gennity, *

D. C. Hillman, D. H. O'Brien, R. A. Pyles, R. A. Stockton, A. E. Wheeler and R. A. Zingaro

\author{
Department of Chemistry \\ *Department of Biochemistry and Biophysics \\ Texas A\&M University, College Station, Texas 77843
}

Marine algae take up arsenic (selenium) when grown in a medium containing

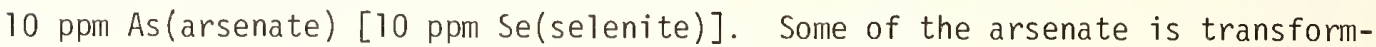
ed into an arsenic-containing lipid. Selenium has been found in protein-cellulose, lipid and amino acid/carbohydrate fractions. The identification of organic arsenic and selenium compounds requires compound-specific, sensitive analytical techniques. High pressure liquid chromatography with a graphite furnace atomic absorption spectrometer as an element-specific detector is presently the most versatile technique for these analytical problems. NMR investigations of a model system for the methylation of arsenic compounds consisting of methylcobaloxime and methyldihaloarsines in chloroform solution showed that methyl-transfer occurs easily and involves several steps. Work to elucidate the mechanism is in progress.

Key words: arsenate; arsenic methylation; biological transformation; graphite furnance atomic absorption spectrometer: high pressure liquid chromatography; selenite.

\section{Introduction}

Life developed in the presence of trace elements. Some of these elements are essential, others are innocuous; several are toxic and some may possess a combination of these attributes depending on concentrations. During their evolution organisms presumably adapted to toxic trace elements at low concentrations and developed mechanisms for their detoxification. A thorough understanding of the role of trace elements in the environment can be obtained only: (a) when their concentrations, as well as those of their compounds, in a system are reliably known; (b) when the transformations experienced by trace element compounds have been studied; and (c) when the interactions of these compounds with biologically important molecules have been elucidated. The task of fulfilling these requirements places a heavy burden on the entire spectrum of experts in biochemistry, biology and chemistry.

Increasingly sensitive methods for the determination of total trace element concentrations, irrespective of the chemical nature of the compounds containing these trace 
elements, have been developed during the past decades [1, 2]. Analytical capabilities have evolved to a state of refinement that every element can be at least detected in every sample. However, the accuracy and perhaps the precision of many of the quantitative data representing low total element concentrations are often questionable.

The situation does not appear to be too encouraging when one surveys the methods available for the identification and quantitative determination of trace element compounds. If one is interested in compounds which are either volatile or can be converted to volatile derivatives, work can proceed unimpeded. The literature abounds in articles describing devices, and procedures, some of them successful, employing chemical modification of trace element compounds to make them volatile [3]. It is now well-established that nature produces many trace element compounds which are not volatile and cannot be chemically altered to make them volatile without the loss of structural information. These nonvolatile compounds which are difficult to identify and determine at the present time, probably play a most important role in trace element cycles and are essential for the well-being of organisms. To make progress in the area of environmental trace element chemistry, in toxicology, public health, and pertinent governmental regulations, compoundspecific, sensitive and reliable analytical techniques must be available. It is no longer sufficient to determine the total concentration of a single trace element. When trace element compounds present at low concentrations are to be determined the application of only one analytical technique will very likely provide results of questionable value. Matrix problems and other interferences make analytical results unreliable unless they are corroborated by at least one independent technique.

During the past few years a number of research groups have identified trace element compounds in organisms [4]. The results of these investigations begin to provide a few valuable pieces belonging to a complex mosaic the whole of which is still largely hidden. Studies of the transformations of trace element compounds by organisms under controlled conditions are urgently needed. The growth medium must be well-defined. The energy input into the system must be known, the type of organism or collection of various organisms in the system must be controlled, and the various trace element compounds formed in the system from a well-defined starting material must be determined. Successful experiments carried out in this manner will tell how various organisms transform certain trace element compounds.

2. Growth of Algae in the Presence of Arsenic or Selenium Compounds

Biologists know that many different kinds of algae exist. Chemists, generally not experienced in the care and feeding of these organisms, rely on the biologists to select algal species at the base of the food web for trace element uptake and transformation studies. An initial screening of algae with respect to efficient uptake showed that Tetraselmis chui, a unicellular green flagellate, grew well in an arsenate-containing medium and accumulated arsenic in appreciable quantities $(\sim 0.1 \mathrm{mg}$ in $1.0 \mathrm{~L}$ of culture containing $1 \times 10^{9}$ cells) [5]. Large scale growth experiments were successfully conducted 
in four $1500 \mathrm{~L}$ tanks in an artificial sea water medium containing $10 \mathrm{ppm}$ As in the form of arsenate. Extraction of the harvested algae with methanol/chloroform and chromatography on a variety of column materials finally produced a phospholipid fraction which contained $0.5 \%$ arsenic. High pressure liquid chromatography with a graphite furnance atomic absorption detector indicated that this fraction contained at least two arsenic compounds [6]. Not much additional work on the transformation of arsenic compounds in algae has been carried out during the past two years because the development of urgently needed analytical techniques exhausted all available funds and personnel.

It is reasonable, however, on the basis of the information developed, to suggest that arsenic is incorporated into lipids, forming arsenolecithins 1 [7]. Benson and coworkers [8] have shown that 2-carboxyarsenocholine 2 ( $R=\mathrm{COOH}$ ) is probably present in many lipids of marine organisms. Arsenocholine $2(R=H)$ has not yet been detected in biological materials. Arsenobetaine 3 has been extracted from rock lobster [9] and the ribosyldimethylarsine oxide 4 has been found in the sea weed Ecklonia radiata [10]. It is safe to predict that many more organoarsenic compounds will be discovered in organisms.

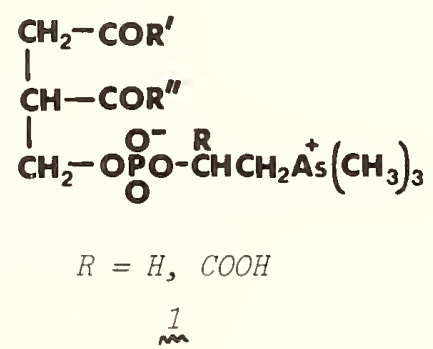

$\left(\mathrm{CH}_{3}\right)_{3} \stackrel{+}{A} \mathrm{~s} \mathrm{CH}_{2} \mathrm{COO}^{-}$

in

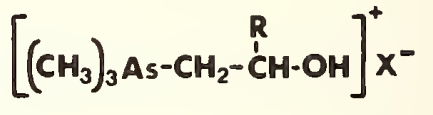

$R=I I, C O O H$

2

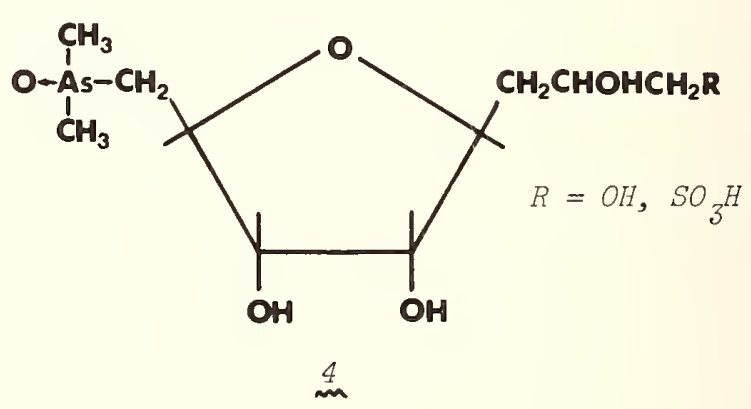

These discoveries will be made much easier by liquid chromatographic separation methods using sensitive, arsenic-specific detectors, and will raise interesting questions about the mode of formation of these compounds, their fate, their function, and their toxicological properties. In-depth studies of these compounds will be facilitated by the availability of synthetic samples of these derivatives. The task of finding methods for the preparation of organoarseric compounds must be assigned to an organometallic chemist, who thus becomes 
a valuable member of the interdisciplinary group investigating the transformation of trace element compounds.

In order to follow the transformation of inorganic selenium compounds in algae, six genera of unicelluiar marine algae were exposed to selenate or selenite [11]. It came as a surprise that these algae did not survive in a medium containing $10 \mathrm{ppm}$ Se(selenate), although they grew well in the presence of selenite at concentrations of $100 \mathrm{ppm}$ Se (Figure 1). The algae were grown on a larger scale in a medium containing $10 \mathrm{ppm}$

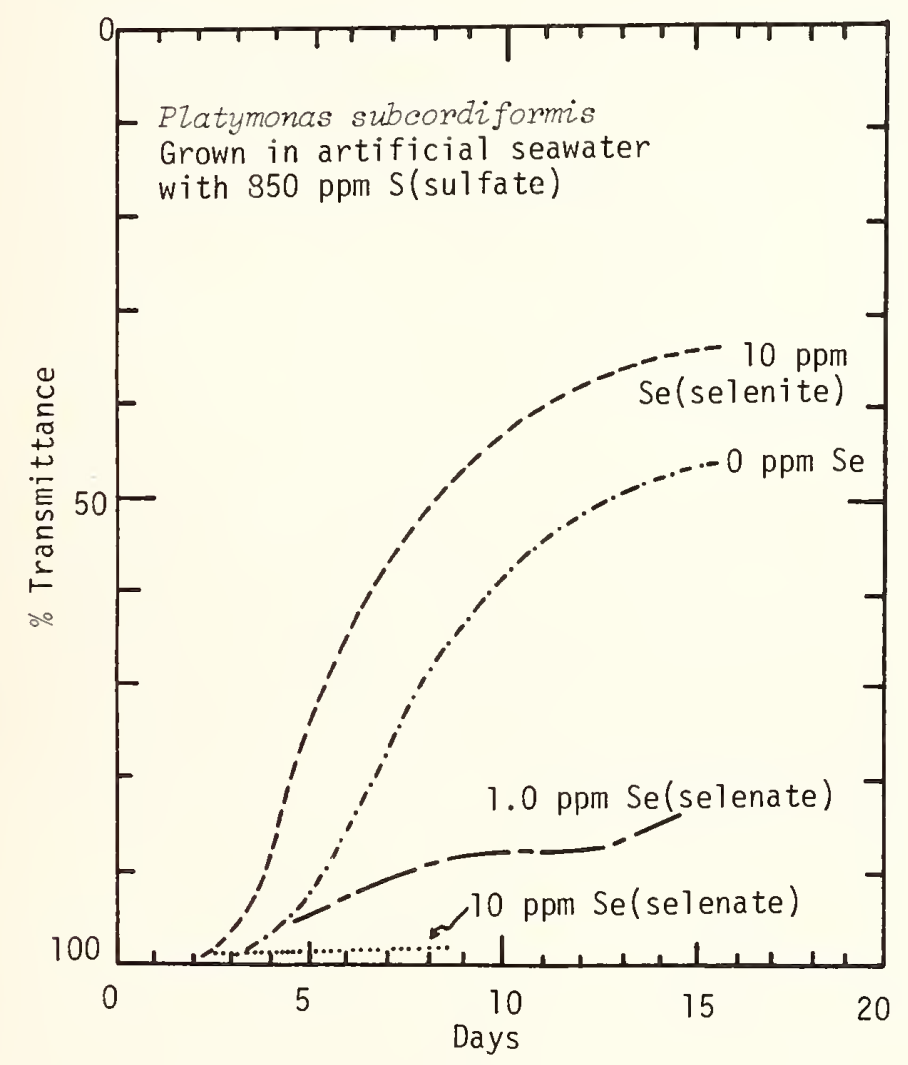

Figure 1. The growth of Platymonas subcordiformis in artificial seawater containing selenite or selenate.

Se(selenite). The algae were harvested by centrifugation when they had reached the stationary phase. Determination of the selenium content of the algal cells by graphite furnace atomic absorption spectrometry identified Tetraselmis chui and Platymonas subcordiformis as prolific selenium accumulators (Table 1).

The homogenized algal cells were fractionated into protein/cellulose, lipids, and amino acids/carbohydrates. Table 2 summarizes the results of selenium determination in these fractions obtained from Dunaliezla and Chzorezza. Data from the other algae are not yet available. Most of the selenium was found in the amino acid/carbohydrate fraction. 
Table 1. Selenium uptake by marine algae

\begin{tabular}{|c|c|c|}
\hline \multirow[b]{2}{*}{ Alga } & \multicolumn{2}{|c|}{ Selenium content, $\mu \mathrm{g} \mathrm{Se} / g$ algae } \\
\hline & $\begin{array}{l}\text { Growth medium with } \\
10 \mathrm{ppm} \text { Se(selenite) }\end{array}$ & $\begin{array}{l}\text { Growth medium with } \\
0.01 \mathrm{ppm} \mathrm{Se} \text { (selenate) }\end{array}$ \\
\hline $\begin{array}{l}\text { Chlorelza sp. } \\
\text { Dunaliella primolecta } \\
\text { Platymonas subcordiformis } \\
\text { Platymonas sp. } \\
\text { Tetraselmis chui }\end{array}$ & $\begin{array}{r}516 \\
392 \\
2953 \\
740\end{array}$ & $\begin{array}{l}\star \\
\star \\
\star \\
\star \\
\star \\
\text { trace }\end{array}$ \\
\hline
\end{tabular}

*Below detection 1 imit.

Table 2. Selenium concentrations in protein/cellulose, $1 \mathrm{ipid}$, and amino acid/carbohydrate fractions obtained from Dunaliezza and Chzorezla grown in $10 \mathrm{ppm}$ Se(selenite)

\begin{tabular}{|l||cc|cc|}
\hline \multicolumn{1}{|c||}{} & \multicolumn{2}{c|}{ Dunaziezza } & \multicolumn{2}{c|}{ Chzorezza } \\
\cline { 2 - 4 } & $\begin{array}{l}\text { Mass of } \\
\text { Fraction }\end{array}$ & $\begin{array}{c}\text { Percent of Se* } \\
\text { in Fraction }\end{array}$ & $\begin{array}{l}\text { Mass of } \\
\text { Fraction }\end{array}$ & $\begin{array}{l}\text { Percent of Se } \\
\text { in Fraction }\end{array}$ \\
\hline \hline $\begin{array}{l}\text { proteins and } \\
\text { cellulose } \\
1 \text { ipids }\end{array}$ & $28 \mathrm{mg}$ & $16 \%$ & $300 \mathrm{mg}$ & $1 \%$ \\
$\begin{array}{l}\text { amino acids and } \\
\text { carbohydrates }\end{array}$ & $31 \mathrm{mg}$ & $12 \%$ & $53 \mathrm{mg}$ & $1 \%$ \\
\hline
\end{tabular}

*Total selenium content $127 \mu \mathrm{g} . \quad$ Total selenium content $833 \mu \mathrm{g}$.

The amino acid/carbohydrate fractions were chromatographed on a Dowex $1\left(\mathrm{H}^{+}\right)$cation exchange column. Figure 2 shows the chromatogram obtained with the fraction from Dunaziezza. Four of the peaks were attributed to selenium-containing compounds tentatively identified as selenite and/or selenocarbohydrates, selenocysteic acid, selenomethionine/ selenocystine and dimethylselenohomocystine. Mass spectral, NMR, and chromatographic experiments are in progress to unequivocally identify these selenium compounds.

3. Analytical Techniques for the Speciation of Arsenic and Selenium Compounds

A number of sensitive techniques are available for the determination of inorganic and organoarsenic compounds either directly or after their reduction to volatile 


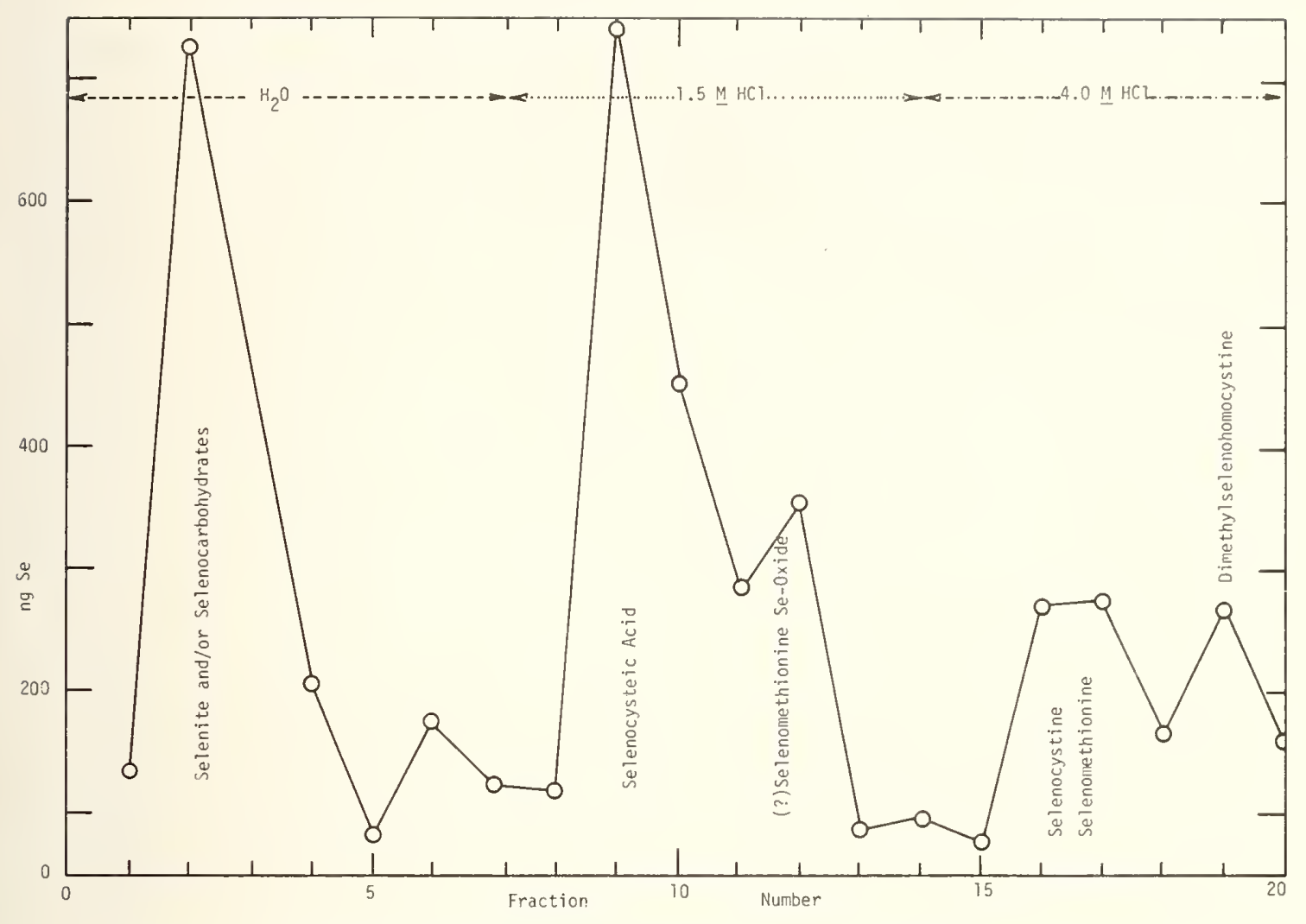

Figure 2. Chromatogram of the carbohydrate/amino acid fraction extracted from Dunaliezla primolecta.

hydrides [12]. Solutions containing arsenic compounds at sub-ppb concentrations have been successfully analyzed. Selenium compounds including selenite, selenate and methylated selenium derivatives can be determined by similar methods [13], although interferences more severe than those encountered in the case of arsenic compounds have been reported [14]. Unfortunately, many arsenic and selenium compounds occur in nature which are neither volatile nor reducible to volatile derivatives.

At the present time, the best system for the identification and determination of such recalcitrant compounds combines high pressure 1 iquid chromatography (HPLC) with a graphite furnace atomic absorption spectrometer (GFAA) as an element-specific detector. Perkin Elmer [15] and Hitachi Zeeman graphite furnace spectrometers [12, 16] have been interfaced with high pressure 1 iquid chromatographs. Instruments from other companies might serve equaliy well as element-specific detectors. Instead of HPLC an ion chromatograph may be used to separate ionic compounds. Aliquots of the column effluent are automatically injected into the graphite cup and analyzed. The time intervals between successive analyses, which are easily adjusted by the operator, can be as short as 30 seconds. The chromatogram showing the separation of selenite and selenate by ion chromatography is 
reproduced in Figure $3[17]$. The advantage of a GFAA detector is its responsiveness only

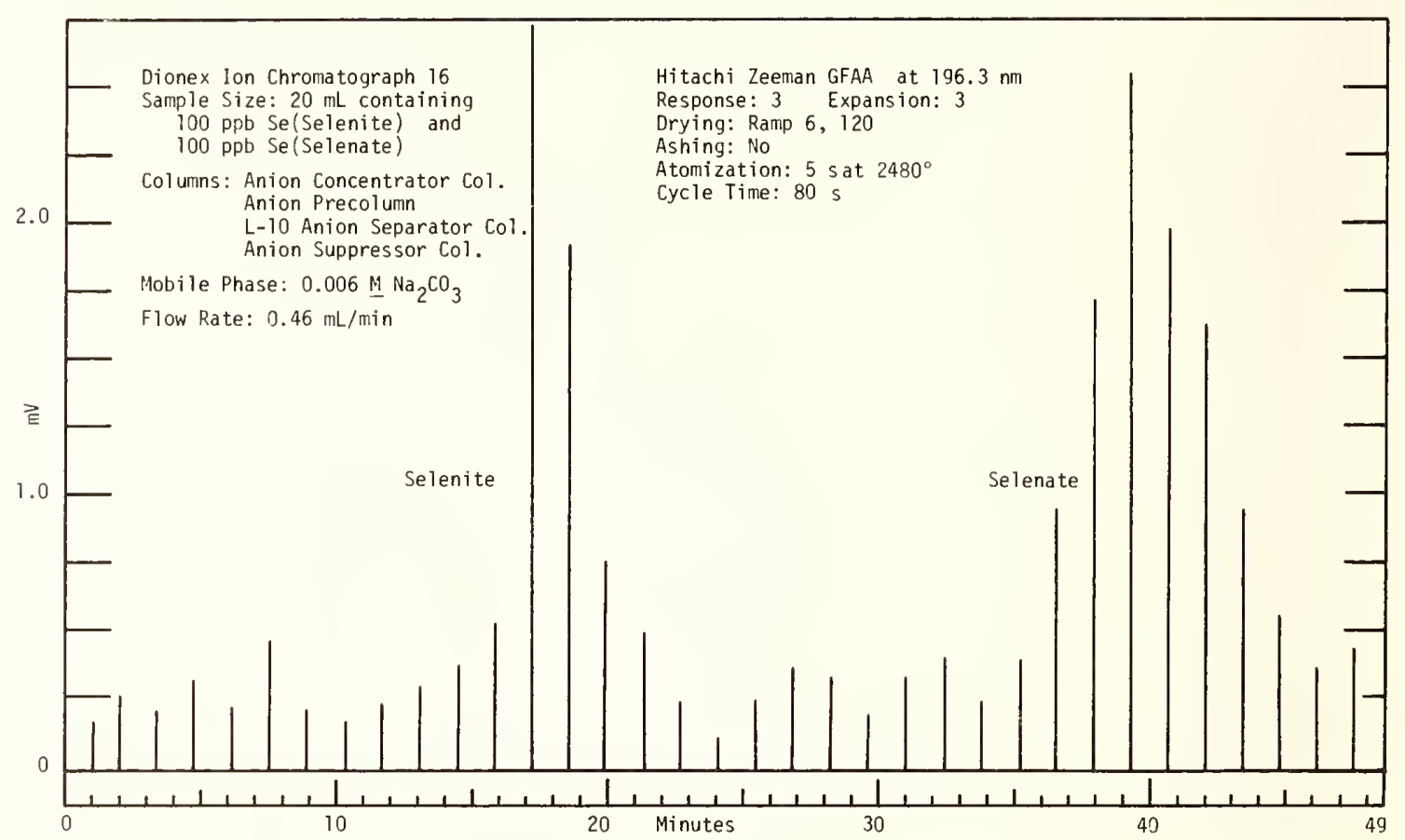

Figure 3. The separation of selenite and selenate by ion chromatography with a Hitachi Zeeman atomic absorption spectrometer as a selenium-specific detector.

to compounds containing the element selected for detection. Thus, the minimal number of compounds of the selected element present in a sample can be determined even when the chromatographic conditions do not allow the separation of these compounds from other substances.

GFAA is one of the most sensitive techniques for the determination of trace elements. This sensitivity is retained, of course, in the HPLC-GFAA system. However, chromatography spreads the compounds in an injected sample into a band, from which aliquots are taken for analysis. Each aliquot must contain a concentration of the element which corresponds to the detection limit of the GFAA. The detection limit of the HPLC-GFAA system can reasonably be expected to be 100 times the detection limit of the GFAA. Preconcentration techniques can counteract this loss of sensitivity.

GFAA, as are other analytical techniques, is plagued by matrix interferences, many of which are unknown and unsuspected. In our work with arsenic compounds, we noted discrepancies in the arsenic concentrations found in drinking water samples employing various techniques. The values obtained by GFAA were consistently low. A search for the causes revealed that distilled water solutions of arsenite and/or arsenate can be successfully analyzed at an ashing temperature of $1100^{\circ}$. However, in solutions containing common ions such as $\mathrm{Na}^{+}, \mathrm{Al}^{3+}, \mathrm{K}^{+}, \mathrm{Cl}^{-}, \mathrm{SO}_{4}{ }^{2-}$ and $\mathrm{PO}_{4}{ }^{3-}$ at low ppm levels, low results are produced at $1100^{\circ}$. Quantitatively reliable values were obtained at an ashing temperature of 
$900^{\circ}$. Water samples should, therefore, be analyzed for arsenic by first determining the proper ashing temperature in the presence of a nickel salt and performing the analysis at a temperature on the plateau of the ashing curve [18].

The methods presently available for the identification and quantitative determination of trace element compounds are much better than they were only a few years ago. However, experience in several laboratories indicates that these methods are not yet sufficiently developed for routine applications with guaranteed accurate and precise results. This statement is specially pertinent for the HPLC-GFAA system, which requires much additional work. It is still difficult to reliably analyze for trace elements at the sub-ppm level. It should not come as a surorise that these difficulties are compounded when one attempts to determine specific trace element compounds, the compositions of which are unknown, at ppb concentrations under experimental conditions which are optimal for the task only at rare and lucky instances. Painstaking, patient, and time-consuming work is still required for these analyses and for the further development of methods.

\section{Biochemical Aspects}

Many trace element compounds are chemically changed under the influence of the biochemical apparatus of organisms. In some cases, we know the nature of the starting material; in fewer instances we have information about the final product, and in most cases we are ignorant about the interim events. The biologically-mediated methylation of inorganic arsenic compounds is a good example for this state of affairs. That arsenite can be converted to trimethylarsine has been known for more than half a century [19]. We still know little about the mechanism for this transformation.

We investigated a model system for the methylation of trivalent arsenic compounds consisting of methylcobaloxime 5 and methyldihaloarsines in chloroform solution by proton NMR techniques. This system, although far removed from biological conditions, turned out to be, contrary to expectations, rather complicated. Upon mixing methyl(pyridinato)bis(dimethylglyoximato)cobalt(III) and methyldihaloarsines in chloroform several signals generated by intermediates and products appeared (Figure 4). It was not possible to unequivocally assign all the singlet methyl signals. Assignment of signals to reaction intermediates must by largely based on comparing intensities and intensity changes as a function of time. Since the resonances of the methyl groups in the cobaloxime are not sufficiently resolved to give reliable integrals, final interpretation of the spectra must await results of additional experiments which will be performed with a higher field NMR spectrometer. A tentative reaction scheme, partly supported by NMR data, is outlined in equation 1. Broadening of NMR peaks assignable to methyldihaloarsines suggests that the arsines may be complexed to pyridine and/or cobalt atoms. It is postulated that the intramolecular transfer of the methyl group (as a carbonium ion) from cobalt to arsenic is preceded by an isomerization reaction which shifts the apical methyl group into an equatorial position. Concomitant with the methyl transfer, halogen might migrate to the cobalt. The reaction mixtures finally deposited green crystals, which turned red 


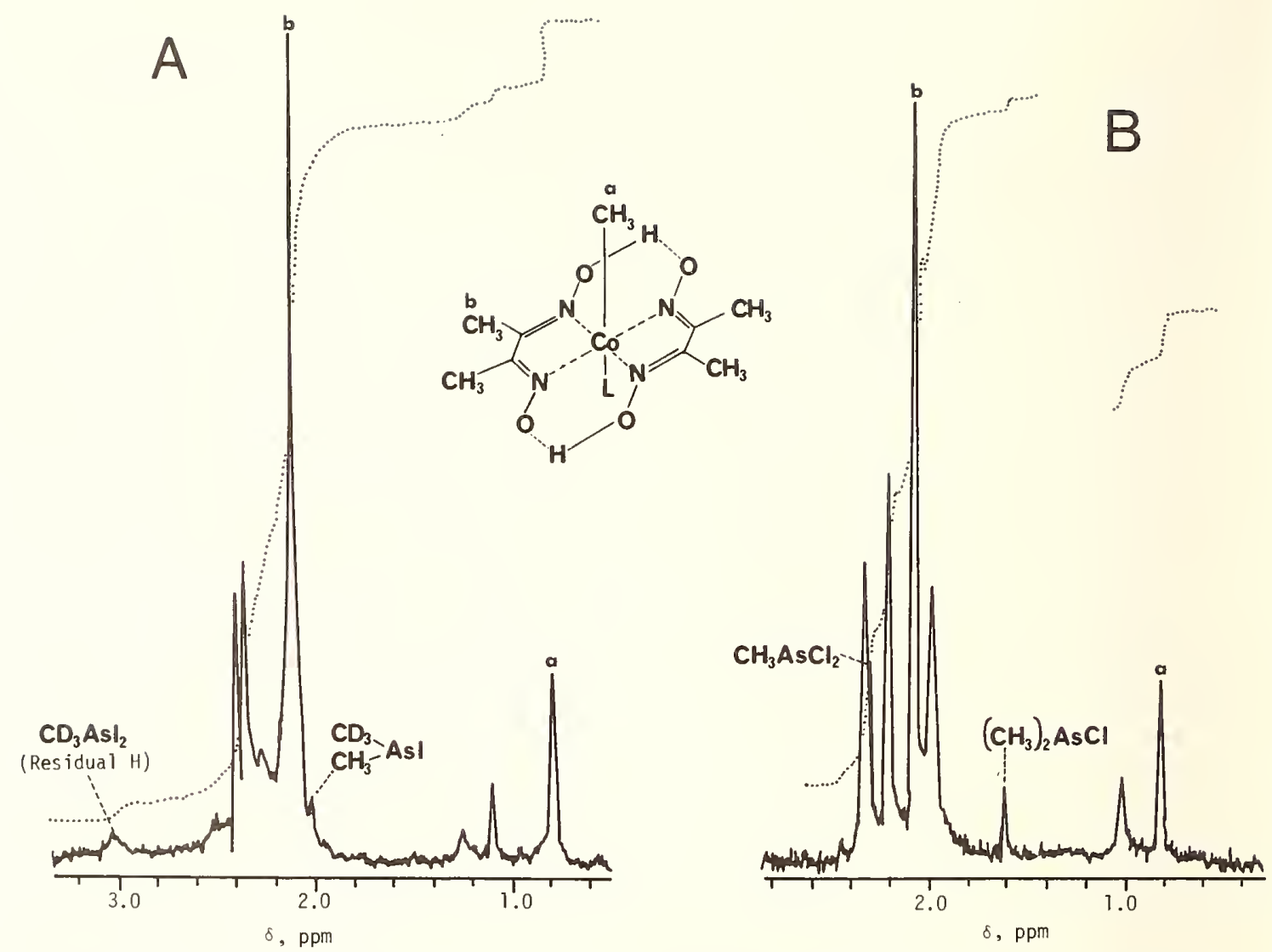

Figure 4. The proton NMR spectra of $\mathrm{CDCl}_{3}$ solutions of (A)methyl (pyridinato)bis(dimethylgloximato)cobalt(III) and deuteromethyldiiodoarsine fifteen minutes after mixing, and of (B) methyl (pyridinato)bis(dimethylglyoximato)cobalt (III) and methyldichloroarsine 144 hours after mixing.

upon exposure to air. The elemental analyses of the green crystals produced results very close to those expected for the arsonium salt 6 (equation 1).

The study of these model systems provide results which will facilitate investigations with methylcobalamin and trivalent arsenic compounds such as arsenite, methyldihydroxyarsine, and dimethylhydroxyarsine. Experiments with variously substituted arylarsenic derivatives in studies of the rates of methyl transfer reactions will tell whether the methyl group migrates as a carbanion or a carbonium ion [20].

\section{Conclusions}

A detailed study of the transformation of trace element compounds in biological systems would not have been very successful only a few years ago. Progress is being made in understanding the behavior of a few trace elements, for which arsenic, selenium, and tin may serve as examples, to allow for the development of reasonable 


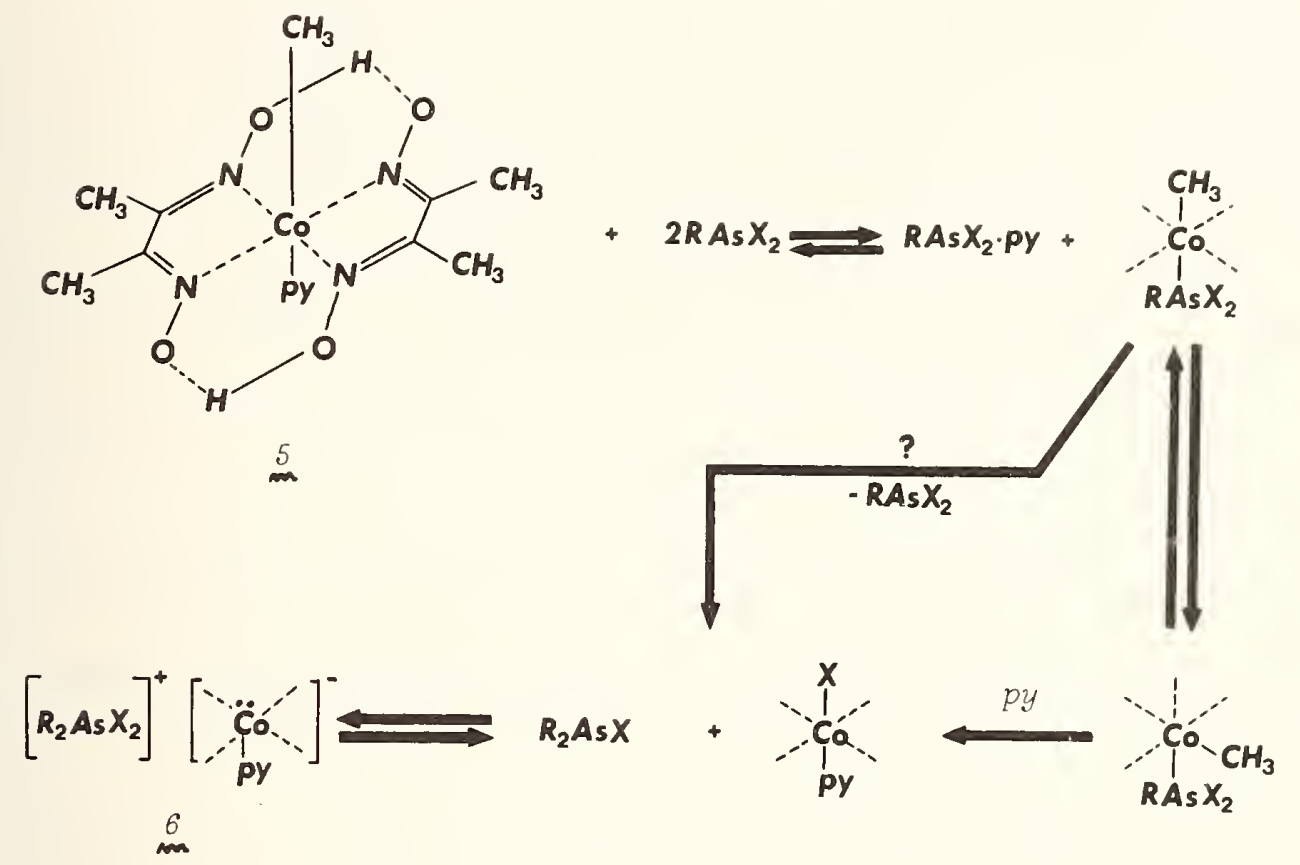

plans for more sophisticated investigations. Analytical techniques capable of determining trace elements at sub-ppb levels and trace element compounds at high ppb levels are now available. Several research groups have begun to mount an interdisciplinary attack focused on the transformation of trace element compounds. The explanation of the biochemical pathways which organisms employ to transform trace element compounds represents a formidable challenge which is being met.

An understanding of the transformation of trace elements in the environment is at least as important as it is difficult to achieve. Cooperation among biologists, biochemists, analytical chemists, organometallic chemists, synthetic chemists and NMR experts is needed to make progress in this area. Results are not obtained easily or quickly. The identities of most of the trace element compounds, which are generally present in the ppb to ppm range in organisms, are initially not known and compoundspecific, analytical techniques must be developed as a project progresses. Team work is essential. It is difficult to find graduate students and technicians willing to perform the not-so-clean work associated, for instance, with growing, harvesting and extracting microorganisms on a large scale. It is difficult and expensive to maintain a we11functioning mass culture facility. Projects of this nature are time consuming. Funding agencies must recognize that adequate support for at least five years is an essential prerequisite for building and maintaining an interdisciplinary, productive group of investigators.

Environmental issues associated with trace elements must be decided on the basis of sound knowledge concerning the chemical and physiological behavior of a substance in 
question. Decisions which establish exposure limits for any element or its compounds must not be based on fear or bias which may have its roots in ignorance accumulated over centuries. The speciation of environmentally active substances and knowledge about the manner in which they are passed from one living organism to another is of fundamental importance for the protection of the public health. Such knowledge can also prevent the establishment of unnecessary stringent limits of exposure to specific substances. Such regulations, when unnecessary, can be the cause of huge expenditures while bringing about little or no benefit.

\section{Acknowledgement}

The work discussed in this paper was supported by the Robert A. Welch Foundation of Houston, Texas; by the Environmental Protection Agency, Grant No. R 8047740 10; by the National Institute of Environment Health Sciences, Grants No. ES 01125, ES 02051; Texas A\&M University's Center for Energy and Mineral Resources, and the Texas Agriculture Experiment Stations.

\section{References}

[1] Pinta, Maurice. Modern methods for trace element analysis. Ann Arbor, Mich., Ann Arbor Science Publishers Inc.; 1978. 492 p.

[2] Pinta, Maurice. Detection and determination of trace elements. Ann Arbor, Mich., Ann Arbor Science Publishers Inc.; 1975. 588 p.

[3] National Academy of Sciences. Arsenic. Washington, D.C., 1977. p. 261.

[4] Brinckman, F. E.; Bellama, J. M. Organometals and organometalloids; occurrence and fate in the environment. ACS Symposium Series, Vol. 82, 1978. 447 p.

[5] Bottino, N. R.; Newman, R. D.; Cox, E. R.; Stockton, R.; Hoban, M.; Zingaro, R. A.; Irgolic, K. J. The effects of arsenate and arsenite on the growth and morphology of the marine unicellular algae Tetraselmis chui (Chlorophyta) and Hymenomonas carterae (Chrysophyta). J. Exp. Mar. Biol. Ecol., 33: 153-168; 1978.

[6] Bottino, N. R.; Cox, E. R.; Irgolic, K. J.; Maeda, S.; McShane, U!. J., Stockton, R. A.; Zingaro, R. A. Arsenic uptake and metabolism by the alga Tetraselmis chui. ACS Symp. Series 82: 116-129; 1978.

[7] Irgolic, K. J.; Woolson, E. A.; Stockton, R. A.; Newman, R. D.; Bottino, N. R.; Zingaro, R. A.; Kearney, P. C.; Pyles, R. A.; Maeda, S.; McShane, W. J.; Cox, E. A. Characterization of arsenic compounds formed by Daphnia magna and Tetraselmis chui from inorganic arsenate. Environ. Health Perspect. 19: 61-66; 1977.

[8] Cooney, R. V.; Mumma, R. 0.; Benson, A. A. Arsoniumphospholipid in algae. Proc. Nat1. Acad. Sci. USA 75(9): 4262-4264; 1978.

[9] Edmonds, J. S.; Francesconi, K. A.; Cannon, J. R.; Raston, C. L.; Skelton, B. W.; White, A. H. Isolation, crystal structure and synthesis of arsenobetaine, the arsenical constituent of the western rock lobster Panulimus Longipes Cygnus George. Tetrahedron Letters 1977(18): 1543-1546. 
[10] Edmonds, J. S.; Francesconi, K. A. Arseno-sugars from brown kelp (Ecklonia radiata) as intermediates in cycling of arsenic in marine ecosystems. Nature 289: 602-604; 1981.

[11] Wheeler, A. E.; Zingaro, R. A.; Irgolic, K. J.; Bottino, N. R. The effect of selenate, selenite and sulfate on the growth of six unicellular marine algae. J. Exp. Mar. Biol. Ecol., in press.

[12] Irgolic, K. J. Speciation of arsenic compounds in water supplies. Final Report for EPA Grant R 8047740 10, (in review to be issued by NTIS) 1981.

[13] Robbrecht, H. J.: Van Grieken, R. E. Sub-part-per-billion determination of total dissolved selenium and selenite in environmental waters by $X$-ray fluorescence spectrometry. Anal. Chem. 52: 449-453; 1980; and references therein.

[14] Meyer, A.; Hofer, Ch.; Tölg, G.; Raptis, S.; Knapp, G. Elementstörungen bei der spurenanalytischen Selen-Bestimmung nach dem Hydrid-AAS-Verfahren. Fresenius $Z$. Anal. Chem. 296: 337-343, 1979.

[15] Brinckman, F. E.; Blair, W. R.; Jewett, K. L.; Iverson, W. P. Application of a liquid chromatograph coupled with a flameless atomic absorption detector for speciation of trace organometallic compounds. J. Chromatogr. Sci. 15: 493-503; 1977.

[16] Stockton, R. A.: Irgolic, K. J. The Hitachi-Zeeman graphite furnance atomic absorption spectrometer as an automated, element-specific detector for high pressure 1iquid chromatography: the separation of arsenobetaine, arsenocholine and arsenite arsenate. Intern. J. Environ. Anal. Chem. 6: 313-319; 1979.

[17] Chakraborti, D.; Hillman, D. C.; Zingaro, R. A.; Irgolic, K. J. The speciation of selenite and selenate by ion chromatography with a graphite furnace atomic absorption spectrometer as selenium-specific detector. In preparation.

[18] Chakraborti, D.; Adams, F.; Irgolic, K. J. Arsenic determinations in water samples by Hitachi-Zeeman graphite furnace atomic absorption spectrometry. In preparation.

[19] Reference 4, p. 1.

[20] Zingaro, R. A.; Irgolic, K. J. The methylation of arsenic compounds. Science 187: $765-766 ; 1975$.

Discussion

Question (E. A. Woolson): Would you comment on the different sensitivity by GFAA for the different arsenicals? When we use the ammonium carbonate on the Dionex column, we find essentially the same sensitivity between the different compounds.

Answer: It is very likely that it depends on the matrix which you have, because at the high temperature of ashing and atomization...

Question (E. A. Woolson): We use 1250 and $2400{ }^{\circ} \mathrm{C}$. 
Answer: You might have reactions with other anions and cations which are present which produce more volatile arsenic species which of course go off and you lose them. It also depends on the chromatographic conditions. We just used a "high $\mathrm{pH}^{\prime \prime} \mathrm{C}_{18}$ reverse phase column. With the normal ones you can buy, you can't go much above pH 8 or 9 otherwise they break down. With one now commercially available you can go up to 13 . So we have tried that column and separate arsenite, arsenate, methylarsonic acid, dimethylarsinic acid without any problem. I can't give any good answer on why these different sensitivities.

Question (W. Slavin): Are the sensitivity differences taking into account the chromatography also? Those are not calibrated as spectroscopic analyses, they are calibrated through standards that have been chromatographed, therefore, depending upon the integration of the chromatographic peaks?

Answer: Yes.

Question (E. A. Woolson): I believe you all used sodium acetate in your eluting solvents, didn't you?

Answer: No, not in my work.

Comment (F. E. Brinckman): The work that Dr. Irgolic refers to was a different system than Dr. Weiss showed earlier today that used your particular method on the Dionex methano1water ammonium carbonate buffer. Three points: (1) Dr. Slavin already picked up that the system sensitivity includes the band broadening and therefore the dilution. So it is not a spectroscopic detection limit. We always report as a total system detection limit at the 95 percent confidence interva1. (2) That is, the matrix, particularly in large sample inputs, gives some history we've noticed with repeated firings, probably because you're not clearing tubes. There is tube history on these because of heavy repeated use, depending upon the buffer salt. It depends upon whether you are running a range from ammonium acetate, or sodium acetate, which we have used in isocratic mode with SAX columns which are reverse bonded-phase, nonswelling columns, as opposed to the polymer columns such as Dionex which we use in gradient. If you are not careful about the repeat rate and run the GFAA warm, or you don't use chilled water to cool back down to keep the repeat cycle short every time you heat bang the furnace, you can get salt deposit buildup. This occasionally will decrepitate and blow things off. That's why the platform methods and other methods will improve this. Finally, (3) there are intrinsic differences between the relative volatilities of the analytes as they elute in that, the fixed drying thermal program, unless you really heat it to high dry rates. We don't like to do this in some instances, particularly in unknown solutions with a lot of organic component like the oil shale. Most of the organics it will burn off and take out your arsenic. You tend to run rather low drying temperatures, then go immediately to the atomization. It is not an optimal situation 
as I indicated earlier. All of these contribute to this apparent difference in intrinsic sensitivity, but it is chromatographic sensitivity we are really concerned with. Is that a fair statement?

Answer: Yes. If one determines inorganic arsenic, arsenate, arsenite, perhaps selenium, selenite, selenate, and methylated arsenic compounds as those compounds that are reducible to volatile hydride, there is no question that we are in good shape in this general area. But once you get into nonvolatile organic compounds like arsenobetaine, arsenocholine, and arsenic-containing lipids, there is at the moment no better way than HPLC-GFAA. The system sensitivity is not as good as we would like to have it, because of chromatographic problems, not the GFAA. At the moment I don't see the way around that, except if you have enough sample just concentrate it and run it. Many of these things are sample limited. Now there is perhaps something on the horizon which might do a little bit better, but it is an expensive detector for a $\$ 10,000 \mathrm{HPLC}$ system; that is the ICP. You can go away from some of the matrix problems.

Question (W. Slavin): Why do you think that you have less trouble with matrix there?

Answer: You go with $10,000^{\circ} \mathrm{K}$ and, in addition, ARL is coming out with a hydride generation system which can attach directly to the ICP. This doesn't solve the problem of the nonvolatiles or nonreducibles. But, as I say, I don't see any good solution at the moment, getting back to the graphite furnace sensitivity, which we can achieve for arsenic and selenium, once you hook the chromatograph in front of it.

Question (W. Slavin): Obviously, your spectroscopic detector isn't going to do you any good with respect to your problem of peak broadening in the LC. We had exactly the same problem when we were doing deliberate labeling, LC separation, and then atomic absorption detection. The problems are with many of these compounds that you can't get narrow enough peaks to maintain the kind of sensitivity that you are working for. When you go to the ICP for most of the metals that you are talking about, your intrinsic sensitivity is very much less then it is with the graphite furnace so you are giving up the sensitivity. With the hydride attachment you require a much larger amount of material because the intrinsic sensitivity is in the spectroscopic technique. Let me answer the one last thing that I think is important, at least to think about if you are trying to put all these things in balance. One of the other people mentioned that you see some difference in sensitivity with conventional graphite furnace deposited on the wall detection for the various organic species of arsenic. Yes, some, but not the kind of the factors of two and three that that are in your paper. Variations that you are seeing are in the system that you are using in the combination of your liquid chromatography and the way you are handling the particular graphite furnace technique. There is no particular reason to expect that that is going to disappear, though it maybe different when you use an ICP technique for the detection. I think there are a lot of ways to go yet in handling the whole system configuration with 
any of the spectroscopic detectors, to take better advantage of both systems, of both components.

Answer: I think this is a safe statement to make. The graphite furnace is more prone to matrix interferences then ICP is, simply on the basis of the temperatures differences in the furnace compared to the ICP attachment.

Comment (M. A. Anderson): We work with a lot of environmental systems, particularly lake sediments which get pretty messy at times. I recall that we had some additive, nickel. In fact, we did have the differences in detectability when we did not add the nickel, but when we added the nickel everything came out as Dr. Woolson suggested.

Answer (E. A. Woolson): That's fine if you are using the direct injection of standards, you need the nickel. Having gone through the HPLC in our system, the only thing you've got there is ammonium carbonate. You have no other matrix. The ammonium carbonate goes off at $1250^{\circ}$ so in atomization, except with initial solvent front, you have no matrix.

Comment (W. Slavin): The nickel will have the effect, even when you have separate HPLC peaks, of converting of all of the arsenic to a more stable form by the time you go into the high temperature phase of the GFAA. You will be much less likely to have lost the arsenic as a volatile material. So, I think, that it is not unlikely that the heavy metals, if they are not present in the sample in some way, are going to be an advantage even after having gone through a HPLC fractionation.

Question (R. H. Fish): I would like to address something I think is important. One of the reasons for this Workshop is to meld the biological impact of what we are speciating and to get the biologists to help us to define this environmental impact of these compounds. I would like to know about an Ames-type test that we can use for organometallic compounds. In other words, we see all these people, who have all these fractions and hundreds of fractions are used with the Ames test. Well, it doesn't work on organometallic compounds. It seems to me that if DoE wants to know what the biological impact is of energy-related compounds, then we have got to come up with some sort of test. What I've seen here are people doing sophisticated chromatography and not really knowing what fraction is active biologically. I think that is the important thing.

Answer (L. Packer): Of course, you can only respond in a general way. But, in order for anything to be effective, it has to cross the biological membrane. That is the key. What we need to know is whether these substances cross the membrane, how they cross the membrane, and what they compete with when they cross the membrane. If the substance doesn't get in, it is not going to have any affect in an Ames test. If a metallic substance can't get in, it obviously is not going to cause a mutation in bacteria or affect anything. This is 
crucial with any kind of these agents we are looking at, with even simple things like arsenate. If you use arsenate, as Dr. Irgolic has done with algae, I would ask you the question--how much phosphate did you have in the medium?--because phosphate and arsenate compete with each other in every way. Phosphate is known to have two mechanisms for transported across cell membranes, mainly. One of them is a sort of a general mechanism whereby it goes across the membrane in its uncharged form. In its uncharged form, it is permeable; in its charged form it is not, so it is $\mathrm{pH}$ dependent. The second way involves a specific protein carrier, at least in certain cases where it has been studied. It exchanges phosphate into the membrane. It is known that that carrier is inhibited by arsenate competitively. Likewise, it is known all the reactions in which phosphate participates in the cell are competed with by arsenate. So we have to ask the question in those cultures what is the activity for phosphate uptake. The activity for phosphate uptake can be different for different organisms. Then you have to ask, how does that phosphate level compare with the arsenate? If you haven't satisfied yourselves on that, you are not going to be able to understand the arsenate toxicity. You will, of course, be able to find out what kinds of arsenic compounds arise if it gets in. That you can do, if it doesn't kill the essential machinery. If you don't go too far and allow enough arsenic to go in to speciate, but not so much arsenic to go in to kill the essential machinery that allows it to be speciated.

Comment (B. Fowler): The kind of question you are talking about is raised in an issue of Environmental Health Perspectives, Volume 40, which will be out sometime during July or August of 1981. It deals with metals and carcinogenesis; transformations--reduction of chromium(VI) and chromium(III) coming across membranes--in relation to a specific and really important biological process; namely, carcinogenesis. There is also a fairly in-depth consideration of metals as promoting agents or as co-carcinogens of some of these other systems aside from the Ames test sort of thing you are talking about. There are a number of other ways in which metals can interact and these are all laid out pretty completely and very recently in that particular issue.

Comment (G. W. Standberg): In response to your statements, it is not necessary that the metals get into the cells to exert their effect. In microbial systems they could exert their effect on surface-associated enzymes, so you have to be careful making any interpretations in that regard. It wouldn't have to be transported inside but could effect the transport of other metals.

Comment (L. Packer): Anything on that the extracellular surface which is essential, that it could interact with, would also would be susceptible to being effective. Normally, in higher organisms, you would have to exchange across the membranes--the skin, the lung, the cells of the lung lining, or it could be the cells of the intestine. Their membranes would be the first place and so on. 
Comment (G. W. Standberg): In using a microbial system as a test system you couldn't necessarily be concerned this was internal for the metabolism or reaction to take place.

Comment (L. Packer): That is right. Also another thing, in microbial systems at least. For iron in certain bacteria, when they are deficient in iron, and even if they aren't deficient, they produce a substance called a siderochrome or enterochelin, which is a cage-like structure that surrounds the iron and is used to take the iron into the cell. Then back inside the cell, enzymes dismember the structure and the iron is now free to be incorporated. It is a very sophisticated mechanism that bacteria have developed and nobody knows if these kinds of things have been developed for other metals. It has only really been looked for iron maybe it occurs with a group of some of these other metals.

Comment (G. W. Standberg): Metallothionine has been discovered in bacteria now in bluegreen algae.

Comment (B. Fowler): In reference to that, there are a number of these low molecular weight proteins of which metallothionine is the most commonly cited, that have been described in biological systems.

Answer (E. A. Woolson): In answer to your question, the Ames test and most of the bacterial tests will only give you a positive response if the complex or the elements you are looking at alter DNA structure. For the metals and the organometals, for the most part, I think, they probably do not. They might , in case of arsenite, prevent repair if another agent breaks the DNA, 1ike UV 1ight. It will inhibit the repair function of the DNA in $\underline{E}$. coli , for example.

Comment (R. H. Fish): They will coordinate to all kinds of sites in the DNA.

Comment (E. A. Woolson): If the element of interest does not change the DNA structure so that you get a mutation, the Ames test and these other bacterial tests won't really show you an effect.

Comment (L. Packer): That's the reason why you need several kinds of tests. That's an evaluation of the relationship between mutagenicity and carcinogenicity, but not a relationship to other forms of pathology.

Comment (E. A. Woolson): It depends on exactly what you want to look at. If you want to look at whether or not something is going to be carcinogenic or mutagenic, the Ames or some of the other tests will be all right.

Comment (R. H. Fish): I don't think they work on organometallic compounds. As far as I know, people who do the Ames test say that they don't get any large number of revertants. They don't get anything. 
Question (R. J. Mehlhorn): What are you addressing is really one of the issues of toxicity which is DNA transformation. Probably this is one of the most toxic kinds of transformation, potentially, that exists. But proteins also, particularly since there may be very important specific proteins where a single "hit" could kill a cell, conceivable. Least among the targets, I would say, are the lipids. What we know about membrane structures says that lipids are very accommodating; you can alter the lipid structure a great deal without harming the cell. Concerning that, I have a question that concerns these algae. Have you looked at specific selenoamino acids? What is the toxicity of specific selenoacids in terms of are they taken up, are they incorporated? Perhaps that will give us some additional clues as to the mechanism whereby these seleno compounds exert their toxicity and similarly with the arsenobetaines. Have you looked at the arsenobetaines and other specific compounds to see whether they are much more toxic than their inorganic precursors?

Answer (K. J. Irgolic): No, they are not.

Answer (B. Fowler): There are people who are starting to evaluate that too. On the basis that they are not toxic.

Question (P. J. Craig): I would like to make a comment about your mechanism, Dr. Irgolic. I am wondering how you can get your trans-cis isomerism, the path that gets the methyl next to the arsenic, when you've got that great big flat $N_{4}$ equatorial 1 igand in the way?

Answer (K. J. Irgolic): The simple answer is, I don't know.

Question (P. J. Craig): There is an order of which ligands will displace with other. ligands when they are bound to a methyl in that kind of configuration. I had a feeling that it would be the other way around, that pyridine might displace arsenic if it was there, not arsenic displacing pyridine?

Answer (K. J. Irgolic): That's one of the relatively certain things which happens in that system. From NMR indications, a broadening of some of the peaks indicates an exchange going on between the trivalent arsenic compound and the pyridine. You see that not only in the arsenic metal resonances which broaden out, but also in the aromatic region of the pyridine ring which changes. We do not have any equilibrium constant for that yet.

Question (D. A. Klein): Dr. Irgolic, I wanted to ask you again something I asked earlier. Are there any differences between the different species you tested as far as effects on the algal systems in relation to accommodation, or are there any changes physiologically so that a second piece of the organism, after having been exposed, might give you different responses? 
Answer (K. J. Irgolic): Yes, we have tried that, not by design but by necessity. Sometimes something happens to the algae cultures, and in order to avoid growing a new batch to inoculate we took those that survived and started a new culture and surprisingly enough, they didn't take up any arsenic. That, in our eyes at the moment was a failure because it was suppose to do it.

Question (D. A. Klein): Which form was that?

Answer (K. J. Irgolic): Arsenate. We didn't do anything with arsenite for the simple reason that, at the beginning, we couldn't get any radioactive arsenite tracer. Arsenate you can buy and, if you take arsenate and reduce it to arsenite then what every you have in there, although you try to get all the reagent out, it kills the algae.

Question (D. A. Klein): But now you have arsenite?

Answer (K. J. Irgolic): No.

Comment (L. Packer): I would just like to make another general comment on the essentiality of the biological membrane. When these substances kill a cell, how do they kill a cell? You might hit the DNA, you might mess up the protein synthesis, that's clearly one way. If it hits proteins as Dr. Mehlhorn suggested, that's another way, but you would have to hit a lot more proteins because there are many protein copies in the cell. If you punch a hole in the biological membrane, in the general sense, by some affecting some specific exchange mechanism, whether it be protein-catalyzed or just prevented the lipids from assembling properly, that would be enough. The cell could no longer cope with life and it dies. I think a very good example is triphenyltin cation. Triphenyltin, as Dr. Mehlhorn has made the point yesterday, has been shown to be a chloride-hydroxyl exchanger. It will pick up chloride on one side of the membrane, go to the other side, exchange it for hydroxides. In that way it will collapse the $\mathrm{pH}$ gradient which exists across membranes and which is essential for any ion transport, or any life process. It will not collapse the electrical gradient but will collapse the $\mathrm{pH}$ gradient. So it immediately becomes of interest to know what the range of tin compounds that now can be speciated and characterized and are available--what do they do. It is an interesting problem and I would like to see someone do it.

Comment (K. J. Irgolic): We have worried about what happens between the outside of an organism and the inside. Our tools which we are using to determine what is inside and outside are very rough as far as the membranes are concerned. With selenium there is a tiny chance that one has a very fine tool with selenium-77 NMR. If the concentration, by any chance, can be made high enough so that you can see signals when you run the algae cells for two weeks on the spectrometer, that would be a great thing to do. Of course the NMR people say you're crazy--two weeks you're tying up the machine. It really isn't so bad 
because if you consider the time involved to figure out what is going on by any other techniques you are there for six months, but of course that isn't NMR specialist's time, and that makes a difference. We are looking into that right now with selenium in algae and the question is whether we can either get sufficient signal with the NMR machine we have, or whether we can afford to buy the selenium-77 which is available at $\$ 10 / \mathrm{mg}$.

Comment (8. Fowler): I think one point we should bring up here is that most people think of biological membranes as being essentially a set of lipids with proteins floating around in it. The trouble is and the thing that it is frustrating the cell biology people is that the membranes do not appear to be homogeneous substances; in other words, the arrangement of things may not be totally uniform. What this sets up then is a sort of heterogeneous surface that varies depending on what part of the cell we are looking at. The bottom may be different than the top. In kidney tubule cells this is very much the case. I just think that whoever solves that is going to have to pick a very simple membrane. 


\title{
Bacterial Processes for Transformation
} of Metals

\author{
James A. Brierley \\ New Mexico Institute of Mining and Technology \\ Socorro, NM 87801
}

Microorganisms actively participate in the transformation of metals and metalloids by various processes including adsorption, absorption, alkylation, oxidation and reduction reactions. Bacteria of the genera Thiobacillus and Sulfolobus have a chemolithotrophic mode of metabolism and catalyze various metal transformations. The mixotrophic thiobacillus-like facultative thermophilic bacteria also participate in metal transformations. These bacteria are primarily involved in oxidation-reduction reactions of metals. Metal sulfides. can be either directly oxidized by the microbes or oxidized by ferric iron, an end-product of microbial metabolism. These processes result in solubilization of iron, copper, molybdenum, uranium, and many other metals as well. In the absence of oxygen, iron and molyhdenum may be reduced by microbes. Bacteria capable of these reactions are found, and they function in a variety of environments. Conditions which favor their growth are acidic pH ( 1.5 to 3.5) and temperatures which can be as high as $75^{\circ} \mathrm{C}$ for Sulfolobus. The microbes have potential for mobilization of poliutants, or toxic elements, during resource extraction processes.

Key words: chemolithotrophic-bacteria; copper; iron; leaching; metal-reduction; metal-sulfides; mineral-oxidation; molybdenum; oil shale; Sulfolobus; Thiobacillus; uranium.

\section{Introduction}

\subsection{Microbial-Metal Interactions}

Bacteria participate in reactions which can effect the transformation of metals and metal1oids. As such, the microbes are catalytic agents for geochemical processes. These reactions may be either beneficial and lead to recovery of metal values such as the leaching of copper or uranium from low-grade ores, or detrimental by solubilizing potentially toxic elements.

The microbes may interact with metals by one or a combination of four processes: adsorption and absorption; oxidation or reduction; alkylation; and formation or degradation of metal-organic compounds $[1,2]$.

\subsection{Characteristics of Bacteria}

The chemolithotrophic bacteria, by virtue of their metabolism, are effective cata- 
lysts for reactions leading to solubilization of metals. This group of bacteria uses onecarbon compounds as a carbon source for synthesis of biopolymers, and oxidizable inorganic elements and compounds (e.g., sulfur, sulfide, thiosulfate, or ferrous iron) serve as energy sources for growth. Thus, they are able to function in environments such as mine spoils and tailings which have limited organic-nutrient availability. Bacterial genera of this group include Thiobacillus and Sulfolobus $[3,4]$. The unclassified thiobacilluslike (designated $\mathrm{TH}$ ) facultative thermophilic bacteria $[5,6,7,8]$, although not ob] igate chemolithotrophic, are aiso metal-transforming catalysts. All of these bacteria characteristically grow in acidic habitats at pH values less than 3.5, and they oxidize ferrous iron and metallic sulfides for energy. The species I. ferrooxidans catalyze metal transformations at temperatures from 20 to $35^{\circ} \mathrm{C}$; the $\mathrm{TH}$ facultative thermophiles function at 30 to $55^{\circ} \mathrm{C}$, and the sulfolobus species grow at 45 to $70^{\circ} \mathrm{C}$. Thus, metal transformations can be effected by bacteria over a range of conditions. The I. ferrooxidans and Sulfolobus species have a chemolithotrophic mode of metabolism, but the TH facultative thermophiles are mixotrophic; they cannot use single-carbon compounds and must have organic compounds supplied for their growth. However, they do oxidize metal-sulfides and ferrous iron for energy.

\subsection{Microbially-catalyzed Redox Reactions}

This report is limited to an overview of bacterially catalyzed oxidation and reduction reactions of metals. Specifically, microbial oxidation of metal sulfides, ferrous iron, and the consequences of these reactions are discussed. Microbial reduction reactions of molybdate and ferric iron are also considered.

\section{Microbial Redox Reactions}

2.1 Oxidation of Metal-Sulfides and Uranium

There are three mechanisms by which the I. ferrooxidans, TH bacteria, and Sulfolobus participate in solubilization of heavy metals. The microbes produce a strong oxidant, ferric iron, as a result of their oxidation of ferrous iron for energy (1). The ferric

$$
4 \mathrm{FeSO}_{4}+2 \mathrm{H}_{2} \mathrm{SO}_{4}+\mathrm{O}_{2} \rightarrow 2 \mathrm{Fe}_{2}\left(\mathrm{SO}_{4}\right)_{3}+2 \mathrm{H}_{2} \mathrm{O}
$$

iron can oxidize metal sulfides, such as chalcocite (2), solubilizing the copper as a cupric sulfate. The reduced iron can then be reoxidized by the microorganisms. Other

$$
\mathrm{Cu}_{2} \mathrm{~S}+2 \mathrm{Fe}_{2}\left(\mathrm{SO}_{4}\right)_{3} \rightarrow 2 \mathrm{CuSO}_{4}+4 \mathrm{FeSO}_{4}+\mathrm{S}
$$

metal sulfides such as chalcopyrite, covellite, and bismuthinite [9] are also oxidized by ferric iron. Reduced, insoluble uranium as uraninite, can be oxidized and solubilized (3) by ferric iron. This mechanism for solubilizing metals is termed "indirect" since

$$
\mathrm{UO}_{2}+\mathrm{Fe}_{2}\left(\mathrm{SO}_{4}\right)_{3} \rightarrow \mathrm{UO}_{2} \mathrm{SO}_{4}+2 \mathrm{FeSO}_{4}
$$


the end-product of microbial metabolism, ferric iron, is the oxidant of the reduced metal, and the microbial participation may be separated by space and time from the actual metal solubilization. In acidified solutions, I. ferrooxidans reportedly increased the rate of iron oxidation over 500,000 the rate which would occur in their absence [10]. The microbes are able to generate significant amounts of the leaching agent, or lixiviant, for extraction of metals from sulfides.

A second mechanism by which the microbes participate in metal solubilization is termed the "direct" process. Ferric iron is not a required participant in the reaction. Copper, from chalcocite (4), and molybdenum (5) from molybdenite, can be solubilized as a result of

$$
\begin{aligned}
& \mathrm{Cu}_{2} \mathrm{~S}+\mathrm{H}_{2} \mathrm{SO}_{4}+2 \frac{1}{2} \mathrm{O}_{2} \rightarrow 2 \mathrm{CuSO}_{4}+\mathrm{H}_{2} \mathrm{O} \\
& 2 \mathrm{MoS}_{2}+9 \mathrm{O}_{2}+6 \mathrm{H}_{2} \mathrm{O} \rightarrow 2 \mathrm{H}_{2} \mathrm{MoO}_{4}+4 \mathrm{H}_{2} \mathrm{SO}_{4}
\end{aligned}
$$

the bacteria oxidizing the metal-sulfide substrate. The I. ferrooxidans, TH microbes, and Sulfolobus are all capable of copper mobilization by the direct process. However, only Sulfolobus species, growing at $70^{\circ} \mathrm{C}$, are able to oxidize the molybdenite $[11,12]$. This ability is in part due to the remarkable resistance of Sulfolobus to molybdate; they are able to grow in media containing 750 ppm molybdenum. Other metal-sulfide compounds which may be directly attacked by bacteria include arsenopyrite, stibnite, and pentlandite [9].

The leaching microorganisms may also participate in an electrochemical process of mineral oxidation. The metal sulfide acts as an anode (6) and the cathodic reaction occurs with either oxygen (7), ferric iron (8), or a mineral of more positive electrode potential.

$$
\begin{aligned}
& \mathrm{CuS} \rightarrow \mathrm{S}+\mathrm{Cu}^{2+}+2 \mathrm{e} \\
& \mathrm{O}_{2}+4 \mathrm{H}^{+}+4 \mathrm{e}^{-} \rightarrow 2 \mathrm{H}_{2} \mathrm{O} \\
& \mathrm{Fe}(\text { III })+\mathrm{e}^{-} \rightarrow \mathrm{Fe} \text { (II) }
\end{aligned}
$$

The microbes can act as catalysts for the transfer of electrons to oxygen (7), or the generation of ferric iron (8) which serves as the anode. Microbes may also participate in the electrochemical leaching process by removal of sulfur formed during the oxidation step (5). The sulfur accumulation may passivate the metal solubilization process by covering reactive surfaces. The microbe Thiobacillus thiooxidans can remove the sulfur by oxidation (9).

$$
\mathrm{S}+\mathrm{H}_{2} \mathrm{O}+1 \frac{1}{2} \mathrm{O}_{2} \rightarrow \mathrm{H}_{2} \mathrm{SO}_{4}
$$

\subsection{Reduction of Metals}

The chemolithotrophic T. ferrooxidans, I. thiooxidans, and Sulfolobus can reduce 
metals under anaerobic conditions. These microbes reduce ferric iron when oxidizing sulfur [13]. However, it is not certain if anaerobic growth occurs. It has been proposed that thiobacilli may facilitate metals extraction in anaerobic conditions by oxidizing the sulfur (using ferric iron as the oxidant) that covers minerals' surfaces and passivates the metal solubilization process (6). However, in metals-leaching conditions there will be little or no ferric iron available to serve as a possible electron acceptor for support of bacterial growth in anaerobic conditions. Most, if not all, of the ferric iron will be reduced by reaction with metal-sulfide minerals (2). The ferrous iron can only be oxidized under aerobic conditions (1).

Sulfolobus has been shown to oxidize sulfur and reduce molybdate in the absence of oxygen [14]. Hexavalent molybdenum is reduced to the pentavalent state with formation of "moly-blue". The hexavalent molybdenum appears to serve as a terminal electron acceptor, and growth of Sulfolobus occurs in anaerobic conditions. This type of reaction may be involved in molybdenum cycling and transport in various environments.

The reductive reactions may be a detoxification mechanism by which the thiobacilli protect themselves from the adverse effects of some metals. T. ferrooxidans have been shown to reduce mercuric ion to volatile mercury [15]. This reaction may be an important component of the cycling of mercury, particularly in areas where thiobacilli and mercury may coexist e.g., high pyritic content coal spoils. I. thiooxidans, when growing on sulfur, reduce vanadium (V) to vanady $(1 \mathrm{~V}$ ) ion, an apparent detoxification process [16]. This reduction mechanism was equated to a leaching process, since the vanadyl ion is soluble in weakly acid solutions.

3. Discussion

\subsection{Resource Recovery}

The microbial catalysis of mineral oxidation is, in part, responsible for extraction of metals from mine waste and low grade ores. Both copper and uranium are economically recovered by biological processes. Approximately $11 \%$ of the total copper produced nationally was estimated to be obtained by leaching practices [17] and much can be attributed to microbial activity. A large copper mine in the western United States obtained about one-third of total copper by a dump-leaching process involving micrcorganisms. Several recent reviews have dealt with this topic $[9,18,19,20,21]$.

Concentrations of copper in leach solutions may be from 0.8 to $8.0 \mathrm{~g} \mathrm{~L}^{-1}[11]$. This range of concentrations will have little detrimental effect on the microorganisms associated with leaching. The I. ferrooxidans tolerate concentrations of $\mathrm{Zn}, \mathrm{Ni}, \mathrm{Cu}, \mathrm{Co}, \mathrm{Mn}$ and $A 1$ at values up to $10 \mathrm{~g} \mathrm{~L}^{-1}$ when growing on ferrous iron [23].

The microbes catalyzing the leaching reaction appear to be 1 imited in distribution within leach dumps. The I. ferrooxidans have been found in high numbers, $10^{5}$ to $10^{7} \mathrm{~g}^{-1}$ dump material, at the surface of leach dumps and their numbers decrease rapidly within the leaching zone [24]. Their restriction to the upper surface, where oxygen is presumably not limiting, suggests that generation of ferric iron, the leaching lixiviant $(2,3)$, is the important mechanism for solubilization of metals. Recent unpublished data 
(Table 1) indicate that the concentrations of TH facultative thermophiles, which inhabit copper leaching dumps [25], also decrease with depth in a leach dump. The high numbers of these iron-oxidizing bacteria at the dump surface are believed to be due to available oxygen and high temperatures resulting from solar heating. These data also suggest that the microbes are assisting in metal mobilization by production of ferric iron which oxidizes metallic sulfides minerals in the absence of oxygen. However, few studies of microbial distribution within metal leaching systems have been reported, and further data may reveal wider distribution and greater involvement of the bacteria in the direct attack on metal sulfides $(4,5)$.

Table 1. Occurence of facultative-thermophilic thiobacillus-like microbes in a core sample from a copper-leaching mine dump ${ }^{\mathrm{a}}$.

\begin{tabular}{cc}
$\begin{array}{c}\text { Sample depth } \\
\text { below surface } \\
\mathrm{cm}\end{array}$ & $\begin{array}{c}\text { Bacterial-cel1 } \\
\text { concentration } \\
\mathrm{g}^{-1}\end{array}$ \\
\hline $0-15$ & $7.0 \times 10^{6}$ \\
$15-30$ & $6.2 \times 10^{5}$ \\
$30-46$ & $2.6 \times 10^{4}$ \\
\hline
\end{tabular}

${ }^{\mathrm{a}} \mathrm{Ce} 11$ concentrations were determined using a most-probable-number technique with incubation at $50^{\circ} \mathrm{C}$.

Uranium has also been recovered on an industrial scale using microbial processes. Leaching, using I. ferrooxidans, of mined-out zones and low grade heaps has been done at Elliot Lake, Ontario. Values of 4545 to $5455 \mathrm{~kg}$ of $\mathrm{U}_{3} \mathrm{O}_{8}$ have been produced per month by leaching [26]. The process occurs in an acidic solution using biologically-generated ferric iron, (3) as lixiviant.

\subsection{Transport of toxic metals}

In addition to their beneficial role in resource recovery, microorganisms create water pollution problems by mobilizing toxic elements.

Surface mining operations, which result in exposure pyritic and other metal-sulfides, may lead to acid pollution of water. As much as 4 millions tons of acidity per year are produced from both active and abandoned mines in the United States [27]. The I. ferrooxidans are catalysts of the acid generation reaction mechanism [28] and the acid environment encourages microbially-catalyzed solubilization of metal sulfide minerals $(2,3.4,5)$.

Basic iron sulfate or iron hydroxide, known as "yellow-boy", is a product of microbial oxidation of pyrite, marcasite, and other iron-containing metallic sulfide minerals. The "yellow-boy", which covers the bottom of streams polluted with acid mine waters, occurs when the acidic waters, carrying microbially-generated ferric iron, are neutralized. 
Arsenic, as orpiment, arsenopyrite: and enargite can be solubilized by T. ferrooxidans oxidative activity $[29,30]$. These minerals may be found in associations with other metal-sulfide deposits. The arsenic is solubilized as arsenite and arsenate, however presence of iron in solution may precipitate iron arsenite and arsenate.

other metals, including cobalt, nickel, and zinc can be leached as a result of direct oxidation by $I$. ferrooxidans of their respective sulfide minerals [31]. Rates of metal solubilization have been reported: cobalt 490, nickel 555, and zinc $590 \mathrm{mg} \mathrm{L}^{-1} \mathrm{~h}^{-1}$.

Energy production from oil shale, has potential for attendant microbially catalyzed toxic-metal transformations. Raw shale contains high concentrations (25 ppm) of the potentially toxic elements arsenic, boron, fluoride, lithium and molybdenum. Extraction of oil shale may cause redistribution of these elements as a result of mining, retorting, and disposal of processed shale and water [32].

A recent study [33] has considered the possible role of the chemolithotrophic bacteria in the catalysis of metal mobilization. Two species of chemolithotrophic bacteria, Thiobacillus thioparus and Thiobacillus denitrificans, have been found in samples of processed oil shale. Both species oxidize thiosulfate for energy; I. thioparus require oxygen (10), and I. denitrificans can grow with oxygen or nitrate as an oxidant (11).

$$
\begin{gathered}
\mathrm{S}_{2} \mathrm{O}_{3}{ }^{2-}+2 \mathrm{O}_{2}+\mathrm{OH}^{-} \rightarrow 2 \mathrm{SO}_{4}{ }^{2-}+\mathrm{H}^{+} \\
5 \mathrm{Na}_{2} \mathrm{~S}_{2} \mathrm{O}_{3}+8 \mathrm{NaNO}_{3}+\mathrm{H}_{2} \mathrm{O} \rightarrow 9 \mathrm{Na}_{2} \mathrm{SO}_{4}+\mathrm{H}_{2} \mathrm{SO}_{4}+4 \mathrm{~N}_{2}
\end{gathered}
$$

These microbes are not acidophilic, but $I$. thioparus can grow until the pH reaches about 4.5. It is possible that growth of this microbe may promote a microbial succession resulting in a population of acidophilic bacteria.

If a mining process leads to exposure of materials which have acid generation potential and a low buffering capacity, microbial processes can calalyze acid generation and oxidation of metal sulfides. The result will be dissolution of heavy metals which may ultimately find their way into water and the food chain.

4. Concluding Remarks

Bacteria, which oxidize ferrous iron, metal-sulfides, and sulfur, are catalysts for solubilization of metals and metalloids including copper, molybdenum, uranium, nickel, cobalt, zinc, arsenic and sulfur. The bacterial catalysts, which function optimally in slightly acidic solutions, are I. ferrooxidans, I. thiooxidans, TH designated facultative-thermophilic thiobacillus-like microbes, and Sulfolobus. The occurrence and activities of the bacteria can be useful for recovery of metals from mine-wastes and low-grade ores when the processes are controlled. However, these bacteria may also create pollution conditions by leaching of toxic metals and metalloids from disturbed lands.

0xygen requirement largely controls the ability of the bacteria to effect metal leaching. The process of direct bacterial oxidation of metal sulfides and bacterial generation of ferric iron, a lixiviant for leaching, require aerobic conditions. Only 
limited anaerobic bacterial activity appears to contribute to metals leaching by oxidation or reduction reactions.

It is important to understand the conditions which are required for catalysis of metals and metalloid transformation, since definition of the microbiology, geochemistry, and solution chemistry of the mechanisms will lead to control of the processes for enhanced metal recovery and pollution abatement.

The author thanks Corale Brierley for her review and help in preparation of this manuscript. Some of the data reported here was obtained through a grant from the Department of Energy (Trace Elements in 011 Shale, \#EV-10298). I thank Dr. Fred Brinckman for the invitation to participate in the DOE/NBS Workshop on Environmental Speciation and Monitoring Needs where the information contained in this paper was presented.

\section{References}

[1] Jernelov, A.; Martin, A-L. Ecological implications of metal metabolism by microorganisms, in Annual Review of Microbiology, Vol. 29. M.P. Starr, J.L. Ingraham, S. Raffel, ed. Palo Alto, CA: Annual Reviews Inc.; 1975. 61-77.

[2] Iverson, W.P.; Brinckman, F.E. Microbial metabolism of heavy metals, chapter 8 in Water pollution microbiology, Vol. 2. R. Mitchel1, ed. New York, NY: John Wiley \& Sons; 1978. 201-232.

[3] Brock, T.D.; Brock, K.M.; Belly, R.T.; Weiss, R.L., Sulfolobus: A new genus of sulfur-oxidizing bacteria living at low pH and high temperature. Arch. Mickrobiol. 84: 54-68; 1972.

[4] Brierley, C.L.; Brierley, J.A., A chemoautotrophic and thermophilic microorganism isolated from an acid hot spring. Can. J. Microbiol. 19: 183-188; 1973.

[5] LeRoux, N.W.; Wakerley, D.S.; Hunt, S.D. Thermophilic thiobacillus-type bacteria from Icelandic thermal areas. J. Gen. Microbiol. 100(1): 197-201; 1977

[6] Brierley, J.A.; LeRoux, N.W. A facultative thermophilic Thiobacillus-like bacterium: oxidation of iron and pyrite. Schwartz, W. ed. Conference bacterial leaching 1977; 1977 March 23-26; Braunschweig, FDR. Gesellsch. Biotechnol. Forsch. Monogr. Ser. 4; 1977. 55-66.

[7] Brierley, J.A.; Norris, R.P.; Kelly, D.P.; LeRoux, N.W. Characteristics of a moderately thermophilic and acidophilic iron-oxidizing Thiobacillus. Eur. J. Appl. Microbiol. Biotechnol. 5: 219-299; 1978.

[8] Norris, P.R.; Brierley, J.A.; Kelly, D.P. Physiological characteristics of two facultatively thermophilic mineral-oxidizing bacteria. FEMS Micro. Letts. 7: 119122; 1980.

[9] Kelly, D.P.; Norris, P.R.; Brierley, C.L. Microbiological methods for the extraction and recovery of metals, in Microbial Technology, Society for General Microbiology Symposium 29. A.T. Bu11, D.C. Ellwood, C. Ratledge, ed. New York, NY. Cambridge University Press. 1979. 263-308.

[10] Lacey, D.T.; Lawson, F. Kinetics of the Tiquid-phase oxidation of acid ferrous su1fate by the bacterium Thiobacillus ferrooxidans. Biotechnol. Bioeng. 12: 29-50; 1970.

[11] Brierley, C.L.; Murr, L.E. Leaching: Use of a thermophilic and chemoautotrophic microbe. Science 179: 488-490; 1973.

[12] Brierley, C.L. Molybdenite-leaching: use of a high temperature microbe. J. Less Common Metals 36: 237-247; 1974. 
[13] Brock, T.D.; Gustafson, J. Ferric iron reduction by sulfur-and iron-oxidizing bacteria. Appl. and Environ. Microbio1. 32(4): 567-571; 1976.

[14] Brierley, C.L., Brierley, J.A. Reduction of molybdenum by a thermophilic bacterium. Program of the international conference of heavy metals in the environment; 1975 October 27-31; Toronto. 211.

[15] 01son, G.J.; Iverson, W.P.; Brinckman, F.E. Volatilization of mercury by Thiobacillus ferrooxidans. Curr. Microbio1. 5: 115-118; 1981.

[16] Jack, T.R.; Sullivan, E.A.; Zajic, J.E. Growth inhibition of Thiobacillus thiooxidans by metals and reductive detoxification of vanadium (V). 9(1): $21-30 ; 1980$.

[17] Wadsworth, M.E. Physico-Chemical aspects of solution mining. Kim, Y.S. ed. Symposium inplace leaching and solution mining; 1975 November 10-14; Mackay School of Mines, University of Nevada, Reno. 1975. Chap 8.

[18] Torma, A.E. The role of Thiobacillus ferrooxidans in hydrometallurgical processes, in Advances in Biochemical Engineering, Vol. 6. T.K. Ghose, A. Frechter, N. Blackebrough, ed. New York, NY: Springer Verlag; 1977. 1-37.

[19] Brierley, C.L. Bacterial 1eaching. CRC Crit. Revs. Microbiol. 6: 207-262; 1978.

[20] Lundgren, D.G.; Silver, M. Ore leaching by bacteria, in Annual Reviews of Microbiology, Vol. 34. M.P. Starr, J.L. Ingraham, A. Balows, ed. Palo Al to, CA: Annual Reviews Inc.; 1980. 263-283.

[21] Murr, L.E. Theory and practice of copper sulphide leaching in dumps and in-situ. Min. Sci. Eng. 12(3): 121-189;1980.

[22] Sheffer, H.W.; Evans, L.G. Copper leaching practices in the western United States. Bur. of Mines (U.S.) Inform. Circ. 8341; 1968. 57 p.

[23] Tuovinen, O.H.; Niemela, S.I.; Gyllenberg, H.G. Tolerance of Thiobacillus ferrooxidans to some metals. Antonie van Leeuwenhook $374: 489-496 ; 1971$.

[24] Bhappu, R.B; Johnson, P.H.; Brierley, J.A.; Reynolds, D.H. Theoretical and practical studies on dump leaching. Trans. Soc. Min. Engs. AIME 244: 307-320; 1969.

[25] Brierley, J.A.; Lockwood, S.J. The occurrence of thermophilic iron-oxidizing bacteria in a copper 1eaching system. FEMS Microbiol. Lett. 2: 163-165; 1977.

[26] MacGregor, R.A. Recovery of $\mathrm{U}_{308}$ by underground leaching. Can. Min. Meta1. Bu11. 59: $583-5871966$.

[27] Lundgren, D.G.; Vesta1, J.R.; Tabita, F.R. The microbiology of mine drainage pol1ution, chapter 4 in Water pollution microbiology, R. Mitchell, ed. New York, NY: John Wiley \& Sons; 1972. 69-88.

[28] Singer P.G.; Stumm, W. Acidic mine drainage: the rate-determining step. Science 167: $1121-1123.1970$.

[29] Ehrlich, H.L. Bacterial oxidation of arsenopyrite and enargite. Econ. Geol. 59 : 1306-1312; 1964 .

[30] Ehrlich, H.L. Bacterial action on orpiment. Econ. Geol. 58(6): 991-994; 1963.

[31] Torma, A.E. Microbiological oxidation of synthetic cobalt, nickel and zinc sulfides by Thiobacillus ferrooxidans. Rev. Can. Biol. 30(3): 209-216. 1971 .

[32] Redistribution of accessory elements in mining and mineral processing. Part I: Coal and oil shale. National Academy of Sciences (U.S.). Washington, D.C.; 1979. $180 \mathrm{p}$.

[33] Brierley, C.L.; Brierley, J.A. Microbial thiosulfate oxidation and its effect on the quality of water in oil shale retorting. Progress report for Department of Energy (U.S.). 1981 . 
Question (E. A. Woolson): In well waters that have been identified as having high arsenic concentration, you frequently find arsenate and you also find $\mathrm{H}_{2} \mathrm{~S}$. Would this be due to bacterial decomposition of a mineral?

Answer: I rather suspect not in the case of $\mathrm{H}_{2} \mathrm{~S}$. The sulfate-reducing microorganisms which are fairly widely distributed, for the most part, will utilize an organic compound as a reductant for sulfate to sulfide, although hydrogen can serve as a reductant as we 11. They would not, to my knowledge, attack a mineral. The arsenate may be a consequence of microbial mobilization, but it is not necessarily due to the oxidation of enargite or orpiment or one of the arsenic-containing minerals. Rather, it could be due to an organic chelation reaction. This will be addressed by Dr. Klein specifically in his oil shale work looking at arsenic transformations; it would not be a phenomenon of these types of organisms I have been describing.

Question (F. E. Brinckman): A Russian group has reported [N. N. Lyalikova, Mikrobiologiya, 43:941 (1974)] on a Stibiobacter, an obligate microorganism, which involves antimony for an energy cycle in its cell metabolism; I don't recall whether it was an oxidation or reductive process with respect to antimony. Do you see prospects for more organisms of this type which require heavy metals or metalloids in direct processes? This presumably involves cell uptake (cellular storage) rather than just respiration of metals and metalloids.

Answer: Indeed, we will see more of that. Certainly, uptake is a very real phenomenon. Now, these organisms here we don't know if they are involved with uptake at all, but we have examined Sulfolobus, we have done a STEM and an energy dispersive $x$-ray to see molybdenum accumulation. I am not sure if I really understood your question.

Question (F. E. Brinckman): My question comes from my bias as a chemist. At this stage, with increasing sophistication in analytical tools, such as the STEM, one can now get element mapping of cell parts. You get the idea that there is a remarkable accumulation of elements being found. I mentioned antimony, but that seems very unusual to me; I can't imagine it is a good energy process, but this is the argument, at least, of that particular group. In consequence, it would seem that there is no part of the Periodic Table which will find relief from microorganisms, so chemists will look to the microbiologists to find those bugs. This is really the heart of my question: are we now going to see a range of papers coming along which will start showing unusual or unexpected transformations of elements in oxidation states? I am fascinated, for example, by the apparent going against the energy gradient in some of the redox reactions which you showed. Vanadium, for example, is of interest to me in the five-to-four couple and also the molybdenum couple.

Answer: I am not sure the molybdenum couple is against energy. 
Question (F. E. Brinckman): That may not be, that was anaerobic.

Answer: I think that is quite true. Many of these reactions are probably detoxification reactions, where you may reduce a metal and it subsequently accumulates. We have seen this with a lot of other metals--these will be reduced, commonly, in some types of microorganisms.

Question (T. F. Yen): Vanadium is known to be existing in tunicates, and some of the dry weight is very high in vanadium content. It is a hemovanadine; some people call it that. Apparently, it is probably involved in the transport process. It is still clouded today. What sort of role is the vanadium involved in the oxygen transport in your organisms?

Answer: In the organisms that you speak about, I presume it is an oxygen transport role. It's equivalent to hemoglobin using vanadium as an oxygen carrier, but in these bacteria it has no role--it is detoxification.

Question (Voice not identified): Will these sulfur bacteria show selectively toward different sulfur bonds in the coal, for example, pyrite and sulfate and organic sulfur?

Answer: The ones that we are dealing with here will oxidize pyritic sulfur in coals. They will not go after organic sulfur, and, of course, sulfate. There may be an oxidation product of previous oxidations so that Sulfolobus and Thiobacillus can remove sulfur from coal by oxidation.

Question (J. D. Walter): Could you discuss briefly mobilization of toxic pollutants by these microorganisms?

Answer: Later, perhaps, if there is time, but Dr. Strandberg will address this area in his paper. You mean by copper and uranium? 
Microbial Accumulation of Uranium, Radium, and Cesium*

G. W. Strandberg, S. E. Shumate II,

J. R. Parrott, Jr., and S. E. North

Chemical Technology Division

Oak Ridge National Laboratory

Oak Ridge, Tennessee 37830

Diverse microbial species varied considerably in their ability to accumulate uranium, cesium, and radium. Mechanistic differences in uranium uptake by Saccharomyces cerevisiae and Pseudomonas aeruginosa were indicated. S. cerevisiae exhibited a slow (hours) surface accumulation of uranium which was subject to environmental factors, whereas $P$. aeruginos a cumulated uranium rapidly (minutes) as dense intracellular deposits and did not appear to be affected by environmental parameters. Metabolism was not required for uranium uptake by either organism. Cesium and radium were concentrated to a considerably lesser extent than uranium by the several species tested.

Key words: cesium; metal accumulation; microbial; radium; uranium.

\section{Introduction}

The intent of this report is to summarize our findings concerning some fundamental aspects of radionuclide accumulation by microbial cells, to consider these results with respect to what has been reported about microbial metal biosorption, and to illustrate the complexities attendant to an understanding of the phenomenon. The studies described here were carried out in conjunction with our efforts to develop a process to utilize microbial cells as a biosorbent for the concentration and removal of heavy metals from select aqueous waste streams - in particular, nuclear processing wastewaters. We felt from the beginning that an understanding of the mechanism(s) of metal uptake would provide a better rationale for process design and would potentially enable the enhancement of metal uptake through environmental or genetic manipulation of the microorganisms being utilized.

Although microorganisms are capable of concentrating a variety of metal species via metabolically mediated and growth-associated processes (see refs. $1-3$ for reviews and other papers in these proceedings), the phenomenon of biosorption (i.e., the physical/ chemical complexation of metals by cellular components) appeared to have significant

*Research sponsored by office of Nuclear Waste Management and office of Environmental Research, U.S. Department of Energy, under contract W-7405-eng-26 with the Union Carbide Corporation. 
advantages for process application [4]. The use of metal biosorption for the treatment of wastewater and recovery of valuable heavy metals had been suggested as early as 1949 by Ruchoft [5]. Other workers have since reported schemes for the biosorptive removal of metal radionuclides from aqueous streams [6-9], and even the biosorptive extraction of uranium from natural waters has been proposed [10-11].

As indicated, biosorption is generally considered as a complexation between metal cations and negatively charged extracellular components. For instance, Ruchoft [5] attributed the ability of activated sludge to remove ${ }^{239} \mathrm{Pu}$ to a microbial population providing a gelatinous matrix for metal adsorption. Other investigators [8, 12-14] have also suggested that microbial extracellular polymers having negatively charged constituents were responsible for metal ion complexation. A detailed investigation by Rothstein and Meier [15] provided evidence that surface-associated reactive groups chemically similar to high-molecular-weight polyphosphates were responsible for uranium uptake by $S$. cerevisiae. Dounce and Flagg [16] concluded that the carboxyl groups of proteins were effective in complexing uranium. Complimentary studies by Beveridge and Murray [17] and Matthews and Doyle [18] showed that the carboxyl groups of the peptidoglycans in cell walls of Bacillus subtilis are the primary sites of divalent metal complexation. Tsezos and Volesky [19] have suggested that the primary site of uranium and thorium binding by Rhizopus arrhizus is the chitin component within the cell walls of this fungus. However, their electron micrographs appeared to show considerable thorium accumulation at the outer wall surface.

Our own studies have been directed at a characterization of uranium uptake by S. cerevisiae and Pseudomonas aeruginosa. These organisms were selected for study from an earlier survey [20] because they demonstrated significant uranium uptake, they had both been used in previous metal uptake studies, and many fundamental aspects of their physiology and structure were well documented.

The ability of a variety of microorganisms to accumulate cesium and radium was considered in regard to potential treatment processes for two radioactively contaminated waste solutions. The results of these studies are discussed briefly to further demonstrate the complexities of the biosorption phenomenon.

\section{Methods}

The detailed methodology used in our experiments has been described previously [4, 20, 21]. Essentially, washed cells were resuspended in an aqueous solution containing a known concentration of the radionuclide. At the desired time intervals, cells were removed from aliquots of the primary suspension by centrifugation. The remaining soluble uranium was assayed spectrophotometrically using Arsenazo III reagent [4]. Cesium-137 and 226Ra were assayed by gamma radiation counting. Cell-free controls were run concurrently. 
Growth-associated ${ }^{137} \mathrm{Cs}$ and ${ }^{226} \mathrm{Ra}$ accumulations were determined as above after growing the organisms in an appropriate medium containing the radionuclides.

3. Results and Discussion

\subsection{Uranium}

Biosorptive complexation of metal cations by definition does not require metabolic activity by the microorganism, nor is preexposure or adaptation to the metal required. However, it is possible that preexposure could result in an increase in biosorption sites if the organism was capable of utilizing the phenomenon as a detoxification mechanism. Conversely, preexposure might induce a population with a lesser affinity for potentially toxic metals. In our uranium uptake experiments and in those of the other workers previously cited, the cells were cultured in the absence of uranium. Additionally, they were washed free of extraneous nutrients prior to exposure to uranium. Thus the measured uranium uptake was considered to be due to complexation sites normally occurring within the cell structure. Uranium uptake by S. cerevisiae and $P$. aeruginosa was found to occur rapidly ( $1-2 \mathrm{~h}$ and a few minutes respectively). In fact, using a specially devised ion-exchange procedure [21], we have determined that when $P$. aeruginosa is exposed to a solution containing $100 \mathrm{~g} / \mathrm{m}^{3}$ urany1 nitrate, approximately $99 \%$ of the uranium becomes firmly associated with the cells in less than $10 \mathrm{~s}$. As a consequence of this rapid uptake rate, the apparent lack of any effect of the conditions imposed during uranium uptake by this organism may be due to our inability to monitor the time course of reaction within a time frame of several seconds.

Both species have a substantial capacity for uranium in that they can accumulate from 10 to $15 \%$ of their original dry cell weight as uranium. This capacity is similar to that obtained for a mixed culture of denitrifying bacteria [22] and for $R$. arrhizus [9].

Electron micrographs of $S$. cerevisiae cells that had been exposed to uranium revealed that the metal accumulated as needle-like fibrils in a layer approximately $0.2 \mu m$ thick on the cell surfaces [21]. Furthermore, only $32 \%$ of the cells within a population had uranium deposits. Since only $32 \%$ of the cells possessed uranium deposits, the metal concentration on that fraction approaches $50 \%$ on a dry weight basis. It was difficult to imagine that there were sufficient binding sites to account for this much uranium. However, Beveridge and Murray [23] observed a nonstoichiometric accumulation of tnetals on isolated walls of $B$. subtilis. They suggested that metal ions complex with existing reactive sites and that additional metal crystallizes on these bound molecules.

In contrast to the surface accumulation exhibited by $S$. cerevisiae, uranium was found as dense intracellular deposits in $P$. aemginosa [21]. These deposits did not 
appear to be associated with a particular structure or physical location within the cells. Intracellular deposition was demonstrated in cells exposed to uranium for 2 h. Electron microscopic examination after shorter exposure times has not been attempted. Although we lack visual evidence of immediate intracellular deposition of uranium, we do know that uranium is firmly associated with the cells within a few seconds. As was observed with S. cerevisiae, not all cells of $P$. deruginosa possess uranium deposits. Only 40 to $45 \%$ of the cells did so.

Our current investigation is being directed at the question of why only a fraction of the cells within a population of either species is capable of accumulating uranium. This has significant process implications, for if we can induce all of the cells to accumulate uranium, we can greatly enhance the potential for utilizing these cells as biosorbents. We also feel that this question is of fundamental importance to understanding the mechanism of metal uptake in these cells. We have found that the rate of uranium uptake and total cellular capacity for the metal by $S$. cerevisiae is affected by growth conditions, presumably through growth rate-induced changes in the cell wall composition [21,24]. We are currently attempting to correlate cell wall composition with growth and uranium uptake rates and to determine if that fraction of cell population accumulating uranium is altered by growth conditions.

Consistent with the view that metal biosorption occurs by complexation of positively charged metal ions with negatively charged reactive sites (e.g., carboxyl and phosphate groups), uranium uptake by $S$. cerevisiae was affected by environmental parameters including $\mathrm{pH}$, temperature, and competing cations [21]. Once bound, uranium could not be removed by water washing. Metal complexing; agents such as ammonium carbonate, nitric acid, and disodium ethylenediaminetetraacetic acid (al1 $0.1 \underline{M}$ ) were only partially effective, removing $83.5,59.3$, and $72.3 \%$, respectively, of the bound uranium after 16 h. Any interpretation of the environmental effects observed must take into account the effect of the environment on the reactive metal binding sites as well as the complex solution chemistry of uranium.

Although we have not specifically identified the uranium complexing sites on the surface of $S$. cerevisiae, experiments employing chemical pretreatment of the cells (i.e., formaldehyde) and pure wall components (i.e., amino acids, phosphomannan) suggest that both phosphate and protein moieties could be involved [21].

Uranium uptake by $S$. cerevisiae and $P$. aeruginosa was not metabolical1y mediated [21]. With the caveat that we have been unable to measure the transition from initial to equilitrium states during uranium uptake by $P$. aemginosa, none of the conditions and treatments. which affect uranium uptake by $S$. cerevisiae have an effect on $P$. aemginosa. We are currently unable to explain the uranium uptake phenomenon in this organism. 


\subsection{Cesium}

The ability of microorganisms to remove ${ }^{137} \mathrm{Cs}$ from solution was considered in regard to a potential treatment process for select high-level radioactively contaminated waste solution (SRSSW). The actual waste solution was simulated for our laboratory studies with a mixture of reagent-grade chemicals. It contained several metal species other than cesium and high concentrations of nitrate. Unlabeled CSC1 was added to SRSSW and to the other test solutions to attain the concentrations shown in Table 1; also added was about $50 \mu \mathrm{Ci}$ of ${ }^{137} \mathrm{CsCl}$ as a tracer.

As shown in Table 1, the distribution coefficients obtained were relatively low, and in all cases the bulk of the cesium (as evidenced by soluble radioactivity measurements) remained in solution. The denitrifying bacteria grew little, if at all, in the presence of cesium when ethanol was the carbon source and when the cultures were incubated anaerobically under a nitrogen atmosphere.

Table 1. Uptake of ${ }^{137} \mathrm{Cs}$ by microorganisms

\begin{tabular}{|c|c|c|c|c|c|}
\hline Microorganism & $\begin{array}{l}\text { Cell } \\
\text { Stage }\end{array}$ & $\begin{array}{l}\text { Culture } \\
\text { medium }\end{array}$ & $\begin{array}{l}\text { Initial cesium } \\
\text { concentration } \\
\qquad\left(\mathrm{g} / \mathrm{m}^{3}\right)\end{array}$ & $\begin{array}{c}\text { Cell } \\
\text { concentration } \\
(\mathrm{g} / 100 \mathrm{~mL})\end{array}$ & $\begin{array}{l}\text { Distribution } \\
\text { coefficient }^{a}\end{array}$ \\
\hline \multirow{4}{*}{$\begin{array}{l}\text { Pseudomonas } \\
\text { aeruginosa }\end{array}$} & Rest & SRSSW at $\mathrm{pH} 4$ & 0.12 & 0.4 & 11 \\
\hline & & SRSSW at $\mathrm{pH} 7$ & 0.12 & 0.4 & 12 \\
\hline & & SRSSW at $\mathrm{pH} 10.2$ & 0.12 & 0.4 & 9 \\
\hline & Growth & Complex organic ${ }^{b}$ & 0.017 & 0.2 & 16 \\
\hline \multirow{2}{*}{$\begin{array}{c}\text { Saccharomyces } \\
\text { cerevisiae }\end{array}$} & Rest & Water at $\mathrm{pH} \sim 6$ & 0.006 & 0.6 & 26 \\
\hline & Growth & Complex organic ${ }^{b}$ & 0.017 & 0.4 & 37 \\
\hline \multirow{6}{*}{$\begin{array}{l}\text { Mixed culture of } \\
\text { denitrifying } \\
\text { bacteria }\end{array}$} & Growth & Denitrifying $^{c}$ & 0.013 & $0.002,0.003$ & 228,469 \\
\hline & Growth & $\mathrm{SRSSW}^{\mathrm{c}}$ & 0.013 & 0.04 & 9 \\
\hline & & & 0.013 & 0.04 & 15 \\
\hline & & & 0.013 & $0.006,0.010$ & 95,137 \\
\hline & & & 0.013 & 0.03 & 21 \\
\hline & & & 0.913 & 0.05 & 49 \\
\hline
\end{tabular}

${ }_{\text {Distribution coefficient: }} \frac{\mathrm{cpm}{ }^{137} \mathrm{Cs} \text { per } \mathrm{g} \text { cells }}{\mathrm{cpm}{ }^{137} \mathrm{Cs} \text { per } \mathrm{g} \text { solution }}$.

${ }^{b}$ Complex organic medium (see ref. 21).

${ }^{c}$ Ethanol (0.5\% v/v) as carbon source (see ref. 20). 
Published reports of microbial cesium accumulation indicate that both growth-related and adsorptive phenomena occur [8, 25-30]. The growth stage at which maximum accumulation occurs varies in these reports. Also, it has been found that cesium is not permanently associated with growing cells and that firm binding is more significant in old cells and detritus.

We attempted to compare our results with those in the literature. Notably, it has been shown that cesium accumulation factors or distribution coefficients decrease as the cesium concentration increases. For example, Fisel et al. [8] observed that Paecizlomyces marquandii exhibits maximum accumulation ( $34 \%$ of added ${ }^{137} \mathrm{Cs}$ ) at the lowest cesium concentration tested $(\sim 0.008 \mathrm{mM} \mathrm{Cs})$. With ChIorella pyrenoidosa [28], increasing the cesium concentration from a tracer level (10 $\left.\mu \mathrm{Ci}{ }^{137} \mathrm{Cs} / \mathrm{L}\right)$ to $0.5 \mathrm{mM}$ decreases the concentration factor by three fold. Williams [29] also found that a cesium concentration of $0.15 \mathrm{mM}$ significantly reduces the concentration factor in Euglena intermedia. Cesium incorporation studies done by other workers [26, 27, 29] involved very low ${ }^{137} \mathrm{Cs}$ levels (2 to $20 \times$ $10^{-5} \mu \mathrm{Ci} / \mathrm{mL}$ ), and relatively high distribution coefficients were obtained.

The results in the literature as well as our own are presented as distribution coefficients or accumulation factors. Microbial cells appear to have a finite capacity for accumulating metal ions by biosorption [4, 9, 21] when they are exposed to solutions containing increasing concentrations of metal ions. Once they have adsorbed all of the metal possible, soluble metal ions may not inhibit further metal uptake but merely depress the observed distribution coefficient. We were unable to deduce the loading capacity from the data in the literature, and our own experiments were not designed to obtain this value. However, a very rough estimate from our data indicated a loading capacity of less than $10 \mathrm{\mu g}$ of cesium per gram of cells. In all cases, the greater portion of cesium remained in solution, which provides evidence that the cells were saturated with cesium under the conditions imposed.

\subsection{Radium}

Radium-226 incorporation by microbial cells was considered with regand to another radioactive waste problem - namely, contaminated waste storage ponds. In addition to ${ }^{226} \mathrm{Ra}$, the water contains a variety of other metal species and $1.3 \%$ nitrate. Samples of the pond water were treated as indicated in Table 2. Radium-226 incorporation was determined for resting cells and under growth conditions.

It can be seen that some organisms can accumulate ${ }^{226} \mathrm{Ra}$ under resting cell or growth conditions (Table 2). However, the distribution coefficients are relatively low. 
Table 2. Uptake of $226 \mathrm{Ra}(345 \mathrm{pCi} / \mathrm{L})$ from contaminated pond water by growing cultures and resting cells

Microorganisms and conditions $\quad \begin{aligned} & \text { Distribution } \\ & \text { coefficient }\end{aligned}$

Growing cultures

\begin{tabular}{|c|c|c|}
\hline \multicolumn{3}{|l|}{$\begin{array}{l}\text { Mixed culture of } \\
\text { denitrifying bacteria }\end{array}$} \\
\hline \multicolumn{2}{|l|}{$\begin{array}{l}\text { Glucose grown }(20 \mathrm{~d}) \\
\text { Ethanol grown }(20 \mathrm{~d})\end{array}$} & $\begin{array}{l}104,119 \\
124,126\end{array}$ \\
\hline \multicolumn{3}{|l|}{ Chlorelza pyrenoidosa } \\
\hline \multicolumn{2}{|l|}{$\begin{array}{l}\text { Shake culture (17 d) } \\
\text { Static culture (17 d) }\end{array}$} & $\begin{array}{l}51 \\
41\end{array}$ \\
\hline \multicolumn{3}{|l|}{ WS algae ${ }^{b}$} \\
\hline \multicolumn{2}{|l|}{$\begin{array}{l}\text { Shake culture (17 d) } \\
\text { Static culture (17 d) }\end{array}$} & $\begin{array}{l}46 \\
32\end{array}$ \\
\hline \multicolumn{3}{|c|}{ Resting cells } \\
\hline Pseudomonas aeruginosa & $\begin{array}{ll}\mathrm{pH} & 4 \\
\mathrm{pH} & 6.9\end{array}$ & $\begin{array}{l}<<1^{c} \\
<<1^{c}\end{array}$ \\
\hline Saccharomyces cerevisiae & $\mathrm{pH} 4$ & $\begin{array}{l}<<1^{c} \\
<<1\end{array}$ \\
\hline Ashbya gossypii & $\mathrm{pH} 7.7$ & 344 \\
\hline Penicillium chrysogenum & $\mathrm{pH} 7.7$ & 624 \\
\hline \multirow{2}{*}{$\begin{array}{l}\text { Mixed culture of } \\
\text { denitrifying } \\
\text { bacteria }\end{array}$} & $\begin{array}{ll}\mathrm{pH} & 3.9 \\
\mathrm{pH} & 5.7\end{array}$ & $\begin{array}{r}7 \\
95\end{array}$ \\
\hline & $\mathrm{pH} 7.7$ & 38 \\
\hline
\end{tabular}

Distribution coefficient: $\frac{\mathrm{pCi}{ }^{226} \mathrm{Ra} / \mathrm{g} \text { cells }}{\mathrm{pCi}{ }^{226} \mathrm{Ra} / \mathrm{g} \text { solution }}$.

bixed algal, blue-green algal population isolated from pond water.

${ }_{\mathrm{pCi}}{ }^{226} \mathrm{Ra} / \mathrm{g}$ cells essentially equivalent to background.

Little is known about the microbial accumulation of radium. Jilek et al. [6] observed the removal of ${ }^{226} \mathrm{Ra}$ from a waste stream by chemically derivitized mycelia of Penicizzium chrysogenum, but no distribution coefficients or cellular capacities were reported. P. A. Taylor of the Chemical Process Department, Y-12 Development Division, Union Carbide Corp., Nuclear Division, Oak Ridge, Tennessee (unpublished), found 95\% of the ${ }^{226} \mathrm{Ra}$ removed during long-term (months) growth of denitrifying microorganisms 
in the same pond water we examined. Methanol was used as a carbon source. In contrast, we found very little ${ }^{226} \mathrm{Ra}$ removal either by biosorption or during short-term (weeks) growth experiments. Further experimentation will hopefully resolve these differences.

4. Conclusion

Our studies and the work of others provide adequate evidence that the biosorptive association of metal cations with microbial cells involves varied and complex phenomena. There are significant differences in the extent of accumulation as well as the mechanisms by which accumulation occurs. In a process environment, using pure or defined mixed cultures, it is possible to exercise some degree of control over the phenomenon. However, in a natural environment containing a multitude of microbial and chemical species, it would be difficult to predict, except in a general way, the association of radionuclides with microbial cells.

5. References

[1] Silverman, M. P.; Erlich, H. L. Microbial formation and degradation of minerals. Adv. App1. Microbio1. 6: 153-206; 1964.

[2] Jernelöv, A.; Martin, A. Ecological implications of metal metabolism by microorganisms. Ann. Rev. Microbiol. 29: 61-77; 1975.

[3] Summers, A. O. Microbial transformations of metals. Ann. Rev. Microbiol. 32: 637-72; 1978.

[4] Shumate, S. E. II; Strandberg; G. W.; Parrott, J. R., Jr. Biological removal of metal ions from aqueous process streams. Biotechnol. Bioeng. Symp. 8: 13-20; 1978.

[5] Ruchoft, C. C. The possibilities of disposal of radioactive wastes by biological treatment methods. Sewage Works J. 21: 877-83; 1979.

[6] Jilek, R.; Prochazka, H.; Stamberg, K.; Katzer, J.; Nemec, P. Nekteré vlastnosti a výroj nakultivoraného biologického sorbentu (Some properties and development of cultivated biosorbent). Rudy 23: 282-86; 1975.

[7] Norris, P. R.; Kelley, D. P.; Accumulation of metals by bacteria and yeasts. Dev. Ind. Microbiol. 20: 299-308; 1979.

[8] Zajic, J. E.; Chiu, Y. S. Recovery of heavy metals by microbes. Dev. Ind. Microbiol. 13: 91-100; 1972 .

[9] Tzezos, M.; Volesky, B. Biosorption of uranium and thorium. Biotechnol. Bioeng. 23: 583-604; 1981 .

[10) Sakaguchi, T.; Horikoshi, T.; Nakajima, A. Uptake of uranium from seawater by microalgae. J. Ferment. Technol. 56: 561-65; 1978.

[11] Heide, E.; Paschke, M.; Wagner, K.; Wald, M. Aus kultivierbaren Mutanten von einzelligen Grünalgen bestehende Matrix sowie Verfahren zur Urangewinnung dieser Matrix. German patent 2,345,430; 1975. 
[12] Dugan, P. R.; Pickrum, H. M. Removal of mineral ions from water by microbially produced polymers. Purdue Univ. Eng. Ext. Ser. Eng. Bu1l. 141: 1019-38; 1972.

[13] Costerton, J. W.; Geesey, G. G.; Cheng, K. -J. How bacteria stick. Sci. Am. 238: 86-95; 1978.

[14] Corpe, W. A. Metal-binding properties of surface materials from marine bacteria. Dev. Ind. Microbiol. 16: 249-55; 1975.

[15] Rothstein, A.; Meier, R. The relationship of cell surface to metabolism. VI. The chemical nature of uranium-complexing groups on cell-surface. J. Cell. Comp. Physiol. 38: 245-70; 1951.

[16] Dounce, A. L.; Flagg, J. F. The chemistry of uranium compounds in pharmacology and toxicology of uranium compounds, Part I. C. Voegtlin and H. C. Hodge, eds. New York: McGraw-Hill; 1949. 55-145.

[17] Beveridge, T. L.; Murray, R. G. E. Sites of metal deposition in the cell wall of Bacizlus subtizis. J. Bacteriol. 141: 876-87; 1980.

[18] Matthews, T. H.; Doyle, R. J. Abstr. Ann. Meeting Am. Soc. Microbiol.; 1979; K86. $159 \mathrm{p}$.

[19] Tsezos, M.; Volesky, B. Biosorptive concentration of nuclear fuel elements. Symposium on microbial processes for metals accumulation and sulfur nitrogen removal from fuels; Las Vegas, NV; Amer. Chem. Soc. Aug. 24-29, 1980.

[20] Shumate, S. E. II; Hancher, C. W.; Strandberg, G. W. ; Scott, C. D. Biological processes for environmental control of effluent streams in the nuclear fuel cycle. Waste management and fuel cycles. R. G. Post and M. E. Wacks, eds. Tucson, Arizona: Univ. Arizona Press; 1978. 347-55.

[21] Strandberg, G. W.; Shumate, S. E. II; Parrott, J. R., Jr. Microbial cells as biosorbents for heavy metals: Accumulation of uranium by Saccharomyces cerevisiae and Pseudomonas aemiginosa. App1. Environ. Microbio1. 41: 237-45; 1981.

[22] Shumate, S. E. II; Strandberg, G. W.; McWhirter, D. A.; Parrott, J. R., Jr.; Bogacki, G. M.; Locke, B. R. Separation of heavy metals from aqueous solutions using "biosorbents" - Development of contacting devices for uranium removal. Biotechno1. Bioeng. Symp. 10: 27-34; 1980.

[23] Beveridge, T. J.; Murray, R. G. E. Uptake and retention of metals by cell walls of Bacizlus subtilis. J. Bacteriol. 127: 1502-18; 1976.

[24] McMurrough, I.; Rose, A. H. Effect of growth rate and substrate limitation on the composition and structure of the cell wall of Sacharomyces cerevisiae. Biochem. J. 105: 189-203; 1967.

[25] Fisel, S.; Dulman, V.; Cecal, A. Enrichment of $\mathrm{Cs}^{+}, \mathrm{Ca}^{2+}$, and $\mathrm{Tl}^{+}$ions with microbiological collectors. J. Radioanalyt. Chem. 34: 285-89; 1976. 
[26] Harvey, R. S.; Patrick, R. Concentration of ${ }^{137} \mathrm{Cs},{ }^{65} \mathrm{Zn}$, and ${ }^{85} \mathrm{Sr}$ by freshwater algae. Biotechnol. Bioeng. 9: 449-56; 1967.

[27] Plato, P.; Denovan, J. T. The influence of potassium on the removal of ${ }^{137} \mathrm{Cs}$ by live Chlorella from low level radioactive wastes. Radiat. Bot. 4: 37-41; 1974.

[28] Williams, L. G. Uptake of Cesium-137 by cells and detritus of Euglena and ChZorelza. Limnol. Oceanog. 5: 301-11; 1960.

[29] Williams, L. G. Concentration of strontium-85 and cesium-137 from water solutions by Cladophora and Pithophora. J. Phycol. 6: 314-16; 1970.

[30] Williams, L. G.; Swanson, H. D. Concentration of cesium-137 by algae. Science 127: $187-88 ; 1958$.

\section{Discussion}

Question (R. J. Mehihorn): Have you attempted to test your idea that these are carboxyls or phosphates that may be binding these metals, by chemical modfication techniques of those groups?

Answer: Not yet; we intend to do it. We were mostly looking at this from a process standpoint and just were trying to do what we could in this area. From a microbiology standpoint, I was more interested in this, but I had to work on the process development.

Question (R. H. Filby): Looking at the uranium data, given the concentration levels of hundred parts per million, the phenomenon looks much like precipitation rather than adsorption. The surface distribution and, of course, the $\mathrm{pH}$ of the solution is not necessarily the $\mathrm{pH}$ of the cell membrane. Have you considered the possibility of all precipitation under these conditions; whether there is something going on involving, say phosphate?

Answer: Precipitation apart from its association with the cell?

Question (R. H. Filby): Right, actual precipitation on the surface.

Answer: It's a difficult thing, our only evidence is that we can see the uranium. The demonstration that it is on the cells was done at $\mathrm{pH} 4$. At initial pH 4, the uranium should stay soluble under those conditions.

Question (R. H. Filby): If you got 15 percent uranium by weight, it is hard to see that that could be adsorption? 
Answer: We don't have any way of separating uranium from cells after it is on there. We've definitely shown that there's not uranium precipitating; we can do this under controlled $\mathrm{pH}$ conditions. It seems to be associated with the cells. That's all I can say.

Comment (N. A. Nadkarni): If it is precipitation, you will expect radium to act probably the same way as uranium which it didn't seem to.

Question (R. H. Filby): Although the concentration is not so high, radium probably does not exceed its solubility product with any salt?

Answer: Usually we don't see any uranium precipitation in our experiments until we get above $\mathrm{pH} 5$ to 5.5. In these solutions, even though there is a $\mathrm{pH}$ change, it doesn't get that high. So we expect uranium is staying soluble and is being taken up by the cells. With the Pseudomonas I don't know how you would get the precipitation that fast.

Question (B. A. Fowler): Have you considered using things like ruthenium red or lanthanum to see how they bind at surface? These have been used for years, and, in the recent case ruthenium, their binding sites are pretty well worked out by cell biology people who have been looking at glycoprotein. Another thought is, have you considered trying to separate your population of cells that have a coat from those that don't by differential centrifugation?

Answer: Once the cells have got the uranium on them, we can separate by cesium chloride centrifugation. We tried to culture cells out of the bands. The separation is not 100 percent complete, but what we have cultured out of the two bands has the same uptake characteristics as the original culture.

Question (J. J. Cooney): I'm fascinated by your observation that you get intracellular inclusions of uranium even in killed cells or inhibited cells?

Answer: I won't say that this occurs intracellularly in the killed cells. We have had problems getting the electron microscopy done and this is something we definitely want to look at.

Question (J. J. Cooney): Then, I guess you have not attempted to isolate those inclusions to see what form you have. In regard to your observation that only 40 percent of the cells take up uranium, of course, a large number of cells in any population are nonliving. Do you have any feel for what percentage of the population is viable?

Answer: Before or after uranium treatment? 
Question (J. J. Cooney): If you do a direct count versus a viable count, what percent of the cells are able to form colonies?

Answer: Not directly in that sense. We know the uranium is lethal to them. We have studied viability after exposure to uranium.

Question (J. J. Cooney): Uranium is lethal to them?

Answer: Yes. It is not so bad with the yeast. We can still get about 20 percent survival with the yeast after 24 hours in the uranium solution.

Question (J. J. Cooney): If only 40 percent of the total number of all cell bodies there are able to form colonies, that would suggest that only viable cells are taking it up?

Answer: That, or there's just enough taken up by the others to do them in.

Question (M. A. Anderson): One way to check precipitation mechanism is to ask the questions: what is the thickness of the uranium layer? What's your "absorption density"? How many moles per unit surface area do you have? If you've got more than one molecule, you're obviously got some other process, whether it is polymerization or precipitation. It may be polymerization, and you're right that the $\mathrm{pH}$ at interfaces are quite different even in a nonliving interface. The $\mathrm{pH}$ at the interface is different than in the bulk of the solution, and you may get precipitation, or I was thinking of hydrolysis. I don't know about uranium hydrolysis, perhaps somebody in the audience knows. But you could get a polymerization somewhat like iron, you'd get a polymer coating and those things are pretty thick.

Answer: These are about 0.2 micron thick layers on the surface.

Comment (M. A. Anderson): The time process is right for precipitation, but I think adsorption is rather quick and it looks like you got an adsorption. That may be the initial mechanism, but I think once that occurs then you get a rapid polymerization at the surface.

Question (R. H. Filby): Did you attempt to vary the concentration and get absorption isotherms? How successful was that; plotting Freundlich or Langmuir isotherms?

Answer: No, it didn't make any difference whether we varied the cell concentration or the uranium concentration, we got the same results I showed. We didn't plot isotherms. 
Microbiological Mobilization of Arsenic from Retorted $0 i 1$ Shales-Speciation and Monitoring Requirements

D. A. Klein and R. A. Hassler

Department of Microbiology

Colorado State University

Fort Collins, Colorado 80523

\begin{abstract}
Microbial effects on arsenic mobilization from retorted oil shales were investigated to better assess chemical speciation and analytical monitoring requirements for this type of study. Shake cultures were used for soluble arsenical monitoring while volatile products were recovered using gas flow trains with $\mathrm{KI} / \mathrm{I}_{2}$ trapping solutions. Increased microbial growth which occurred in the presence of balanced nutrients generally led to decreased supernatant arsenic levels, while nitrogen additions, which did not lead to higher microbial populations, resulted in distinct increases in supernatant arsenic. Low, but detectable, volatile arsenic release from retorted shale also occurred under aerobic conditions with added nutrients. With added dimethylarsinic acid (DMA), nutrient amendments resulted in increased As volatilization, which was highest under aerobic conditions and in the presence of retorted shale, in comparison with added soil. Monitoring and speciation requirements suggested by these studies include the need to better understand ammonium ion effects on arsenic solubilization, to develop criteria for abiotic controls, and to maintain species stability prior to sample analysis.
\end{abstract}

Key words: arsenic; dimethylarsinic acid; microbial growth; mobilization; nutrients; oil shale; retorting; soil; speciation; volatilization.

\title{
1. Introduction
}

Microorganisms play important roles in the global cycles for arsenic, as documented in many recent reviews [1-7]. This metalloid is a common constituent of soils, plant materials, and higher organisms [8], and has been used in a wide range of industrial and biocidal applications. Retorted oil shale is of particular interest in relation to arsenic cycling, due to the high arsenic levels found in this material, in the range of $60 \mu \mathrm{g} / \mathrm{g}$, and the retention of most of this arsenic in the solid waste after processing [9].

With the known ability of microorganisms to participate in transformations of arsenic, including solubilization, oxidation, reduction, and alkylation $[3,5,6,7,10,11,12]$, it is important to have information available on the effects of microbial growth on these processes. This is of direct concern for better understanding and managing the disposal and reclamation of retorted shale and other residual products from oil extraction. 
Moisture which might remain in the processed materials or which could be added to retorted shale as a result of natural drainage, dust control, or co-disposal of liquid wastes could allow microbial growth resulting in arsenic biotransformation. In addition, the availability of organic matter, either from vegetation or the movement of nutrientcontaining water into retorted shale, could stimulate microbial growth which might influence the form and mobility of arsenic and other trace metals.

In relation to the specific concerns of this meeting, microorganisms may play important and even unrecognized roles in influencing the form and availability of particular metals. Not only can metals influence the function of particular diagnostic organisms (including microorganisms), but in addition, microorganisms may influence the availability, form, and potential effects of metals on other indicator organisms.

In this report, recent experiments concerned with the effects of microbial growth in soil-retorted shale mixtures on volatile and soluble arsenic release are summarized. Temperature, nutrient, oxygen, and mineral amendment variables have been considered in these experiments.

\section{Methods}

\section{1 Retorted Shale and Soil}

Retorted oil shale and soil samples were taken during the construction of oil shale revegetation plots at the intensive study area in the Piceance Basin, supervised by the Range Science Department at Colorado State University. The soil and retorted shale were sieved through a 32-mesh screen prior to use.

\subsection{Glassware and Implement Preparation}

A11 sieves, spatulas, and glassware used in these experiments were soaked in 10 percent analytical grade nitric acid for at least 16 hours and rinsed in de-ionized water until a neutral $\mathrm{pH}$ of the rinse water was obtained.

\subsection{Mobilization Experiment Design}

Soil and shale samples were mixed in the following manner: $5.0 \mathrm{~g}$ shale, $5.0 \mathrm{~g}$ soil, $5.0 \mathrm{~g}$ shale plus $100 \mathrm{mg}$ soil, or $5.0 \mathrm{~g}$ soil, with $110 \mathrm{~mL}$ of a sterile basal salts medium containing minerals for a $130 \mathrm{~mL}$ volume. Stock solutions of 10.0 percent $\mathrm{w} / \mathrm{v}$ glucose, 1 percent $w / v$ glucose, and 0.1 percent $w / v \mathrm{NH}_{4} \mathrm{NO}_{3}$ were prepared and filter sterilized through $0.45 \mu \mathrm{m}$ membrane filters. The stock solutions plus sterile de-ionized water were added to give a total volume of $20 \mathrm{~mL}$ to yield the following final concentrations: 0.8 percent $w / v$ glucose, 0.1 percent $w / v \mathrm{NH}_{4} \mathrm{NO}_{3}$, and 0.8 percent $w / v$ glucose plus 0.1 percent $w / v$ 
$\mathrm{NH}_{4} \mathrm{NO}_{3}$. Sterile controls with 0.8 percent $w / v$ glucose plus 0.1 percent $w / v \mathrm{NH}_{4} \mathrm{NO}_{3}$ and deionized water were also prepared and treated in the same manner as test samples.

All flasks were weighed, and incubated at 200 rpm on a New Brunswick Gyrorotary shaker at $25{ }^{\circ} \mathrm{C}$. Prior to analysis, the flasks were weighed and any water lost as a result of evaporation was replaced by the addition of sterile de-ionized water.

\subsection{Microorganism Enumeration}

Fungi were enumerated using rose bengal agar plates consisting of $10.0 \mathrm{~g}$ of glucose, $5.0 \mathrm{~g}$ peptone, $1.0 \mathrm{~g} \mathrm{KH}_{2} \mathrm{PO}_{4}, 0.5 \mathrm{~g} \mathrm{MgSO}_{4} \cdot 7 \mathrm{H}_{2} 0,0.33 \mathrm{~g}$ of rose bengal, $20.0 \mathrm{~g}$ of agar, and $1000 \mathrm{~mL}$ of de-ionized water. This medium was sterilized, and after cooling to $45{ }^{\circ} \mathrm{C}, 3 \mathrm{~mL}$ of a streptomycin solution was added to the medium using the procedures of Martin [13].

The bacteria were enumerated with sodium caseinate agar which consisted of $1.0 \mathrm{~g}$ sodium caseinate, $1.0 \mathrm{~g}$ glucose, $0.2 \mathrm{~g} \mathrm{MgSO}_{4}, 0.2 \mathrm{~g} \mathrm{~K}_{2} \mathrm{HPO}_{4}, 0.1 \mathrm{~g} \mathrm{FeSO}_{4}, 15.0 \mathrm{~g}$ agar, and $1000 \mathrm{~mL}$ of de-ionized water [14]. The samples were diluted using phosphate buffer dilution blanks and plates were inoculated with $0.1 \mathrm{~mL}$ inocula and spread using an alcohol-flamed curved glass rod. Plates were incubated for one week at $25^{\circ} \mathrm{C}$. The fungi were counted on rose bengal agar and the bacteria were counted on the sodium caseinate medium. At the time of sampling, the $\mathrm{pH}$ values were measured using a Fisher Accumet $\mathrm{pH}$ meter with buffer standards of $\mathrm{pH} 7.0$ and 9.0 .

\subsection{Metal Samples and Analysis}

For the analysis of metals in the supernatant solutions, at three week intervals $30 \mathrm{~mL}$ samples of each slurry were centrifuged for 30 minutes at $10,000 \mathrm{rpm}$ at $12{ }^{\circ} \mathrm{C}$. Using acid-washed pipettes, $20 \mathrm{~mL}$ of supernatant was removed and transferred to a $30 \mathrm{~mL}$ Sybron/Nalgene bottle with $0.1 \mathrm{~mL}$ of $3 \mathrm{X}$ distilled $\mathrm{HNO}_{3}$. The $\mathrm{HNO}_{3}$ was held in a FEP Nalgene bottle presoaked for three days in $6 \mathrm{~N}$ reagent grade $\mathrm{HNO}_{3}$. The samples were analyzed for arsenic levels by Dr. R. R. Meglen of the Environmental Trace Substances Laboratory, University of Colorado.

\subsection{Volatile Arsenical Trapping System}

The trapping system used in this experiment was a modified version of the system used by Woolson [15]. A single apparatus consisted of a $500 \mathrm{~mL}$ Erlenmeyer flask connected to two $150 \mathrm{~mm} \times 25 \mathrm{~mm}$ test tubes in series. The connections were made with glass and polyethylene tubing. Premoistened air or U.S.P. grade nitrogen was passed over the soil or shale in the flask and then bubbled through trapping solutions contained in test tubes. Neoprene stoppers were used throughout, since rubber has been reported to adsorb volatile arsenicals [3]. All glassware was soaked in 10 percent analytical grade nitric acid and rinsed in de-ionized water before use. 


\subsection{Volatile Arsenical Experiment Preparation}

Low $\mathrm{pH}$ soil, retorted oil shale, and dimethylarsinic acid (DMA) were mixed in $500 \mathrm{~mL}$ flasks in the following manner: $100.0 \mathrm{~g}$ soil plus $3.7 \mathrm{mg}$ DMA, $100.0 \mathrm{~g}$ shale plus $3.7 \mathrm{mg}$ DMA, or $100.0 \mathrm{~g}$ shale without DMA. All flasks were amended with $6.0 \mathrm{~g}$ of soybean meal as a nutrient source, and adjusted to approximately $30 \mathrm{kPa}$ water tension with $34.0 \mathrm{~mL}$ of de-ionized water. Duplicate flasks were prepared for each variable.

Volatile arsenicals were trapped in $20 \mathrm{~mL}$ of an $0.01 \mathrm{~N}$ KI solution contained in each of the test tubes. The trapping solutions were kept at equilibrium by periodic addition of solid $\mathrm{I}_{2}$. All flasks were then weighed and incubated without shaking at $23{ }^{\circ} \mathrm{C}$. One set of flasks was incubated anaerobically by continual flushing with U.S.P. grade nitrogen at a flow rate of approximately $35 \mathrm{~mL}$ per minute. A second set of flasks was incubated aerobically by continual flushing with air at an equivalent flow rate. Periodically, the flasks were weighed and any water lost as a result of evaporation was replaced with de-ionized water.

At appropriate intervals, usually three weeks, the trapping solutions were collected in $30 \mathrm{~mL}$ Sybrun/Nalgene PP bottles and held at $12{ }^{\circ} \mathrm{C}$ until arsenic analyses were completed.

3. Results

\subsection{Supernatant Experiments}

Based on previous studies which suggested that nutrient additions and microbial growth could influence supernatant arsenic levels, additional experiments were completed in which specific carbon and/or nitrogen sources (glucose and ammonium ion) were added. The responses of the bacteria and fungi to these carbon and nitrogen amendments are shown in Figure 1. Retorted shale, to some extent, appears able to serve as a source of nitrogen, but this material apparently is an extremely poor source of carbon for the support of microbial growth. With added nitrogen in the form of $\mathrm{NH}_{4} \mathrm{NO}_{3}$, essentially no increases in viable counts were observed in comparison with the controls. However, this material appears to serve to some degree as a nitrogen source, as microbial increases did occur after glucose additions. With addition of both glucose and $\mathrm{NH}_{4} \mathrm{NO}_{3}$, bacterial populations increased to $10^{8}$ to $10^{9} / \mathrm{mL}$, indicating that nitrogen was 1 imiting microbial growth with added 0.8 percent $w / v$ glucose. Similar results were observed when $100 \mathrm{mg}$ of soil was present with $5.0 \mathrm{~g}$ of retorted shale.

The $\mathrm{pH}$ values for the retorted shale slurries also changed in response to those amendments (Figure 2). In the control and nutrient-amended slurries, sharp increases to higher $\mathrm{pH}$ values occurred during the first three weeks of incubation. These slurries continued to show gradual increases in pH up to twelve weeks. The glucose plus $\mathrm{NH}_{4} \mathrm{NO}_{3}$ 


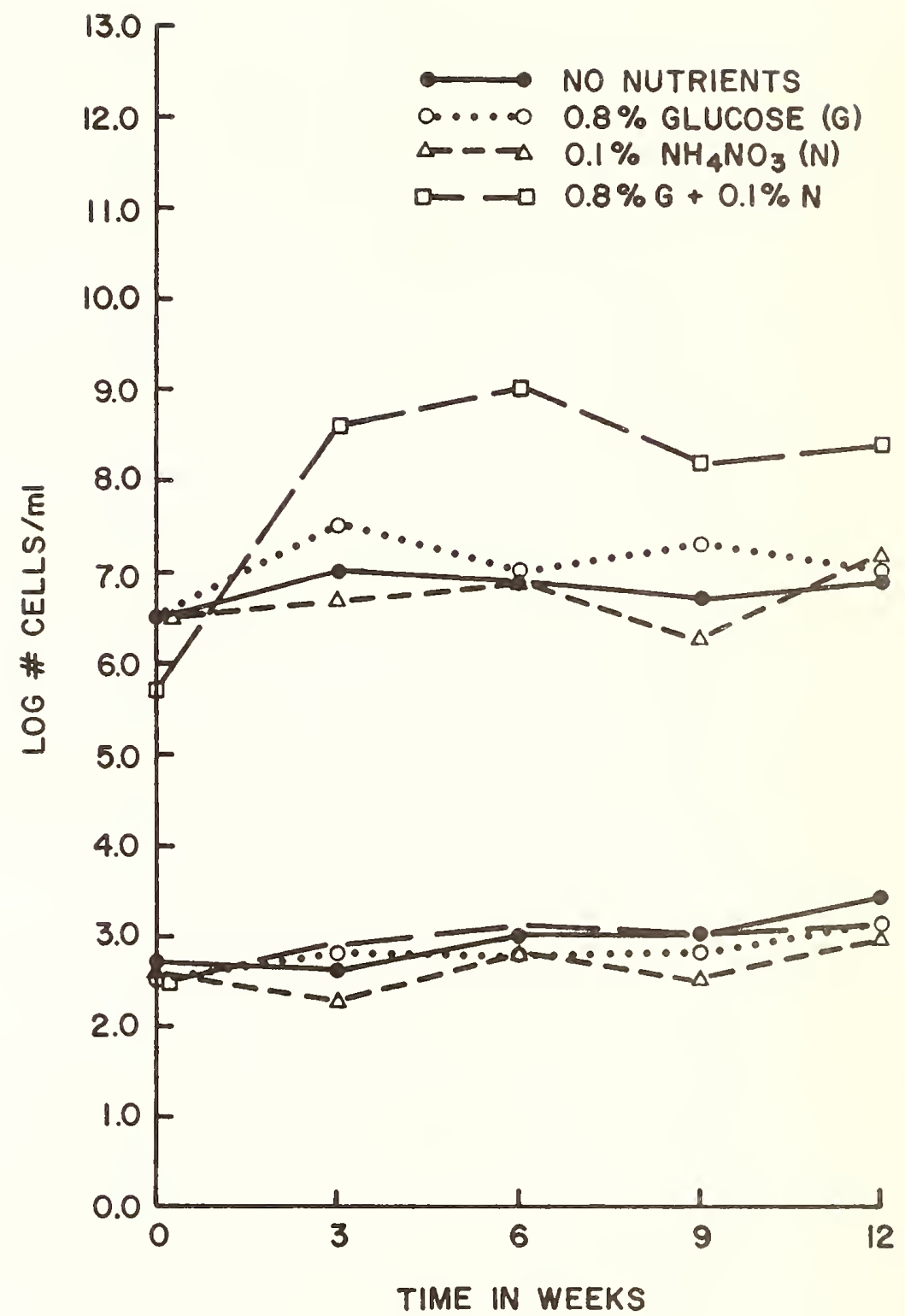

Figure 1. The effects of glucose and/or ammonium ion additions on bacterial (top) and fungal (lower) viable populations in a $5.0 \mathrm{~g}$ retorted oil shale slurry.

amended slurries also had an overall trend of increasing $\mathrm{pH}$. An interesting $\mathrm{pH}$ trend was noted with $\mathrm{NH}_{4} \mathrm{NO}_{3}$ amendments. After an initial increase to 8.0 , the $\mathrm{pH}$ steadily dropped to 6.7 at the end of twelve weeks. This change can best be explained by the growth of nitrifying bacteria, which oxidize ammonium ion to nitrate. Similar pH trends were seen in slurries with $5.0 \mathrm{~g}$ shale plus $100 \mathrm{mg}$ soil and $5.0 \mathrm{~g}$ shale plus $5.0 \mathrm{~g}$ soil, although the $\mathrm{pH}$ decreases observed with nitrogen-amended shale were not observed with these systems. 


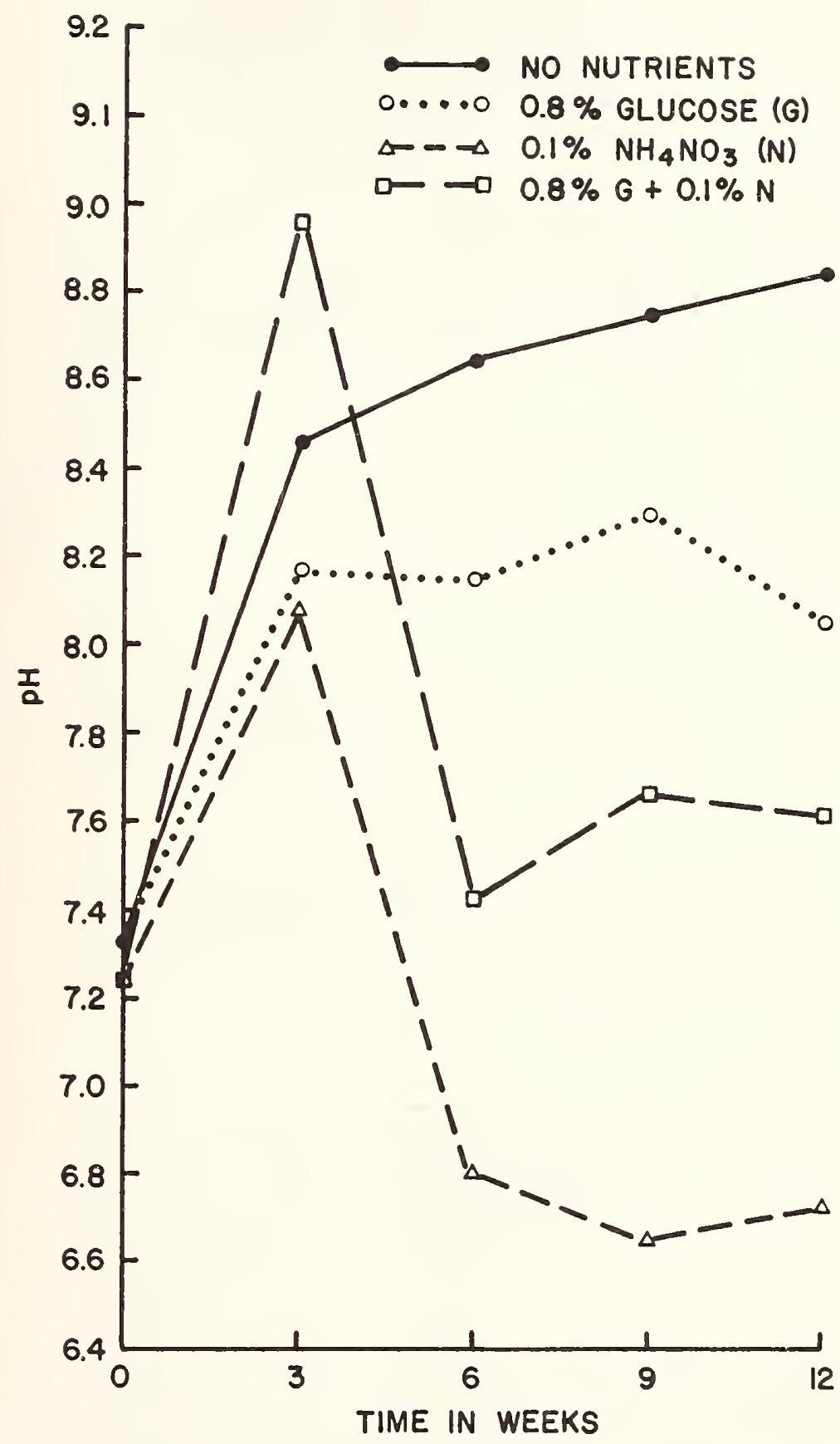

Figure 2. The effects of added glucose and/or ammonium ion additions on $\mathrm{pH}$ in $5.0 \mathrm{~g}$ retorted oil shale slurries. 


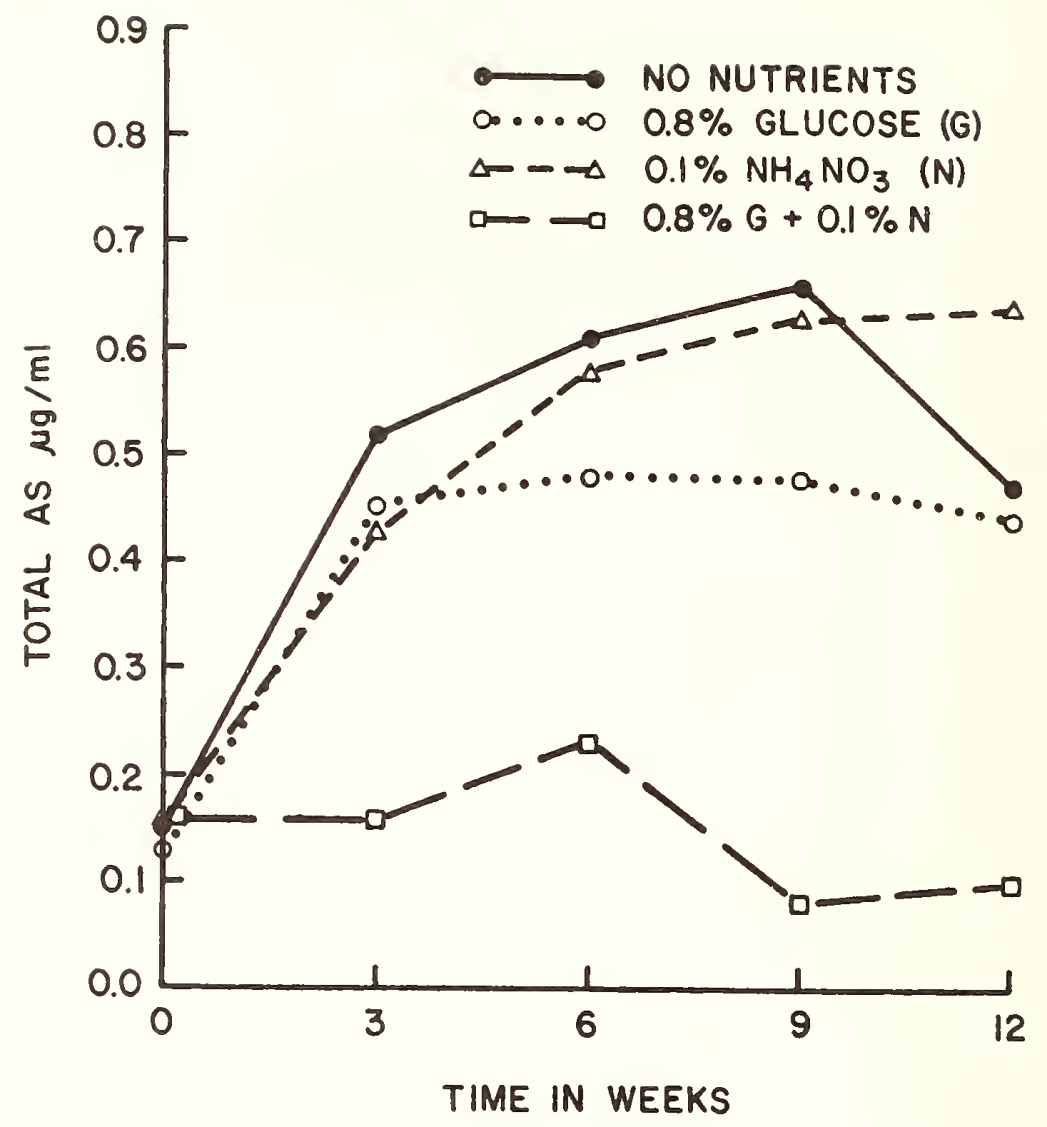

Figure 3. The effects of added glucose and/or ammonium ion additions on supernatant arsenic levels in $5.0 \mathrm{~g}$ retorted oil shale plus $100 \mathrm{mg}$ soil slurries. $\sigma=0.020 \mu \mathrm{g} / \mathrm{mL}$.

The supernatant arsenic values for $5.0 \mathrm{~g}$ shale plus $100 \mathrm{mg}$ soil slurries indicate that the highest arsenic levels, $0.47 \mu \mathrm{g} / \mathrm{mL}$ and $0.64 \mu \mathrm{g} / \mathrm{mL}$, were found in control and nitrogen-amended slurries respectively (Figure 3). Interestingly, these conditions also resulted in the least amount of bacterial and fungal growth. Glucose, and glucose plus $\mathrm{NH}_{4} \mathrm{NO}_{3}$-amended slurries contained the highest viable populations, but the lowest supernatant arsenic levels with $0.44 \mu \mathrm{g} / \mathrm{mL}$ and $0.1 \mu \mathrm{g} / \mathrm{mL}$, respectively, being detected. Similar relationships were found with shale and shale plus soil. (Figures 4 and 5 ). Under these conditions, nitrogen amendments resulted in higher levels of supernatant arsenic, which was most pronounced at the three week sampling. These trends indicate that arsenic may be immobilized by increases of bacterial and fungal biomass, or lost by increased volatilization.

It was not possible to establish a relationship between $\mathrm{pH}$ changes and supernatant arsenic levels. However, for shale and shale plus soil slurries, supernatant arsenic levels exceeding $0.45 \mathrm{\mu g} / \mathrm{mL}$ were found in slurries amended with $\mathrm{NH}_{4} \mathrm{NO}_{3}$ and having $\mathrm{pH}$ values of less than 8.1 . 

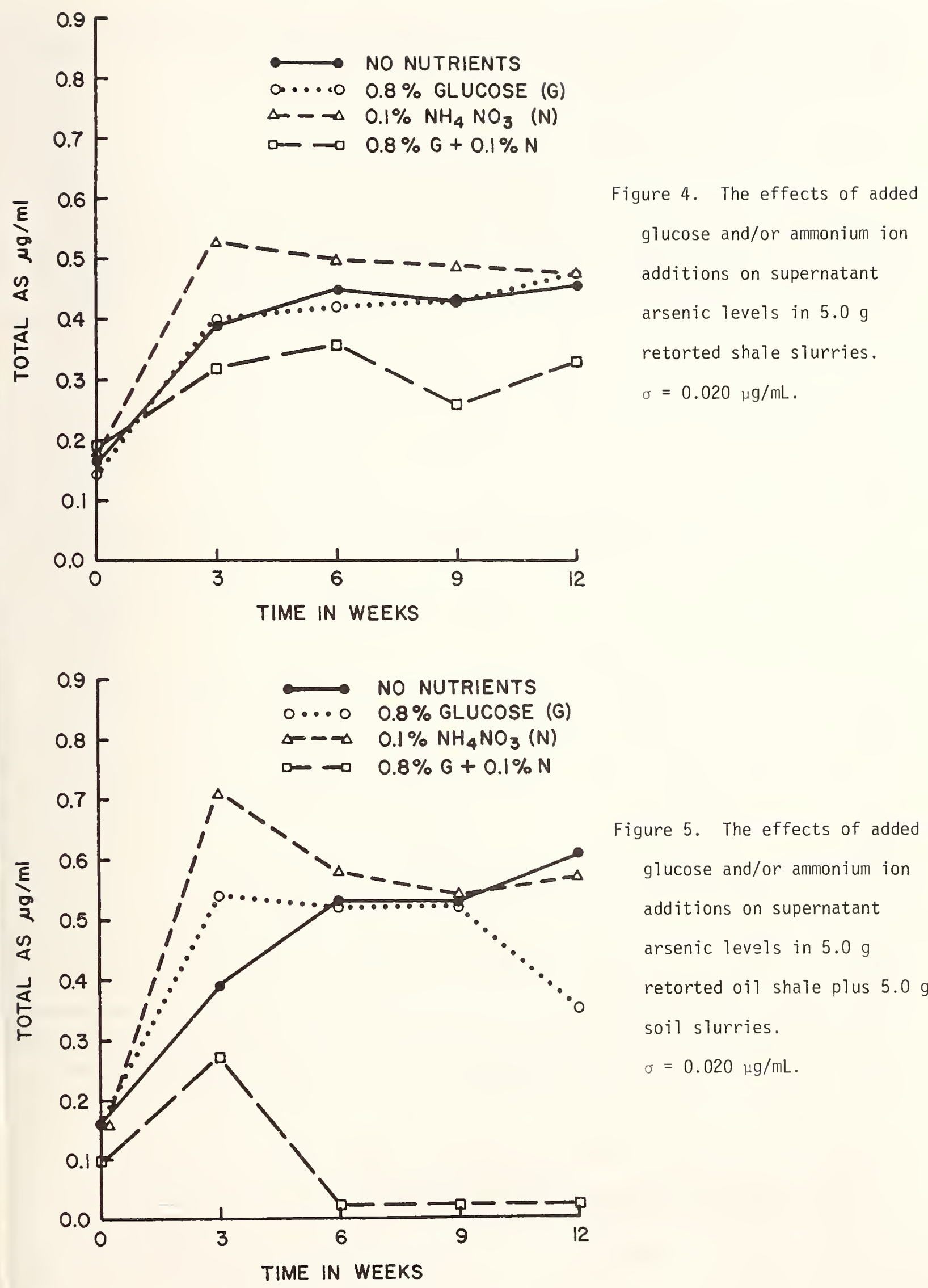

Figure 5. The effects of added glucose and/or ammonium ion additions on supernatant arsenic levels in $5.0 \mathrm{~g}$ retorted oil shale plus $5.0 \mathrm{~g}$ soil slurries. $\sigma=0.020 \mu \mathrm{g} / \mathrm{mL}$. 
The Piceance Basin soil used in this experiment appears to be extremely low in arsenic. Less than $0.02 \mu \mathrm{g} / \mathrm{mL}$ of supernatant arsenic was found in soil slurries suggesting that the surface soil is not a major contributor of this metal to the environment.

\subsection{Volatile Arsenical Experiments}

The amounts of volatile arsenicals trapped over twelve weeks are shown in Figure 6 , giving cumulative amounts of released arsenic from these test systems. After one week, volatile arsenic compounds were detected at $7.2 \mu \mathrm{g} / 100 \mathrm{~g}$ soil and $7.0 \mu \mathrm{g} / 100 \mathrm{~g}$ shale under aerobic conditions with added DMA. No arsenic was detected with anaerobic incubation at one week.

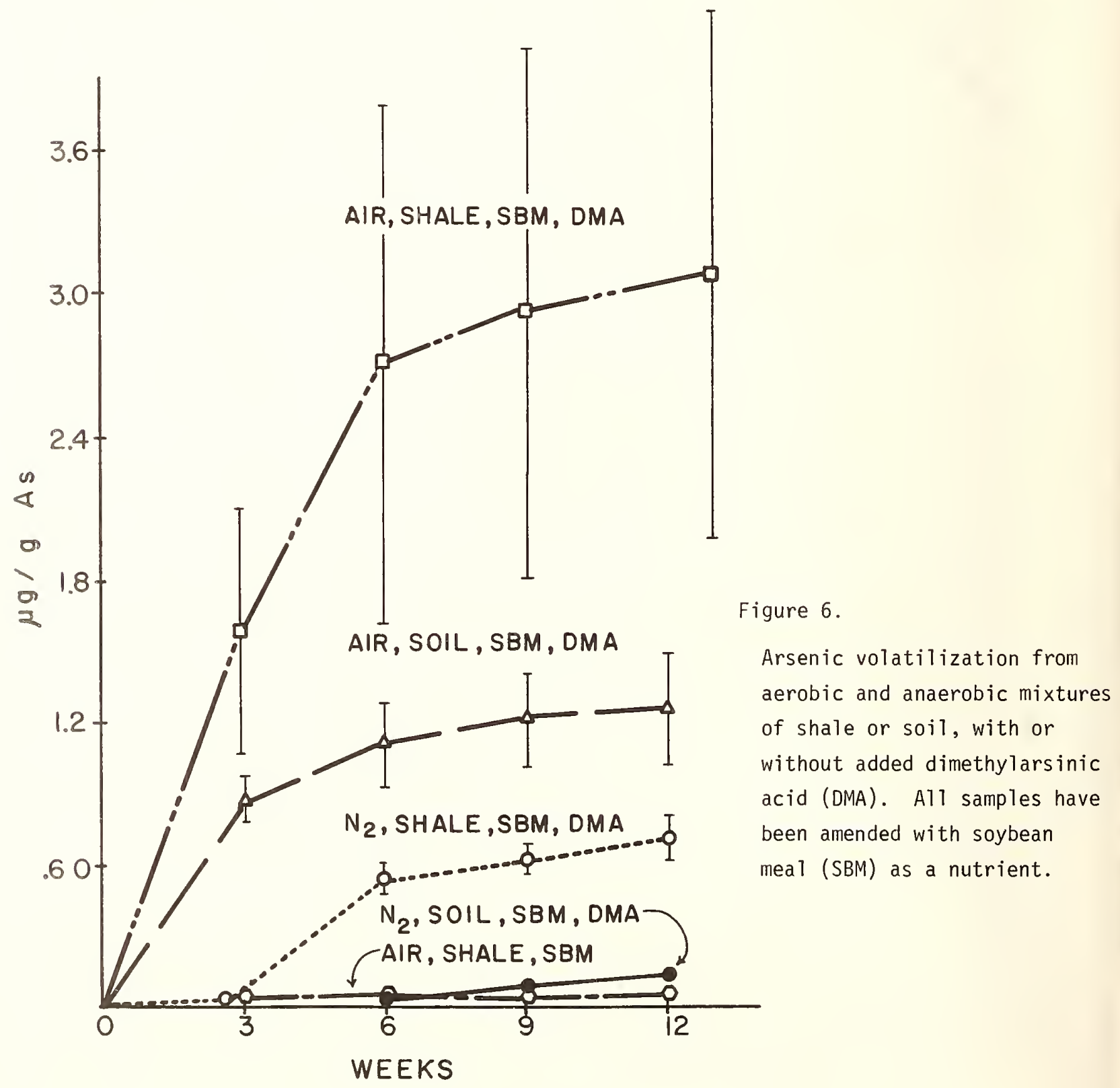


By three weeks of incubation, the aerobic soil system with added DMA had lost $81.0 \mu \mathrm{g}$ As/100 g soil, while the corresponding system with shale lost nearly double that amount, possibly indicating that the high $\mathrm{pH}$ values associated with retorted shale may be more favorable to arsenic volatilization. In comparison, the anaerobic shale system with added DMA lost $3.4 \mu \mathrm{g} \mathrm{As} / 100 \mathrm{~g}$ shale, far less than found under aerobic conditions. Of special interest was the observation of arsenic volatilization from shale held under aerobic conditions without DMA additions where $2.9 \mu \mathrm{g} \mathrm{As} / 100 \mathrm{~g}$ shale were released.

This 12-week experiment suggested two major points regarding the role of microorganisms in arsenic volatilization from retorted shales: (1) arsenic volatilization occurs more efficiently under aerobic conditions; and (2) the presence of retorted shale, in comparison with soil, allows higher amounts of added arsenic to be volatilized. Maximum arsenic release under aerobic conditions was noted at three-weeks with shale present, being approximately twice the amount observed with soil. Under anaerobic conditions with added DMA, retorted shale not only increased the amount of arsenic released, but maximum release was observed at six weeks incubation, while with soil the maximum rates occurred later in the experiment, at the 9 and 12 week samplings. Without added DMA, as noted in Figure 6, only a small amount of arsenic was volatilized from retorted shale in the presence of added organic matter, which occurred in the first three weeks of the experiment.

4. Discussion

These studies have indicated that nutrient additions and subsequent microbial growth can lead to changes in arsenic mobilization from retorted shale, or from DMA-shale mixtures. With carbon (glucose) additions, some increases in microbial populations occurred, suggesting that retorted shale, to a limited extent, was able to serve as a nitrogen source for microbial growth. With nitrogen additions, in contrast, no major increases in microbial populations occurred, indicating that retorted shale is a particularly poor source of carbon for microbial growth. High supernatant arsenic levels appear to be related to low levels of bacterial and fungal biomass, as seen in control and nitrogen-amended cultures.

The addition of DMA and nutrients led to more distinct arsenic release, which occurred more rapidly under aerobic conditions and in the presence of retorted shale. It is of interest that low but detectable amounts of volatile arsenic were released from retorted shale after three weeks of aerobic incubation with no added nutrients. These processes will be critical for predicting relationships between source matrix characteristics and arsenic availability for release in processing and disposal of retorted shales.

In relation to the "dynamic process environment" and monitoring and control concerns, observations of possible microbial contributions to arsenic dynamics indicate that more specific abiological and biological monitoring of these processes will be required to understand factors influencing arsenic mobilization, and also to develop more effective pollution control and mitigation procedures. 
The speciation and monitoring needs which have been identified as a result of this study include the following:

(1) To be able to separate abiotic from biotic contributions to arsenic dynamics in these systems, without, in the process of sterilization, altering the chemical characteristics of the systems to too great a degree. It will most likely be best to simulate the temperatures and conditions used in retorting and then to amend samples with appropriate previouslysterilized liquids and nutrients, to be able to compare results with and without the contribution of microorganisms to arsenic mobilization dynamics. This point will be especially important in evaluating mechanisms by which added nitrogen compounds (in this case ammonium nitrate) can lead to increases in supernatant arsenic levels.

(2) Another important consideration is to have acceptable definitions of species solubility available for use in experimental design, sampling, sample storage, and final analysis: In the studies which have been carried out to date, supernatants produced by centrifugation have been used, and a more rigorous procedure for production of différent classes of arsenic physical classes may be needed. This might involve the use of selective filtration, but again a point of concern is whether such filtration might lead to adsorption of particular arsenic species.

(3) Species stability should be able to be maintained and monitored prior to any final analysis.

(4) Sample storage is a continuing concern, especially related to possible unknown or unrecognized biological contributions to speciation changes.

Frequently, samples of retort process waters and other materials are held for long periods before used in experiments. The microbiologist can contribute by providing information on storage condition effects on potential microbial growth. It is important not only to be able to arrest such processes, but to recognize that they can occur during sample storage, and that they may influence the results of experiments carried out using the same material at different times.

With the diversity of function which exists within microbial communities, representatives of this group can act both to change the chemical form of arsenic, as well as to serve as useful monitoring agents for changes in bioavailability of metals in reclamation and recycling efforts.

As observed with oil shale reclamation programs which have been carried out to the present [16] microorganisms and microbially-derived enzymatic systems may prove to be useful, inexpensive, and rapid bioindicators of increased availability of particular materials from retorted shales. 
This potential dual role of microorganisms in influencing trace metal availability and speciation, and also for effects monitoring, suggests that understanding speciation processes on a microbial level will allow more effective management of these programs.

\section{Acknowledgments}

This research was carried out with support from the Department of Energy under a grant awarded to the University of Colorado, Trace Substances Environmental Program. The assistance of Dr. R. R. Meglen and Dr. R. Sistko with arsenic analyses is appreciated.

\section{References}

[1] Wood, J. M. Biological cycles for toxic elements in the environment. Science. 183: $1049-1052 ; 1974$.

[2] Chau, Y. K. ; Wong, P. T. S.; Silverbert, B. A.; Luxon, P. L. ; Bengert, G. A. Methylation of selenium in the aquatic environment. Science. 192: 1130-1131; 1976.

[3] McBride, B. C.; Edwards, T. L. Role of the methanogenic bacteria in the alkylation of arsenic and mercury. In: Biological implications of metals in the environment. H. Drucker and R. E. Wildung, Eds. Technical Information Center, ERDA; 1977. 1-19.

[4] Arsenic. Washington, DC: National Academy of Sciences; 1977. 332.

[5] Ridley, W. P.; Dizikes, L.; Chech, A.; Wood, J. M. Recent studies on biomethylation and demethylation of toxic elements. Environ. Health Perspect. 19: 43-46; 1977.

[6] Summers, A. 0.; Silver, S. Microbial transformations of metals. Ann. Rev. Microbio1. 32: $637-672 ; 1978$.

[7] Wood, J. L.; Chech, A.; Dizikes, L. J.; Ridley, W. P. ; Rakow, S.; Lakowicz, J. R. Mechanism for the biomethylation of metals and metalloids. Fed. Proc. (Fed. Am. Soc. Exp. Biol.) 37: 16-21; 1978.

[8] Lisk, D. J. Trace metals in soil, plants, and animals. Adv. Agron. 24: 257-325; 1972.

[9] Shendrikar, A. D.; Faudel, G. B. Distribution of trace metals during oil shale retorting. Environ. Sci. Tech. 12: 332-334; 1978.

[10] Timoney, J. R.; Port, J.; Giles, J; Spanier, J. Heavy-metal and antibiotic resistance in the bacterial flora of sediments of New York Bight. App 1. Environ. Microbiol. 36: $465-472 ; 1978$.

[11] Andreae, M. 0.; Klumpp, D. Biosynthesis and release of organoarsenic compounds by marine algae. Environ. Sci. Tech. 13: 738-741; 1979.

[12] Cheng, C. N.; Focht, D. D. Production of arsine and methylarsines in soil and in culture. Appl. Environ. Microbio1. 38: 494-498; 1979.

[13] Martin, J. P. Use of acid, rose bengal, and streptomycin in the plate method for estimation of soil fungi. Soil Sci. 69: 215-232; 1950.

[14] Society of American Bacteriologists. Manual of microbiological methods. New York: McGraw-Hill Book Co.; 1957.

[15] Woolson, E. A. Generation of alkylarsines from soi1. Weed Sci. 25: 412-416; 1976. 
[16] Sorensen, D. L.; Klein, D. A.; Ruzzo, W. J.; Hersman, L. E. Microbial activities in revegetated surface soil overlying spent Paraho process oil shale. J. Environ. Qual. (in press). 1981.

\section{Discussion}

Question (J. J. Cooney): Are you sure phosphorus is not limiting in your system?

Answer: We have used the basic components in Rushnel1-Haas medium, other than carbon, sulfur, but we do have phosphate salts added and everything else. Hopefully its not being tied up. We should have that maintained.

Question (J. J. Cooney): Even when you do not supplement, you still have a persistent population of about $10^{7}$ bacteria over rather long period of 12 weeks. I think it would be rather more useful to get a measure of microbial activity, as in flux of radiolabeled carbon or hydrogen through glucose, or glycolate, or something like that, as a measure of what may be going on. The plate count just tells you how many cells there are capable of forming a colony, as there may be turnover of cells and changes in metabolic rate.

Answer: I would mention we have done that type of work where we've looked at ATP, and nitrogen fixation.

Question (J. J. Cooney): When did you observe the early peaks of volatilization of arsenic?

Answer: They grew it in different systems. In that case, in solid systems. We weren't monitoring those.

Question (R. W. Traxler): Is there any evidence for emulsification of that shale oil?

Answer: I could envision it. We have not seen it occurring.

Question (J. D. Walker): Is there any particular reason that you selected actinomycetes and fungi?

Answer: Again you may have noticed that simple sodium caseinate-agar bacteria, actinomycetes, and then the fungi, so its a very simple crude formula that we use.

Question (J. D. Walker): Have you examined urea and potassium nitrate as nitrogen sources? 
Answer: No, not yet. You have to separate those out. I think we will get some very interesting results when we get those controlled.

Question (R. A. Nadkarni): Has any work been done on microbial use from shale oils, rather than from recovery waters, for removal of arsenic?

Answer: As far as the shale oils, I don't know of any. Hersman (at LETC) worked on the microbiology of retort waters. We were concerned with the metals, 95 percent of those will apparently end up in solid constituents.

Question (R. A. Nadkarni): Still, there is too much in the shale oil for processing in the refineries.

Answer: Yes, the papers I'm quoting on retorting effect on distribution of metals, came out about a year and a half or so ago [Shandrikar, Faude1, Environ. Sci. Technol. 12: 332 (1978); Fruchter et al., ibid. 14:1374 (1980)].

Question (R. H. Fish): I'd like to get some information on how you actually run these experiments. These are spent shale that you have ground up?

Answer: No, we don't grind it. We figure if we start grinding it, we expose other surfaces, so we simply take 32 mesh material, all the larger things we discard.

Question (R. H. Fish): Do you know the arsenic concentration in those spent shales to start with?

Answer: Yes, some of them we do. This particular sample came from when they were building the field site out in the Piceance Basin and we have some values. It is somewhere in that range; it can be different. I think its range is 30 to 60 micrograms per gram.

Question (R. H. Fish): Why are you adding dimethylarsinate?

Answer: The reason we're doing that is to be able to see, if given sufficient arsenic, volatilization occurring, at least from that source. Again, we're trying to bridge into the existing literature in which that has been used in soils, to give some relevance and to know that we are trapping and we are volatilizing.

Question (R. H. Fish): But without added dimethylarsinic acid, do you see the same concentrations?

Answer: No, not at all. That was the point. Only very, very small amounts, and those only under aerobic conditions with nutrients. When it went anaerobic, or you didn't add nutrients, it might take a while before you even begin to see it. 
Question (E. A. Woolson): Did you attempt to characterize the volatile gases coming off either from the MDA or from the shale itself?

Answer: We are in the process of doing that. We have one dual detector ready and we're working with Or. Meglan. We use literature methods to selectively shift $\mathrm{pH}^{\prime} \mathrm{s}$ and get these things off.

Question (E. A. Woolson): I would suspect that you would get dimethyl- and trimethylarsines from the cacodylic acid. From your shale oil, the fact that there is a fair amount of phenylarsonic acid, you may get the phenylarsine.

Answer: We are just waiting to start processing these, but I think that's our next step, to ask what forms there are and if they differ over time. So I think that will be really exciting when we get to that point. 
Mechanisms of Bacterial Resistances to Toxic Heavy Metals:

Arsenic, Antimony, Silver, Cadmium, and Mercury

\section{Simon Silver}

\section{Biology Department, Washington University}

St. Louis, MO 63130

Bacteria from many species and sources have genes that confer resistances to specific toxic heavy metals. These resistances often are determined by extrachromosomal DNA molecules (plasmids). The same resistances and mechanisms of resistances occur in bacteria from soil, water, industrial, and clinical sources. The mechanism of mercury and organomercurial resistance is the enzymatic detoxification of the mercurials into volatile species (methane, ethane, metallic $\mathrm{Hg}^{\circ}$ ) which are rapidly lost from the environment. The genetic control of this resistance has been studied and the enzymes responsible have been purified and characterized. Cadmium resistance and arsenate resistance are due to separate blocks on the net accumulation of these toxic materials. Efficient efflux systems cause the rapid excretion of $\mathrm{Cd}^{2+}$ and $\mathrm{AsO}_{4}{ }^{3-}$. The mechanisms of arsenite and of antimony resistance, which are usually found associated with arsenate resistance, are not known. Silver resistance is due to lowered affinity of the cells for $\mathrm{Ag}^{+}$, which can be complexed with extracellular halides, SH groups, or organic compounds. Sensitivity is due to binding of $\mathrm{Ag}^{+}$more effectively to cells than to $\mathrm{Cl}^{-}$.

Key words: antimony; arsenic; bacterial resistances; cadmium; detoxification; mercury; organomercury; plasmids; silver; toxic heavy metals.

\section{Introduction}

Living cells divide the Periodic Table into three classes. Some elements are necessary for intracellular metabolism [1]; some elements are not used generally within the cell but abound in natural environments and can be "coupled" to extracellular structural or regulatory functions. Finally, some elements are toxic and have no useful function [2]. Potassium and phosphorus are examples of the first class; calcium and chlorine are examples of the second class; and arsenic, mercury, and cadmium are examples of toxic elements without biological function. This report will deal with toxic elements and their compounds.

The occurrence of toxic elements in natural environments cannot be ignored since the levels are high enough to be of human concern; they pop up sporadically--with or without man's help.

Free-living bacterial cells and higher organisms as well have evolved resistance mechanisms to cope with toxic heavy metal pollution. It seems as if for every toxic heavy metal that nature provides, bacteria have devised a highly specific resistance mechanism, one by one. The genes determining these resistance mechanisms abide on small non-chromosomal DNA 
molecules called plasmids. These resistance plasmids also have genes conferring resistances to most known antibiotics--although this coupling is not obligatory. The existent knowledge in this area was reviewed three years ago [2]. I shall try to provide a general picture and newer information for this workshop.

\section{Mercury and Organomercurial Resistances}

The mercury cycle in the environment is the best known case of microbial metabolism affecting the distribution and chemical form of a toxic heavy metal pollutant.

Microbial activity is associated with mercury transformations including methylation and demethylation of $\mathrm{Hg}^{2+}$ and oxidation and reduction of inorganic mercury. Since this discussion is limited to resistance mechanisms, I will deal only with the transformations from left to right (as drawn in Figure 1). Metallic mercury is less toxic than ionic mercury in most biological systems and ionic methylmercury is far more toxic than $\mathrm{Hg}^{2+}$. Thus, the transformations from right to left, although important to understanding microbial effects on heavy metal pollutants, do not contribute to bacterial resistance to mercury or to organomercurials.

\section{$\mathrm{CH}_{3} \mathrm{Hg}^{+} \rightleftharpoons \mathrm{Hg}^{2+} \rightleftharpoons \mathrm{Hg}^{\circ}$}

Figure 1. Environmental transformations of mercury.

Earlier studies of plasmid-mediated resistance to $\mathrm{Hg}^{2+}$ were mainly with clinical isolates. Plasmid-determined resistance to $\mathrm{Hg}^{2+}$ and to organomercurials occurs in both Staphylococcus aureus [3] and Escherichia coli [4]. The frequency of $\mathrm{Hg}$ (II) resistance determinants among clinical isolates can be over 50 percent [5,6], and among a collection of over 800 plasmids introduced into $\underline{E}$. coli K-12 in London, about 25 percent conferred $\mathrm{Hg}$ (II) resistance [7]. More recently, mercuric and organomercurial-resistant strains with very similar properties have been found in a wide variety of bacterial species from soil, water, and marine environments [8-11]. In fact, the first $\mathrm{Hg}^{2+}$-resistant strain to be studied in great detail [12-17] was a pseudomonad isolated from phenylmercury-polluted industrial soil.

A small number of resistance patterns for organomercurials was found among strains with plasmids [18]: (a) In E. coli over 90 percent of the mercury-resistance plasmids confer resistance to the organomercurials merbromin and fluorescein mercuric acetate (FMA) but to no other tested organomercurial (Figure 2). These are "narrow spectrum" mercurialresistance plasmids [18], and the other four percent "broad spectrum" plasmids conferred additional resistances to phenylmercuric acetate (PMA) and thimerosal. (b) The plasmids in Pseudomonas aeruginosa also divided into "narrow" and "broad" spectrum with regard to resistance to organomercurials [19]; however, about 50 percent fell into each class. 


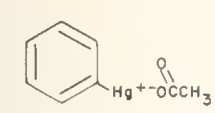

PHENYLMERCURIC ACETATE

$\mathrm{CH}_{3} \mathrm{Hg}^{+} \mathrm{Cl}^{-}$

METHYLMERCURIC CHLORIDE

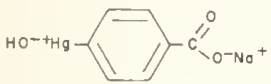

D-HYOROXYMERCURIBENZOATE

(DHMB)
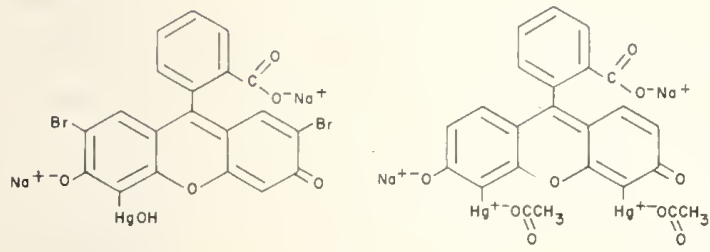

MERBROMIN (MERCUROCHROME) FLUORESCEIN MERCURIC ACETATE (FMA)
A. MERCURIC REDUCTASE<smiles>[18OH][13CH2]C1CO1</smiles>

B. ORGANOMERCURIAL HYDROLASE (S)

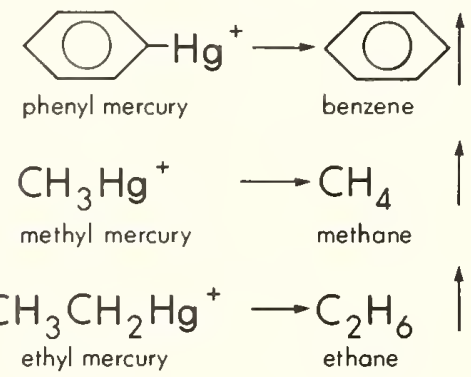

Figure 2. Structures of the organomercurial compounds.
Figure 3. Enzymatic detoxification of $\mathrm{Hg}$ (II) and organomercurial ions.

Furthermore, the "narrow spectrum" Pseudomonas plasmids also confer resistance to $\mathrm{p}^{-}$ hydroxymercuribenzoate (pHMB) and the "broad spectrum" Pseudomonas plasmids show additional resistance to methylmercuric and ethy]mercuric compounds $[18,19]$. (c) Only a single pattern has been reported with $\underline{S}$. aureus plasmids $[18,20]$. This pattern is different from those with the Gram-negative bacteria because all the $\underline{S}$. aureus plasmids confer resistances to PMA, PHMB, and FMA but not to thimerosal or to merbromin.

In the last few months, the first thimerosal-resistant $\underline{S}$. aureus was found [F. D. Porter and S. Silver, unpublished]. Figure 2 shows only those organomercurials that have been tested. As additional organomercurials become of environmental interest, they should be brought to my attention. The conclusion is not that there is a single pattern of resistance, but rather that there are a very limited number of patterns and that these have begun to be understood in terms of the biochemistry of the enzymes involved. $\mathrm{Hg}(\mathrm{II})-$ resistant plasmid-bearing soil and marine Bacillus have become available [11,21; D. Reanney, personal communication]. These plasmids all conferred a pattern of resistance to $\mathrm{Hg}$ (II) and organomercurials [T. G. Kinscherf, unpublished] identical to that published for $\underline{S}$. aureus $[20]$. 
2.1 Enzymatic Mechanism of Mercury and Organomercurial Detoxification

$\mathrm{Hg}^{2+}$ resistance results from enzymatic detoxification leading to the volatilization of mercury from the growing bacterial culture. This was discovered independently in two laboratories in Japan $[12,14,22,23]$, and in St. Louis [24]. The volatile mercury was shown to be metallic $\mathrm{Hg}^{\circ}$ in each case and the enzyme responsible is called mercuric reductase.

Several organomercurials are also enzymatically detoxified to volatile compounds. These organomercurials include methylmercury and ethylmercury ions, PMA, pHMB, and thimerosal (Figures 2 and 3 ); benzene is produced by PMA, methane from methylmercury and ethane from ethylmercury. The enzymes responsible for cleaving the $\mathrm{Hg}-\mathrm{C}$ bond are organomercurial hydrolases. In a soil pseudomonad (for which a plasmid has never been demonstrated), Tezuka and Tonomura $[15,16]$ were able to separate two smal1 soluble hydrolase enzymes. Both have molecular weights of about 19,000 and require thiol reagents such as thioglycolate. The two hydrolases were difficult to separate by chromatographic methods, but when thís was accomplished [16], it was found that one enzyme cleaved PMA, PHMB, and methylmercury, while the other enzyme cleaved only PMA and PHMB. With a plasmid-containing E. coli, there was no evidence for hydrolysis of pHMB [18] and Schotte1 [25] was unable to separate the two hydrolases. Nevertheless, kinetic analysis indicated that there were two enzymes active toward PMA but only one active toward methyl- and ethylmercury ions. The $\underline{E}$. coli organomercurial hydrolases appeared to have a somewhat greater molecular weight, but otherwise the general properties of the enzymes from the soil pseudomonad and E. coli were essentially similar.

Mercuric reductase has been studied in greater detail both with plasmid-bearing $\underline{E}$. coli $[22,25]$ and with the soil pseudomonad [14]. The intact enzyme has a molecular weight of about 170,000 and appears to contain identical subunits [25], each with an FAD molecule. The enzyme is strictly NADPH-dependent and one NADPH is oxidized per $\mathrm{Hg}$ (II) reduced [25].

Antibodies have been prepared against purified mercuric reductases coded by two different plasmids in E. coli [T. G. Kinscherf, and S. Silver, in preparation]. All reductases obtained from different Gram-negative sources reacted with these antibodies, as shown by inhibition of enzyme activity and by formation of precipitation bands on double-diffusion gels. The enzymes divided into two major subclasses, based on only partial immunological identity (Figure 4). The prototype of the first enzyme class is coded by transposon Tn501, the first well-studied mercuric resistance transposon [26]. This enzyme class also includes mercuric reductases governed by a variety of plasmids found in clinical isolates of enteric bacteria and $\underline{P}$. aeruginosa, in marine pseudomonads, and in Pseudomonas putida (the MER plasmid). The MER plasmid harbors a transposon, Tn1861, which appears indistinguishable [8] from Tn501 [26], which originated in a clinical $\underline{P}$. aeruginosa isolate. One strong conclusion from studies of plasmid-determined mercuric resistance is that the same system appears widely in clinical isolates and in bacteria from other environments. However, newer $\mathrm{Hg}^{2+}$ - (and in one case, phenylmercuric-) resistance transposons from soil microbes 
show different patterns of digestion by restriction endonuclease enzymes [27], indicating that, although the systems are related immunologically, they are not identical in terms of DNA sequences.

The second immunological subgroup of the Gram-negative mercuric reductases has as its prototype the enzyme coded by plasmid R100, one of the earliest and most thoroughly studied of the antibiotic resistance plasmids. It is with this plasmid that the genetic structure of the mercuric resistance operon was studied in detail [28,29]. This subgroup also includes enzymes from plasmids of a wide variety of incompatability groups and also the enzyme determined by a second characterized Pseudomonas mercury transposon, Tn502, [T. G. Kinscherf, in preparation; V. Stanisich, in preparation]. Although all of the mercuric reductases from Gram-negative bacteria were immunologically related, the antibodies prepared against the two classes of Gram-negative enzymes did not crossreact with mercuric reductases from $\underline{S}$. aureus strains and marine and soil Bacilli. These enzymes from Grampositive sources showed similar masses and functional requirements to those from the Gramnegative bacteria [20], but they are immunologically distinct.

To summarize briefly the current understanding of plasmid-determined mercuric and organomercurial resistances: (a) they occur widely in both Gram-positive and Gram-negative species and are the best understood of all plasmid-coded heavy metal resistances; (b) resistance is due to enzymatic detoxification of the mercurials to volatile compounds of lesser toxicity that escape from the growth media; (c) the enzymes responsible (mercuric reductases and organomercurial hydrolases) have been purified and studied in vitro.

\section{Arsenic and Antimony Resistances}

Arsenic and antimony resistances are governed by the same plasmids that code for other heavy metal resistances [3,31,32]. The first detailed report of arsenate, arsenite, and antimony(III) resistances, however, has just appeared [30] and will be summarized here along with more recent studies [Silver, in preparation].

Arsenate, arsenite, and antimony(III) resistances are coded for by an inducible operonlike system in both $\underline{S}$. aureus and $\underline{E}$. coli [30]. Each of the three ions induces all of the three resistances. When following arsenate resistance by measuring decreased uptake of radioactive ${ }^{74} \mathrm{AsO}_{4}{ }^{3-}$ (Figure 5), $\mathrm{Bi}$ (III) was seen to be a gratuitous inducer of arsenate resistance, in that $B i$ (III) "turns on" the resistance system (Figure 6 ), even though there is no plasmid-determined resistance to $B i(I I I)$ in $\underline{E}$. coli. $\underline{S}$. aureus does have plasmidmediated $B$ i(III)-resistance [3], but this is governed by a different genetic determinant [33] and the mechanism of $B i($ III) resistance is not known. Not all oxyanions induce the arsenate/arsenite/antimony(III) system. $\mathrm{V}_{4}{ }_{4}{ }^{-}$, which is highly toxic for $\underline{E}$. coli, does not function as an inducer; and plasmid R773 (used in Figures 5 and 6) does not confer resistance to $\mathrm{VO}_{4}{ }^{3-}$ [unpublished data]. 


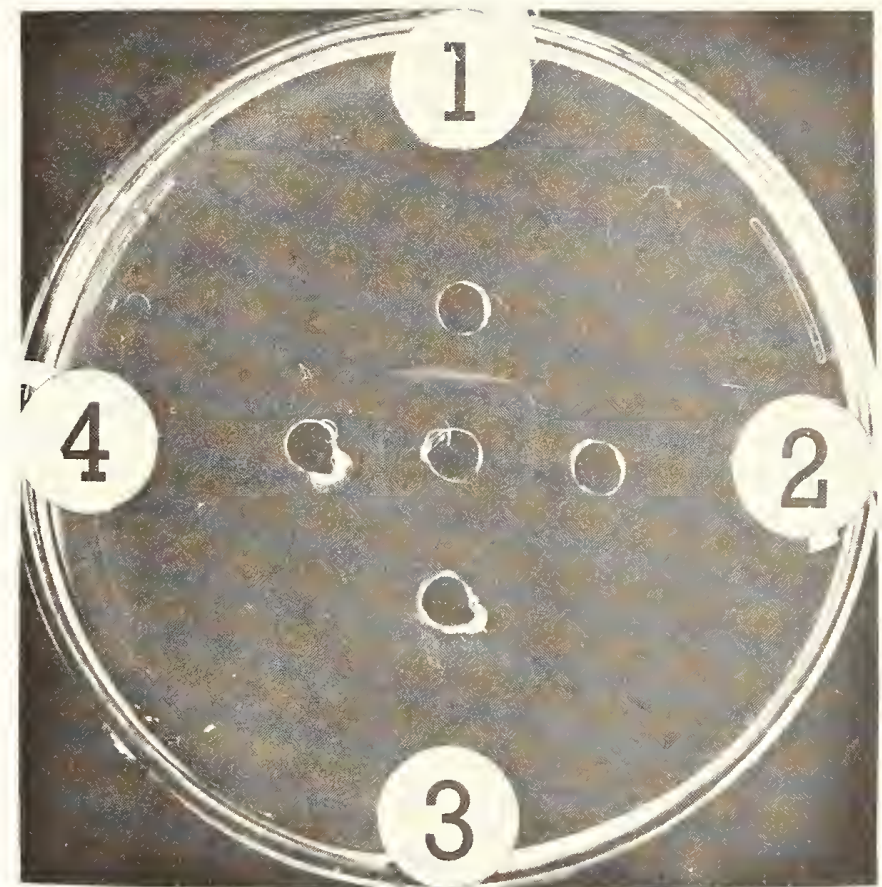

Figure 4. Antibody immunodiffusion gel showing two immunological classes of mercuric reductase. In the center well was placed antibody prepared against enzyme from transposon Tn501. In the other wells were placed crude mercuric reductase from plasmids pVS1::Tn501 (1); RIP135 (2); RP1::Tn502 (3); and NRT (pRR130) (4).

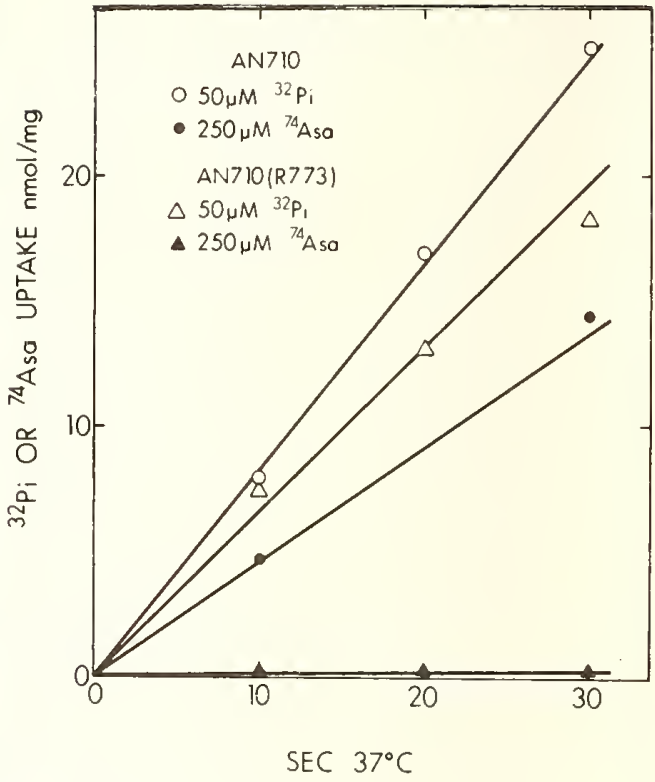

Figure 5. Arsenate and phosphate uptake by sensitive and resistant $\underline{E}$. coli $[30]$.

The mechanism of arsenate resistance is a reduced accumulation of arsenate by induced resistant cells (Figure 5). Arsenate is normally accumulated via the cellular phosphate transport systems, of which bacterial cells appear to have two [1]. Phosphate protects cells from arsenate toxicity, just as high Mn(II) protects sensitive $\underline{S}$. aureus from Cd(II) toxicity [R. D. Perry, unpublished; see below]. The distinction between arsenate and arsenite resistances was shown by finding that phosphate did not protect against arsenite [30]. Genetic studies with $\underline{S}$. aureus plasmids also demonstrated that the gene for arsenate resistance is different from but closely linked to the gene for arsenite resistance, which in turn may not be the same as that for antimony(III) resistance [33]. The presence of the resistance plasmid does not alter the kinetic parameters of the cellular phosphate transport systems, not even the $k_{j}$ for arsenate acting as a competitive inhibitor of phosphate transport. This finding, coupled with direct evidence for plasmid-governed energy-dependent efflux of arsenate (Figure 7), suggests that the block on uptake in Figure 5 may result from rapid efflux. The energy-dependence of the efflux process is shown by its sensitivity to "uncouplers" such as CCCP and tetrachlorosalicylanilide and ionophore antibiotics such as nigericin and monensin. $\mathrm{Hg}^{2+}$ and $\mathrm{PCMB}$ inhibit the efflux system and the inhibition by $\mathrm{Hg}^{2+}$ is readily reversed by mercaptoethanol. A detailed report of the properties of this efflux 


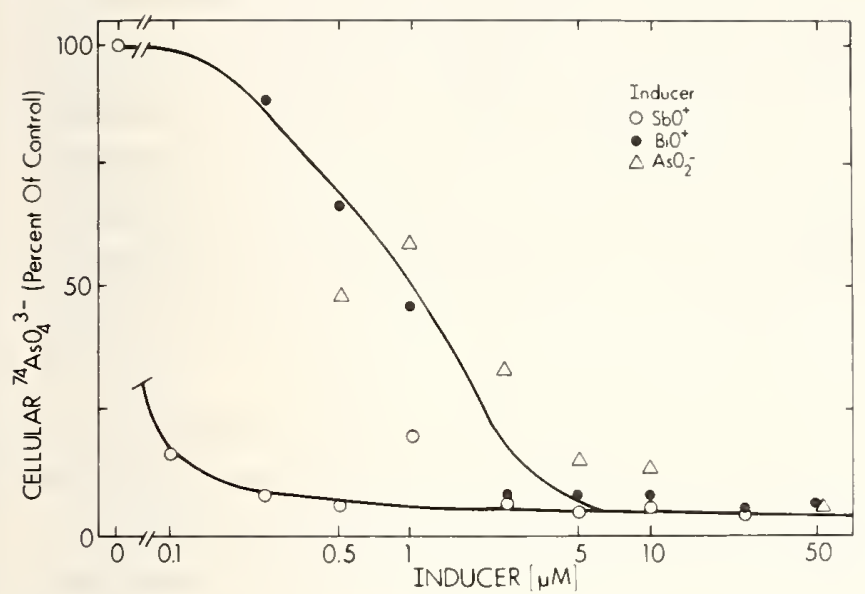

Figure 6. Induction of reduced arsenate uptake in E. Coli J53(R773). Cells were grown in broth and exposed to inducers for the last hour before centrifugation, washing, and assay of $250 \mu \mathrm{M}$ ${ }^{74} \mathrm{AsO}_{4}{ }^{3-}$ uptake for $2 \mathrm{~min}$ at $37^{\circ}$ [conditions as in ref. 30].

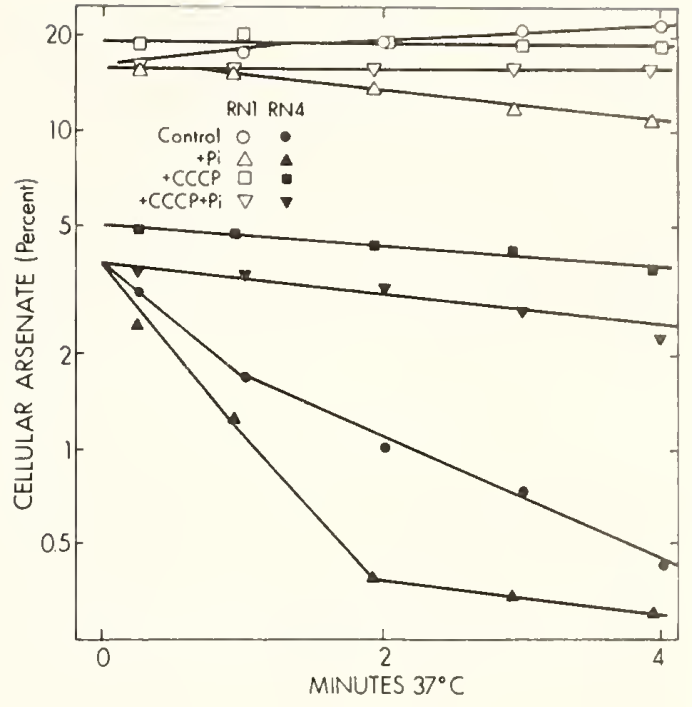

Figure 7. Accelerated energy-dependent efflux of arsenate by resistant S. aureus cells (RN4) but not by the sensitive cells (RN1). Cultures were grown, induced with arsenite, and concentrated to 25 percent (cell vol/medium vol) in $5 \mathrm{mM}^{74} \mathrm{AsO}_{4}{ }^{3-}$. After $1 \mathrm{~h}$ at room temperature, the efflux process was initiated by a $200 x$ dilution into standard [30] transport medium with glucose present. $40 \mu \mathrm{M}$ CCCP was added 5 min before dilution and $5 \mathrm{mM} \mathrm{Pi}$ was present in the dilution medium where indicated [Silver, in preparation].

system will appear next year [Silver, in preparation]. The tentative conclusion today is that $\mathrm{AsO}_{4}{ }^{3-}$ efflux is directly coupled to a $\mathrm{pH}$-sensitive ATPase-like transport system. The inhibition by uncouplers (at low pH only) and the inhibition by nigericin but not by valinomycin are consistent with that hypothesis [Silver, in preparation]. This will make the $\mathrm{AsO}_{4}{ }^{3-}$ efflux system somewhat different from the apparently chemiosmotic $\mathrm{Cd}^{2+}$ efflux system described below.

A current question about the arsenate efflux system concerns its specificity. Although arsenate generally functions as a phosphate analogue and is accumulated by bacteria via 
phosphate transport systems [1,30], the arsenate-resistance efflux system should not "pump" out phosphate as well as arsenate. The cells would become phosphate starved, which would not give them much advantage over being arsenate inhibited! A basic conclusion from our work on arsenate (and on $\mathrm{Cd}^{2+}$ resistance; see below) is that toxic heavy metals often get into cells by means of transport systems for normally required nutrients [1,2]. Energydependent efflux systems functioning as resistance mechanisms must discriminate strongly against the needed nutrient; these efflux systems must be highly specific for the toxic anion or cation.

The mechanism(s) of arsenite and of antimony resistances are not known. Arsenicals and antimonial compounds are toxic by virtue of inhibiting thiol-containing enzymes [34]. Some dithiol reagents such as BAL (British anti-Lewisite) protect against arsenicals and antimonials. Growing resistant cells do not excrete soluble thiol compounds into the medium to bind arsenite and antimony, since pregrowth of resistant cells in medium containing these toxic ions does not allow subsequent growth of sensitive or of uninduced resistant ceils [30]. Arsenite is not oxidized to the less toxic arsenate by plasmid-bearing E. coli or $\underline{\text { S. aureus }}$ [30]. The absence of "detoxification" measured by medium shift experiments eliminates all other possible mechanisms involving changes in extracellular chemical species. Although plasmid-mediated resistance to $\mathrm{As}$ (III) and $\mathrm{Sb}$ (III) does not involve chemical transformations, many bacteria and fungi are known to oxidize, reduce, methylate, and demethylate arsenicals and antimonials [most recently summarized in ref. 27]. For plasmid-mediated resistance, only the untested hypotheses of an alteration in uptake or a change in a key intracellular target are left.

\section{Cadmium Resistance}

Plasmid-determined cadmium resistance has been found only in $\underline{s}$. aureus [3]. In some clinical collections, Cd(II) resistance is the most common of the $\underline{s}$. aureus plasmid resistances, exceeding in frequency both mercury and penicillin resistances [5]. Gram-negative cells without plasmids are just as resistant to $C d(I I)$ as are staph cells with plasmids [6], probably because of relatively reduced $\mathrm{Cd}(\mathrm{II})$ uptake by the cells [Silver, unpublished]. This is a "soft" conclusion, since there are occasional Gram-negative bacteria that are sensitive or even "hypersensitive" to $\operatorname{Cd}(\mathrm{II})$ [9; T. Barkay, unpublished]. The basis of Cd(II) sensitivity and resistance in other bacterial species is a subject in need of more effort.

The mechanism of $\mathrm{Cd}(\mathrm{II})$ resistance is a constitutive block on the accumulation of Cd(II) by the resistant cells [35-39]. This was initially considered a direct permeability block [36], but it was later found that $\mathrm{Cd}(\mathrm{II})$ enters $\underline{s}$. aureus cells as an alternative substrate for the cellular Mn(II) transport system $[1,39]$. Resistance plasmids prevent $\mathrm{Cd}$ (II) accumulation through this transport system (Figure 8 ). Most recentiy, it has been shown that the lowered accumulation is due to a plasmid-coded efflux system that rapidly excretes $\mathrm{Cd}(\mathrm{II})$ rather than a direct effect on the uptake process itself [40]. 
Figure 9 shows the current model of $\mathrm{Cd}(\mathrm{II})$ resistance including the shared $\mathrm{Mn}$ (II)/Cd(II) uptake system found in both sensitive and in resistant $\underline{S}$. aureus cells and the $\mathrm{Cd}(\mathrm{II}) / 2 \mathrm{H}^{+}$ exchange system that functions only in resistant cells. Studies with membrane vesicle ghosts [R. D. Perry, submitted] support this picture by showing identical kinetic parameters for $\mathrm{Cd}(\mathrm{II})$ and $M n(I I)$ transport in right-side out vesicles from sensitive and from resistant cells (Figure 10). Unfortunately, the type of inside-out vesicle studies used by McMurry et al. [41] to demonstrate a similar efflux transport system for tetracycline in plasmid containing $\underline{E}$. coli have not succeeded in $\underline{S}$. aureus.

\section{Silver Resistance}

Microbial silver toxicity is found in situations of industrial pollution, especially associated with use of photographic film. In hospitals, silver salts are the preferred antimicrobial agents for burns covering wide areas of body surface [42]. It is thus not surprising that silver-resistant bacteria have been found in environmental samples [43] and that silver-resistant bacteria [44-46] and silver-resistance plasmids have recently been described [47]. Only one known Ag-resistance plasmid was transferrable by conjugation [47].

R. W. Hedges [personal communication] produces a recombinant between plasmid R1 and a

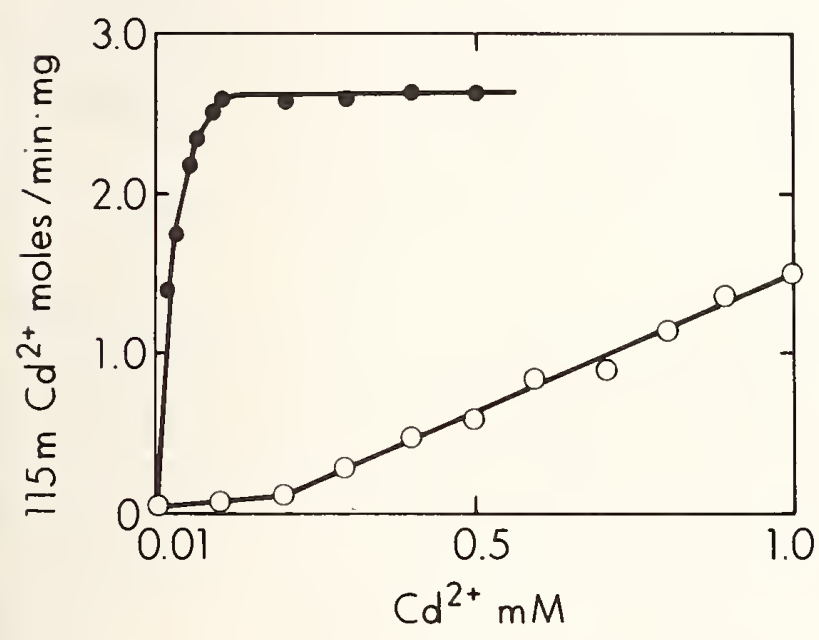

Figure 8. Cadmium uptake by sensitive and by resistant $\underline{\mathrm{S}}$. aureus. Initial rate of accumulation of $115 \mathrm{~m} \mathrm{Cd}^{2+}$ as a function of $\mathrm{Cd}^{2+}$ concentration by a resistant plasmidcontaining strain $(0)$ and its sensitive plasmid-less variant (0) [37].

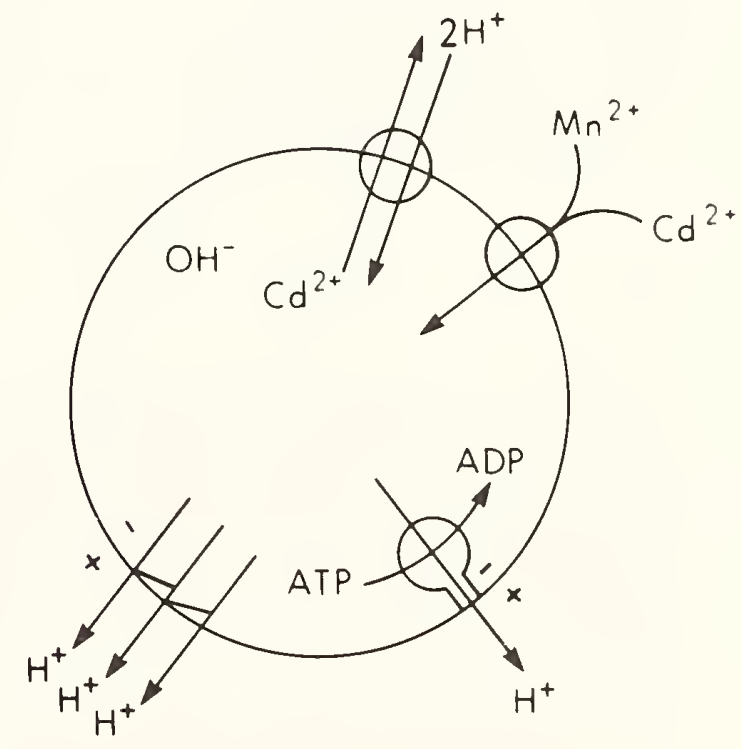

Figure 9. Model for $\mathrm{Cd}^{2+}$ uptake and efflux systems [40]. 
$\mathrm{Ag}^{+}$-resistance plasmid from Citrobacter [46] and introduced it into an E. coli $\mathrm{K}-12$ strain. Silver resistance is constitutive in $\underline{E}$. coli , like $\mathrm{Cd}(\mathrm{II})$ resistance in $\underline{\mathrm{s}}$. aureus, but unlike $\mathrm{Hg}(\mathrm{II})^{-}$, arsenate-, arsenite-, and antimony-resistances. The plasmid-determined resistance is very great and the ratio of minimum-inhibitory concentrations can be greater than 1000:1 (Figure 11B). The level of resistance is strongly dependent upon available halide ions; and without $\mathrm{Cl}^{-}$, there is relatively little difference between the cells with or without a plasmid (Figure $11 \mathrm{~B}$ ). $\mathrm{Br}^{-}$and $\mathrm{I}^{-}$at concentrations far below those required for $\mathrm{Cl}^{-}$confer resistances on both plasmidless cells and cells with the plasmid. These results have led to the current hypothesis that both sensitive and resistant cells bind $\mathrm{Ag}^{+}$tightly and are killed by effects on cell respiration [48] and other cell surface functions $[49,50]$. Once bound extracellularly, $\mathrm{Ag}^{+}$enters the cells and is found in high speed centrifugal supernatant fluids [unpublished data]. $\mathrm{Ag}^{+}$precipitates extracellularly with $\mathrm{Cl}^{-}$, as the solubility product for $\mathrm{AgCl}$ is only $1.6 \times 10^{-10} \mathrm{M}$ at $15^{\circ} \mathrm{C}$ (and those for $\mathrm{AgBr}$ and $\mathrm{AgI}$ are much lower yet). The hypothesis is that the sensitive cells bind $\mathrm{Ag}^{+}$so tightly that they extract it from $\mathrm{AgCl}$ and environmental chelates, whereas the cells with the resistance plasmid do not compete successfully with $\mathrm{Ag}^{+}$-halide precipitates for $\mathrm{Ag}^{+}$. In polluted environmental settings, a wide variety of $\mathrm{Ag}^{+}$-binding substances would be expected in addition to $\mathrm{Cl}^{-}$. This includes both inorganic and organic materials. For example, serum albumin protects $\mathrm{Ag}^{+}$-resistant cells (but not sensitive cells) from $\mathrm{Ag}^{+}$. Because topically applied $\mathrm{AgNO}_{3}$ ointments caused tissue chloride loss and staining by colloidal $\mathrm{Ag}^{\circ}$, silver sulfadiazine has significantly replaced $\mathrm{AgNO}_{3}$ in clinical practice [42]. As seen in Figure $11 \mathrm{~A}$, the $\mathrm{AgNO}_{3}$-resistance plasmid confers resistance as well towards silver sulfadiazine. However, added $\mathrm{Cl}^{-}$was without effect on the inhibitory concentrations of silver sulfadiazine. This result was expected, since adding $\mathrm{NaCl}$ to solutions of silver sulfadiazine does not cause $\mathrm{AgCl}$ precipitates to form. Although some $\mathrm{Ag}^{+}$-resistant isolates have determinants of sulfadiazine resistance as well, these determinants can be on separate plasmids [Hedges, personal communication]. The function of sulfadiazine in topical preparations is not to inhibit bacterial growth directly, the concentrations released are too low [42], but rather to bind silver in a form subject to slow release.

\section{Other Heavy Metal Resistances}

There are many other plasmid heavy metal resistances $[2,43]$. Yet, nothing today is known about the mechanisms of resistance to bismuth, boron, cobalt, nickel, tellurium, or zinc ions. Chromate resistance in a pseudomonad isolated from river sediment seems to be due to reduction of toxic $\mathrm{Cr}$ (VI) to less toxic Cr(III) [Bopp and Ehrlich, Abstract Q111, 1980 American Society for Microbiology Meetings] and this resistance appears to be plasmid determined [A. M. Chakrabarty, personal communication]. However, caution on this point is needed, since bacteria capable of oxidizing toxic As(III) to less toxic As(V) are also known, but this turned out not to be the mechanism of plasmid-governed resistance. 


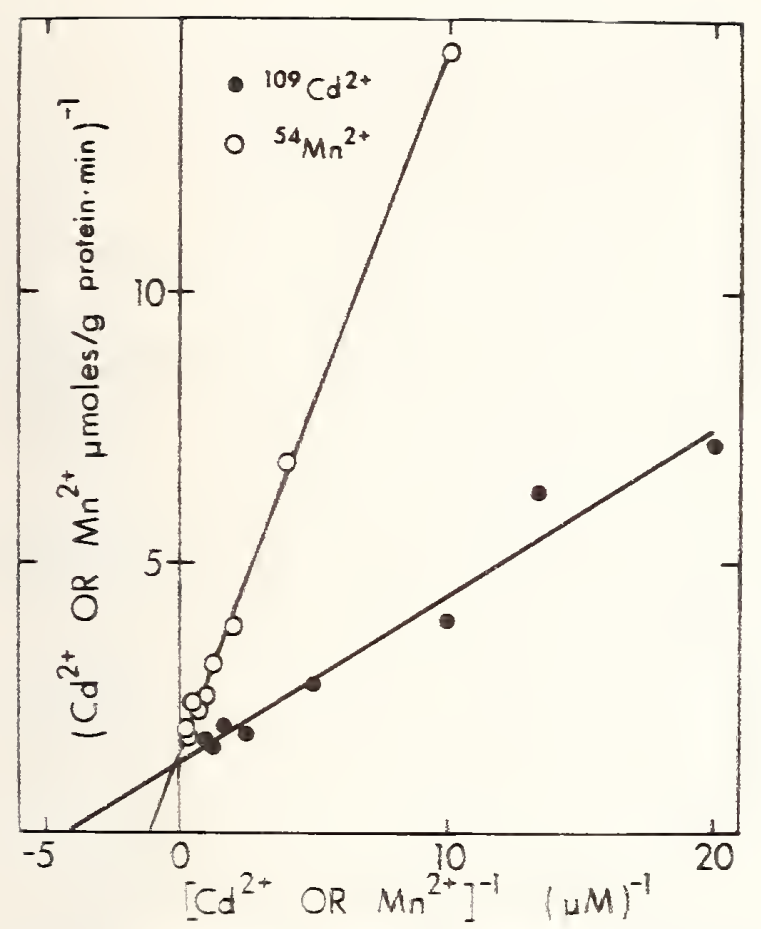

Figure 10. Kinetics of $\mathrm{Cd}^{2+}$ and $\mathrm{Mn}^{2+}$ transport by subceitutar membrane vesicles of S. aureus. Membranes were prepared with Tysostaphin and osmotic Tysis, washed and assayed for cation uptake by methods that will be described shortiy by R. D. Perry [manuscript, in preparation].

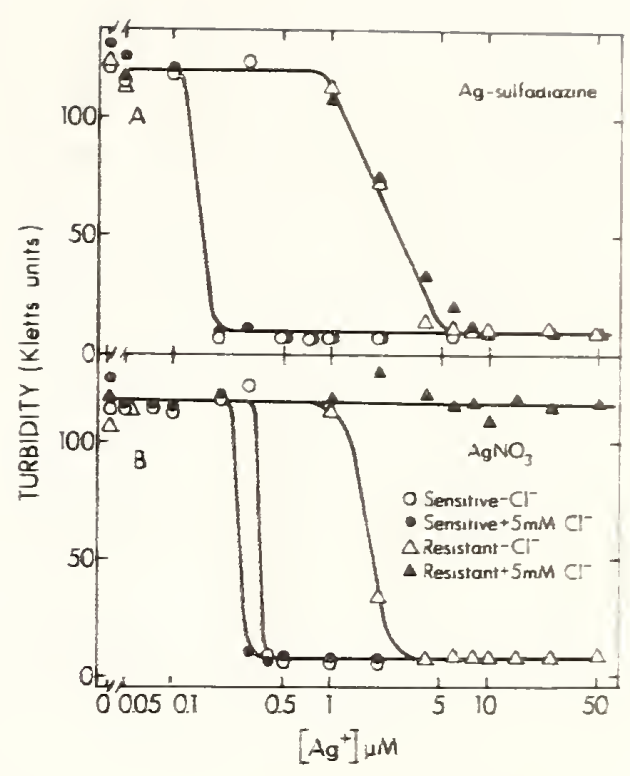

Figure 11. Resistance of E. coli strains J62 (sensitive) or J62 (pSC35) (resistant) to $\mathrm{Ag}$ sulfadiazine and $\mathrm{AgNO}_{3}$ in low and high $\mathrm{CT}^{-}$ [SiTver, in preparation].

One may ask why these heavy metal resistance plasmids occur in clinical strains with high frequencies--in the apparent absence of direct selection. Selective agents in hospital and "normal human" environments are onty beginning to be examined, but I believe that there is no such thing as "a free ride" as far as these determinants are concerned. Where they exist, there is selection by either non-human or human sources of heavy metals. Radford et al. [52] found their $\mathrm{Hg}^{2+}$-resistant soil microbes in agricultural soil, with no known human mercurial input. In such settings, the prevalence of resistant microbes may be very Tow, and these may come into much greater quantitative prominance after industrial or agricultural pollution [11,12,51,52]. This situation wil] then be closely analogous to that with antibiotic-resistance plasmids, which are found in low frequencies in antibiaticvirgin populations $[53,54]$, but which become dominant with extensive human use of antibiotics.

\section{Acknowiedgment}

Recent work in our laboratory on these topics has been supported by grants from the National Science Foundation PCM79-03986 and the National Institutes of Health AII5672. Laure Hogan helped with the preparation of this report. 


\section{References}

[1] Silver, S. Transport of cations and anions, in bacterial transport, B. P. Rosen, ed. New York: Marcel Dekker, Inc.; 1978. 221-324.

[2] Summers, A. 0.; Silver, S. Microbial transformations of metals. Ann. Rev. Microbiol. 32: $637-672 ; 1978$.

[3] Novick, R. P.; Roth, C. Plasmid-linked resistance to inorganic salts in Staphylococcus aureus. J. Bacterio1. 95: 1335-1342; 1968.

[4] Smith, D. H. R factors mediate resistances to mercury, nickel, and cobalt. Science. 156: $1114-1116 ; 1967$.

[5] Nakahara, H.; Ishikawa, T.; Sarai, Y.; Kondon, I. Distribution of resistances to metals and antibiotics of Staphylococcal strains in Japan. Zentralbl. Bakteriol. Parasitenkd. Infektionskr. Hyg. 1 Abt. Orig. A 237: 470-476; 1977.

[6] Nakahara, H.; Ishikawa, T.; Sarai, Y.; Kondo, I.; Kozukue, H.; Silver, S. Linkage,of mercury, cadmium, and arsenate and drug resistance in clinical isolates of Pseudomonas aeruginosa. Appl. Environ. Microbiol. 33: 975-976; 1977.

[7] Schottel, J.; Mandal, A.; Clark, D.; Silver, S.; Hedges, R. W. Volatilization of mercury and organomercurials determined by inducible R-factor systems in enteric bacteria. Nature. 251: 335-337; 1974.

[8] Friello, D. A.; Chakrabarty, A. M. Transposable mercury resistance in Pseudomonas putida, plasmids, and transposons: environmental effects and maintenance mechanisms, C. Suttard and K. R. Rozee, eds. New York: Academic Press; 1980. 249-260.

[9] 01 son, B. H.; Barkay, T.; Colwe11, R. R. Role of plasmids in mercury transformation by bacteria isolated from aquatic environment. App1. Environ. Microbio1. 38: 478-485; 1979.

[10] 01son, G. J.; Iverson, W. P.; Brinckman, F. E. Volatilization of mercury by Thiobacil1us ferrooxidans. Current Microbiol. 5: 115-118; 1981.

[11] Timoney, J. F.; Port, J.; Giles, J.; Spanier, J. Heavy-metal and antibiotic resistance in the bacterial flora of sediments of New York Bight. Appl. Environ. Microbiol. 36: $465-472 ; 1978$.

[12] Furukawa, K.; Suzuki, T.; Tonomura, K. Decomposition of organic mercurial compounds by mercury-resistant bacteria. Agric. Biol. Chem. 33: 128-130; 1969.

[13] Furukawa, K.; Tonomura, K. Enzyme system involved in the decomposition of phenylmercuric acetate by mercury-resistant Pseudomonas. Agric. Biol. Chem. 35: 604-610; 1971.

[14] Furukawa, K.; Tonomura, K. Metallic mercury-releasing enzyme in mercury-resistant Pseudomonas. Agric. Biol. Chem. 36: 217-226; 1972.

[15] Tezuka, T.; Tonomura, K. Purification and properties of an enzyme catalyzing the splitting of carbon-mercury linkages from mercury-resistant Pseudomonas K-62 strain. I. splitting enzyme 1. J. Biochem. 80: 79-87; 1976.

[16] Tezuka, T.; Tonomura, K. Purification and properties of a second enzyme catalyzing the splitting of carbon-mercury linkages from mercury-resistant Pseudomonas K- 62 . J. Bacteriol. 135: 138-143; 1978.

[17] Tonomura, K.; Kanzaki, F. The reductive decomposition of organic mercurials by cel1free extract of a mercury-resistant pseudomonad. Biochim. Biophys. Acta 184: 227-229; 1969. 
[18] Weiss, A. A. ; Schottel, J. L.; Clark, D. L.; Beller, R. G.; Silver, S. Mercury and organomercurial resistance with enteric, staphylococcal, and pseudomonad plasmids, in Microbiology 1978. D. Schlessinger, ed. Washington, D.C.: American Society for Microbiology; 1978. 121-124.

[19] Clark, D. L.; Weiss, A. A.; Silver, S. Mercury and organomercurial resistance determined by plasmids in Pseudomonas. J. Bacterio1. 132: 186-196; 1977.

[20] Weiss, A. A.; Murphy, S. D.; Silver, S. Mercury and organomercurial resistances determined by plasmids in Staphylococcus aureus. J. Bacteriol. 132: 197-208; 1977.

[21] Izaki, K. Enzymatic reduction of mercurous and mercuric ions in Bacillus cereus. Can. J. Microbiol. 27: 192-197; 1981.

[22] Izaki, K.; Tashiro, Y.; Funaba, T. Mechanism of mercuric chloride resistance in microorganisms. III. Purification and properties of a mercuric ion reducing enzyme from Escherichia coli bearing R factor. J. Biochem. 75: 591-599; 1974.

[23] Komura, I.; Funaba, T.; Izaki, K. Mechanism of mercuric chloride resistance in microorganisms. II. NADPH-dependent reduction of mercuric chloride and vaporization of mercury from mercuric chloride by a multiple drug resistant strain of Escherichia coli. J. Biochem. 70: 895-901; 1971.

[24] Summers, A. 0.; Silver, S. Mercury resistance in a plasmid-bearing strain of Escherichia coli. J. Bacteriol. 112: 1128-1136; 1972.

[25] Schottel, J. L. The mercuric and organomercurial detoxifying enzymes from a plasmidbearing strain of Escherichia coli. J. Biol. Chem. 253: 4341-4349; 1978.

[26] Bennett, P. M.; Grinsted, J.; Choi, C. L.; Richmond, M. H. Characterization of Tn501, a transposon determining resistance to mercuric ions. Mol. Gen. Genet. 159: 101-1 $\overline{06}$; 1978.

[27] Pickett, A. W.; McBride, B. C.; Cullen, W. R.; Manji, H. The reduction of trimethylarsine by Candida humicola. Can. J. Microbio1. 1981, in press.

[28] Foster, T. J.; Nakahara, H.; Weiss, A. A. ; Silver, S. Transposon A-generated mutations in the mercuric resistance genes of plasmid R100-1. J. Bacteriol. 140: 167-181; 1979.

[29] Nakahara, H.; Silver, S.; Miki, T.; Rownd, R. H. Hypersensitivity to $\mathrm{Hg}^{2+}$ and hyperbinding activity associated with cloned fragments of the mercurial resistance operon of plasmid NR1. J. Bacteriol. 140: 161-166; 1979.

[30] Silver, S.; Budd, K.; Leahy, K. M. ; Shaw, W. V.; Hammond, D. ; Novick, R. P.; Willsky, G. R.; Malamy, M. H.; Rosenberg, H. Inducible plasmid-determined resistance to arsenate, arsenite, and antimony(III) in Escherichia coli and Staphylococcus aureus. J. Bacteriol. 146: 983-996; 1981.

[31] Hedges, R. W.; Baumberg, S. Resistance to arsenic compounds conferred by a plasmid transmissible between strains of Escherichia coli. J. Bacteriol. 115: 459-460; 1973.

[32] Smith, H. W. Arsenic resistance in Enterobacteria: its transmission by conjugation and by phage. J. Gen. Microbiol. 109: 49-56; 1978.

[33] Novick, R. P.; Murphy, E.; Gryczan, T. J.; Baron, E.; Edelman, I. Penicillinase plasmids of Staphylococcus aureus: restriction-depletion maps. Plasmid. 2: 109-129; 1979.

[34] Albert, A. Arsenicals, antimonials, and mercurials, in Selective toxicity. 5th Ed. London: Chapman and Hal1; 1973. 392-397.

[35] Chopra, I. Decreased uptake of cadmium by a resistant strain of Staphylococcus aureus. J. Gen. Microbio1. 63: 265-267; 1970. 
[36] Chopra, I. Mechanism of plasmid-mediated resistance to cadmium in Staphylococcus aureus. Antimicrob. Agents Chemother. 7: 8-14; 1975.

[37] Tynecka, Z.; Gos, Z.; Zajac, J. Reduced cadmium transport determined by a resistance plasmid in Staphylococcus aureus. J. Bacteriol. 147: 305-312; 1981.

[38] Tynecka, Z.; Zajac, J.; Gos, Z. Plasmid dependent impermeability barrier to cadmium ions in Staphylococcus aureus. Acta Microbiol. Pol. 7: 11-20; 1975.

[39] Weiss, A. A.; Silver, S.; Kinscherf, T. G. Cation transport alteration associated with plasmid-determined resistance to cadmium in Staphylococcus aureus. Antimicrob. Agents Chemother. 14: 856-865; 1978.

[40] Tynecka, Z.; Gos, Z.; Zajac, J. Energy-dependent efflux of cadmium coded by a plasmid resistance determinant in Staphylococcus aureus. J. Bacteriol. 147:313-319; 1981.

[41] McMurry, L.; Petrucci, R. E. Jr.; Levy, S. B. Active efflux of tetracycline encoded by four genetically different tetracycline resistance determinants in Escherichia coli. Proc. Nat1. Acad. Sci. U.S.A. 77: 3974-3977; 1980.

[42] Fox, C. L., Jr. Silver sulfadiazine--a new topical for Pseudomonas in burns. Arch. Surg. 96: 184-188; 1968.

[43] Summers, A. 0.; Jacoby, G. A.; Swartz, M. N.; McHugh, G.; Sutton, L. Metal cation and oxyanion resistances in plasmids of Gram-negative bacteria, in Microbiology 1978.

D. Schlessinger, ed. Washington, D.C.: American Society for Microbiology; 1978. 128-131.

[44] Annear, D. I.; Mee, B. J.; Bailey, M. Instability and linkage of silver resistance, lactose fermentation and colony structure in Enterobacter cloacae from burn wounds. J. Clin. Path. 29: 441-443; 1976.

[45] Bridges, K.; Kidson, A.; Lowbury, E. J. L.; Wilkins, M. D. Gentamicin- and silverresistant Pseudomonas in a burns unit. Brit. Med. J. 1: 446-449; 1979.

[46] Hendry, A. T.; Stewart, I. 0. Silver-resistant enterobacteriaceae from hospital patients. Can. J. Microbiol. 25: 915-921; 1979.

[47] McHugh, G. L.; Moellering, R. C.; Hopkins, C. C.; Swartz, M. N. Salmonella typhimurium resistant to silver nitrate, chloramphenicol, and ampicillin. Lancet 1: $235-240 ; 1975$.

[48] Bragg, P. D.; Rainnie, D. J. The effect of silver ions on the respiratory chain of Escherichia coli. Can. J. Microbiol. 20: 883-889; 1974.

[49] Fox, C. L., Jr.; Modak, S. M. Mechanism of silver sulfadiazine action on burn wound infections. Antimicrob. Agents Chemother. 5: 582-588; 1974.

[50] Rosenkranz, H. S.; Carr, H. S. Silver sulfadiazine: effect on the growth and metabolism of bacteria. Antimicrob. Agents Chemother. 2: 367-372; 1972.

[51] Nelson, J. D., Jr.; Colwell, R. R. The ecology of mercury-resistant bacteria in Chesapeake Bay. Microb. Eco1. 1: 191-218; 1975.

[52] Radford, A. J.; 01 iver, J.; Kelly, W. J.; Reanney, D. C. Translocatable resistance to mercuric and phenylmercuric ions in soil bacteria. J. Bacteriol. 17: ; 1981, in press.

[53] Gardner, P.; Smith, D. H.; Beer, H.; Moellering, R. C., Jr. Recovery of resistance (R) factors from a drug-free community. Lancet 2: 774-776; 1969.

[54] Maré, I. J. Incidence of $R$ factors among Gram-negative bacteria in drug-free human and animal communities. Nature. 220: 1046-1047; 1968. 
Discussion

Question (E. A. Woolson): On the resistant cells exposed to arsenate, have you looked to see if it is arsenate that is being pumped out or is it metabolized to cacodylic acid and then pumped out?

Answer: Its chromatographically arsenate, both in the cells and what's left outside. We separated the cells from the medium; this was done largely with radioactive arsenic-74 and it was arsenate. There is no sign of any change in species.

Question (D. A. Klein): I've used terms of accommodation and tolerance, which you will see in the literature, which would perhaps imply a nongenetic level of change in the organisms or some sort of use of an alternative pathway that's already functioning. What is your reaction to those terms? I feel very uncomfortable using them; what's your reaction to that sort of concept?

Answer: They are standard terms. They're more ill-defined and often when really looked at, it doesn't happen. There have been reports of cadmium accommodation in $\underline{E}$. coli which is nongenetic. There have been reports of that being related to metallothionine production, or products of a small protein high in sulfur. I'm rather uncomfortable about it. Often, things that are called accommodation involve selection of resistant organisms from out of a mixed population, and there have been reports of accommodation to mercury which were erroneous. You start out with a population where one in a thousand bugs might be resistant, and after exposure for a while those have been inhibited or killed, and all of the bugs that survive have the resistance. So I think those are not satisfactory and so I really am unhappy with them. The cadmium case in particular, I'm very skeptical about it.

Question (J. D. Walker): Are you planning on examining the metal at all, or any other forms of antimony?

Answer: We're looking at the resistance to antimony(III) as a salt. If we get a mechanism for resistance, which we currently don't have, it does not seem to be a detoxification. Maybe I'm not clear on your question. We weren't planning on looking at methyl-or ethylantimony compounds.

Question (J. D. Walker): I asked if you were going to look at the metal and other possible antimony compounds--say antimony sulfide, antimony trioxide, or antimony pentoxide--any of those? 
Answer: We're looking at the resistance, mainly to soluble cations or oxy ions. The mercury, in particular, since the product of the enzyme is metallic mercury. We know that the resistance to mercury $(0)$ is very, very much greater. The ionic form is much more toxic than the metallic form. Simply that it's bioavailable, to use the phrase that was used yesterday.

Question (W. P. Iverson): What is your feeling toward the universality of this concept with silver? Do you suppose if you looked among a greater variety of organisms you would find a detoxification effect?

Answer: I don't know. I'm sure its known that Anne Sommers and colleagues found silverresistant bugs in abundance outside Eastman Kodak or Polaroid in Boston. These phenomena, as far as we have looked at them, seem to be widespread through a variety of organisms of soil, marine, or clinical origin. It doesn't seem to matter. We have not found different mechanisms of resistance. Wherever we have looked there has been just a single mechanism of resistance. For mercury, for arsenate, where we found that in gram positives and gram negatives, and about a dozen different plasmids more. I don't know for silver, in that we've only looked at two examples. Our past experience has been that nature has evolved a single mechanism as widespread as the resistance, and that mechanism holds.

Question (R. J. Mehlhorn): In these arsenate-resistant bugs, is there a phosphate depletion?

Answer: To get in, there is a competition between the arsenate and the phosphate; so if we add enough arsenate, that does prevent phosphate from getting in. That's competitive inhibition for uptake. That's not the mechanism of resistance: that goes on in the sensitive and the resistant cells equally. The mechanism for resistance is, if you add enough arsenate or increase your arsenate-phosphate level high enough, some arsenate does get in and it's toxic. Arsenate toxicity is not due to phosphate starvation. The arsenate gets in and competes at the enzyme level and makes apparently unstable arsenical compounds that just hydrolyze ATP.

Question (R. J. Mehlhorn): Is this pump that you described, is that specific for arsenate or does it also pump phosphate?

Answer: When a toxic heavy metal compounds gets in, as far as we are aware, in the two cases we know well, it gets in by a normal nutrient pump which is presumably intended for phosphate and arsenate, and just happens to get in on it. Vanadate gets in on it also, but it is not pumped out, so vanadate inhibits phosphate uptake; but there is no plasmidmediated vanadate resistance. There are two genetically known phosphate pumps in $\underline{E}$. coli, also in Staphylococcus. They have different kinetic parameters which can be studied, but that are not involved in the plasmid resistance. That's also true of cadmium versus 
manganese. The reason that gram-negative bacteria tend to be resistant to cadmium without plasmids even, is that their chromosomally-determined manganese pump has a higher specificity. Whereas, in Staphylococcus aureus, the chromosomally-determined manganese pump has a quite high affinity for cadmium. So is that responsive to your question?

Question (R. J. Mehlhorn): No, but it may get too lengthy.

Answer: If you can generalize, which is dangerous, my prejudice is that nothing gets across the cell membrane by chance and most toxic things get in by being alternative substrates for metabolically needed transport systems.

Question (R. J. Mehlhorn): This issue that you raised is that you can either block the uptake in the first place or, if you can't do that, then we can get rid of it when it is taken up. Dealing with this arsenate-phosphate competition then raises the issue: if it does get in, how can you selectively get rid of the arsenate and still retain the phosphate?

Answer: I think that's a good question, and a good generalization comes from it. The pumps for getting in, which are chromosomal pumps for nutrients, are much less specific. The resistance pumps, the two we have which are cadmium and arsenate, have to have incredible specificity, because if the arsenate pump-out also pumped out phosphate, the cells would be starved. The arsenate pumping-out pump, which is an ATPase-dependent mechanism--we know something about its bioenergetics--does not respond to vanadate or phosphate. It is specific for arsenate. The cadmium pumping-out pump does not pump out manganese; its specific for cadmium. The going-in pump, which is determined by the chromosome, doesn't need that kind of specificity. Its the resistance system which has to be specific for the toxic thing, otherwise it would starve the cells by pumping out the nutrients. Maybe that's your point.

Question (F. E. Brinckman): This is another universal question that relates to the previous questions in respect to specificity or pumping in or pumping out. In the case of mercury, you have shown, for example, a two-stage degradation mode involving two enzymic events: the cleavage of a sigma-carbon bond to the mercury followed by a hydrolysis which undergoes reduction for rejection--that's a pump taking in but its certainly getting rid of mercury. Of course, degradation of organometals, that is, metals or metalloids sigma-bonded to carbon ligands, has been suggested for other metals. I don't know about the documentation at the genetic levels, at the enzyme level. My question: what about the construction of metal- or metalloid-carbon bonds as the selective pumping out; can you make any observations about this in view of what you have said?

Answer: The mercury system doesn't involve a pumping out. We don't know how the gaseous element mercury gets out. If we don't shake them vigorously, we've got $200 \mathrm{~mL}$ of the 
suspension of all that is in a test tube that whipping back and forth at $200 \mathrm{rpm}$, really fast. If we slow that down, the mercury doesn't volatilize; it's reduced but it doesn't volatilize. We know its reduced because if we put in an organic solvent, such as chloroform or toluene, we can bring it into the organic solvent, whereas ionic mercury doesn't dissolve in organic solvents. So it may be an air-cell interface where it goes out and I never studied the process of metallic mercury getting out.

Comment (F. E. Brinckman): If you grow stab cultures, for example, in a homogeneous agar medium where you have diffusion-controlled mercuric ion available in the nutrient system, you will see, after a period of time, the exhalation of elementary mercury in a totally symmetric aura around the cells. It doesn't presume the mercury did it inside of the ce11. It only says that you've converted inorganic $\mathrm{Hg}^{2+}$ into $\mathrm{Hg}^{\circ}$ in some way, which is precipitating out symmetrically with respect to growth.

Answer: We put, very early on, droplets of metallic mercury into the cell cultures and metallic mercury, in droplet form which will then form a saturated vapor, is relatively harmless to these things.

Question (F. E. Brinckman): I wanted to get after the queston of generality-universality: whether or not you know or anticipate a similar enzymic apparatus for either degradation or formation of these other organometal systems.

Answer: Mercury is the only enzymatic system at the moment. We wanted to find them because they are easier to work with biochemically. There are soil microbes which oxidize arsenite to arsenate, and that is maybe a breaking down of these universa]ities. That process has to be enzymatic. That is not plasmid-mediated, as far as we know. That is not what goes on here, because we measured with the soil microbes which are also arsenite-resistant, the rate of arsenite oxidation to arsenate, and it's going on at least 2000-fold above the background level of the zero we can detect there. So there are enzymatic redoxes; there is said to be, by Chakrabarty in an unpublished abstract, a plasmidmediated chromium(VI) to chromium(III) reduction as a resistance mechanism.

Question ( $S$. Silverstein): Do you have any idea how these resistance enzymes and plasmids evolved? Did they evolve de novo or from pre-existing enzymes?

Answer: A good question and we've tried to address it. It's not an experimental question. They have been around for a long time because you can find them in unpolluted, in unselective situations. For example, in clinical isolates, such as in Japanese clinical collections, you can have up to 70 to 80 percent of the bugs of any kind resistant to mercury or arsenic. If you go to New Guinea Highlanders who have never been exposed to antibiotic or contemporary medicine, or to some soils in the outback of Australia, and isolate soil bugs there, these resistances still appear at a very low level ( 0.5 percent to 0.1 percent). So these determinants have been around for a long time. They have 
only become prominant as we have human input. We know that the hospital collections are very high in mercurials, which is a good question for EPA. Apparently, mercurials were added to hospital soaps--the disinfectant that people wash their hands with--merthiolate phenylmercury. The pseudomonads were quite happy to grow on these hospital soaps, using the carbon of the soap and detoxifying the mercury, and at that time the levels of mercurial resistances in hospital strains were incredibly high, $1 / 3$ to $2 / 3$ of isolates. About eight years ago the mercurials were forbidden in hospital soaps, and in a collection we took over the last few months the percentage of mercurial resistance dropped to 4 out of 194, once you remove the selective pressure. Maybe the answer to your question is that these resistances have been around for a long, long time due to natural selections. They become prominant when there is industrial or human selection. I once tried to answer a question like this by saying, "I get my arsenic in shrimp, my cadmium in oysters, and my methylmercury in swordfish." None of those are due to pollution. Those foods are just naturally rich in those toxic heavy metals.

Question (S. Silverstein): If you examine the genes from the Australian outback, are they the same as the ones you find in the hospitals or have they evolved quite a bit in the hospitals?

Answer: No, they tend to be the phenomenally same in the few cases that we know. For example, on molecular biology grounds we have in Pseudomonas putida, which is a soil microbe, a transposon--a stretch of DNA which is six million long--for mercury resistance and has specific cut sites for restriction endonucleases so we can fingerprint the DNA. It is indistinguishable, at the moment, from the DNA-determining mercury resistance in a particular Pseudomonas aeruginosa from a cystic fibrosis case. So, we think as far as the comparative immunology of those enzymes goes, all seems to indicate that some genes are in marine, soil, and clinical collections, and that they could move from oil microbes, to lettuce, to people who get sick.

Question (R. H. Fish): Or. Klein, to continue our earlier discussion, we're trying to go from a biogeochemical source, shale oil, to the retort waters. What we find predominately is arsenate, along with methyl- and phenylarsonic acids. This seemed to be consistent in these various processing materials or the source. We don't see any dimethylarsinate in detectable amounts. Dr. Woolson brought up the fact that you are seeing a volatilization, so I would presume a methylation or a hydride source for reduction.

Answer (E. A. Woolson): The volatile material from the shale oil will probably be dimethylarsine, and possibly phenylarsine, based on what you said is there. 
Question (R. H. Fish): This is the spent shale?

Answer (D. A. Klein): This is the residue.

Comment (E. A. Woolson): But if you have only arsenate in the shale, the spent shale, you will probably find dimethyl- and trimethylarsine.

Answer (R. H. Fish): Yes. The speciation of those things then is obviously important.

Answer (D. A. Klein): That's what we are hoping, too. We are looking to get some advice on these procedures and to see if we can sort these things out and can be selective for $\mathrm{pH}$ shifts and reductions.

Comment (E. A. Woolson): You can take those traps and run them directly on an HPLC, too.

Answer (D. A. Klein): Right. I think that's a good point, we're just beginning to rough out any microbial responses.

Question (R. H. Fish): Why not grind shale samples so you'll have more surface area?

Answer (D. A. Klein): Again, we were worried about having a different heat transfer and the heat effects on the materials--again we get a tremendous difference in the sizes of this material. You can see, visibly, at least some types of difference in the physical characteristics when you crack a little bit apart. I think you would get a different type of material if ground, as opposed to using only the material at that small mesh size. Thus, we're restricting our universe as it were, for better or worse. Again we might get different results using different beginning materials.

Question (R. H. Fish): This is also physiological pH at 7.4?

Answer (D. A. Klein): That's right. Again, I think we can make that decision. We might just try that later on. Again we have to start somewhere, we figured we would avoid making physical artifacts as far as what might come out of it.

Comment (R. H. Fish): It's very interesting, exciting work.

Comment (F. E. Brinckman): The question of phenylarsonic acid has plagued Dr. Fish and me. The first time we saw it, independently in our two laboratories, repeatedly in the retort waters, and now, with the preliminary evidence that Dr. Weiss talked about in the extract from an on-going Bureau Standard Reference Material 0il Shale. This is by no way an examination of a large number of source oil shales, and certainly not retort waters, although we looked at retort waters from seven sites which were provided to us. One can 
envision in the process of retorting, since you have a large activation energy in any of these cases, a great deal of hydrochemistry going on at high temperatures. It's well known since the German 1iterature back at the turn of the century [Mayer, Ber. 16:1439 (1883)] that arsenate or arsenite in superheated steam in the presence of a whole host of organic moieties, either alkyl or aromatic, makes organoarsenicals. In fact, they were first made this way and still are. So one can synthesize phenylarsonates. But I am going the long way around to a question that I want to address to Dr. Silver, and to the other microbiologists generally. I don't know anything about biophenylation in either modern or primordial algal mats. I certainly know about methylarsenic formation there, there's ample evidence for this in modern algae and bacteria. You can envision an uptake into the primordial matter which finally went to make up kerogen, particularly from algae. My question is, does anybody know anything about biophenylation?

Answer: I think the answer is no. Degradation (of phenylmercury), yes.

Comment (R. H. Fish): I think the Workshop has been, from my point of view, a very successful interaction among chemists and biologists in being able to focus on environmental speciation. Not only when you try to identify the compound and its impact on the environment or aquatic species, or man, I think we went a long way in defining the problems that we all have, i.e., the microbiologists and the chemists, and what we should do. One thing I see from the chemists' point of view, in the synfuel area discussed by Professors Yen, Filby, and Manahan, is the formation and/or release of possible toxic organometallic compounds. It seems that there is a need to study whether during processing, such things as phenylarsonic acid are synthesized and released, then go to our biologist friends and ask "Here are these compounds. What are their consequences in the various systems?"

Comment (E. A. Woolson): In terms of phenylarsonic acid in the environment, it will get degraded to inorganic arsenate and phenol, I presume, and get incorporated into humic acid or into soil organic matter. I think the problem is that we have two different questions that need to be asked. One, is it acutely toxic, or second, is it chronically toxic? With any of these materials that are generated, you are talking about different magnitudes.

Question (R. H. Fish): Yes, and what kind of bioassays do you use? That was my point. You need an Ames-type test for organometallic compounds, and there doesn't appear to be one on the horizon, or if there is, this shouid be brought out to people involved.

Answer (E. A. Woolson): For the organoarsenical compounds, I can't speak about the others, once they get into the environment the microorganisms will work on them and they will go to arsenate. We know a lot about arsenate effects and movement in the environment. So you have got that transitury period until it gets degraded to worry about with the organoarsenical. I don't have first-hand knowledge about the other compounds, I can't speak to those. 
Comment (D. A. Klein): I want to react to the question on biophenylation. I can envision something going on in soil organic matter formation where you get a whole series of phenolic types which can come up within biological means. These things do go on and, perhaps, somewhere one might find that type of process going on. You see metals accumulation in those types of soil zones, and that's where I would at least look.

Comment (E. A. Woolson): The kinetics will take it the other way. In that type of soil there are some types of microorganisms that would phenylate...

Question (D. A. Klein): Under any particular pH or abiotic conditions where it might go the other way, where it won't be looked at?

Answer (J. D. Walker): You might find this under anaerobic conditions rather than aerobic conditions.

Comment (D. A. Klein): There are many zones in soil and muds, and so forth, that might be more conducive. It's something to think about.

Comment (W. H. Kirchhoff): I am speaking on behalf of ASTM [American Society for Testing and Materials] which has recently formed a new committee E-47 on Biological Effects and Environmental Fate. The purpose of the Committee is to try to establish test methodology in those two areas. The initial formation consists primarily of people like mammalian toxicologists, aquatic toxicologists, and physical chemits who are interested in such processes as how do you measure vapor pressure, or how do you measure solubility. The Committee is attempting to struggle with standardization of methodology where standard methodology would be appropriate, where it would be helpful for people to try and use standard conditions. The Committee is presently dealing with its scope and with the directions in which it wishes to go. As Chairman of the Committee I would encourage you, if you think this kind of standard methodology is needed in your particular area, to get in touch with me; we're always open for new subcommittees.

Comment (M. A. Anderson): I'd like to pose a challenge. It seems to me that this relates to what this Workshop has been talking about for speciation needs, we've been talking about more and more sophisticated methods of detection [Prof. Anderson shows figure below - Eds.] This conveys the challenge--an obligation to do things that relate to mankind and the tax dollars that we are getting. We have had our conference here on speciation and speciation needs. Now the way I look at this--this scheme is not my idea by the way, it is a summation of what Werner Stumm said a few months ago. That was, as our detection limit has increased, the way we deal with waste products in the environment as man's wastes, changes. We used to talk about our own excretions, and those were main problems that we dealt with years ago; then we were at the parts per thousand detection limits. We had poorer techniques, but we were dealing with human waste so we could talk about speciation in terms of BOD, COD, or other bulk parameters. We said that if the 


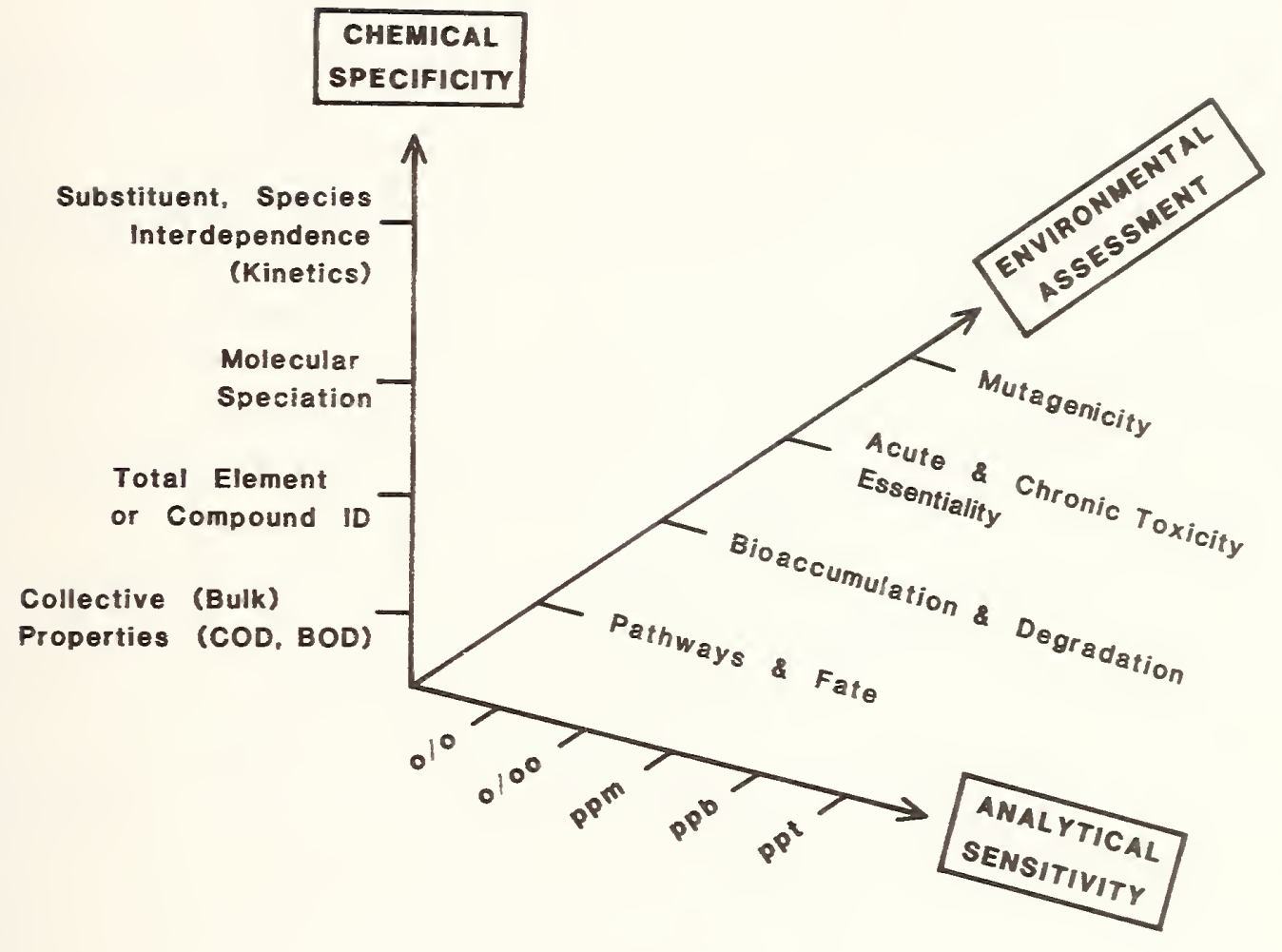

$B O D$ and $C O D$ were too high, then the stream was polluted. Now we've started to work in parts per million, parts per bilition, parts per trillion, and even beyond, and our speciation gets to specific elements. In other words, we talked about defining specific elements, then we got into the forms of the element, whether it was in the plus three oxidation state, the plus five oxidation state, and we got into this by matrix analysis. We've learned there was interelement dependence. Along with this came new questions; we'd made broad decisions here in environmental matters or the biology, about whether things were polluted. But now we could not just say it was polluted or not polluted. Now that we've got better speciation and detection limits, we've started talking about acute toxicity or chronic toxicity. We've started worrying about carcinogenicity, and as we got into interelemental dependencies we got into mutagenicity. The problem is that we're expanding this system or matrix into many dimensions as I've shown. We have to make some new decisions; we have to make a choice. What's toxic? The challenge here is to make a choice on what kinds of simple testing protoccls--we have a messy expanding system here-these can be. We've got to give the administrators some sort of tools with which to say, under these sets of circumstances, this element is going to be toxic. I don't have the answers, but what we've been doing, we've been increasing our detection limit and we've been generating more problems. 
Comment (F. E. Brinckman): There's a show that all of you have seen on public broadcasting, I expect, where the moderator always says, "You've had the last word." I think we've just heard it. In light of Dr. Wolf's discussion and reality, in the vector of decision, based on environmental impact, you did not indicate in your scheme that aspect of essentiality. I'd appreciate it if you'd put that on the vector, too [cf. above figure --Eds.]. Toxicity and essentiality are part of the interdependence that we must determine and respond to. The question ultimately is, why speciate unless you want to make better decisions?

Dr. Fish and I thank all of you for being here. We've discussed a remarkable cross section of on-going active research, primarily in the United States, but representative of that which is happening in the world. It makes very clear that "speciation" adopted by chemists for their own various purposes, from the biologists, has become a word which may put them back together. The issue has to do obviously, with the molecular basis of interaction, and Dr. Anderson has just summarized that, elegantly. We thank you all very much because, by your being here, you've made a workshop--this was not a symposium or a set piece--we've had a structure of some formal speakers as you know, with an almost tentative agenda. We could put no speaker in the correct order, but I think all of you put matters in the correct order. We hope the written legacy of this you will find acceptable. Let us hope it will convince people there is merit in the work scientifically and there is merit in the work for decision making. This adjourns the meeting. 
BIBLIOGRAPHIC DATA

SHEET (See instructions)

4. TITLE AND SUBTITLE

$$
\begin{aligned}
& \text { 1. PUBLICATION OR } \\
& \text { REPORT NO. } \\
& \text { NBS SP } 618
\end{aligned}
$$

2. Performing Organ. Report No. 3. Publication Date

November 1981

Environmental Speciation and Monitoring Needs for Trace

Metal-Containing Substances from Energy-Related Processes -Proceedings of the DoE/NBS Workshop held at the National Bureau of Standards, Gaithersburg, MD, May 18-20, 1981.

5. AUTHOR(S)

Frederick E. Brinckman and Richard H. Fish, Editors.

6. PERFORMING ORGANIZATION (If joint or other than NBS, see instructions)

NATIONAL BUREAU OF STANDARDS

DEPARTMENT OF COMMERCE

WASHINGTON, D.C. 20234

9. SPONSORING ORGANIZATION NAME AND COMPLETE ADDRESS (Street, City. Stote. ZIP)
$\begin{aligned} & \text { National Bureau of Standards } \\ & \text { Washington, DC } 20234\end{aligned}$
$\begin{aligned} & \text { Department of Energy } \\ & \text { Research } \\ & \text { Washington, DC } 20545\end{aligned}$

10. SUPPLEMENTARY NOTES

Library of Congress Catalog Card Number: 81-600140

$\square$ Document describes a computer program; SF-185, FIPS Software Summary, is attached.

11. ABSTRACT (A 200-word or less foctual summory of most significont information. If document includes a significant bibliogrophy or literoture survey. mention it here)

This book presents the Proceedings of the DoE/NBS Workshop on Environmental Speciation and Monitoring Needs for Trace Metal-Containing Substances from EnergyRelated Processes held at the National Bureau of Standards, Gaithersburg, MD, on May 18-20, 1981. The Workshop was sponsored by the Office of Health and Environmental Research, DoE, and the Office of Recycled Materials, NBS.

The volume contains refereed papers submitted by 24 invited speakers, along with substantially complete text of the discussion following the papers, edited by the co-chairpersons. The Proceedings address three major topic areas forming the overal1 objective of the Workshop: (1) what are the general and specific types of metal- or metalloid-containing substances occurring in energy-related process materials such as coals, oil shales, and waste products? (2) what are the current status and future prospects of element- and compound-specific measurement methods suitable for speciation of trace (ppm, ppb) metal- and metalloid-containing substances transmitted to the environment by energy-processing or waste cycling technologies? (3) for what toxic molecular forms of speciated process effluents should biological dose-response data be generated to assure reliable environmental impact and monitoring measurements? Main questions focused on providing assurance that the speciation methods (or their development) fit basic bioassay criteria along with appropriate standard reference materials for meeting quantitative process and waste monitoring or control needs.

12. KEY WOROS (Six to twelve entries; alphobetical order; copitolize only proper nomes; and separate key yords by semicolons) bacterial mobilization; biogeochemical cycles; biological uptake; celfular toxicityessentiality mechanisms; chromatography; element-selective speciation; environmental monitoring; fossil fuels; metal(loid) complexes; organometallic compounds; trace element \begin{tabular}{|ll|l}
\hline 13. AVAILABIL!TY & standards; waste CyCTing. NO. OF
\end{tabular}

XX Unlimited

$\square$ For Official Distribution. Do Not Release to NTIS

[?] Order From Superintendent of Documents, U.S. Government Printing Office, Washington, D C 20402. PRINTED PAGES

XXOrder From National Technical Information Service (NTIS), Springfield, VA. 22161 





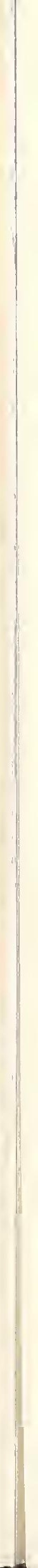




\section{PERIODICALS}

JOURNAL OF RESEARCH-The Journal of Research of the National Bureau of Standards reports NBS research and development in those disciplines of the physical and engineering sciences in which the Bureau is active. These include physics, chemistry, engineering, mathematics, and computer sciences. Papers cover a broad range of subjects, with major emphasis on measurement methodology and the basic technology underlying standardization. Also included from time to time are survey articles on topics closely related to the Bureau's technical and scientific programs. As a special service to subscribers each issue contains complete citations to all recent Bureau publications in both NBS and nonNBS media. Issued six times a year. Annual subscription: domestic \$16; foreign $\$ 20$. Single copy, $\$ 3.75$ domestic; $\$ 4.70$ foreign.

NOTE: The Journal was formerly published in two sections: Section A "Physics and Chemistry" and Section B "Mathematical Sciences."

DIMENSIONS/NBS-This monthly magazine is published to inform scientists, engineers, business and industry leaders, teachers, students, and consumers of the latest advances in science and technology, with primary emphasis on work at NBS. The magazine highlights and reviews such issues as energy research, fire protection, building technology, metriç conversion, pollution abatement, health and safety, and consumer product performance. In addition, it reports the results of Bureau programs in measurement standards and techniques, properties of matter and materials, engineering standards and services, instrumentation, and automatic data processing. Annual subscription: domestic $\mathbb{1} 11$; foreign $\$ 13.75$.

\section{NONPERIODICALS}

Monographs-Major contributions to the technical literature on various subjects related to the Bureau's scientific and technical activities.

Handbooks-Recommended codes of engineering and industrial practice (including safety codes) developed in cosperation with interested industries, professional organizations, and regulatory bodies.

Special Publications-Include proceedings of conferences sponsored by NBS, NBS annual reports, and other special publications appropriate to this grouping such as wall charts, pocket cards, and bibliographies.

Applied Mathematics Series-Mathematical tables, manuals, and studies of special interest to physicists, engineers, chemists, biologists, mathematicians, computer programmers, and others engaged in scientific and technical work.

National Standard Reference Data Series-Provides quantitative data on the physical and chemical properties of materials, compiled from the world's literature and critically evaluated. Developed under a worldwide program coordinated by NBS under the authority of the National Standard Data Act (Public Law 90-396)
NOTE: The principal publication outlet for the foregoing data is the Journal of Physical and Chemical Reference Data (JPCRD) published quarterly for NBS by the American Chemical Society (ACS) and the American Institutc of Physics (AIP). Subscriptions, reprints, and supplements available from ACS, I155 Sixteenth St., NW, Washington, DC 20056.

Building Science Series-Disseminates technical information developed at the Bureau on building materials, components, systems, and whole structures. The series presents research results, test methods, and performance criteria related to the structural and environmental functions and the durability and safety characteristics of building elements and systems.

Technical Notes-Studies or reports which are complete in themselves but restrictive in their treatment of a subject. Analogous to monographs but not so comprehensive in scope or definitive in treatment of the subject area. Often serve as a vehicle for final reports of work performed at NBS under the sponsorship of other government agencies.

Voluntary Product Standards-Developed under procedures published by the Department of Commerce in Part 10, Title 15, of the Code of Federal Regulations. The standards establish nationally recognized requirements for products, and provide all concerned interests with a basis for common understanding of the characteristics of the products. NBS administers this program as a supplement to the activities of the private sector standardizing organizations

Consumer Information Series-Practical information, based on NBS research and experience, covering areas of interest to the consumer. Easily understandable language and illustrations provide useful background knowledge for shopping in today's technological marketplace.

Order the above NBS publications from: Superintendent of Documents, Government Printing Office, Washington, DC 20402

Order the following NBS publications-FIPS and NBSIR's-from the National Technical Information Services, Springfield, VA 22161.

Federal Information Processing Standards Publications (FIPS PUB)-Publications in this series collectively constitute the Federal Information Processing Standards Register. The Register serves as the official source of information in the Federal Government regarding standards issued by NBS pursuant to the Federal Property and Administrative Services Act of 1949 as amended, Public Law 89-306 (79 Stat. 1127), and as implemented by Executive Order 11717 (38 FR 12315, dated May I1, 1973) and Part 6 of Title 15 CFR (Code of Federal Regulations).

NBS Interagency Reports (NBSIR)-A special series of interim or final reports on work performed by NBS for outside sponsors (both government and non-government). In general, initial distribution is handled by the sponsor; public distribution is by the National Technical lnformation Services, Springfield, VA 22161, in paper copy or microfiche form. 
U.S. DEPARTMENT OF COMMERCE

National Bureau of Standards

Washington, D.C. 20234

POSTAGE AND FEES PAID

U.S. DEPARTMENT OF COMMERCE

$C O M=295$

SPECIAL FOURTH-CLASS RATE BOOK 